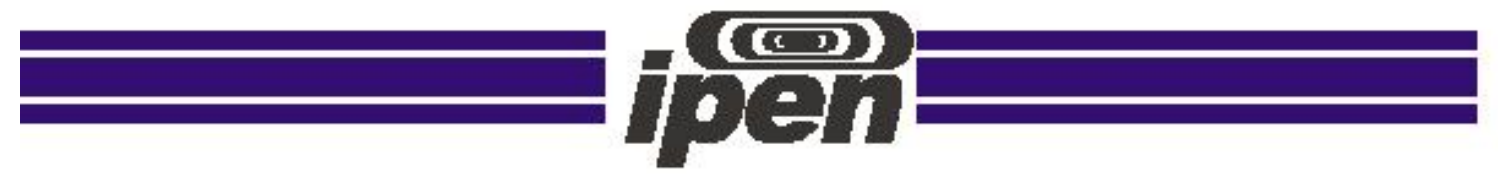

AUTARQUIA ASSOCIADA À UNIVERSIDADE DE SÃO PAULO

Estudo experimental dos efeitos da temperatura em pavimento de concreto instrumentado

Fábio Raia

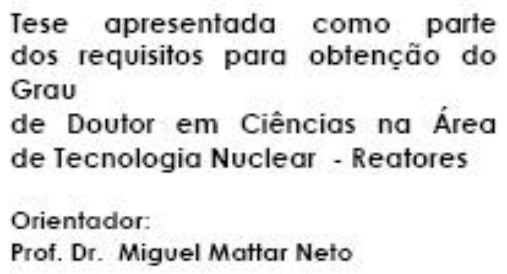


INSTITUTO DE PESQUISAS ENERGÉTICAS E NUCLEARES

Autarquia associada à Universidade de São Paulo

\title{
ESTUDO EXPERIMENTAL DOS EFEITOS DA TEMPERATURA EM PAVIMENTO DE CONCRETO INSTRUMENTADO
}

\author{
FÁBIO RAIA
}

Tese apresentada ao Instituto de Pesquisas Energéticas e Nucleares como um dos pré requisitos para a obtenção do grau de doutor em ciências.

Área de concentração: Tecnologia de Reatores

Orientador:

Dr. Miguel Mattar Neto

SÃO PAULO

2010 
Aos meus filhos, Fábio, Mário, Marcos e a ela, minha esposa, Silza. Que, sem sua ajuda nada teria acontecido. Ao meu Pai Mário e a minha saudosa Mãe, Áurea. 


\section{AGRADECIMENTOS}

A Deus, por ter provido saúde, paz e pela Sua presença constante em todos os momentos que, com Sua infinita sabedoria, me conduziu na realização do presente trabalho.

Ao meu orientador Dr. Miguel Mattar Neto pelo constante apoio durante o desenvolvimento do trabalho.

Ao coordenador do curso de Mecânica da Universidade Presbiteriana Mackenzie Prof. Dr. Antônio Gonçalves de Mello Júnior pelas sugestões e pelo apoio dado no decorrer do trabalho Ao Professor Dr. Prof. João Virgílio Merighi por ter disponibilizado parte do laboratório de ensaios para a execução do trabalho.

Ao Professor Dr. Alfonso Papallardo pelas sugestões e observações realizadas no trabalho e por ter reservado tempo para realizar simulações numéricas no software ANSYS ${ }^{\circledR}$

Ao Professor Msc. Paulo Moura pela ajuda na parte de ensaios de solo.

Ao professor Dr. José Tadeu Balbo por ter reservado tempo para atender minhas dúvidas, pelo auxílio e sugestões realizadas no trabalho.

Ao Professor Dr. Alex Bandeira pela ajuda na parte numérica.

Ao Professor Dr. Edvaldo Ângelo pelas sugestões na área térmica.

Ao Professor Dr. Pedro Afonso de Almeida por ter reservado tempo para oferecer sugestões do processo experimental.

Ao Professor Dr. Sérgio Sérgio Delijaicov por ter reservado tempo para oferecer sugestões importantes para o processo experimental.

Ao Eng. Luis Fernando Togni pelas sugestões dadas no processo experimental.

Ao Eng. André Luiz da empresa Lynx pelo pronto atendimento dado aos meus chamados e pela constante ajuda dada ao projeto.

Ao Eng. Ricardo Tanaka da empresa Lynx por ter reservado tempo para atender minhas dúvidas sobre detalhes do sistema ADS 500.

À professora Msc. Ana Lúcia Monteiro F. B. Pinheiro pelas sugestões na formatação do trabalho e bibliografia.

À professora Rachel Cynrot pelas sugestões na parte de tratamento de dados. 


\section{LABORATÓRIO DE ESTRUTURAS:}

Técnico Abner Cabral Neto (Cabral) pelo auxílio e sugestões nas diversas fases do projeto

\section{LABORATÓRIO DE MATERIAIS:}

Técnica Maria Lioba Lúcia Luciancencov Crespo (Liúba) e Técnico Luiz Henrique Silveira pela ajuda na aferição dos termômetros.

\section{LABORATÓRIO DE USINAGEM:}

Técnico Mecânico Edson Agostinho Lima da Silva e Técnico Mecânico Emerson da Silva por terem disponibilizado os equipamentos da oficina na fase de construção do pavimento

\section{LABORATÓRIO DE SOLDA:}

Técnico José Antonio dos Santos Neto (Branco) e acadêmico Elson Barão Soares (Barão) pela ajuda na construção do rolo de compressão e outras partes do projeto.

\section{LABORATÓRIO DE SOLOS:}

Técnico Osmar Alves pela análise de solo e determinação do CBR do solo utilizado no subleito da placa 1 e ter permitido o uso de equipamentos para o estudo das características do poliuretano.

\section{LABORATÓRIO DE ENSAIOS DE MATERIAIS:}

Técnico José Carlos Sobrinho e Técnico José Maria pelos ensaios dos corpos de prova, pelo cálculo do traço, ajuda na construção da placa e pelo controle tecnológico do concreto.

Aos acadêmicos José Fernando Paz Gonzáles e Thiago Arrabal Uemura pelo auxílio no conserto da máquina de compressão.

Aos funcionários das áreas de manutenção e serviços gerais do Instituto Presbiteriano Mackenzie 
A viagem da descoberta consiste não em achar novas paisagens, mas em ver com novos olhos. (Valentin Louis Georges Eugène Marcel Proust) - (Marcel Proust) 


\title{
ESTUDO EXPERIMENTAL DOS EFEITOS DA TEMPERATURA EM PAVIMENTO DE CONCRETO INSTRUMENTADO
}

\author{
FÁBIO RAIA
}

\section{RESUMO}

Este trabalho descreve um estudo experimental dos efeitos da temperatura em um elemento de pavimento de concreto, construído em laboratório interno e instrumentado com sensores de deformação, deslocamento, força e temperatura. A estrutura foi construída em duas camadas (placa e base) assentadas sobrepostas, sem aderência, sobre um subleito artificial. Os efeitos térmicos foram gerados artificialmente seguindo padrões sazonais da natureza. Os carregamentos estáticos foram realizados por meio de uma máquina hidráulica referenciados a um eixo simples de roda simples. A estrutura foi dimensionada e construída em uma escala de tamanho reduzido, distorcida e montada sobre uma laje de reação. Sob a placa do pavimento foi construído um sistema térmico auto controlado para causar diferencial de temperatura entre o fundo e o topo da placa pela passagem de um fluido. No topo um sistema térmico com controle manual foi construído para gerar gradientes térmicos através da estrutura. Todas as ações foram registradas automaticamente por meio de um sistema de aquisição de dados. Os resultados combinam com os dados da literatura, com experimentos realizados em pistas experimentais e se correlacionam com simulações realizadas por meio de software específico. Isso implica que a metodologia usada é apropriada para ser utilizada em outras situações e experimentos. 


\title{
ESTUDO EXPERIMENTAL DOS EFEITOS DA TEMPERATURA EM PAVIMENTO DE CONCRETO INSTRUMENTADO
}

\author{
FÁBIO RAIA
}

\begin{abstract}
This paper describes the experimental study of the effects of temperature on a element of concrete pavement, constructed an internal laboratory and instrumented with sensors of strain, displacement, force and temperature. The structure was built in two layers (slab and base) overlapping settled without grip on an artificial subgrade. The thermal effects were achieved artificially following nature seasonal patterns. The static loads were performed by means of a hydraulic machine referred to a simple wheel axle. The structure was sized and built on distorted small scale and assembled over a slab of reaction. Under the pavement a selfcontrolled heating system was built to cause a temperature gradients between the slab top and bottom from a passing fluid. On the top a manual heating system was built to generate thermal gradients across the structure. All the actions were recorded automatically through a data system. The results agree with the literature data, with experiments performed on experimental roads and correlate themselves with simulations performed by using specific software. This implies that the methodology used is appropriate for use in other situations and experiments.
\end{abstract}




\section{LISTA DE SÍMBOLOS}

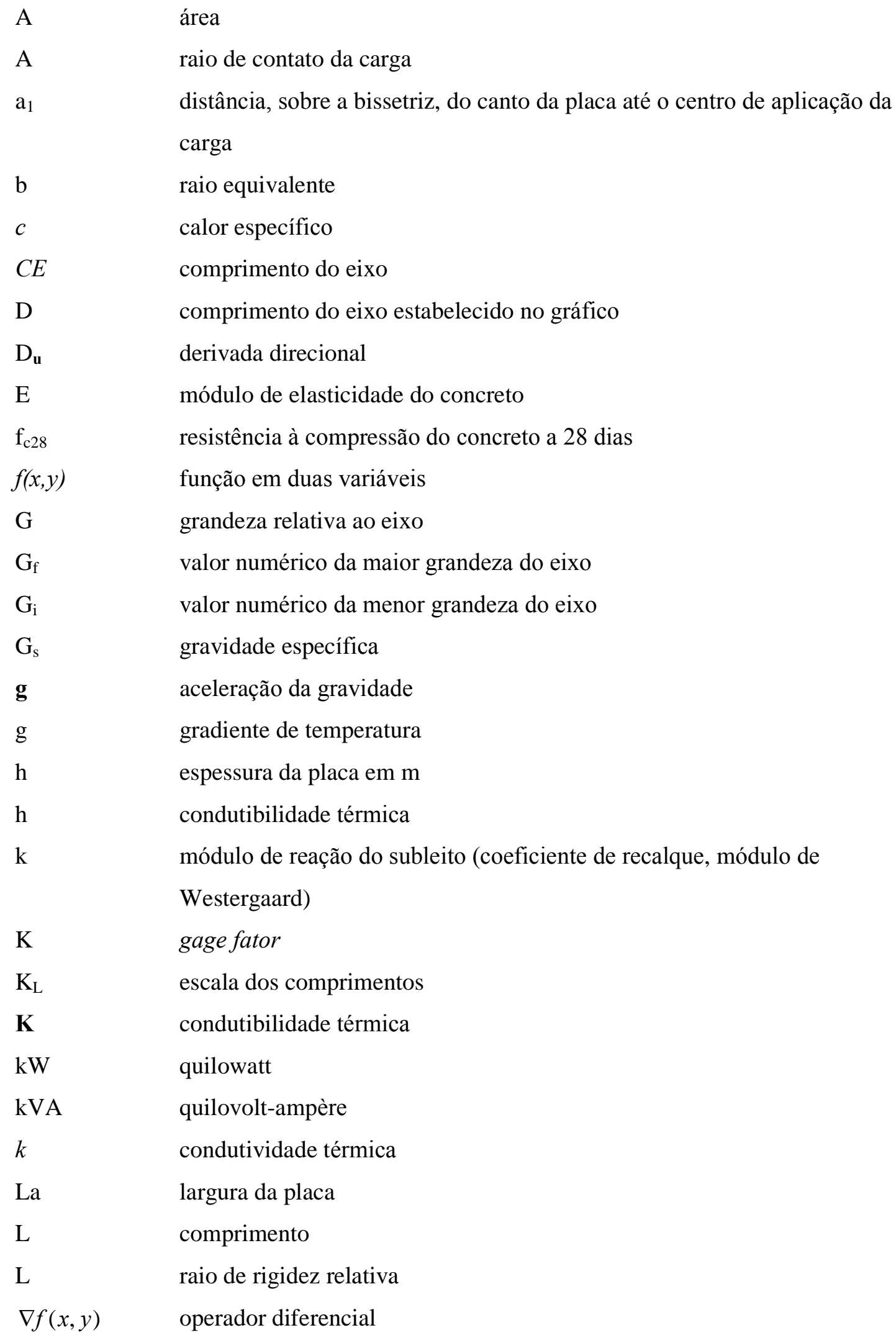




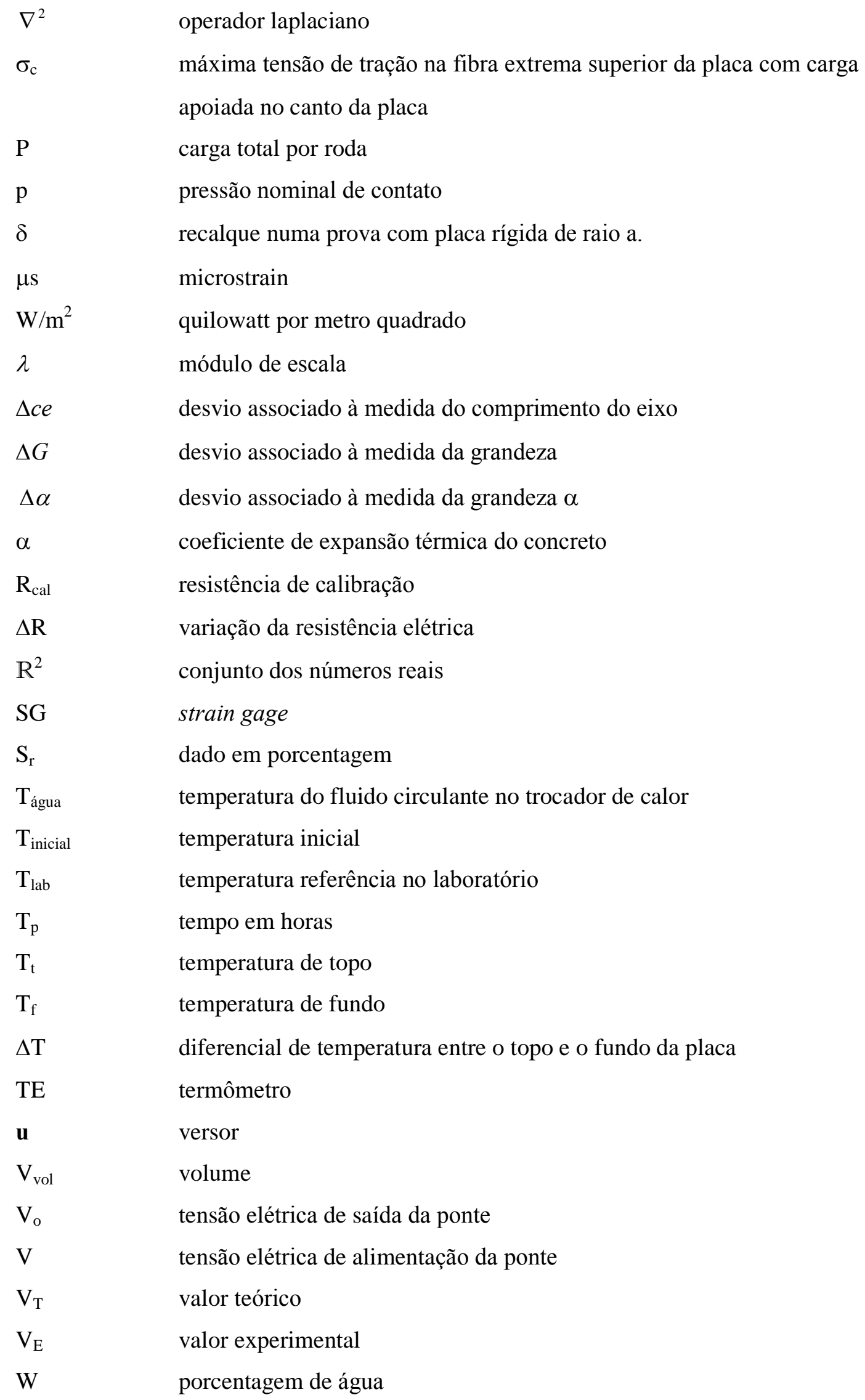




$\begin{array}{ll}\gamma & \text { densidade } \\ \sigma & \text { tensão na placa } \\ \varepsilon & \text { deformação } \\ \varepsilon_{\mathrm{f}} & \text { deformação na flexão } \\ \varepsilon_{\mathrm{n}} & \text { deformação normal } \\ \varepsilon_{\mathrm{t}} & \text { deformação devido à temperatura } \\ \cup & \text { coeficiente de Poisson } \\ \tau_{p u} & \text { tensão de cisalhamento da pasta de concreto } \\ \sigma_{p u} & \text { tensão normal da pasta } \\ \sigma_{\mathrm{e}} & \text { máxima tensão de tração na fibra extrema inferior da placa } \\ \sigma_{\mathrm{i}} & \text { máxima tensão de tração na fibra extrema inferior da placa } \\ \mu & \text { coeficiente de atrito entre pasta e agregado } \\ \rho & \text { resistividade } \\ \rho & \text { densidade } \\ \delta & \text { recalque numa prova com placa rígida de raio a } \\ \Pi & \text { número “pi”, indicação de números adimensionais }\end{array}$




\section{LISTA DE ABREVIATURAS E SIGLAS}

2D

3D

AASHO

AASHTO

$\mathrm{ABCP}$

ABNT

AEA

ANSYS

ARALDITE

ASTM

BG

BGTC

CPII-20

$\mathrm{BR}$

CAD

CBR

$\mathrm{CCP}$

CCR

CD-ROM

$\mathrm{CE}$

CE6-CE15D

CED

CIT

COPPE

$\mathrm{CP}$

DNER

DNIT

ECIL

EER

EEUPM
Duas dimensões espaciais

Três dimensões espaciais

American Association of State Highway Officials

American Association of State Highway and Transportation Officials

Associação Brasileira de Cimento Portland

Associação Brasileira de Normas Técnicas

Associação dos Engenheiros Automotivos

Software multifunção (comercial) para análise de estruturas pelo método dos elementos finitos

Cola epoxi bi-componente

American Society for Testing and Materials

Brita graduada

Brita graduada tratada com cimento

classificação para resistência final da argamassa

Brasil

Concreto de alto desempenho

Califórnia Bearing Ratio

Concreto de cimento Portland

Concreto compactado a rolo

Compact disk-Read only memory

Célula de embutimento ou de deformação

Célula de embutimento $6 \mathrm{em} 1 / 2$ ponte com célula de embutimento dummy

Célula de embutimento tipo dummy

Célula de inserção de temperatura

Instituto Alberto Luiz Coimbra de Pós-graduação e Pesquisa de Engenharia

Corpo de prova

Departamento Nacional de Estradas de Rodagem

Departamento Nacional de Infra-estrutura de Transportes

Temperatura industrial - fabricante de sensores de temperatura

Extensômetros elétricos de resistência

Escola de Engenharia da Universidade Presbiteriana Mackenzie 
ERE Extensômetro de resistência elétrica

ESRS Eixo simples roda simples

EUA Estados Unidos da América

EVERFE Software baseado no método dos elementos finitos

FEI Fundação Inaciana de Ensino

FHWA Federal Highway Administration

GUI Graphical user interface

IEC International electrotechnical commission

ILLI-SLAB Software específico (comercial) para projeto e análise de pavimento rígido

INMETRO Instituto Nacional de Metrologia Padronização e Qualidade Industrial

IPEN Instituto de Pesquisas Energéticas e Nucleares

IPR Instituto de pesquisas rodoviárias

IPT Instituto paulista de tecnologia

ISC Índice suporte Califórnia

LabView Linguagem de programação para controle automático e aquisição de dados

LTPP Long-Term Pavement Performance

LVDT Linear variable diferential transformer

MEF Método dos elementos finitos

MINITAB Software específico para análise estatística

MP Mackpesquisa

NBR Norma brasileira

N0 - N15 Temperatura nos níveis; zero (fundo) a quinze(superfície)

PID Sigla para sistema de controle proporcional integral derivativo

PVC Policloreto de vinila

PCA Portland Cement Association

PCMCIA Personal computer memory card international association

pdf Portable document format

PHYWE Fabricante de equipamentos didáticos

PI Poço de inspeção

POT Sensor potenciométrico para medida de deslocamento

Pt100 Sensor de resistência de platina

RBC Rede brasileira de calibração

SMP Seasonal Monitoring Program

SG Strain gage 
TAMB Temperatura externa ao laboratório

TCP/IP Transmission control protocol/Internet protocol

TE Sensor de temperatura

TFUN Termômetro localizado sobre a superfície da base

TERMOFLEX Software desenvolvido durante experimentos da placa 1

TIAFLEX Fabricante de fios e cabos

TLAB Temperatura ambiente no laboratório

TTOPO Termômetro no topo da placa

TVE Techglass FTVE-G10 (NEMA-10) - laminado com base de tecido de vidro

UFRJ Universidade Federal do Rio de Janeiro

UNICAMP Universidade de Campinas

UPM Universidade Presbiteriana Mackenzie

USP Universidade de São Paulo

WTUD Whitetopping ultradelgado 


\section{LISTA DE DESENHOS}

Desenho 1. Devido ao posicionamento do local do experimento, a umidade e a temperatura apresentaram valores com pouca variação em relação ao lado externo do prédio.

Desenho 2. Aspecto dos esforços nas camadas de um pavimento produzidos por uma carga externa: (a) pavimento rígido. (b) pavimento flexível ................................ 17

Desenho 3. Secção de um elemento de placa ................................................................ 23

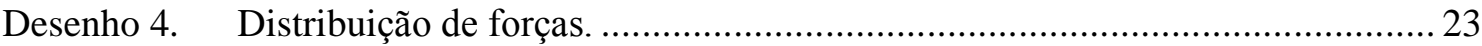

Desenho 5. Forma do elemento devido a tensões internas........................................... 23

Desenho 6. Comportamento do pavimento segundo as condições de temperatura diária .. 28

Desenho 7. Vista isométrica do comportamento da placa sob ação de um diferencial de

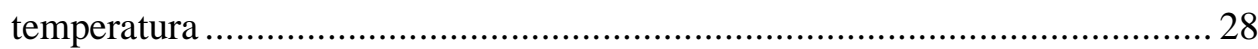

Desenho 8. Vista em planta da plataforma de aquecimento mostrando a disposição dos

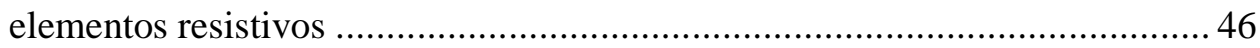

Desenho 9. Vista em planta do sistema de resfriamento/aquecimento no fundo da placa de CCP: (1) tubos "conduítes", (2) fundo da placa, (3) reservatório, (4) bomba hidráulica, (5) controlador de temperatura, (6) aquecedor, (7) e (8) válvulas e (9) sensor de temperatura 51

Desenho 10. Vista em corte da seção transversal da placa, com sistema refrigeração / aquecimento. Todas as medidas estão em centímetros ................................ 52

Desenho 11. Representações dos modelos mais utilizados para representação do comportamento de um solo, imposto um carregamento. ............................ 77

Desenho 12. Corte transversal do poço, onde está localizado o sistema célula de carga e base magnética. Esse procedimento foi utilizado para detectar o empenamento da placa. 80

Desenho 13. Corte transversal do poço, onde está localizada a nova célula de carga e como está posicionada.

80

Desenho 14 (a) ilustração da técnica proposta para formação de células em meia ponte, utilizando a CIT, (b) aspecto da célula de inserção de temperatura CIT ......... 88

Desenho 15. Corte longitudinal da placa, no plano (yoz), indicando a posição dos termômetros. Todas as medidas estão em centímetros. 89

Desenho 16. Corte transversal da placa, no plano (xoz), indicando a posição dos termômetros. Todas as medidas estão em centímetros. 
Desenho 17. Vista no plano (xoy), em planta, da placa indicando a posição dos termômetros. Todas as medidas estão em centímetros. ................................. 90

Desenho 18. Corte transversal da placa, no plano (xoz), indicando a posição das células de embutimento. Todas as medidas estão em centímetros.................................. 91

Desenho 19. Corte longitudinal da placa, no plano (yoz), indicando a posição das células de embutimento. Todas as medidas estão em centímetros............................... 91

Desenho 20. Vista no plano (xoy), em planta, da placa indicando a posição das células de embutimento. Todas as medidas estão em centímetros. 91

Desenho 21. (a) circuito interno ao sistema de aquisição com a nomenclatura utilizada nos testes e as ligações dos cabos ao borne de entrada, (b) desenho esquemático mostrando a disposição dos elementos resistivos (extensômetros) 1 e 2 dos resistores fixos 3 e 4 . 92

Desenho 22. Disposição das células de embutimento no interior da placa, com a função de medir flexão sem gradiente (taxa de variação térmica) de temperatura. Os traços na vertical indicam a posição do poço de inspeção PI......................... 94

Desenho 23. Esquema de ligação interno ao sistema de aquisição de dados..................... 94

Desenho 24. Disposição das células de embutimento no interior da placa, com a função de medir flexão com tração sem temperatura..................................................... 94

Desenho 25. Esquema de ligação interno ao sistema de aquisição de dados...................... 95

Desenho 26. Disposição das células, internamente à placa, para medida de tração com ou sem gradiente (taxa de variação térmica) de temperatura. 95

Desenho 27. Esquema de ligação interno ao sistema de aquisição de dados na configuração de ponte completa. 95

Desenho 28. Posição genérica de duas células, ligadas em ponte, para ocorrer a soma dos efeitos de deformação. O traço escuro representa a posição do extensômetro dentro da célula de embutimento........................................................... 96

Desenho 29. Situação estilizada quando a placa sofrer um diferencial de temperatura $\mathrm{T}_{\text {topo }}$

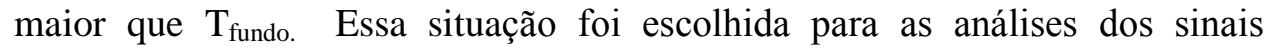
aquisitados. 97

Desenho 30. Posição das células nos bornes do ADS 500. A célula "1" refere-se à CE e a célula " 2 " refere-se à CIT.

Desenho 31. CE sendo solicitada na flexão com extensômetro posicionado na parte superior da CE. 
Desenho 32. CE sendo solicitada na flexão com extensômetro posicionado na parte superior da CE .98

Desenho 33. CE sendo solicitada na flexão com extensômetro posicionado na parte inferior da CE. 98

Desenho 34. CE sendo solicitada na flexão com extensômetro posicionado na parte superior da CE. 98

Desenho 35. Modelo para interação entre pasta e agregado. 102

Desenho 36. Procedimento para modelagem da perda de contato entre camadas 102

Desenho 37. Carga transferida de uma placa para outra através do 'intertravamento' existente quando da realização de uma junta serrada...... 103

Desenho 38. Aspecto da malha de um sistema de duas camadas produzido pelo software...... 103

Desenho 39. Apresentação gráfica, como interface com o usuário, da simulação de temperatura. 104

Desenho 40. Aspecto da tela gráfica para inserção da geometria da placa....................... 105

Desenho 41. Aspecto da tela gráfica para inserção dos dados físicos da placa................. 105

Desenho 42. Aspecto da tela gráfica para inserção do carregamento da placa. Nesse desenho, foi utilizado apenas o carregamento térmico. 106

Desenho 43. Aspecto da tela gráfica apresentada quando da geração da malha de elementos finitos 107

Desenho 44. Vista em corte do conjunto pavimento e plataforma de aquecimento 110

Desenho 45. (a) Bloco de madeira serviu de suporte para a aplicação da carga (q) e o elastômero que serviu como ajuste de nivelamento para a aplicação da carga e também como simulação das características dos pneus dos veículos, (b) Imprimação do formato de um pneu sobre um pavimento

Desenho 46. Desenho esquemático das partes constituintes da célula de embutimento .... 191

Desenho 47. Diagrama esquemático da ligação para verificação da sensibilidade da célula de embutimento . 198

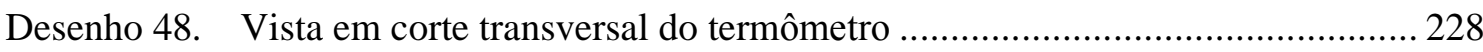

Desenho 49. Mapa da localização dos sensores internos na placa ................................... 232

Desenho 50. Dimensões da placa de concreto................................................................ 233

Desenho 51. Nomenclatura dos resistores e malhas da ponte de Wheatstone, conforme utilizado nas demonstrações 
Desenho 52. Aspecto da deformação da placa sob carga estática quando aplicada na borda. A placa e a base, não deformadas, aparecem traçadas sob a placa em linhas contínuas. 246

Desenho 53. Aspecto da deformação da placa sob carga estática quando aplicada na borda. A placa e a base não deformadas aparecem traçadas sob a placa em linhas

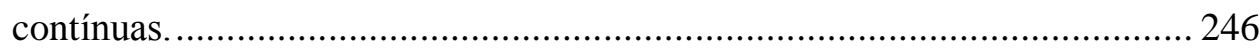

Desenho 54. Corte transversal do pavimento, propriedades físicas e condições de contorno da análise térmica transiente............................................................... 247

Desenho 55. Corte transversal do pavimento, campo de temperatura incial. ................... 247

Desenho 56. Corte transversal do pavimento, campo de temperatura após 1 hora ............ 247

Desenho 57. Corte transversal do pavimento, campo de temperatura após 2 horas........... 248

Desenho 58. Corte transversal do pavimento, campo de temperatura após 3 horas........... 248

Desenho 59. Corte transversal do pavimento, campo de temperatura após 4 horas........... 248

Desenho 60. Corte transversal do pavimento, campo de temperatura após 5 horas........... 248

Desenho 61. Vista do pavimento, campo de temperatura após 5 horas (modelo 3D)....... 249

Desenho 62. Corte transversal do pavimento, detalhe do campo de temperatura após 5 horas (modelo 3D) 


\section{LISTA DE FOTOGRAFIAS}

Fotografia 1. Pavimento de concreto simples: (a) Placas separadas pelo corte transversal com trinca induzida. Corredor de ônibus avenida Vicente Rao, São Paulo, trecho próximo à avenida Whashington Luis (2006) . (b) Vista em corte e planta de um pavimento de concreto simples......................................................... 19

Fotografia 2. Molde utilizado para confecção do CP e testes de embutimento, dimensões 100,0x 100,0x 500,0 mm................................................................... 36

Fotografia 3. Vigota isolada termicamente nas laterais e instrumentada com sensores de

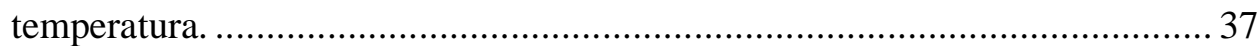

Fotografia 4. Molde para construção da vigota de testes preliminares............................... 39

Fotografia 5. Aspecto do molde com a vigota moldada. .................................................. 39

Fotografia 6. Teste de flexão para verificação da sensibilidade da célula de embutimento.. 40

Fotografia 7. Sensor de embutimento pronto para uso...................................................... 42

Fotografia 8. (a) Máquina de ensaio universal em processo de teste, (b) detalhe da amostra submetida à flexão em três pontos, (c) sistema próprio de aquisição de dados....

Fotografia 9. Dispositivo utilizado para calibração das células de embutimento: (a) indicador digital em (mV/V) da célula de carga, (b) mesa de desempeno, (c) indicador digital em $(\mathrm{mV} / \mathrm{V})$ da célula de embutimento, (d) ponte de Wheatstone da célula de embutimento, (e) célula de embutimento sob tração, (f) polia, (g) cabo de aço, (h) célula de Carga, (i) massores, (j) suporte de tração. 44

Fotografia 10. Aspecto do termômetro acabado utilizado para as medições de temperatura.. 45

Fotografia 11. (a) plataforma de aquecimento revestida com lâmina de alumínio, (b) detalhe dos isoladores cerâmicos utilizados na montagem dos elementos resistivos (resistências) na plataforma. 47

Fotografia 12. Aspecto do autotransformador (variável) responsável por estabelecer as tensões sobre as resistências da placa de aquecimento.

Fotografia 13. Disposição dos equipamentos utilizados no processo de aquecimento do fundo da placa. 51

Fotografia 14. Utilizando um paquímetro na obtenção do passo utilizado em gráfico. 54

Fotografia 15. Aspecto do molde já com a placa de poliuretano colocado e um termômetro no centro para leitura da temperatura no subleito (TE14) .68 
Fotografia 16. Colocação da base sobre o subleito. No centro foi colocado um tubo de 120,0 mm de diâmetro para moldar o poço onde foi colocada a célula de carga....... 69

Fotografia 17. Detalhe da amostra de poliuretano sob teste de compressão. ......................... 74

Fotografia 18. Colocação da manta plástica para evitar a aderência da placa de concreto. Vista do posicionamento dos sensores na placa e colocação dos conduítes para resfriamento ou aquecimento do fundo da placa. ..................................... 77

Fotografia 19. Detalhe do conjunto termômetro e célula de deformação presos no cavalete. 78 Fotografia 20. Proteção dos sensores com concreto antes da colocação da totalidade de massa. Isso evita que ocorra algum deslocamento dos sensores, devido à pressão que a massa impõe sobre esses componentes. .78

Fotografia 21. Aspecto da placa já terminada após 28 dias, tendo sob ela a laje de reação e sobre ela uma máquina hidráulica para testes de carregamento estático. 79

Fotografia 22. (a) célula de carga com base magnética para fixação no piso da laje de reação, (b) base com a cavidade de abrigo (poço) da célula de carga, (c) célula de carga posicionada dentro da cavidade.

Fotografia 23. (a) visão geral do sistema de aquisição de dados, (b) aspecto do equipamento de aquisição e (c) detalhe dos canais onde são ligados os sensores e das micochaves. 81

Fotografia 24. Posição dos termômetros dentro do molde do pavimento, fixados sobre a base, antes da concretagem da placa. 88

Fotografia 25. Placa sendo submetida a teste de temperatura com sensores ligados no sistema de aquisição de dados. 110

Fotografia 26. Sensor colocado no canto do pavimento para medida de deslocamento e, no desenho ao lado, as posições de medida dos deslocamentos.

Fotografia 27. Vista das partes que compõem a célula de embutimento 191

Fotografia 28. Dispositivo para medida da dilatação linear do TVE. (a) base, (b) TVE, (c) micrômetro e (d) multímetro. 192

Fotografia 29. Notas explicativas de cada componente da mesa de testes. A mesa de desempeno em todos os testes foi nivelada e fixada na bancada. 196

Fotografia 30. A célula de carga foi posicionada na haste de suporte dos massores. 197

Fotografia 31. a) Estação gravimétrica colocada no piso do laboratório de ensaios mecânicos; b) detalhe identificando a estação com o respectivo valor de " $\mathrm{g}$ ". 199

Fotografia 32. Disposição dos equipamentos utilizados nos testes de calibração por meio de um shunt resistivo 207 
Fotografia 33. Banho termostatizado com quatro sensores em teste.

217

Fotografia 34. Forno utilizado para a calibração dos termômetros. Fabricante ECIL Temperatura Industrial Modelo Júpiter 650

218

Fotografia 35. Conjunto de calibração envolvendo banho termostatizado, termômetros (em azul), condicionadores de sinal e notebook com placa de aquisição

Fotografia 36. Disposição dos equipamentos utilizados para calibração do termômetro e do

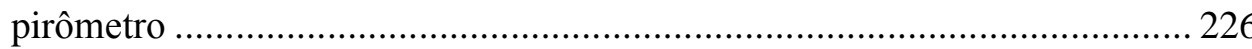

Fotografia 37. Ligação entre o medidor de simulação Cappo plus e o pirômetro 227

Fotografia 38. Aspecto do molde da placa já com o solo compactado e um termômetro no centro da placa para leitura da temperatura no subleito 230

Fotografia 39. Colocação da base da placa 231

Fotografia 40. Colocação da manta plástica para evitar a aderência da placa de concreto. Vista do posicionamento dos sensores na placa e colocação de reforços nas paredes do molde 232

Fotografia 41. Vista de um sensor de deformação apoiado sobre um cavalete e, detalhe..... 233 Fotografia 42. Detalhe de um conjunto termômetro e célula de deformação presos no cavalete 233

Fotografia 43. Proteção dos sensores com concreto antes da colocação da totalidade de massa. Isso evita que ocorra algum deslocamento dos sensores, devido à pressão que a massa impõe sobre esses componentes. 234

Fotografia 44. Aspecto da placa em sua fase final de construção 234

Fotografia 45. Disposição do sistema de gerenciamento e aquisição de sinais TERMOFLEX ..

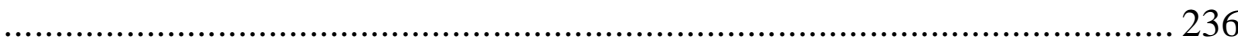

Fotografia 46. Ligação dos sensores ao sistema de aquisição de dados..... 237 


\section{LISTA DE GRÁFICOS}

Gráfico 1. Concepção analítica de Thomlinson (a) e verificação experimental de Balbo e

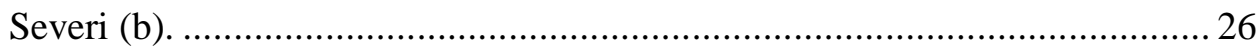

Gráfico 2. Variação da temperatura em quatro posições distintas no CP (vigota). .......... 38

Gráfico 3. Resposta da célula embutida na vigota ao ensaio de flexão.......................... 40

Gráfico 4. Distribuição da radiação solar dia 09/01/08. A linha cheia representa a tendência da radiação caso não fossem as ações de sombras causadas por nuvens. A linha de tendência foi traçada automaticamente por meio do método de Winter. Utilizado em séries temporais cujos componentes têm características de sazonalidade. ............................................................... 48

Gráfico 5. Potência dissipada pelo conjunto de resistências na plataforma de aquecimento.

Gráfico 6. Distribuição da temperatura em dia comum (09/01/08). A linha cheia representa a tendência da temperatura. ...................................................... 49

Gráfico 7. Ação do controle de tensão sobre o efeito da temperatura.............................5 50

Gráfico 8. Medida do comprimento do eixo abscissas indicando um intervalo de vinte e quatro horas equivale a 120,56 mm. A medida do eixo das ordenadas indica em um intervalo de $25^{\circ} \mathrm{C}$ equivalente a $40,49 \mathrm{~mm}$. O gráfico refere-se ao comportamento da temperatura em uma das placas da pista experimental construída na Cidade Universitária (USP), São Paulo................................... 54

Gráfico 9. Variação de temperatura no topo da placa com cálculo da razão $3,5^{\circ} \mathrm{C} / \mathrm{h}$ do

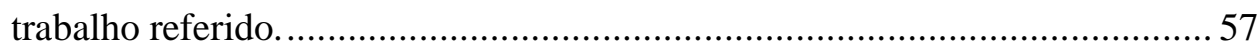

Gráfico 10. Variação da temperatura média do topo de várias placas de concreto, estrada

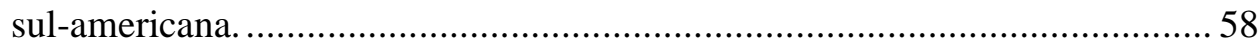

Gráfico 11. Variação da temperatura no topo em placas de concreto instrumentadas,

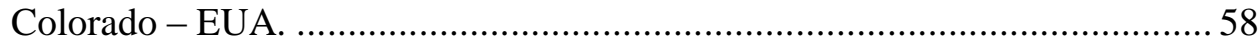

Gráfico 12. Variação da temperatura no topo da placa de concreto instrumentada, mês ... 59

Gráfico 13. Variação da temperatura em função do tempo, no topo de placa de pavimento instrumentado na Flórida - EUA, para estudo de deformações. .................... 59

Gráfico 14. Variação de temperatura do ar, em função do tempo, nas imediações de pavimento instrumentado no Kentucky EUA............................................. 60 
Gráfico 15. Variação de temperatura típica, diária, em função do tempo em dia frio, com sol na superfície do pavimento.

Gráfico 16. Variações da temperatura em função do tempo em 15 de agosto de 1984, na Flórida - EUA, nas imediações do pavimento instrumentado. 61

Gráfico 17. Variações de temperatura em função do tempo no verão de 2003, na interestadual I-70 Flórida - EUA............................................................ 61

Gráfico 18. Aspecto do acréscimo da temperatura em uma vigota de concreto instrumentada. Inverno de 2006. São Paulo - Campus da Universidade Presbiteriana Mackenzie com análise por regressão no software MINITAB. . 62

Gráfico 19. Aspecto do aumento da temperatura em pavimento de concreto no corredor de ônibus Diadema - São Paulo. 63

Gráfico 20. Curvas utilizadas no estabelecimento das taxas de aquecimento, aplicadas sobre a placa de concreto pela placa de aquecimento. 64

Gráfico 21. Aspecto da temperatura ao longo da espessura da placa e da base, onde é possível verificar a variação do gradiente (taxa de variação) ao longo do

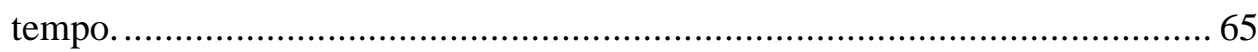

Gráfico 22. Distribuição de temperatura durante o mês de julho de 2006........................ 65

Gráfico 23. Curva característica de tensão por deformação utilizada para determinação do módulo de reação. 74

Gráfico 24. Curva característica de tensão vs. deformação para determinação do módulo de elasticidade do poliuretano e ponto de ruptura do CP................................. 75

Gráfico 25. Teste de verificação de estabilidade das células de embutimento num período de 24 horas com temperatura constante. ...................................................... 84

Gráfico 26. Período de estabilidade verificado durante os testes. ................................. 85

Gráfico 27. Comportamento das células mediante o aquecimento do topo da placa......... 86

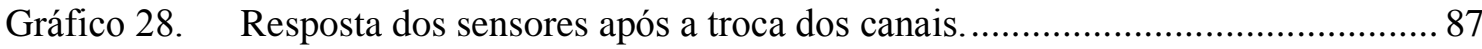

Gráfico 29. Comportamento das temperaturas durante um ciclo de testes realizado na placa de CCP. N-10 $\rightarrow$ temperatura entre subleito e base a $0,25 \mathrm{~m}$ do topo, N0 $\rightarrow$ temperatura no fundo da placa $0,15 \mathrm{~m}$ do topo, $\mathrm{N} 15 \rightarrow$ temperatura da superfície da placa com termômetro embutido, TTOPO $\rightarrow$ temperatura no topo da placa com termômetro colocado sobre a sua superfície, TELAB $\rightarrow$ temperatura do ar dentro do laboratório de testes e $\mathrm{TAMB} \rightarrow$ temperatura externa tomada pela estação de coleta de dados localizada no telhado do prédio do laboratório, essa medida foi feita no dia 28/08/2008. 109 
Gráfico 30. Comportamento da temperatura em um dia ensolarado.

Gráfico 31. Processo para determinação das taxas de temperatura, T1, taxa de elevação da tempreratura de topo, T2, taxa de elevação da temperatura de fundo.

Gráfico 32. Simulação de um dia ensolarado, segundo o gráfico 26 Severi (2001)......... 114

Gráfico 33. Correlação entre os dados de temperatura de ambos os experimentos, Severi (2002) e ensaio de laboratório.

Gráfico 34. Comportamento da temperatura em um dia ensolarado. ............................ 116

Gráfico 35. Simulação de um dia ensolarado, segundo o gráfico 30 Severi (2001)......... 116

Gráfico 36. Dia quente com chuva no período.......................................................... 117

Gráfico 37. Simulação em laboratório de um dia quente com chuva no período............. 117

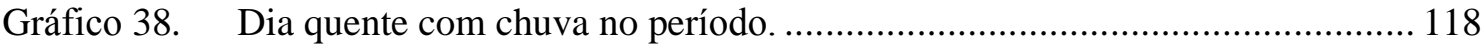

Gráfico 39. Simulação em laboratório de um dia quente com chuva no período............. 119

Gráfico 40. Comportamento da temperatura em um dia claro de verão. .......................... 120

Gráfico 41. Simulação de um dia claro e ensolarado, segundo o gráfico 36 Armaghani (1987).

Gráfico 42. Correlação entre os dados de temperatura de ambos os experimentos,......... 121

Gráfico 43. Comportamento da temperatura em um dia claro de verão. ........................ 122

Gráfico 44. Simulação de um dia claro e ensolarado, segundo o gráfico 39 Armaghani (1987). 122

Gráfico 45. Comportamento típico diurno da temperatura........................................... 123

Gráfico 46. Thompson (1987) Simulação do comportamento diurno da temperatura...... 124

Gráfico 47. Correlação entre os dados de temperatura de ambos os experimentos,......... 125

Gráfico 48. Simulação do comportamento diurno da temperatura, Thompson (1987).... 125

Gráfico 49. Comportamento da temperatura a 2,5 cm do topo, ponto médio e a 2,5 $\mathrm{cm}$ do fundo do pavimento....................................................................... 126

Gráfico 50. Simulação de Richardson e Armaghani (1987)......................................... 127

Gráfico 51. Correlação entre os dados de temperatura de ambos os experimentos, ,........ 128

Gráfico 52. Comportamento da temperatura a $2,5 \mathrm{~cm}$ do topo, ponto médio e a 2,5 $\mathrm{cm}$ do fundo do pavimento............................................................................... 128

Gráfico 53. Simulação de Richardson e Armaghani (1987)........................................... 129

Gráfico 54. Aspecto do comportamento temporal da temperatura ao longo da espessura da placa do pavimento.

Gráfico 55. Aspecto do comportamento temporal da temperatura ao longo da espessura da placa do pavimento. 130 
Gráfico 56. Aspecto do comportamento temporal da temperatura ao longo da espessura da placa do pavimento num período de 48 horas.

Gráfico 57. Distribuição da temperatura ao longo da espessura e sua dependência com o tempo.

Gráfico 58. Distribuição da temperatura ao longo da espessura e sua dependência com o tempo. Situação quando o topo da placa foi resfriado com gelo

Gráfico 59. Distribuição da temperatura ao longo da espessura e sua dependência com o tempo. Situação quando o topo da placa foi molhado, simulando chuva. ..... 132

Gráfico 60. Relação entre o carregamento sobre a placa de concreto pela força registrada no fundo da placa pela célula de carga (tanstec), intervalo de confiança 95\% e $\mathrm{R}^{2}=99,5 \%$

Gráfico 61. Deslocamento medido na lateral esquerda no sentido transversal em $(\mathrm{x}, \mathrm{y} / 2)$ devido a um carregamento central. Intervalo de confiança $95 \%$ e $\mathrm{R}^{2}=99,7 \% 136$

Gráfico 62. Deslocamento medido na lateral esquerda no sentido transversal em (x,y/2) devido a um carregamento central. Simulação no software EverFe 2.24. Intervalo de confiança $95 \%$ e $\mathrm{R}^{2}=100,0 \%$

Gráfico 63. Deslocamento medido no canto esquerdo devido a um carregamento no centro da placa. Intervalo de confiança $95 \%$ e $\mathrm{R}^{2}=96 \%$

Gráfico 64. Deslocamento medido no canto esquerdo devido a um carregamento no centro da placa. Simulação realizada no sotware EverFe 2.24. Intervalo de confiança $95 \%$ e $\mathrm{R}^{2}=99,7 \%$

Gráfico 65. Deslocamento medido na lateral esquerda no sentido transversal em (x,y/2) devido a um carregamento na borda direita. Intervalo de confiança 95\% e $\mathrm{R}^{2}=99,1 \%$

Gráfico 66. Deslocamento medido na lateral esquerda no sentido transversal em $(\mathrm{x}, \mathrm{y} / 2)$ devido a um carregamento na borda direita. Simulação no software EverFe 2.24. Intervalo de confiança $95 \%$ e $\mathrm{R}^{2}=99,8 \%$ 138

Gráfico 67. Deslocamento medido no canto esquerdo a um carregamento na borda direita. Intervalo de confiança $95 \%$ e $\mathrm{R}^{2}=99,2 \%$

Gráfico 68. Deslocamento medido no canto esquerdo a um carregamento na borda direita. Simulação no software EverFe 2.24. Intervalo de confiança $95 \%$ e $\mathrm{R}^{2}=100 \% \ldots$.

Gráfico 69. Comportamento de flexão da placa, devido à variação de temperatura. 142 
Gráfico 70. Gradiente térmico em função do tempo durante o processo de aquecimento da placa. 142

Gráfico 71. Comportamento tensional da placa, devido à variação de temperatura 143

Gráfico 72. Comportamento tensional da placa, devido à variação de temperatura. Teste

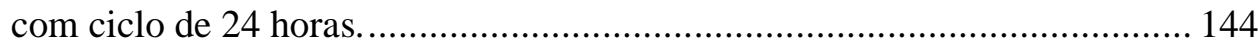

Gráfico 73. Deslocamento no canto da placa sob aquecimento superficial em função do diferencial de temperatura $\Delta \mathrm{T}$ e do momento do evento. 145

Gráfico 74. Deslocamento no canto da placa sob aquecimento superficial em função do diferencial de temperatura $\Delta \mathrm{T}$ e do momento do evento. 145

Gráfico 75. Deslocamento no canto da placa sob aquecimento superficial com potência constante e em função do $\Delta \mathrm{T}$ e do instante do evento. 146

Gráfico 76. Deslocamento da borda, no canto da placa sob aquecimento e um resfriamento simulando um dia de chuva em função do instante do evento e do $\Delta \mathrm{T}$. 147

Gráfico 77. Deslocamento da borda, no canto da placa sob resfriamento superficial em função do instante do evento e do $\Delta \mathrm{T}$. 147

Gráfico 78. Medida do deslocamento no canto da placa de um pavimento real sob aquecimento natural. 148

Gráfico 79. Medida do deslocamento no canto da placa de um pavimento real sob aquecimento natural. 148

Gráfico 80. Distribuição temporal da temperatura ao longo da espessura da placa para aquecimento no fundo. 151

Gráfico 81. Deslocamento da borda, no canto da placa sob aquecimento no fundo da placa.

Gráfico 82. Deslocamento da borda, no canto da placa sob aquecimento no fundo da placa. 153

Gráfico 83. Deformação medida por CE7 devido a um carregamento no centro. Intervalo de confiança $95 \%$ e $\mathrm{R}^{2}=97,8 \%$. Posição da célula $(81,149,6) \mathrm{cm}$, desenhos 18,19 e 20. 153

Gráfico 84. Deformação medida por CE7, a $1 / 4$ de ponte, devido a um carregamento no centro. Intervalo de confiança $95 \%$ e $\mathrm{R}^{2}=97 \%$. Posição da célula $(81,149,6)$ $\mathrm{cm}$, desenhos 18,19 e 20 . 
Gráfico 85. Deformação simulada na posição de CE7 devido a um carregamento no centro. Intervalo de confiança $95 \%$ e $\mathrm{R}^{2}=98,9 \%$. Posição da célula $(81,149,6) \mathrm{cm}$, desenhos 18,19 e 20 . 155

Gráfico 86. Deformação medida por CE7+CIT, em 1/2 de ponte, devido a um carregamento no centro. Intervalo de confiança $95 \%$ e $\mathrm{R}^{2}=98,9 \%$. Posição da célula $(81,149,6) \mathrm{cm}$, desenhos 18,19 e 20 . 155

Gráfico 87. Deformação medida por CE9+CIT, em $1 / 2$ de ponte, devido a um carregamento no centro. Intervalo de confiança $95 \%$ e $\mathrm{R}^{2}=99,2 \%$. Posição da célula $(81,149,13) \mathrm{cm}$, desenhos 18,19 e 20 . 156

Gráfico 88. Deformação ocasionada em CE10+CE13D, transversal à placa, segundo a simulação de um dia ensolarado. 158

Gráfico 89. Deformação ocasionada em CE10+13D, segundo simulação de um dia ensolarado com variação na taxa de aquecimento. 158

Gráfico 90. Deformação ocasionada em CE10+CE13D, segundo simulação de um dia ensolarado com variação na taxa de aquecimento. 158

Gráfico 91. Deformação ocasionada em CE7+CE8, segundo simulação de um dia ensolarado com variação na taxa de aquecimento. 159

Gráfico 92. Deformação ocasionada em CE7+CE8, segundo simulação de um dia ensolarado com variação na taxa de aquecimento. 159

Gráfico 93. Deformação ocasionada em CE7+CE8, segundo simulação de um dia ensolarado com variação na taxa de aquecimento. 160

Gráfico 94. Deformação ocasionada em CE8+CE9, segundo simulação de um dia ensolarado com variação na taxa de aquecimento. 160

Gráfico 95. Deformação ocasionada em CE8+CE9, segundo simulação de um dia ensolarado com variação na taxa de aquecimento. 161

Gráfico 96. Deformação ocasionada em CE8+CE9, segundo simulação de um dia ensolarado com variação na taxa de aquecimento. 162

Gráfico 97. Deformação ocasionada em CE7+CIT, segundo simulação de um dia ensolarado com pequena variação na taxa de aquecimento. 163

Gráfico 98. Deformação ocasionada em CE7+CIT, segundo simulação de um dia ensolarado com pequena variação na taxa de aquecimento. 163

Gráfico 99. Deformação ocasionada em CE7+CIT, segundo simulação de um dia ensolarado com pequena variação na taxa de aquecimento. 164 
Gráfico 100. Deformação ocasionada em CE10+CIT, segundo simulação de um dia ensolarado com variação na taxa de aquecimento. .................................... 164

Gráfico 101. Deformação ocasionada em CE10+CIT, segundo simulação de um dia ensolarado com variação na taxa de aquecimento. 165

Gráfico 102. Deformação ocasionada em CE7+CIT, segundo simulação de um dia

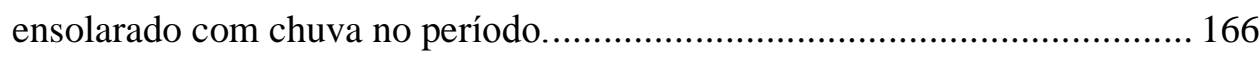

Gráfico 103. Deformação ocasionada em CE10+CIT, segundo simulação de um dia ensolarado com chuva no período........................................................... 166

Gráfico 104. Deformação ocasionada em CE11+CIT, segundo simulação de um dia ensolarado com chuva no período............................................................ 166

Gráfico 105. Deformação ocasionada em CE7+CIT, segundo simulação de um dia ensolarado passando a nublado no período. 167

Gráfico 106. Deformação ocasionada em CE8+CIT, segundo simulação de um dia ensolarado passando a nublado no período. .......................................... 168

Gráfico 107. Deformação ocasionada em CE12+CIT, segundo simulação de um dia ensolarado passando a nublado no período. .......................................... 168

Gráfico 108. Deformação ocasionada em CE7+CIT, devido a ocorrência de um resfriamento no topo do pavimento 169

Gráfico 109. Deformação ocasionada em CE01+CIT, devido a ocorrência de um resfriamento no topo do pavimento. 170

Gráfico 110. Deformação ocasionada em CE11+CIT, devido a ocorrência de um resfriamento no topo do pavimento. 170

Gráfico 111. Temperatura nos níveis de referência durante os testes de carregamento combinado.

Gráfico 112. Aspecto do carregamento imposto sobre a estrutura em duas posições distintas, centro e borda 171

Gráfico 113. Deslocamento da placa mediante a um carregamento combinado, térmico e estático no centro e borda.

Gráfico 114. Deformação da placa mediante a um carregamento combinado, térmico e estático no centro e borda. 173

Gráfico 115. Força no fundo da placa mediante a um carregamento combinado, térmico e estático no centro e borda 174

Gráfico 116. Deformação causada por carga dinâmica em pavimento real instrumentado.175 
Gráfico 117. Deformação devido a carga térmica e devido ao tráfego em uma seção da estrada I-265 -Kentucky -USA. ....................................................... 176

Gráfico 118. Deformação em pavimento instrumentado quando da ocorrência de carga móvel. 177

Gráfico 119. Deslocamento de placa de pavimento em um trecho da Pan-Americam Highway - Chile.

Gráfico 120. Comportamento de placa de pavimento sob carga térmica. Os deslocamentos foram medidos no centro, borda e canto através de LVDT $(1 " \rightarrow 2,54 \mathrm{~cm})$. . 178

Gráfico 121. Estabelecimento da dependência da temperatura e determinação do coeficiente de dilatação do material TVE - DUROFLEX. 193

Gráfico 122. Estabelecimento da dependência da temperatura e determinação do coeficiente de dilatação do material TVE - DUROFLEX por meio da associação CE+CIT.

Gráfico 123 Resposta das células com respeito ao carregamento ................................. 201

Gráfico 124 Resposta das células com respeito ao carregamento ................................. 201

Gráfico 125 Resposta das células com respeito ao carregamento ................................ 202

Gráfico 126 Resposta das células com respeito ao carregamento ................................... 202

Gráfico 127. Resposta das células com respeito ao carregamento .................................. 203

Gráfico 128. Resposta das células em $\mu$ s em função do carregamento ............................ 204

Gráfico 129. Resposta das células em $\mu$ s em função do carregamento ............................ 205

Gráfico 130. Resposta das células em $\mu$ s em função do carregamento ............................ 205

Gráfico 131. Resposta das células em $\mu$ s em função do carregamento ............................ 206

Gráfico 132. Resposta das células em $\mu$ s em função do carregamento ............................ 206

Gráfico 133. Relação entre deformação e valor médio em $\mathrm{mV} / \mathrm{V}$ para efeito de calibração da célula de embutimento em função da deformação..................................... 207

Gráfico 134. Resposta das CE em mV/V em função do carregamento. ........................... 209

Gráfico 135. Resposta das CE em mV/V em função do carregamento. ........................... 209

Gráfico 136. Resposta das CE em mV/V em função do carregamento. ........................... 210

Gráfico 137. Resposta das CE em mV/V em função do carregamento. ............................. 210

Gráfico 138. Resposta das CE em mV/V em função do carregamento. .......................... 211

Gráfico 139. Resposta das CE em mV/V em função do carregamento. ............................ 211

Gráfico 140. Resposta das CE em mV/V em função do carregamento. .......................... 212

Gráfico 141. Resposta das CE em mV/V em função do carregamento. .......................... 212 
Gráfico 142. Resposta das CE em mV/V em função do carregamento. ........................... 213

Gráfico 143. Resposta das CE em mV/V em função do carregamento. ........................... 213

Gráfico 144. Resposta das CE em mV/V em função do carregamento. ............................ 214

Gráfico 145. Resposta das CE em mV/V em função do carregamento. ............................ 214

Gráfico 146. Resposta das CE em mV/V em função do carregamento. ........................... 215

Gráfico 147. Resposta das CE em mV/V em função do carregamento. ........................... 215

Gráfico 148. Resposta das CE em mV/V em função do carregamento. ........................... 216

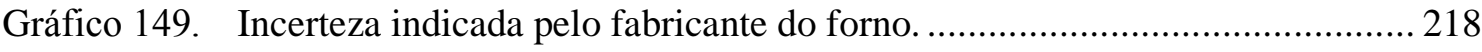

Gráfico 150. Comparação entre os valores de temperatura do banho com os valores médios

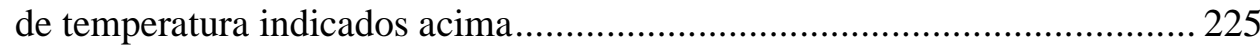

Gráfico 151. Comportamento dos termômetros para variação de temperatura.................. 229

Gráfico 152. Correlação entre o módulo de reação (coeficiente de recalque) e o CBR ..... 244

Gráfico 153. Distribuição da temperatura ao longo da espessura da placa para um aquecimento no fundo, em um período de 5 horas. È possível observar a discrepância que existe entre a temperatura de topo (N15) para a temperatura imediatamente abaixo (N11) Isso mostra que houve algum problema com os tubos do trocador de calor. È por esse motivo que se optou para a simulação com elementos finitos......................................................................... 250

Gráfico 154. Aspecto da resposta bruta das células embutidas com carregamento variado em

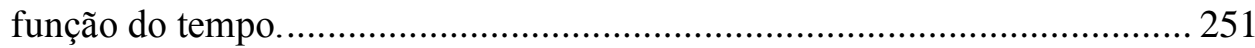

Gráfico 155. Valores referenciados em função do tempo. ............................................ 252

Gráfico 156. Valores dos carregamentos aplicados sobre a estrutura e respectiva

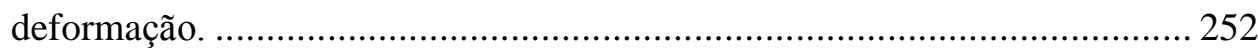

Gráfico 157. Reta de regressão mostrando a deformação sofrida pela célula CE7 devido a carregamento estático. Intervalo de confiança $95 \%$ e $\mathrm{R}^{2}=99 \%$................. 253 


\section{LISTA DE TABELAS}

Tabela 1. Materiais, propriedades e quantidade do concreto utilizado para construção das

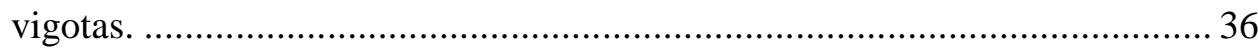

Tabela 2. Padrão de tensão estabelecido durante os testes.......................................... 49

Tabela 3. Síntese das taxas de variação da temperatura dos trabalhos pesquisados....... 63

Tabela 4. Dados obtidos do gráfico 26.................................................................... 113

Tabela 5. Dados de temperatura de topo e fundo de ambos os experimentos............... 114

Tabela 6. Dados retirados do gráfico 36................................................................ 119

Tabela 7. Dados de temperatura de topo e fundo de ambos os experimentos............... 120

Tabela 8. Dados utilizados retirados do gráfico 41 e utilizados para correlação. ......... 123

Tabela 9. Dados de temperatura de topo de ambos os experimentos ......................... 124

Tabela 10. Dados retirados do gráfico 45 e utilizados para correlação .......................... 126

Tabela 11. Dados de temperatura de topo de ambos os experimentos .......................... 127

Tabela 12. Dados de temperatura e de deformação do ensaio da CE para determinação do coeficiente de dilatação térmica do TVE .................................................. 193

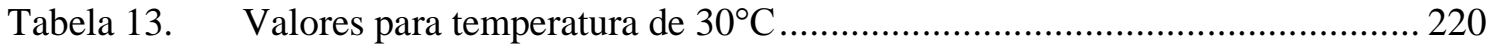

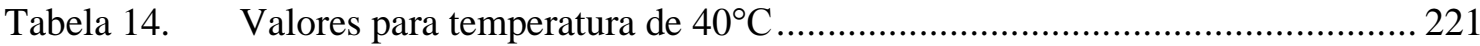

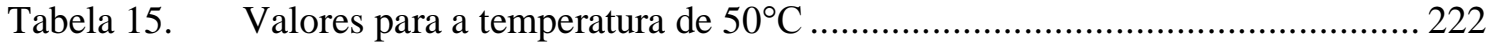

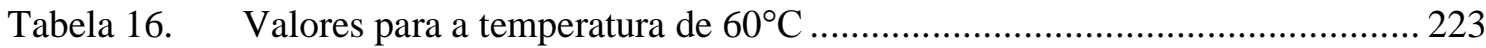

Tabela 17. Valores a $0,0^{\circ} \mathrm{C}$ apresentados pelos termômetros ..................................... 224

Tabela 18. Valores comparativos para calibração do sistema de aquisição.................... 226

Tabela 19. Valores simulados para calibração do pirômetro ........................................ 227

Tabela 20. Dados obtidos a partir do carregamento na célula CE7 ............................. 253 


\section{LISTA DE QUADROS}

Quadro 1. Ensaios tecnológicos do concreto utilizado na base e na placa. A última coluna mostra dados do subleito (Valores médios)............................................. 70

Quadro 2. Localizações dos sensores internos à placa. As medidas da coordenada $\mathrm{z}$ foram tomadas do fundo para o topo da placa.................................................. 89

Quadro 3. Comparativo entre o processo experimental e simulação, tomando-se como referência o valor de $548800,0 \mathrm{~N} / \mathrm{m}^{2}\left(5,6 \mathrm{kgf} / \mathrm{cm}^{2}\right.$ - eixo simples roda simples).

140

Quadro 4. Resumos dos testes práticos e das simulações para deslocamento de borda. 149

Quadro 5. Aplicação de carga no centro do pavimento. Comportamento das células

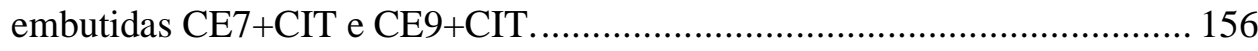

Quadro 6. Equações de regressão dos experimentos realizados.

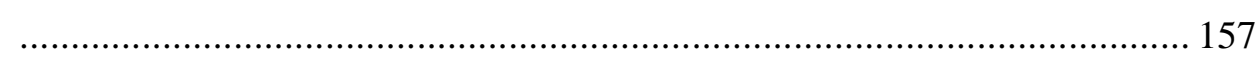

Quadro 7. Dados analisados e calculados em relação aos níveis N15 e N7 163

Quadro 8. Valores médios individuais em $\mathrm{mV} / \mathrm{V}$ em função do carregamento 198

Quadro 9. Valores das leituras das células em $\mathrm{mV} / \mathrm{V}$ acompanhadas do respectivo desvio. 200

Quadro 10. Valores médios em $\mathrm{mV} / \mathrm{V}$ e valores médios da média com respectivo desvio padrão 208 


\section{SUMÁRIO}

Página

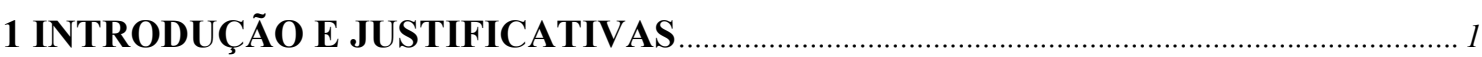

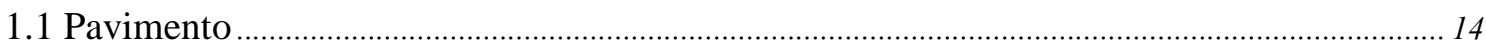

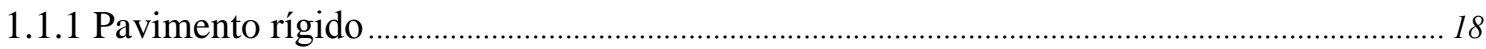

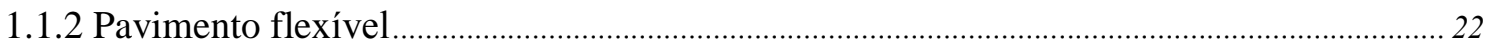

1.1.3 Efeito da temperatura - empenamento da placa de concreto................................................... 22

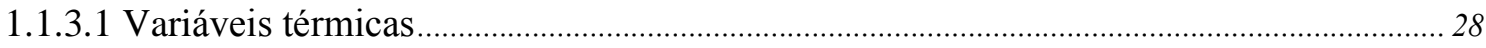

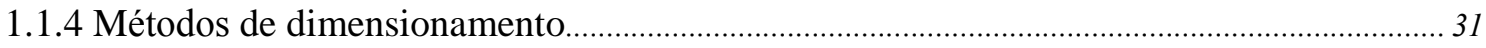

2 METODOLOGIA PARA A INSTRUMENTAÇÃO DA PLACA DE CONCRETO ..... 34

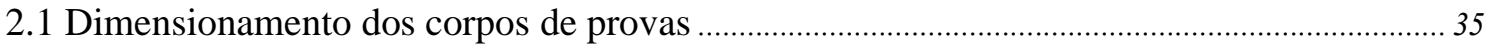

2.1.1 Ensaios de durabilidade e sensibilidade nos termômetros e células de embutimento ....... 36

2.1.2 Sensores de deformação - células de embutimento...................................................................... 41

2.1.2.1 Ensaios na flexão para a calibração das células de embutimento............................................ 42

2.1.2.2 Ensaio na tração para a calibração das células de embutimento.............................................. 43

2.1.3 Sensores de temperatura - termômetros................................................................................... 44

2.2 Desenvolvimento do sistema de aquecimento para a placa de concreto - plataforma de

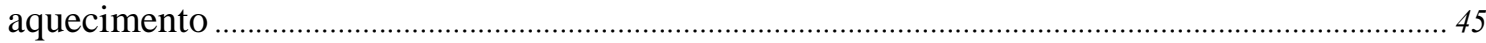

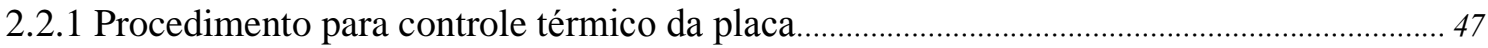

2.3 Desenvolvimento do sistema de aquecimento e resfriamento para o fundo da placa de concreto 50

2.3.1 Procedimento utilizado para obtenção dos dados de temperatura a partir de gráficos apresentados em artigos científicos. 52

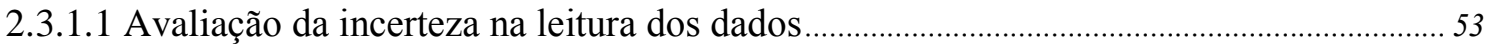

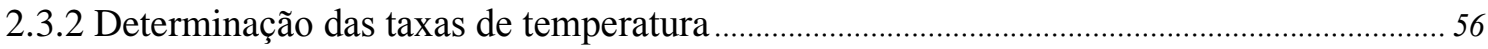

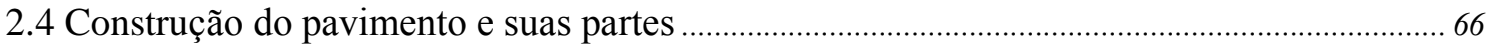

2.4.1 Determinação do módulo de reação para o subleito ................................................................. 70

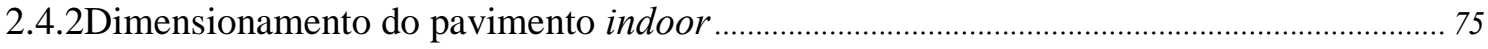

2.4.3 Escolha do modelo físico para simulação do solo de fundação ……………………………..... 76

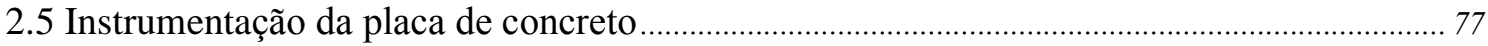

2.6 Sistema de aquisição de dados e condicionamento de sinais....................................................... 81

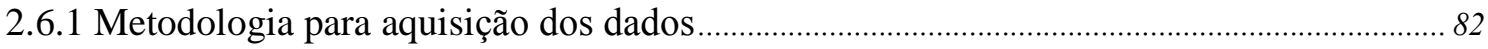

2.6.1.1 Ligação dos sensores ao sistema de aquisição de dados .......................................................92

2.6.2 Posição das células na placa e interpretação dos sinais ............................................................ 95

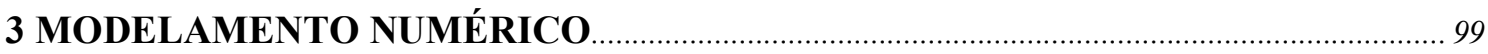

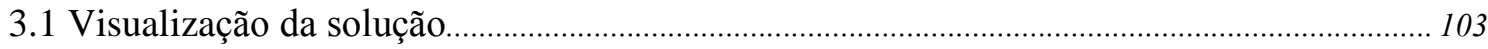




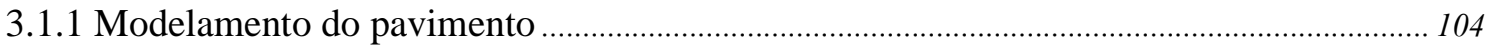

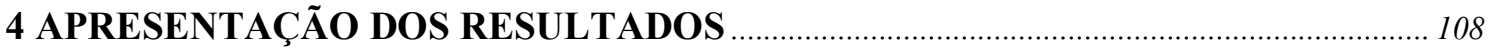

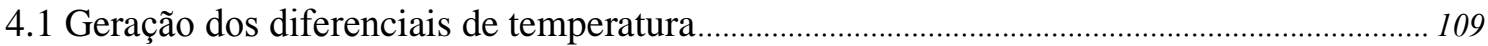

4.2 Simulação das distribuições de temperatura e dados correlacionados....................................... 111

4.3 Carregamento estático no centro e borda da placa......................................................................... 133

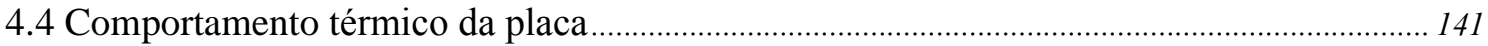

4.5 Deslocamento de canto devido ao aquecimento / resfriamento no topo da placa. ….......... 144

4.6 Deslocamento de canto devido ao aquecimento / resfriamento no fundo da placa............. 150

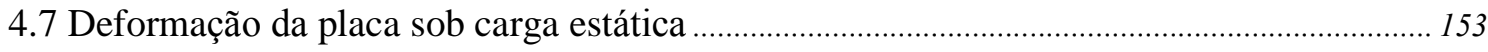

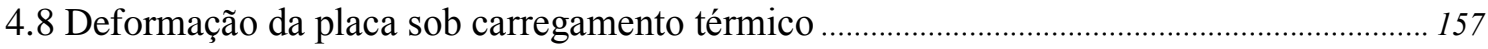

4.9 Deformação e deslocamento da placa sob carregamento estático e térmico.......................... 170 4.9.1Comparações dos resultados obtidos com trabalhos realizados em pistas reais e

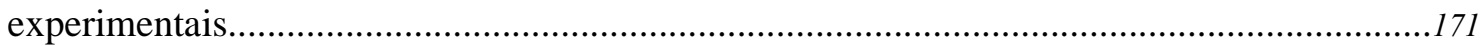

5 CONCLUSÃO

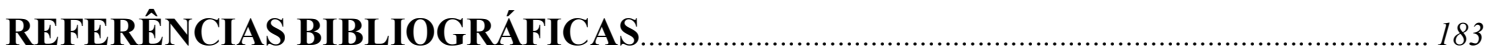

Apêndice A - Construção e calibração das células de embutimento .................................................. 190

Apêndice B - Construção, testes de calibração para os termômetros e canais de aquisição de

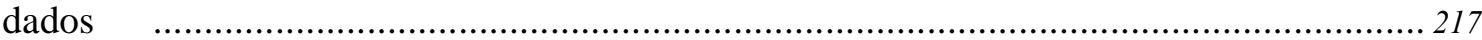

Apêndice C - Construção e instrumentação da placa de concreto do pavimento 1 .................... 230

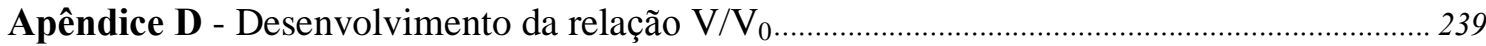

Apêndice E - Determinação teórica do gage factor de um E.E.R (ERE)........................................ 241

Anexo A - Correlação CBR - Módulo de reação ................................................................................... 244

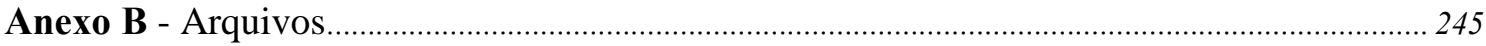

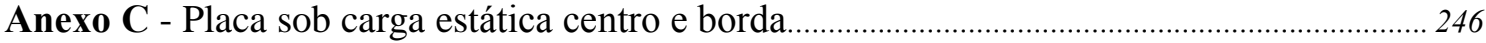

Anexo D - Campo de temperatura ao longo da espessura da placa. modelos em $2 \mathrm{~d}$ e $3 \mathrm{~d}$....... 247

Anexo F - Procedimento para interpretação dos dados sob carga estática.................................... 251 


\section{INTRODUÇÃO E JUSTIFICATIVAS}

O estudo do pavimento, como estrutura, exibe uma característica interdisciplinar complexa abrigando, ao seu redor, vários campos da Ciência. Além disso, o pavimento foi uma solução técnica aplicada às vias de transporte para proporcionar facilidades sociais, econômicas e humanas. E, sem dúvida, favoreceu a integração dos povos desde as primeiras construções que remontam ao Egito antigo. Desde então os pavimentos vêm sofrendo modificações de ordem técnica e construtiva, evoluindo para um estado atual em que os mais utilizados são os de asfalto e de concreto. $\mathrm{O}$ estudo do pavimento, como área de pesquisa, mostra uma história rica de métodos analíticos e empíricos desenvolvidos desde a década de 1920 até a simulação numérica, contando com recursos computacionais, dos anos 1990. Entretanto, não significa que todas as dúvidas tenham sido sanadas e que o assunto tenha chegado a uma solução final. Ao contrário, sua amplitude exige, do projetista de pavimento, um olhar atento a novas teorias e tecnologias e, principalmente, às mudanças conceituais de dimensionamento, sobretudo na evolução de técnicas e novas metodologias.

No que se refere ao projeto de um pavimento, um dos fatores que recebe grande consideração é o custo e isso, em linhas gerais, pede economia de material e otimização de processos, aliando-se qualidade, segurança e durabilidade. Uma das formas de se minorar o custo, no caso do pavimento de concreto, é estabelecer uma espessura ótima para a placa, que é um dos componentes da estrutura, responsável por receber todas as solicitações, quer sejam climáticas ou mecânicas. Nesse ponto, os métodos de dimensionamento mostram a sua utilidade e que, vez por outra, sofrem alterações advindas de resultados de pesquisas realizadas.

Por outro lado, a exposição da placa do pavimento aos eventos do cotidiano traz o aparecimento de patologias que, apesar de serem conhecidas, levam os especialistas a realizar experimentos específicos, no sentido de obter maiores conhecimentos a respeito delas, fazendo desse componente estrutural um atrator para a realização de estudos e experimentos. Então, na tentativa de propor soluções a problemas práticos e técnicos, esse ramo da Ciência enveredou por vários caminhos, um deles é aquele que busca refinamento teórico com informações geradas por experiências conduzidas em campo por meio de pistas reais ou em 
pistas experimentais. As informações geradas por esses experimentos são então tratadas, interpretadas e levadas novamente a campo, aprimorando, dessa forma, os métodos utilizados.

Esse refinamento, feito pela mensuração dos fenômenos físicos, por meio dos processos experimentais, é uma boa maneira para estudar o comportamento do pavimento frente às solicitações às quais ele estará sujeito durante a sua vida. Dentre elas podem-se destacar as variações da temperatura, as deformações e as tensões. Essas informações têm, a partir de então, um papel fundamental para ajuste de teoria ou validações em modelos matemáticos ou, ainda, confrontação para modelos estatísticos de previsão.

A pesquisa realizada indicou que, em todas as situações estudadas, as placas foram analisadas in situ, sob condições ambientais normais e expostas à sazonalidade. Apesar desse processo retratar a veracidade do comportamento da placa, impede que alguns procedimentos possam ser revistos, repetidos ou modificados. Além do mais, sabe-se que, mesmo em uma estação do ano, um dia não é exatamente igual ao anterior, sem contar que não existe a possibilidade da realização de testes acelerados com repetição de ciclos rápidos de temperatura. Em razão desses detalhes, o trabalho aqui proposto visou à confecção de uma placa de concreto de cimento Portland (CCP), em tamanho reduzido, para ensaiar as condições de campo em situações controladas dentro de um laboratório e estudar as tensões e deformações sob carregamento térmico.

A instrumentação em pavimentos de concreto de cimento Portland vem sendo realizada desde antes dos primeiros testes controlados na pista experimental da American Association Of State Highway Officials (AASHO Road Test) em Ottawa, EUA, na década de 1950. O objetivo era, na época, verificar de forma empírica os conceitos para projeto de pavimentos (USA, 1962).

Após os experimentos da AASHO, outros foram realizados no sentido de atender novas proposições e hipóteses. Alguns foram realizados em pistas experimentais e outros em trechos de estradas. Equipamentos foram construídos para estudar o perfil do pavimento e suas partes, máquinas de simulação de tráfego foram idealizadas para serem utilizadas nas pistas experimentais ou estradas (BALBO, 2007; MEDINA, 1997).

A vantagem da realização de experimentos em pistas experimentais instrumentadas é a monitoração e o controle sobre alguns parâmetros importantes, tais como intensidade das cargas impostas, número de passagens, deformações, temperaturas ou, ainda, estudos estruturais com diferentes composições de espessuras, diferentes composições de bases (sub-base), tipos de revestimentos e até medidas de aderência entre placa e base. No entanto, o mais importante é a possibilidade de realização de testes acelerados. O mesmo não 
se pode dizer das pistas reais instrumentadas, cujos testes demandam intervalos de tempo relativamente longos, meses ou anos. Em compensação, elas têm a vantagem de mostrar, através dos seus experimentos, como o pavimento se comporta diante dos acontecimentos cotidianos, pois, nesse caso, dá-se atenção aos eventos não previstos, tais como carregamentos acima do especificado, número de solicitações além ou aquém do projetado e, sem dúvida, a observação de outros fatores mais incertos, tais como ação de solventes a base de hidrocarbonetos provenientes de vazamentos dos veículos ou, ainda, acidentes.

A intenção técnica desses experimentos sempre foi a busca de dados que pudessem ser confrontados ou utilizados pelos critérios de dimensionamento empírico ou mecanicista, utilizados pelos projetistas, no sentido de obter informações capazes de estimar o comportamento do pavimento frente às solicitações às quais fica exposto.

Pesquisas dessa natureza visam a otimização do pavimento com relação à sua geometria e vislumbram a economia de material, bem como tempo de execução e projeto. As pistas experimentais foram e são, até hoje, construídas à semelhança de pistas comuns, podendo fazer parte de um pavimento de uso contínuo ou em lugares reservados especialmente para testes e coletas de dados. Há de se ressaltar que apesar do automatismo envolvido atualmente, a coleta de dados, no que tange a obtenção de dados físicos periódicos ou sazonais, apresenta certa problemática, em termos logísticos e econômicos, devido ao pavimento encontrar-se ao relento e, muitas vezes, distante dos locais de análise; estradas, por exemplo. Outros obstáculos que se interpõem são as intempéries naturais e a segurança, tal qual relata Pereira (2003) $)^{1}$ sobre a depredação de condicionadores ocorrida durante trabalhos de pesquisa em trecho da estrada SP-79.

No Brasil, a aplicação do concreto, segundo Severi e Balbo, (2001) e Rodolfo, (2001), como uma estrutura para pavimentação, remonta à década de 1940 com a construção de pavimentos rodoviários e pistas de aeroportos. No entanto, as primeiras experiências com instrumentação começaram na década de 1970. No Estado de São Paulo, os experimentos iniciais foram realizados na primeira pista experimental, construída na Universidade de São Paulo no ano de 1999 por ocasião do trabalho realizado por Rodolfo (2001), onde se buscou calibrar um modelo numérico com os dados oriundos do pavimento instrumentado

As pesquisas realizadas, no país, nas últimas décadas, têm influenciado os projetistas ao ponto de utilizarem resultados na incorporação dos procedimentos de projeto de pavimento. Como exemplo, cita-se, entre outras referências, a IP-06 e a IP-07 (SÃO PAULO,

\footnotetext{
${ }^{1}$ Conforme descrito por Pereira (2003, p. 79).
} 
2002) (instrução para projeto) da Secretaria Municipal da Infra-Estrutura Urbana que utiliza os resultados do estudo realizado por Cervo (2006) que indica a necessidade de novos modelos para os critérios de dimensionamento da fadiga. Nessa referência, Cervo (2006), foi verificado um conservadorismo com relação à espessura da placa, quando se compara com o método da Portland Cement Association (PCA).

Esses estudos têm grande importância para a análise das falhas da estrutura, que podem ser do tipo funcional, quando o pavimento não produz segurança provocando solicitações de desconforto sobre os usuários dos veículos e do tipo falha estrutural, que está ligada à falência do revestimento em suportar cargas para as quais foi projetado. A previsão de ocorrência da falha é baseada na estimativa da vida útil do pavimento, pois espera-se que, dentro desse prazo, ele resista adequadamente.

O presente trabalho não explora especificamente os estudos de fadiga, porém deve-se ter em mente que a alternância de ciclos de aquecimento e resfriamento conjugados com esforços estáticos poderá gerar resultados de interesse sobre a vida útil do pavimento. Sobre isso, Roesler e Barenberg (1999) relatam um estudo de fadiga em placa instrumentada, sobre um solo adequado para a experiência, interna a um laboratório, e estabelecem uma correlação com vigas construídas com as mesmas características das placas que, no caso deles, representavam um pavimento rodoviário. Esse ensaio tem grande significado, pois mostra que, além de outras informações, dados oriundos de testes simulados podem ser correlacionados com dados obtidos em campo.

A literatura consultada mostrou que o dimensionamento do pavimento vem acompanhado de experiência feita no campo e que os procedimentos de projeto de pavimentos rígidos são baseados em correlações obtidas de testes de controle tecnológicos conduzidos em laboratório, ou em pavimentos (vias ou estradas) reais instrumentados, considerando-se as diversas formas de carregamento a que são submetidos.

Com esses dados e informações, são desenvolvidos procedimentos de projeto com margens de segurança adequadas, para evitar os diversos modos de falha possíveis. Em princípio são consideradas tensões de solicitações da carga de roda, atrito com a base e módulo de reação de cada camada. De acordo com o trabalho de Severi (2002), a temperatura atuante sobre o pavimento provoca distorções dimensionais, alterando suas características funcionais e podendo levá-lo à falha estrutural.

No método de dimensionamento de pavimento adotado pelo Departamento Nacional de Infra-Estrutura de Transportes, (DNIT) o efeito da temperatura não é considerado, pois julga que é intrínseco ao método de projeto, ao passo que nova versão da 
AASHTO, de 1998, considera o efeito da temperatura no projeto do pavimento (SEVERI, 2001, 2002).

O comportamento do pavimento, com relação ao carregamento térmico, aliado ao carregamento estático, poderá servir, com seus dados, para os estudos da falha do pavimento sob as circunstâncias impostas. Esse aspecto é investigado por Mahboub, Liu e Allen (2004), que mostraram a necessidade de acrescentar conhecimento sobre o comportamento da placa sob carregamento térmico e aqueles induzidos pela carga rodoviária.

Por outro lado, a IP-07 da Prefeitura de São Paulo inclui no projeto de pavimentos rígidos o efeito da temperatura sobre seu comportamento. Rodolfo (2001) desenvolve um trabalho que expõe uma visão mais mecanicista e incorpora não só os efeitos do gradiente de temperatura como também estuda, via elementos finitos, o comportamento do pavimento.

Apesar das várias pesquisas, uma condição pré-definida, sob a qual irá ocorrer uma falha no pavimento, é de difícil previsão e caracterização nas condições atuais, porém pode-se supor que o acúmulo de dados e pesquisas venha a fornecer tal resposta.

Diante do panorama exposto, o presente trabalho visa construir parte de um pavimento em uma escala reduzida e distorcida, cujo elemento estrutural, placa, será instrumentado com sensores de deformação e de temperatura. Essa estrutura será construída interna a um laboratório capaz de dar suporte a todas as exigências que o experimento necessitar. Nessas condições, a proposta é que, ao invés de instrumentar um pavimento em escala real para a retirada de dados, pode-se realizar o mesmo procedimento em laboratório onde, com controle de algumas variáveis e possibilidade de repetição de testes, se possam fornecer e fortalecer respostas adequadas para o projeto de um pavimento, quando sujeito às mesmas circunstâncias.

Apesar dos métodos de projeto estarem além do objetivo desse trabalho, vale acrescentar que, mesmo consagrados, muitos trabalhos científicos discutem novas técnicas e aplicações no projeto e execução de pavimentos, sendo que o método utilizado atualmente, segundo Pitta (1998), está baseado naquele ditado pela Portland Cement Association (PCA/84). Um aspecto que se deve destacar é que o trabalho aqui proposto não investiga a influência da base, nem a transferência de carga entre placas contíguas. Porém, sabe-se que o desempenho da fundação (sub-base e subleito) é fator importante do projeto para evitar o fenômeno do bombeamento de finos ${ }^{2}$, reduzir os efeitos das mudanças volumétricas do solo e criar uniformidade de suporte para o pavimento. As bases (sub-base) mais comuns utilizadas

\footnotetext{
${ }^{2} \mathrm{O}$ bombeamento de finos em pavimentos rígidos é caracterizado pela migração de uma parcela fina do solo de subleito para a base (placa) do pavimento devido ao carregamento provocado pelo tráfego de veículos.
} 
no dimensionamento de um pavimento são compostas por solo-cimento, solo melhorado, brita graduada tratada com cimento (BGTC), brita graduada (BG) e concreto compactado a rolo (CCR). No presente trabalho, será utilizado como subleito um polímero e como base (subbase) CCR. A escolha do tipo de suporte para o pavimento, bem como os materiais a serem envolvidos na construção é uma atribuição para o projetista, que tem, entre outras preocupações, a de minimizar o custo de projeto e execução. Apesar do presente trabalho não abordar tal tema, pode-se imaginar que os dados vindos dessa pesquisa possam contribuir com informações relevantes a ponto de afetar os métodos de projeto na diminuição dos custos envolvidos.

Sendo assim, no sentido de acrescentar conhecimento e contribuir com maiores informações sobre o comportamento da placa, colocando-a em um estado de repouso, isolada de interferências de fatores externos, para obtenção de dados "limpos" de deformações e temperaturas, com controle absoluto sobre as condições de testes que venham a se adequar às diversas situações e condições utilizadas na construção de pavimentos, bem como, indiretamente, apresentar uma metodologia para testes acelerados, em laboratório, em placas de concreto com alternância do estado térmico, justifica-se a elaboração do presente trabalho baseado no desenvolvimento de um estudo de correlação, com a intenção de que a confrontação dos dados possa contribuir para ajustes nos métodos de dimensionamento de pavimento e que possa, também, através da base de dados, anexada, fornecer subsídios para futuras pesquisas.

Os aspectos de relevância e ineditismo do trabalho foram analisados com uma visão social, técnica e econômica. Sob o aspecto sócio-ambiental, a metodologia proposta acena com a possibilidade de minimizar impactos em áreas reservadas para testes in situ. Sob o aspecto econômico, pode-se almejar vantagens com relação ao custo de projeto, execução, duração dos experimentos e manutenção. $\mathrm{O}$ aspecto de relevância, sob o prisma da engenharia, foi a facilidade da manipulação dos diversos parâmetros ambientais e mecânicos que conduziram a resultados experimentais tão significativos quanto aqueles realizados em pavimentos de CCP reais. Por outro lado, o ensaio de um elemento de pavimento interno a um laboratório, como se fosse uma pista experimental, possibilitou a aplicação da metodologia para outros testes devido a sua mobilidade, aplicação de procedimentos de projeto dentro de um ambiente de laboratório e, senão o mais importante, controle das variáveis de ensaio.

\section{$\underline{\text { Objetivo }}$}

Relativo aos fatos acima expostos, o objetivo do trabalho é o desenvolvimento de uma metodologia experimental que permita a obtenção de resultados aplicáveis a 


\section{pavimentos reais por meio de ensaios de pavimento instrumentado e testado em laboratório.}

Para atender o objetivo proposto, cinco etapas foram executadas e consideradas como objetivos específicos.

$\mathrm{Na}$ primeira etapa procurou-se dominar a técnica de construção de sensores de deformação e de temperatura, tomando, como ponto de partida, a literatura e visitas técnicas a empresas ligadas a esse ramo de atividade. Durante essa etapa, várias experimentações foram realizadas com diferentes tipos de sensores, bem como diferentes tipos de materiais. Fornecedores foram consultados para emitirem opiniões sobre a melhor forma de construção dos sensores em termos técnicos e econômicos. Após a construção dos sensores, houve a realização dos procedimentos de calibração em que se pôde utilizar termômetros e células de carga padrão, pertencentes aos laboratórios da Escola de Engenharia da Universidade Presbiteriana Mackenzie (EEUPM) e do Instituto de Pesquisas Energéticas e Nucleares (IPEN).

Numa segunda etapa, procurou-se dominar a técnica de embutimento dos sensores na massa de CCP. Para tanto, foram construídos corpos de prova, na forma de vigotas, nas quais foram embutidos sensores de deformação e de temperatura, com a finalidade de se verificar a durabilidade, a estanqueidade e resistência ao ataque químico produzido pela massa de concreto. Os testes estáticos para a avaliação dos sinais de deformação foram realizados em uma máquina de compressão pertencente ao laboratório de ensaios de força da EEUPM. Os testes térmicos foram realizados expondo os corpos de prova à insolação diária para poder estudar linearidade, repetibilidade e sensibilidade dos termômetros embutidos.

Numa terceira etapa, procurou-se estabelecer uma capacitação específica na área de pavimentação, buscando o conhecimento das técnicas e métodos de dimensionamento, bem como o estado da arte em pavimentação rodoviária. Durante esse processo, toda atenção foi dedicada aos problemas que envolviam deformações devido a variações de temperatura e seus efeitos combinados com cargas estáticas. Uma atenção especial foi dada aos métodos matemáticos analíticos e numéricos utilizados na pesquisa e no dimensionamento de tais estruturas. Nesse período, foi escolhido o software EverFE2.24 para as simulações numéricas.

Numa quarta etapa, foi construída uma placa pequena de dimensões $0,1 \mathrm{~m}$ x $1,2 \mathrm{~m}$ x 1,2 m, apoiada sobre uma base e subleito para que fossem realizados testes térmicos, mecânicos e também procedimentos de aquisição de dados. Isso foi conseguido por meio da elaboração de um projeto de pesquisa apresentado à Universidade Presbiteriana Mackenzie 
(UPM), sob fomento do fundo de incentivo à pesquisa, Mackpesquisa ${ }^{3}$, com o título "Análise Experimental e Numérica de Tensões em Placas de Pavimento de Concreto Submetidas a Variações de Temperatura”. Esse projeto foi aprovado para o período de 2006 e contou com uma equipe de pesquisadores que se envolveram em aspectos específicos do projeto. Um dos pontos foi a elaboração do projeto e execução da construção de uma placa de concreto instrumentada, visando gerar dados para análises em modelos de elementos finitos e efetiva relação com dados adquiridos. O financiamento permitiu, ainda, o desenvolvimento de novos sensores com novos materiais, desenvolvimento de metodologia computacional para aquisição de dados de deformação e temperatura, bem como a compra de diversos equipamentos, dentre os quais se destacam módulos de condicionamento de sinais, responsáveis por interligar os sensores embutidos na placa de concreto ao sistema de aquisição de dados e ao computador de controle.

O corpo de prova relativo ao projeto de pesquisa descrito acima, quando mencionado no texto, será referenciado como pavimento 1 , pois algumas das informações serão utilizadas no presente trabalho. De certa forma, pode-se imaginar que esse projeto foi um estudo preliminar para a criação de competência para a execução de um novo pavimento, que é motivo desse trabalho.

Os desenvolvimentos mais importantes e os resultados obtidos com o pavimento 1 foram as seguintes:

a) caracterização do traço do concreto;

b) aplicação de técnicas para aderência dos sensores de deformação que foram embutidos no concreto;

c) construção de corpos de provas (vigota) para ensaios de qualificação do concreto e testes de embutimento de sensores de temperatura;

d) análise da distribuição dos diferenciais térmicos no concreto, feita através das vigotas com o ensaio realizado em campo livre;

e) desenvolvimento dos sensores de temperatura e de deformação;

f) técnicas de embutimento e posicionamento dos sensores no interior da placa do pavimento 1 .

A quinta etapa refere-se ao pavimento em estudo, o qual foi construído sobre uma laje de reação, onde um sistema hidráulico, disponível no local e pertencente ao laboratório de

\footnotetext{
${ }^{3}$ Mackpesquisa é o título dado a um processo de subvenção a pesquisas e tem como objetivo básico incentivar a prática da investigação, pura ou aplicada, financiando projetos de pesquisa de interesse institucional, de acordo com a viabilidade econômica do Fundo e da relevância científica do projeto. Fonte: http://www.mackenzie.br/88.html
} 
Estruturas da EEUPM, foi responsável pela aplicação de cargas estáticas sobre a estrutura, especificamente sobre a placa. O pavimento foi construído em três camadas (placa, base e subleito), tendo como subleito um polímero, cuja função foi a de substituir o solo. Entre a base (sub-base) e a placa foi construído um sistema de troca de calor capaz de gerar vários diferenciais de temperatura do fundo para o topo da placa. Para a geração dos diferenciais térmicos do topo para o fundo da placa, foi construído um sistema de aquecimento sobre ela. Os sistemas de controle dos sistemas de aquecimento foram desenvolvidos durante essa etapa.

Foram embutidos quinze sensores de deformação e treze de temperatura perfazendo o dobro de instrumentos daqueles utilizados no pavimento 1. Essas providências permitiram observações mais completas em relação àquelas realizadas na placa do pavimento 1. Os sensores foram aperfeiçoados e calibrados de uma forma mais meticulosa, com a finalidade de atender às exigências do projeto e o mesmo se deu no sistema de aquisição de dados.

O presente estudo utilizou como referência, além das experiências internacionais, cinco trabalhos nacionais, listados e brevemente comentados a seguir. Eles dispõem de dados de temperatura e de deformações, obtidos em condições ambientais reais em placas de pavimentos experimentais instrumentados.

Rodolfo (2001), procurou estabelecer um modelo numérico por meio de um pavimento instrumentado em pista experimental, onde, por meio do uso do método dos elementos finitos, modelou as tensões principais maiores em pavimentos constituídos de placas de concreto de cimento Portland e bases cimentadas não-aderidas submetidas a cargas rodoviárias e gradientes térmicos (taxa de variação térmica). Os valores dos gradientes térmicos foram obtidos na pista experimental do Laboratório de Mecânica de Pavimentos, que fica situada no campus de São Paulo da Universidade de São Paulo. Outra observação é que quando se consideram os efeitos do empenamento da placa, devido ao efeito térmico, no dimensionamento, tem-se como resposta espessuras maiores que as de costume tanto da placa quanto da base. Com relação ao consumo da resistência à fadiga, os dados mais relevantes indicam que apenas a placa fica sujeita ao fenômeno da fadiga, ao passo que a base tem um consumo menor.

Pereira (2001) realizou um estudo de gradientes térmicos e deformaçãoes em pavimento tipo whitetopping ultradelgado (WTUD) instrumentado. Trata-se de um pavimento onde o concreto asfáltico foi fresado e deu lugar a placas de concreto de pequena espessura assentadas e aderidas sobre ele. O principal achado foi que os gradientes térmicos dependem de vários fatores climáticos e que os gradientes encontrados não são importantes para o 
acréscimo dos níveis de tensão nas placas, não reduzindo sua vida à fadiga. Verificou ainda a aderência entre valores de tensão medidos e aqueles obtidos no modelamento numérico.

Severi (2002) avaliou padrões da distribuição da temperatura sazonais, de clima tropical, durante um ano, sobre uma pista experimental, propondo ainda modelos empíricos para a previsão da temperatura de topo e análise de tensões de empenamento da placa, mostrando com isso que o efeito combinado das cargas e gradientes térmicos eleva a tração na flexão nas placas de concreto e que o método PCA/84 subestima esses valores de tensão na flexão para qualquer diferencial térmico. Mostra, ainda, que as mesmas considerações feitas para pavimentos rodoviários podem ser aplicadas a pisos industriais.

Pereira (2003) realizou estudos sobre aderência de pavimentos em duas pistas, uma de WTUD e outra de concreto simples, executadas sem a manta plástica entre placa e base mas com a imprimação de emulsão asfáltica. O trabalho foi desenvolvido em laboratório utilizando metodologia adequada para o estudo da resistência ao cisalhamento entre CCP e concreto compactado a rolo (CCR). Nas duas pistas experimentais, executadas de acordo com a nova prática, verificou o comportamento monolítico da estrutura WTDU, ao passo que a estrutura de CCP apresentou-se não monolítica.

Cervo (2006) elaborou um estudo da resistência à fadiga de concreto utilizado para pavimentação que permitiu construir modelos de ruptura por fadiga para este tipo de concreto utilizado normalmente para pavimentação e para concreto de alto desempenho (CAD). Os ensaios foram conduzidos com tensão constante e váriavel. O maior achado refere-se ao conservadorismo do modelo à fadiga utilizado nessas estruturas.

\section{$\underline{\text { Metodologia }}$}

Para a obtenção dos dados de temperatura e deformação, foi construída uma placa de CCP a qual foi instrumentada e assentada sobre uma base e um subleito formando um elemento de um pavimento real. O conjunto, composto por três camadas sobrepostas, formou uma estrutura não monolítica, tendo como destaque o fato da placa e base não estarem aderidas e que o subleito foi formado através de um polímero. O conjunto, com geometria retangular e em escala linear e distorcida ${ }^{4}$, em relação aos pavimentos reais, foi construído interno a um laboratório de ensaios mecânicos em uma área de $30,0 \mathrm{~m}^{2}$ com pé direito de 6,0 $\mathrm{m}$, localizado entre outros dois laboratórios existentes e protegido por portas de aço para passagem de materiais e uma porta de passagem comum, do tipo corta-fogo. Devido a essa posição, as condições ambientais, tais como umidade e temperatura, se mantêm com pouca

\footnotetext{
${ }^{4}$ No presente trabalho as dimensões de comprimento e largura estão em uma escala de $1: 2$, enquanto que, a espessura possui relação de 1:1. Nessa situação a escala pode ser encarada como distorcida.
} 
variação em relação ao ambiente externo. Isso é importante, pois, sendo o concreto um material higroscópico, mesmo após a cura pode absorver ou perder água em função da umidade do ar, apresentando dilatação ou contração (retração). Segundo a American Concrete Institute (AMERICAN CONCRETE INSTITUTE,1988), a mudança de um estado úmido para um estado seco com $50 \%$ de umidade pode causar uma retração de $0,6 \%$ na placa. O mesmo efeito pode ocorrer nas mudanças de temperatura. O local é dotado de ar condicionado e infraestrutura capaz de suportar as necessidades técnicas que exigiu a experiência. Percebe-se que o local onde foi realizado o estudo impôs resistência às intempéries naturais, permitindo assim dar suporte aos processos experimentais e controles impostos na placa do pavimento. Esse procedimento foi necessário para possibilitar simulações contínuas e repetidas em que as variáveis externas, temperatura e umidade, tivessem pouca influência nas operações de aquecimento da placa. Isso é uma vantagem, pois os testes que foram conduzidos nesse ambiente sofreram pouca influência das condições externas.

No entanto, nos momentos em que placa estava no processo de resfriamento, percebeu-se um decaimento mais lento do que o natural pois, diferente do campo, o pavimento indoor não é resfriado com a brisa noturna que realiza a troca de calor.

O pavimento foi construído sobre uma laje de reação e sob uma máquina de ensaios de tração/ compressão, acionada por um cilindro hidráulico e instrumentada com uma célula de carga com capacidade de até 1,5 MN. As condições ambientais dentro do laboratório, em termos de temperatura e umidade, se mantiveram estáveis e não apresentaram variações abruptas a ponto de mascarar ou interferir nos resultados. A temperatura ambiente foi controlada por meio de condicionadores de ar que a mantiveram na faixa de $24,0{ }^{\circ} \mathrm{C}$ a 26,0 ${ }^{\circ} \mathrm{C}$. A medição da umidade não foi realizada por intermédio do sistema de aquisição de dados devido à ausência de um sensor adequado. Para sanar essa deficiência, ela foi medida diariamente por meio de um higrômetro, não rastreado, portátil, marca LUTRON, modelo HT-3005, O laboratório de ensaio apresentou durante todo o período de testes valores que oscilaram entre $40 \%$ e $60 \%$, mesmo nos dias em que ocorreram chuva ou garoa.

Quanto à umidade externa ao laboratório, seu valor foi coletado por uma antena de dados meteorológicos, instalada na laje do prédio do laboratório a aproximadamente $60,0 \mathrm{~m}$ deste. Vale lembrar que o experimento foi realizado em um espaço anexo ao laboratório de ensaios mecânicos e atrás do laboratório de processos de soldagem da EEUPM. A planta baixa, mostrada no desenho 1 , indica a posição dos laboratórios e o local onde foram realizados os testes. 


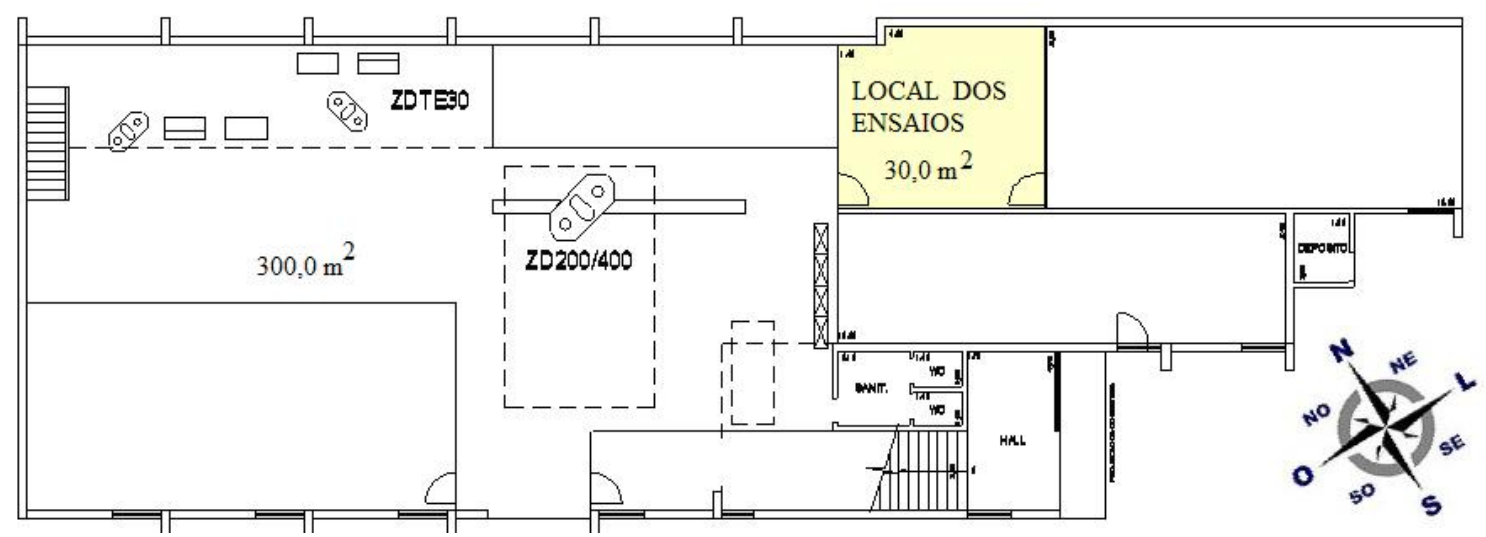

Desenho 1. Posicionamento do local do experimento.

Fonte: Acervo próprio (2008).

A título de informação, o condicionamento de ar fica inoperante nos finais de semana e ao final do expediente que, durante o ano letivo, vai das $7 \mathrm{~h} 30 \mathrm{~min}$ às $23 \mathrm{~h} 00 \mathrm{~min}$. Nos períodos de recesso e férias escolares, o acionamento é facultativo.

O pavimento foi construído em um molde de madeira de espessura de $2,5 \mathrm{~cm}$, que serviu como isolante térmico durante os testes de aquecimento, evitando a ocorrência de troca de calor pelas laterais da estrutura. O molde foi escorado lateralmente com suportes fixados na base da laje de reação. Deve-se notar que essa fixação não foi classificada como um vínculo, mesmo porque não impôs restrições aos movimentos da placa ou ao conjunto.

Com relação à composição da massa, foi seguido o mesmo traço utilizado na placa do pavimento 1 e o controle tecnológico foi efetuado nos laboratórios da EEUPM (os dados podem ser vistos no quadro 1, página 69).

No momento da concretagem da placa do pavimento, sensores de deformação e de temperatura (termômetros) foram embutidos na massa fresca do concreto em posições específicas e identificados segundo a sua posição geométrica no interior da placa. $\mathrm{O}$ embutimento dos sensores foi executado segundo os trabalhos realizados por Sargand e Khory (1999).

O processo construtivo dos sensores de deformação foi o mesmo daquele utilizado para os experimentos com a placa do pavimento 1, ou seja, os strain gages (também conhecidos como extensômetros elétricos de resistência - EER ou extensômetros de resistência elétrica - ERE) foram colados em substrato de fibra de vidro, formando uma célula de carga chamada célula embutimento (CE) ou célula de deformação. Essa extensometria de embutimento segue as mesmas considerações e técnicas utilizadas na extensometria de 
superfície. Uma descrição mais detalhada do processo de calibração e construção encontra-se no apêndice A.

O processo construtivo dos sensores de temperatura (TE) foi o mesmo utilizado para os experimentos com a placa do pavimento 1. Eles foram construídos utilizando termorresistências tipo Pt100 enclausuradas em um recipiente de cobre. No apêndice B, encontra-se a descrição da construção e calibração dos termômetros.

Um cuidado especial foi tomado com relação à dependência térmica com a temperatura das células de embutimento. Para tanto, foram embutidas células sem função de medir deformação chamadas células dummy (CED), que serviram para realizar a compensação térmica quando fosse utilizada a configuração em meia ponte. Essas células foram embutidas na massa de concreto, porém não foram aderidas e, para tanto, foram banhadas com graxa automotiva comum. Esse procedimento visou evitar que os movimentos da placa influenciassem as leituras vindas desse tipo de sensor.

O restante dos sensores (células de deformação - CE) foram mergulhados em resina a base de epóxi tipo compound S200 da Vedacit ${ }^{\circledR}$ (VEDACIT, 2006) e posteriormente em areia fina $n^{0} 10$. Esse procedimento foi adotado, com base nos trabalhos de Papallardo et al. (2006), para garantir a aderência da célula na massa de concreto evitando a ocorrência de movimento, a não ser aquele causado pela placa.

A conexão elétrica entre os sensores e o sistema de aquisição de dados foi realizada por meio de cabos blindados que foram referenciados (aterrados) ao sistema de aquisição. O condicionamento dos sinais foi realizado através de um sistema fabricado pela empresa Lynx Tecnologia Ltda, modelo ADS 500, capaz de suportar, sem multiplexação, dezesseis canais diferenciais.

A interpretação dos sinais foi realizada por um software, desenvolvido na linguagem de programação $\mathrm{C}^{++}$fornecido pelo fabricante, chamado AqDados e a análise dos dados de deformação e de temperatura foi realizada por outro software fornecido pelo fabricante, conhecido como AqDanalysis v.7.02.

Todos os dados foram sistematizados pelo software estatístico MINITAB ${ }^{\circledR}$ e planilhas do Microsoft Excel $^{\circledR}$ e estão disponíveis no anexo $\mathrm{B}^{5}$, em um CD-ROM que acompanha o presente trabalho (sempre que necessário será indicado na área útil dos gráficos o nome ou número do arquivo. Ele será precedido pelo símbolo \#)

\footnotetext{
${ }^{5}$ Todos os gráficos produzidos durante o presente trabalho estão disponíveis em CD-ROM no anexo B. Eles estão identificados com o símbolo \#.
} 
Para a geração dos diferenciais térmicos positivos foi construída uma plataforma de madeira e placas de drywall (placas de gesso acartonadas), cujo coeficiente de condutibilidade térmica $\mathbf{K}=0,02 \mathrm{~W} / \mathrm{mK}\left(0,4 \mathrm{kcal} / \mathrm{hm}^{\circ} \mathrm{C}\right)$ lhe confere características de um material isolante. As placas foram revestidas com papel alumínio e resistências tubulares foram fixadas. A potência máxima conseguida por esse "aquecedor" foi de 7,4 kW e, por radiação térmica, processos de convecção e condução, pode-se conseguir o aquecimento da placa de concreto.

Para a geração dos diferencias térmicos, negativos ou positivos, foi construída uma espécie de trocador de calor no fundo da placa de concreto, onde tubos tipo conduíte a base de poli cloreto de vinila (PVC) foram colocados no sentido longitudinal da placa por onde se fez circular água quente ou fria. A construção desses dois sistemas, a plataforma de aquecimento e o trocador de calor, possibilitou a geração dos múltiplos diferenciais térmicos entre o topo e o fundo da placa.

O controle do aquecimento superficial da placa de concreto foi realizado por meio da atuação manual sobre um variac (autotransformador variável - fotografia 12; nota de roda pé 12) que teve a função de variar a tensão elétrica sobre as resistências, possibilitando gerar curvas de aquecimento semelhantes às condições impostas pela natureza. As taxas de aquecimento foram retiradas de trabalhos científicos, cujos estudos foram realizados em pistas experimentais e em pistas comuns.

A curva de aquecimento inicial utilizada nos testes realizados na placa foi obtida nos primeiros ensaios realizados com um corpo de prova na forma de uma vigota, que foi instrumentada com termômetros e exposta ao relento, no verão de 2006.

Para obtenção das taxas de aquecimento foram utilizados dados provenientes da literatura, tais como Armaghani el al. (1987), Choubane, Tia (1995), Harik et. al (1994), Richardson, Armaghani (1987), Severi, Balbo (2001), Thompson et al. (1987), Yu et al. (1998) e dados colhidos in situ, no corredor de ônibus da Avenida Vicente Rao (São Paulo), durante cinco dias no verão de 2007-2008.

\subsection{PAVIMENTO}

O pavimento tem a função de resistir e distribuir os esforços verticais, horizontais e tangenciais, sendo que sua construção deve se opor ao desgaste e propiciar conforto ao usuário. Essa estrutura é construída após a terraplanagem do terreno e destinada a distribuir ao subleito os esforços verticais, oriundos dos veículos, melhorar as condições de rolamento 
quanto ao conforto e à segurança e resistir aos esforços horizontais, tornando mais durável a sua superfície (SOUZA (1980), BALBO, (2007).

"O pavimento é uma estrutura construída após terraplenagem e destinada, econômica e simultaneamente, em seu conjunto, a:

a) Resistir e distribuir ao subleito os esforços verticais produzidos pelo tráfego;

b) Melhorar as condições de rolamento quanto à comodidade e segurança;

c) Resistir aos esforços horizontais que nela atuam, tornando mais durável a superfície de rolamento." (ABNT - NBR-7207, 1982).

O projeto de um pavimento depende da análise do solo, das camadas inferiores à placa que são capazes de suportar as cargas solicitantes e vários outros fatores (BRASIL, 2004a). Cargas de roda, por exemplo, originam tensões de flexão, que dependem da carga aplicada, da área de contato, da pressão do ar nos pneus, do meio elástico sobre o qual se apóia a placa, da espessura da placa e da posição da carga na placa, tendo como ponto crítico, segundo Westergaard (1926), a borda da placa. Esse conjunto de camadas, que compõe o pavimento, possui comportamento elástico, linear, sendo as camadas: base (sub-base) e subleito caracterizados pelos módulos de reação "k".

Nogueira (1961) classifica o pavimento como sendo o revestimento constituído por ligantes de cimento, cuja espessura é fixada em função da resistência à flexão das lajes de concreto. Para Souza (1972), o pavimento é um sistema de camadas de espessuras finitas, assentes sobre um semi-espaço infinito, que é o subleito. Augusto (1992) descreve que o pavimento é composto por um subleito (que é o terreno de fundação do pavimento), por um reforço do subleito (camada executada sobre o subleito, com capacidade de suporte maior que o subleito), sub-base (camada complementar à camada base), base (camada destinada a receber e distribuir os esforços,devido ao tráfego). Senço (1999) classifica o pavimento como uma estrutura construída sobre a terraplanagem, cujas características técnicas se prestam a resistir e distribuir esforços verticais, horizontais e tangenciais. No que concerne ao pavimento de concreto, segundo Balbo (2007), a terminologia moderna vem utilizando o termo base como aquela adjacente à placa e sub-base logo abaixo da base.

As camadas que compõem a estrutura são formadas por: subleito (construído de material natural consolidado e compactado), reforço do subleito (camada de reforço com solo de melhor qualidade), base, sub-base (podem ser construídas por solo estabilizado naturalmente, mistura de solo e agregados, tais como brita graduada tratada com cimento) e placa. 
De acordo com essa nomenclatura, as partes integrantes do pavimento podem ser descritas de acordo com a (ASSOCIAÇÃO BRASILEIRA DE NORMAS TÉCNICAS, NBR7207 (1982) como sendo:

\section{$\underline{\text { SUBLEITO }}$}

Terreno da fundação

\section{REFORÇO DO SUBLEITO}

Camada de espessura constante transversalmente e variável longitudinalmente, de acordo com o dimensionamento do pavimento, fazendo parte integrante do pavimento e que, por circuntâncias técnico-econômicas, é executada sobre o subleito.

\section{$\underline{\text { SUB-BASE }}$}

Camada corretiva do subleito ou complementar à base, executada quando, por circunstâncias técnico-econômicas, não for aconselhável construir diretamente sobre o leito regularizado ou sobre o reforço do subleito.

A sub-base é estabilizada granularmente quando constituída de camadas de solos, misturas de solos e materiais de pedra britados ou produtos totais de britagem de pedras ou ainda qualquer combinação desses materiais.

\section{$\underline{B A S E}$}

Camada destinada a suportar e distribuir esforços oriundos do trânsito e sobre a qual é construído o revestimento.

A base é estabilizada granularmente quando constituída de camadas de solos, misturas de solos e materiais de pedra britados ou produtos totais de britagem de pedras ou ainda por qualquer combinação desses materiais.

\section{REVESTIMENTO (PLACA)}

Camada, tanto quanto possível impermeável, que recebe diretamente a ação de rolamento dos veículos e se destina a:

a) melhorar as condições do rolamento quanto à comodidade e segurança;

b) resistir aos esforços horizontais e verticais que atuam no revestimento,tornando mais durável a superfície do rolamento. 
O desenho 2 mostra as diferenças básicas entre os tipos de pavimentos, rígido desenho $2 \mathrm{a}$ e flexível, desenho $2 \mathrm{~b}$ e como as tensões se distribuem nas camadas componentes da estrutura. Isso quer dizer que, quando o pavimento é solicitado por uma carga de veículo $\mathrm{Q}$, que se desloca com uma velocidade v, recebe uma tensão vertical $\sigma$ (de compressão) e uma tensão horizontal $\tau$ (de cisalhamento). As várias camadas componentes da estrutura do pavimento também terão, então, a função de diluir a tensão vertical aplicada na superfície.
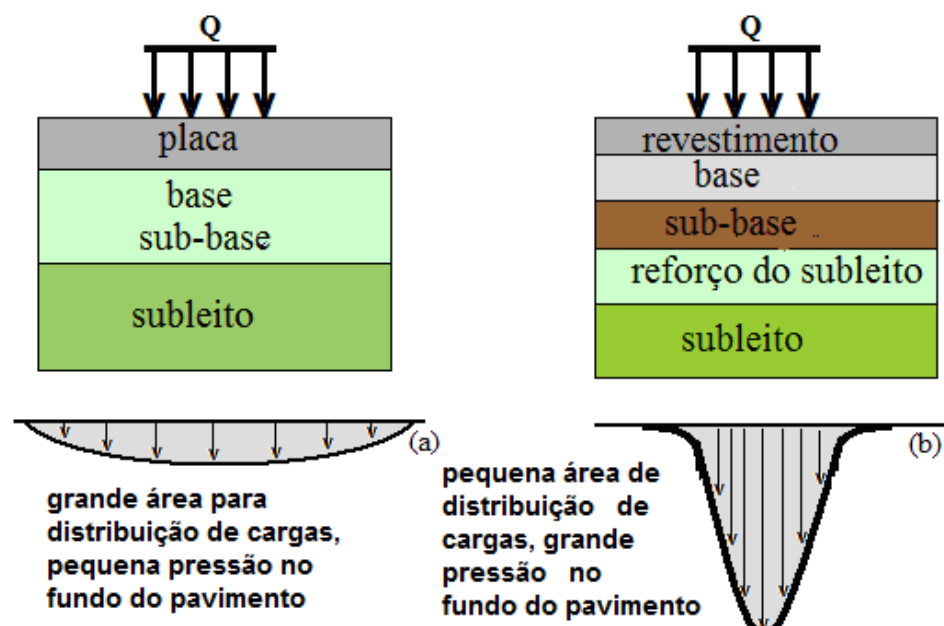

Desenho 2. Aspecto dos esforços nas camadas de um pavimento produzidos por uma carga externa: (a) pavimento rígido. (b) pavimento flexível Fonte: Acervo próprio (2009).

Com respeito às implicações econômicas, Giusti (2004) comenta que o pavimento de concreto de CCP traz economia, tanto para o poder público, como para o usuário, uma vez que cada dólar investido em uma estrada com pavimento de CCP corresponde à economia de três dólares em custo operacional. Tecnicamente, estudos demonstram que o pavimento de CCP é uma excelente solução para vias públicas com tráfego intenso, caso em que o custo de construção é mais competitivo em relação ao pavimento do tipo concreto asfáltico (também conhecido como pavimento flexível). Levando-se em conta também as condições do terreno, o pavimento de $\mathrm{CCP}$ (também conhecido como pavimento rígido) é resistente às chuvas, altas temperaturas (aquece menos do que o pavimento flexível), ajuda a poupar energia de iluminação pois, sendo de superfície clara, reflete melhor a luz, permitindo que um número menor de postes de iluminação seja utilizado.

No Brasil, apesar dos pavimentos asfálticos serem predominantes e possuírem a preferência na execução de obras viárias, a utilização do $\mathrm{CCP}$ em pavimentação vem 
ganhando, ao longo do tempo, certa preferência devido ao custo de execução e planejamento, equiparando-se ao custo do concreto asfáltico. Outro aspecto a ser considerado é que a indústria de cimento Portland atingiu uma capacidade de produção capaz de suprir uma possível demanda e outros fatores relevantes, tais como durabilidade e pouca manutenção, tornam o uso desse material atrativo (AMARANTE et al. 2002).

\subsubsection{PAVIMENTO RÍGIDO}

Os pavimentos rígidos, de acordo com Oliveira (2000), podem ser construídos através de uma placa simples, armada, ou protendida, com ou sem barras de transferência. $\mathrm{O}$ concreto, para essa finalidade, pode ter a adição de fibras ou ser construído com diferentes tecnologias, por exemplo, concreto rolado

De forma geral, o pavimento de concreto simples é constituído por placas de concreto individuais unidas por barras de aço que interligam placas justapostas tanto no sentido transversal como no longitudinal, que repousam sobre uma base, que pode ou não estar aderida à placa. A estrutura conta ainda com uma placa, uma base e um subleito (solo). Outra característica é a presença de acostamentos e sistema de drenagem (quando se tratar de pavimentos rodoviários).

No pavimento rígido de concreto simples, a espessura da placa depende do carregamento aplicado pela roda, da resistência à tração na flexão do concreto e da capacidade de suporte da base. O pavimento de concreto simples é formado por placas apoiadas sobre a fundação que oferecem uma resistência aos esforços de tração e / ou compressão. A separação das placas é realizada por meio de cortes transversais, chamadas juntas serradas ou, ainda, podem ser moldadas, encaixando-se uma a outra. Essa técnica visa controlar a fissuração provocada por empenamento, dilatação térmica e ao fenômeno da retração. Na fotografia 1 podem ser vistas duas placas contíguas, bem como as dimensões mais usuais, unidas pela interligação (entrosagem)dos agregados em uma junta serrada e impermeabilizada com cimento asfáltico 

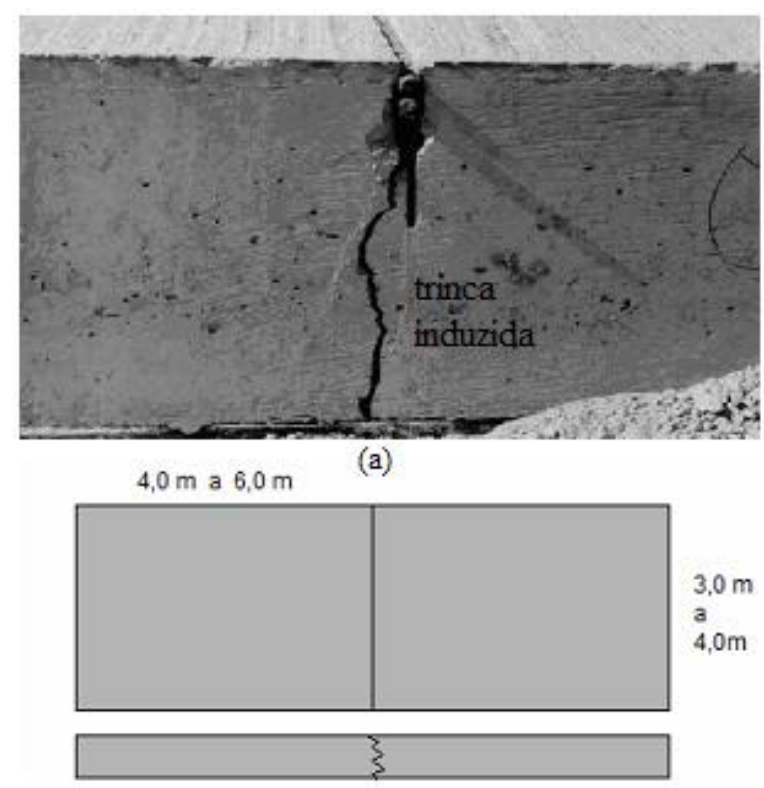

(b)

Fotografia 1. Pavimento de concreto simples: (a) Placas separadas pelo corte transversal com trinca induzida. Corredor de ônibus avenida Vicente Rao, São Paulo, trecho próximo à avenida Whashington Luis (2006) . (b) Vista em corte e planta de um pavimento de concreto simples.

Fonte: Acervo próprio (2006).

O pavimento experimental desenvolvido no presente estudo foi do tipo simples ${ }^{6} \mathrm{e}$ visto como uma estrutura composta por uma placa, base e subleito, onde se tentou criar uma condição próxima à dos pavimentos reais, cujas características construtivas foram vistas de formas diferentes com o passar dos anos. Sendo assim, o pavimento experimental foi construído como uma estrutura em que foram aplicadas as técnicas comuns de dimensionamento valendo-se do conhecimento das características mecânicas da base e subleito.

Uma classificação dada para pavimentos, segundo um procedimento de projeto baseado na tensão limite para $\mathrm{CCP}$, é estar abaixo da resistência à tração do concreto. Em outras palavras, a parte inferior do revestimento (placa) trabalha essencialmente à tração. As tensões são modeladas pelo uso das equações de Westergaard ${ }^{7}$, baseadas na teoria da elasticidade, na qual a placa vem apoiada sobre um líquido denso (SOUZA, 1980).

Observa-se, a partir das definições, que a placa é o principal componente estrutural e sua elevada resistência à tração tende a aliviar as tensões nas camadas inferiores.

\footnotetext{
${ }^{6}$ A escolha desse tipo de pavimento se deveu a sua versatilidade em aplicações que vão desde a área urbana até a industrial.

${ }^{7}$ Harold Malcolm Westergaard (1888-1950) Professor de Mecânica Aplicada na Universidade de Illinois.
} 
Definição dada pela norma NBR7583 (execução de pavimentos de concreto simples, por meio mecânico) da ABNT (ASSOCIAÇÃO BRASILEIRA DE NORMAS TÉCNICAS, 1984):

[...] é o pavimento de concreto de cimento Portland no qual as tensões solicitantes são combatidas tão somente pelo próprio concreto e que não contém nenhum tipo de armadura distribuída, não, se considerados como tal, eventuais sistemas de ligação ou de transferência de carga entre as placas formadas pelas juntas longitudinais e transversais, nem as madeiras de retração, também, eventualmente exigidas pelo projeto e aplicadas em poucas placas isoladas de forma, tamanho e função inusuais.

As expressões originais de Westergaard estão descritas pelas equações 1, 2,3, 4 e 5 .

$$
\begin{gathered}
\sigma_{c}=\frac{3 P}{h^{2}}\left[1-\left(\frac{E h^{3}}{12\left(1-\mu^{2}\right) k}\right)^{-0,15} a_{1}^{0,6}\right] \\
\sigma_{i}=\frac{3(1+\mu) P}{2 \pi h^{2}}\left(\log _{e} \frac{l}{a}+0,6159\right) \\
l=\sqrt[4]{\frac{E h^{3}}{12\left(1-\mu^{2}\right) k}} \\
b=\sqrt{1,6 a^{2}+h^{2}}-0,675 h \\
k=\frac{p}{\delta}
\end{gathered}
$$

sendo:

$\mathrm{b}$ - raio equivalente;

1 - raio de rigidez relativa;

$\sigma_{c}$ - máxima tensão de tração na fibra externa superior da placa, quando a carga é apoiada no canto da placa;

$\mu$ - coeficiente de Poisson do concreto;

$\mathrm{E}$ - módulo de elasticidade do concreto $\left(E=\frac{\sigma}{\varepsilon}\right)$;

k - módulo de reação do sub-leito (coeficiente de recalque, módulo de Westergaard);

$\mathrm{P}$ - carga total por roda em $\mathrm{N}$;

$\mathrm{a}_{1}$ - distância, sobre a bissetriz, do canto da placa até o centro de aplicação da carga, supondo com raio a; 
a - raio de contato da carga

$\mathrm{h}-$. espessura da placa em $\mathrm{m}$;

$\sigma_{\mathrm{e}}$ - máxima tensão na fibra externa inferior da placa, quando a carga é apoiada na borda da placa (ou como Souza (1980) 'no bordo livre da placa');

$\sigma_{\mathrm{i}}$ - máxima tensão na fibra externa inferior da placa, quando a carga é apoiada no interior da placa;

$\mathrm{p}$ - pressão nominal de contato;

$\delta$ - recalque numa prova com placa rígida de raio a.

Com o passar do tempo, modificações foram realizadas nas equações originais incluindo novos fatores para descrever o comportamento da placa de concreto. Uma definição adequada e usual é que o pavimento será rígido quando a exigência de projeto estiver baseada na resistência à tração.

Pela teoria clássica de placas na flexão, um pavimento só pode deformar de duas maneiras: contrair-se ou expandir-se (fletir), mantendo a seção transversal plana. O primeiro tipo de deformação pode ser causado por um componente da temperatura uniforme, o segundo tipo pode ser causado pelo efeito combinado de temperatura e carga devido ao tráfego sobre o pavimento (CHOUBANE, TIA, 1995).

Uma placa pode ser definida como um elemento estrutural laminar que também pode ser caracterizada por apresentar uma dimensão desprezível, pequena, em relação às outras duas. As placas são planas e a espessura é identificada pela distância entre as superfícies.

De acordo com o material de que é feita, elas podem ser classificadas como:

a) isótropas: quando as propriedades forem as mesmas em qualquer direção;

b) ortótropas: quando as propriedades forem diferentes em duas direções ortogonais;

c) anisótropas: quando as propriedades forem diferentes em todas as direções.

A relação da espessura h pelo comprimento L classifica a placa como:

a) delgada caso aconteça a relação ...................................................... $\frac{1}{100}<\frac{h}{L} \leq \frac{1}{5}$;

b) muito delgada caso as dimensões obedeçam a relação ............................... $\frac{h}{L} \leq \frac{1}{100}$;

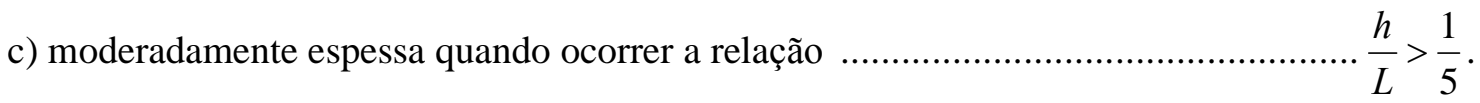

Por hipótese, a placa será considerada isótropa e, devido às suas dimensões 3,00 m de comprimento, 1,78 m de largura e 0,15 m de espessura, será classificada como delgada. 


\subsubsection{PAVIMENTO FLEXÍVEL}

Outro tipo de pavimento comumente encontrado é conhecido como pavimento flexível que se caracteriza quando submetido a uma carga, por elevada deflexão recuperável e baixa área de atuação, se comparado ao pavimento rígido. Também se caracteriza geralmente como sendo aquele que possui revestimento asfáltico e camadas de base granular que não trabalham à tração. Em relação ao pavimento de concreto, possui uma geometria mais complexa (SOUZA, 1980). Com relação às deformações e tensões que ocorrem na estrutura, pelas condições climáticas ou pelas cargas de rodas do tráfego, são de tal forma, que, as camadas que o compõem tendem a aliviá-las. Essa estrutura é composta geralmente de diversas camadas de materiais que podem acomodar esta flexão da estrutura.

\subsubsection{EFEITO DA TEMPERATURA - EMPENAMENTO DA PLACA DE CONCRETO}

A tendência da placa de concreto sofrer um empenamento devido a diferenciais de temperatura entre o topo e o fundo é fato conhecido desde os primeiros estudos analíticos realizados por Westergaard (1927). Posteriormente, várias experiências práticas em pavimento de cimento de concreto foram conduzidas no sentido de medir deformações provocadas pelo empenamento ou, ainda, verificar a perda de contato com a base.

Os métodos para estudo ou análise do comportamento da placa ou do pavimento com as influências das camadas inferiores ou, ainda, o efeito de cargas combinadas sob diferencial térmico geraram vários modelos matemáticos em que os fenômenos foram abordados sistematicamente na forma analítica e numérica, sendo esse último mais moderno, explorando a técnica dos elementos finitos. Uma descrição dessas abordagens e modelos pode ser vista em Severi (2002) que, de forma metódica, relatou cronologicamente os modelos e soluções clássicas e modernas a respeito dos problemas que envolvem o estado térmico da placa de concreto e suas consequências.

No trabalho pioneiro sobre o comportamento da placa de CCP, realizado por Westergaard (1926), a placa foi considerada estando sobre uma fundação elástica, com contato pleno entre ela e o subleito (que atua como um conjunto de molas idênticas e dispostas de tal forma a responder esforços externos na vertical, sem ocorrer esforços na horizontal), sem carregamento (placa simples), sem base e fundação semi-infinita, mas nenhuma menção a respeito da influência da temperatura. 
Posteriormente, Westergaard (1927) considerou os efeitos da temperatura, sendo que sua variação, ocorrendo em toda a extensão da placa, provocaria variações nas dimensões da placa e, consequentemente, apareceriam tensões decorrentes do atrito com a base (subbase). As variações de temperatura, ao longo da altura da placa, dão origem às tensões de flexão, tendendo a levantá-la, porém, devido ao peso próprio, ela se mantém na sua posição, ocasionando tensões de compressão no topo e tensões de tração no fundo.

Uma visão gráfica a respeito do comportamento da placa submetida a variações de temperatura, para o cálculo de tensões, foi dada por Thomlinson (1940), que mostrou como a variação da temperatura ao longo da placa afeta a sua geometria. Os desenhos 3 a 5 , extraídos do texto original, mostram, levando em consideração a teoria da elasticidade e fazendo ressalva sobre o apoio da placa, como ela fica perante uma distribuição não linear da temperatura.

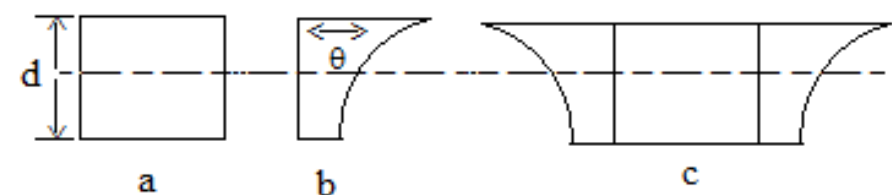

a

b

C

Desenho 3. Secção de um elemento de placa Fonte: Adaptado de Thomlinson (1940).

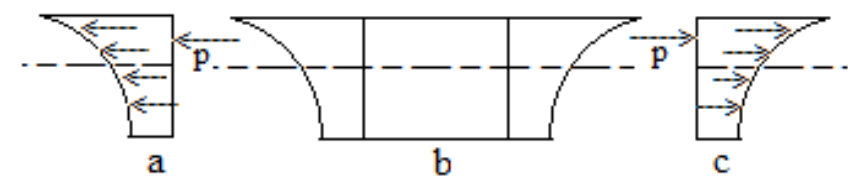

Desenho 4. Distribuição de forças. Fonte: Adaptado de Thomlinson (1940).

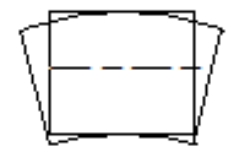

a

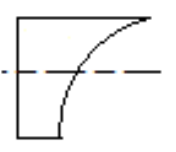

$\mathrm{b}$

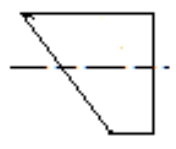

c

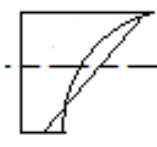

d

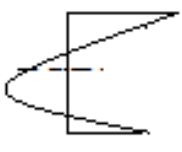

e

Desenho 5 Forma do elemento devido a tensões internas. Fonte: Adaptado de Thomlinson (1940).

Na descrição de Thomlinson (1940): 
O desenho 3 representa a elevação normal de uma secção transversal de um elemento de uma placa de espessura d para uma temperatura uniforme, assumindo, por exemplo (para efeito de simplicidade), que o efeito da variação de temperatura é produzir mudança no comprimento do plano do diagrama somente e não simultâneo com a mudança similar no comprimento no plano normal do diagrama. Se a distribuição de temperatura assume a forma mostrada no desenho $3 \mathrm{~b}$, assumindo a placa ser feita de camadas infinitesimalmente finas, ela assumirá a forma mostrada no desenho 3c. Suponha que cada extremidade do elemento distorcido esteja sujeita à forças $\mathrm{p}$ (desenho 4) distribuídas da mesma maneira como a temperatura e igual em intensidade para $\varepsilon \mathrm{E} \theta$, onde $\mathrm{E}$ representa o módulo de Young para o material da placa; $\varepsilon$ representa o coeficiente de expansão linear; $\theta$ representa a temperatura para uma profundidade qualquer.

Sob a ação de forças distribuídas, o elemento assumirá a sua forma original (desenho 4a). Assumiremos agora que o elemento está sujeito a forças concentradas $\mathrm{P}$, iguais em intensidade mas em direção oposta à resultante das forças distribuídas e coincidindo com a resultante das forças distribuídas. A tensão no elemento resultante dessas forças concentradas $\mathrm{P}$ tem uma distribuição linear (como uma coluna carregada excentricamente (desenho 5c) enquanto a tensão resultante das forças distribuídas como mostrado na desenho $5 \mathrm{~b}$. O resultado líquido é que as forças externas imaginárias $\mathrm{p}$ e $\mathrm{P}$ balançam uma para outra, o elemento é distorcido da sua forma original e estará sob a ação das forças imaginárias concentradas e o elemento é tensionado de acordo com a soma algébrica das tensões devido às duas forças imaginárias externas $\mathrm{p}$ e $\mathrm{P}$ (desenho $5 \mathrm{~d}$ ). Essa tensão será referida como tensão interna.

Se a temperatura do elemento original é incrementada e distribuída como mostrado na desenho $3 b$, a distribuição resultante das tensões serão tal que a tensão nas fibras externas será compressiva enquanto o interior da placa está sob tração e a força total em qualquer seção é zero. Desenho 5 e.

Harr e Leonards (1959), em um dos pioneiros trabalhos elaborados com um computador, realizando um processo de solução numérica, mostraram que diferenciais de temperatura de $2,0{ }^{0} \mathrm{C}\left(40,0{ }^{0} \mathrm{~F}\right)$, entre superfície e fundo, provocam tensões que se aproximam do módulo de ruptura da placa, e que tensões produzidas por temperatura podem ser computadas por placas finitas.

Sobre os trabalhos de Westergaard, Ioannides et al. (1999) realizaram uma ampla discussão a respeito das soluções e considerações feitas, mostrando como os avanços tecnológicos alcançados nas últimas três décadas, método dos elementos finitos, análises de regressão estatística e redes neurais artificiais, interpretam as soluções dadas no começo do século passado.

A obtenção de tensões desenvolvidas na placa é também explorada por Tang et al. (1993) que expõem essa característica de empenamento e desenvolvem analiticamente expressões para o cálculo das tensões originadas pelo diferencial de temperatura. No mesmo trabalho é mostrado que as configurações geométricas da placa de CCP tendem a apresentar, mediante essas variações, um formato convexo durante o dia, devido ao diferencial de 
temperatura, e um formato côncavo no período noturno. Liang e Niu (1998), também de forma analítica, verificam a influência da temperatura com a profundidade, destacam a sua não linearidade e propõem que o cálculo do empenamento ou das tensões causadoras desse efeito seja manipulado com modelo não linear.

Lee (1999), utilizando o programa ILLI-SLAB trabalhado com o conceito de placas finitas, observou tensões de empenamento para diferencial de temperatura em torno de $18,0{ }^{0} \mathrm{C}\left(33,0{ }^{0} \mathrm{~F}\right)$.

Severi (2002), por meio de estudos baseados em dados para clima tropical, retirados de pista experimental, percebeu o comportamento não linear ao longo da placa e propôs, ainda, modelos empíricos para a previsão dos diferenciais de temperatura ao longo da placa para diversas ocorrências ambientais. Alguns desses modelos foram testados e fazem parte do corpo do presente trabalho.

A descrição analítica feita por Thomlinson (1940), que utilizou uma equação de onda unidimensional como premissa no desenvolvimento do cálculo de tensões, e o trabalho experimental de Severi (2002) são compatíveis com relação ao tratamento térmico diário e sazonal, mostrando como a placa se comporta perante o estado térmico em que se encontra.

Esses trabalhos são significantes pois, mesmo após sessenta anos, existe uma preocupação técnica em relação a esse tipo de estrutura e como ela é afetada pelas condições ambientais.

O gráfico 1 mostra as concepções dos comportamentos da temperatura ao longo da espessura da placa, dada por Thomlinson (1940), e aquele obtido experimentalmente por Severi (2002). Nota-se que o comportamento diário da temperatura aproxima-se realmente de uma função do tipo senoidal e pode, em determinadas situações, ser tratada como tal. A influência dessa oscilação foi mostrada por Siddique et al. (2005), que realizou um comparativo rigoroso entre uma placa instrumentada com um modelo em elementos finitos e comentou que a alternância dos ciclos diários pode ocasionar a fadiga do material, levando-o à falha.

Cabe nesse momento referir um trabalho anterior em que Richardson e Armaghani (1987), examinando por hipótese que o pavimento construído em Gainesville, Flórida - USA, tinha apresentado trincas prematuras, devido à não linearidade da temperatura, concluíram que esse impacto não teve condições de afetar o seu desempenho. Em contra partida, Mahboub et al. (2004), trabalhando em uma seção da Gene Synder Freeway., Kentuck - USA, verificaram que os fatores ambientais são preponderantes e recomendam que os modelos de 
fadiga, baseados exclusivamente na cargas de tráfego, sejam modificados para incluir os efeitos cíclicos da temperatura.

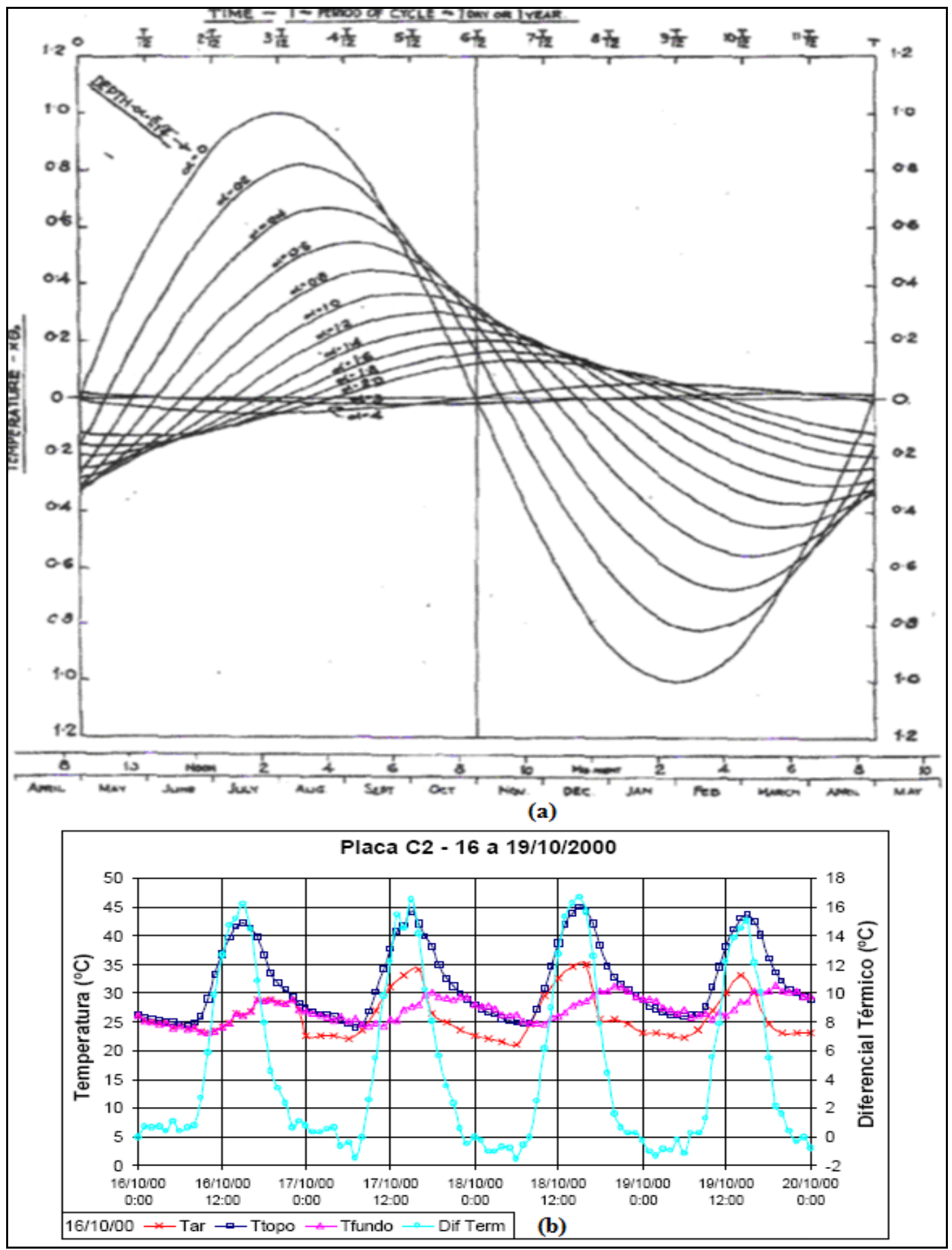

Gráfico 1. Concepção analítica de Thomlinson (a) e verificação experimental de Balbo e Severi (b).

Fonte: Adaptado de (a) Thomlinson (1940), (b) e Severi (2002). 
A respeito das deformações que podem ocorrer na placa de concreto por efeitos ambientais, Wells et al. (2006) analisaram esse acontecimento em duas situações distintas, imediatamente após a pavimentação e depois de um período de 10 meses em uma seção da SR-22 em Murrysville, Pennsylvania - USA. Notaram que as deformações seguem ritmos diferentes, dependendo da estação do ano e que a amplitude das deformações varia com o aumento da profundidade do pavimento.

Outro aspecto que gera certa discussão é sobre a existência de um gap no fundo da placa quando essa estiver sob regime térmico diário. Armaghani et al. (1987), através da instrumentação realizada em pista experimental, sobre o movimento de flexão da placa quando do surgimento de tensões, não comentam diretamente a existência de um gap, mesmo com uma sensível instrumentação realizada com sensores de deslocamento, linear variable diferential transformer (LVDT), fixados nos extremos longitudinais da placa e no solo. Porém, como comentado, em determinadas condições climáticas, os bordos da placa se deslocaram para cima ou para baixo e isso leva a crer que, de forma indireta, existe a possibilidade da existência de haver um gap. No presente trabalho, observações semelhantes foram feitas e concordam com as realizadas por Armaghani et al. (1987).

A existência de uma temperatura crítica, indicada por Tang et al. (1993), baseada na teoria de placas e relativa às soluções de Westergaard de um pavimento apoiado sobre uma fundação tipo Winkler, indica a ocorrência de um gap entre a placa de concreto e a base, ilustrado de forma exagerada pelo desenho 6. O desenho 7 ilustra uma vista isométrica do comportamento da placa mediante um diferencial de temperatura. A existência desse espaço entre placa e base também foi abordada indiretamente por Yu (1998), quando da análise de cargas combinadas, temperatura e tráfego em uma seção instrumentada da I-70 em Kansas, Colorado - USA. Esse trabalho contempla um gráfico do levantamento das bordas da placa em função do tempo, quando sob efeito da temperatura. Isso quer dizer que, se a placa não for aderida e tiver a capacidade de vencer atrito entre as superfícies, existe a possibilidade do surgimento desse espaço.

O trabalho de Rodolfo (2001) indica que, devido ao peso próprio, a placa não exibe tal gap. Porém, Rufino e Roesler (2006), através de um trabalho sobre interação de placa com a base, em um pavimento aeroportuário instrumentado, mostram a existência de um gap no fundo da placa.

Tal "abertura" só poderia existir se ocorresse um alívio da reação normal de apoio e, isso, causaria a ruptura na placa devido a perda de contato com a sub-base sob ação do número de solicitações. Nesse caso, o fenômeno da fadiga se faria presente, pois a placa 
estaria submetida à flexão repetida, resistindo até certo número de solicitações. Souza (1972), relata que tem sido observado, experimentalmente, que o concreto resiste as solicitações desde que a tensão de tração seja inferior a 50 \% do módulo e ruptura.

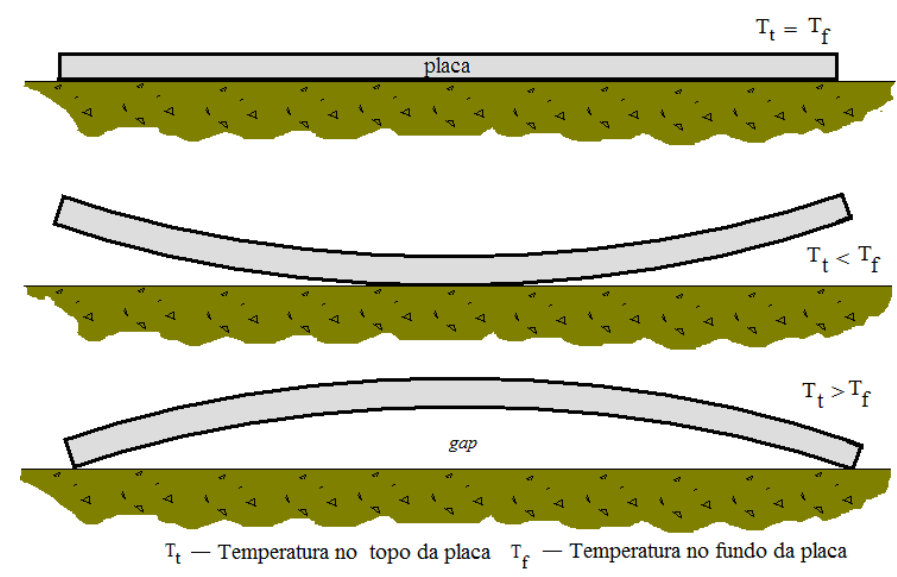

Desenho 6. Comportamento do pavimento segundo as condições de temperatura diária Fonte: Acervo próprio, adaptado de Armaghani (1987).

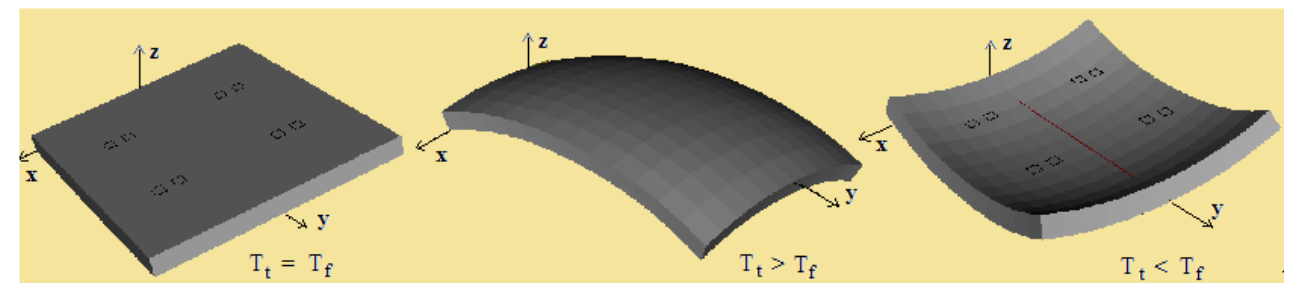

Desenho 7. Vista isométrica do comportamento da placa sob ação de um diferencial de temperatura

Fonte: Acervo próprio,gerado a partir do software EverFE 2.24 (2009).

\subsubsection{VARIÁVEIS TÉRMICAS}

O procedimento escolhido para aquecimento da placa de concreto baseou-se na idéia do enclausuramento térmico do conjunto das camadas, que é feito por meio de resistências elétricas. Dessa forma, a temperatura da placa ficou sujeita à eficiência da plataforma de aquecimento, através da transmissão de calor por radiação, bem como por convecção. A transmissão de calor por condução ocorreu devido às ações anteriores e só pôde ser observada ao longo da espessura da placa e da sub-base.

Chama-se condução de calor em corpos sólidos, a transmissão de calor através deles sem a ocorrência de movimentos internos e interferência da radiação. $O$ calor flui, dentro de um corpo, da região de temperatura mais alta para a de temperatura mais baixa. Esse conhecimento, aliado aos processos de radiação e convecção tem grande significado para 
a compreensão da marcha térmica dentro do pavimento, a começar pela placa. O processo de transmissão de calor possui tratamento analítico e apóia-se em análises realizadas após a metade do século XIX. A condução de calor em um sólido regular, como é o caso de uma placa de pavimento, vem sendo estudada com certas condições limites e considerada um sólido semi-indefinido (SILVEIRA, 1961).

Alguns fatores influenciaram o estado térmico da placa. A "inércia" térmica, devido a grande massa de concreto se apresentou em todas as fases e experimentos realizados no período. Isso foi sentido principalmente nas etapas de resfriamento da placa, após os procedimentos de aquecimento. Um problema que também atuou nos experimentos foram as trocas forçadas de calor, não previstas, devido a circulação indevida de ar por sobre a placa. Isso pôde ser observado todas as vezes que uma corrente de ar percorria no sentido do laboratório de ensaios para o de solda, segundo o desenho 1.

A temperatura ambiente teve pouca influência durante os testes, servindo como condição inicial em todas as situações. Os testes foram realizados sempre com a umidade reinante, pois a mesma não foi controlada.

O molde para modelagem da placa foi feito de madeira e serviu como isolante térmico evitando perdas de calor pelas laterais, principalmente por sua parte inferior.

A placa e a sub-base ficaram separadas por um filme plástico para que não ocorresse a aderência entre elas e, nessa interface, não foi considerada a resistência térmica.

A condução do calor é tratada pela lei de Fourier, onde se estabelece: a quantidade de calor que passa através de uma área "A", perpendicular ao fluxo na unidade de tempo é produto da área pelo gradiente térmico. O qual é normalmente empregado para determinar uma razão de variação da temperatura pela espessura. Expresso então como: a diferença das temperaturas de topo e fundo dividido pela espessura.

Porém, o gradiente em $\mathrm{R}^{2}$ é definido como sendo a direção de um vetor que se projeta sobre o plano xoy e é denotado por:

$$
\nabla f(x, y)=f_{x}(x, y) \vec{i}+f_{y}(x, y) \vec{j}
$$

Com essa notação a derivada direcional pode ser escrita como:

$$
D_{\mathrm{u}} f(x, y)=\nabla f(x, y) \cdot \mathrm{u}
$$

Em outras palavras, o produto escalar do gradiente com o vetor u produz a derivada direcional de $f$ na direção do vetor $\mathbf{u}$.

A derivada é realizada sobre expressões que representam funções, isso implica que, em gráficos onde se mostra a relação entre profundidade por temperatura a derivada não 
pode ser realizada, pois a curva em questão não representa uma função. Como exemplo, o gráfico 2 mostra a relação de $\mathrm{t}\left({ }^{\circ} \mathrm{C}\right)$ versus espessura $(\mathrm{m})$, nesse caso a derivada não se aplica. No entanto, é possível determinar a uma taxa de variação do progresso da temperatura ao longo da espessura.

Por outro lado, caso os mesmos valores do gráfico 2 forem combinados para formar uma tripla ordenada que, quando plotados, gerem uma superfície, a definição de diferencial se aplica e é possível.

A lei de Fourier ${ }^{8}$, para condução térmica em um sólido em uma única direção pode ser escrita como:

$$
\frac{d Q}{d t}=-k_{c} A \frac{d \theta}{d x}
$$

Cuja quantidade $\frac{d \theta}{d x}$ é chamada de gradiente térmico que expressa a funcionalidade entre a temperatura e o fluxo de calor. O gradiente se processa no sentido do fluxo. Isto é, no sentido das temperaturas crescentes. Sendo assim, $\theta$ diminui quanto $\mathrm{x}$ aumenta e $\frac{d \theta}{d x}$ é negativo. O caráter geral da expressão (08) tomada através de uma derivada total, pode ser estendida para regime permanente e variável. Conforme o fluxo de calor flui em uma ou mais direções, o fluxo será uniderecional, bidirecional e tridirecional.

A partir dela pode-se definir superfícies isotérmicas e linhas de fluxo, na situação em que o primeiro membro da (08) for zero.

$\mathrm{O}$ fator de proporcionalidade $\mathrm{k}$ que figura na fórmula (03) recebe o nome de condutibilidade térmica $\left(\mathrm{W} / \mathrm{m}^{2 \circ} \mathrm{C}\right)$.

$\mathrm{Na}$ equação de Fourier os gradientes são expressos em forma de derivadas parciais onde se admite uma função do tipo $\theta(x, y, z, t)$. E podem ser vistos na expressão abaixo.

$$
\frac{\partial \theta}{\partial t}=h^{2}\left(\frac{\partial^{2} \theta}{\partial x^{2}}+\frac{\partial^{2} \theta}{\partial y^{2}}+\frac{\partial^{2} \theta}{\partial z^{2}}\right)=h^{2} \nabla^{2} \theta
$$

Sendo assim, pelo fato do operador gradiente necessitar de uma função para executar a operação, no presente trabalho será utilizado o termo taxa de variação em

\footnotetext{
${ }^{8}$ Jean-Baptiste-Joseph Fourier (1768 - 1830) - Professor de matemática na École Militar de Auxerre.
} 
substituição ao termo gradiente. O termo, diferencial de temperatura, será utilizado para expressar a magnitude entre uma temperatura e outra.

As grandezas de radiações: térmica emitida (pela placa), incidente, refletida, absorvida, convecção com o ambiente e a transmitida não foram tratadas e nem simuladas isoladamente devido às limitações da experiência. Porém, em campo, vários modelos de previsão foram construídos tomando-se por base princípios térmicos da termodinâmica. Dentre os modelos pode-se citar Adkins e Merkley (1990) e Severi (2001).

A condução de calor ao longo da placa, considerada semi infinita, foi tratada de forma transiente.

Um aspecto que deve ser considerado é o fato dos materiais sofrerem deformação por origem térmica, devido a não possuírem coeficiente de dilatação nulo. Mediante a isso, o surgimento de tensões em um sólido é inevitável, desde que exista uma diferença de temperatura atuante sobre ele. Ou, não sendo assim, tenha a liberdade de movimento restrita. Fatores que também influenciam esta deformação: condutibilidade térmica, calor específico e considerações hipotéticas costumeiras como isotropia e homogeneidade. As tensões térmicas originadas no concreto devido à dilatação têm inconveniências quando ocorrerem de forma a produzir tração. Essas tensões têm relevante importância em outros ramos da engenharia a citar, de acordo com Timoshenko, Goodier (1980) nas áreas automotiva, aeroespacial e nuclear.

\subsubsection{MÉTODOS DE DIMENSIONAMENTO}

As abordagens mais utilizadas para o dimensionamento de pavimentos são aquelas baseadas no método empírico (CBR - método do DNIT) e o mecanista (fadiga e deformações).

O método empírico é baseado na observação dos efeitos e comportamentos de trechos experimentais, cujos parâmetros mais importantes são o clima, carregamentos e materiais

O método mecanista ou analítico emprega a teoria da elasticidade e exige um conhecimento dos materiais empregados e suas propriedades tais como: módulo de elasticidade ou módulo de Young, coeficiente de Poisson, módulo de resilência, fadiga e, creep. A análise é baseada através do cálculo de tensões, deformações e deslocamentos. Os dois métodos de dimensionamento buscam a otimização da espessura da placa. 
Essas metodologias são também conhecidas como método da Portland Cement Association (PCA) de 1984 e o da American Association Of Highway And Transportation Officials (AAHSTO) de 1993. O método da PCA foi desenvolvido a partir dos fundamentos de Westergaard e o dimensionamento é feito em função do consumo de resistência à fadiga e aplica-se tanto para pavimentos de concreto simples, como aos dotados de armadura distribuída, utilizando modelos estruturais pelo método dos elementos finitos. O método inclui a ação repetida de carga de tráfego durante o período estabelecido para o projeto (SENÇO, 1999). O método da AASHTO foi desenvolvido com base nos resultados obtidos na pista experimental da AASHO Road Test.

Atualmente os métodos de projeto contam com a ajuda de softwares, baseados no método dos elementos finitos, que possibilitam a análise de tensões e deformações. Dentre os programas pode-se destacar o software EverFE 2.24, desenvolvido por Davis, (2007), disponível no site do desenvolvedor e que possui características profissionais para projeto de pavimentos de CCP. Por outro lado, softwares comerciais também são utilizados para o projeto e pesquisas sobre pavimentos. Siddique et al. (2005) descrevem um modelo em elementos finitos em três camadas, utilizando o software ANSYS $^{\circledR}$, para o estudo das deformações provocadas por diferencial de temperatura, o qual se utiliza de dados obtidos no campo.

Esses dois softwares exemplificam o estado atual no dimensionamento de pavimentos sendo o EverFE 2.24 um software acadêmico gratuito, dedicado à simulação numérica 3D de pavimentos e o outro (ANSYS), comercial, generalista e capaz de simulação numérica, análises não lineares termo-estruturais 2D ou 3D com aplicação em vários ramos da engenharia.

No presente trabalho, o dimensionamento do pavimento foi realizado em duas frentes, o método da PCA/84 foi utilizado para projetar o pavimento, enquanto um modelo semelhante foi modelado, numericamente, pelo software EverFE 2.24. Esse processo teve a finalidade de realizar, de acordo com o teste, comparação e calibração dos dados obtidos experimentalmente.

Esse item teve a função de apresentar uma introdução ao trabalho justificando implicitamente a importância no seu desenvolvimento. $\mathrm{O}$ objetivo e metodologia foram apresentados dando a abrangência das experiências realizadas, foi descrito a problemática envolvida no dimensionamento de um pavimento, apresentou-se uma bibliografia inicial que deu sustentação aos resultados. O local de testes, as instituições envolvidas e as variáveis térmicas e mecânicas também foram expostas, bem como a caracterização inicial dos 
materiais e as descrições dos métodos construtivos. A estrutura foi mostrada sob o aspecto técnico e as equações históricas utilizadas no dimensionamento de pavimentos foram descritas. Explorou-se ainda, o comportamento da estrutura frente aos fatores térmicos e as questões sobre o encurvamento da placa. 


\section{METODOLOGIA PARA A INSTRUMENTAÇÃO DA PLACA DE CONCRETO}

A instrumentação em pavimentos mostra-se uma importante ferramenta para monitorar o desempenho do pavimento sob diferentes condições ambientais e cargas de tráfego. A literatura tem mostrado que, tal qual o trabalho de Loulizi et al. (2006), vários projetos visaram medir tensões, deformações, deflexões, temperatura e outras grandezas.

Com relação ao Brasil, segundo Silva (2001), a experiência em instrumentação é pequena e conta com alguns testes realizados em Santa Catarina, num trecho da BR-101; a instrumentação do painel de pavimento flexível, construído na COPPE/UFRJ em 1979; a pista experimental circular do IPR/DNER instrumentada em 1993 para a pesquisa de concreto rolado; a instrumentação da Pista Linear Experimental da Universidade Federal do Rio Grande do Sul para estudar o desempenho de misturas asfálticas e a instrumentação, em 1998, da Pista Circular Experimental do IPR/DNER com seis extensômetros e duas células de carga, para a pesquisa de whitetopping.

Em São Paulo, os trabalhos mais significativos em instrumentação de pavimentos foram realizados na Escola Politécnica da Universidade de São Paulo, especificamente pelo departamento de transportes da Escola de Engenharia Civil com o trabalho de Rodolfo (2001) em que foi construída uma pista com várias seções para testes de tensões e deformações devido à ação da temperatura e outro realizado por Pereira (2001) para estudar o comportamento de placas de WTUD quando submetidas ao efeito do empenamento térmico.

No presente trabalho, diferente das experiências citadas, o pavimento foi instrumentado interno a um laboratório onde se pode ter controle de um importante parâmetro que é a temperatura. A instrumentação da placa foi realizada por meio de sensores construídos com características próprias e capazes de atender os testes que foram realizados. A opção pelo desenvolvimento e construção dos sensores teve implicações econômicas, pois, se os mesmos fossem comprados no mercado, elevaria o custo da execução do pavimento. De certo modo, essa decisão acrescentou vantagens acadêmicas, tais como aquisição de conhecimento e competência técnica, sem mencionar novos procedimentos com a introdução de técnicas de embutimento de sensores na placa de CCP e metodologia para interpretação de dados. 
Após algumas experiências, realizadas com um corpo de prova prismático (vigota) e com a construção do pavimento 1 (apêndice C) e conseqüente instrumentação da placa 1, conseguiu-se construir sensores que fossem resistentes aos processos mecânicos de embutimento, que possuíssem repetibilidade de transdução, bem como estabilidade de transdução durante o processo de aquecimento e resfriamento da placa, em ciclos contínuos.

\subsection{DIMENSIONAMENTO DOS CORPOS DE PROVAS}

Para a construção do pavimento atual, foram elaborados corpos de prova para a determinação do traço ${ }^{9}$ do concreto, para averiguação da eficiência dos sensores e para testar a forma de fixá-los dentro da massa do concreto. Para tanto, foram construídos três corpos de provas, duas vigotas prismáticas, com dimensões de $0,1 \mathrm{~m} \times 0,1 \mathrm{~m} \times 0,5 \mathrm{~m}^{10}$ e o pavimento 1 dimensionado para possuir $1,2 \mathrm{~m} \times 1,2 \mathrm{~m} \times 0,3 \mathrm{~m}$, sendo a placa (placa 1) com $0,1 \mathrm{~m}$ de espessura.

Uma vigota foi construída para o estudo de embutimento dos sensores de temperatura, a qual, por sinal, foi utilizada para um primeiro levantamento da distribuição da temperatura ao longo da espessura e, também, para determinação das curvas de aquecimento.

A outra vigota foi construída para o estudo do procedimento de fixação (embutimento) dos sensores de deformação (células de embutimento) e verificação da sensibilidade.

A construção do pavimento 1 possibilitou atestar os resultados obtidos com as vigotas. A composição do concreto utilizado na construção dos corpos de prova e da placa 1 foi a seguinte de acordo com a Tabela 1.

\footnotetext{
9 O concreto é uma mistura dos vários componentes em determinadas proporções que, na linguagem da construção civil, denomina-se dosagem ou traço.

${ }^{10}$ Por uma questão de praticidade, pois já existiam moldes prontos, a vigota não foi feita segundo a norma NBR 5738 (ASSOCIAÇÃO BRASILEIRA DE NORMAS TÉCNICAS,2008) que prescreve as dimensões de 150,0 x $150,0 \times 500,0 \mathrm{~mm}$ para ensaios tecnológicos do concreto
} 
Tabela 1. Materiais, propriedades e quantidade do concreto utilizado para construção das vigotas.

\begin{tabular}{lll}
\hline Material & quant. & unidade \\
\hline Areia & 856,5 & $\mathrm{~kg} / \mathrm{m}^{3}$ \\
Brita & 1172,3 & $\mathrm{~kg} / \mathrm{m}^{3}$ \\
Água & 140,0 & $\mathrm{~L}$ \\
Relação água cimento & 0,6 & ------ \\
Plastificante & Não & $\mathrm{L} / \mathrm{m}^{3}$ \\
Abatimento & 20,0 & $\mathrm{~mm}$ \\
Resistência na compressão aos 28 dias & 13,8 & $\mathrm{MPa}$ \\
\hline
\end{tabular}

Fonte: Elaborada a partir dos ensaios realizados (2005).

A cura das vigotas e dos corpos de provas cilíndricos foi realizada em câmara úmida e somente aos 28 dias se iniciaram os testes. A fotografia 2 mostra o molde das vigotas, bem como as dimensões.

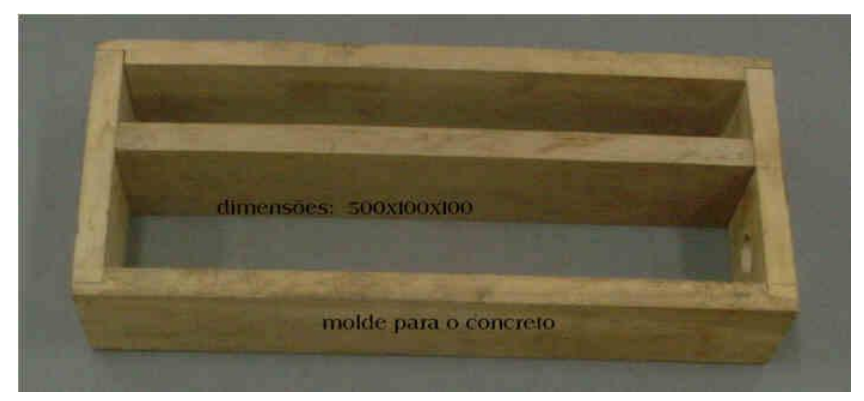

Fotografia 2. Molde utilizado para confecção do CP e testes de embutimento, dimensões $100,0 \times 100,0 \times 500,0 \mathrm{~mm}$.

Fonte: Acervo próprio (2005).

\subsubsection{ENSAIOS DE DURABILIDADE E SENSIBILIDADE NOS TERMÔMETROS E CÉLULAS DE EMBUTIMENTO}

Os primeiros ensaios com os sensores de temperatura foram realizados na vigota durante o inverno de 2006, dentro do campus da UPM em local com boas condições de insolação. A fotografia 3 mostra a disposição dos sensores de temperatura embutidos na vigota, bem como um termômetro de referência, rastreado ${ }^{11}$, (termopar) no topo da vigota para monitoramento da temperatura superficial. Essa experiência inicial mostrou os primeiros indícios do comportamento não linear da temperatura e como ela varia no ciclo diário.

\footnotetext{
${ }^{11}$ Termo utilizado para designar quando um equipamento foi calibrado em relação a outro, de mesma natureza, calibrado em laboratório acreditado pelo Instituto Nacional de Metrologia Padronização e Qualidade Industrial (INMETRO).
} 
A vigota ficou exposta à variação de temperatura diária e os dados colhidos, em quatro posições distintas a partir do topo: 0,0 m (topo), 0,025 m (1/4 da espessura 25,0 mm), $0,050 \mathrm{~m}(1 / 2$ meio da vigota $50,0 \mathrm{~mm})$ e $0,075 \mathrm{~m} \mathrm{(3/4}$ da espessura $75,0 \mathrm{~mm})$, determinaram a forma do crescimento e decrescimento da temperatura bem como a velocidade com que ocorre a alteração da temperatura no interior do concreto. O gráfico 2 mostra a distribuição as temperaturas na vigota ao longo das quatro posições da sua espessura. Apesar da pequena espessura, a distribuição de temperatura mostra sinais de não linearidade, fato esse observado na literatura, principalmente nos trabalhos de Severi (2002), Rodolfo (2001) e Pereira (2001).

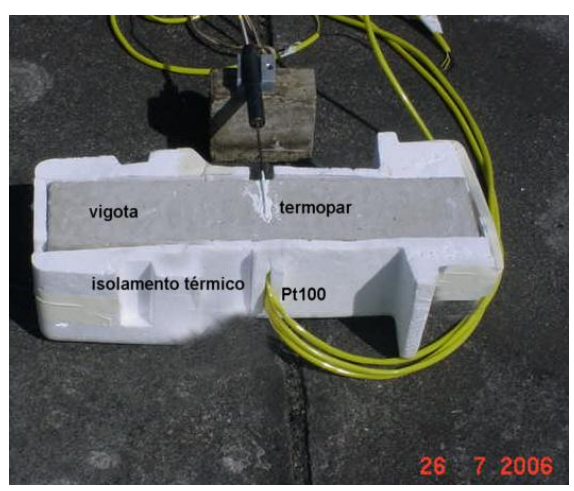

Fotografia 3. Vigota isolada termicamente nas laterais e instrumentada com sensores de temperatura.

Fonte: acervo próprio (2006).

O fenômeno do empenamento não pôde ser observado com o teste da vigota, pois a dimensão de comprimento era demasiadamente pequena $(0,5 \mathrm{~m})$ para que se pudesse realizar medições de deformação ou empenamento. No primeiro pavimento com a placa 1 , também não foi possível verificar o surgimento de uma abertura (gap) entre a placa e a base (sub-base), apesar dos dados obtidos pelos sensores de deformação indicarem essa tendência. Porém, no segundo pavimento com a placa 2 (referida a partir de agora como placa), a observação foi mais conclusiva devido à instalação de uma célula de carga no centro do pavimento. 


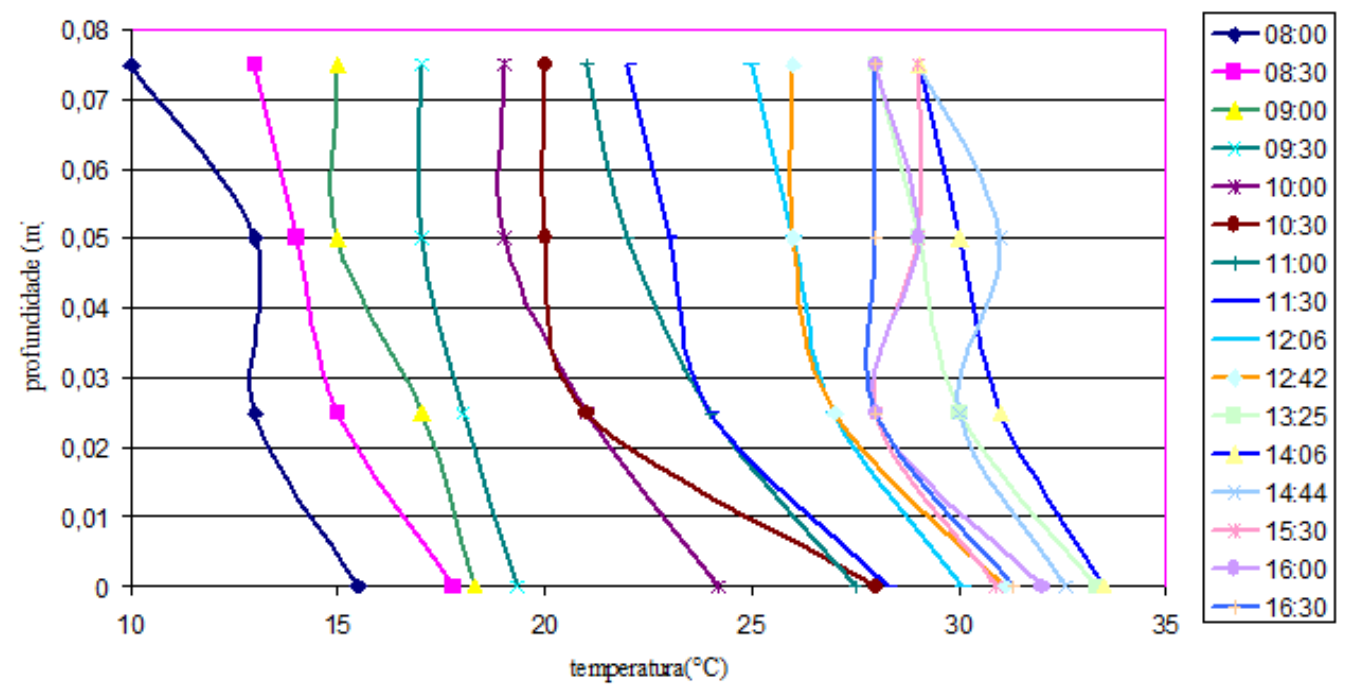

Gráfico 2. Variação da temperatura em quatro posições distintas no CP (vigota).

Fonte: Acervo próprio (2006).

Como exposto anteriormente, nos primeiros ensaios antes da construção das placas, vigotas foram construídas para abrigar os sensores. A intenção foi verificar, dentre outros detalhes, a funcionabilidade e durabilidade dos sensores. Essas vigotas foram submetidas a testes mecânicos de tração na flexão e, além desses parâmetros, outros puderam ser observados, tais como:

a) estanqueidade, a célula mostrou-se muito eficiente indicando que o procedimento de fechamento com cola com base em epóxi e o banho de resina apresentaram ótimos resultados;

b) isolação do cabo de sinal, o cabo escolhido também apresentou ótimos resultados resistindo à intensa umidade e ataque químico induzido pela massa de concreto.

A fotografia 4 mostra o molde para a construção de uma vigota com a célula posicionada para receber o concreto. 


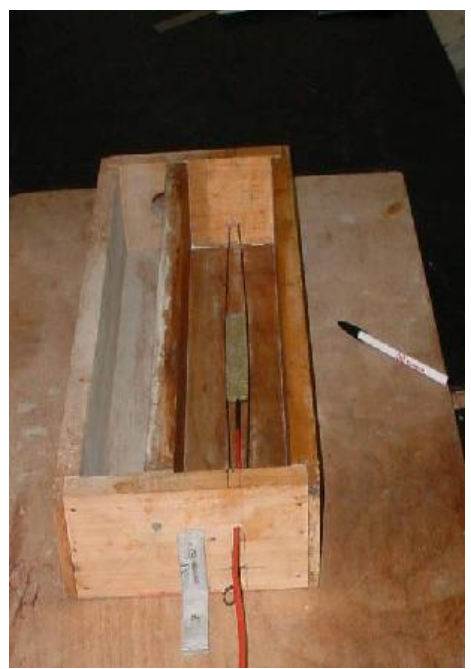

Fotografia 4. Molde para construção da vigota de testes preliminares.

Fonte: Acervo próprio (2005).

A fotografia 5 mostra o molde preenchido e pronto para deixar a cura. Quando da desforma, a vigota foi levada para a câmara úmida e ficou pronta para testes após 28 dias.

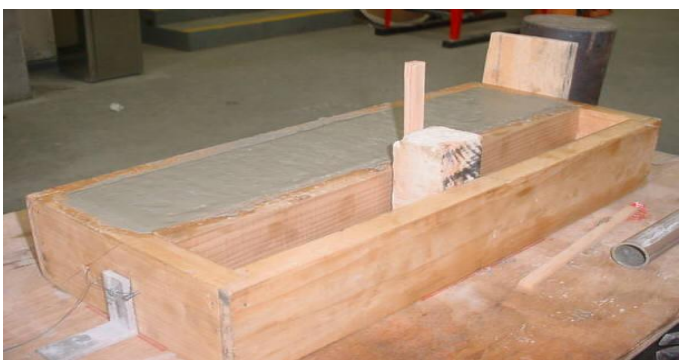

Fotografia 5. Aspecto do molde com a vigota moldada. Fonte: Acervo próprio (2005).

Passado o período de cura, a vigota foi submetida a teste de flexão em três pontos, com cutelos posicionados a $0,1 \mathrm{~m}$ dos extremos. As dimensões da vigota foram feitas com as mesmas características daquelas utilizadas nos testes de fadiga apresentados por Cervo (2006).

O teste de flexão mostrado na fotografia 6 foi realizado em uma máquina de ensaios mecânicos, com capacidade máxima de $800,0 \mathrm{kN}$. A vigota foi submetida à força máxima de $8,0 \mathrm{kN}$ e não foi levada à ruptura. 


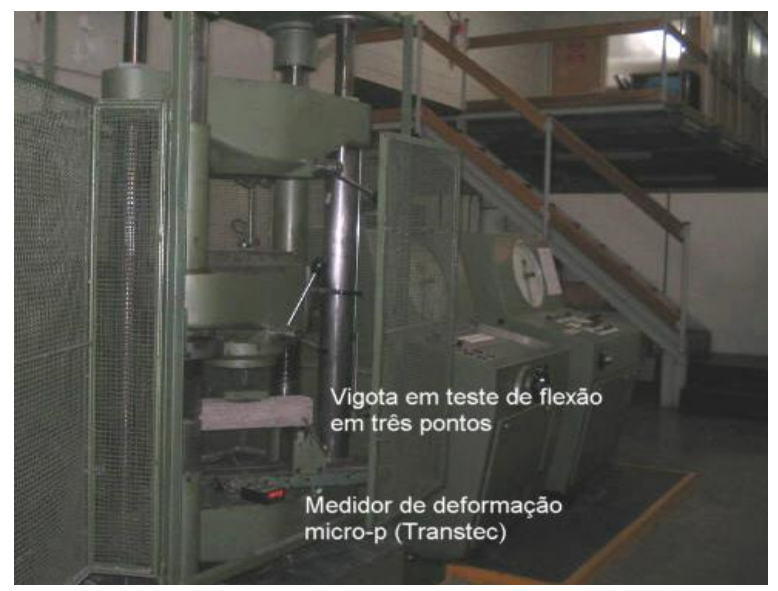

Fotografia 6. Teste de flexão para verificação da sensibilidade da célula de embutimento. Fonte: Acervo próprio (2005).

A resposta da vigota à força aplicada é mostrada no gráfico 3 em que se pode observar a resposta linear no trecho entre 10 e $35 \mu$ s (microstrain) e sofrendo distorção próxima aos extremos. O gráfico 3 permite ainda assumir uma sensibilidade para a célula de

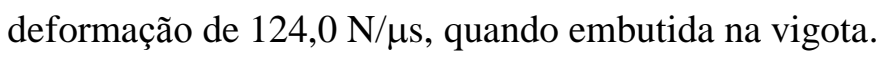

Os testes indicaram que a célula é imune à umidade, possui adequada resistência mecânica, linearidade entre força e deformação e boa isolação elétrica. Porém, percebeu-se uma dependência muito grande da temperatura, problema que foi solucionado, utilizando configurações específicas para compensação desse efeito e com metodologia própria para a aquisição de sinais. Essa problemática pode ser vista no item 2.62.

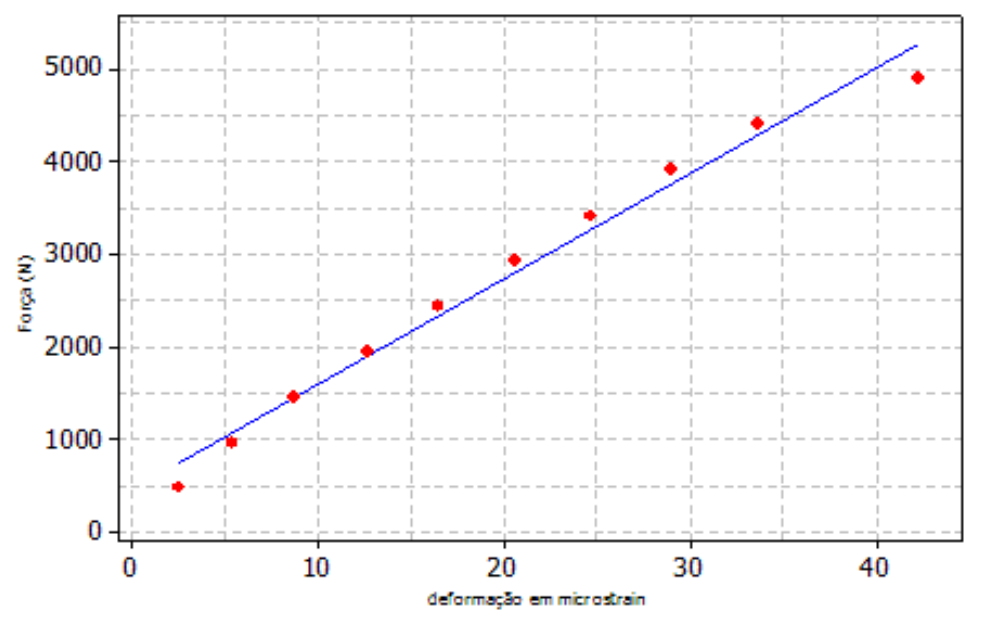

Gráfico 3. Resposta da célula embutida na vigota ao ensaio de flexão.

Fonte: Elaborado a partir dos dados cedidos pelo laboratório de ensaio de materiais (2005). 


\subsubsection{SENSORES DE DEFORMAÇÃO - CÉLULAS DE EMBUTIMENTO}

As células de deformação ou células de embutimento foram construídas com sensores de deformação do tipo strain gage ou extensômetro elétrico de resistência (EER) de 100,0 mm de comprimento, resistência ôhmica de 120,0 $\Omega$, com gage 2 (fator de sensibilidade 2) o qual foi colado sobre um material feito com base em resina e fibra de vidro tipo TVE DUROGLASS ${ }^{\circledR}$. Esse material foi escolhido devido ao baixo coeficiente térmico, baixa absorção de umidade, alta isolação elétrica, alta resistência mecânica e fácil usinabilidade, fato verificado na fase de construção da célula. Os testes para a determinação do coeficiente de dilatação do material podem ser vistos no apêndice A.

As células embutimento são sensores que completam um circuito eletrônico para a transformação de um sinal elétrico em leitura de deformação. Para tanto, apresentam-se as principais características deste tipo de sensor:

Faixa: nos testes realizados a célula respondeu entre $-1000,0 \mu \mathrm{s}$ a $+1000,0 \mu \mathrm{s}$;

Resolução: 0,075mV/V $\rightarrow 153,1 \mathrm{~N}$ com incerteza de $0,001 \mathrm{mV} / \mathrm{V}$;

Linearidade: Apresentada via gráficos - apêndice A;

Histerese: Não foi avaliada.

Os extensômetros foram comprados no mercado nacional ${ }^{13}$, Excel Indústria e Comércio, devido à facilidade de aquisição e o custo ser inferior aos sensores importados. A fotografia 7 mostra a célula pronta para ser utilizada. As dimensões da célula de deformação foram escolhidas levando-se em conta as propriedades mecânicas do concreto e sua heterogeneidade. No apêndice A, são encontrados os valores e os gráficos utilizados para calibração das células.

\footnotetext{
${ }^{12}$ Fator do extensômetro, gage factor, é igual à variação relativa da resistência elétrica dividida pela deformação relativa. $\mathrm{O}$ apêndice $\mathrm{E}$ detalha analiticamente a obtenção do gage factor.

${ }^{13}$ Os extensômetros utilizados apresentaram, individualmente, gage factor distintos, porém nunca excedendo a $2 \%$ do valor referência 2 .
} 


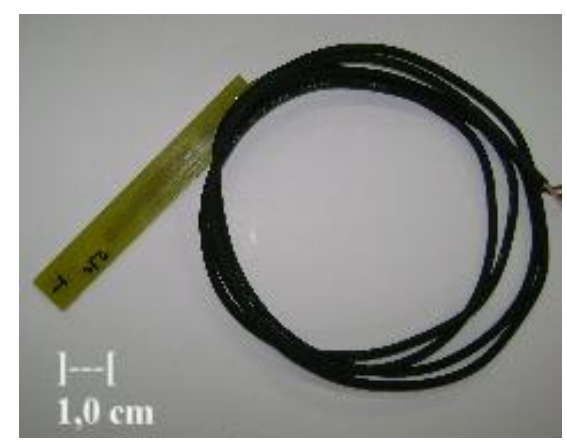

Fotografia 7. Sensor de embutimento pronto para uso.

Fonte: Acervo próprio (2007).

\subsubsection{ENSAIOS NA FLEXÃo PARA A CALIBRAÇÃo DAS CÉLULAS DE EMBUTIMENTO}

O ensaio na flexão foi realizado em uma máquina universal automática em três pontos. Os dados do comportamento da célula foram computados automaticamente pela máquina e por um sistema próprio, desenvolvido especialmente para essa finalidade e utilizado em projetos anteriores similares. O item 2.6 dará destaque para o sistema de aquisição automático utilizado nesse teste.

A fotografia 8 mostra o aspecto da máquina e do sistema próprio de aquisição de dados. A máquina foi regulada para promover, adequadamente em função do tempo, uma deformação de $0,8 \mathrm{~mm}$ na célula de embutimento. Os dados de força e deformação foram simultaneamente computados para que se pudesse estabelecer uma calibração entre a máquina universal e o sistema de aquisição de dados. Esse teste serviu para verificar o comportamento da célula na situação em que o pavimento sofrerá empenamento. Dados experimentais, Yu et al. (1998), mostram que valores próximos a 35,0 $\mu$ s ( microstrain $)^{14}$ tendem a promover a flexão no pavimento quando este estiver submetido a diferenciais de temperatura.

\footnotetext{
${ }^{14}$ Strain é a relação entre a elongação de um corpo, quando submetido a uma força, pelo seu comprimento e é dado por: $\varepsilon=\Delta \mathrm{l} / \mathrm{l}$. Apesar da grandeza ser adimensional, a literatura a trata como deformação específica, deformação mecânica ou, simplesmente, deformação.
} 

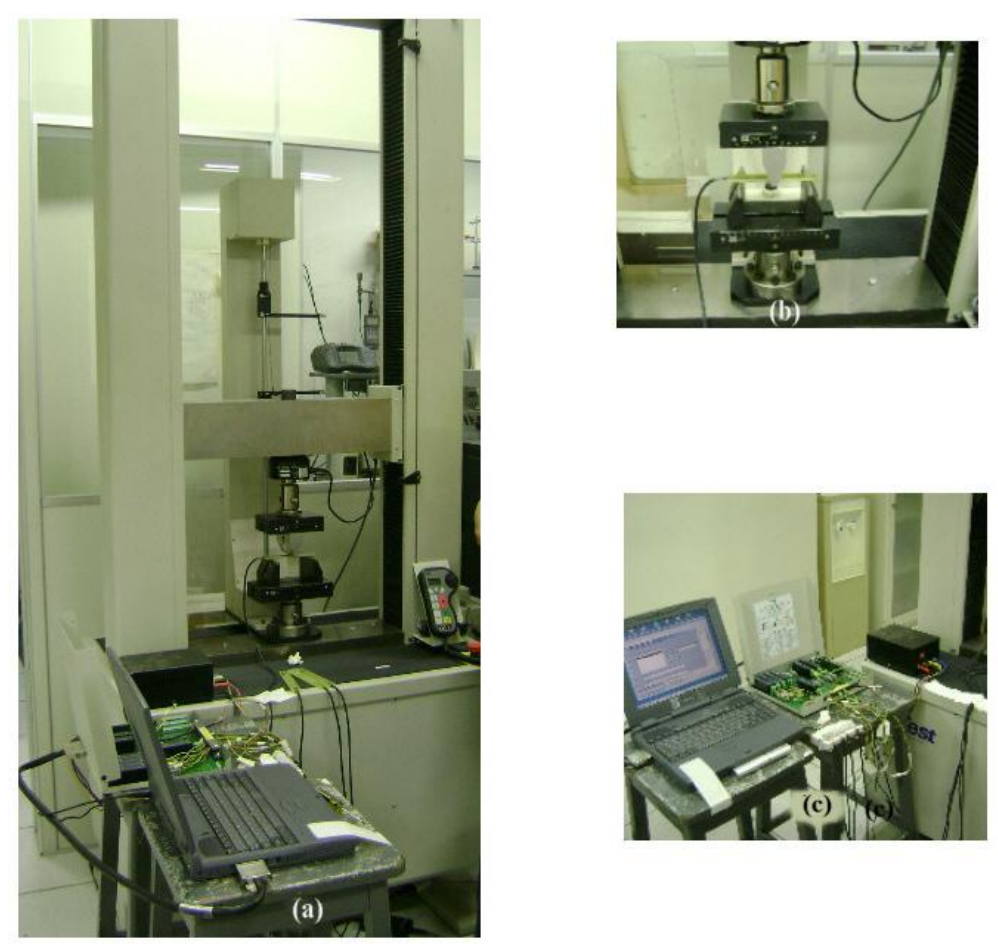

Fotografia 8. (a) Máquina de ensaio universal em processo de teste, (b) detalhe da amostra submetida à flexão em três pontos, (c) sistema próprio de aquisição de dados.

Fonte: Acervo próprio (2008).

\subsubsection{ENSAIO NA TRAÇÃo PARA A CAlibraÇão DAS CÉlulas de EMBUTIMENTO}

Para interpretação plena dos sinais enviados pelas células de embutimento (deformação), foram necessários ensaios de tração para que se pudesse avaliar a sensibilidade da célula nessa condição.

Para tanto, foi necessária a construção de um dispositivo capaz de tracionar as células sem provocar, sobre elas, flexão ou torção, permanecendo uma tração simples. O dispositivo foi construído com uma mesa de desempeno (equipamento utilizado em oficinas de usinagem), suporte de tração, polia de metal, cabo de aço de $0,5 \mathrm{~mm}$ de diâmetro, suportes para a célula de embutimento, massores calibrados, porta massores, célula de carga e um indicador digital de 5 1⁄2 dígitos. Esses componentes podem ser vistos na fotografia 9.

As células foram colocadas uma a uma na mesa de testes e submetidas à tração provocada pelos massores depositados, um a um, até a massa final de 15,0 kg. Como comparação, duas leituras foram feitas: uma obtida da célula de embutimento e outra da célula de carga. Os dados obtidos geraram gráficos de calibração das células. 


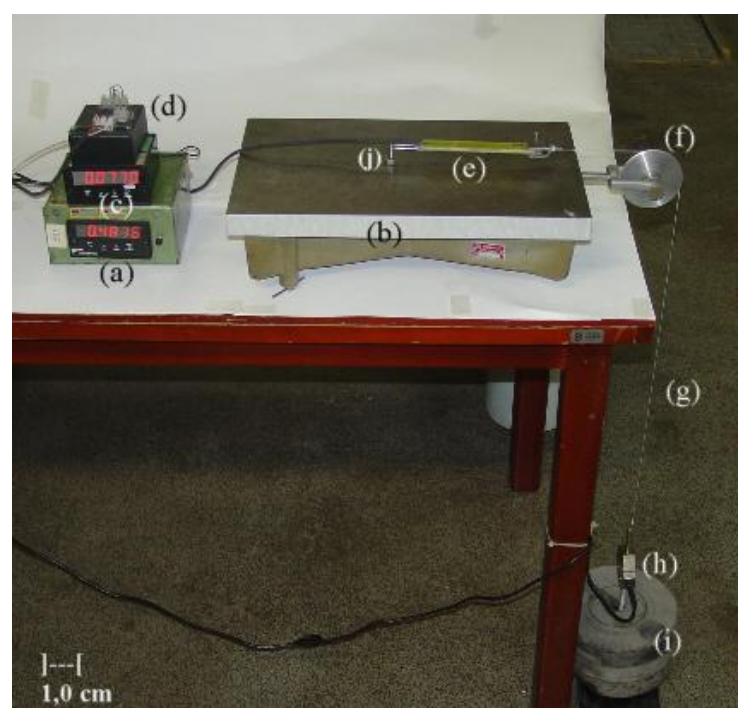

Fotografia 9. Dispositivo utilizado para calibração das células de embutimento: (a) indicador digital em (mV/V) da célula de carga, (b) mesa de desempeno, (c) indicador digital em $(\mathrm{mV} / \mathrm{V})$ da célula de embutimento, (d) ponte de Wheatstone da célula de embutimento, (e) célula de embutimento sob tração, (f) polia, (g) cabo de aço, (h) célula de Carga, (i) massores, (j) suporte de tração.

Fonte: Acervo próprio (2008).

\subsubsection{SENSORES DE TEMPERATURA - TERMÔMETROS}

A medição da temperatura interna na placa foi realizada por termômetros construídos tomando como base o termoresistor tipo Pt100 (sensor de resistência de platina) classe B (MOREIRA, 2006). Foi necessário desenvolver um termômetro capaz de suportar a umidade inicial da massa de concreto garantindo a estanqueidade, isolação e as solicitações mecânicas impostas pelas variações de temperatura. A fotografia 10 mostra o aspecto final do termômetro. A escolha do tipo de sensor se deveu à facilidade de manuseio, faixa de utilização, estabilidade térmica, repetibilidade, pequena incerteza nas medidas, pelo fato de ser normalizado segundo IEC751 ${ }^{15}$ e ainda dispensar processos de compensação.

O apêndice B faz uma descrição da calibração e construção dos termômetros

\footnotetext{
${ }^{15}$ IEC - International Electrotechnical Commission - IEC751 norma que trata da calibração de termoresistores (Industrial platinum resistance thermometer sensors).
} 


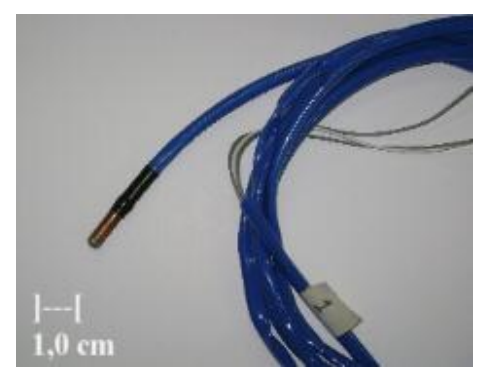

Fotografia 10. Aspecto do termômetro acabado utilizado para as medições de temperatura. Fonte: Acervo próprio (2007).

\subsection{DESENVOLVIMENTO DO SISTEMA DE AQUECIMENTO PARA A PLACA DE CONCRETO - PLATAFORMA DE AQUECIMENTO}

Para estabelecer os diferenciais de temperatura adequados, descritos na literatura, (ARMAGHANI, et al., 1987; CHOUBANE e TIA, 1995; BALBO e SEVERI, 2002; HARIK, et al., 1994; MAHBOUB, et al., 2004; POBLETE, et al., 1998; SIDDIQUE, et al., 2005), foi necessária a construção de um aquecedor capaz de fornecer energia suficiente para promover o aquecimento superficial adequado. Esse dispositivo, chamado, de agora em diante, plataforma de aquecimento, foi construído com resistências de fio de níquel-cromo envoltos por cerâmica e interno a tubos de aço que, posteriormente, passaram por um processo de trefilação. As resistências foram fixadas em uma estrutura de madeira e placas de $d r y w a l l$, por meio de espaçadores cerâmicos. A potência total dissipada pela placa de aquecimento foi de $7,4 \mathrm{~kW}$ quando ligada à alimentação trifásica. As placas de drywall foram revestidas com papel alumínio para elevar o índice de reflexão e evitar a perda por condução térmica. $\mathrm{O}$ aquecimento por convecção pôde ser controlado fazendo com que a plataforma de aquecimento se aproximasse a partir de $6,0 \mathrm{~cm}$ do topo da placa de concreto, formando assim um mini-clima favorável ao aparecimento de um efeito estufa. A configuração geométrica das resistências, na plataforma de aquecimento, propiciou uma distribuição uniforme de temperatura sobre a superfície do pavimento (placa de concreto). $\mathrm{O}$ desenho 8 mostra a distribuição das resistências, bem como as dimensões da plataforma de aquecimento.

As dimensões da plataforma e do pavimento foram feitas em concordância para garantir uma distribuição uniforme de energia térmica. Para evitar a perda de calor para o ambiente e garantir o efeito estufa, uma proteção de tecido (vide fotografia 25) foi colocada na borda da plataforma de aquecimento de tal forma que, quando a plataforma estivesse na posição de aquecimento, o tecido envolveria completamente o pavimento. 
Para as finalidades práticas de aquecimento, a placa de concreto pôde ser submetida a potências desde $0,0 \mathrm{~kW}$ a $7,4 \mathrm{~kW}$. Considerando-se uma área útil de $5,3 \mathrm{~m}^{2}$, resultando em uma potência incidente de $1123,6 \mathrm{~W} / \mathrm{m}^{2}$. Como referência e não como relação direta, esse valor é bem coerente com aquele preconizado por Bezerra (1979) que cita o valor da contribuição radiação solar global de $1000,0 \mathrm{~W} / \mathrm{m}^{2}$ em países tropicais, no verão. Nessas condições, mesmo admitindo-se perdas energéticas, devido à troca de calor com o meio, o sistema de aquecimento possui energia suficiente para produzir temperaturas superficiais necessárias ao estabelecimento dos diferenciais de temperatura exigidos para o experimento ${ }^{16}$.

Para a cidade de São Paulo, no mesmo local da realização do presente trabalho, dados colhidos pela estação e coleta de dados meteorológicos da Escola de Engenharia da $\mathrm{UPM}^{17}$ indicaram valores máximos de até $1200,0 \mathrm{~W} / \mathrm{m}^{2}$, durante o período da realização dos testes de temperatura.

A produção das rampas de aquecimento, utilizadas na criação dos diferenciais de temperatura da placa, foi baseada em dados de trabalhos realizados na América do Sul e nos Estados Unidos. A obtenção dos dados foi feita através da interpretação dos gráficos publicados nesses artigos. Uma descrição mais detalhada será fornecida no item 2.3.2.

O desenho 8 mostra uma vista em planta do posicionamento das resistências, bem como as respectivas cotas relativas à placa de aquecimento e a fotografia 11 mostra o aspecto das placas de drywall que serviram como suporte às resistências.

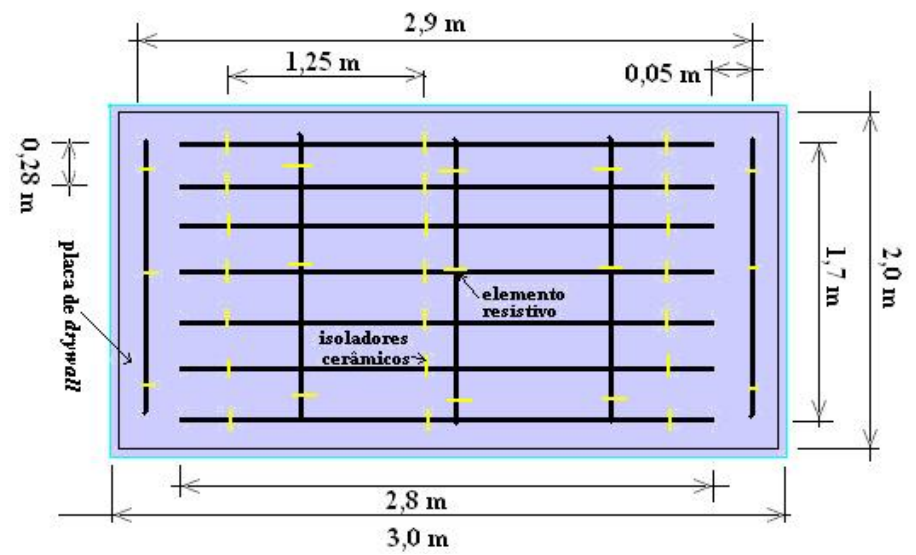

Desenho 8. Vista em planta da plataforma de aquecimento mostrando a disposição dos elementos resistivos Fonte: Acervo próprio (2008).

\footnotetext{
${ }^{16}$ Nota-se que a radiação solar é composta por energia devido às radiações na região do infravermelho, visível e ultravioleta, compondo assim a radiação global.

17 A antena fornece dados via Internet $\mathrm{e}$ pode ser acessada através da URL: http://engmecanica.mackenzie.com.br
} 

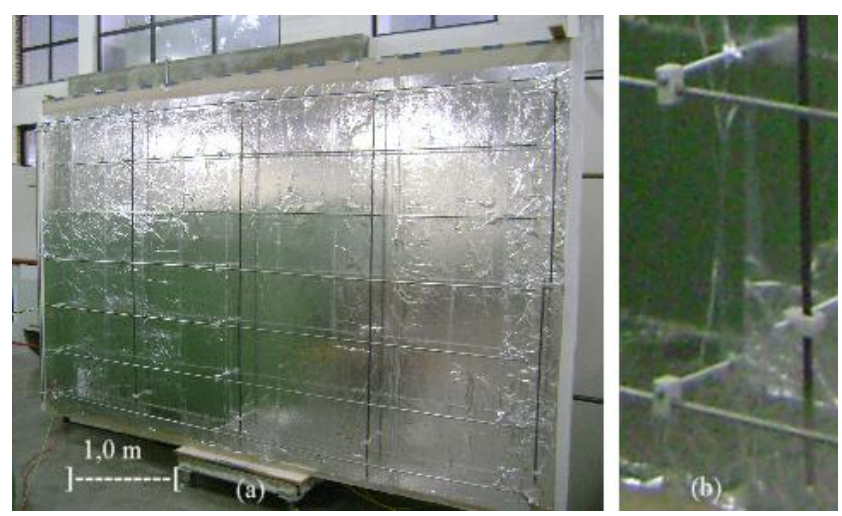

Fotografia 11. (a) plataforma de aquecimento revestida com lâmina de alumínio, (b) detalhe dos isoladores cerâmicos utilizados na montagem dos elementos resistivos (resistências) na plataforma.

Fonte: Acervo próprio (2007).

\subsubsection{PROCEDIMENTO PARA CONTROLE TÉRMICO DA PLACA}

O controle térmico da placa foi realizado por um sistema eletromecânico, composto por um autotransformador variável trifásico de 9,0 kVA, capaz de suportar a potência exigida pela plataforma de aquecimento. A fotografia 12 mostra o aspecto do autotransformador utilizado no sistema. Ele possibilitou o controle da tensão de saída, por meio de uma manivela, manejada em intervalos freqüentes para atingir as taxas de crescimento desejadas. A tensão de saída foi monitorada por um voltímetro acoplado a uma das fases do autotransformador ${ }^{18}$.

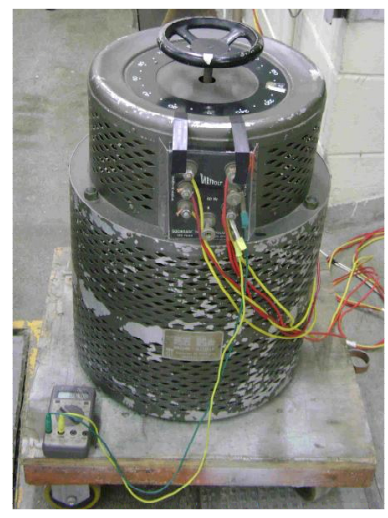

Fotografia 12. Aspecto do autotransformador (variável) responsável por estabelecer as tensões sobre as resistências da placa de aquecimento.

Fonte: Acervo próprio (2008).

\footnotetext{
${ }^{18}$ Um autotransformador variável, também conhecido como variac, consiste num enrolamento sobre um núcleo de ferrite toroidal onde uma escova de carvão, fixada a um eixo rotativo, pode deslizar sobre as espiras do enrolamento. Essa ação altera o valor de tensão de saída do autotransformador.
} 
Apesar do aspecto rudimentar, o equipamento é capaz de introduzir passos de tensão de $1,0 \mathrm{~V}$. A reprodução das taxas de aquecimento foi realizada com sucesso e um padrão típico, utilizado para gerar uma rampa de aquecimento, é dado pela Tabela 2, em que é possível observar os instantes de manobra, bem como observar os valores de potência dissipada pelas resistências

A geração dos diferenciais de temperatura foi baseada na curva de radiação solar devido ao ciclo diário. O gráfico 4 mostra o comportamento da radiação solar que serviu de base para a produção das simulações (dados tirados da estação de dados meteorológicos da Escola de Engenharia Mecânica).

O gráfico 5 mostra como fica a potência dissipada pela plataforma de aquecimento em função do tempo baseado nos dados da Tabela 2. Esse gráfico é uma representação média das ações térmicas impostas sobre a placa de concreto. Como informação, o gráfico 6 mostra a variação da temperatura do ar segundo a radiação solar. O gráfico 7 mostra a sobreposição de dois efeitos: o aspecto da manobra para obtenção do padrão de aquecimento e o comportamento da temperatura quando da ação da variação da tensão.

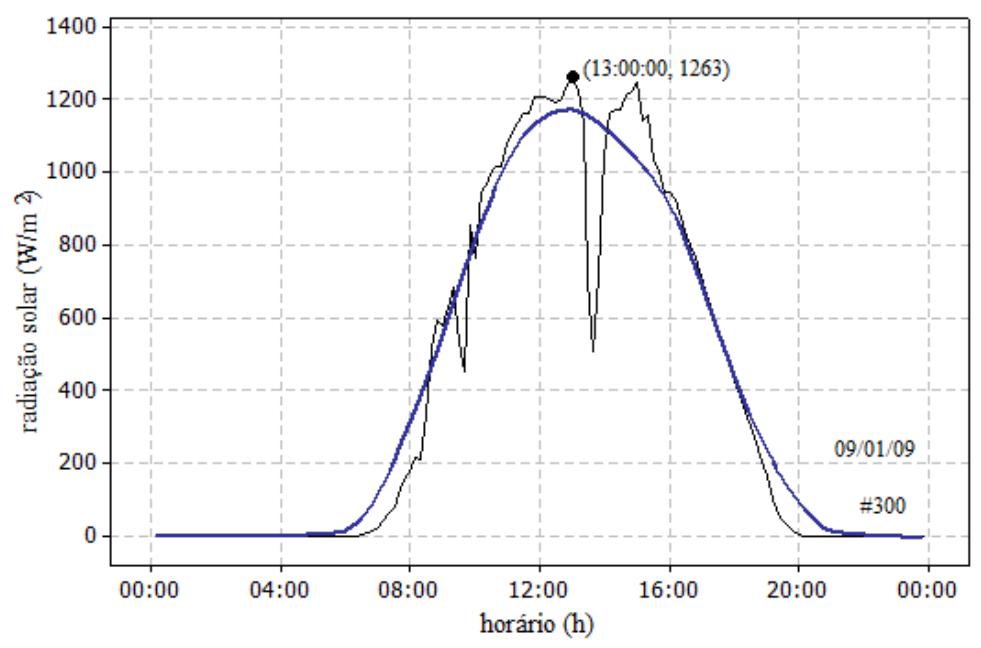

Gráfico 4. Distribuição da radiação solar dia 09/01/08. A linha cheia representa a tendência da radiação caso não fossem as ações de sombras causadas por nuvens. A linha de tendência foi traçada automaticamente por meio do método de Winter. Utilizado em séries temporais cujos componentes têm características de sazonalidade.

Fonte: Elaborado a partir dos dados da estação meteorológica Mackenzie (2008). 
Tabela 2. Padrão de tensão estabelecido durante os testes.

\begin{tabular}{cccc}
\hline tensão (V) & tempo absoluto $(\mathrm{h})$. & potência $(\mathrm{W})$ & intensidade $\left(\mathrm{W} / \mathrm{m}^{2}\right)$ \\
\hline 70,0 & $08: 40$ & 751,1 & 140,7 \\
90,0 & $09: 00$ & 1241,6 & 232,5 \\
110,0 & $09: 30$ & 1857,7 & 315,0 \\
120,0 & $10: 38$ & 2207,2 & 445,0 \\
150,0 & $12: 03$ & 3448,8 & 645,8 \\
160,0 & $13: 23$ & 3924,0 & 734,8 \\
150,0 & $14: 37$ & 2207,2 & 562,6 \\
100,0 & $15: 44$ & 1532,2 & 286,9 \\
0,0 & $16: 15$ & 0,0 & 0,0 \\
\hline
\end{tabular}

Fonte: Elaborada a partir dos ensaios realizados (2008).

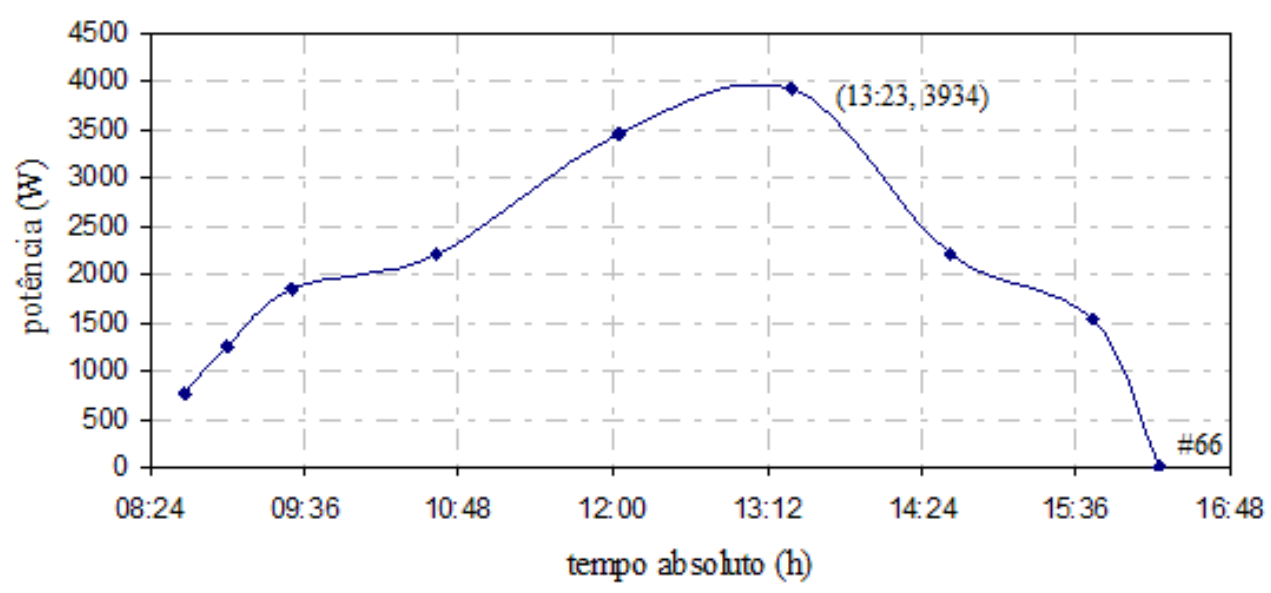

Gráfico 5. Potência dissipada pelo conjunto de resistências na plataforma de aquecimento. Fonte: Elaborado a partir dos ensaios realizados (2008).

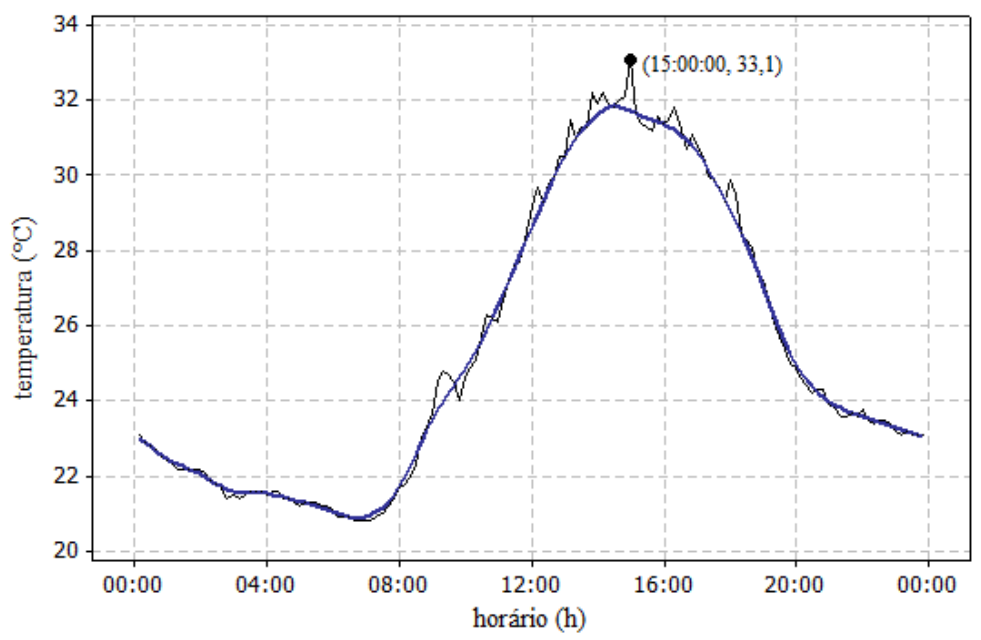

Gráfico 6. Distribuição da temperatura em dia comum (09/01/08). A linha cheia representa a tendência da temperatura.

Fonte: Elaborado a partir dos dados da estação meteorológica Mackenzie (2008). 


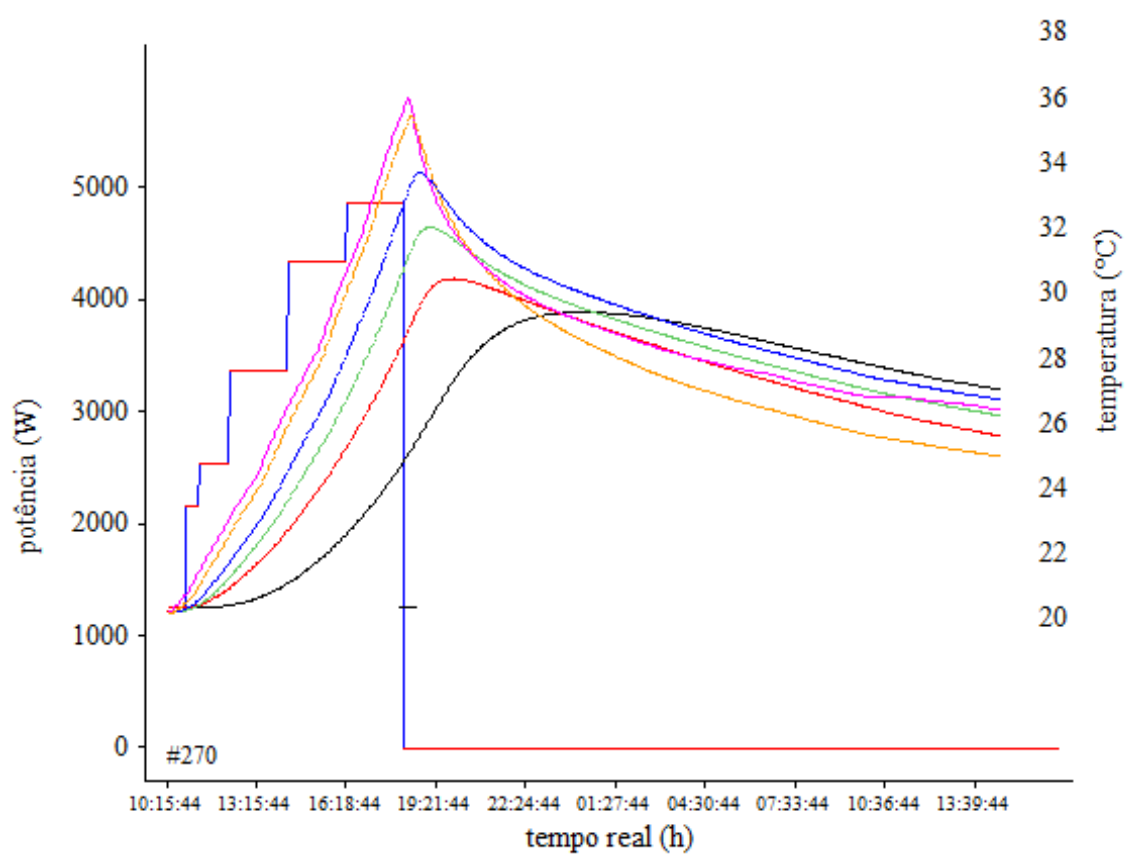

Gráfico 7. Ação do controle de tensão sobre o efeito da temperatura.

Fonte: Elaborado a partir dos ensaios realizados (2008).

\subsection{DESENVOLVIMENTO DO SISTEMA DE AQUECIMENTO E RESFRIAMENTO PARA O FUNDO DA PLACA DE CONCRETO}

Para alterar o estado térmico do fundo da placa, foi construído um sistema de troca de calor formado por uma tubulação composta por "conduítes" colocados sobre a base de CCR no sentido longitudinal ao molde do pavimento e fundidos na placa de CCP. Por eles circulou água quente ou fria, conforme a necessidade do experimento. Um reservatório armazenou o fluido que foi forçado a circular por uma bomba hidráulica. Um controlador marca OMRON, modelo E5XA, possibilitou o controle proporcional integral e derivativo (PID), em malha fechada, na situação de aquecimento da água através do aquecedor, cuja capacidade de 5000,0 W foi suficiente para elevar a temperatura do fluido até o ponto estabelecido (set point) pelo controlador. Válvulas de passagem foram utilizadas para o controle de fluxo do fluido. A tomada da temperatura de referência foi realizada por um termômetro colocado na entrada do trocador de calor.

O desenho 9 apresenta o diagrama esquemático do sistema de aquecimento / resfriamento e a fotografia 13 mostra em detalhes os equipamentos utilizados para o controle do aquecimento do fundo da placa. 


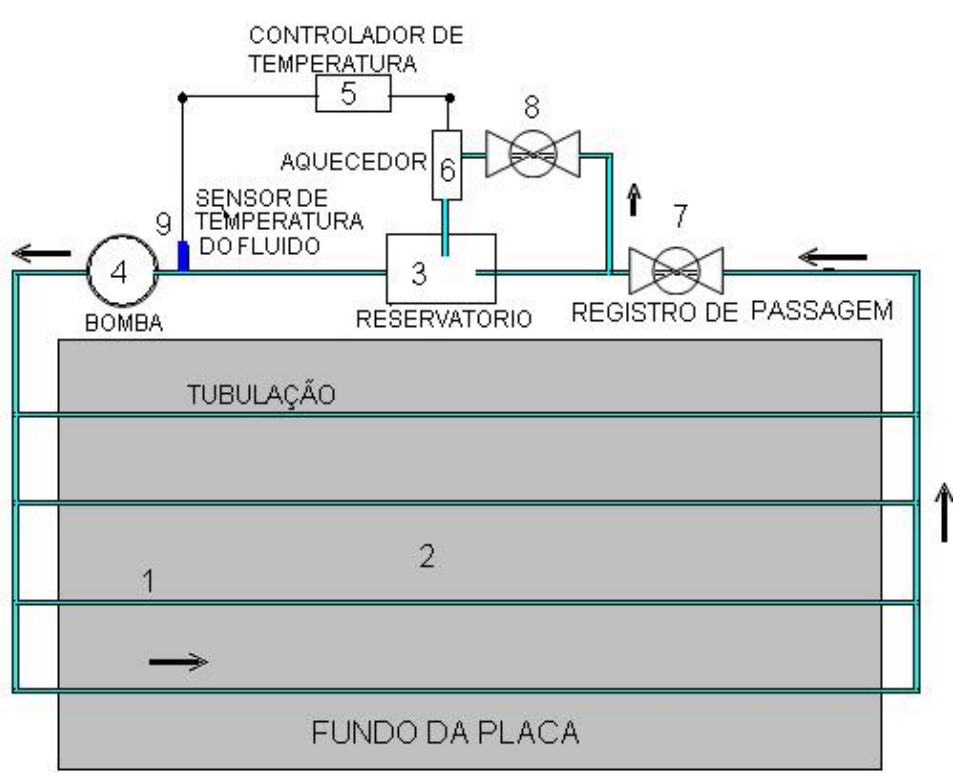

Desenho 9. Vista em planta do sistema de resfriamento/aquecimento no fundo da placa de CCP: (1) tubos "conduítes", (2) fundo da placa, (3) reservatório, (4) bomba hidráulica, (5) controlador de temperatura, (6) aquecedor, (7) e (8) válvulas e (9) sensor de temperatura. Fonte: Acervo próprio (2008).

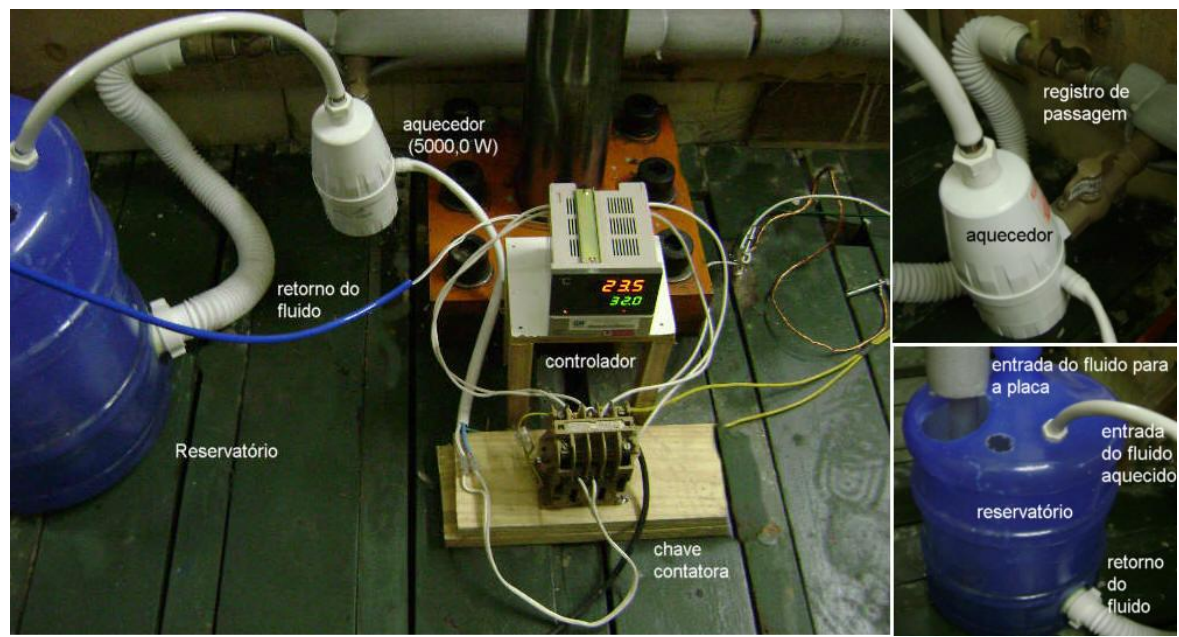

Fotografia 13. Disposição dos equipamentos utilizados no processo de aquecimento do fundo da placa.

Fonte: Acervo próprio (2008).

O desenho 10 mostra a secção transversal do pavimento com a disposição dos “conduítes". Eles foram escolhidos por possuírem diâmetro $(32,0 \mathrm{~mm})$ adequado à vazão da bomba e por serem flexíveis ao ponto de não terem imposto restrição às deformações que a placa sofreu durante os procedimentos térmicos. 


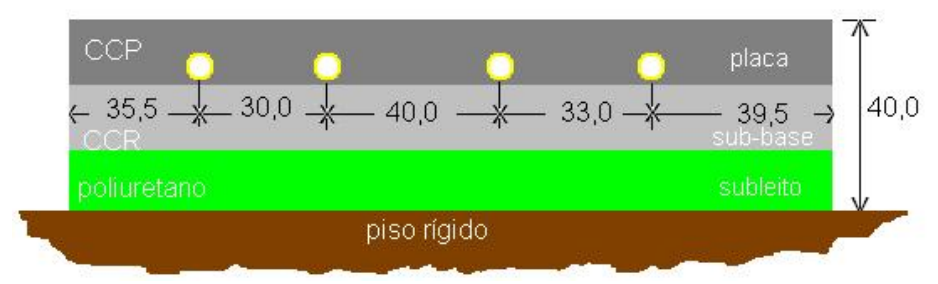

Desenho 10. Vista em corte da seção transversal da placa, com sistema refrigeração / aquecimento. Todas as medidas estão em centímetros.

Fonte: Acervo próprio (2008).

\subsubsection{PROCEDIMENTO UTILIZADO PARA OBTENÇÃO DOS DADOS DE TEMPERATURA A PARTIR DE GRÁFICOS APRESENTADOS EM ARTIGOS CIENTÍFICOS}

Alguns dados obtidos em campo não são necessariamente, na sua totalidade, publicados nos artigos ou livros da área de interesse, em que, normalmente, se utiliza o recurso da construção gráfica para a demonstração do fenômeno estudado. $O$ gráfíco cartesiano expressa, então, em uma forma visual, as Tabelas de dados obtidas durante a fase de observação.

A realização da construção de um gráfico cartesiano, atualmente, fica por conta de softwares especializados, dos mais simples aos mais sofisticados, os quais, alimentados com dados obtidos manual ou automaticamente, são capazes de produzir fotografias bastante precisas referentes ao fenômeno estudado. Porém, não foi percebido algum software que faça o processo inverso, ou seja, a partir de um determinado gráfico, ser capaz de gerar os dados utilizados em sua construção. Sendo assim, forçosamente, somos obrigados a retirar as informações necessárias dos gráficos. Uma maneira simples para a obtenção de tais dados seria utilizar uma escala (régua) ou um paquímetro para a medida do passo utilizado na escala do gráfico. Isso levaria à dedução da equação da escala utilizada na sua construção, obtendo, assim, os dados necessários. Por outro lado, a avaliação de uma escala pode ser realizada utilizando recursos computacionais disponíveis em alguns softwares de uso cotidiano, tal qual o Adobe Acrobat ${ }^{\circledR}$ Professional 6.0. Nesse software é possível encontrar a "ferramenta", medidas (measurement), que permite estabelecer o comprimento entre dois pontos quaisquer sobre o texto mostrado. Esse recurso é importante, pois, normalmente, todo artigo digital possui extensão portable document format (pdf), tornando-se possível, assim, a utilização de tal facilidade. Essa metodologia mostrou-se mais adequada, pois muitos artigos que compõem o presente trabalho foram obtidos na forma digital por meio eletrônico, através das bibliotecas 
digitais que disponibilizam artigos ou trabalhos de mestrado ou doutorado nos portais das universidades e centros de pesquisa. Os artigos obtidos através de revistas ou livros também podem passar pelo mesmo processo. Nesse caso, existe um procedimento a mais, que é fazer a fotocópia do artigo e torná-lo "visível" ao software, bastando para tanto imprimi-lo no formato pdf.

Essa metodologia possibilitou fazer uma manipulação por vezes mais rápida ou com menor incerteza associada à medida efetuada.

Os dados obtidos para os estudos de correção, salvo mencionado ao contrário, foram obtidos a partir dos gráficos publicados nos artigos das revistas consultadas.

\subsubsection{AVALIAÇÃO DA INCERTEZA NA LEITURA DOS DADOS}

A seguir, está apresentado um exemplo para a obtenção de dados a partir de um gráfico cartesiano. O estudo em questão foi baseado em um trabalho realizado por Balbo e Severi (2002). Um gráfico foi fotocopiado a partir de uma revista em uma máquina genérica de cópia. Posteriormente, passou por outro processo de fotocópia (scanner) para que se pudesse realizar a geração de um arquivo em pdf.

Por meio da ferramenta medida, já mencionada anteriormente, o cursor foi posicionado em um ponto da escala, do artigo em questão, sobre o eixo das abscissas e fixado em outro equidistante a esse, determinando o comprimento do eixo. A obtenção do passo para a escala do eixo das ordenadas se deu de maneira semelhante. No gráfico 8 , está indicado como foram realizadas as medidas. É possível observar pelas setas com a cota associada.

Para a obtenção de outros dados, com a finalidade de construir uma Tabela, o processo foi repetido para ambos os eixos.

Caso as medidas fossem realizadas com um paquímetro, as leituras poderiam ser avaliadas com o mesmo grau de incerteza que, no caso, iria depender da habilidade do operador em manter a repetibilidade na colocação das "orelhas" do paquímetro sobre as linhas do gráfico.

A fotografia 14 mostra a obtenção de uma medida sendo efetuada sobre um gráfico, utilizando-se um paquímetro.

A utilização de uma escala (régua) também seria viável caso não fosse exigida baixa incerteza nas medidas realizadas. 


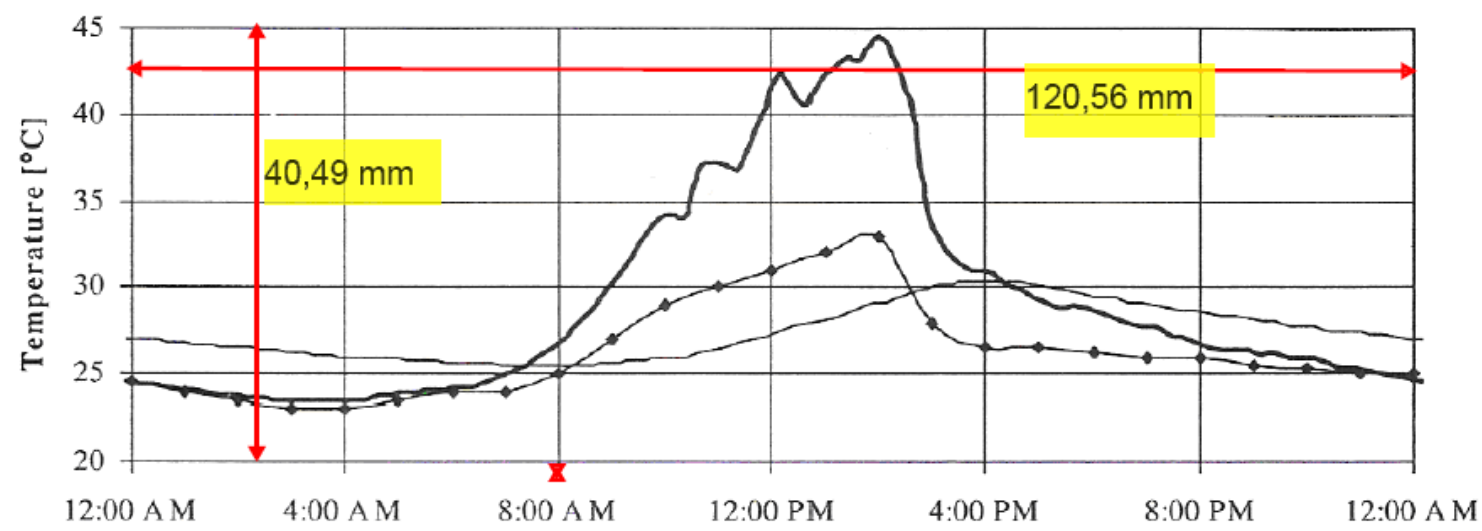

Gráfico 8. Medida do comprimento do eixo abscissas indicando um intervalo de vinte e quatro horas equivale a $120,56 \mathrm{~mm}$. A medida do eixo das ordenadas indica em um intervalo de $25^{\circ} \mathrm{C}$ equivalente a $40,49 \mathrm{~mm}$. O gráfico refere-se ao comportamento da temperatura em uma das placas da pista experimental construída na Cidade Universitária (USP), São Paulo.

Fonte: Elaborado a partir dos dados de Balbo, Severi, (2002), modificado.

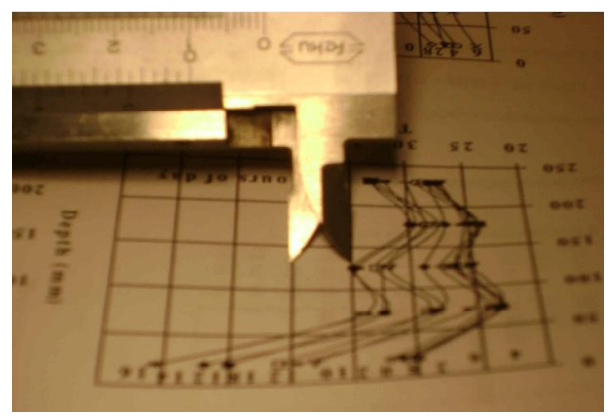

Fotografia 14. Utilizando um paquímetro na obtenção do passo utilizado em gráfico. Fonte: Acervo próprio (2008).

Dos métodos propostos, foi adotado aquele que utiliza a ferramenta "medida" disponível no software Adobe.

A avaliação do erro no posicionamento do cursor dependeu da espessura da linha utilizada pelo autor na confecção do gráfico, isso é relevante, pois, dependendo da posição em que é colocada a referência, lado interno ou externo da linha, poderá ocasionar um acúmulo ou uma distorção na avaliação do erro. No presente estudo, o posicionamento da referência foi realizado sempre do lado interno das linhas de grade do gráfico. Uma inspeção no formato dos gráficos publicados em artigos científicos, em sua maioria, mostra que a espessura das linhas está localizada no intervalo entre $0,08 \mathrm{~mm}$ a $0,10 \mathrm{~mm}$.

Outro desvio a ser considerado refere-se aos valores de temperatura que, em momento algum, nos artigos pesquisados, é especificado. Porém, normalmente, os textos referem-se aos sensores utilizados e essa informação é importante para balizar qual a ordem 
de grandeza da incerteza associada. No artigo utilizado como exemplo, sabe-se que os sensores de temperatura foram construídos com termoresistores tipo Pt-100 e, nesse caso, com base nos estudos descritos no apêndice B desse trabalho, observa-se que essa classe especifica uma incerteza de $0,3^{\circ} \mathrm{C}$.

Para a determinação dos pares coordenados a serem retirados dos gráficos, bem como o desvio associado à medida, foi utilizada a equação 10 conhecida como equação da escala. A avaliação do erro associado na determinação do módulo de escala foi feita, utilizando-se a teoria clássica da propagação de erros.

$$
d=\lambda\left(G_{f}-G_{i}\right)
$$

sendo:

d - comprimento do eixo estabelecido no gráfico

$\lambda$ - módulo de escala

$\mathrm{G}_{\mathrm{f}} \rightarrow$ valor numérico da maior grandeza do eixo

$\mathrm{G}_{\mathrm{i}} \rightarrow$ valor numérico da menor grandeza do eixo

Sendo:

$$
\lambda=\frac{d}{G_{f}-G_{i}}
$$

O desvio relativo ao módulo de escala será dado por:

$$
\Delta \lambda=\lambda\left(\frac{\Delta c e}{c e}+\frac{\Delta G}{G}\right)
$$

sendo:

$c e$ - comprimento do eixo $(d \equiv c e)$

$\mathrm{G}$ - grandeza relativa ao eixo

$\Delta c e$ - desvio associado à medida do comprimento do eixo

$\Delta G$.- desvio associado à medida da grandeza

Por questões práticas, foi adotado o desvio de $0,1 \mathrm{~mm}$ nas medidas realizadas com a ferramenta "medidas" do Adobe, $0,3^{\circ} \mathrm{C}$ nas medidas de temperatura e $0,0003 \mathrm{~h}$ nas medidas de tempo.

O desvio para o eixo da temperatura (ordenadas) assume a seguinte forma: 


$$
\Delta \lambda=\lambda\left(\frac{0,1}{c e}+\frac{0,3}{\Delta T}\right)
$$

De modo semelhante o desvio do módulo de escala para o eixo das abscissas assume o seguinte formato:

$$
\Delta \lambda=\lambda\left(\frac{0,1}{c e}+\frac{0,00003}{\Delta T_{p}}\right)
$$

sendo: Onde: $\mathrm{T}_{\mathrm{p}} \rightarrow$ tempo em horas

O cálculo dos módulos de escala para os valores retirados do gráfico 5 é descrito a seguir:

Dados: comprimento do eixo das abscissas $120,56 \pm 0,05 \mathrm{~mm}$

comprimento do eixo das ordenadas $40,49 \pm 0,05 \mathrm{~mm}$

desvio na leitura de temperatura $0,3^{\circ} \mathrm{C}$

desvio na leitura do tempo $0,00003 \mathrm{~h}$.

Substituindo os valores do processo gráfico e utilizando as relações 13 e 14, são obtidos os seguintes valores para os módulos de escala:

Eixo das abscissas (tempo): $\lambda=5,023 \pm 0,002 \frac{\mathrm{mm}}{\mathrm{h}}$

Eixo das ordenadas (temperatura): $1,61 \pm 0,02 \frac{\mathrm{mm}}{{ }^{\circ} \mathrm{C}}$

De posse desses valores, estabeleceu-se uma regra de proporção para cada um dos eixos para obtenção dos valores que compõem a curva do gráfico 9. Esse procedimento foi utilizado para a avaliação das curvas de aquecimento dos trabalhos analisados.

\subsubsection{DETERMINAÇÃO DAS TAXAS DE TEMPERATURA}

O aquecimento da placa foi realizado seguindo padrões apresentados pela variação temporal da temperatura diária em várias situações. Para tanto, foi necessário o estabelecimento de padrões de aquecimento a partir de informações retiradas de artigos técnicos. Isso foi feito pela análise de nove artigos com gráficos capazes de fornecer as informações necessárias. Outros dados de temperatura foram aproveitados das informações retiradas de testes feitos em um CP experimental (vigota) e de um levantamento de temperaturas in situ no corredor de ônibus na avenida Vicente Rao (São Paulo), no verão 
2007-2008. Os dados foram analisados através do processo descrito nos itens 2.3 .1 e 2.3.1.1 e o tratamento dos dados foi realizado com o software MINITAB ${ }^{\circledR}$ e os dados estão no CDROM como arquivo\#taxa.

O primeiro trabalho a ser analisado é de autoria de Severi (2002) e foi desenvolvido em São Paulo - Brasil em pista experimental, no período entre 1999 - 2001. O gráfico 9 mostra os dados plotados e, com ajuda do processo de regressão, foi determinada a inclinação da reta, obtendo-se uma taxa de $3,5^{\circ} \mathrm{C} / \mathrm{h}$.

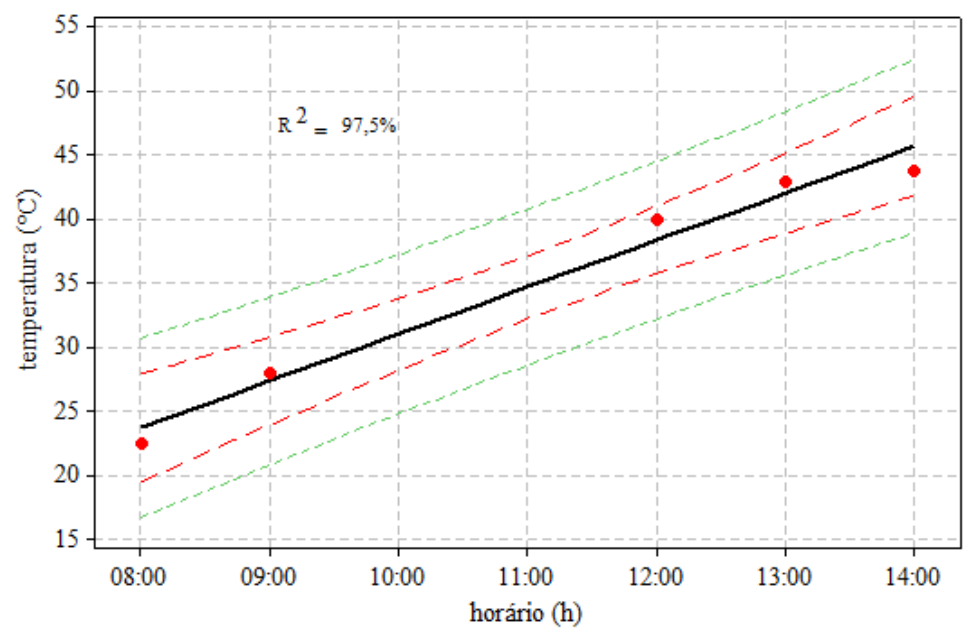

Gráfico 9. Variação de temperatura no topo da placa com cálculo da razão $3,5^{\circ} \mathrm{C} / \mathrm{h}$ do trabalho referido. Intervalo de confiança $95 \%, \mathrm{R}^{2}=97,5 \%$

Fonte: Adaptado a partir dos dados de Severi (2002).

No segundo trabalho Poblete et al. (1988) realizaram um levantamento de temperaturas em placas de concreto instrumentadas em toda a extensão da estrada panamericana no território chileno. A partir dos gráficos, foi possível extrair dados para o levantamento do gráfico $10 \mathrm{e}$, por inspeção da inclinação da reta, obter o valor de $3,6^{\circ} \mathrm{C} / \mathrm{h}$ de incremento na temperatura,

O terceiro trabalho, de Yu et al. (1998), é um estudo com placas instrumentadas, sobre a resposta do pavimento por meio de carga térmica, realizado no Colorado - USA. Através da análise dos dados pôde-se levantar o gráfico 11, que mostra a variação da temperatura em função da profundidade do pavimento, de que se pode retirar, analiticamente, o valor de $2,3^{0} \mathrm{C} / \mathrm{h}$ como taxa de variação da temperatura em relação ao tempo de insolação. 


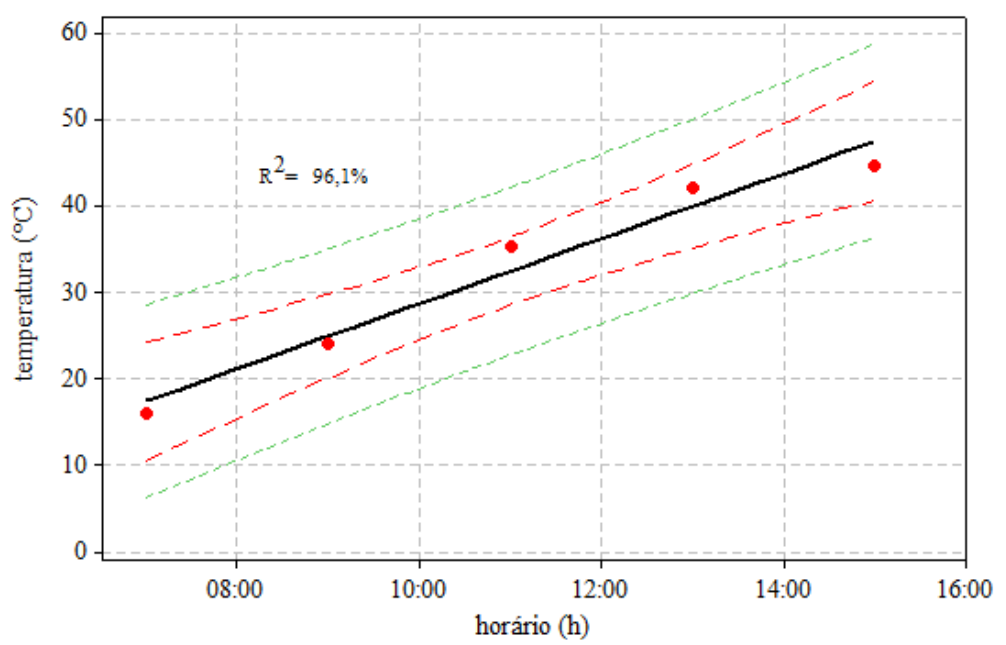

Gráfico 10. Variação da temperatura média do topo de várias placas de concreto, estrada sulamericana. Intervalo de confiança $95 \%, R^{2}=96,1$.

Fonte: Adaptado a partir dos dados de Poblete (1988).

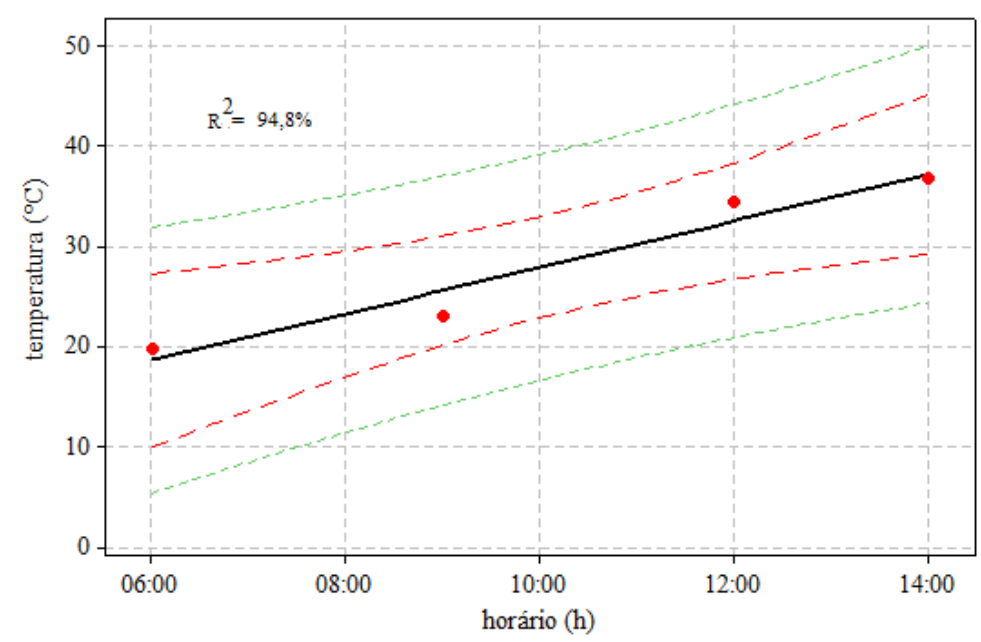

Gráfico 11. Variação da temperatura no topo em placas de concreto instrumentadas, Colorado - EUA. Intervalo de confiança $95 \%, \mathrm{R}^{2}=94,4 \%$

Fonte: Modificado a partir dos dados de Yu et al. (1998).

O quarto trabalho analisado é sobre um modelo computacional para estudo da transferência de calor em pavimentos de concreto em Illinois, EUA, elaborado por Thompson et al. (1987). Através dos gráficos apresentados foi possível estabelecer, analiticamente, o valor de $1,0{ }^{\circ} \mathrm{C} / \mathrm{h}$. como taxa de variação da temperatura em relação ao tempo de insolação. Esse valor foi extraído do gráfico 12 . 


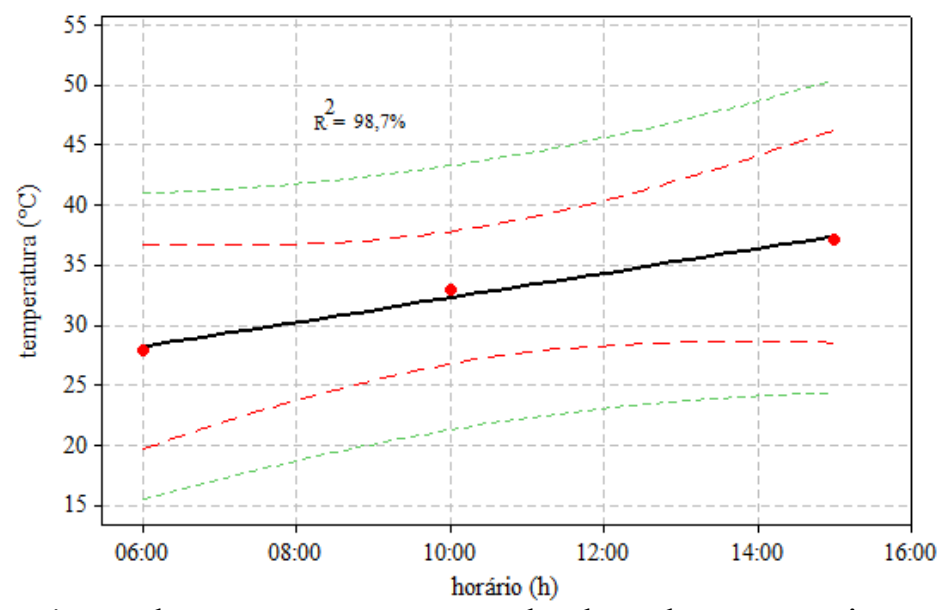

Gráfico 12. Variação da temperatura no topo da placa de concreto instrumentada, mês de julho, Illinois - EUA. Intervalo de confiança $95 \%, \mathrm{R}^{2}=98,7 \%$.

Fonte : Adaptado a partir dos dados de Thompson et al. (1987).

O quinto trabalho analisado toma como base os dados de temperatura de placas de concreto instrumentadas por Armaghani et al. (1987), do qual foi possível obter, pela análise do gráfico14, 1, $6^{\circ} \mathrm{C} / \mathrm{h}$ como taxa de variação. Esse valor foi obtido pela análise do gráfico13.

No sexto trabalho realizado por Mahboub et al. (2004), sobre a variação de tensão - deformação em placa de concreto, como parte da estrada I-265 no Kentucky, foi identificado como variação de temperatura em função do tempo o valor de $1,0{ }^{\circ} \mathrm{C} / \mathrm{h}$. Esse resultado foi obtido por meio do gráfico 14.

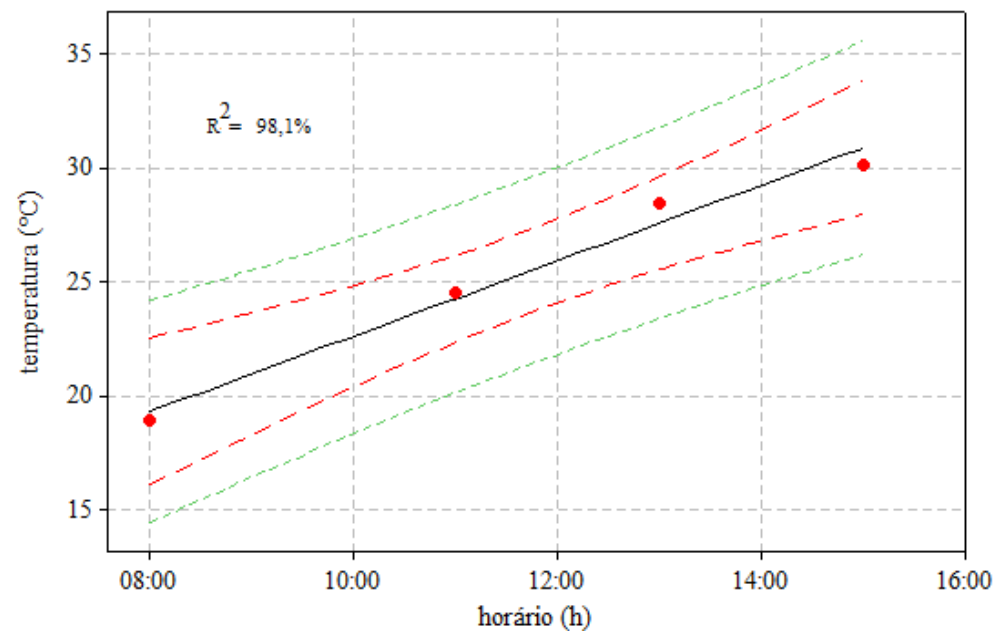

Gráfico 13. Variação da temperatura em função do tempo, no topo de placa de pavimento instrumentado na Flórida - EUA, para estudo de deformações. Intervalo de confiança 95\%, $\mathrm{R}^{2}=98,1 \%$.

Fonte: Adaptado a partir dos dados de Armaghani et al. (1987). 


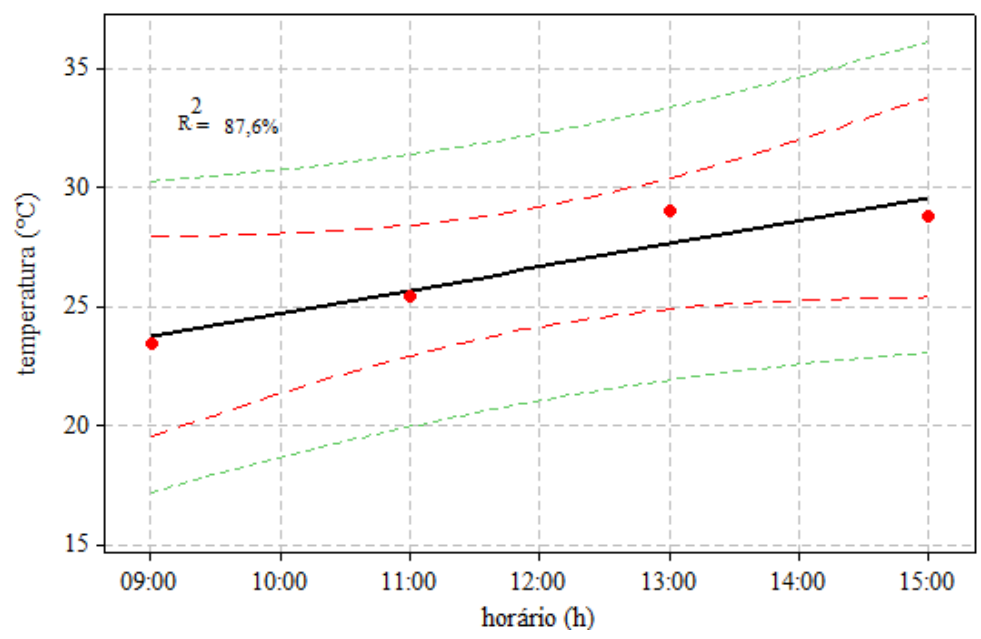

Gráfico 14. Variação de temperatura do ar, em função do tempo, nas imediações de pavimento instrumentado no Kentucky EUA. Intervalo de confiança $95 \%, \mathrm{R}^{2}=87,6 \%$.

Fonte: Adaptado a partir dos dados de Mahboub et al. (2004).

O sétimo trabalho, em que Adkins e Merkley (1990) estudaram os mecanismos físicos de aquecimento em placas de concreto, com modelo computacional por diferenças finitas através de dados climáticos do hemisfério Norte, durante um inverno normal, apresentou dados mostrados no gráfico 15 , do qual é possível retirar o valor de $2,0{ }^{0} \mathrm{C} / \mathrm{h}$ como taxa de variação.

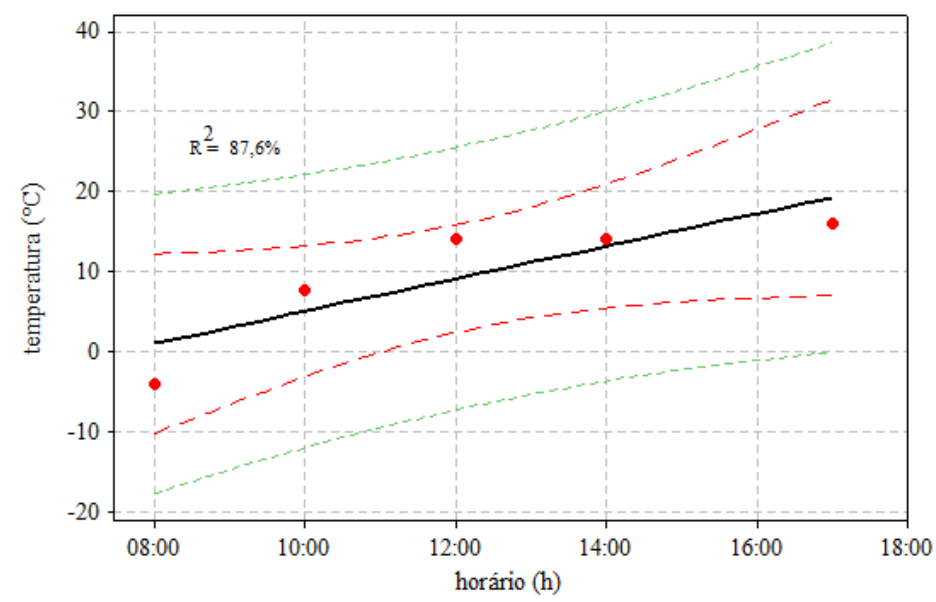

Gráfico 15. Variação de temperatura típica, diária, em função do tempo em dia frio, com sol na superfície do pavimento. Intervalo de confiança $95 \%, \mathrm{R}^{2}=87,6 \%$. Fonte: Adaptado a partir dos dados de Adkins e Merkley (1990).

Do oitavo trabalho, em que Richardson e Armaghani (1987) estudaram as tensões causadas em pavimentos de concreto devido a gradientes de temperatura, foram obtidos dados 
para a construção do gráfico 16, a partir de um pavimento instrumentado situado na Flórida EUA, durante o mês de agosto de 1984, sendo possível extrair um valor intermediário de 1,8 ${ }^{0} \mathrm{C} / \mathrm{h}$.

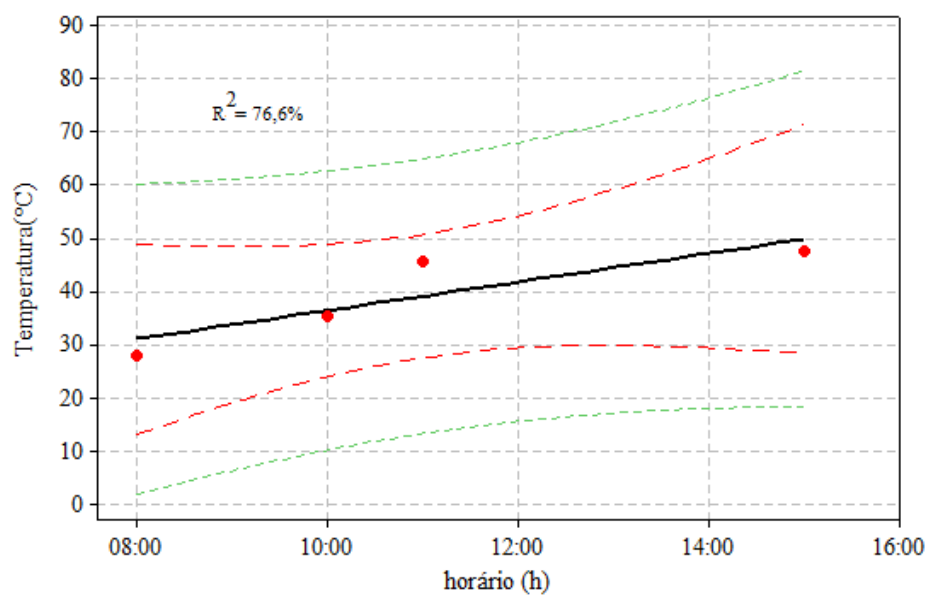

Gráfico 16. Variações da temperatura em função do tempo em 15 de agosto de 1984, na Flórida - EUA, nas imediações do pavimento instrumentado. Intervalo de confiança 95\%, $\mathrm{R}^{2}=76,6 \%$

Fonte: Adaptado a partir dos dados de Richardson, Armaghani (1987).

O nono trabalho, de Siddique et al. (2005), sobre o estudo do empenamento da placa de concreto, com variação de temperatura, em pavimento de estrada interestadual-70, nos EUA, durante o verão de 2003, possibilitou a obtenção de dados para a construção do gráfico 17 e a determinação do valor de $2,5{ }^{\circ} \mathrm{C} / \mathrm{h}$ como taxa de aquecimento devido à insolação diária.

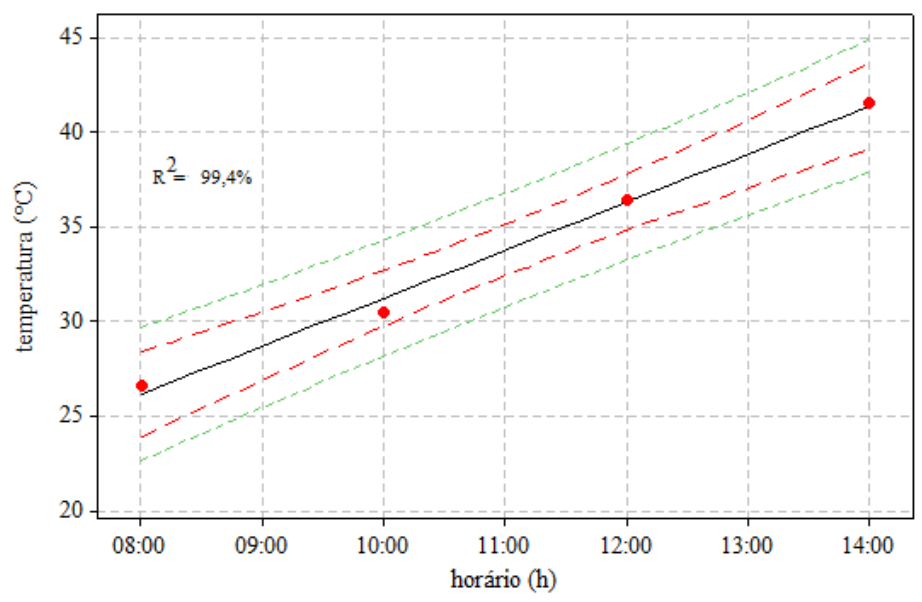

Gráfico 17. Variações de temperatura em função do tempo no verão de 2003, na interestadual I-70 Flórida - EUA. Intervalo de confiança $95 \%, R^{2}=99,4 \%$.

Fonte: Adaptado a partir dos dados de Siddique et al. (2005). 
O gráfico 18 refere-se ao comportamento da temperatura em uma vigota instrumentada no inverno de 2006, como início dos testes de temperatura para o presente trabalho. Esse levantamento apresentou valores que permitiram determinar a taxa de $2,0^{0} \mathrm{C} / \mathrm{h}$.

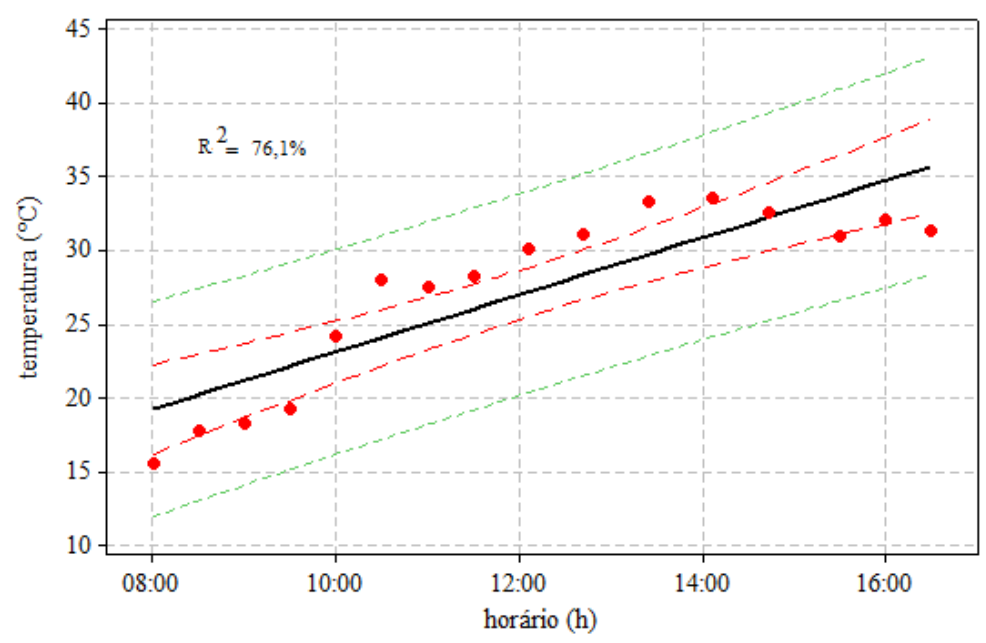

Gráfico 18. Aspecto do acréscimo da temperatura em uma vigota de concreto instrumentada. Inverno de 2006. São Paulo - Campus da Universidade Presbiteriana Mackenzie. Intervalo de confiança $95 \%, \mathrm{R}^{2}=76,1 \%$.

Fonte: Elaborada a partir dos dados experimentais (2006).

O décimo primeiro trabalho refere-se aos dados que foram computados a partir do levantamento da temperatura superficial no período compreendido entre os dias 24/12 e 28/12 de 2007, na superfície do pavimento de concreto do corredor de ônibus Diadema- São Paulo, na avenida Vicente Rao - São Paulo, altura do número 1014. As medições foram realizadas com um termômetro infravermelho, da marca Mesco modelo TL-100, tomadas sempre no mesmo local, tendo como referência um termômetro público postado no canteiro central no local das medições.

O gráfico 19, quando inspecionado nos pontos marcados, apresentou uma taxa de variação de $2,5^{\circ} \mathrm{C} / \mathrm{h}$.

Baseando-se nas análises gráficas, pôde-se planejar as taxas de aquecimento que foram aplicadas na superfície da placa. O modelo estatístico adotado, regressão linear, no intervalo das $8 \mathrm{~h} 00 \mathrm{~min}$ às $16 \mathrm{~h} 00 \mathrm{~min}$ em todos os trabalhos mostrou baixa dispersão e forte correlação entre os dados. 


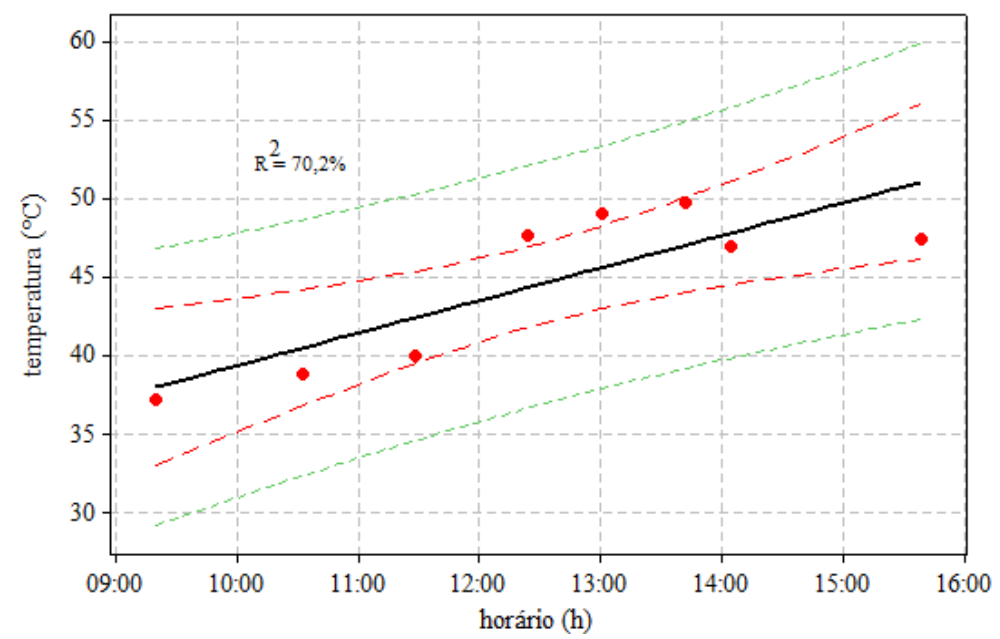

Gráfico 19. Aspecto do aumento da temperatura em pavimento de concreto no corredor de ônibus Diadema - São Paulo. Intervalo de confiança $95 \%, \mathrm{R}^{2}=70,2 \%$.

Fonte: Elaborada a partir dos dados colhidos no local (2008).

A Tabela 3 sintetiza as taxas de temperatura, bem como a época em que os dados foram obtidos.

Tabela 3.Síntese das taxas de variação da temperatura dos trabalhos pesquisados.

\begin{tabular}{lccc}
\hline \multicolumn{1}{c}{ Trabalho } & Taxa de variação $\left({ }^{\circ} \mathrm{C} / \mathrm{h}\right)$ & Estação do ano & Ano \\
\hline Severi & 3,3 & verão & $1999-2001$ \\
Poblete et al. & 3,7 & inverno & 1987 \\
Yu et al. & 2,3 & verão & 1994 \\
Thompson et al. & 2,0 & verão & 1988 \\
Armaghani et al. & 1,2 & - & $1983-1986$ \\
Mahboub et al. & 1,0 & - & 2000 \\
Adkins et al. & 2,0 & & 1990 \\
Richardson et al. & 2,2 & primavera & $1983-1984$ \\
Siddique et al. & 2,5 & verão & 2003 \\
Vigota & 2,0 & inverno & 2006 \\
Pavimento (Av. Vicente Rao) & $>2,0$ & verão & 2007 \\
\hline
\end{tabular}

Fonte: Elaborada a partir da análise dos trabalhos descritos acima (2008).

O controle da temperatura imposta à placa do pavimento foi realizado manualmente, através de um ajuste temporal do autotransformador, gerando uma potência capaz de promover variações baseadas na Tabela 3, que permite ainda estabelecer três intervalos 
distintos, possibilitando a construção das curvas de aquecimento, mostradas pelo gráfico 20 . Os intervalos utilizados foram:

a) $1,0^{0} \mathrm{C} / \mathrm{h}$ até $2,0^{0} \mathrm{C} / \mathrm{h}$

b) $2,0^{\circ} \mathrm{C} / \mathrm{h}$ até $3,0^{\circ} \mathrm{C} / \mathrm{h}$ e

c) $3,0^{\circ} \mathrm{C} / \mathrm{h}$ até $4,0^{0} \mathrm{C} / \mathrm{h}$

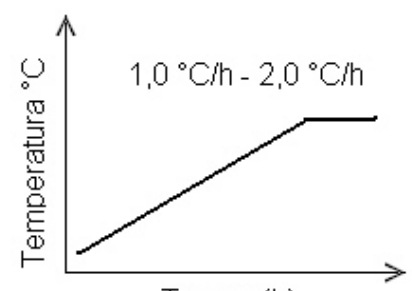

Tempo (h)

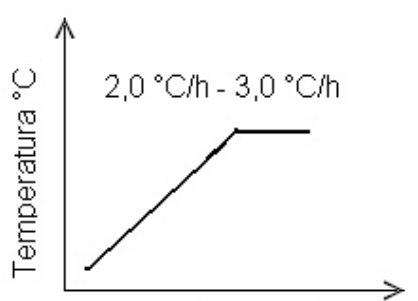

Tempo (h)

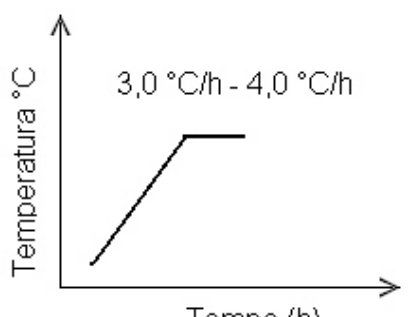

Tempo (h)

Gráfico 20. Curvas utilizadas no estabelecimento das taxas de aquecimento, aplicadas sobre a placa de concreto pela placa de aquecimento.

Fonte: Elaborado a partir dos dados analisados (2008).

Cabe observar que esses primeiros ensaios mostraram semelhanças com relação aos resultados obtidos com a vigota no que se refere ao comportamento da temperatura no concreto.

Por outro lado, o diferencial de temperatura em função da distância do topo, para a vigota ensaiada, apresentou um valor de $0,04{ }^{\circ} \mathrm{C} / \mathrm{mm}$ enquanto Adkins e Merkeley (1990), para uma profundidade de coleta de $6,0 \mathrm{~mm}$, Huang (1993) sugere valores de $0,055^{\circ} \mathrm{C} / \mathrm{mm}$ a $0,077^{\circ} \mathrm{C} / \mathrm{mm}$, Rodolfo (2001) em pista instrumentada obteve valores de $0,06^{\circ} \mathrm{C} / \mathrm{mm}$ e $\mathrm{Yu}$ et al. (1998) em pista instrumentada a uma taxa de aquecimento de $2,0^{\circ} \mathrm{C} / \mathrm{mm}$, obteve $0,0055^{\circ} \mathrm{C} / \mathrm{mm}$.

Durante os testes com a placa, muitos valores de gradientes térmicos (taxa de variação térmica) foram conseguidos e pode-se simular adequadamente os gradientes (taxa de variação térmica) descritos na literatura. No gráfico 21, como exemplo, a uma taxa de aquecimento de $1,5^{\circ} \mathrm{C} / \mathrm{h}$, durante oito horas e resfriamento natural, obteve-se gradiente máximo de $0,047^{\circ} \mathrm{C} / \mathrm{mm}$ e mínimo de $-0,004^{\circ} \mathrm{C} / \mathrm{mm}$. As linhas cheias representam o período de aquecimento e as tracejadas o de resfriamento.

Outro aspecto que deve ser observado é sobre o momento em que ocorre o valor máximo da temperatura. Armaghani et al. (1981) comentam que a temperatura superficial do concreto atinge o seu valor máximo de uma a duas horas após o ambiente ter atingido o seu 
valor máximo e que a temperatura, pelos dados observados, tende a ficar de $3,0^{\circ} \mathrm{C}$ a $9,0^{\circ} \mathrm{C}$ acima da temperatura ambiente na superfície do pavimento (placa).

No teste realizado com a vigota, a temperatura superficial foi de $33,5^{\circ} \mathrm{C}$ às $14 \mathrm{~h}$ 00min, enquanto a temperatura máxima do ar foi de $28,0^{\circ} \mathrm{C}$, segundo dados obtidos no site oficial do Ministério da Agricultura (BRASIL, 2006), que pode ser observado no gráfico 22 (nesse período a antena de coleta de dados meteorológicos da UPM estava em manutenção).

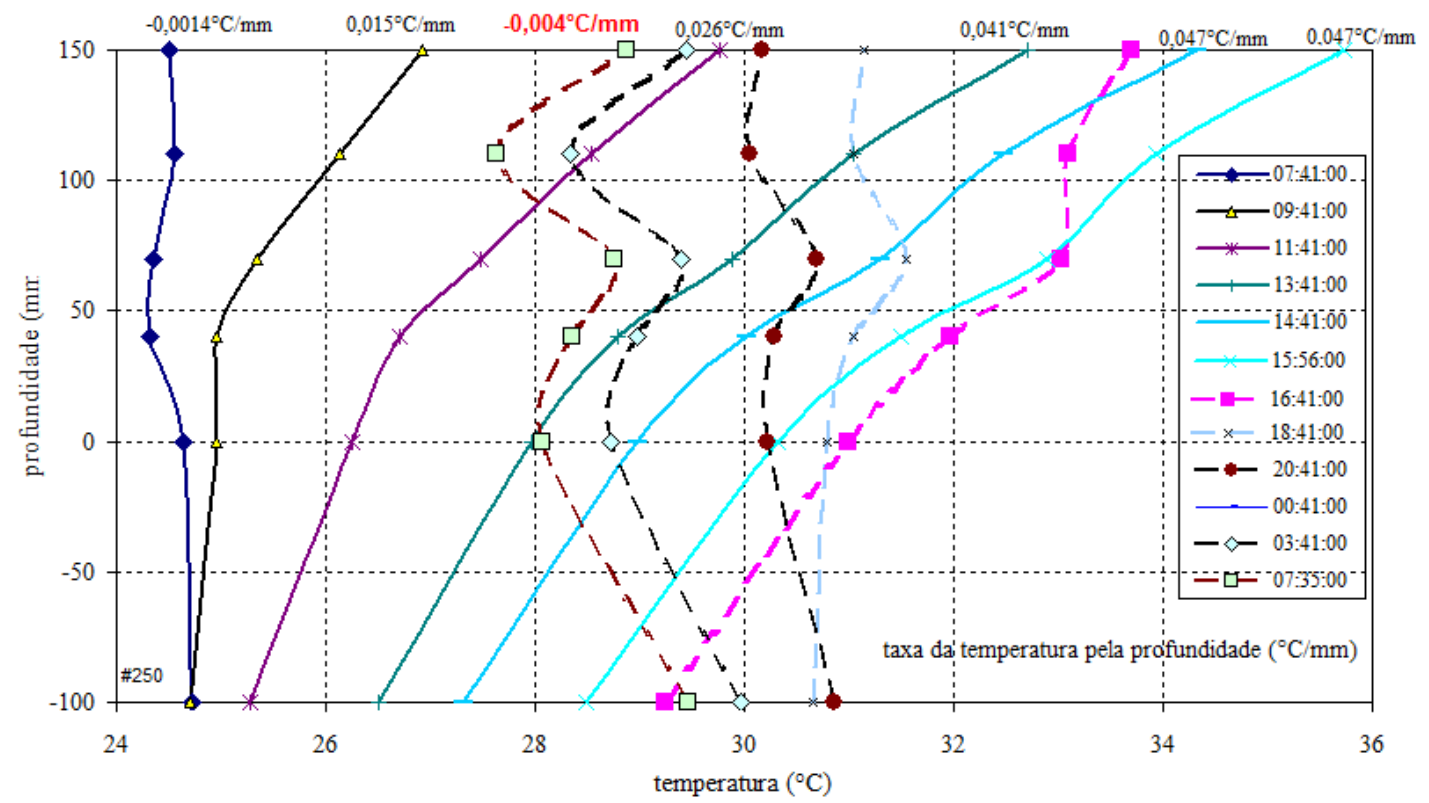

Gráfico 21. Aspecto da temperatura ao longo da espessura da placa e da base, onde é possível verificar a variação do gradiente (taxa de variação) ao longo do tempo.

Fonte: Elaborado a partir dos dados analisados (2008).

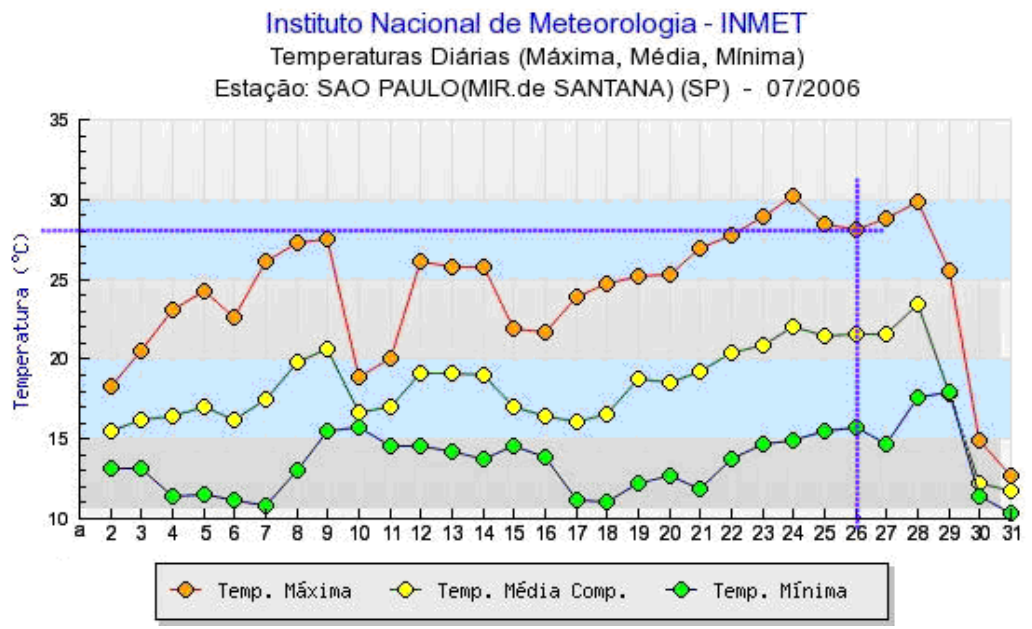

Gráfico 22. Distribuição de temperatura durante o mês de julho de 2006.

Fonte: adaptado do INMET (BRASIL, 2006). 


\subsection{CONSTRUÇÃO DO PAVIMENTO E SUAS PARTES}

A estrutura foi planejada seguindo informações obtidas quando da construção do pavimento 1 (ver apêndice C), ou seja, o elemento de pavimento, ou simplesmente pavimento, foi construído em três camadas: subleito, base e placa. A execução seguiu os procedimentos normais para dimensionamento de um pavimento comum, encontrado em pisos industriais e pavimentos rodoviários. A contenção da massa foi realizada através de um molde de madeira, reforçado pelas laterais e com orifícios para a passagem dos cabos dos sensores. A construção da placa do pavimento só foi iniciada após o período de cura da base e posicionamento dos sensores. As dimensões do pavimento ficaram limitadas ao espaço disponível para a sua construção, no que se refere ao comprimento e à largura. A área total ocupada pela estrutura foi de 5,7 $\mathrm{m}^{2}$ com as seguintes dimensões: 3,0 $\mathrm{m}$ de comprimento, 1,78 $\mathrm{m}$ de largura e 0,4 $\mathrm{m}$ de espessura. A escala de redução foi distorcida, tendo em vista que um pavimento real possui, dependendo do terreno e da utilização, 7,0 $\mathrm{m}$ de comprimento, 3,8 $\mathrm{m}$ de largura e 0,4 m de espessura entre placa e base (PITTA, 2000).

Essa adequação dimensional foi devida ao espaço útil sob a máquina universal, onde foi construída a estrutura que limitou o seu tamanho e isso implicou uma verificação da possível aplicação teoria de semelhança sobre o estudo que foi desenvolvido. As dimensões geométricas foram escolhidas para serem as mais próximas das reais, lembrando que essas são escolhidas de acordo com a utilidade do pavimento. A aplicação da análise dimensional no estudo de pavimentos rígidos, segundo Ioannides e Murua (1989), é distinguir entre parâmetros de entrada e variáveis independentes, bem como valores de saída e variáveis dependentes.

A análise dimensional apresenta uma aplicação que é o estabelecimento de semelhança física, que relaciona protótipos com modelos utilizados em experimentos. Para que um modelo ${ }^{19}$ possa representar as características do protótipo, ou seja, que os resultados vindos do ensaio possam ser levados ao protótipo, é necessário que ocorra uma semelhança geométrica. Segundo Andolfato (2002), na área de engenharia, a principal aplicação é o estabelecimento das semelhanças físicas que relacionam modelo e protótipo. Ele define ainda alguns tipos de modelos:

a) modelo indireto - modelo para o qual o carregamento e os materiais não têm relação direta aos usados no protótipo;

\footnotetext{
${ }^{19}$ Modelo é usualmente construído em escala reduzida.
} 
b) modelo direto - modelo carregado da mesma forma que o protótipo, de tal forma que as tensões e as deformações sejam similares ao protótipo;

c) modelo elástico - modelo direto que representa geometricamente o protótipo, mas com materiais elásticos e homogêneos;

d) modelo de resistência última - modelo que representa geometricamente o protótipo, bem como as características do material. Tal modelo pode prever o comportamento do protótipo em qualquer carga, até a última.

No caso específico desse estudo, isso foi conseguido pois o pavimento e seus componentes puderam ser construídos em uma escala distorcida o que quer dizer, por exemplo, que a escala dos comprimentos $\mathrm{K}_{\mathrm{L}}$ não guardou igual proporção entre comprimento, largura e espessura em relação a um pavimento real. No entanto, uma condição não suficiente para que ocorra semelhança física é a semelhança geométrica e, nos experimentos com modelo, costuma-se definir fator de escala como relação entre a grandeza representativa do modelo e a grandeza do protótipo. Então, para que ocorra semelhança física, segundo Carneiro (1996), é condição necessária e suficiente que, em princípio, todos os números П, fatores de forma ${ }^{20}$ e funções de forma ${ }^{21}$ devem ser os mesmos entre modelo e protótipo. Distorções de escala podem ocorrer, tornando importante a análise dos resultados para o estabelecimento de conclusões.

Sobre o estudo de um elemento de pavimento, em escala, interno a um laboratório, ressalta-se que a literatura não especifica escala de redução para pavimento ou placas de concreto, no entanto, alguns estudos, tais como de Sinha e Hendry (1970) apud Maurício (2005), em que foi conduzido um estudo de cargas horizontais em paredes de um edifício de cinco pavimentos, em relação a um modelo na escala 1:6, não produziram efeitos significativos nas grandezas estudadas. Porém, o mais significativo foi o trabalho realizado por Martins (1990), aplicando a teoria dos modelos e apontando condições para o estudo de estruturas em concreto por meio de um modelo em microconcreto. Nesse trabalho, encontrase uma informação relevante atribuía a Neth (1971), apud Martins, mostrando graficamente que o efeito escala começa a se fazer presente somente com relações acima de 1:4. Essa informação pode ser verificada no trabalho de Andolfato (2002) que realizou testes com material selecionado na confecção de blocos de alvenaria, resaltando que os instrumentos de

\footnotetext{
${ }^{20}$ Os fatores de forma são variáveis adimensionais que definem um parâmetro segundo um outro que tenha o mesmo tipo de grandeza. Por exemplo: Altura de 20,0 cm e largura de 30,0 cm que podem ser escritas como duas alturas e três larguras.

${ }^{21}$ Situação em que não é possível uma representação por fatores de forma, sendo a representação por meio de uma equação matemática mais adequada.
} 
medida não requerem o processo de semelhança física, o que implica dizer que as leituras das grandezas mecânicas puderam ser feitas diretamente. Não obstante, é inevitável que distorções ocorram durante a aplicação do processo de semelhança e como exemplo, pode-se citar a impossibilidade de definir em escala geométrica as partículas que compõem o cimento. Essa consideração também foi tratada por Sabnis e Mirza (1979), quando foram investigados os efeitos do tamanho amostra em modelo de concreto, não ocorrendo tal efeito com outros materiais que podem ser geometricamente reduzidos, como, por exemplo, areia e brita.

Outro aspecto a ser considerado é aquele ligado à temperatura, que não pôde ser geometricamente escalonada e que foi tratada como conseqüência da energia utilizada nos processos de aquecimento. Em termos térmicos, os testes de aquecimento foram considerados em regime transitório ${ }^{22}$.

A fotografia 15 mostra o molde do pavimento com a placa de poliuretano já ajustada. É possível observar, sobre o polímero, um termômetro, na posição central, para medição da temperatura entre o topo do subleito e o fundo da base. Esse termômetro foi codificado como TFUN.

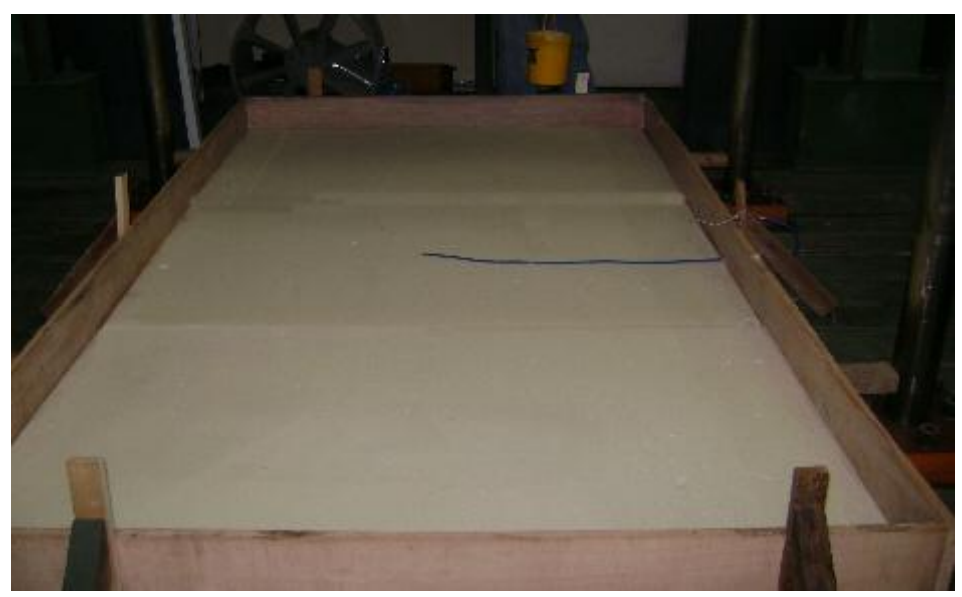

Fotografia 15. Aspecto do molde já com a placa de poliuretano colocado e um termômetro no centro para leitura da temperatura no subleito (TE14). Fonte: Acervo próprio (2007).

A base foi construída seguindo o manual de concreto compactado a rolo da ASSOCIAÇÃO BRASILEIRA DE CIMENTO PORTLAND, (2007) e apresentou, no momento da concretagem, abatimento próximo de zero. A compactação foi realizada

${ }^{22}$ O regime transitório é uma situação em que alguma propriedade, como a temperatura, está variando temporalmente. Dependendo do tipo de interação térmica que o corpo esteja fazendo com o meio ambiente, a temperatura poderá deixar de variar. Neste ponto, diz-se que o regime permanente é alcançado. 
manualmente com um rolo de aço desenvolvido para essa finalidade. O processo de cura foi realizado mantendo a estrutura coberta com lona plástica. A figura 16 mostra a base concluída e, em detalhe, o rolo compactador. Nessa mesma fotografia, pode ser observada, no centro do molde, a delimitação de um espaço, onde foi colocada uma célula de carga que teve a função de indicar a flexão convexa da placa durante os procedimentos de aquecimento.

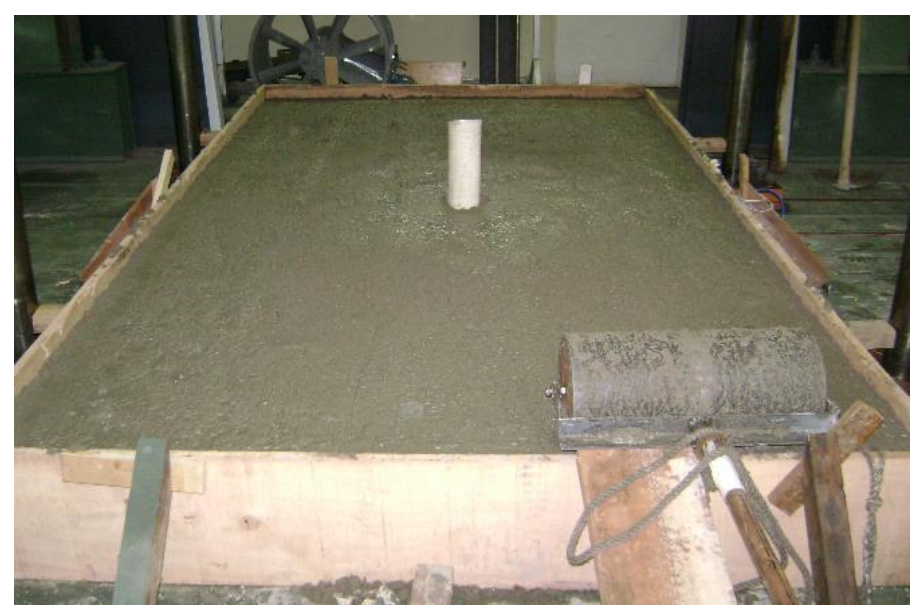

Fotografia 16. Colocação da base sobre o subleito. No centro foi colocado um tubo de $120,0 \mathrm{~mm}$ de diâmetro para moldar o poço onde foi colocada a célula de carga. Fonte: Acervo próprio (2006).

O concreto da placa foi lançado vinte e oito dias após a concretagem da base, tendo uma manta plástica entre elas com a finalidade de caracterizar o pavimento como não aderido, prevenir a perda de água para a base evitando fissuras de retração plástica e serviu para diminuir o atrito, permitindo maior mobilidade da placa, quando sujeita aos diferenciais de temperatura. No preparo do concreto, foi utilizado cimento classificado como CPII-20, da

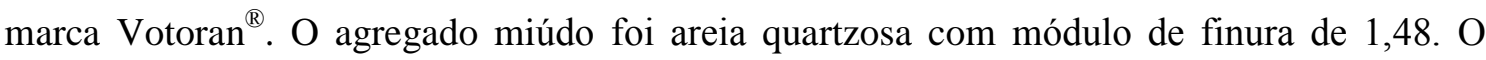
agregado graúdo foi classificado como "Brita 1". A água de amassamento do concreto foi retirada da rede interna da Universidade, foi realizado a adição de plastificante e a massa não foi vibrada, pois esse procedimento poderia deslocar os sensores. Contudo, apresentou boa trabalhabilidade no momento do preenchimento do molde. Os ensaios tecnológicos obedeceram a normalização brasileira ${ }^{23}$ e foram realizados no Laboratório de Ensaio de

\footnotetext{
${ }^{23}$ ASSOCIAÇÃO BRASILEIRA DE NORMAS TÉCNICAS NBR 9776 - Agregados - Determinação da massa específica de agregados miúdos por meio do frasco de Chapman, ASSOCIAÇÃO BRASILEIRA DE NORMAS TÉCNICAS NBR 7217 - Agregados - Determinação da composição granulométrica, ASSOCIAÇÃO BRASILEIRA DE NORMAS TÉCNICAS NBR 7223 - Concreto - Determinação da consistência pelo abatimento do tronco de cone e NBR 5739, ASSOCIAÇÃO BRASILEIRA DE NORMAS TÉCNICAS NBR
} 
Materiais da EEUPM. O quadro 1 mostra quantitativamente as proporções utilizadas na confecção da estrutura.

\begin{tabular}{|c|c|c|c|c|c|c|}
\hline Registros & Unidade & \multicolumn{2}{|l|}{ Base } & \multicolumn{2}{|c|}{ Placa (pavimento) } & $\begin{array}{l}\text { Subleito } \\
\text { poliuretano }\end{array}$ \\
\hline Traço & ------- & \multicolumn{2}{|c|}{$1: 9: 0,67$} & \multicolumn{2}{|c|}{$1: 4,5: 0,39$} & --------- \\
\hline Cimento & $\mathrm{kg} / \mathrm{m}^{3}$ & \multicolumn{2}{|l|}{227} & \multicolumn{2}{|l|}{408} & --------- \\
\hline Areia & $\mathrm{kg} / \mathrm{m}^{3}$ & \multicolumn{2}{|l|}{908} & \multicolumn{2}{|l|}{781} & --------- \\
\hline Brita & $\mathrm{kg} / \mathrm{m}^{3}$ & \multicolumn{2}{|l|}{1135} & \multicolumn{2}{|l|}{1055} & --------- \\
\hline Água & $\mathrm{L}$ & \multicolumn{2}{|l|}{152} & \multicolumn{2}{|l|}{159} & --------- \\
\hline Relação água-cimento & $\mathrm{L} / \mathrm{kg}$ & \multicolumn{2}{|l|}{0,67} & \multicolumn{2}{|l|}{0,39} & --------- \\
\hline Teste de Compressão & & & --------- \\
\hline 7 dias & $\mathrm{MPa}$ & \multicolumn{2}{|l|}{25,4} & \multicolumn{2}{|l|}{37,5} & --------- \\
\hline 28 dias & $\mathrm{MPa}$ & \multicolumn{2}{|l|}{27,2} & \multicolumn{2}{|l|}{44,2} & --------- \\
\hline & & centro & terços & centro & terços & --------- \\
\hline Teste de tração na flexão & $\mathrm{MPa}$ & 3,6 & 2,8 & 8,6 & 7,2 & --------- \\
\hline Módulo de elasticidade & $\mathrm{GPa}$ & \multicolumn{2}{|l|}{29,0} & \multicolumn{2}{|l|}{36,0} & 0,0046 \\
\hline Massa específica & $\mathrm{kg} / \mathrm{m}^{3}$ & \multicolumn{2}{|l|}{2406,0} & \multicolumn{2}{|l|}{2406,0} & 44,0 \\
\hline Módulo de reação & $\mathrm{GPa} / \mathrm{m}$ & \multicolumn{2}{|l|}{----- } & \multicolumn{2}{|l|}{----- } & 0,049 \\
\hline
\end{tabular}

Quadro 1. Ensaios tecnológicos do concreto utilizado na base e na placa. A última coluna mostra dados do subleito (Valores médios).

Fonte: Dados obtidos a partir das informações do laboratório de ensaios de materias (2008).

\subsubsection{DETERMINAÇÃO DO MÓDULO DE REAÇÃO PARA O SUBLEITO}

Um fator determinante no comportamento da placa, no que se refere aos vários carregamentos impostos pelo tráfego e pelas condições ambientais, é o módulo de reação ou $\mathrm{k}$, que qualifica o solo como capaz de manter o suporte das camadas superiores. Tanto o solo, subleito, como a base podem ser tratados ou melhorados para proporcionar um comportamento adequado do pavimento.

O dimensionamento de pavimentos de concreto é baseado nas suas propriedades, resistência à tração na flexão, por exemplo, e na capacidade de suporte do subleito. As funções da base de um pavimento rígido são atender a uniformidade para o apoio da placa e 
evitar tanto a ocorrência do bombeamento de finos plásticos ${ }^{24}$ que poderiam estar presentes no solo de fundação a mudança de volume do solo.

No pavimento em estudo, a base foi feita em concreto rolado e o processo de execução foi realizado segundo a norma sobre pavimento de CCP compactado com rolo (BRASIL, 2004). As dimensões de 10,0 cm de espessura e resistência à compressão aos sete dias de 6,0 MPa foram determinadas em função da construção da placa e estão de acordo com a norma do DNIT (Brasil, 2005b).

Para evitar o manuseio de solo e os processos de compactação dentro do laboratório, o subleito do pavimento foi feito utilizando poliuretano de alta densidade, ao invés de um solo comum. As placas de poliuretano foram encomendadas e feitas sob medida pela empresa RIGILAINE ${ }^{\circledR}$. Elas foram confeccionadas com 150,0 mm de espessura, 2000,0 mm de comprimento e 1200,0 mm de largura. Dimensões máximas limitadas pelos moldes do fabricante.

O poliuretano foi escolhido devido à estabilidade estrutural que oferece em relação ao solo comum, tais como ser pouco sensível à umidade do ambiente, homogêneo, estável com relação aos testes mecânicos realizados e apresentar uniformidade de suporte à base, tendo em vista que na primeira experiência, pavimento 1, o subleito foi confeccionado com solo comum argiloso. Quando a aderência entre o subleito a base foi investigada, no final do projeto, verificou-se que, em alguns pontos no fundo da base, havia ocorrido a perda de contato entre os dois elementos da estrutura.

Uma das aplicações do poliuretano em pavimentação é como isolante térmico em pisos industriais, principalmente em câmaras frigoríficas, que, nesse caso, têm a função de realizar o isolamento entre o piso de concreto e a base (sub-base) ou subleito.

A opção da utilização de um polímero como subleito surgiu da necessidade de evitar o aparecimento de um parâmetro sazonal difícil de controlar, que é a umidade, tendo em vista que esse parâmetro induz mudança no valor do módulo de reação, causando a perda de suporte das camadas acima dele. Vários estudos são realizados nesse sentido, em destaque Heydinger (2003) que expõe o solo como fator importante no desempenho do pavimento e mostra essa importância, descrevendo uma pesquisa baseada na comparação do desempenho real de seções de pavimentos rodoviários, a partir de uma base de dados dos experimentos Long-Term Pavement Performance (LTPP) do Federal Highway Administration (FHWA),

\footnotetext{
${ }^{24}$ Infiltração de água através de fissuração resulta na expulsão de finos do material de fundação do pavimento através das juntas, bordas ou trincas, quando da passagem das cargas de tráfego.
} 
que inclui um programa de monitoramento sazonal Seasonal Monitoring Program (SMP), também descrito por Nascimento (2005) que faz uma análise detalhada desse procedimento.

Apesar da comodidade e vantagem que o polímero pode apresentar, algumas características mecânicas tiveram que ser levantadas, pois o fabricante não as dispunha. Os parâmetros de interesse foram os seguintes: densidade (massa específica), módulo de elasticidade e capacidade de suporte. Para esse último, dois métodos foram adotados: o teste do Califórnia Bearing Ratio (CBR) (\%) e o ensaio de placa (MPa/m). Todos os ensaios foram realizados nos laboratórios da EEUPM.

Inicialmente, foi tentado o estabelecimento do teste do $(\mathrm{CBR})^{25}$ ou índice suporte Califórnia (ISC), em uma amostra do polímero. Porém, esse teste mostrou-se inexequível, pois vários itens da norma NBR 9895 (ASSOCIAÇÃO BRASILEIRA DE NORMAS TÉCNICAS, 1987) não puderam ser atendidos como, por exemplo, a compactação do material com a energia apropriada e preparação da amostra com o teor de umidade adequado, tendo em vista que o poliuretano é pouco solúvel em água.

O estabelecimento de uma correlação do polímero com a Tabela de classificação de solos, criada pelo Corpo dos Engenheiros do Exército dos Estados Unidos da América (US Army Corps of Engineers) (USA Corps, 1984), também mostrou-se falho devido ao fato da impossibilidade na determinação do grau de saturação, $\mathrm{S}_{\mathrm{r}}$, que é função da percentagem de água (w) contida na amostra. A relação 15 estabelece a dependência entre essas grandezas. A respeito desse tipo de teste com relação à classificação do solo, Augusto Junior (1992) ressalta que para solos tropicais a classificação do Corpo de Engenheiros nem sempre é verdadeira.

$$
S_{r}=\frac{W}{\left(\frac{62,4}{\gamma}\right)-\left(\frac{1}{G_{s}}\right)}
$$

sendo:

$\mathrm{S}_{\mathrm{r}}$ - dado em porcentagem $\%$,

W - porcentagem de água,

$\gamma$ - densidade do material seco,

$\mathrm{G}_{\mathrm{s}}$ - gravidade específica.

\footnotetext{
${ }^{25} \mathrm{O}$ teste CBR é um teste de comparação, não de rigidez, em relação à capacidade de suporte de um material em relação ao suporte de uma quantidade de brita bem-graduada. Foi desenvolvido pela divisão de estradas da Califórnia, por volta de 1930. Esse procedimento vem sendo adotado nos Estados Unidos e várias partes do planeta. Como norma pode-se citar entre outras a ASTM DI883-94 e a ASTM D4429-93.
} 
O teste do CBR é relevante, pois mede a resistência do solo do subleito que influencia diretamente a espessura final da placa. Esse parâmetro é muito utilizado no dimensionamento de pavimentos, quer sejam industriais ou rodoviários. Porém, quando se tratar de pavimentos rígidos, emprega-se o módulo de reação, k, que pode se relacionar com o CBR por meio gráfico, conforme a prática IP-07, utilizada pela prefeitura da cidade de São Paulo (SÃO PAULO, 2002).

O teste de prova de carga estática, o segundo a ser tentado para a determinação do módulo de reação do subleito ${ }^{26}$, mostrou-se mais adequado ao tipo de material utilizado. Porém, não pôde ser executado de acordo com a norma 055/2004-ME (BRASIL, 2004a) devido à ausência do equipamento apropriado e pela falta de poliuretano que atendesse à norma, porque ela especifica que o solo (no caso o poliuretano) deve ser submetido a uma compressão provocada por uma placa de aço de $0,799 \mathrm{~m}$ de diâmetro acionada por um processo hidráulico. Como o material disponível não tinha uma superfície relativa a $0,799 \mathrm{~m}$ de diâmetro, foi necessário fazer uma adaptação conceitual na norma. Ou seja, em vez de medir a deflexão com uma amostra de 0,799 m sob compressão, como preconiza a norma, foram confeccionados três corpos de prova de dimensões menores, com diâmetros de 0,095 m e alturas de 0,095 m, mantendo-se a geometria cilíndrica do CP. Os corpos de prova foram submetidos individualmente ao teste de compressão realizado em uma máquina universal de testes mecânicos marca MTS-Qtest, mod. 815. A fotografia 17 destaca, em detalhe, o posicionamento do $\mathrm{CP}$ durante a execução do teste.

Os dados obtidos produziram os gráficos 23 e 24 que mostram, respectivamente, a curva tensão por deformação para determinação do módulo de reação k e a curva tensão por deformação para o cálculo do módulo de elasticidade E.

A análise das curvas, tomando como referência a região linear, mostrou que o módulo de reação apresentou o valor de 49,0 MPa/m com incerteza de $0,5 \mathrm{MPa} / \mathrm{m}$, enquanto o módulo de elasticidade apresentou um valor de 4,6 MPa com incerteza de 0,3 $\mathrm{MPa}$.

\footnotetext{
${ }^{26} \mathrm{O}$ módulo de reação do subleito $(\mathrm{k})$ é realizado in situ pela capacidade de suporte de uma placa de aço de no mínimo $0,762 \mathrm{~m}$ de diâmetro que é pressionada no solo por meio de um sistema estrutural, composto por uma viga de reação e um cilíndro hidráulico. Como norma padrão pode-se citar a ASTM D1196 - 93.
} 


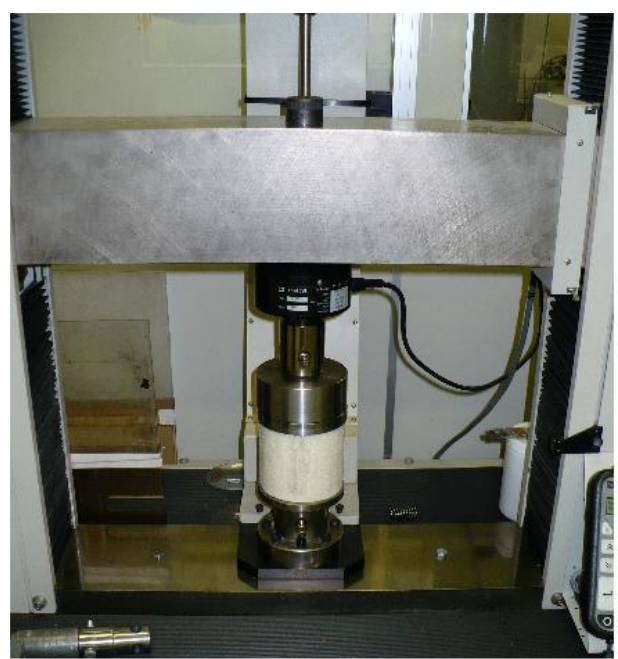

Fotografia 17. Detalhe da amostra de poliuretano sob teste de compressão. Fonte: Acervo próprio (2008).

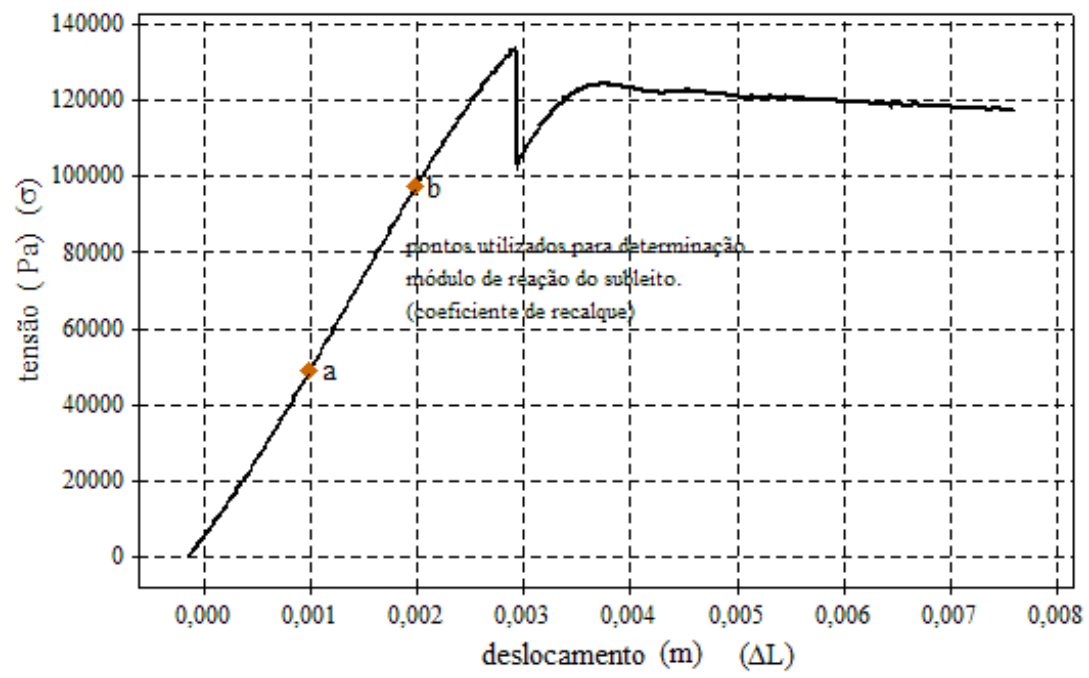

Gráfico 23. Curva característica de tensão por deslocamento utilizada para determinação do módulo de reação.

Fonte: Elaborado a partir dos dados experimentais (2008).

A partir do valor do coeficiente de módulo de reação, estabeleceu-se uma correlação com o CBR o qual apresentou o valor de $8 \%$. No anexo A, encontra-se o gráfico de correlação bem como o valor obtido. Sobre essa correlação, Hall et al. (1995) comentam que a primeira carta de correlação entre o CBR e o módulo de reação foi realizada em 1942 pelo corpo dos engenheiros do exército americano.

A densidade foi determinada pelo método da balança hidrostática, apresentando o valor de $44,0 \mathrm{~kg} / \mathrm{m}^{3}$ com incerteza de $0,5 \mathrm{~kg} / \mathrm{m}^{3}$. 


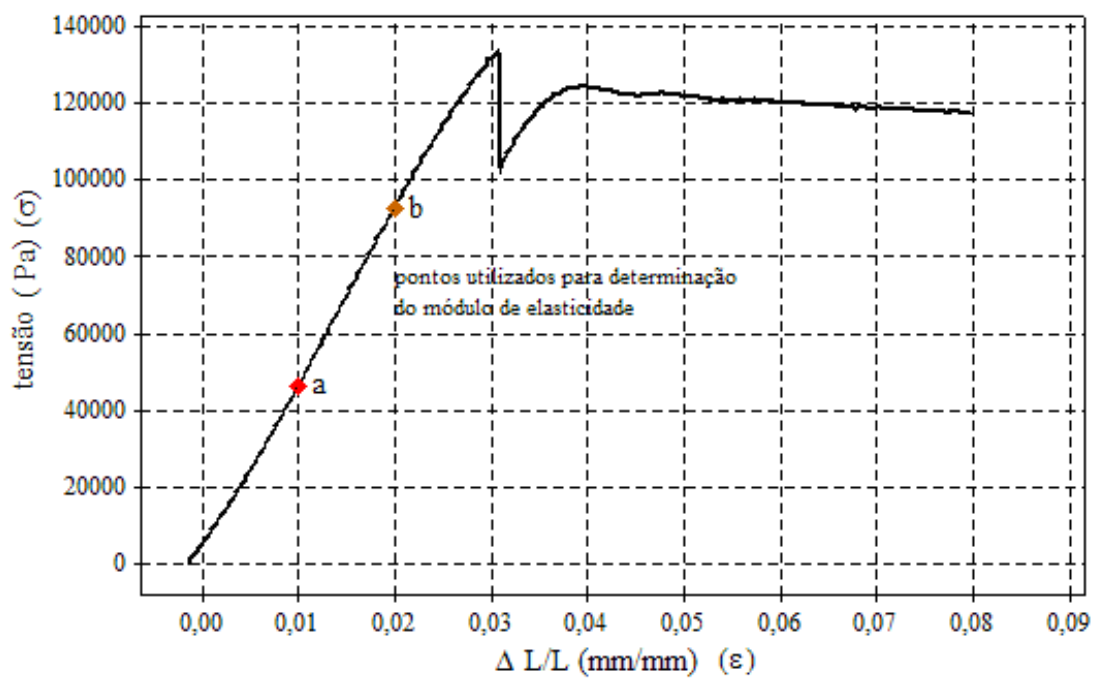

Gráfico 24. Curva característica de tensão vs. deformação para determinação do módulo de elasticidade do poliuretano e ponto de ruptura do CP.

Fonte: Elaborado a partir dos dados experimentais (2008).

\subsubsection{DIMENSIONAMENTO DO PAVIMENTO INDOOR}

Em situações reais, o dimensionamento estrutural de um pavimento tem por finalidade a determinação das espessuras das camadas constituintes. Para tanto, são realizados estudos referentes ao tráfego, subleito e quais materiais atenderão ao projeto. Ou como Balbo (2007) define: "[...] de modo a conceber uma estrutura capaz de suportar um volume tráfego preestabelecido, nas condições climáticas locais".

O elemento de pavimento que foi construído interno ao laboratório buscou assemelharse a um pavimento real no que tange à sua funcionalidade. È certo que tal pavimento não irá sofrer as ações climáticas do cotidiano e, nem tão pouco, servirá como via de acesso a algum lugar. Porém, o seu dimensionamento foi feito de tal forma que levou em consideração um período de projeto, tráfego médio e um imaginário estudo de tráfego. Além do subleito, feito artificialmente, outras duas camadas, sub-base (concreto compactado a rolo) e placa foram construídas dentro do laboratório.

Ele foi dimensionado segundo o método da PCA/84, como sendo uma placa de revestimento rígido (concreto simples), sem acostamento, resistência à tração na flexão de 7,2 MPa e CBR de 8\% $(\mathrm{k}=49,0 \mathrm{MPa} / \mathrm{m})$. O módulo de reação da base foi estimada em 133,0 $\mathrm{MPa} / \mathrm{m}$, espessura de $10,0 \mathrm{~cm}$. O fator de segurança foi considerado como sendo 1,1 (tráfego médio), feita em concreto rolado. Os demais parâmetros foram retirados de estudos acadêmicos, onde foi suposto o número de cargas por eixo (simples, duplo e triplo), cargas 
por eixo (fator de segurança multiplicado por cargas por eixo) e número de repetições previstas. As tensões equivalentes foram obtidas por ábacos vistos em Pitta (1998) onde, também, pôde ser visto um procedimento de cálculo.

\subsubsection{ESCOLHA DO MODELO FÍSICO PARA SIMULAÇÃO DO SOLO DE FUNDAÇÃO}

De acordo com Pinto (2002), os solos são constituídos por partículas que têm a capacidade de reter ar e água nos espaços intermediários. Essas partículas têm liberdade de movimento, sendo que em algumas situações pode ocorrer uma pequena cimentação, não sendo, contudo, classificada como cristais de rocha. Essa característica impede que modelos determinísticos possam prever algum comportamento.

A adoção do modelo físico apropriado para a simulação numérica do solo depende das simplificações que serão realizadas durante o processo, tendo em vista a complexidade do solo devido as suas características. Isso fomentou a criação de modelos simples aos mais elaborados.

O modelo clássico utilizado para uma placa repousando sobre um solo médio é conhecido como modelo de Winkler, em que o comportamento do solo é simplificado por meio de um líquido denso ou uma região repleta de molas imaginárias individuais, colocadas continuamente abaixo da estrutura e perfiladas na posição vertical, capazes de se opor somente ao peso e aos carregamentos impostos pelo conjunto placa e base (sub-base) (DALOGLU e VALLABHAN, 2000), (SAXENA, 1973).

A constante de proporcionalidade que figura entre o carregamento e a deformação é conhecida como módulo de reação. Esse valor não é individual, mas resultante da reação sobre o conjunto placa e base.

Outro modelo, mais elaborado que o anterior, é conhecido como sólido elástico e tenta contornar as imprecisões ou limitações do modelo anterior. As propriedades consideradas nesse caso são o módulo de elasticidade e o coeficiente de Poisson. Esse modelo se aproxima mais da realidade, considerando não somente esforços normais como esforços cisalhantes. No desenho 11, (a) reproduz o comportamento real de um solo médio; (b) a idealização do modelo de Winkler (liquído denso) e (c) o modelo do sólido elástico. $\mathrm{O}$ modelo líquido denso impõe ao solo um modelamento descontínuo, enquanto o modelamento segundo um sólido elástico impõe ao solo uma característica contínua. 
Os testes com o poliuretano indicaram um comportamento semelhante, se não igual, à idealização de um líquido denso. Isso é pertinente, pois, em diversos estudos, o modelo de Winkler é usado na prática e foi utilizado para descrever o comportamento da fundação no presente trabalho quando das simulações numéricas com o software EverFE 2.24 (DAVIDS, et al. 2003).

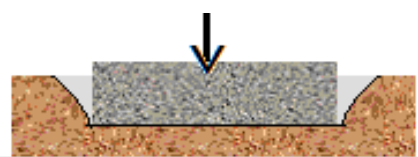

(a)

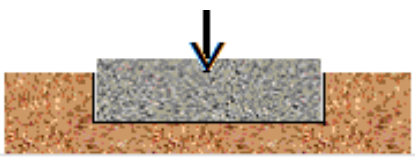

(b)

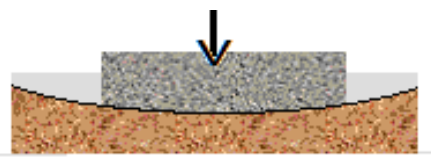

(c)

Desenho 11. Representações dos modelos mais utilizados para representação do comportamento de um solo, imposto um carregamento.

Fonte: Acervo próprio (2008).

\subsection{INSTRUMENTAÇÃO DA PLACA DE CONCRETO}

Antes da colocação do concreto, os sensores foram depositados em lugares estratégicos e devidamente mapeados. A fotografia 18 mostra a disposição dos sensores e a tubulação utilizada para geração de diferenciais térmicos do fundo para o topo da placa. Os sensores de temperatura foram fixados em hastes verticais presas na base. Os sensores de deformação - células de embutimento - foram presos em "cavaletes" de arame de aço de 1,0 mm de diâmetro por meio de presilhas de plástico tire up (enforca gato ou cable ties). A fotografia 19 mostra em primeiro plano como foram fixadas as células de embutimento e, em segundo, como foram fixados os termômetros.

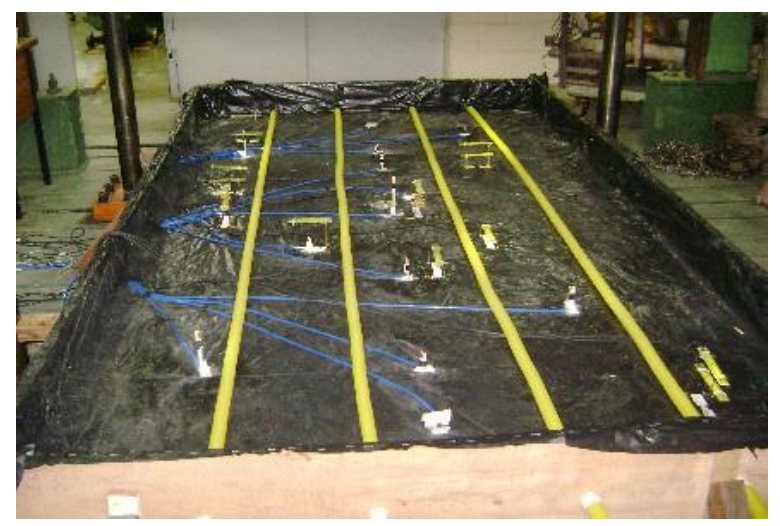

Fotografia 18. Colocação da manta plástica para evitar a aderência da placa de concreto. Vista do posicionamento dos sensores na placa e colocação dos conduítes para resfriamento ou aquecimento do fundo da placa.

Fonte: Acervo próprio (2007). 


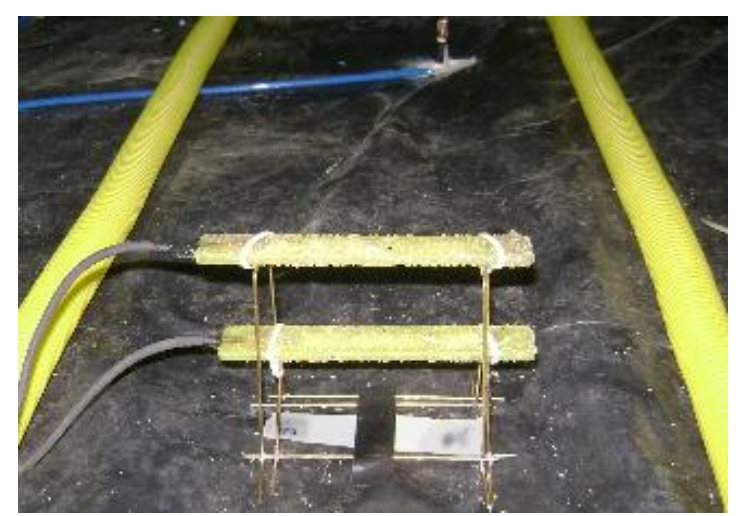

Fotografia 19. Detalhe do conjunto termômetro e célula de deformação presos no cavalete. Fonte: Acervo próprio (2007).

Para evitar o deslocamento dos sensores da posição pré-estabelecida, eles foram inicialmente cobertos com a massa de concreto e, após, seguiu-se a concretagem. Essa metodologia foi utilizada por Sargand e Khoury, (1999). A fotografia 20 mostra como foi efetuada a proteção das células de embutimento durante a concretagem. A fotografia 21 mostra a placa finalizada, sendo também possível observar a proteção térmica dos tubos de aquecimento do fundo da placa (trocador de calor).

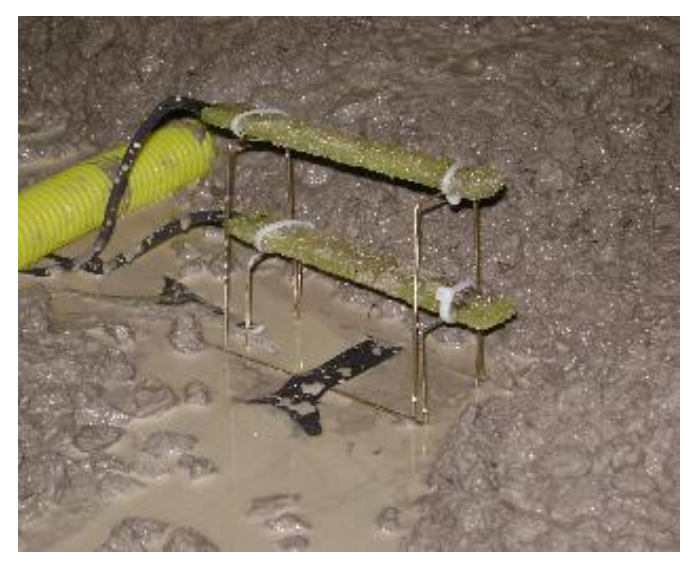

Fotografia 20. Proteção dos sensores com concreto antes da colocação da totalidade de massa. Isso evita que ocorra algum deslocamento dos sensores, devido à pressão que a massa impõe sobre esses componentes.

Fonte: Acervo próprio (2008). 


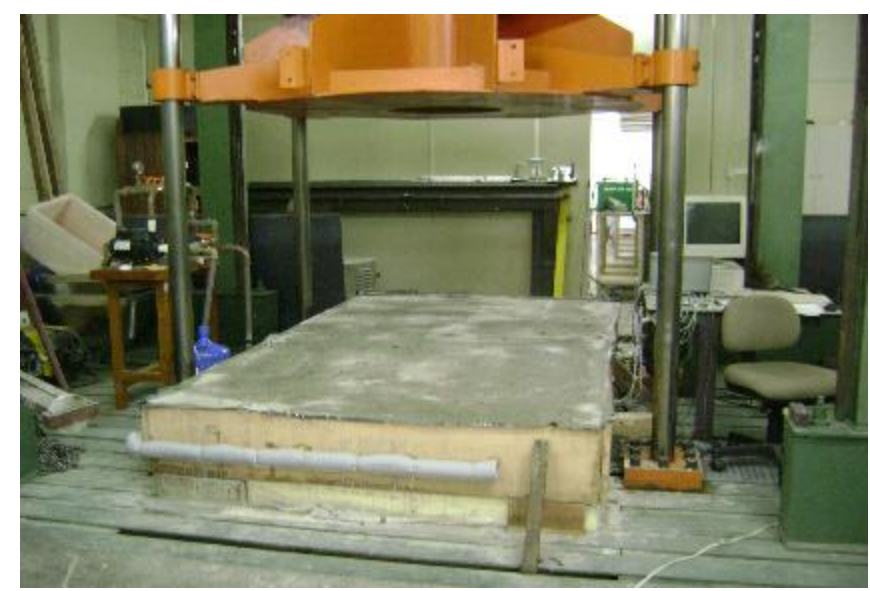

Fotografia 21. Aspecto da placa já terminada após 28 dias, tendo sob ela a laje de reação e sobre ela uma máquina hidráulica para testes de carregamento estático. Fonte: Acervo próprio (2008).

Para observar o empenamento da placa, foi colocada no centro da mesma uma célula de carga. Ela foi fixada entre o fundo da placa e a superfície da laje de reação, transpassando a base e o subleito.

$\mathrm{Na}$ fotografia 22, (a) mostra a célula de carga e seus componentes; (b) a base do pavimento com a cavidade central para a colocação da célula de carga, e (c) a célula posicionada dentro da cavidade já fixada, magneticamente, na laje de reação.

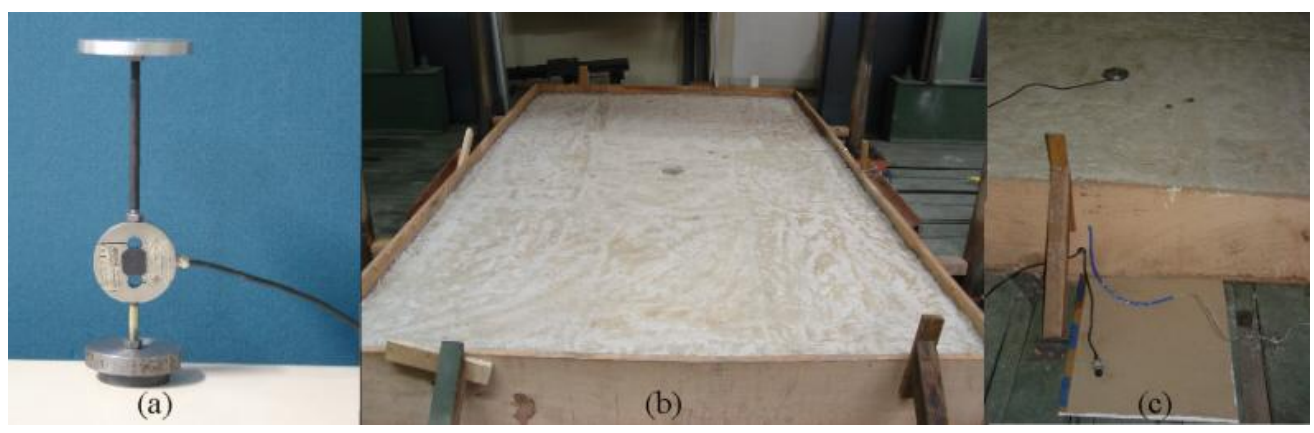

Fotografia 22. (a) célula de carga com base magnética para fixação no piso da laje de reação, (b) base com a cavidade de abrigo (poço) da célula de carga, (c) célula de carga posicionada dentro da cavidade.

Fonte: Acervo próprio (2008).

A célula de carga, chamada de transtec, foi colocada e fixada dentro da cavidade antes da concretagem da placa. A fixação foi realizada através de um anteparo de alumínio que foi interconectando, mecanicamente, à célula por meio de uma haste de aço. O desenho 
12 traz a representação em corte transversal do pavimento, ilustra a disposição da célula dentro da cavidade e como ela ficou disposta entre as camadas do pavimento.

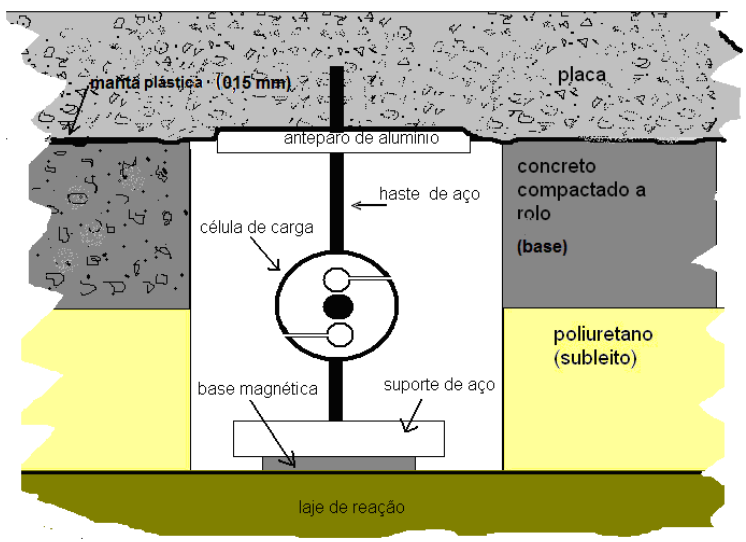

Desenho 12. Corte transversal do poço, onde está localizado o sistema célula de carga e base magnética. Esse procedimento foi utilizado para detectar o empenamento da placa.

Fonte: Acervo próprio (2008).

Os dados gerados devido a esse processo foram significativos e indicaram como a placa de comporta devido ao aparecimento dos diferenciais de temperatura. Porém essa célula deixou de funcionar dois meses após ser instalada. No sentido de obter mais dados, outra célula foi colocada em seu lugar, mas os resultados não foram tão significativos quanto os anteriores.

O desenho 13 mostra, esquematicamente, como a nova célula foi posicionada no lugar da anterior.

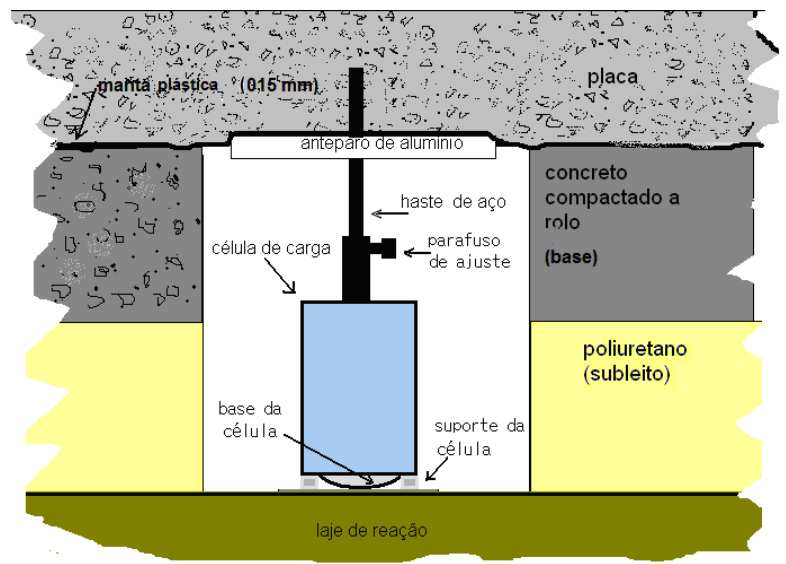

Desenho 13. Corte transversal do poço, onde está localizada a nova célula de carga e como está posicionada.

Fonte: Acervo próprio (2009). 


\subsection{SISTEMA DE AQUISIÇÃO DE DADOS E CONDICIONAMENTO DE SINAIS}

A leitura dos dados de deformação, temperatura e tensão foi conseguida por meio de um sistema automático de coleta de dados, feito inicialmente para estudos do pavimento 1 e desenvolvido na plataforma LabView ${ }^{\circledR}$ e condicionadores da National Instruments (o apêndice $\mathrm{C}$ mostra o sistema de aquisição desenvolvido em LabView). Posteriormente, esse sistema foi substituído pelo da Lynx Tecnologia modelo ADS-500, acompanhado dos softwares de coleta e análise de dados, AqDados e AqDAnalysis, ambos na versão 7.0. O sistema Lynx possui dezesseis canais independentes que podem, simultaneamente, realizar leituras de temperatura e de deformação em $1 / 2,1 / 4$ ou ponte completa. A fotografia 23 (a) mostra a disposição do sistema formado por um computador pessoal, marca IBM, com processador Intel ${ }^{\circledR}$ Pentium ${ }^{\circledR}$ III e pelo equipamento de aquisição de dados.

Os sinais oriundos dos sensores foram inicialmente filtrados através de um filtro passa baixo ajustável e sintonizado em $35,0 \mathrm{~Hz}$. Os sinais também puderam ser amplificados mediante microchaves (dip-swicht) presentes no painel do equipamento.

Os sensores de deformação (células de embutimento) puderam ser conectados a 1/2, $1 / 4$ ou parte completa, mediante uma programação adequada realizada por outro grupo de microchaves.

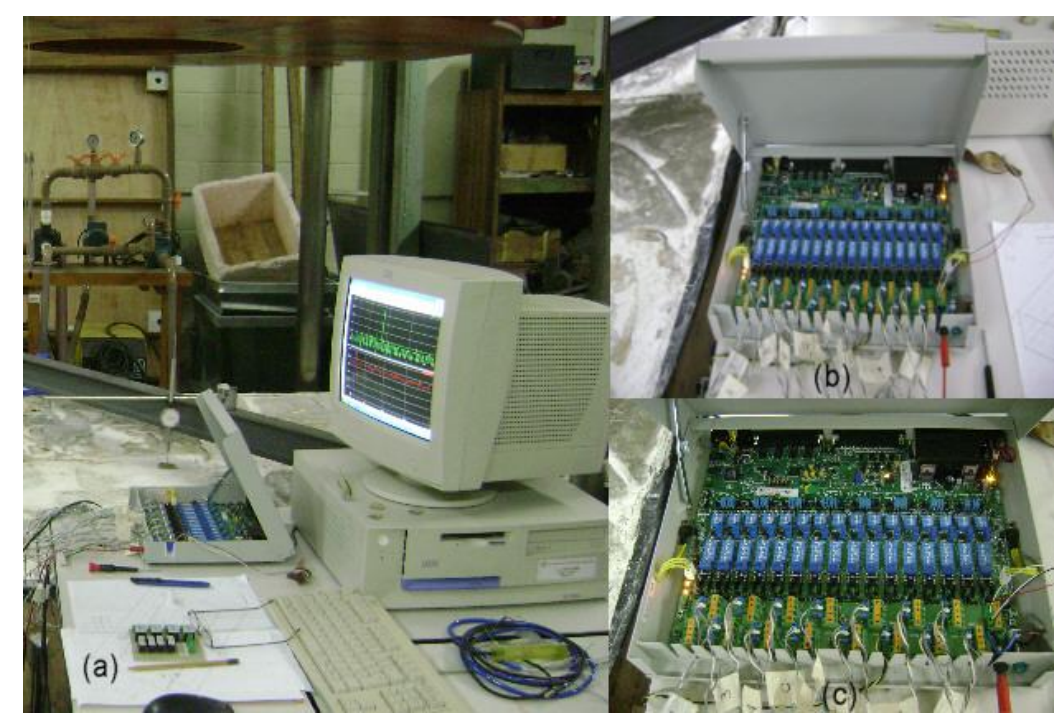

Fotografia 23. (a) visão geral do sistema de aquisição de dados, (b) aspecto do equipamento de aquisição e (c) detalhe dos canais onde são ligados os sensores e das mico-chaves.

Fonte: Acervo próprio (2008). 
A calibração dos canais para a leitura dos sensores de temperatura foi realizada por meio de um gerador de corrente, fornecido pelo fabricante, que garante melhor estabilidade nas leituras, bem como maior facilidade na calibração dos equipamentos.

Para estabelecer a faixa de operação dos termômetros, resistores de precisão (metal film com 1,0\% de tolerância) foram utilizados nas entradas dos canais para fazer o ajuste de correlação em relação aos valores internos ao software de gerenciamento (AqDados).

A calibração dos canais para a leitura dos sensores de deformação foi realizada por meio de um ajuste de zero, na ponte de Wheatstone residente na placa de circuito impresso, por meio de um resistor shunt de $65,0 \mathrm{k} \Omega$, também residente no equipamento. Essa calibração permitiu ajustar a escala do aparelho até $4000,0 \mu \mathrm{s}$.

Os dados aquisitados foram condicionados pelo ADS-500 e enviados via uma conexão em rede local padrão 10/100 através do protocolo (Transmission Control Protocol/Internet Protocol) TCP/IP até o microcomputador em que ficou hospedado o software AqDados, responsável pela geração de arquivos, apresentação dos dados na forma de Tabela e na forma gráfica. Simultaneamente ao processo de aquisição, um arquivo era gerado para acumular os dados. A fotografia 23 (b) e (c) mostra o sistema de aquisição juntamente com detalhes das chaves de ajuste.

\subsubsection{METODOLOGIA PARA AQUISIÇÃO DOS DADOS}

Durante o processo de cura da placa, foram feitas as ligações dos sensores ao sistema de aquisição de dados através de bornes fixos no equipamento. As malhas de blindagem dos cabos das células de embutimento foram interligadas ao terra do equipamento, para que todos ficassem submetidos ao mesmo referencial, assim como o potencial terra do equipamento foi ligado ao potencial terra do laboratório. Esse procedimento visou evitar possíveis interferências eletromagnéticas oriundas do ambiente, as quais poderiam afetar a integridade do sinal dos sensores e do funcionamento do sistema de aquisição. Cabe frisar que o local do experimento se encontra a poucos metros de uma cabine primária que, apesar de atender às normas de compatibilidade eletromagnética, emite radiação de baixa frequência $(60,0 \mathrm{~Hz})$.

Ainda, durante esse período, foram coletadas temperaturas do processo de cura da placa e foram planejadas experiências de aquecimento de topo e fundo da placa. 
Após o período de cura de 28 dias, a placa de concreto ficou pronta para realização dos testes iniciais. Para tanto, estabeleceu-se a ligação dos sensores aos bornes do equipamento e um procedimento de condicionamento foi realizado.

Nesse primeiro teste, foi verificado o sistema de aquisição com sensores de deformação, temperatura, tensão e o sistema de aquecimento de topo e fundo da placa.

Todos os testes foram realizados com intervalos que variaram entre 36, 48 e 72 horas. Nesse tempo, buscava-se a estabilidade térmica entre pavimento e ambiente. Normalmente, esse período foi escolhido para coincidir com o final de semana, momento no qual a Universidade, após as 17 horas do sábado, encerra as atividades até o próximo dia útil.

Até o final de agosto de 2009, duzentos e setenta testes foram realizados, perfazendo um total de aproximadamente 360 dias.

A resposta temporal dos sensores de temperatura e de deformação foi levantada através de vários testes executados sistematicamente com o objetivo de verificar a funcionalidade, sensibilidade e tempo de resposta.

Nessa fase, inicial foi realizada uma verificação entre os resultados dos testes de calibração (apêndices A e B) e os obtidos como resposta aos carregamentos térmicos efetuados na placa.

Foram executados ainda, nessa fase inicial, procedimentos de aquecimento e manobras sobre o variac para controle térmico da plataforma de aquecimento, cujas rampas de aquecimento são aquelas estabelecidas no item 2.3.2, Tabela 3.

Esses testes buscaram, então, as melhores situações para o estabelecimento do controle de aquecimento, escolha dos melhores termômetros, das melhores células de deformação (células de embutimento), melhores configurações das células, ajustes no sistema de aquecimento do fundo da placa e o estudo da estabilidade do conjunto ADS500 com os sensores de temperatura e deformação em períodos de 24 horas, lembrando que durantes essa fase o sistema de aquisição de dados passou por ajustes e calibrações por parte do fabricante no que tange às escalas de medida.

Verificou-se que, em períodos de 24 horas, com temperatura ambiente estável (pouca variação, em torno de $1,0{ }^{0} \mathrm{C}$ até $2,0{ }^{0} \mathrm{C}$ ), a formação em $1 / 4$ de ponte, para os sensores de deformação, apresentou variação de até $\pm 5,0 \mu \mathrm{s}$. Outro cuidado que foi tomado antes do início dos testes refere-se a um período de espera de pelo menos duas horas de estabilização antes do início das experiências. Apesar disso não ter uma explicação plausível, esse procedimento foi adotado após algumas leituras serem influenciadas de forma significativa devido à não observância desse período. Esse cuidado foi tomado, principalmente, durante 
testes que envolviam as medidas de deformação. As medidas de temperatura não apresentaram essa dependência temporal.

A estabilidade dos sensores de deformação (CE) foi verificada por meio de uma avaliação de seu comportamento quando a placa não estivesse sob diferencial térmico (calibração impossível de se fazer na prática). Esse teste impôs o equilíbrio térmico da placa com o ambiente, ou seja, temperatura de fundo igual à de topo. Nesse momento, o sistema de aquisição foi ligado, passando a registrar somente a resposta da CE. Esses dados podem ser vistos nos arquivo\#77 e 78 do CD-ROM localizado no anexo B e através do gráfico 25, em que um teste com duração de vinte e quatro horas mostra a resposta do conjunto célula de deformação e o sistema de aquisição para uma temperatura constante (pouca variação segundo a resposta do TE4). Nesse período, a temperatura variou apenas um $1,0{ }^{\circ} \mathrm{C}$ e teve pouca influência na resposta das CEs. Por outro lado, desde o instante em que o equipamento foi ligado até duas horas depois, as CEs apresentaram variação, estabilizada após esse período.

Para uma visualização melhor, o gráfico 26 apresenta o comportamento individual da célula CE6, sendo possível observar como é o comportamento da CE durante esse período de duas horas.
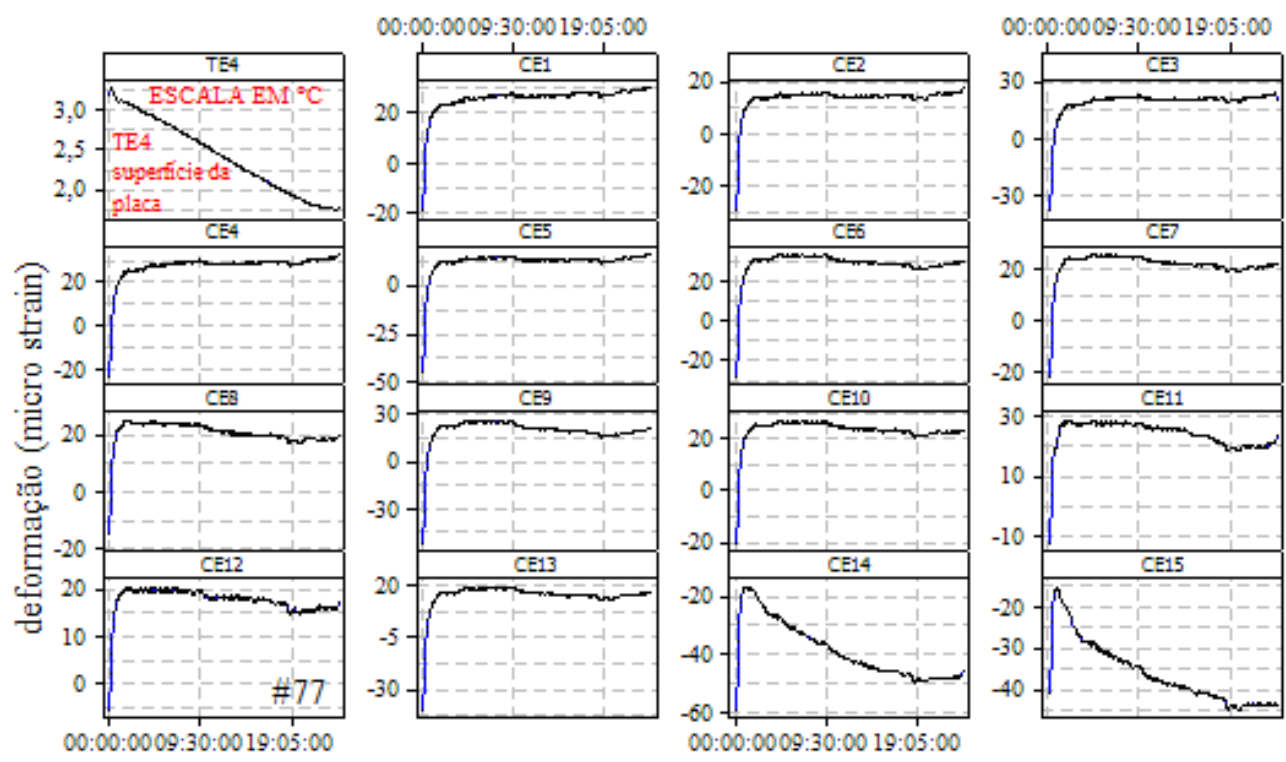

tempo (h)

Gráfico 25. Teste de verificação de estabilidade das células de embutimento num período de 24 horas com temperatura constante.

Fonte: Elaborado a partir dos dados experimentais (2008). 
Outro teste para verificação do comportamento das células e termômetros foi realizado aquecendo o topo da placa com taxa de aquecimento de $2,5^{\circ} \mathrm{C} / \mathrm{h}$ por um período de 6,0 horas. Todos as células foram ligadas em 1/4 de ponte e, apesar da alta dependência com a temperatura que essa configuração traz, esse teste foi importante para a análise do funcionamento e comportamento dos sensores sob a condição de aquecimento. Os sinais colhidos estão representados pelo gráfico 27 em que o comportamento das células pode ser observado. Nota-se que as células CE1, CE2, CE3, CE4 e CE5 formam um grupo distinto, em termos de resposta à deformação, quando comparadas às células CE6, CE7, CE8, CE9, CE10, CE11, CE12 e CE13 e que as células CE14 e CE15 apresentaram a mesma resposta quando realizado o teste de estabilidade (gráfico 28).

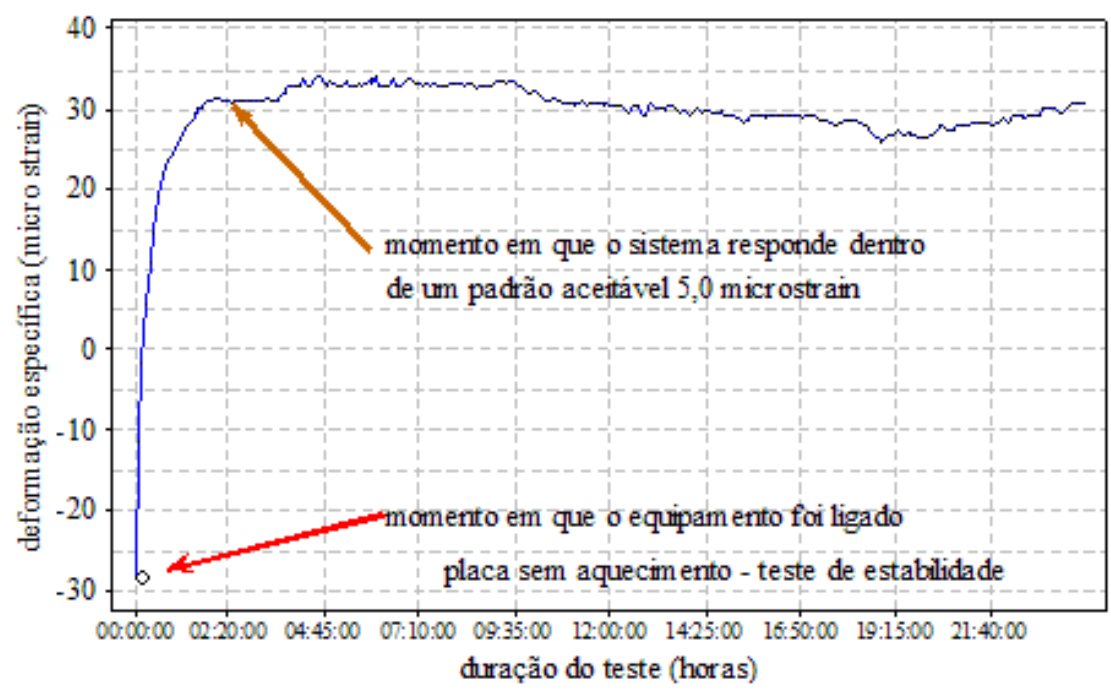

Gráfico 26. Período de estabilidade verificado durante os testes. Fonte: Elaborado a partir dos dados experimentais (2008). 
Teste de aquecimento $1 / 4$ de ponte 24 horas
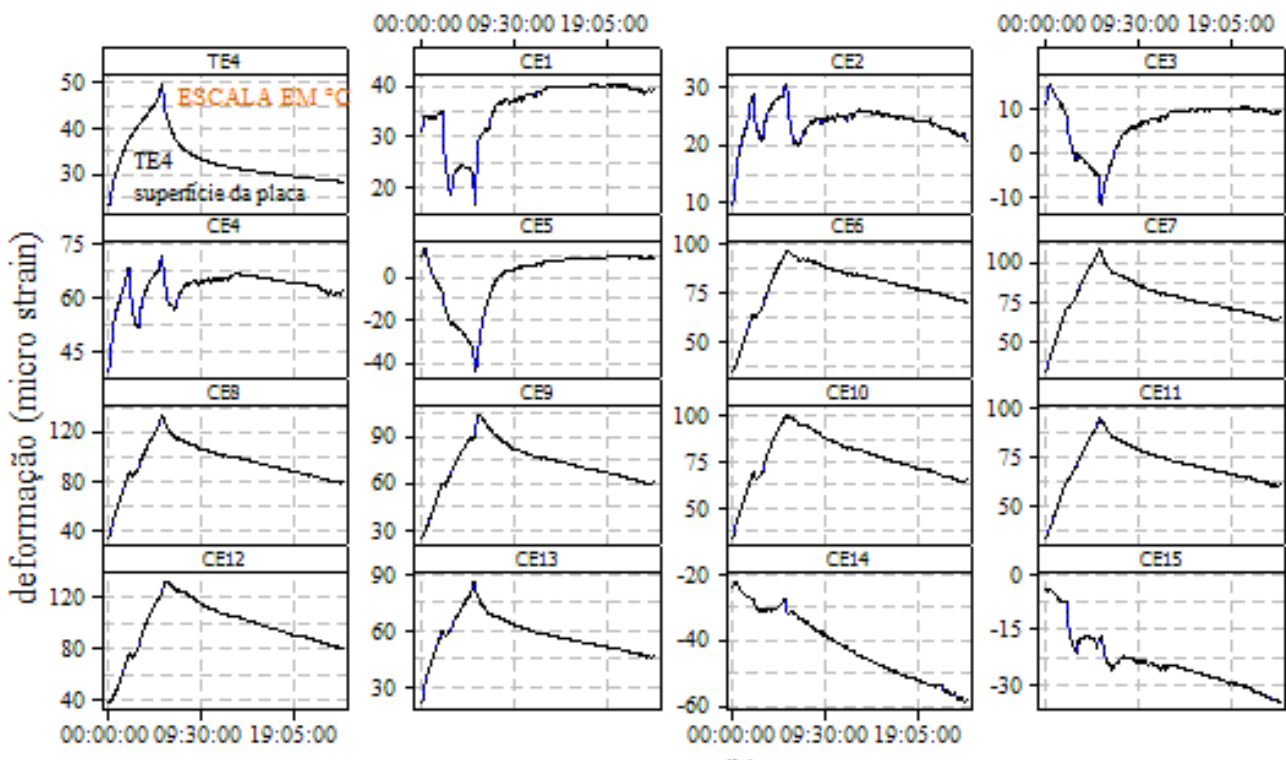

tempo (h)

Gráfico 27. Comportamento das células mediante o aquecimento do topo da placa. Fonte: Elaborado a partir dos dados experimentais (2008).

Esperava-se que todas as células respondessem da mesma maneira, respeitando, é claro, a sua posição relativa dentro da placa. Para confirmar a resposta das células independente das respostas dos canais do sistema de aquisição, foi realizada uma repetição do ensaio trocando-se as posições dos canais com as células e o resultado pode ser visto no gráfico 24. Observando-se os gráficos 27 e 28, nota-se que as células CE1, CE2, CE3, CE4 e CE5 permanecem com as mesmas características, indicando que os canais do sistema de aquisição não estavam interferindo nas respostas das células. Baseando-se nessas observações, optou-se por não utilizar essas células para coleta de dados nos futuros testes.

As células CE14 e CE15 deveriam apresentar uma resposta plana no teste de estabilidade com temperatura constante (ambiente) mas apresentaram a mesma resposta, sempre decrescente, em vários testes. Fato que pode ser observado no teste de estabilidade, gráfico 25, e no teste de aquecimento, gráfico 27. Esse comportamento instável fez com que as células fossem descartadas nos testes de coleta de dados.

A célula CE13, apesar de ser uma célula tipo dummy, assim como as células CE14 e CE15, mostrou o mesmo padrão de resposta em relação às células de embutimento aderidas. 

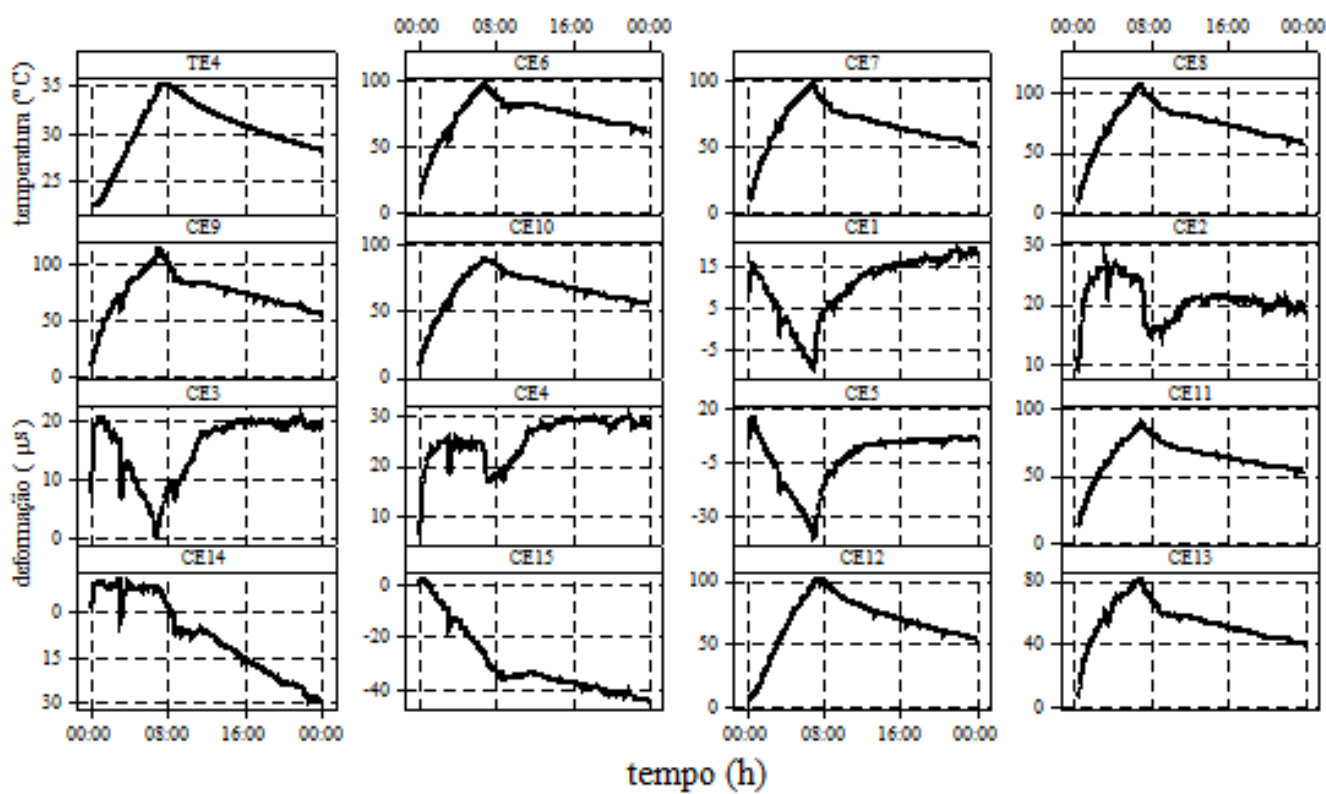

Gráfico 28. Resposta dos sensores após a troca dos canais.

Fonte: Elaborado a partir dos dados experimentais (2008).

As células CE14 e CE15 foram concebidas para atuarem como dummy e tiveram que ser abandonadas devido ao comportamento incerto, sendo consideradas impróprias para fazer parte da composição das configurações de $1 / 2$ de ponte.

Com a perda das células CE14 e CE15, foi necessária outra estratégia para colocação de células tipo dummy. A solução foi a realização de furos na placa de concreto, paralelos e ao mesmo nível das CEs de interesse. Nesses furos, foram inseridas novas células, chamadas de células de inspeção de temperatura (CIT), construídas como o mesmo processo e material das CEs com a função de responderem somente à variação de temperatura, tendo em vista o fato de não estarem aderidas. Elas foram inseridas nesses furos, chamados a partir de agora poços de inspeção (PI). Esse procedimento justificou-se porque as montagens em 1/2 ponte têm a propriedade de eliminar o efeito indesejado da temperatura nas medidas de deformação.

Para eliminar problemas de convecção e favorecendo a condução, o fundo dos PIs foi preenchido, até um nível adequado, com pasta térmica (composto cerâmico com óleos polissintéticos na forma de pasta). 


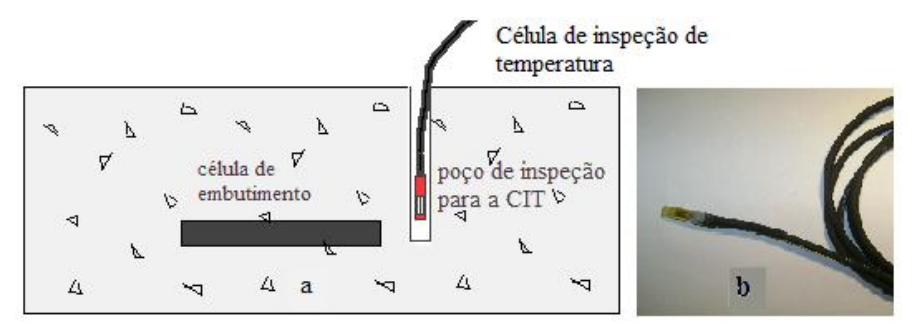

Desenho 14. (a) ilustração da técnica proposta para formação de células em meia ponte, utilizando a CIT, (b) aspecto da célula de inserção de temperatura CIT.

Fonte: Acervo próprio (2008).

Como ilustração, o desenho 14 (a) mostra um corte transversal da placa, indicando como a CIT foi colocada próxima à CE. Ainda no desenho 14, em detalhe, está ilustrado o aspecto de uma CIT (b) utilizada nos testes. As dimensões das CIT foram feitas de modo que pudessem ser inseridas no poço de inspeção cujo diâmetro foi realizado com 9,0 mm.

Os desenhos 15 a 20 mostram cortes transversais e longitudinais da placa, em que pode ser vista a posição geométrica de cada sensor no interior da placa em níveis diferentes ao longo da espessura. O fundo da placa foi tomado como referência inicial para localização dos sensores. Como informação adicional, o termômetro TE14 (TFUN) foi colocado na interface entre o subleito e a base, no ponto central do pavimento.

A fotografia 24 mostra a posição de cada termômetro antes da concretagem da placa e, no quadro 2, está indicada a posição espacial das células de embutimento (CE1 até CE15) e os termômetros (TE1 até TE14). A célula de carga, posicionada no centro da placa e apoiada na laje de reação, está denominada como transtec.

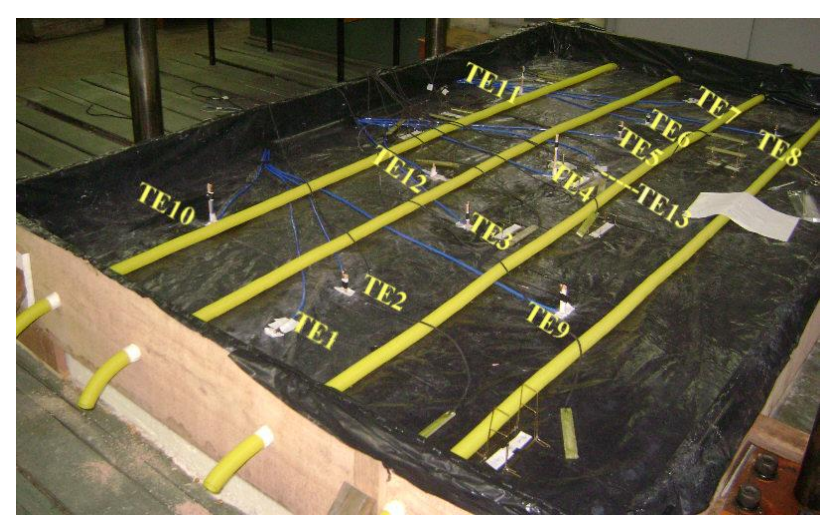

Fotografia 24. Posição dos termômetros dentro do molde do pavimento, fixados sobre a base, antes da concretagem da placa.

Fonte: Acervo próprio (2008). 


\begin{tabular}{|l|c|l|l|l|l|l|c|}
\hline \multicolumn{4}{|c|}{ Coordenadas $(\mathrm{cm})$} & \multicolumn{5}{c|}{ Coordenadas (cm) } \\
\hline células & $\mathrm{x}$ & $\mathrm{y}$ & $\mathrm{z}$ & termômetros & $\mathrm{x}$ & $\mathrm{y}$ & $\mathrm{z}$ \\
\hline CE1 & 150,0 & 50,0 & 13,0 & TE1 & 90,0 & 25,0 & 0,0 \\
\hline CE2 & 50,0 & 100,0 & 5,0 & TE2 & 90,0 & 75,0 & 4,0 \\
\hline CE3 & 50,0 & 100,0 & 10,0 & TE3 & 90,0 & 100,0 & 7,0 \\
\hline CE4 & 30,0 & 271,0 & 7,0 & TE4 & 90,0 & 150,0 & 15,0 \\
\hline CE5 & 81,0 & 149,0 & 11,0 & TE5 & 90,0 & 200,0 & 7,0 \\
\hline CE6 & 60,0 & 175,0 & 6,0 & TE6 & 90,0 & 250,0 & 4,0 \\
\hline CE7 & 81,0 & 149,0 & 6,0 & TE7 & 90,0 & 275,0 & 0,0 \\
\hline CE8 & 147,0 & 152,0 & 8,0 & TE8 & 45,0 & 45,0 & 4,0 \\
\hline CE9 & 147,0 & 152,0 & 13,0 & TE9 & 45,0 & 225,0 & 7,0 \\
\hline CE10 & 120,0 & 175,0 & 11,0 & TE10 & 150,0 & 250,0 & 11,0 \\
\hline CE11 & 151,0 & 120,0 & 6,0 & TE11 & 150,0 & 75,0 & 11,0 \\
\hline CE12 & 150,0 & 50,0 & 4,0 & TE12 & 120,0 & 175,0 & 4,0 \\
\hline CE13 & 151,0 & 120,0 & 11,0 & TE13 & 80,0 & 140,0 & 0,0 \\
\hline CE14 & 30,0 & 271,0 & 12,0 & TE14(TFUN) & $\begin{array}{l}\text { Localizado no centro da placa, } \\
\text { entre a base e o sub-leito (25,0 cm } \\
\text { do topo) }\end{array}$ \\
\hline CE15 & 60,0 & 174,0 & 4,0 & & \multicolumn{3}{|c|c|}{} \\
\hline
\end{tabular}

Quadro 2. Localizações dos sensores internos à placa. As medidas da coordenada $\mathrm{z}$ foram tomadas do fundo para o topo da placa.

Fonte: Elaborado a partir do posicionamento geométrico dos sensores (2008).

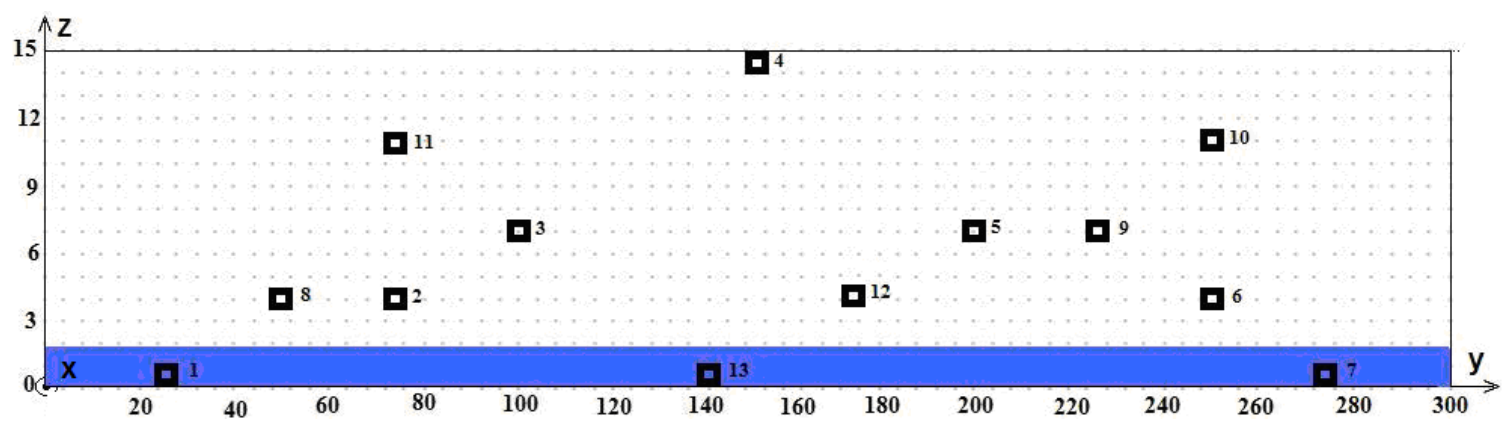

Desenho 15. Corte longitudinal da placa, no plano (yoz), indicando a posição dos termômetros. Todas as medidas estão em centímetros.

Fonte: Acervo próprio (2008). 


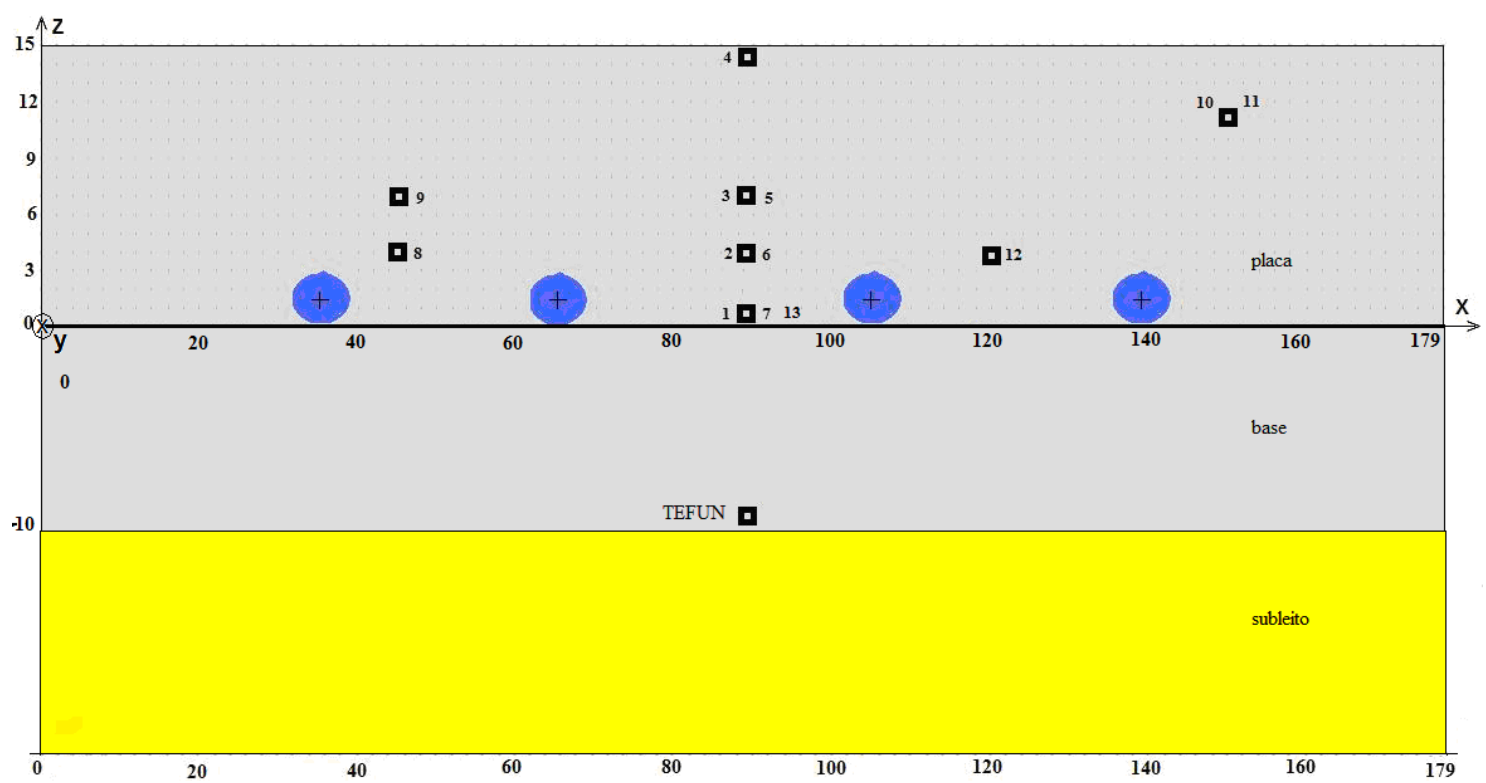

Desenho 16. Corte transversal da placa, no plano (xoz), indicando a posição dos termômetros. Todas as medidas estão em centímetros.

Fonte: Acervo próprio (2008).

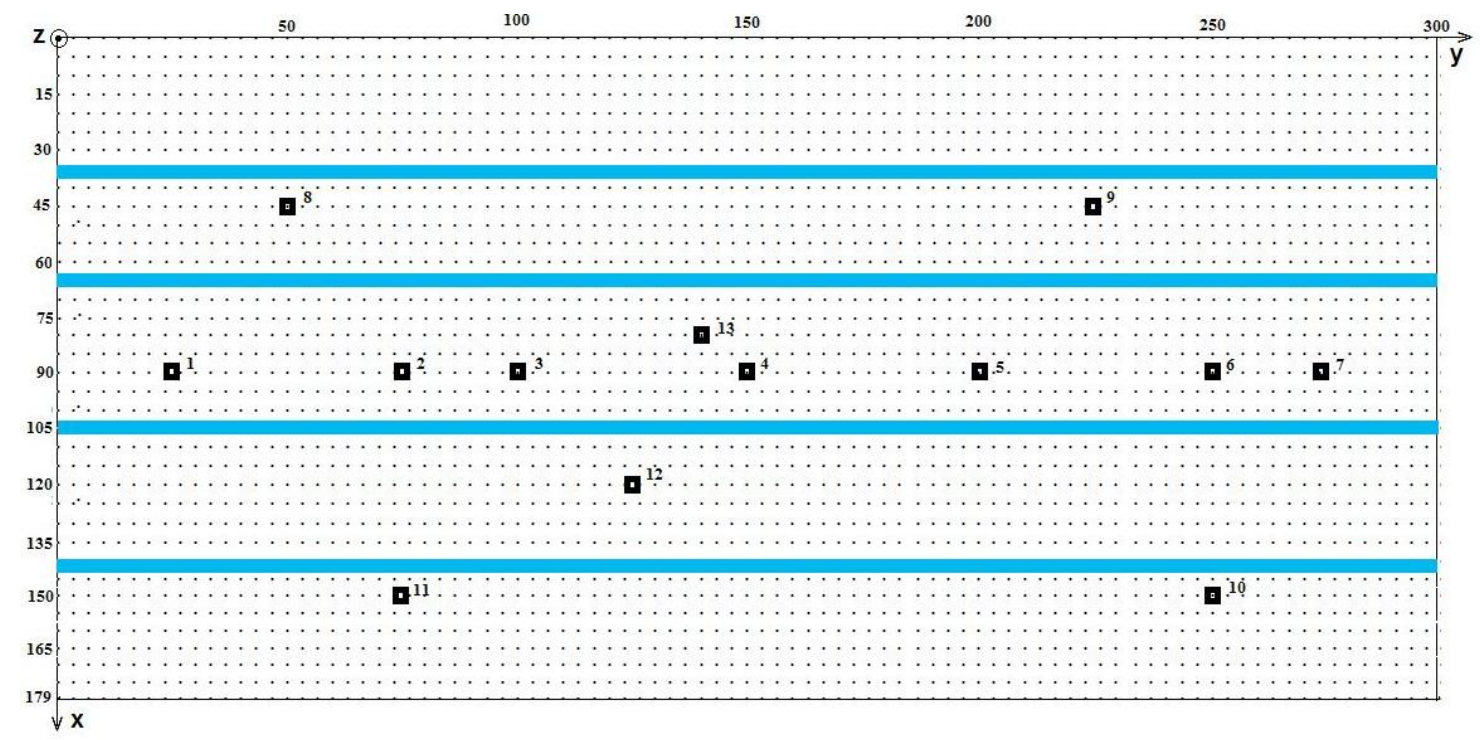

Desenho 17. Vista no plano (xoy), em planta, da placa indicando a posição dos termômetros. Todas as medidas estão em centímetros.

Fonte: Acervo próprio (2008). 


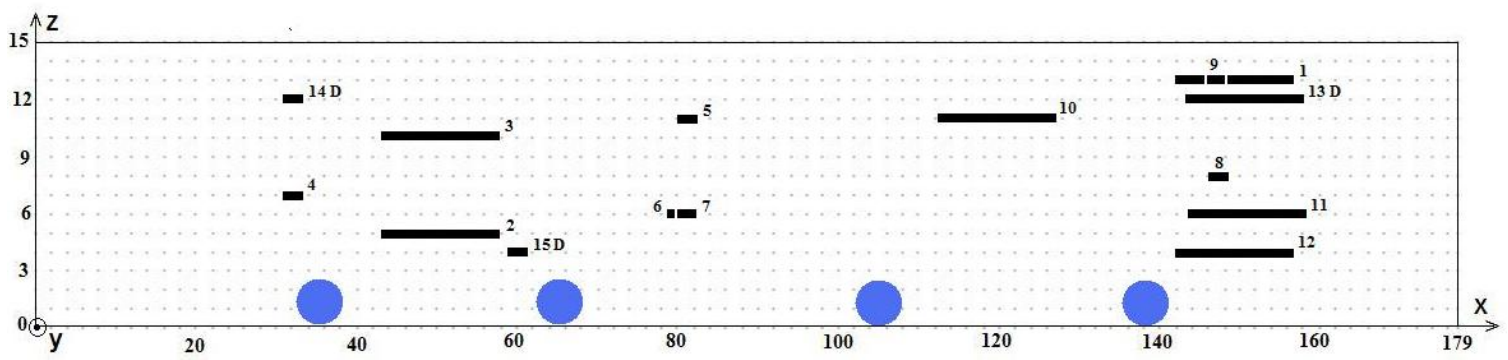

Desenho 18. Corte transversal da placa, no plano (xoz), indicando a posição das células de embutimento. Todas as medidas estão em centímetros.

Fonte: Acervo próprio (2008).

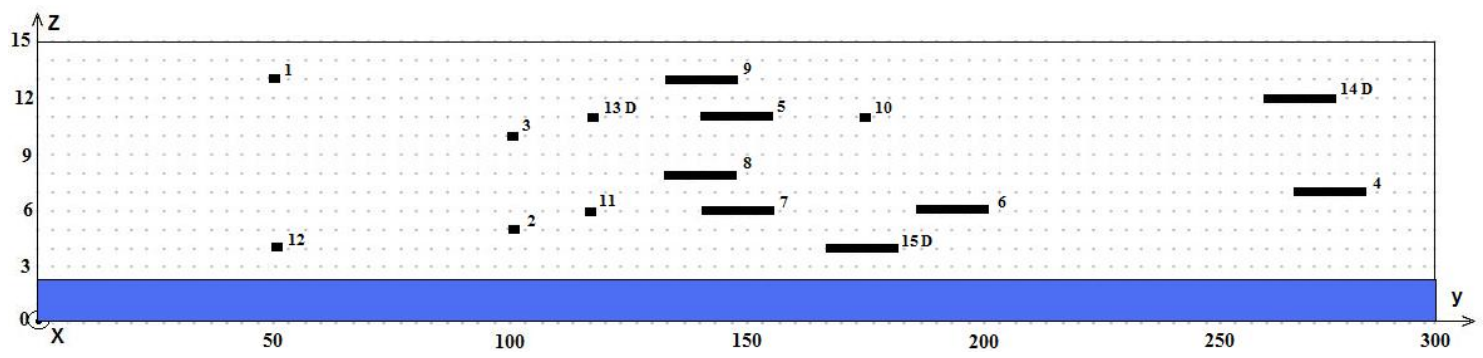

Desenho 19. Corte longitudinal da placa, no plano (yoz), indicando a posição das células de embutimento. Todas as medidas estão em centímetros.

Fonte: Acervo próprio (2008).

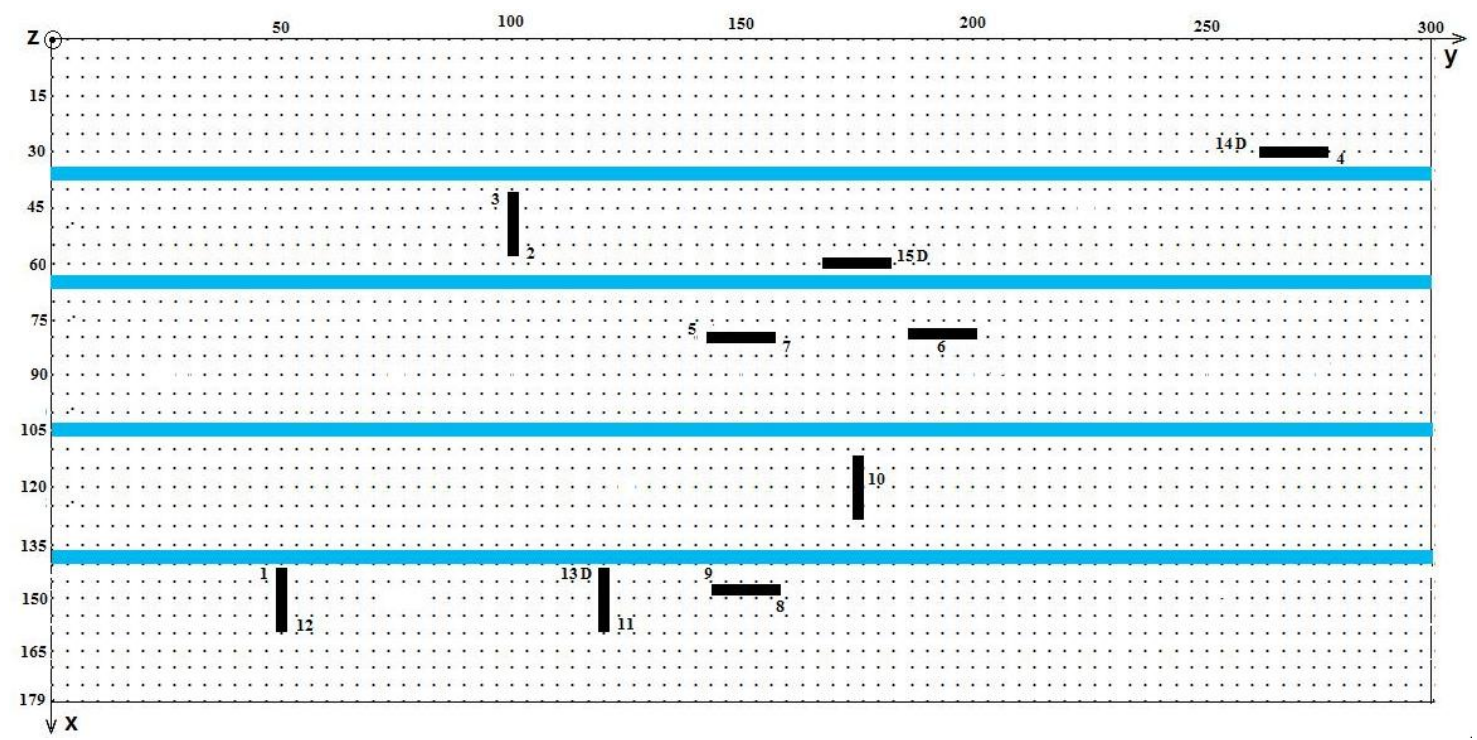

Desenho 20. Vista no plano (xoy), em planta, da placa indicando a posição das células de embutimento. Todas as medidas estão em centímetros.

Fonte: Acervo próprio (2008). 


\subsubsection{LIGAÇÃO DOS SENSORES AO SISTEMA DE AQUISIÇÃO DE DADOS}

Os sensores foram ligados ao sistema de aquisição de acordo com a experiência realizada. O ADS 500 permite que os dezesseis canais de aquisição possam ser ligados com diferentes tipos de sensores. No presente trabalho, foram utilizados os sensores de deformação (CE), termômetros (TE), sensor de deslocamento (potenciométrico) e célula de carga. As CE foram ligadas nas configurações em $1 / 2,1 / 4$ e ponte completa. Porém, na situação em que foi utilizada a configuração em $1 / 2$ ou $1 / 4$ de ponte, as CE ocuparam as posições 1 e 2 na ponte de Wheatstone, conforme mostrado no desenho 21 (a) e em detalhe 21 (b). Os termômetros foram ligados independentes da ponte através de um gerador de corrente, assim como o sensor potenciométrico (POT) e a célula de carga (transtec).
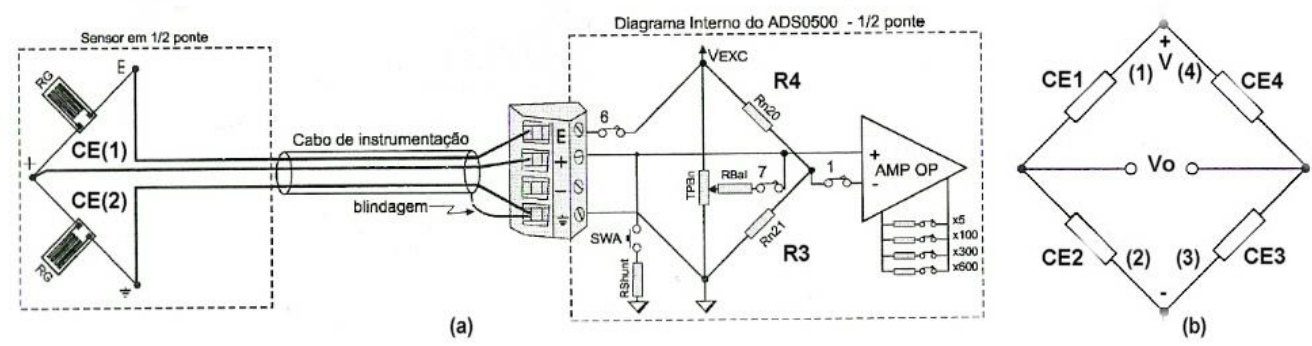

Desenho 21. (a) circuito interno ao sistema de aquisição com a nomenclatura utilizada nos testes e as ligações dos cabos ao borne de entrada, (b) desenho esquemático mostrando a disposição dos elementos resistivos (extensômetros) 1 e 2 dos resistores fixos 3 e 4 .

Fonte:Adaptado do manual do usuário ADS500.

As ligações dos sensores de deformação CE foram dispostas de tal forma a compensar os efeitos da temperatura, em que, segundo Hoffmann (1989), a relação da tensão aplicada na ponte de Wheatstone é tal que:

$$
\frac{V_{0}}{V}=\frac{K}{4}\left(\varepsilon_{1}-\varepsilon_{2}+\varepsilon_{3}-\varepsilon_{4}\right) \text { Ver apêndice D. }
$$

Onde: $\mathrm{V}_{\mathrm{o}} \rightarrow$ tensão de saída da ponte, $\mathrm{V} \rightarrow$ tensão de alimentação da ponte, $\mathrm{K} \rightarrow$ fator gage, $\varepsilon \rightarrow$ deformação dado em microstrain $(\mu \mathrm{s})$.

Devido a isso, as ligações obedeceram às seguintes configurações.

Caso 1

Com a colocação das células dummy (CIT) em alturas distintas ao longo da espessura da placa, qualquer CE pode ser configurada em $1 / 2$ de ponte, pois os efeitos da temperatura, que se faziam presentes, foram eliminados matematicamente. Como as células 
dummy (CIT) estão colocadas internas aos poços de inspeção e, portanto, não aderidas à massa do concreto, os efeitos das deformações serão minimizados, prevalecendo o efeito térmico,

lembrando que :

$$
\varepsilon_{n}=\varepsilon_{f}+\varepsilon_{n}+\varepsilon_{t}, n=1,2,3,4
$$

$\varepsilon_{\mathrm{f}} \rightarrow$ deformação na flexão, $\varepsilon_{\mathrm{n}} \rightarrow$ deformação normal, $\varepsilon_{\mathrm{t}} \rightarrow$ deformação devido à temperatura. (posição 1, CIT dummy desenho 20b)

$$
\varepsilon_{1}=\varepsilon_{t}+\varepsilon_{f}+\varepsilon_{n}, \text { sendo: } \varepsilon_{1}=\varepsilon_{t}+\varepsilon_{f}, \text { pois } \varepsilon_{n}=0
$$

(posição 2, desenho 21b)

$$
\varepsilon_{2}=\varepsilon_{t} \operatorname{com} \varepsilon_{f}=0, \varepsilon_{n}=0
$$

$$
\begin{aligned}
& \varepsilon_{3}=0 \quad R 3-\text { fixo no aparelho } \\
& \varepsilon_{4}=0 R 4-\text { fixo no aparelho }
\end{aligned}
$$

sendo:

Substituindo (19) e (20) na equação (16) se obtém:

$$
\frac{V_{0}}{V}=\frac{K}{4}\left[\left(\varepsilon_{f}+\varepsilon_{n}+\varepsilon_{t}\right)-\left(\varepsilon_{f}+\varepsilon_{n}+\varepsilon_{t}\right)+\varepsilon_{3}-\varepsilon_{4}\right]
$$

Substituindo na (21) as equações $17,18,19$ e 20 se obtém:

$$
\frac{V_{0}}{V}=\frac{K}{4}\left(\varepsilon_{f}\right)
$$

Constatou-se que o sinal de saída não contempla a deformação devido à temperatura. Observando o mesmo procedimento, qualquer célula pôde ser utilizada nas medidas de deformação da placa. Reportando-se aos desenhos 17, 18 e 19, todas as células puderam ser utilizadas nesse processo. No entanto, outras configurações em $1 / 2$ ponte também puderam ser utilizadas sem recorrer às CIT.

\section{Caso 2}

Apesar das células estarem espalhadas na placa, a formação em ponte completa pode ser realizada e, quando configurada, os efeitos de flexão não se fizeram presentes e a configuração impôs o aparecimento da deformação normal, ou seja, a placa pode se comportar como uma balança.

Nesse caso as deformações seriam de tal ordem:

$$
\begin{gathered}
\varepsilon_{1}=\varepsilon_{f}+\varepsilon_{n}+\varepsilon_{t} \\
\varepsilon_{2}=-v\left(\varepsilon_{f}+\varepsilon_{n}\right)+\varepsilon_{t}
\end{gathered}
$$




$$
\begin{gathered}
\varepsilon_{3}=-\varepsilon_{f}+\varepsilon_{n}+\varepsilon_{t} \\
\varepsilon_{4}=-v\left(-\varepsilon_{f}+\varepsilon_{n}\right)+\varepsilon_{t}
\end{gathered}
$$

que, quando substituídas na equação (25), apresenta:

$$
\frac{V_{0}}{V}=2 K \varepsilon_{n}(1+v)
$$

Essa característica pode ser útil no confronto com valores obtidos vindos da célula de carga (transtec) colocada no centro do pavimento e apoiada na laje de reação.

Simbolicamente, as configurações no interior da placa ficaram conforme mostram os desenhos 22, 24 e 26 e os desenhos 23, 25 e 27 mostram as configurações das ligações no sistema de aquisição de dados.

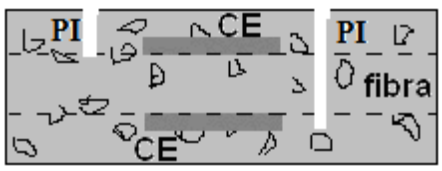

Desenho 22. Disposição das células de embutimento no interior da placa, com a função de medir flexão sem gradiente (taxa de variação térmica) de temperatura. Os traços na vertical indicam a posição do poço de inspeção PI.

Fonte: Acervo próprio (2008).

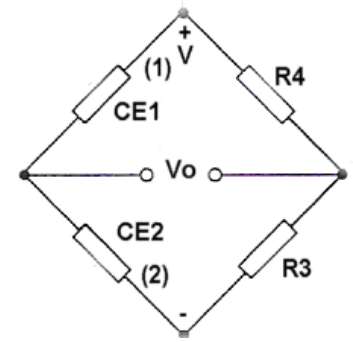

Desenho 23. Esquema de ligação interno ao sistema de aquisição de dados.

Fonte: Acervo próprio (2008).

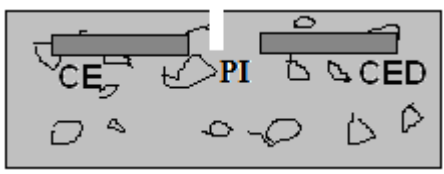

Desenho 24. Disposição das células de embutimento no interior da placa, com a função de medir flexão com tração sem temperatura.

Fonte: Acervo próprio (2008). 


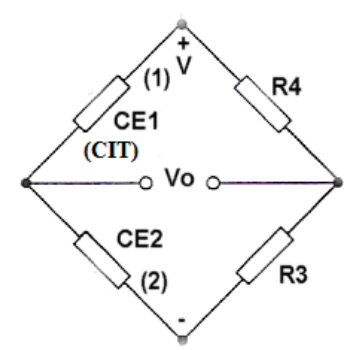

Desenho 25. Esquema de ligação interno ao sistema de aquisição de dados. Fonte: Acervo próprio (2008).

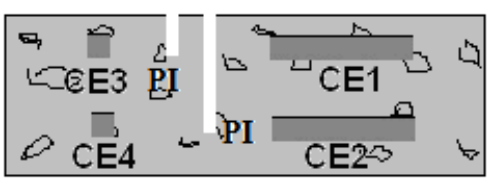

Desenho 26. Disposição das células, internamente à placa, para medida de tração com ou sem gradiente (taxa de variação térmica) de temperatura.

Fonte: Acervo próprio (2008).

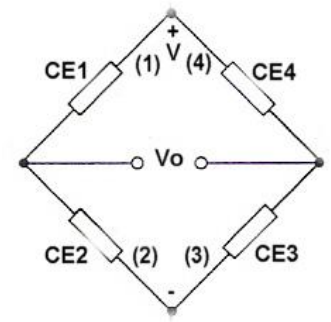

Desenho 27. Esquema de ligação interno ao sistema de aquisição de dados na configuração de ponte completa.

Fonte: Acervo próprio (2008).

As possibilidades para a execução dos testes puderam ser determinadas a partir da necessidade do objeto de estudo. No presente trabalho, foram feitas as seguintes análises para efeito das medidas de deformações.

1- Encurvamento transversal, em que foram utilizadas as células CE10, CE11 e CE12.

2- Encurvamento longitudinal. Onde foram utilizadas as células CE6, CE7, CE8 e CE9.

Em ambos os casos, as CE foram tratadas em $1 \frac{1}{2}$ ponte quando a placa foi aquecida tanto na parte superior como na inferior.

\subsubsection{POSIÇÃO DAS CÉLULAS NA PLACA E INTERPRETAÇÃO DOS SINAIS}

O posicionamento das células de deformação $(\mathrm{CE})$ que estão internas à placa tem a ver com a posição do extensômetro interno a ela. Esse cuidado foi importante pois relacionou 
a diferença de uma célula trabalhando na compressão de outra à tração. Isso significou que a análise das leituras provenientes das células de embutimento ou de deformação foi interpretada obedecendo ao posicionamento relativo dentro da placa. Elas foram fixadas no suporte levando em consideração se o extensômetro interno ao substrato de TVE estava posicionado de tal maneira a produzir um alongamento na flexão ou uma compressão na flexão. Sendo assim, a ligação ao barramento do sistema de aquisição de dados foi feita de modo a indicar sinais positivos como efeito das flexões causadas com o carregamento térmico de topo superior ao de fundo e indicar como sinais negativos, flexões com temperatura de topo inferior à de fundo. $\mathrm{O}$ mesmo procedimento foi tomado quando as células foram combinadas em $1 \frac{1}{2}$ ponte.

Todas as células posicionadas em dupla, ou seja, aquelas colocadas no mesmo suporte (CE1 e CE12, CE2 e CE3, CE5 e CE7, CE8 e CE9) foram posicionadas para apresentar a soma de efeitos quando ligadas em $1 / 2$ ponte.

As células ligadas individualmente (CE6 e CE10) e aquelas (CE4 e CE11) combinadas no mesmo suporte com as células dummy (CE13, CE14, CE15) foram preparadas para subtrair os efeitos quando ligadas em $1 \frac{1}{2}$ ponte.

Convém destacar que as ligações em $1 / 2$ ponte, no barramento do sistema de aquisição, obedeceram critérios para não influenciar nas leituras. O desenho 28 esquematiza, genericamente, a posição de duas células de embutimento e mostra como o extensômetro está colado no substrato.

Quando a placa apresentar a configuração convexa, a temperatura de topo será maior que a temperatura de fundo e, nessa situação, as células a e b serão flexionadas de tal maneira que irá ocorrer a soma dos efeitos da flexão. O desenho 29 ilustra a descrição.

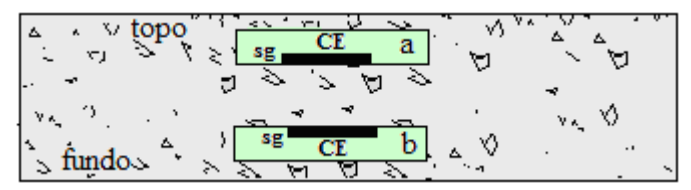

Desenho 28. Posição genérica de duas células, ligadas em ponte, para ocorrer a soma dos efeitos de deformação. $O$ traço escuro representa a posição do extensômetro dentro da célula de embutimento.

Fonte: Acervo próprio (2008). 


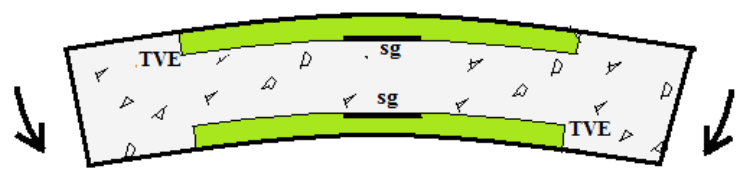

Desenho 29. Situação estilizada quando a placa sofrer um diferencial de temperatura $T_{\text {topo }}$

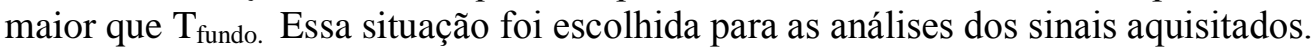
Fonte: Acervo próprio (2008).

Para ocorrer coincidência do efeito de empenamento (desenho 6) com os sinais obtidos pelo sistema de aquisição de dados, a interpretação dos resultados foi baseada levando em consideração que a CIT foi sempre colocada na posição "E” e “+” e a CE sempre colocada na posição "+" e "terra” dos bornes do ADS 500. O desenho 21 e também o desenho 30 ilustram como foram ligadas as células nos bornes do equipamento de aquisição de dados. Em resumo, a posição "1” indica a localização da CIT (ou outra CE, dependendo do tipo de teste) e a posição "2" indica localização da CE. Os desenhos 31 a 34 ilustram como foram interpretados os sinais oriundos das CE.

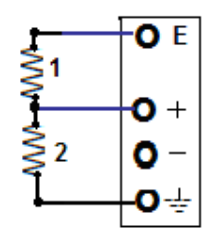

Desenho 30. Posição das células nos bornes do ADS 500. A célula “1” refere-se à CE e a célula " 2 " refere-se à CIT.

Fonte: Acervo próprio (2008).

O planejamento experimental indicou os casos a serem estudados.

Primeira situação-

Quando a CE foi solicitada, como no desenho 31, o sinal aquisitado indicou que a fibra, nessa posição, sofreu uma tração através do sinal “+”.

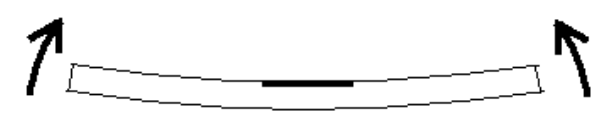

Desenho 31. CE sendo solicitada na flexão com extensômetro posicionado na parte superior da CE.

Fonte: Acervo próprio (2008). 
Quando a CE foi solicitada, como no desenho 32, o sinal aquisitado indicou que a fibra, nessa posição, indicou uma compressão através do sinal “-”.

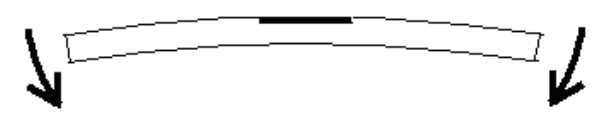

Desenho 32. CE sendo solicitada na flexão com extensômetro posicionado na parte superior da CE.

Fonte: Acervo próprio (2008).

Segunda situação-

Quando a CE foi solicitada, como no desenho 33, o sinal aquisitado indicou que a fibra, nessa posição, sofreu uma compressão através do sinal “-”.

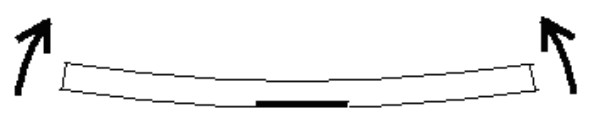

Desenho 33. CE sendo solicitada na flexão com extensômetro posicionado na parte inferior da CE. Fonte: Acervo próprio (2008).

Quando a CE foi solicitada, como no desenho 34, o sinal aquisitado indicou que a fibra, nessa posição, indicou uma tração através do sinal “+”.

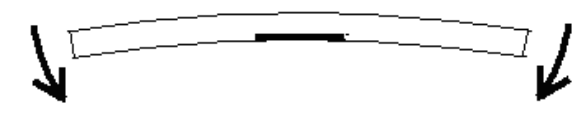

Desenho 34. CE sendo solicitada na flexão com extensômetro posicionado na parte superior da CE. Fonte: Acervo próprio (2008). 


\section{MODELAMENTO NUMÉRICO}

O modelamento numérico, no presente trabalho, foi abordado com a finalidade de apresentar uma visualização do experimento realizado e estabelecer uma comparação entre os resultados experimentais e numéricos.

A grande dificuldade na modelagem numérica é a real caracterização dos materiais frente às suas propriedades. Muitos modelos surgiram para "tentar" descrever o real comportamento da estrutura e sua resposta de que, nem sempre, são adequados aos dados obtidos no experimento. Atualmente, o método mais utilizado para realizar tal modelamento é conhecido como método dos elementos finitos (MEF), que utiliza uma técnica da análise numérica que consiste na discretização (a discretização pode ser definida como a divisão do domínio da análise em subdivisões ou corpos discretos chamados elementos finitos) do meio contínuo em elementos descritos por equações diferenciais parciais, apresentadas na teoria da elasticidade, as quais são resolvidas por modelos matemáticos, mantendo as mesmas características do meio. Esse método foi criado inicialmente para o estudo de tensões em estruturas aeronáuticas e tem sido aplicado à mecânica de pavimentos para cálculo de tensões e deformações. O MEF é baseado na discretização do meio contínuo e suas dimensões são conhecidas, como uma malha de elementos de dimensões finitas e reduzidas.

Contudo, a literatura tem indicado que, aplicado aos problemas envolvendo análises de estruturas de pavimento, o método costuma indicar, em algumas situações, uma majoração de valores em relação àqueles obtidos na prática. Nishizawa e Matsuno (1983), através de modelagem por MEF, mostraram uma discrepância entre valores analisados de um sólido (placa) repousando em duas fundações diferentes, Winkler e tipo elástica. Comparou os resultados com valores medidos. Os resultados não foram compatíveis e, por causa disso, atribuiu as diferenças obtidas à falta de refinamento do método dos elementos finitos. Vinte anos depois, em outro trabalho, Mahboub et al. (2004) observaram que discrepâncias entre valores calculados pelo MEF e valores obtidos experimentalmente são devidas às particularidades da estrutura e dos materiais que não são levados integralmente para o modelo. Certamente, durante esse tempo, houve evolução nas técnicas e no poder de processamento dos computadores. Porém, há de se perceber, que o sucesso de um modelo está 
fortemente ligado à habilidade e conhecimento do projetista e ao desenvolvimento de novos elementos que "capturem" a realidade.

Essas discrepâncias podem estar vinculadas à falta de capacidade que o 'elemento finito' tem em se adaptar às mudanças que ocorrem na estrutura durante a sua vida. Além do mais, observa-se que a natureza apresenta características não lineares e que o elemento finito, segundo Burden e Faires, (2003) é produto de uma linearização de equações diferenciais parciais

Sendo assim, será que um elemento finito, que é uma entidade matemática, representado por uma matriz, poderia comportar-se como uma trinca (que é um acontecimento físico) que surge e manifesta-se no material? Será que esse mesmo elemento finito seria "inteligente" para decidir ser uma trinca ou um vazio no material? Essas indagações se justificam, pois apresentam uma divisão consciente entre dados reais obtidos por instrumentação e dados virtuais obtidos pela inserção de características limitadas e por simplificações da realidade. Por exemplo, no projeto de um pavimento, adota-se o módulo de reação do subleito que, como descrito anteriormente, comporta-se como um líquido denso, em que a placa está apoiada. Esse parâmetro, com comportamento linear, tem grande significância e serve como entrada para projetos de pavimentos, quando se utiliza o MEF. Mas, qual a garantia de que esse parâmetro irá se comportar dessa maneira indefinidamente, se a simples ocorrência da mudança da umidade no subleito já seria o suficiente para alterar o valor de dependência funcional de k, enquanto o 'elemento', utilizado para a modelagem continua a se comportar com outro valor de k ?. Nesse sentido, ou caminhando nessa direção, estudos recentes, Simons e Seaman (2000), apontam para a utilização do método dos elementos finitos na previsão do estado futuro da estrutura, utilizando o método para a análise de fadiga na vida do pavimento.

Diante disso, reforça-se, mais uma vez, que a melhor maneira de se estudar a prática vem por meio da instrumentação e que, através dela, montam-se diretrizes para que os pesquisadores possam desenvolver elementos finitos mais próximos da realidade para que o modelamento seja o mais fiel possível.

Para auxiliar o processo de interpretação e, aferição dos dados gerados pelo sistema de aquisição de dados, será utilizado o software EverFE 2.24 desenvolvido pela Universidade do Maine e pelo departamento de engenharia civil da Universidade de Washington (DAVIS, 2007). 
Esse software foi idealizado tendo como base o método dos elementos finitos e, apesar de ser um software livre, tem sido útil para a análise de pavimentos rígidos tanto para pesquisadores como para projetistas.

Ele é capaz de executar análises em três dimensões (3D), lineares ou não lineares, para pavimentos simples ou com juntas e possui elementos que buscam uma semelhança com o concreto e as várias interações entre as partes constituintes do pavimento. Dentro do mesmo software, são realizados o pré-processamento, a solução e o pós-processamento. A visualização das análises é realizada por uma interface gráfica ou pela utilização do banco de dados gerado durante o processamento.

O software EverFE2.24 utiliza um modelo de interligação entre o cimento e o agregado para estabelecer transferência de carga entre eles. Desenvolvido por Walvaren (1981), as partículas do agregado são idealizadas como esferas incompressíveis de tamanho variado e distribuídas de acordo com a curva de Fuller $^{27}$. Os agregados interceptam a face da trinca em várias profundidades, dependendo da distribuição estatística dentro do concreto. As tensões são computadas assumindo que a área de contato relaciona-se com o escorregamento das partes.

A expressão constitutiva é:

$$
\tau_{p u}=\mu \sigma_{p u}
$$

Onde: $\tau_{p u}$ - tensão de cisalhamento da pasta de concreto; $\sigma_{p u}$ - tensão normal da pasta; $\mu$ - coeficiente de atrito entre pasta e agregado.

O desenho 35 ilustra esquematicamente o conceito da modelagem da ligação entre partículas.

O software EverFE 2.24 incorpora capacidades gráficas para visualização da composição do pavimento, possibilitando a realização de geometrias complexas, com uma ou várias placas, com ou sem juntas, várias camadas e vários outros fatores, tais como efeitos de temperatura. O subleito é modelado como um líquido denso, sendo que a versão atual assume que a fundação e a placa são linearmente elásticas. O modelamento para a perda de contato

\footnotetext{
${ }^{27}$ Graduação para a densidade máxima do tamanho do agregado por meio gráfico. É conhecida como Curva de Fuller cuja relação é $\mathrm{P}=(\mathrm{d} / \mathrm{D})^{\mathrm{n}}$ x 100

onde "d" é o diâmetro da peneira, P é a porcentagem total passante ou mais fina que a peneira, " $D$ " é o tamanho máximo do agregado e "n" é um coeficiente variável. Para se obter a densidade máxima de um agregado, o coeficiente " $n$ " deve ser igual a 0,5. Universidade Federal de Juiz de Fora, Faculdade de Engenharia Departamento de Transportes e Geotecnia, Disponível em www.pavimentacao.ufjf.br/Cap5.pdf, acesso em $12 / 02 / 09$
} 
entre placa e suporte, quando não aderidas, tem grande significado para o estudo do empenamento da placa. O EverFE 2.24 trata esse problema vinculando os nós da malha base com os nós da malha da placa. Para capturar a ligação entre a placa e a base, o EverFE 2.24 utiliza um elemento de interface quadrática de espessura zero, segundo Davis (2007). O desenho 36 ilustra esquematicamente como o programa realiza essa modelagem.

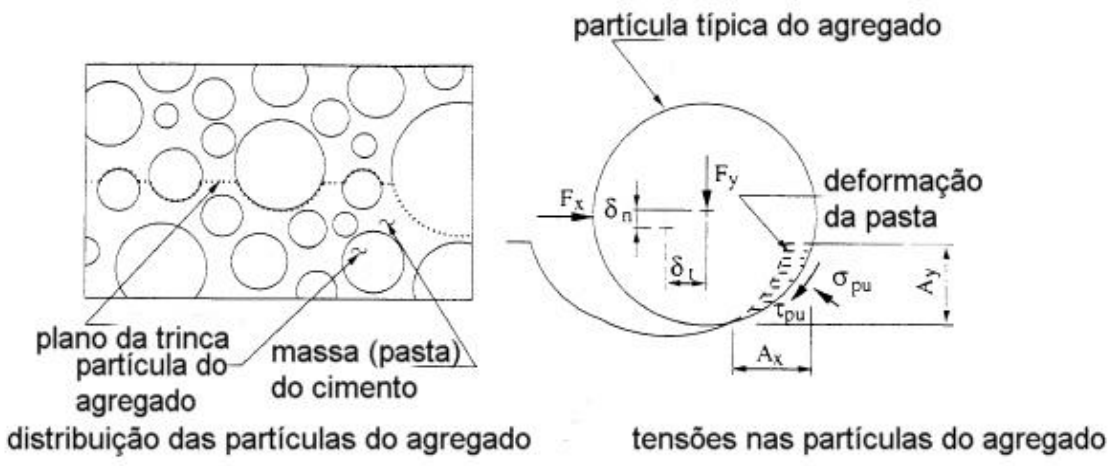

Desenho 35. Modelo para interação entre pasta e agregado. Fonte: Adaptado e modificado a partir de (Davis, 2007).

Os elementos são caracterizados por um valor de rigidez, semelhante ao aplicado para a fundação (DAVIS, 2007).

O intertravamento entre placas pode ser exemplificado através do desenho 37 , que mostra a comunicação de cargas de cisalhamento entre duas placas contíguas. Esse efeito, apesar de não representar como se dá o atrito entre base e placa, indica a sutileza do elemento finito para capturar tal acontecimento. No presente trabalho, as simulações foram realizadas com pleno deslizamento entre as placas.
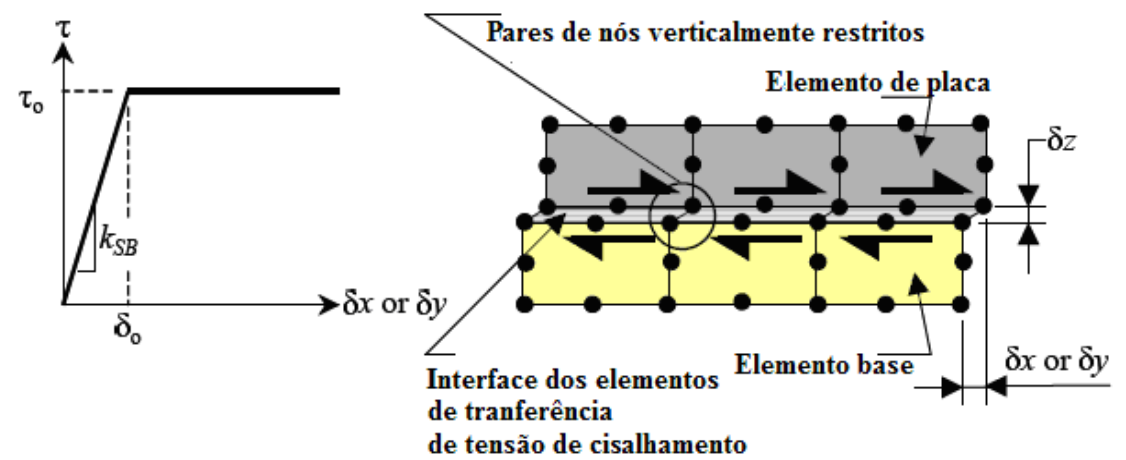

Desenho 36. Procedimento para modelagem da perda de contato entre camadas. Fonte: Adaptado de (DAVIS, 2007). 


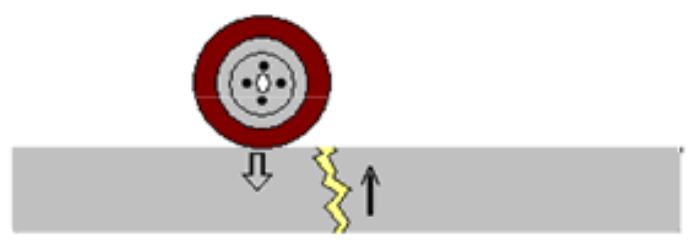

Desenho 37. Carga transferida de uma placa para outra através do 'intertravamento' existente quando da realização de uma junta serrada.

Fonte: Acervo próprio (2008).

\subsection{VISUALIZAÇÃO DA SOLUÇÃO}

A interface gráfica do software utiliza a interface gráfica do usuário (GUI) (Graphical User Interface), um tipo de interface que permite a interação com dispositivos digitais através de elementos gráficos como ícones e outros indicadores visuais.

O software gera uma malha de elementos hexaédricos para a base e outras camadas e elementos de superfície para o subleito. A decisão de refinamento e tempo de processamento depende do modelo e da opção dada pelo usuário. O desenho 38 mostra uma malha típica gerada pelo EverFE 2.24.

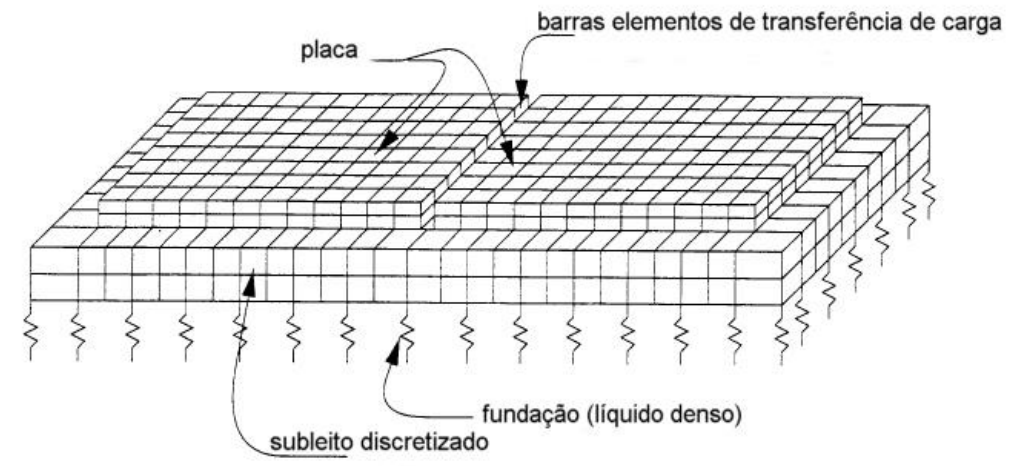

Desenho 38. Aspecto da malha de um sistema de duas camadas produzido pelo software.

Fonte: Elaborado a partir de (DAVIS, 2007).

As tensões podem ser visualizadas graficamente ou através de mapas de cores que são gerados durante a simulação. O software permite deslocar o molde (camadas) para que possa ser visto em três dimensões. Os valores numéricos são alcançados selecionando nós sobre o molde. Os valores de tensão e deformação são armazenados em bancos de dados 
específicos. O desenho 39 dá um indicativo da apresentação visual das tensões e deformações de uma placa simulada com um carregamento térmico.

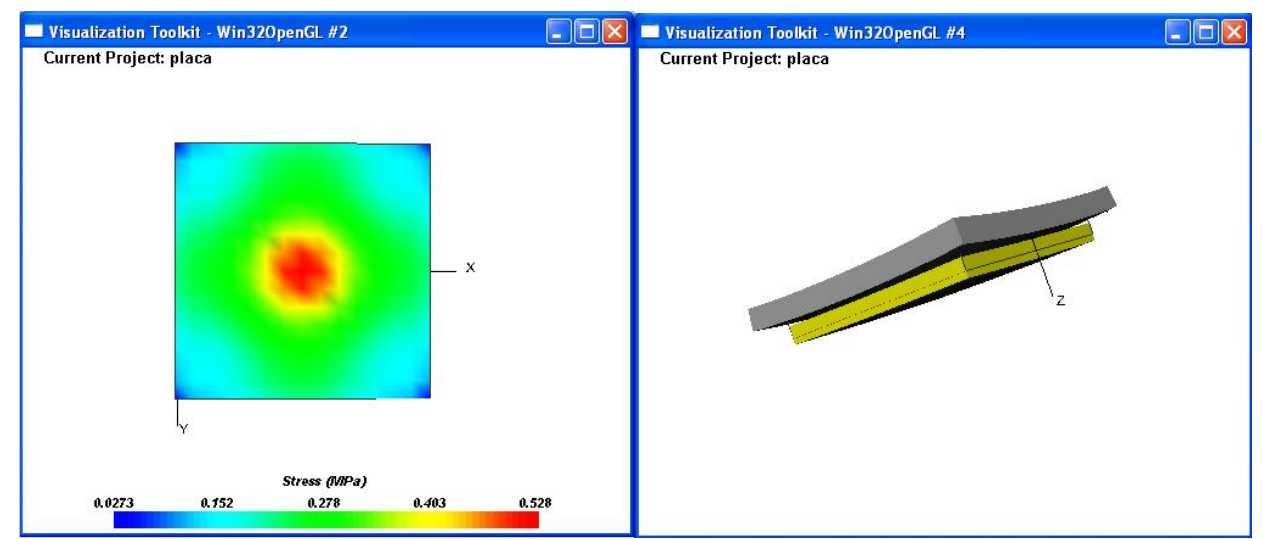

Desenho 39. Apresentação gráfica, como interface com o usuário, da simulação de temperatura.

Fonte: Adaptado do software EverFe 2.24 (DAVIS, 2007).

O EverFE 2.24 permite a mudança de temperatura em toda espessura da placa. Assim, quando um gradiente (taxa de variação térmica) térmico bi-linear é especificado, a malha de elementos finitos deve ter um número par de elementos através da sua espessura para assegurar a previsão precisa de tensões e deformações. Do mesmo modo, se um gradiente térmico (taxa de variação térmica) tri-linear é especificado, deve haver 3, 6 ou 9 elementos através da espessura da laje.

\subsubsection{MODELAMENTO DO PAVIMENTO}

Os dados utilizados no modelamento são os mesmos apresentados no quadro 1. Os dados de temperatura foram acrescentados em cada análise realizada. A sistemática na condução e inserção de dados, no software EverFE 2.24, seguiu os seguintes passos:

1. determinação da geometria da placa, desenho 40;

2. identificação das camadas inferiores à placa, desenho 41 ;

3. aplicação do carregamento, mecânico, térmico ou ambos, desenho 42;

4. geração da malha de elementos finitos, desenho 43;

5. processamento dos dados. 


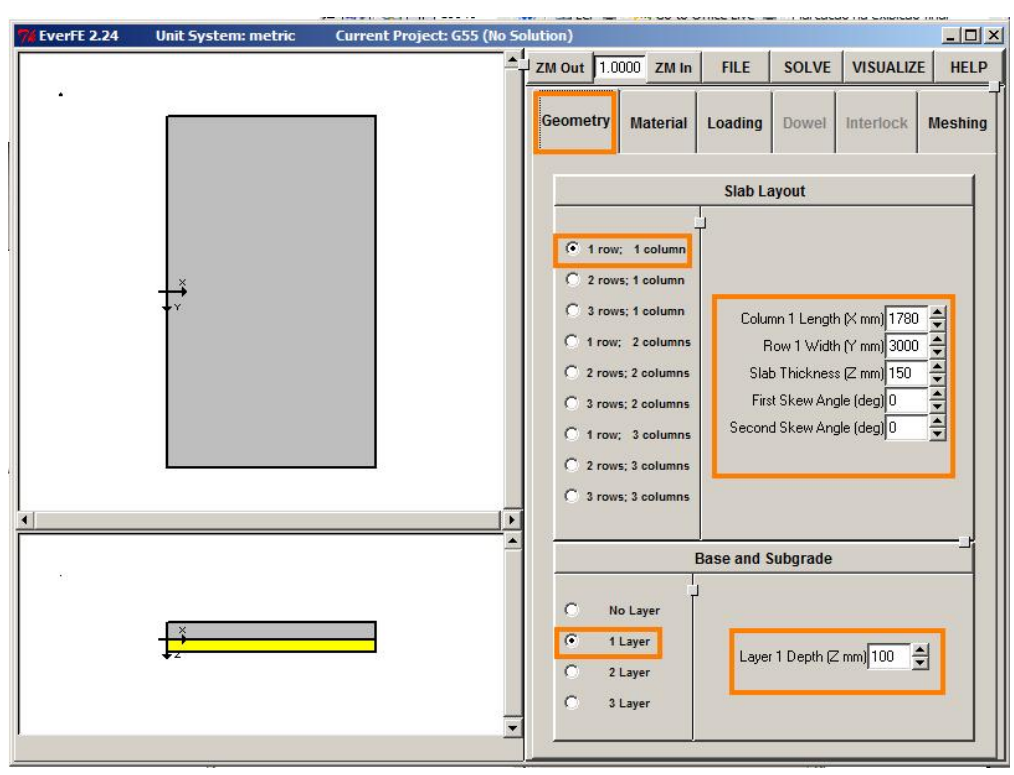

Desenho 40. Aspecto da tela gráfica para inserção da geometria da placa. Fonte: Adaptado do software EverFe 2.24 (DAVIS, 2007).

A entrada de dados está destacada em retângulos sobre cada campo afetado. No desenho 40 estão destacadas as dimensões da placa e subleito. No desenho 41 destaca-se a entrada de dados referente às características dos materiais constituintes do pavimento.

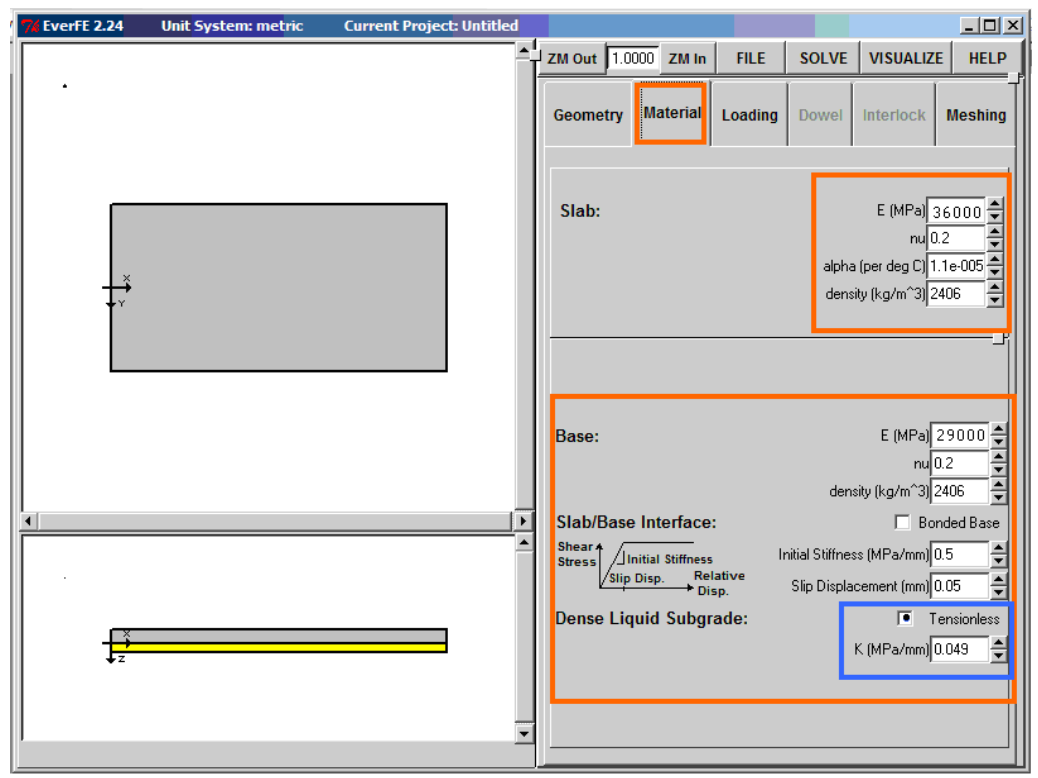

Desenho 41. Aspecto da tela gráfica para inserção dos dados físicos da placa. Fonte: Adaptado do software EverFe 2.24 (DAVIS, 2007). 
Vale observar que o software declara a modelagem de líquido denso (Winkler) e também apresenta o recurso da base ser ou não aderida à placa. $\mathrm{O}$ desenho 41 expõe essa entrada de dados. No caso as "molas" irão responder somente à compressão.

No desenho 42, a tela do software mostra a entrada dos dados do tipo de carregamento utilizado. Podendo ser desde uma simples roda até eixo tandem duplo, no presente trabalho foi utilizado um carregamento de uma roda simples nas posições centro e borda com carregamento de $548,8 \mathrm{kN} / \mathrm{m}^{2}\left(5,6 \mathrm{kgf} / \mathrm{cm}^{2}\right)$. Para a avaliação do carregamento térmico, o software só permite a inserção de quatro posições distintas de temperatura ao longo da espessura da placa. Não existe a possibilidade de uma verificação do comportamento da placa pela variação temporal da temperatura.

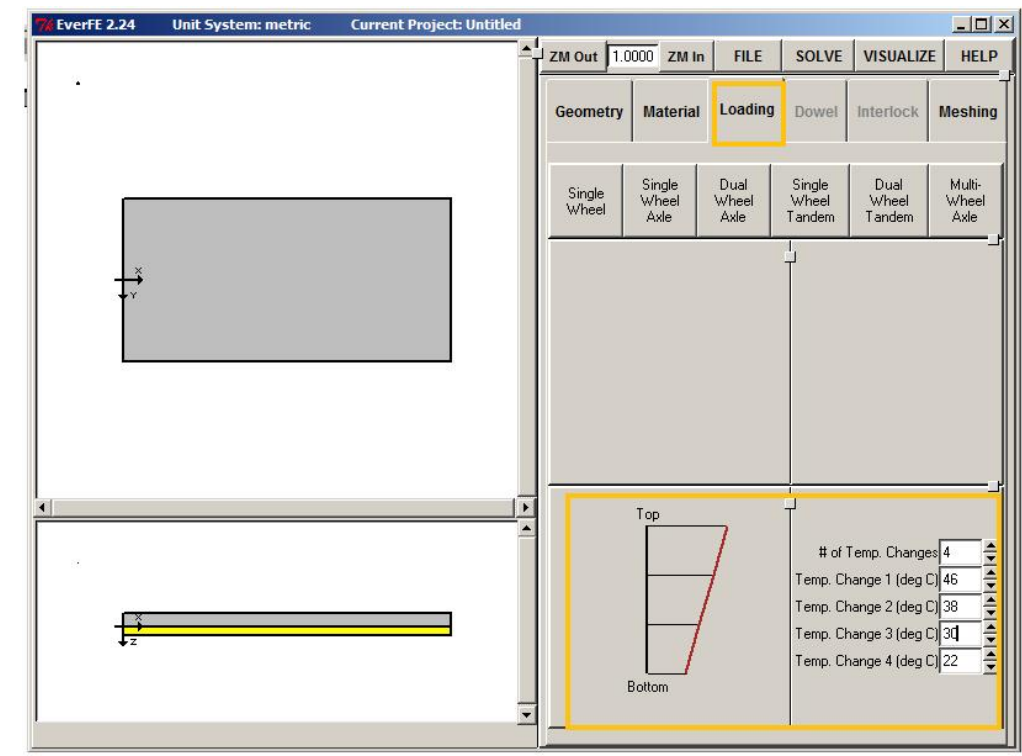

Desenho 42. Aspecto da tela gráfica para inserção do carregamento da placa. Nesse desenho, foi utilizado apenas o carregamento térmico.

Fonte: Adaptado do software EverFe 2.24 (DAVIS, 2007).

O desenho 43 mostra a malha de elementos finitos ao longo da espessura e superfície, utilizada pelo software para os cálculos de tensão e deformação. O software não exibe o recurso para modificar a densidade da malha de elementos finitos em outras regiões da estrutura. As malhas de elementos finitos, geradas pelo EverFE 2.24 são retilíneas. O número de elementos na direção x para cada coluna e na direção y para cada linha, na placa são especificados de forma independente. Além disso, o número de elementos através da espessura da placa, base e subleito também são especificados pelo usuário. No entanto, o 
número de elementos através da espessura da laje pode ser limitada pela simulação de um gradiente térmico bilinear ou trilinear.

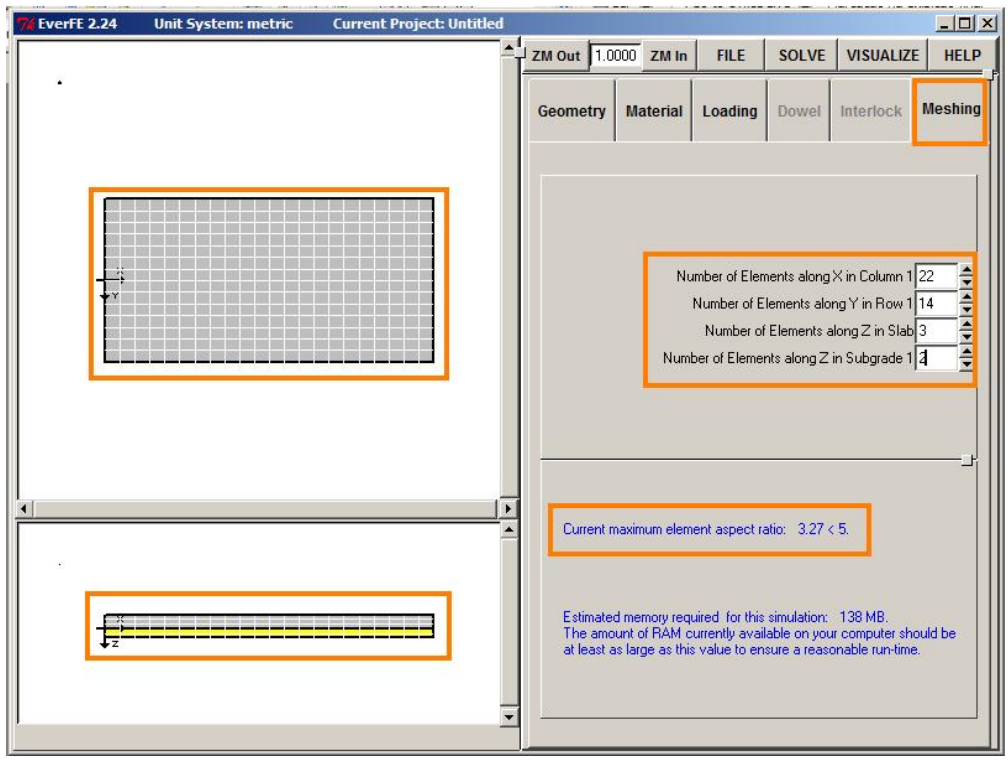

Desenho 43. Aspecto da tela gráfica apresentada quando da geração da malha de elementos finitos.

Fonte: Adaptado do software EverFe 2.24 (DAVIS, 2007).

Esse item mostrou, de uma forma mais detalhada, como foi realizada a construção do pavimento, partindo-se de corpos de prova até a feitura de uma pequena placa instrumentada. Os materiais e suas características mecânicas foram apresentados através de quadros e tabelas; o método construtivo da estrutura e o de dimensionamento e todos os testes; as metodologias para caracterização do sub-leito e para a elaboração de tabelas a partir de dados científicos; a construção e modo de calibração dos sensores, bem como a localização destes dentro da placa, foram descritas por meio de gráficos e tabelas. O processo de aquisição e interpretação dos resultados e as incertezas associadas foram caracterizadas, e também quais sensores foram utilizados e a problemática que os envolveram. Foram apresentados os procedimentos para aquecimento da placa e a forma de controle, tomando como referência eventos naturais. Foi realizada a construção das taxas de aquecimento baseada na literatura e justificou-se o processo de similaridade utilizado, a colocação de uma célula central ao pavimento e os problemas ocorridos. O software de referência foi descrito e mostrada sua operação. 


\section{APRESENTAÇÃO DOS RESULTADOS}

Os resultados obtidos nos testes de aquecimento e de deformação foram comparados a trabalhos disponíveis na literatura e com as simulações geradas pelo software EverFE 2.24, mostrando que a metodologia desenvolvida foi capaz de, não só reproduzir parte dos eventos cotidianos que acontecem em um pavimento real, mas também de colocar a placa em situações que não acontecem sazonalmente. A metodologia utilizada mostrou-se capaz e poderá ser utilizada para avaliações funcionais ou como elemento de teste para novos materiais ou procedimentos.

Como a temperatura é um parâmetro importante nos procedimentos executados com o pavimento, foi levantado um conjunto de curvas representativas do estado térmico do local das experiências, no sentido de assegurar que o ambiente não influenciou nos resultados obtidos. O gráfico 29 mostra, em um teste genérico, como a temperatura variou em cinco pontos distintos de medição. Destaca-se a leitura da temperatura ambiente (TLAB) e, como ela varia, devido ao processo de aquecimento. A temperatura (TAMB) indica a temperatura externa ao laboratório no mesmo dia em que foi feito o teste e a temperatura de topo (TTOPO) indica o valor lido por um termômetro colocado sobre a superfície da placa.

Em uma primeira análise, percebe-se que o processo de resfriamento não acompanha adequadamente o natural. Isto pode ser explicado devido à placa ficar enclausurada durante o processo de aquecimento e, quando o teste termina, ou seja, a placa de aquecimento é desligada e levantada pela máquina de ensaio, a troca de calor não é adequada devido ao fato da temperatura do laboratório possuir um valor constante durante todos os procedimentos.

No entanto, o procedimento de aquecimento é semelhante ao processo natural, imposto sobre os pavimentos em ruas e avenidas. Esse fato fica evidenciado pela comparação das temperaturas indicadas por TTOPO e TAMB que são, respectivamente, a temperatura de topo do pavimento e a temperatura externa. Com relação à temperatura do laboratório, podese enfatizar que tem pouca influência sobre o processo principal. Isso pode ser reparado pela constância da temperatura indicada pelo TELAB. As temperaturas nos níveis zero (N0) e quinze (N15) mostram como se comporta a placa mediante o aquecimento e resfriamento. Esse foi um dos únicos experimentos em que houve uma sincronização entre o procedimento de aquecimento e o aquecimento natural. 


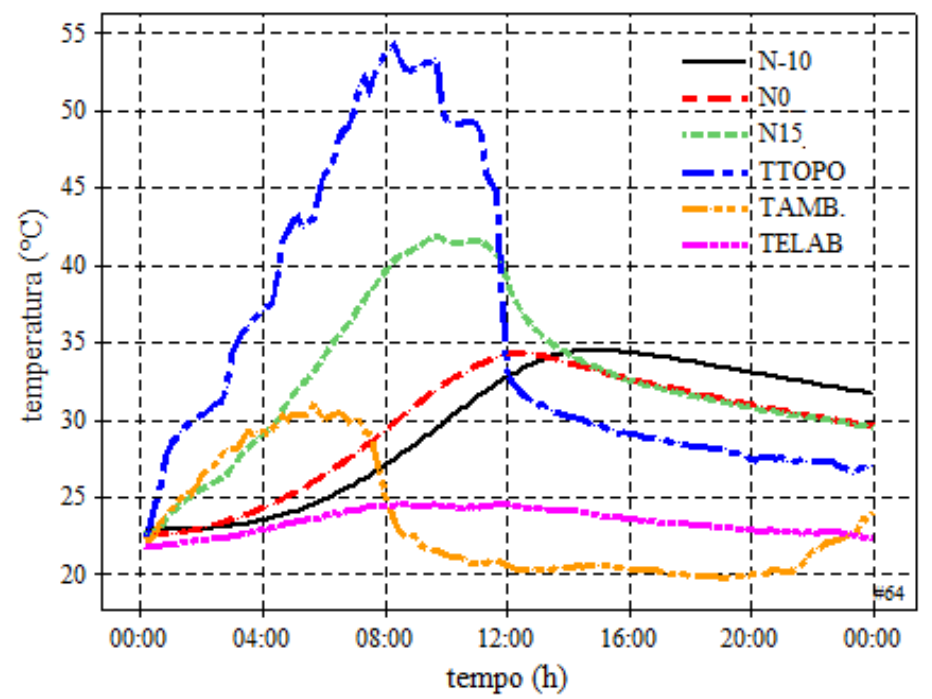

Gráfico 29. Comportamento das temperaturas durante um ciclo de testes realizado na placa de CCP. $\mathrm{N}-10 \rightarrow$ temperatura entre subleito e base a $0,25 \mathrm{~m}$ do topo, $\mathrm{N} 0 \rightarrow$ temperatura no fundo da placa $0,15 \mathrm{~m}$ do topo, $\mathrm{N} 15 \rightarrow$ temperatura da superfície da placa com termômetro embutido, TTOPO $\rightarrow$ temperatura no topo da placa com termômetro colocado sobre a sua

superfície, TELAB $\rightarrow$ temperatura do ar dentro do laboratório de testes e TAMB $\rightarrow$ temperatura externa tomada pela estação de coleta de dados localizada no telhado do prédio do laboratório, essa medida foi feita no dia 28/08/2008.

Fonte: Elaborado a partir dos dados experimentais (2008).

\subsection{GERAÇÃO DOS DIFERENCIAIS DE TEMPERATURA}

Posto que o procedimento de aquecimento assemelha-se ao processo natural, estabeleceu-se a geração dos diferenciais de temperatura a partir dos recursos e metodologia desenvolvidos.

Durante o processo de aquecimento no topo da placa, os fenômenos de irradiação e convecção natural ${ }^{28}$ atuaram simultaneamente devido a um mini-clima mantido no topo da placa pela proteção térmica lateral feita com uma manta de tecido de algodão. Essa proteção envolveu totalmente o pavimento, deixando um espaço lateral de aproximadamente $10,0 \mathrm{~cm}$ das laterais para a circulação natural do ar.

A fotografia 25 mostra a plataforma de aquecimento na posição típica para aquecimento da placa, em que pode ser vista a disposição da manta de tecido utilizada na isolação térmica. $\mathrm{O}$ desenho 44 mostra esquematicamente o corte longitudinal do conjunto de aquecimento e pavimento em que pode ser observado como o tecido envolveu a estrutura. As

\footnotetext{
28 Convecção natural é quando o movimento do fluido ocorre por diferença de densidade, induzida pela diferença de temperatura.
} 
cotas indicam as distâncias das laterais do pavimento e da parte superior da plataforma de aquecimento. A altura da plataforma de aquecimento, em relação à placa, foi determinada experimentalmente e foi estabelecida quando houve uma uniformidade na distribuição da temperatura sobre a placa.

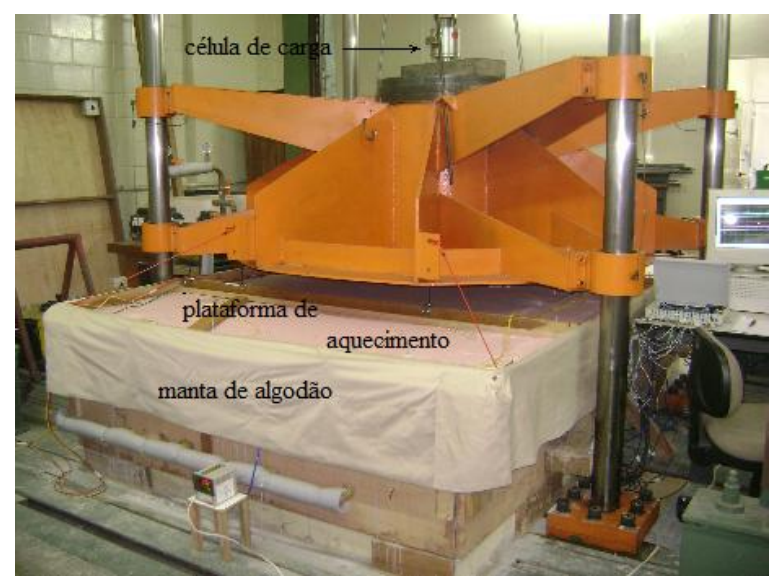

Fotografia 25. Placa sendo submetida a teste de temperatura com sensores ligados no sistema de aquisição de dados.

Fonte: Acervo próprio (2008).

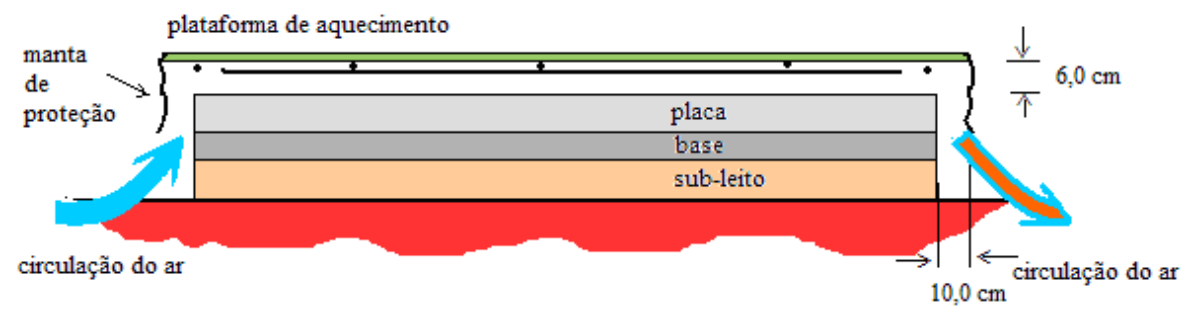

Desenho 44. Vista em corte do conjunto pavimento e plataforma de aquecimento. Fonte: Acervo próprio (2009).

O empenamento convexo da placa foi conseguido aquecendo-se a superfície ou resfriando-se o fundo da placa através da circulação de água fria pelo sistema de troca de calor. Para tanto, gelo picado foi acrescentado em quantidade suficiente para provocar a alteração do estado térmico do fundo da placa. Normalmente de dez a quinze quilos de gelo eram acrescentados ao reservatório (fotografia 13) para provocar diminuição de $1,0^{\circ} \mathrm{C}$ a $2,0^{\circ} \mathrm{C}$ no nível 0 , ou seja, fundo da placa. Para a obtenção do empenamento côncavo, foi utilizado o aquecimento do fundo da placa com água quente forçada a circular pelo sistema de troca de calor. A água quente foi obtida através de um aquecedor doméstico com capacidade de até 5,0 $\mathrm{kW}$ que, quando acionado, aqueceu a água até o ponto estabelecido (set point) pelo 
controlador (fotografia 13). Isso que dizer que a água era aquecida a partir do estado térmico da placa até o ponto estabelecido, ficando constante a partir de então. Infelizmente, esse procedimento não permitiu a geração de rampas de aquecimento.

Com essas manobras e controles, foi possível a produção de condições climáticas semelhantes àquelas ditados pelo ambiente. Cabe relembrar que o fator umidade não foi controlado e manteve-se sempre igual àquele imposto pelo ar condicionado do laboratório.

A distribuição da temperatura no interior da placa foi considerada, por hipótese, constante nos planos em que foram feitas as medidas. Esses planos foram chamados de níveis. Tomando como referência os desenhos 18 e 19, os níveis foram definidos como: N-10, N0, N4, N7, N11 e N15, sendo que o nível N-10 tem como termômetro o TFUN, aquele localizado no topo do subleito ou fundo da base; o N0, TE1, TE7, TE13; o N4, TE2, TE6, TE8, TE12; o N7, TE3, TE5, TE9; o N11, TE10 e TE11 e o N15, o TE4. A localização dos níveis está tomada em relação ao fundo da placa com origem no canto esquerdo (desenho 16). Isso significa que N-10 está $10,0 \mathrm{~cm}$ abaixo do fundo da placa, N0 está no nível $0,0 \mathrm{~cm}$ a partir do fundo, N4 está a 4,0 cm do fundo para o topo, N7 está a 7,0 cm do fundo, N11 está a $11,0 \mathrm{~cm}$ do fundo e N15 está no topo a $1,0 \mathrm{~cm}$ da superfície.

Isso quer dizer que a temperatura foi monitorada em cinco níveis distintos, porém nem sempre todos os termômetros foram utilizados. A apresentação das temperaturas, em cada um dos níveis, foi realizada fazendo-se a média aritmética simples das leituras dos termômetros ligados ao sistema de aquisição. As incertezas associadas às medidas são aquelas determinadas quando das calibrações dos termômetros (apêndice B).

\subsection{SIMULAÇÃO DAS DISTRIBUIÇÕES DE TEMPERATURA E DADOS CORRELACIONADOS}

A certificação dos resultados obtidos em laboratório foi realizada através de uma comparação com os dados oriundos da literatura. Esse processo seguiu os seguintes passos:

a) seleção e classificação de artigos e trabalhos;

b) levantamento da taxa temporal da temperatura de cada trabalho (foi utilizado o método descrito no item 2.3.1);

c) apresentação dos dados obtidos na forma tabular;

d) realização de taxas de aquecimento e apresentação gráfica do resultado.

$1^{\mathrm{o}}$ trabalho. 
O primeiro trabalho analisado para a correlação foi o de Severi (2002), em que, por questões práticas, foram escolhidas duas situações para a realização da comparação. A primeira referiu-se a um dia quente e ensolarado e outra a uma múltipla inversão, assim chamada pela autora, como um dia de sol que inverteu para uma chuva intensa, porém breve. Há de se levar em consideração que a espessura da placa do trabalho de Severi (2002) era de $250,0 \mathrm{~mm}$ enquanto a espessura de placa para o presente trabalho era de $150,0 \mathrm{~mm}$.

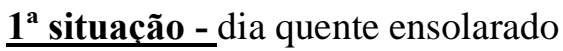

A Tabela 4 exibe os dados extraídos do gráfico 30 obtidos por Severi (2002) em relação a um dia ensolarado, quando foram medidas as temperaturas do topo e do fundo da placa. A autora calculou as taxas de aquecimento a partir do ponto de intersecção da temperatura de fundo com a temperatura de topo, de acordo com o gráfico31.

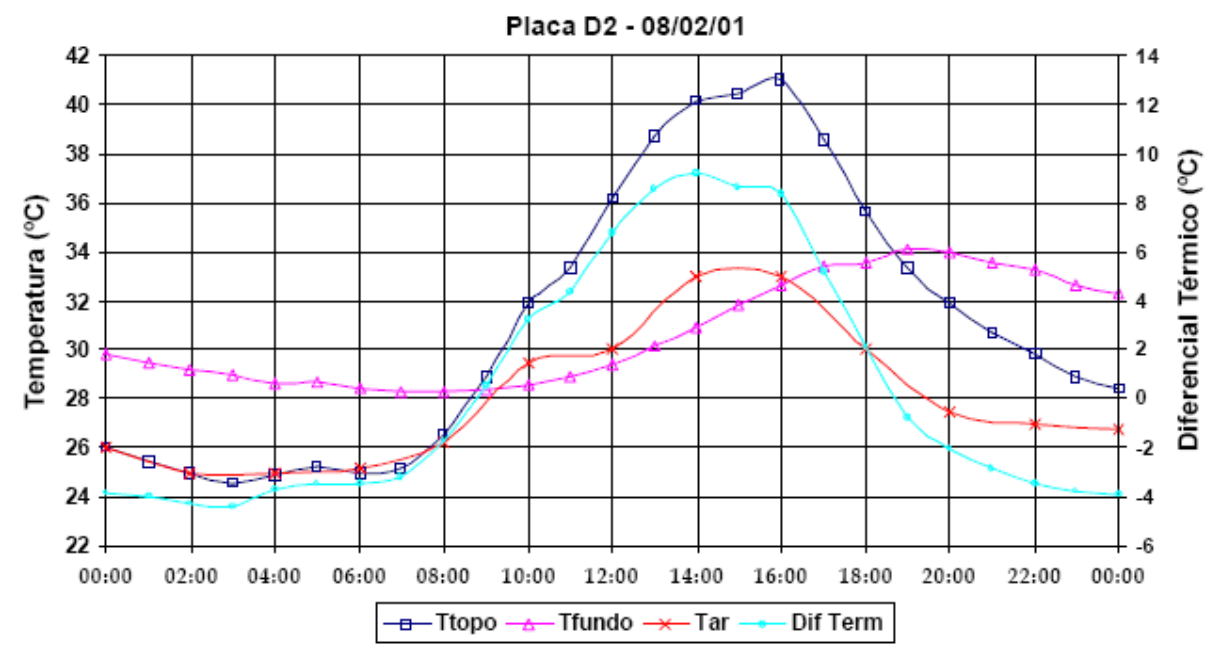

Gráfico 30. Comportamento da temperatura em um dia ensolarado. Fonte: Adaptado e modificado a partir dos dados de - Severi (2002). 
Tabela 4. Dados obtidos do gráfico 26.

\begin{tabular}{ccc}
\hline horário (h) & temperatura $\left({ }^{\circ} \mathrm{C}\right)$ - topo & temperatura $\left({ }^{\circ} \mathrm{C}\right)$ - fundo \\
\hline $8: 00$ & 24,3 & 28,2 \\
$10: 00$ & 32,0 & 28,5 \\
$11: 00$ & 33,3 & 28,8 \\
$12: 00$ & 36,2 & 29,3 \\
$13: 00$ & 38,7 & 30,0 \\
$14: 00$ & 40,0 & 30,8 \\
$15: 00$ & 40,5 & 31,7 \\
$16: 00$ & 41,1 & 32,7 \\
\hline
\end{tabular}

Fonte: Elaborada a partir dos dados analisados (2008).

A partir dessas informações, foi elaborado um plano de simulação contando com o sistema de aquisição de dados e o recurso térmico de aquecimento da placa. Isso foi feito no período correspondente a vinte e quatro horas. Ao final deste prazo, os dados aquisitados foram levados ao software MINITAB $^{\circledR}$ para tratamento estatístico e adequação gráfica. A adaptação térmica foi conseguida utilizando-se a curva do gráfico 20 (a) e o resultado pode ser visto no gráfico 32 (os dados estão disponíveis no anexo B - CD-ROM com o nome de arquivo\# 134).

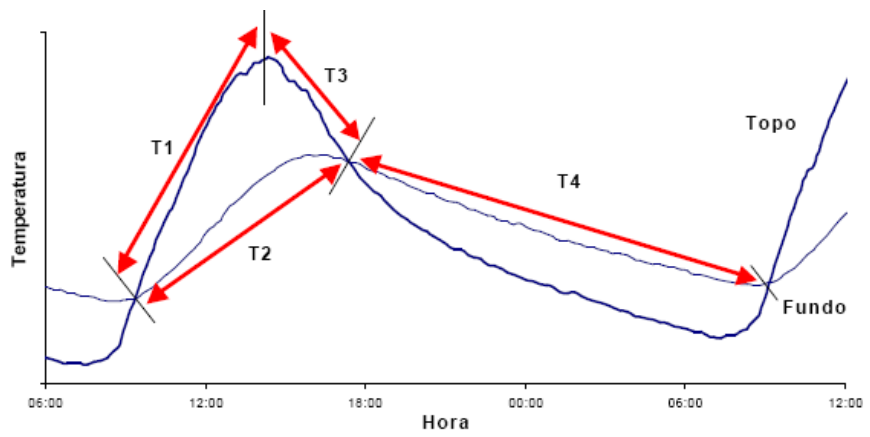

Gráfico 31. Processo para determinação das taxas de temperatura, T1, taxa de elevação da tempreratura de topo, T2, taxa de elevação da temperatura de fundo. Fonte: Adaptado e modificado a partir dos dados de - Severi (2002).

O gráfico 32 mostra a distribuição de temperatura segundo o nível zero (fundo) N0 e o nível de topo N15. O tempo de aquecimento foi de aproximadamente seis horas. 


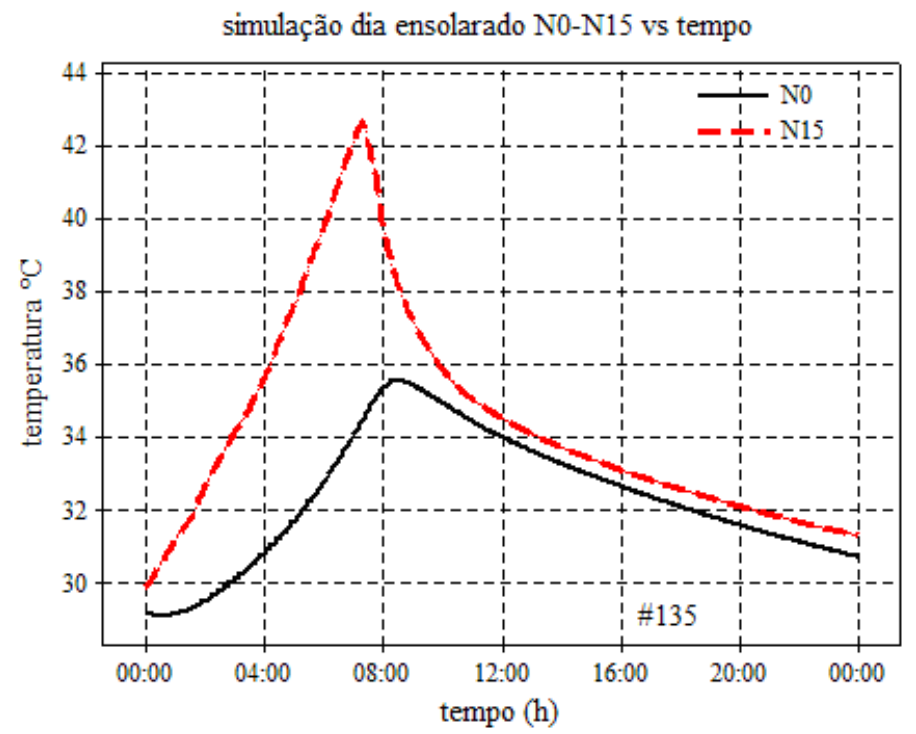

Gráfico 32. Simulação de um dia ensolarado, segundo o gráfico 26 Severi (2001).

Fonte: Elaborado a partir dos dados analisados (2009).

Os dados da Tabela 3 e do gráfico 32 foram utilizados para montar a Tabela 5, que gerou o gráfico 33. Nesse gráfico, é possível perceber a forte correlação entre as temperaturas de topo dos experimentos mencionados.

Tabela 5. Dados de temperatura de topo e fundo de ambos os experimentos.

\begin{tabular}{|c|c|c|c|c|}
\hline $\begin{array}{c}\text { instante (h) } \\
\text { (Severi) }\end{array}$ & $\begin{array}{c}\text { temperatura }{ }^{\circ} \mathrm{C} \\
\text { topo(Severi) }\end{array}$ & $\begin{array}{c}\text { temperatura }{ }^{\circ} \mathrm{C} \\
\text { fundo }\end{array}$ & $\begin{array}{c}\text { temperatura - topo } \\
\text { N4 }\end{array}$ & $\begin{array}{c}\text { temperatura - fundo } \\
\text { N0 }\end{array}$ \\
\hline 1 & 24,3 & 28,2 & 29,9 & 29,2 \\
\hline 2 & 32,0 & 28,5 & 32,6 & 29,5 \\
\hline 3 & 33,3 & 28,8 & 34,8 & 30,1 \\
\hline 4 & 36,2 & 29,3 & 35,6 & 30,8 \\
\hline 5 & 38,7 & 30,0 & 37,6 & 31,7 \\
\hline 6 & 40,0 & 30,8 & 39,8 & 32,8 \\
\hline 7 & 40,5 & 31,7 & 42,1 & 34,0 \\
\hline 8 & 41,1 & 32,7 & 39,8 & 35,4 \\
\hline
\end{tabular}

Fonte: Elaborado a partir dos dados analisados (2009). 


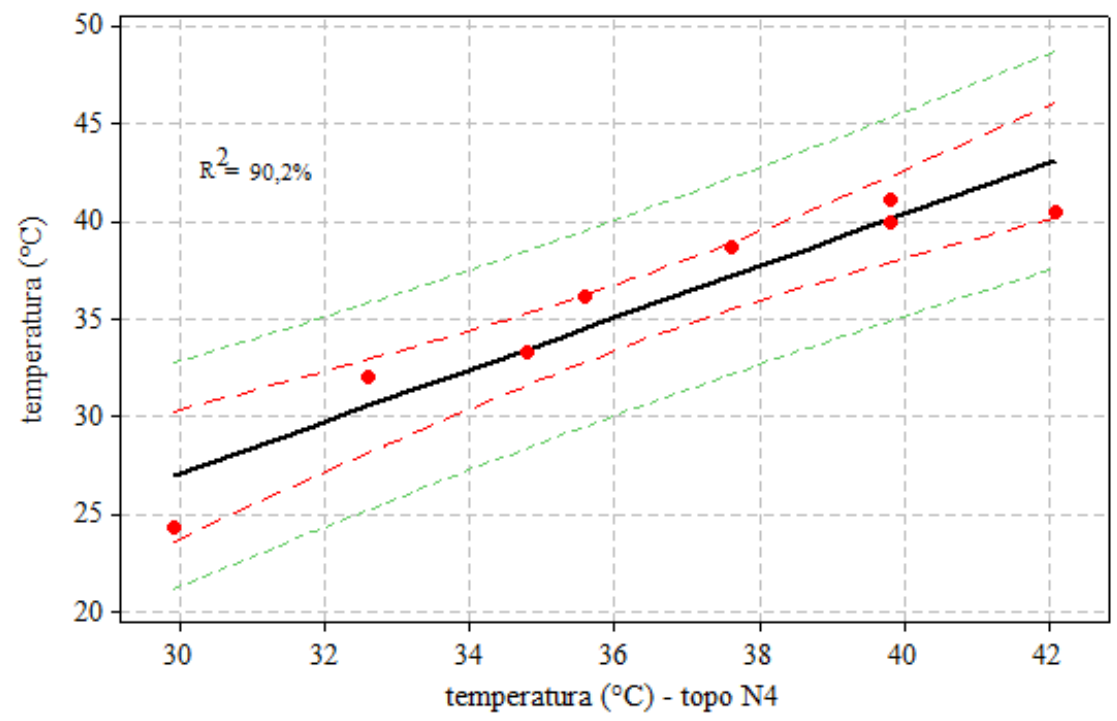

Gráfico 33. Correlação entre os dados de temperatura de ambos os experimentos, Severi (2002) e ensaio de laboratório. Intervalo de confiança $95,0 \%, \mathrm{R}^{2}=90,2 \%$. Fonte: Elaborado a partir dos dados analisados (2009).

Com relação á distribuição da temperatura no interior da placa, ao longo da espessura, foi feita uma comparação entre aquela apresentada por Severi (2002) e a obtida em laboratório pelo processo descrito. Os resultados podem ser vistos através dos gráficos 34 e 35. Apesar das espessuras das placas serem diferentes, $(250,0 \mathrm{~mm}$ para o experimento de Severi (2002) contra 150,0 mm para o experimento em laboratório) observa-se uma grande semelhança na distribuição da temperatura, bem como a não linearidade dessa distribuição. Há de se notar que, o gráfico 35 dá a indicação do comportamento da temperatura da sub-base ao topo do pavimento. Essa informação é importante, pois pode-se obter melhores conclusões, a respeito do comportamento da placa, sabendo como está o comportamento térmico da subbase. Esse tipo de medida, de acordo com literatura consultada, só foi realizada em campo, não em laboratório. 


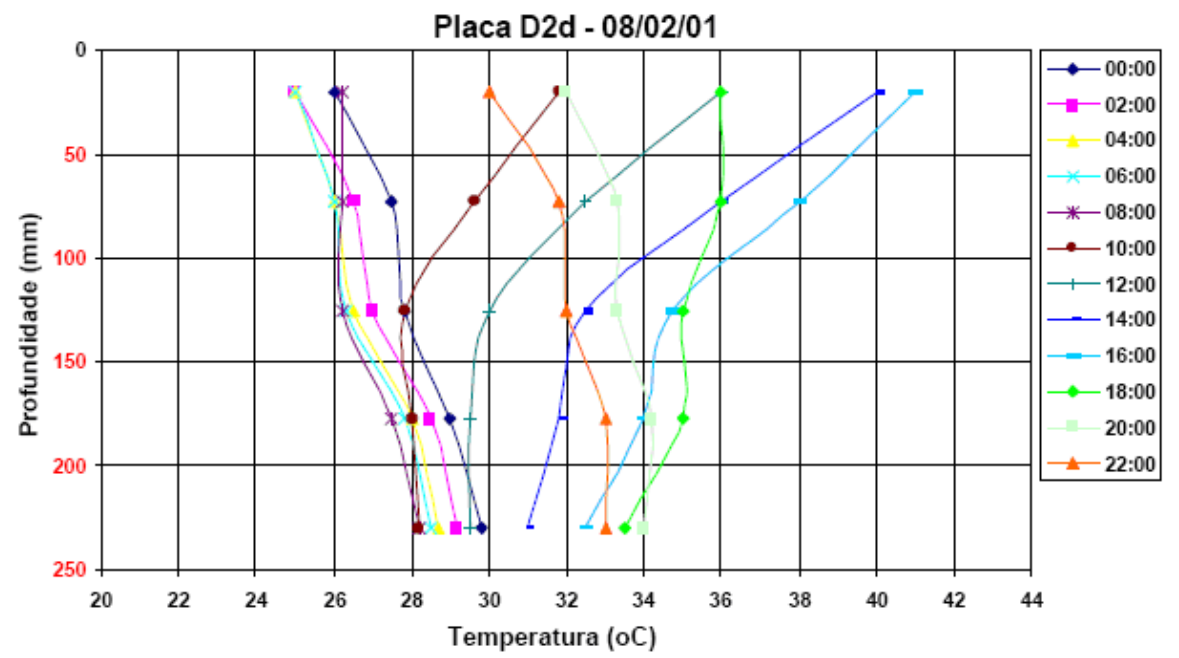

Gráfico 34. Comportamento da temperatura em um dia ensolarado. Fonte: Adaptado e modificado a partir dos dados de Severi (2002).

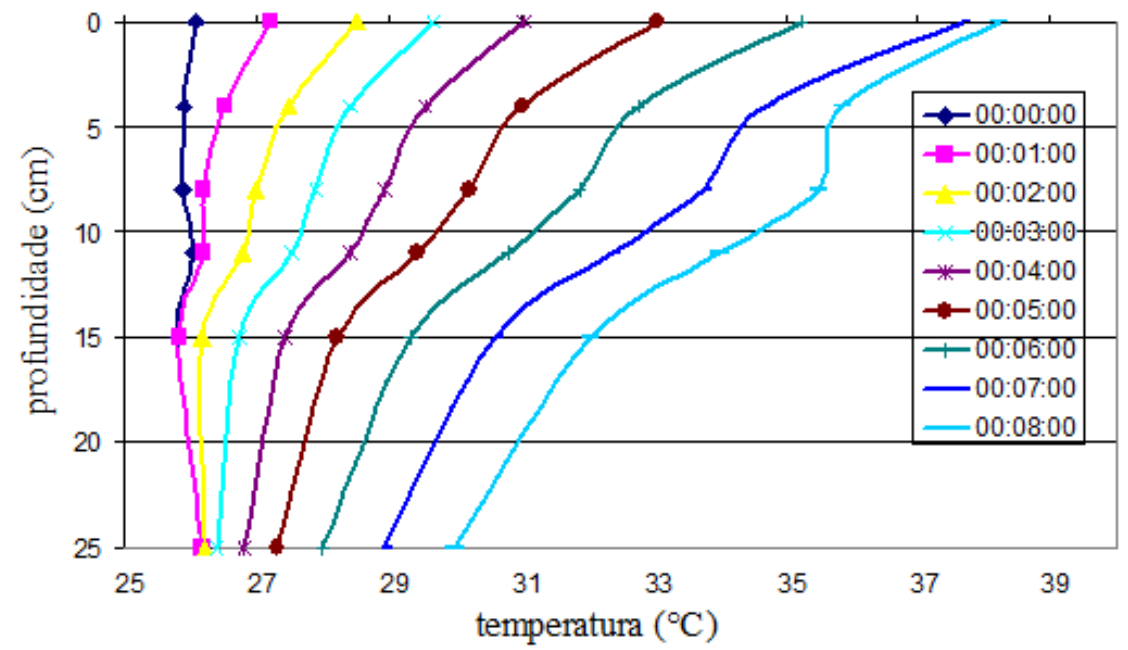

Gráfico 35. Simulação de um dia ensolarado, segundo o gráfico 30 Severi (2001). Fonte: Elaborado a partir dos dados analisados (2009).

$\underline{2^{a} \text { situacão }}$ - ocorrência de múltipla inversão de temperatura

Para essa situação não foi realizada uma correlação, mas sim uma comparação entre o fenômeno natural e o produzido em laboratório.

O gráfico 36 apresenta o comportamento da placa obtido por Severi (2002) em relação a um dia ensolarado com breve chuva no meio da tarde. As medidas referem-se às temperaturas do topo e do fundo da placa. 


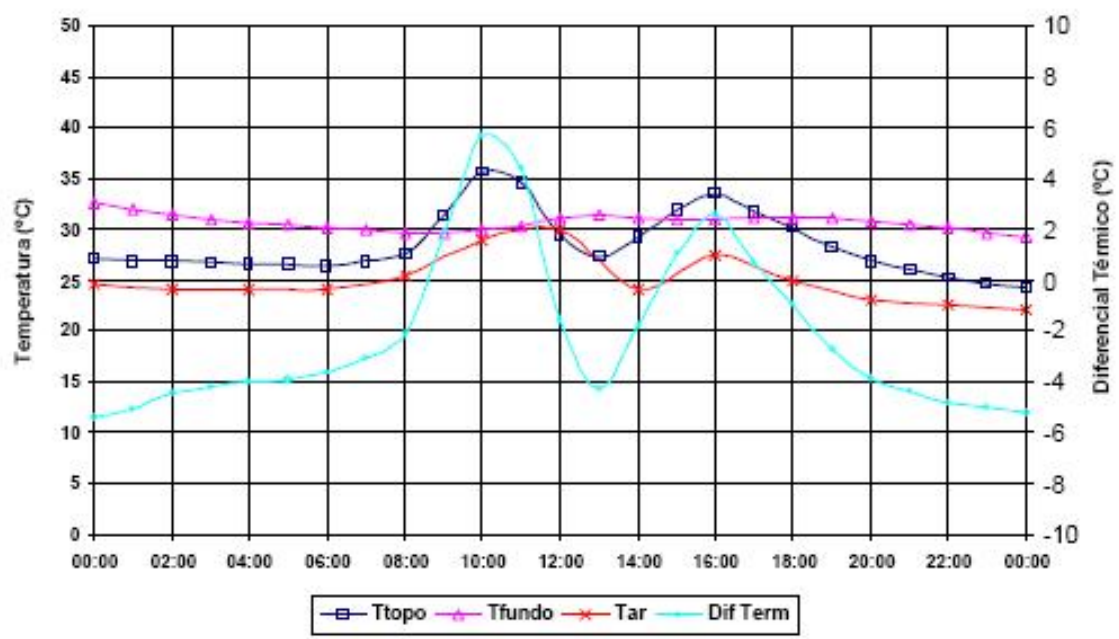

Gráfico 36. Dia quente com chuva no período.

Fonte: Adaptado e modificado a partir dos dados de Severi (2002).

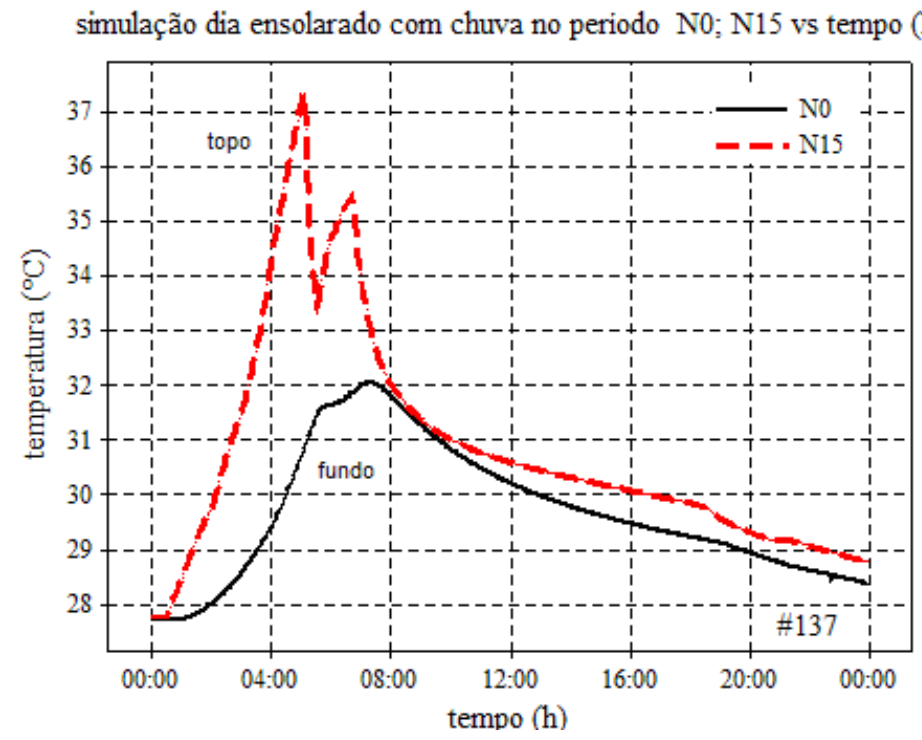

Gráfico 37. Simulação em laboratório de um dia quente com chuva no período.

Fonte: Elaborado a partir dos dados analisados (2009).

Para simular essa situação, foi elaborado um procedimento em que, inicialmente, a placa foi colocada para aquecer por um período de cinco horas, com taxa de $1,5^{\circ} \mathrm{C}$ por hora. Quando sua temperatura atingiu o valor de $37,0{ }^{\circ} \mathrm{C}$, a plataforma de aquecimento foi erguida e gradativamente a placa foi sendo molhada, uniformemente, por toda extensão com um total de quinze litros de água, quantidade capaz de simular uma chuva de verão de pouca duração (dez 
minutos) com precipitação de $3,0 \mathrm{~mm}^{29}$. O resultado da simulação pode ser visto no gráfico 37, em que se nota o comportamento da placa indoor, que corresponde ao acontecido em campo. A semelhança do comportamento frente ao fenômeno natural e aquele simulado é bem grande e mostra que a metodologia é capaz de atender a processos complexos. E isso pode ser visto na reprodução do comportamento da temperatura dos gráficos 38 e 39, que apresentam o resultado da simulação de uma inversão de temperatura no período. $\mathrm{O}$ aspecto não linear da temperatura fica novamente evidenciado e pode ser repetido com grande semelhança através da metodologia desenvolvida

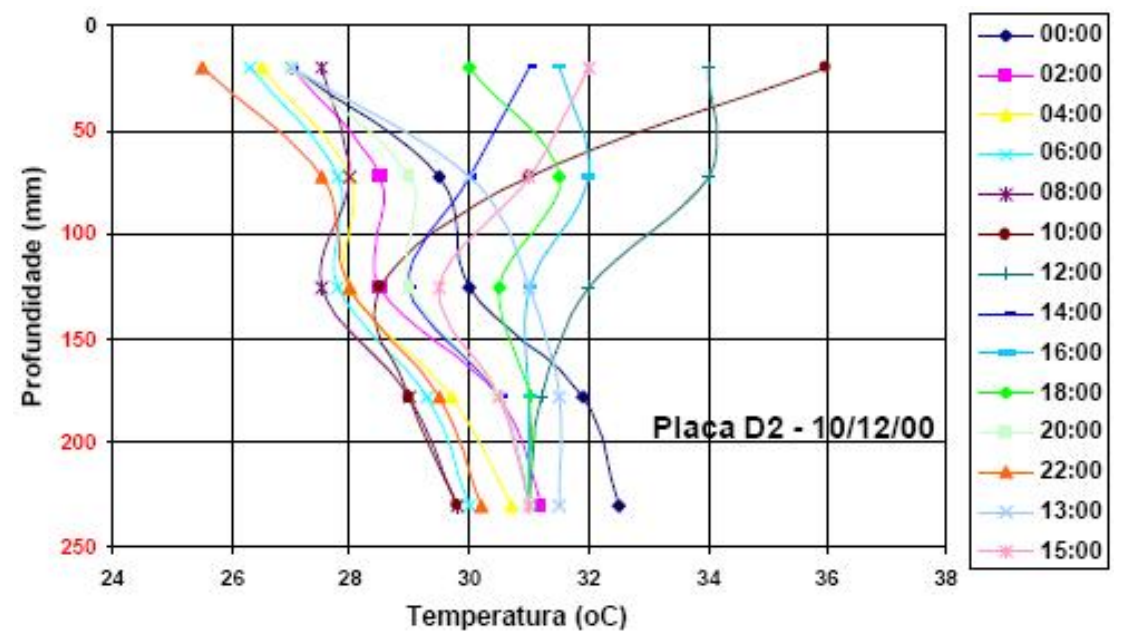

Gráfico 38. Dia quente com chuva no período. Fonte: Adaptado a partir dos dados de Severi (2002).

\footnotetext{
${ }^{29} 1,0 \mathrm{~mm}$ de chuva em relação a $1,0 \mathrm{~m}^{2}$ equivale a $1,0 \mathrm{~L}$.
}

Fonte: Brasil, Ministério da Agricultura e Abastecimento, Agritempo, Sistema de monitoramento agrometeorológico. Disponível em: http://www.agritempo.gov.br/modules.php?name=Encyclopedia\&op=content\&tid=127. Acesso em 6 mar 09. 


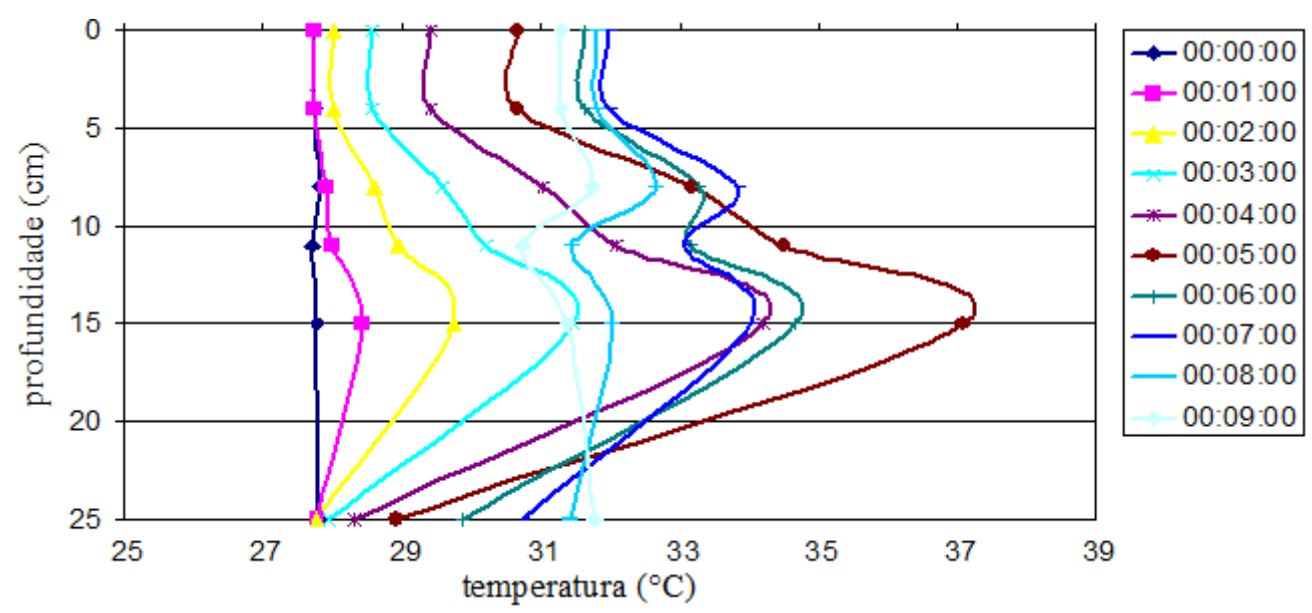

Gráfico 39. Simulação em laboratório de um dia quente com chuva no período. Fonte: Elaborado a partir dos dados analisados (2009).

\section{$\underline{2^{\circ} \text { trabalho }}$}

Nesse trabalho, Armaghani et al. (1987) avaliaram temperaturas e deformações em placas de concreto em uma auto-estrada da Flórida - EUA, durante um período de três anos.

A simulação do comportamento da placa desse trabalho seguiu os procedimentos anteriores, ou seja, os valores utilizados para correlação foram retirados do gráfico apresentado pelos autores, no caso, pelo gráfico 40 e estão apresentados na Tabela 6.

Tabela 6. Dados retirados do gráfico 36.

\begin{tabular}{ccc}
\hline horário (h) & temperatura ${ }^{\circ} \mathrm{F}$ & temperatura ${ }^{\circ} \mathrm{C}$ - topo \\
\hline $08: 00$ & 67,5 & 19,7 \\
$10: 00$ & 73,7 & 23,2 \\
$12: 00$ & 82,4 & 28,0 \\
$14: 00$ & 88,8 & 31,5 \\
$15: 00$ & 89,9 & 32,2 \\
$15: 24$ & 90,0 & 32,2 \\
\hline
\end{tabular}

Fonte: Elaborado a partir dos dados analisados (2009). 


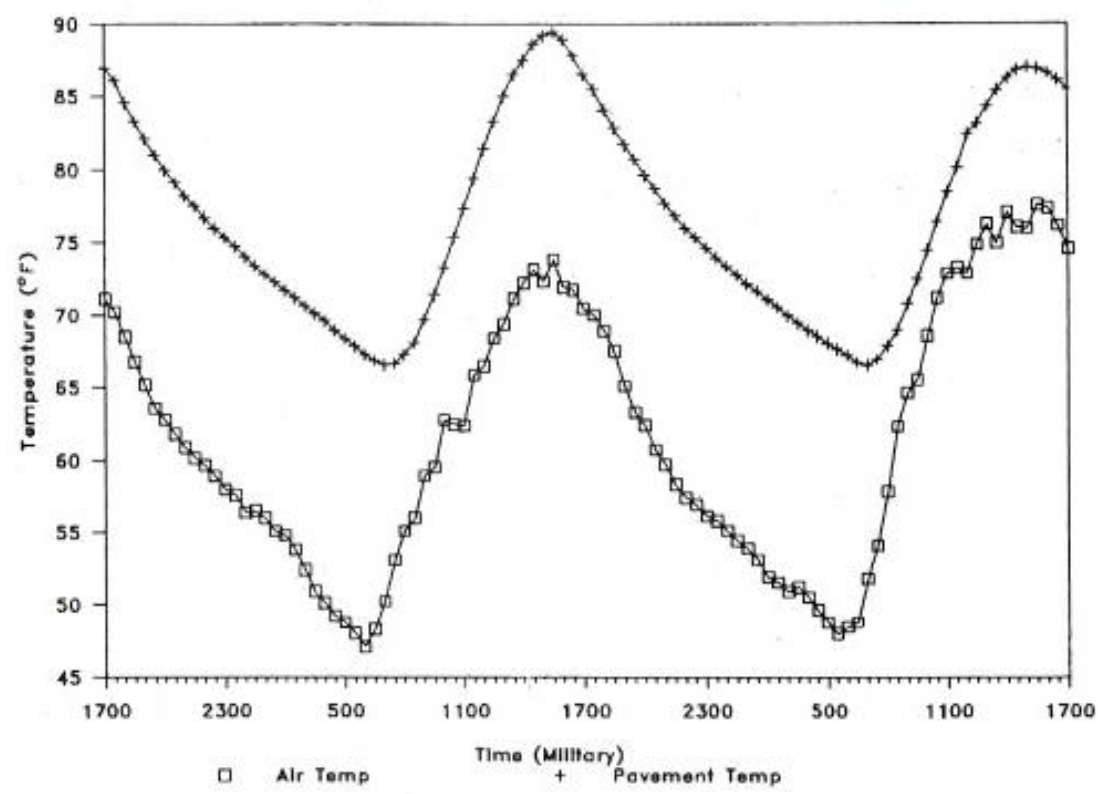

Gráfico 40. Comportamento da temperatura em um dia claro de verão. Fonte: Adaptado a partir dos dados de Armaghani (1987).

Destaca-se que, por limitação na geração de temperatura de topo abaixo da temperatura ambiente, a correlação foi feita com dados mais próximos possíveis daqueles selecionados na base de dados dos arquivos\# (CD-ROM anexo B). Os dados mais adequados para essa correlação foram escolhidos no arquivo\#60 e, alguns pontos, estão representados na Tabela 7. A resposta da simulação está representada pelo gráfico 41 onde é possível observar a resposta da placa em comparação com os dados reais do campo. A correlação para esse teste está representada pelo gráfico42.

Tabela 7. Dados de temperatura de topo e fundo de ambos os experimentos

\begin{tabular}{ccc}
\hline horário (h) & $\begin{array}{c}\text { temperatura }{ }^{\circ} \mathrm{C}-\text { topo } \\
\text { Armaghani }\end{array}$ & $\begin{array}{c}\text { Temperatura }{ }^{\circ} \mathrm{C}-\text { topo } \\
\text { simulação }\end{array}$ \\
\hline $08: 00$ & 19,7 & 20,8 \\
$10: 00$ & 23,2 & 21,3 \\
$12: 00$ & 28,0 & 23,1 \\
$14: 00$ & 31,5 & 25,0 \\
$15: 00$ & 32,2 & 26,1 \\
$15: 24$ & 32,2 & 28,0 \\
\hline
\end{tabular}

Fonte: Elaborada a partir dos dados analisados (2009). 


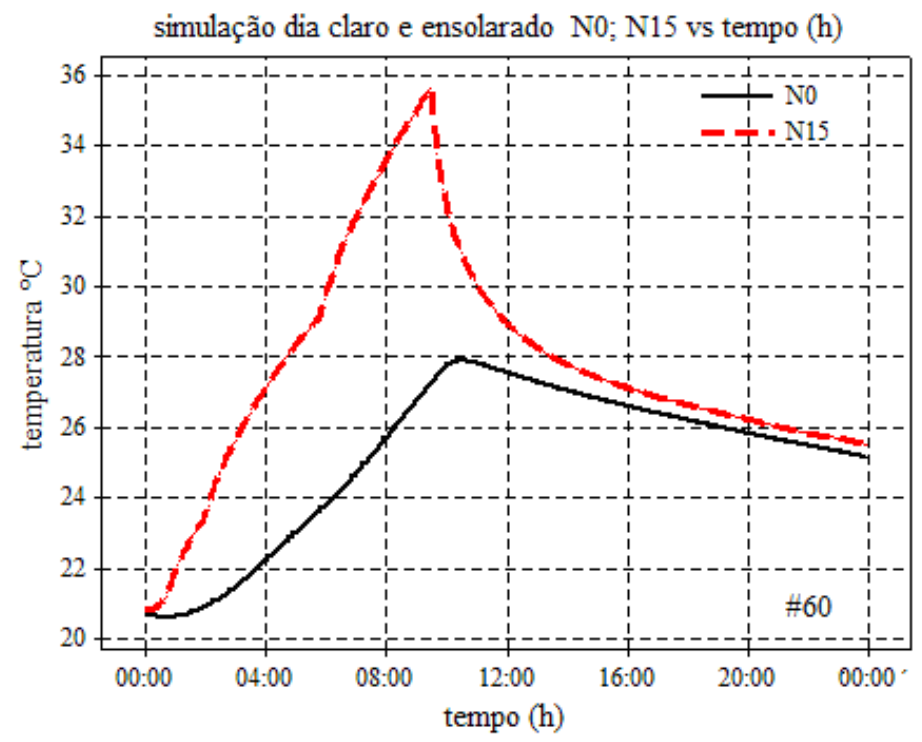

Gráfico 41. Simulação de um dia claro e ensolarado, segundo o gráfico 36 Armaghani (1987).

Fonte: Elaborado a partir dos dados analisados (2009).

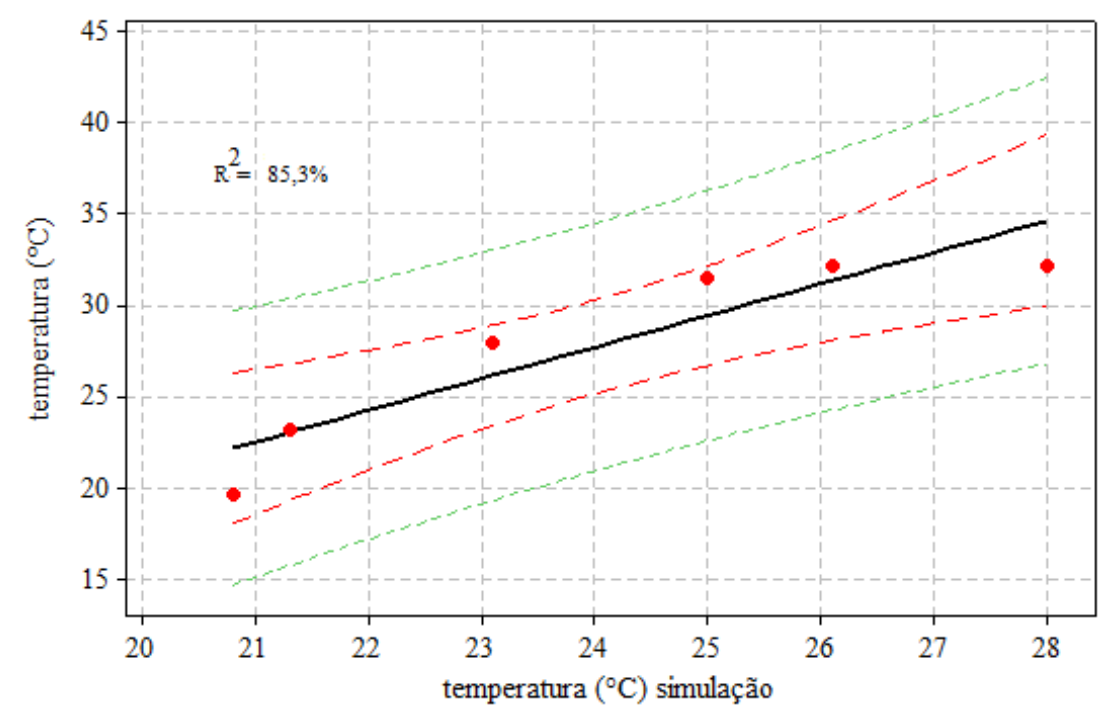

Gráfico 42. Correlação entre os dados de temperatura de ambos os experimentos, Armaghani (1987) e ensaio de laboratório.

Fonte: Elaborado a partir dos dados analisados (2009).

O comportamento da temperatura ao longo da espessura da placa, para ambos experimentos, está representado pelos gráficos 43 e 44 . Novamente o processo indoor mostra a capacidade de reproduzir eventos climáticos, apesar da temperatura superficial inicial da placa não ter sido a mesma daquela apresentada em campo. 


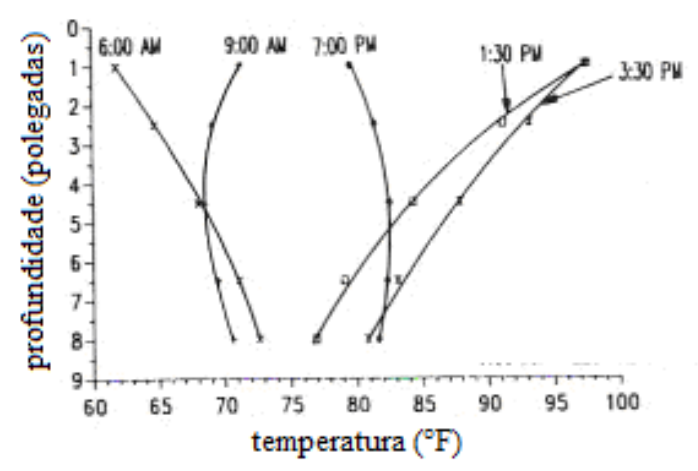

Gráfico 43. Comportamento da temperatura em um dia claro de verão.

Fonte: Adaptado de Armaghani (1987).

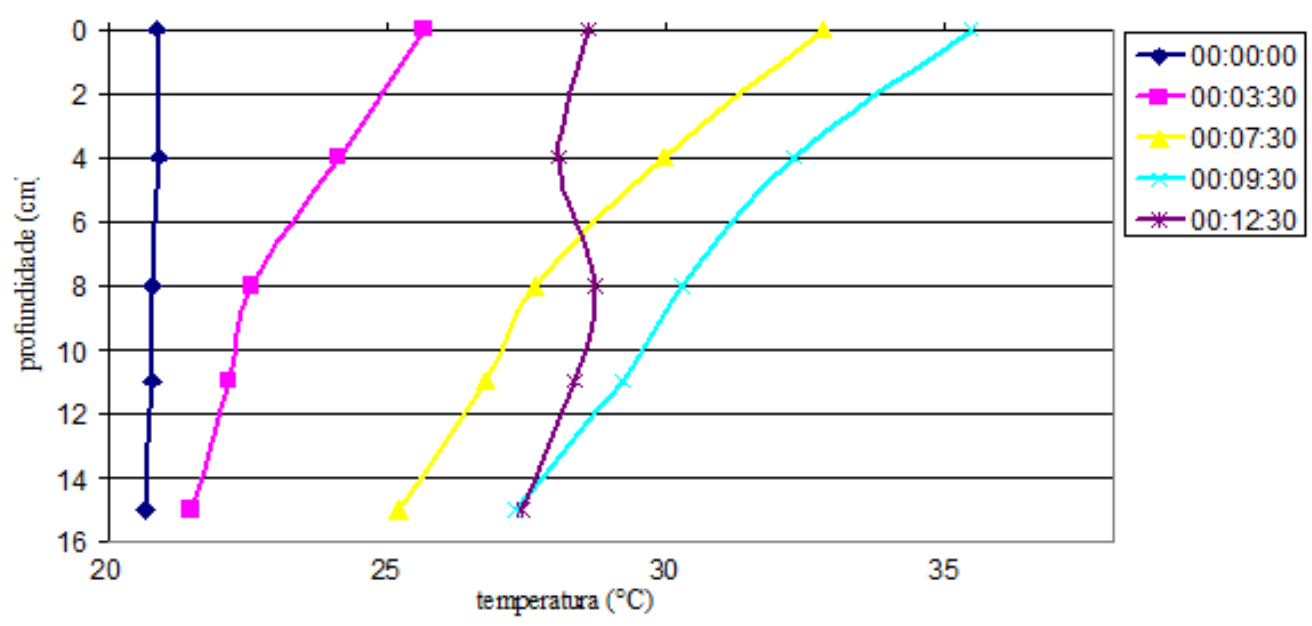

Gráfico 44. Simulação de um dia claro e ensolarado, segundo o gráfico 39 Armaghani (1987). Fonte: Elaborado a partir dos dados analisados (2009).

A correlação entre os experimentos poderia apresentar um índice melhor, caso não fosse a impossibilidade de colocar a temperatura de topo a valores abaixo da temperatura ambiente. Não foi desenvolvido recurso para essa situação. No entanto, mesmo assim, conseguiu-se reproduzir a taxa desejada de $1,9^{\circ} \mathrm{C} / \mathrm{h}$.

\section{$3^{\circ}$ trabalho}

No terceiro trabalho analisado Thompson et al. (1987) desenvolveram metodologia para estabelecer modelos térmicos, utilizando dados de estação meteorológica, para serem utilizados no desenvolvimento e projeto de pavimentos. Esse trabalho tem uma estranha característica. Apesar do pavimento ser aquecido, a temperatura de fundo não altera o valor. 
Isso é bastante incomum, tendo em vista que todos os outros experimentos anteriores mostraram variações alo longo do tempo de aquecimento, o qual o pavimento fica sujeito.

No entanto, como nos estudos anteriores, os dados, para a análise de regressão foram obtidos através de um gráfico original, reproduzido aqui pelo gráfico 45 , cujos dados principais estão tabulados na Tabela 8 .

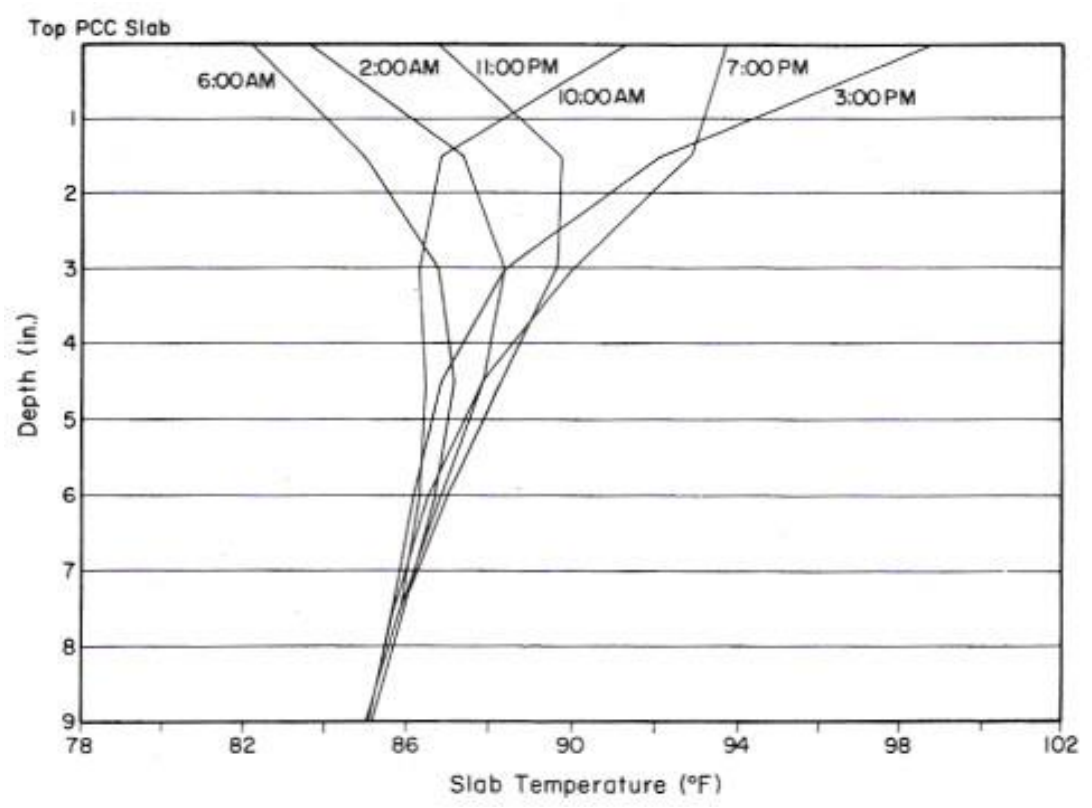

Gráfico 45. Comportamento típico diurno da temperatura. Fonte: Adaptado de Thompson, (1987).

Tabela 8. Dados utilizados retirados do gráfico 45 e utilizados para correlação.

\begin{tabular}{ccc}
\hline horário (h) & temperatura ${ }^{\circ} \mathrm{F}$ & temperatura ${ }^{\circ} \mathrm{C}$ - topo \\
\hline $02: 00$ & 82,1 & 28,6 \\
$06: 00$ & 83,6 & 27,8 \\
$10: 00$ & 86,6 & 32,8 \\
$15: 00$ & 91,0 & 36,9 \\
$19: 00$ & 93,5 & 34,2 \\
$23: 00$ & 98,4 & 30,3 \\
\hline
\end{tabular}

Fonte: Elaborado a partir dos dados analisados (2009).

A simulação para essa situação, que apresentou taxa de aquecimento de $0,5{ }^{\circ} \mathrm{C} / \mathrm{h}$, pode ser vista no gráfico 46. 


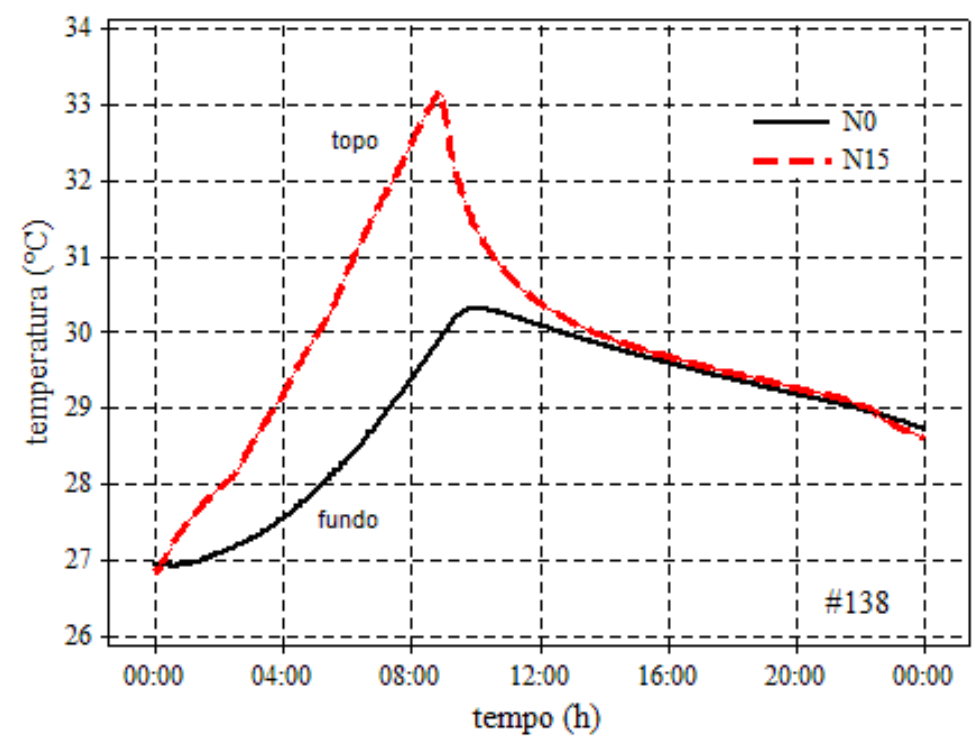

Gráfico 46. Thompson (1987) Simulação do comportamento diurno da temperatura.

Fonte: Elaborado a partir dos dados analisados (2009).

Tabela 9 Dados de temperatura de topo de ambos os experimentos

\begin{tabular}{ccc}
\hline Horário (h) & Temperatura $\left({ }^{\circ} \mathrm{C}\right)$ - Thompson & Temperatura $\left({ }^{\circ} \mathrm{C}\right)$ topo - simulação \\
\hline $6: 00$ & 27,8 & 27,9 \\
$10: 00$ & 32,8 & 29,2 \\
$15: 00$ & 36,9 & 33,2 \\
\hline
\end{tabular}

Fonte: Elaborado a partir dos dados analisados (2009).

A Tabela 9 indica os valores utilizados para correlação dos dados de temperatura do experimento de Thompson (1987) com aqueles produzidos na simulação. No gráfico 47 está indicada a correlação existente entre os dois trabalhos.

O índice de correlação aparentemente indica um distanciamento entre os dados reais e os simulados. Porém, uma correlação de $88 \%$ com poucos pontos indica haver forte coerência entre os experimentos mesmo na obtenção da taxa de aquecimento que foi de 1,0 ${ }^{\circ} \mathrm{C} / \mathrm{h}$. A correlação entre os experimentos poderia ser melhor se o artigo permitisse uma coleta de dados mais detalhada.

O gráfico 48 indica o comportamento da temperatura ao longo da espessura da placa quando submetida aos parâmetros retirados do gráfico 45. Apesar da discordância na temperatura inicial a reprodução mostrou-se bem adequada. 


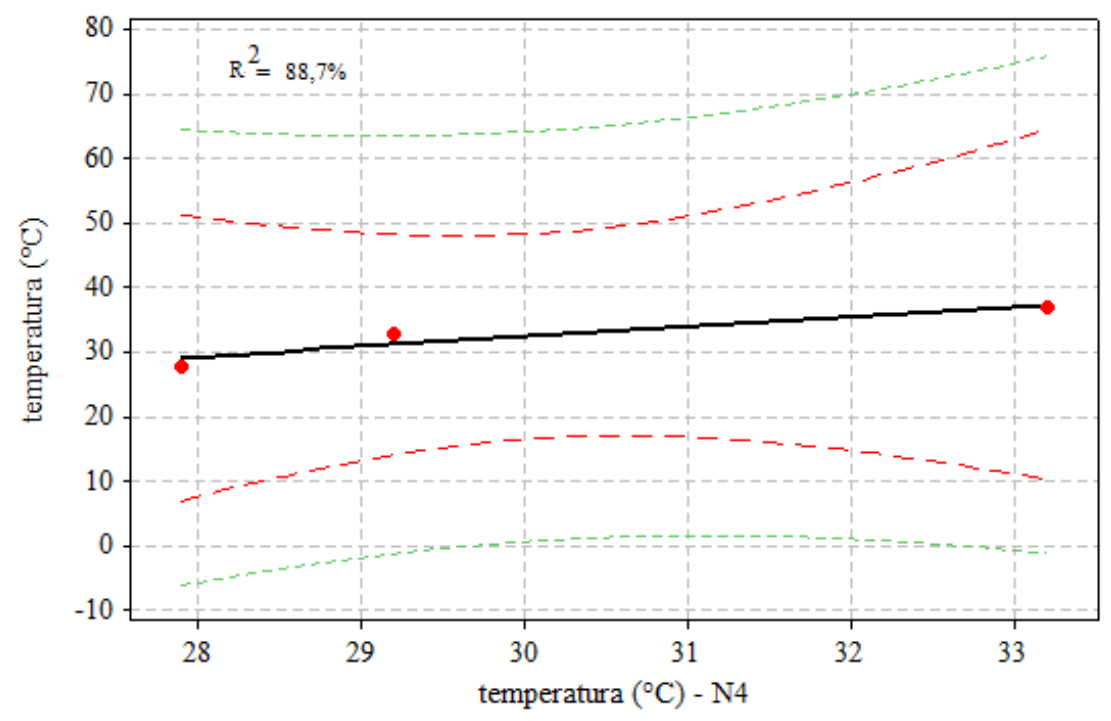

Gráfico 47. Correlação entre os dados de temperatura de ambos os experimentos, Thompson et al. (1987) e ensaio de laboratório. Intervalo de confiança 95, $0 \%, \mathrm{R}^{2}=88,7 \%$. Fonte: Elaborado a partir dos dados analisados (2009).

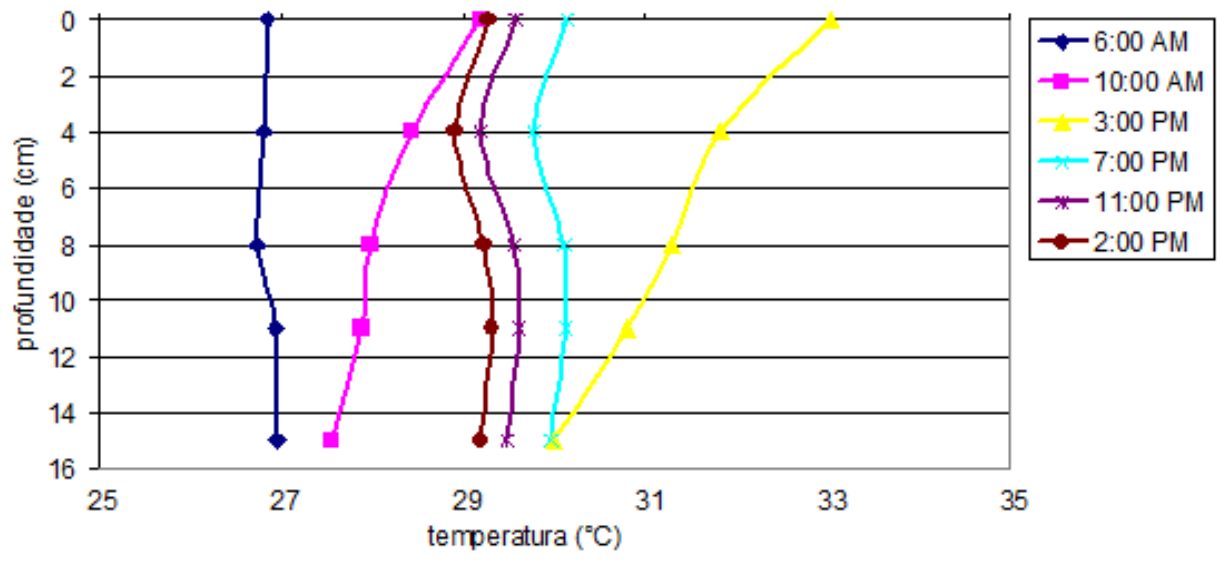

Gráfico 48. Simulação do comportamento diurno da temperatura, Thompson (1987).

Fonte: Elaborado a partir dos dados analisados (2009).

$\underline{4^{\circ} \text { trabalho }}$

O quarto artigo analisado, de Richardson e Armaghani (1987), trata do estudo de tensões causadas pelo gradiente (taxa de variação térmica) não linear da temperatura, em pavimento de teste em Gainesville, Flórida EUA.

O comportamento térmico da estrutura está apresentado através do gráfico 49 de que foram retirados os dados para a análise de regressão e tabulados na Tabela 10. 
Para efeito da simulação foi realizado um aquecimento na placa com taxa de 2,5 ${ }^{\circ} \mathrm{C} / \mathrm{h}$ semelhante ao gráfico 49 e o resultado está apresentado pelo gráfico 50 em que pode ser visto o comportamento da temperatura de topo e fundo.

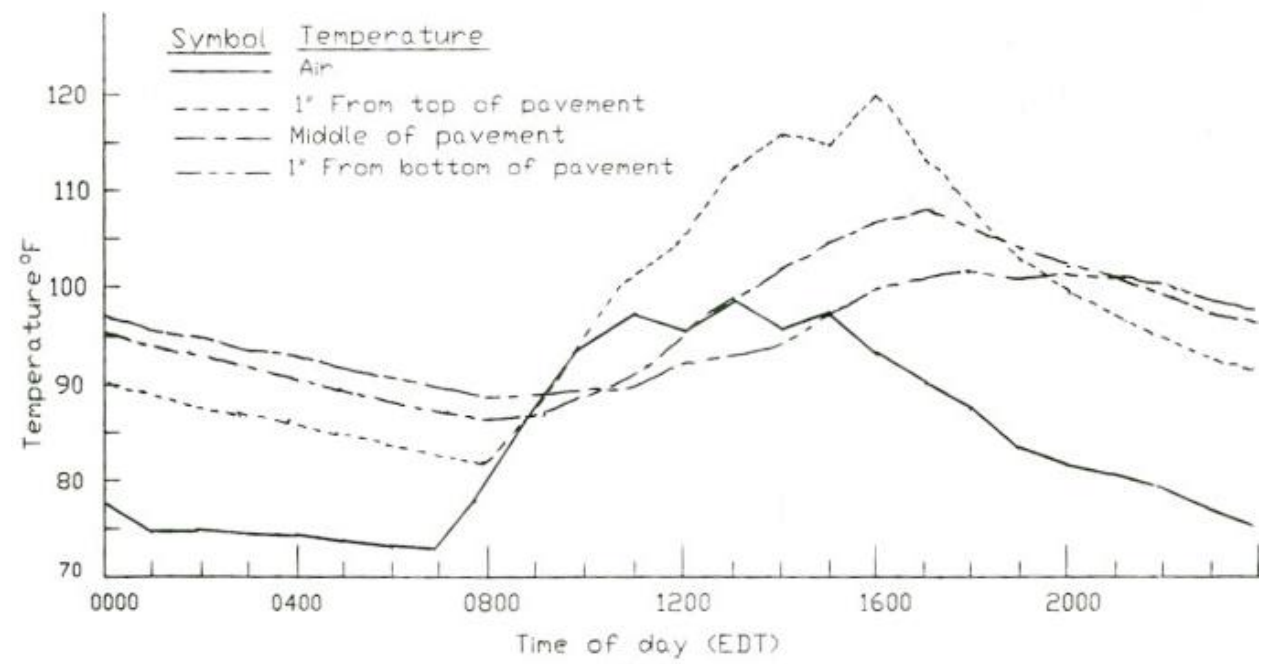

Gráfico 49. Comportamento da temperatura a $2,5 \mathrm{~cm}$ do topo, ponto médio e a $2,5 \mathrm{~cm}$ do fundo do pavimento.

Fonte: Adaptado de Richardson (1987).

Tabela 10. Dados retirados do gráfico 45 e utilizados para correlação.

\begin{tabular}{ccccccc}
\hline \multicolumn{7}{c}{ tempo $(\mathrm{h})$ e temperatura $\left({ }^{\circ} \mathrm{F}\right)$} \\
profundidade (in). & $00: 00: 00$ & $04: 00: 00$ & $08: 00: 00$ & $12: 00: 00$ & $16: 00: 00$ & $20: 00: 00$ \\
\hline 1,0 & 90,0 & 85,8 & 82,7 & 100,0 & 118,4 & 98,4 \\
2,5 & 91,6 & 87,6 & 84,9 & 100,0 & 112,9 & 100,0 \\
4,5 & 93,3 & 90,0 & 87,1 & 97,6 & 107,1 & 100,1 \\
6,5 & 94,2 & 92,9 & 88,4 & 94,9 & 102,9 & 100,2 \\
8,0 & 95,5 & 91,7 & 89,7 & 92,6 & 100,0 & 100,3 \\
\hline profundidade (cm). & $*$ & tempo $(\mathrm{h})$ e temperatura $\left({ }^{\circ} \mathrm{C}\right)$ & $*$ & $*$ & $*$ \\
\hline 2,5 & 32,2 & 29,9 & 28,1 & 37,8 & 48,0 & 36,9 \\
6,4 & 33,1 & 30,9 & 29,4 & 37,8 & 44,9 & 37,8 \\
11,4 & 34,1 & 32,2 & 30,6 & 36,4 & 41,7 & 37,8 \\
16,5 & 34,6 & 33,8 & 31,4 & 34,9 & 39,4 & 37,9 \\
20,3 & 35,3 & 33,2 & 32,1 & 33,7 & 37,8 & 37,9 \\
\hline
\end{tabular}

Fonte: Elaborado a partir dos dados analisados (2009).

O gráfico 51, com os dados da Tabela 11 retirados de ambos experimentos, apresenta a correlação entre o experimento de Richardson e Armaghani (1987) e a simulação realizada em laboratório. Cabe ressaltar que as temperaturas de topo não foram colhidas de forma semelhante, ou seja, enquanto no trabalho de Richardson as leituras foram feitas a 2,5 
$\mathrm{cm}$ do topo, as leituras do presente trabalho foram efetuadas a menos de $1,0 \mathrm{~cm}$ do topo. No entanto observa-se uma correlação muito forte.

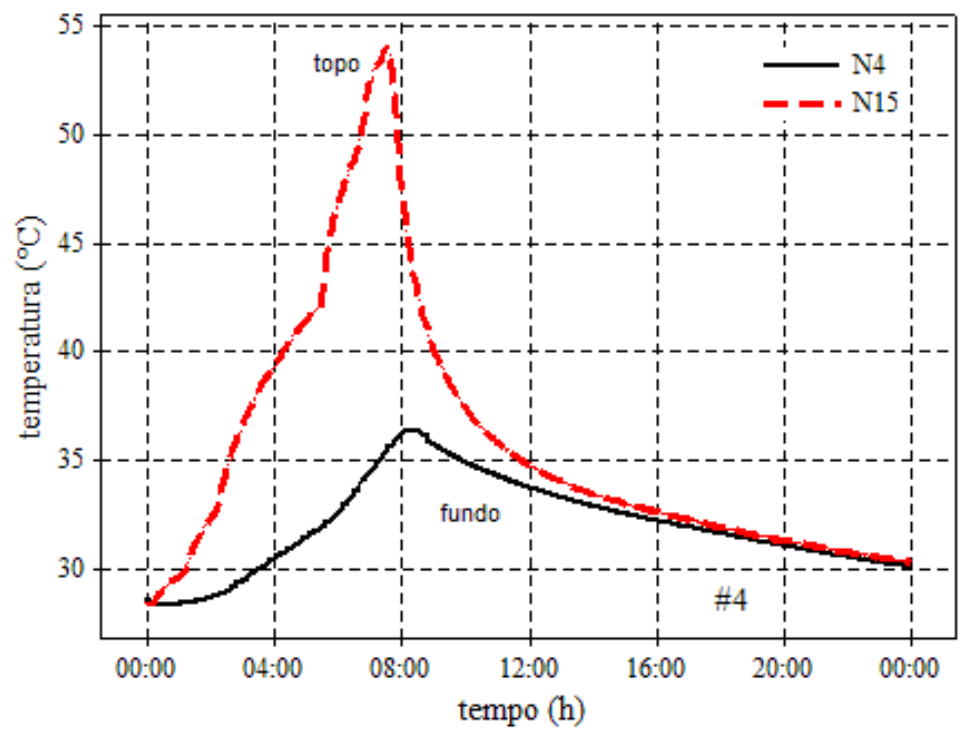

Gráfico 50. Simulação de Richardson e Armaghani (1987).

Fonte: Elaborado a partir dos dados analisados (2009).

Tabela 11. Dados de temperatura de topo de ambos os experimentos

\begin{tabular}{ccc}
\hline instante $(\mathrm{h})$ & temperatura $\left({ }^{\circ} \mathrm{C}\right)$ (Richardson) & temperatura $\left({ }^{\circ} \mathrm{C}\right)$ (simulada) \\
\hline $08: 00$ & 27,6 & 28,4 \\
$10: 00$ & 35,2 & 32,4 \\
$12: 00$ & 40,6 & 39,3 \\
$14: 00$ & 46,3 & 43,8 \\
$16: 00$ & 48,5 & 47,3 \\
\hline
\end{tabular}

Fonte: Elaborada a partir dos dados analisados (2009).

Apesar da apresentação do comportamento temporal ao longo da espessura da placa do artigo não ser a mais usual, é possível, por meio dos dados aquisitados pela simulação realizar uma representação gráfica de tal comportamento. Isso pode ser visto no gráfico 52 que representa os dados reais em campo e, o gráfico 53, que representa a simulação em laboratório. 


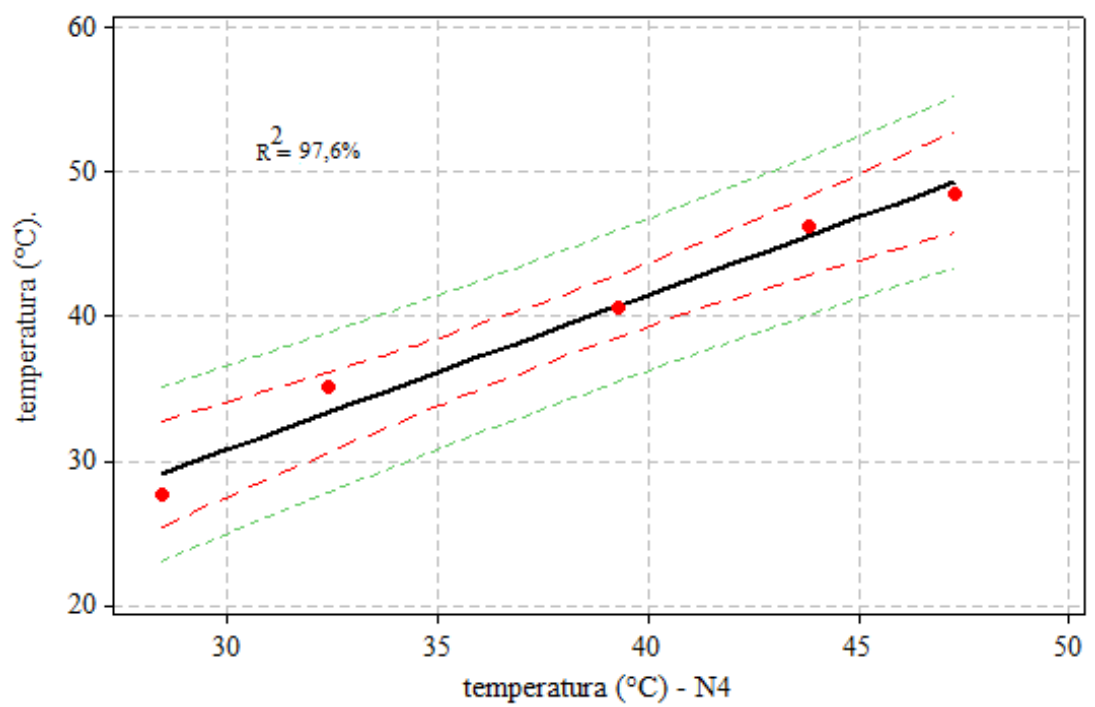

Gráfico 51. Correlação entre os dados de temperatura de ambos os experimentos, Richardson e Armaghani (1987) e ensaio de laboratório. Intervalo de confiança 95,0\%, $\mathrm{R}^{2}=97,6 \%$.

Fonte: Elaborado a partir dos dados analisados (2009).
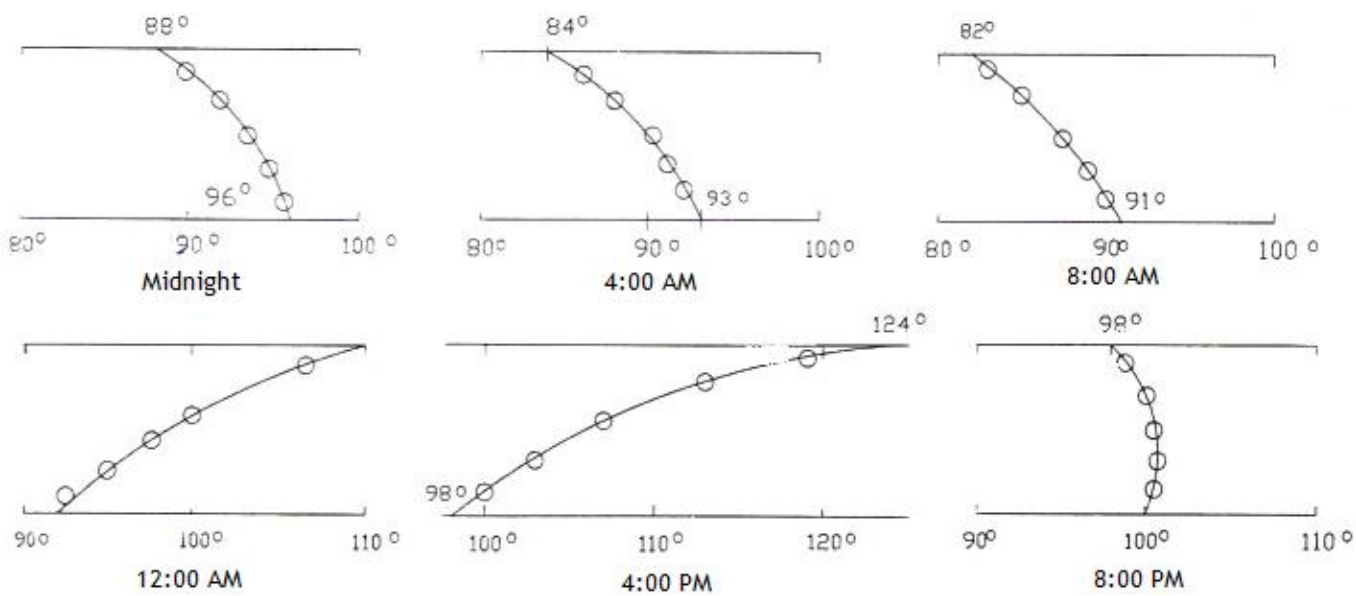

Gráfico 52. Comportamento da temperatura a 2,5 cm do topo, ponto médio e a $2,5 \mathrm{~cm}$ do fundo do pavimento.

Fonte: Adaptado a partir dos dados de Richardson e Armaghani (1987). 


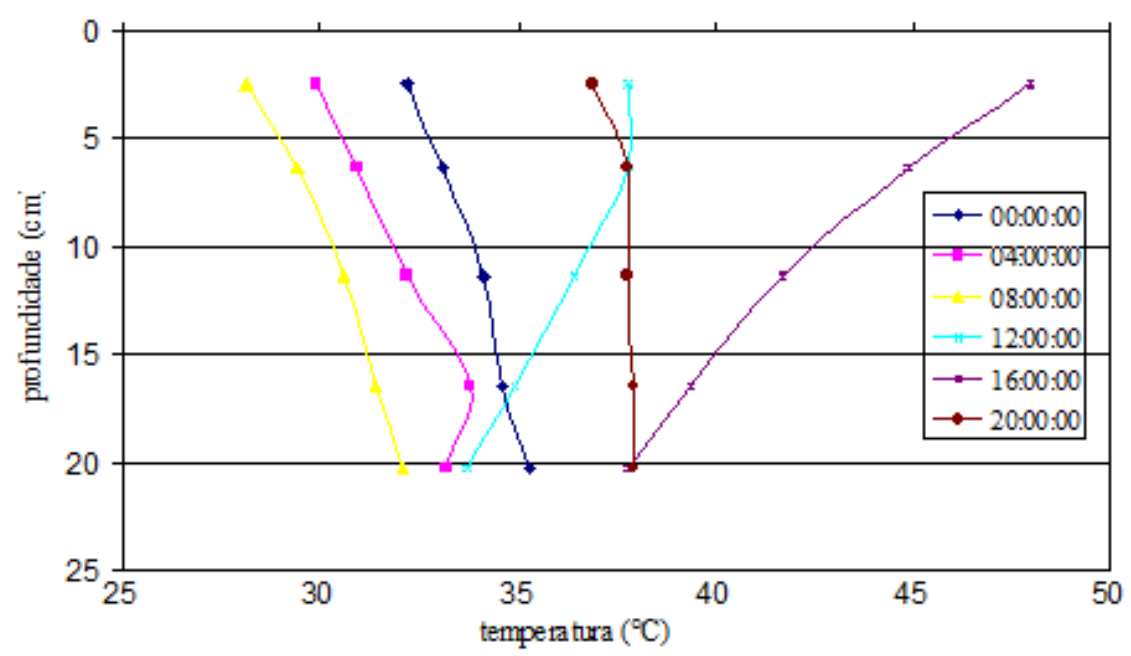

Gráfico 53. Simulação de Richardson e Armaghani (1987)

Fonte: Elaborado a partir dos dados analisados (2009).

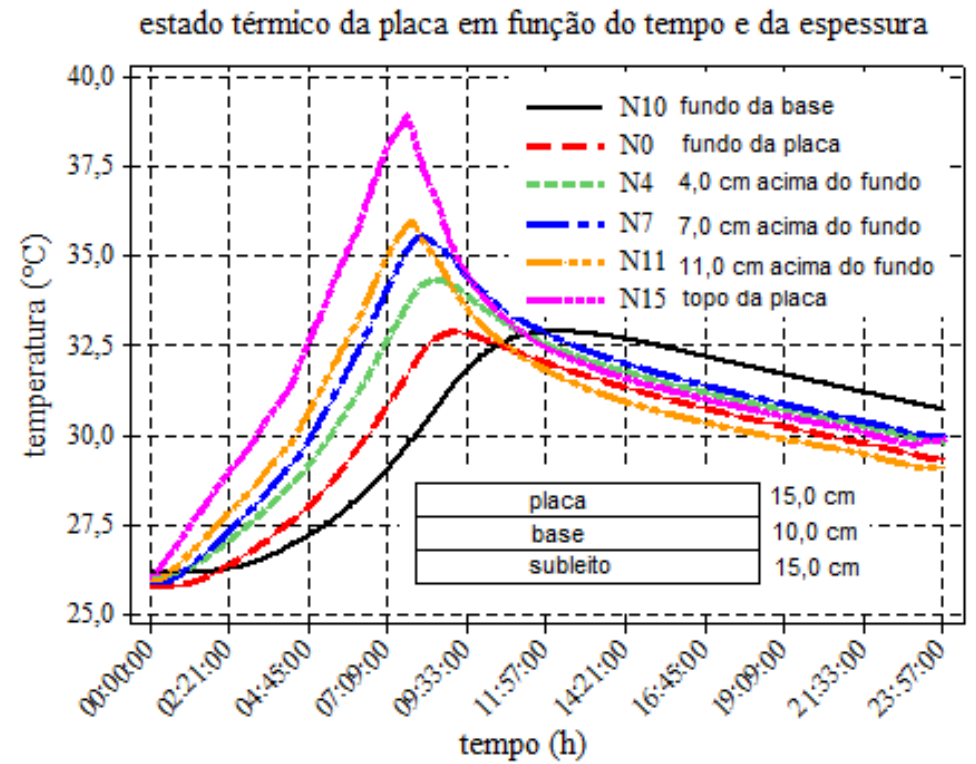

Gráfico 54. Aspecto do comportamento temporal da temperatura ao longo da espessura da placa do pavimento.

Fonte: Elaborado a partir dos dados analisados (2009). 


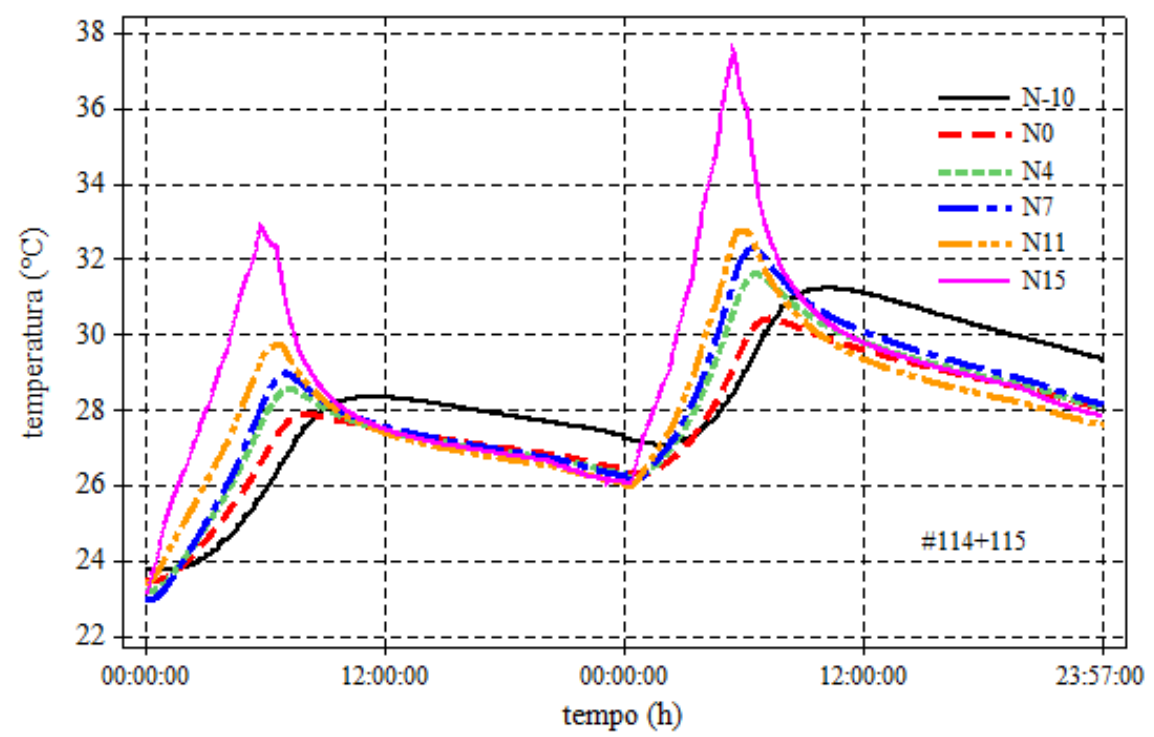

Gráfico 55. . Aspecto do comportamento temporal da temperatura ao longo da espessura da placa do pavimento.

Fonte: Elaborado a partir dos dados analisados (2009).

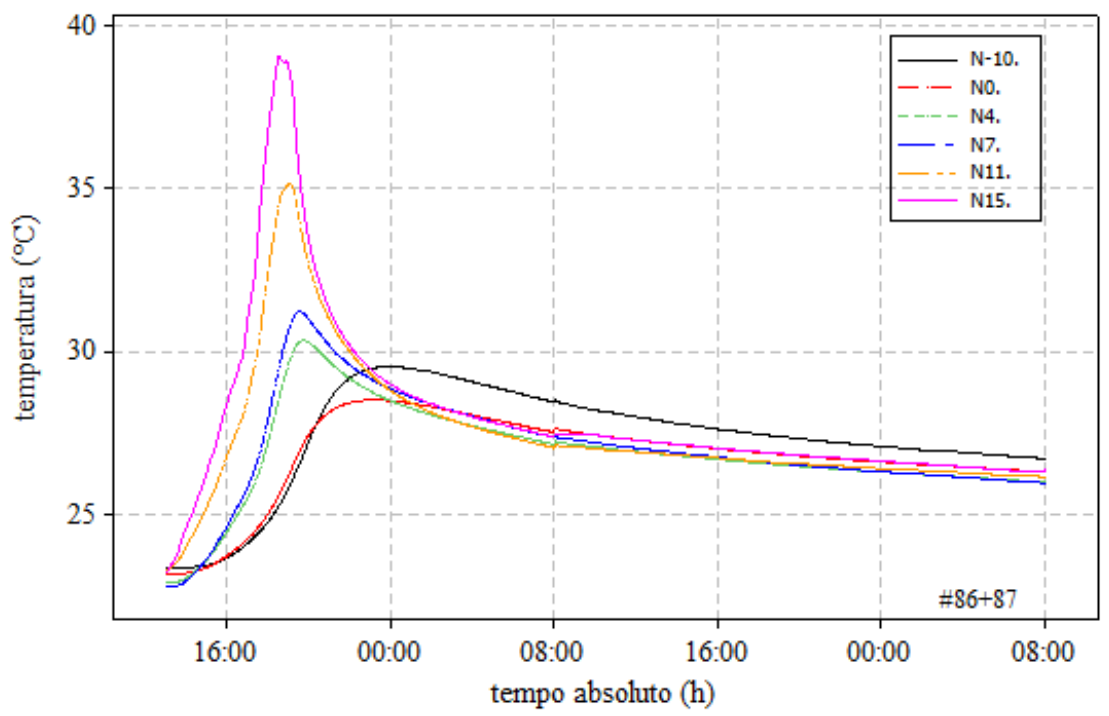

Gráfico 56. Aspecto do comportamento temporal da temperatura ao longo da espessura da placa do pavimento num período de 48 horas.

Fonte: Elaborado a partir dos dados analisados (2009).

O aspecto da distribuição da temperatura, em função das dimensões tempo e espessura está ilustrada através dos gráficos 57,58 e 59. 


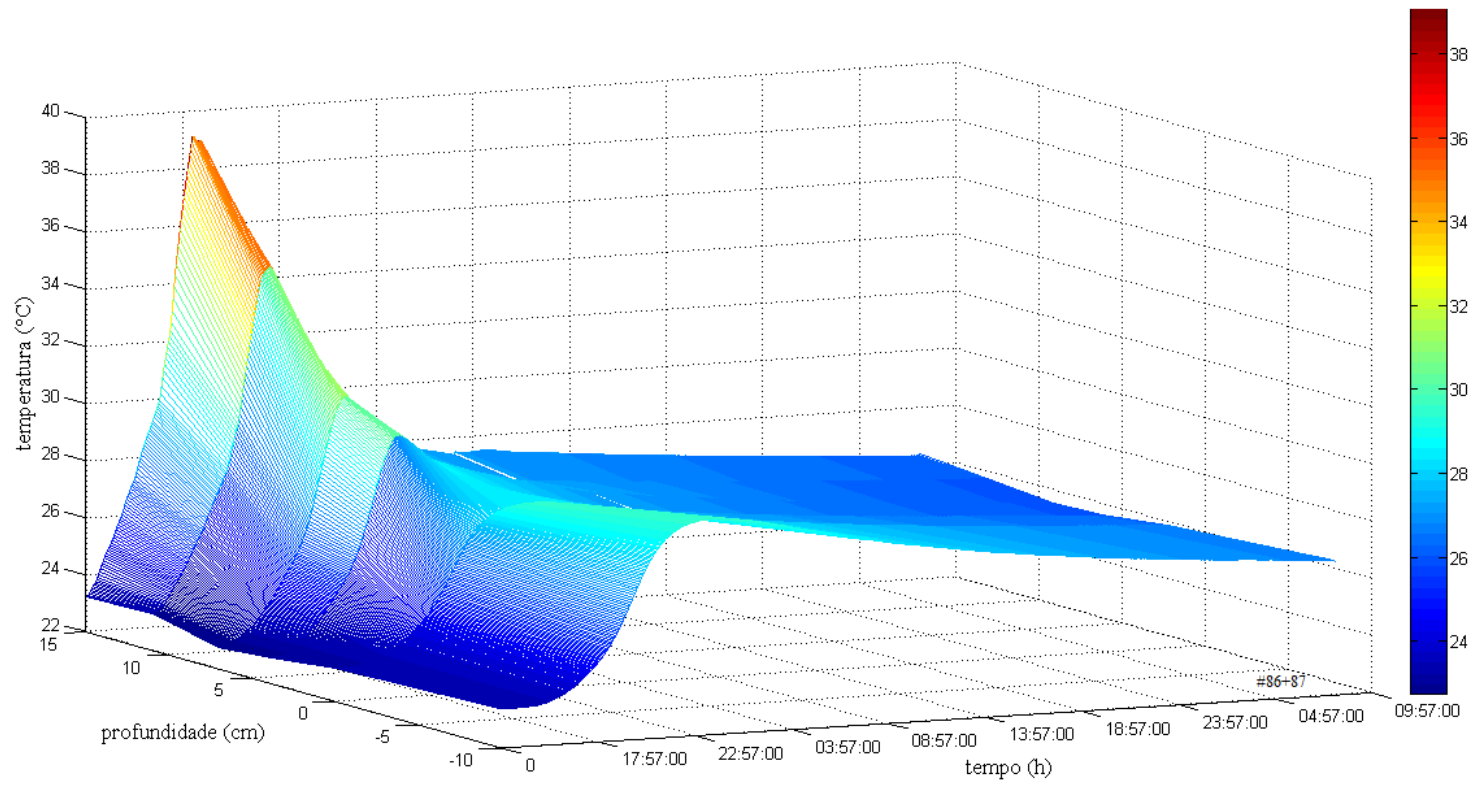

Gráfico 57. Distribuição da temperatura ao longo da espessura e sua dependência com o tempo.

Fonte: Elaborado a partir dos dados analisados (2009).

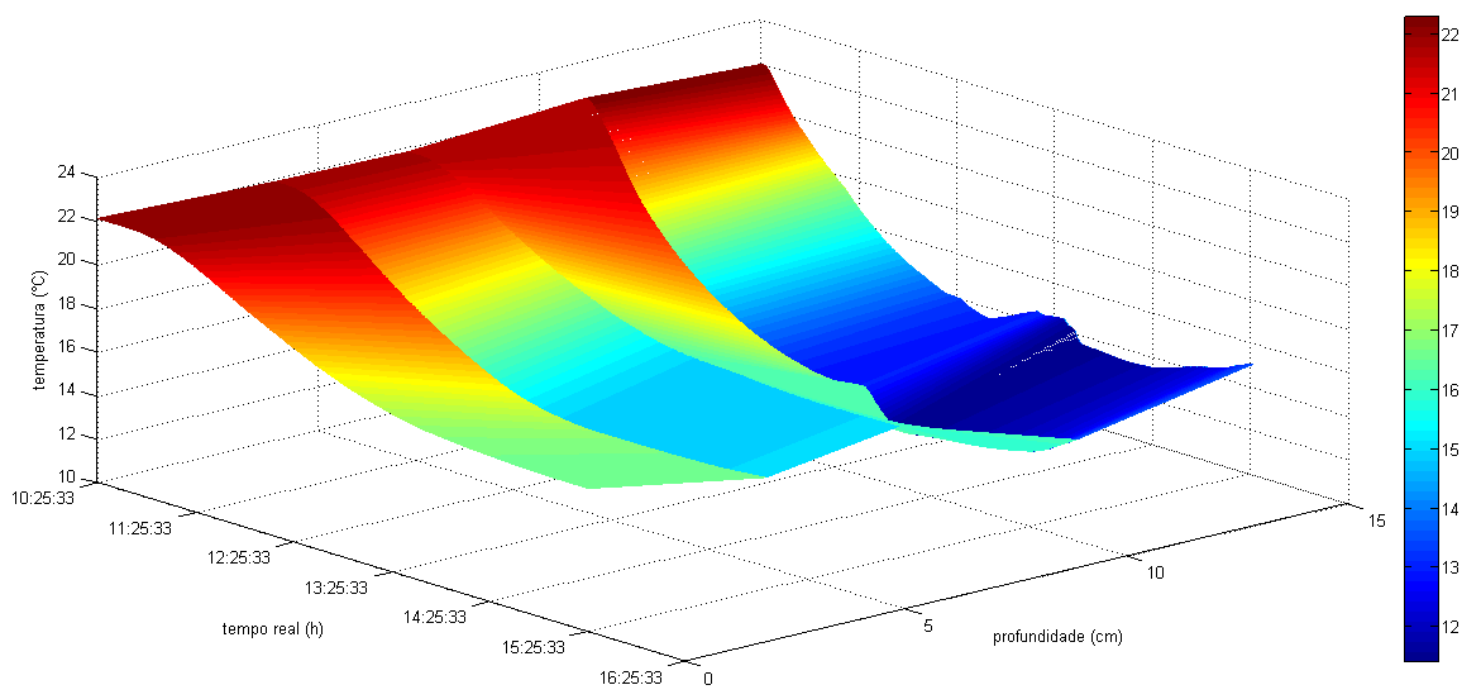

Gráfico 58 Distribuição da temperatura ao longo da espessura e sua dependência com o tempo. Situação quando o topo da placa foi resfriado com gelo.

Fonte: Elaborado a partir dos dados analisados (2009). 


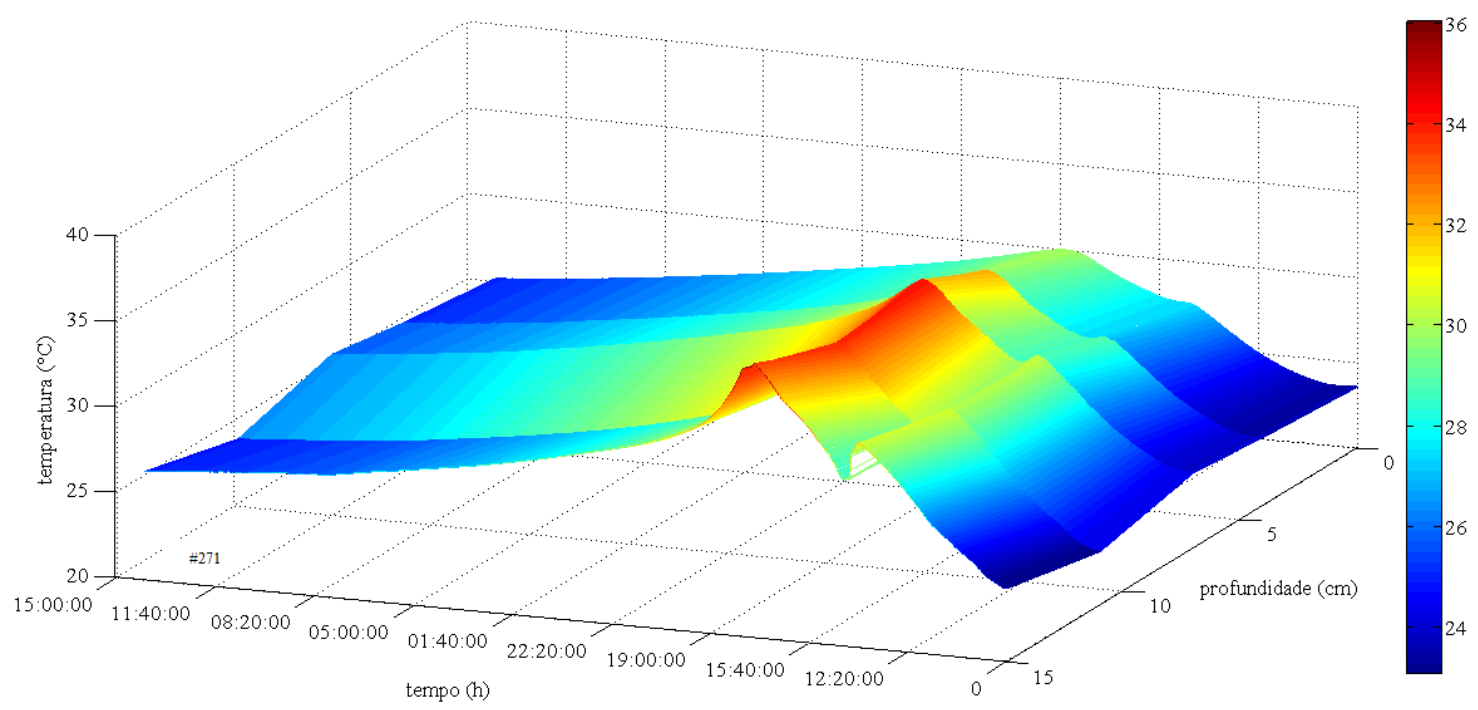

Gráfico 59 Distribuição da temperatura ao longo da espessura e sua dependência com o tempo. Situação quando o topo da placa foi molhado, simulando chuva.

Fonte: Elaborado a partir dos dados analisados (2009).

Os sub-itens 4.1 e 4.2 mostraram que, sob diversas situações que as simulações de estados térmicos corresponderam a visão de não linearidade da temperatura ao longo da placa. Verificou-se que a hipótese de níveis de temperatura, tomada pelo conjunto de termômetros, mostrou-se satisfatória e correspondeu com os dados reais. Processos naturais como ciclos repetidos e resfriamento abrupto da placa e foram apresentados por intermédio de gráficos. Tal como visto através do gráfico 54 , como a placa do pavimento se comporta mediante a um ciclo de 24 horas com um período de aquecimento de 8 horas e um período de resfriamento de 16 horas. Nota-se que no ciclo de resfriamento, as temperaturas das fibras mais inferiores se sobrepõem às superiores e que a base tende a apresentar uma concavidade convexa, enquanto que a placa tende a apresentar uma concavidade côncova.

Com relação aos ciclos repetidos, como visto gráfico 1, a metodologia permitiu tal simulação e, uma delas, é vista no gráfico 55. Nota-se que o fim de um período e começo do outro, não obedece as características vistas em campo. Isso se deve ao processo de resfriamento que se dá de forma mais lenta dentro do laboratório. Para comprovar essa deficiência, o pavimento foi posto a aquecer durante um período de oito horas e deixado esfriar por 48 horas. Dois fatos ficam evidentes, o ambiente do laboratório não reproduz eficientemente trocas de calor, como o meio natural faria. Outra evidência é a comprovação da diferença dos estados térmicos dos componentes da estrutura, ou seja, enquanto a placa 
apresenta uma curvatura côncava, a base se apresenta convexa. Esses efeitos podem ser vistos no gráfico 56.

Com respeito às simulações numéricas, deve-se ressaltar que o processo de aquecimento da superfície do pavimento não é descrito em nenhum dos softwares pesquisados, tais como FEACONS, ISLAB 2000 e EverFE.

Com a finalidade de ilustrar e apresentar uma visão mais clara e abrangente, três situações analisadas (gráficos 57, 58 e 59), foram expostas em gráficos tridimensionais e mostram a distribuição da temperatura em função da espessura e do tempo. A principal função destes gráficos foi a de consolidar uma visão mais crítica do comportamento não linear da distribuição da temperatura.

\subsection{CARREGAMENTO ESTÁTICO NO CENTRO E BORDA DA PLACA}

Para o estudo de empenamento foram gerados diferencias de temperatura, a partir do topo da placa mantendo o fundo na temperatura ambiente e, posteriormente, aquecendo seu fundo mantendo o topo na temperatura ambiente. Esse procedimento visou realizar o empenamento, tanto na forma côncova como convexa. Como referência para as análises, foi realizada uma calibração entre força aplicada sobre o pavimento e a força medida pela célula de carga (transtec), localizada no fundo da placa. A força aplicada nos testes foi de tal forma a produzir uma pressão de $0,548 \mathrm{MPa}\left(5,60 \mathrm{kgf} / \mathrm{cm}^{2}\right)$ sobre a placa de concreto. Isso foi conseguido pelo sistema hidráulico que aplicou uma força sobre um apoio retangular de 279,0 $\mathrm{cm}^{2}$, feito com um bloco de madeira e um elastômero, situação ilustrada no desenho 45 .

$\mathrm{O}$ valor de $0,548 \mathrm{MPa}$ foi retirado do conceito de eixo padrão rodoviário formado por um eixo simples de rodas duplas com as seguintes características:

a) Carga por Eixo (q): 8,2 tf $=>80,0 \mathrm{kN}$

b) Carga por roda (q/4): 2041,0 kgf $=2,04 \mathrm{tf}=>20,0 \mathrm{kN}$

c) Pressão de inflação dos Pneus (p): $80,0 \mathrm{lb} / \mathrm{pol}^{2}=>5,60 \mathrm{kgf} / \mathrm{cm}^{2}=>0,55 \mathrm{MPa}$

d) Pressão de Contato Pneu-Pavimento (pq): $5,6 \mathrm{kgf} / \mathrm{cm}^{2}=>0,55 \mathrm{MPa}$

e) Raio da Área de Contato Pneu-Pavimento (r): 10,8 cm, afastamento entre eixos de rodas: $32,4 \mathrm{~cm}$.

Para efeito de simulação, foi considerado apenas um apoio como se fosse um veículo de eixo simples e rodas simples (ESRS) que, pela legislação vigente, a carga possível por pneu é 30,0 kN (BALBO, 2007). 

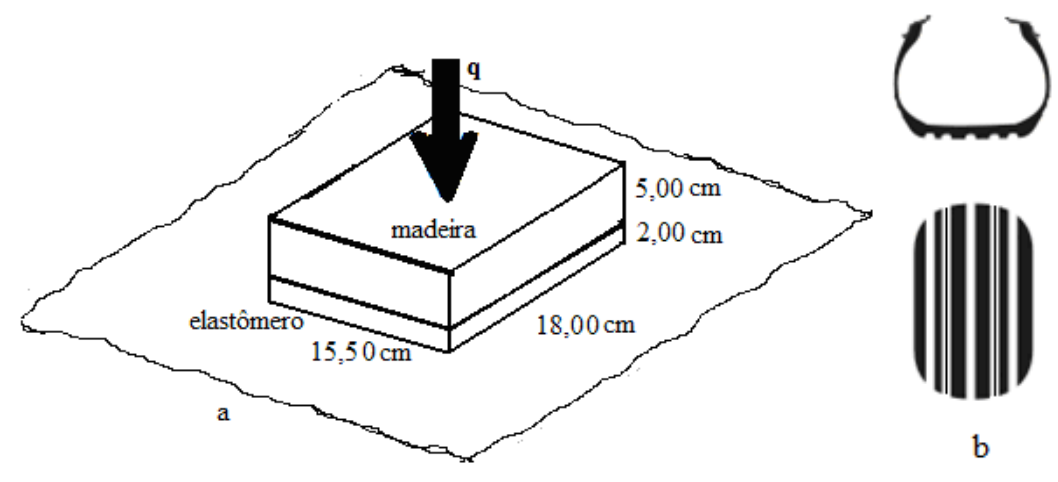

Desenho 45. (a) Bloco de madeira serviu de suporte para a aplicação da carga (q) e o elastômero que serviu como ajuste de nivelamento para a aplicação da carga e também como simulação das características dos pneus dos veículos, (b) Imprimação do formato de um pneu sobre um pavimento.

Fonte: Acervo próprio 2009.

Essa calibração foi realizada com o pavimento livre de tensões induzidas por diferenciais térmicos, ou seja, temperatura de topo igual a temperatura de fundo (estrutura em equilíbrio térmico com o ambiente). O gráfico 60 mostra a relação entre o carregamento aplicado no centro do pavimento e a força percebida pela placa.

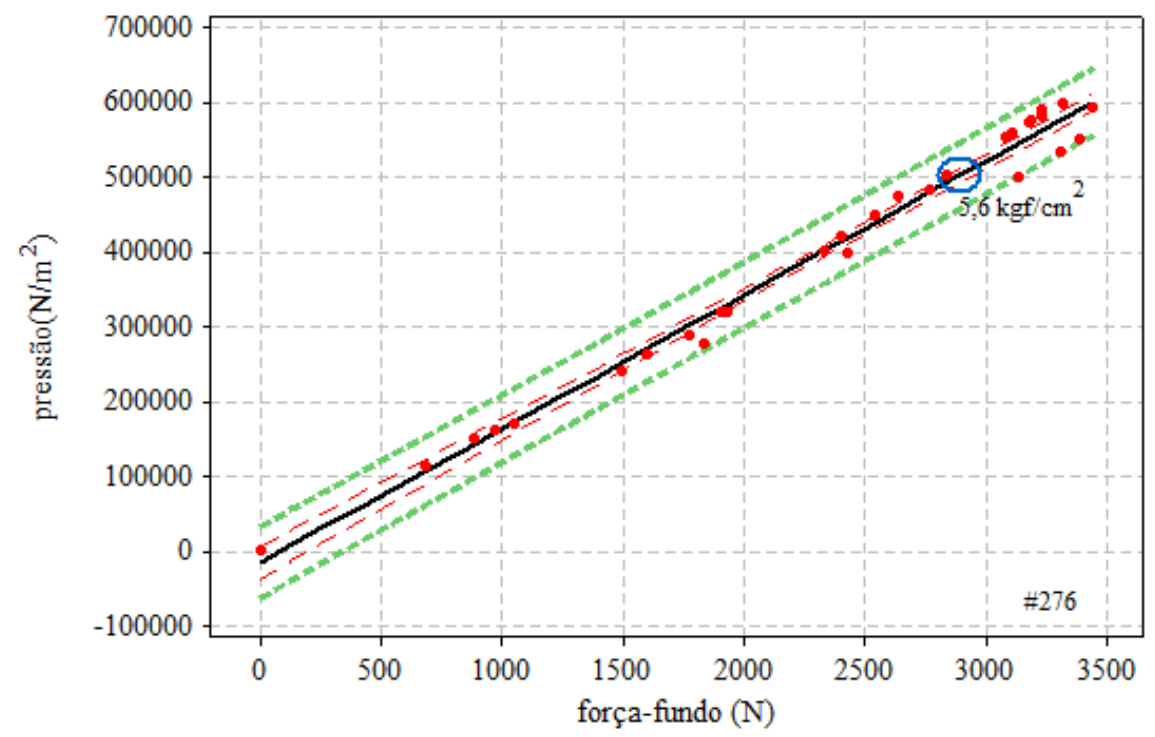

Gráfico 60. Relação entre o carregamento sobre a placa de concreto pela força registrada no fundo da placa pela célula de carga (tanstec), intervalo de confiança 95\% e $\mathrm{R}^{2}=99,5 \%$.

Fonte: Elaborado a partir dos dados analisados (2009). 
A aplicação dos carregamentos variou desde $0,0 \mathrm{~N}$ até $15289,2 \pm 0,3 \mathrm{~N}$ $(1563,3 \pm 0,3 \mathrm{~kg} f)$ com uma velocidade de $1,0 \pm 0,2 \mathrm{~mm} / \mathrm{s}$. Como o controle foi realizado manualmente valores acima do estabelecido também foram computados.

Os deslocamentos da placa foram monitorados por um sensor potenciométrico, capaz de registrar leituras de décimos de milímetro com incerteza de 0,005 $\mathrm{mm}$. Ele foi colocado em duas posições distintas, no canto esquerdo do pavimento e na borda, no ponto médio do comprimento do pavimento. A fotografia 26 mostra o sensor e, em planta baixa, as posições onde foram efetuadas as medidas.

O gráfico 61 mostra o comportamento da placa mediante um carregamento central e medidas de deslocamento efetuadas na borda lateral da placa no ponto médio da aresta. Uma simulação, com dados semelhantes, foi realizada no software EverFe 2.24 e, os resultados são mostrados através do gráfico 62.
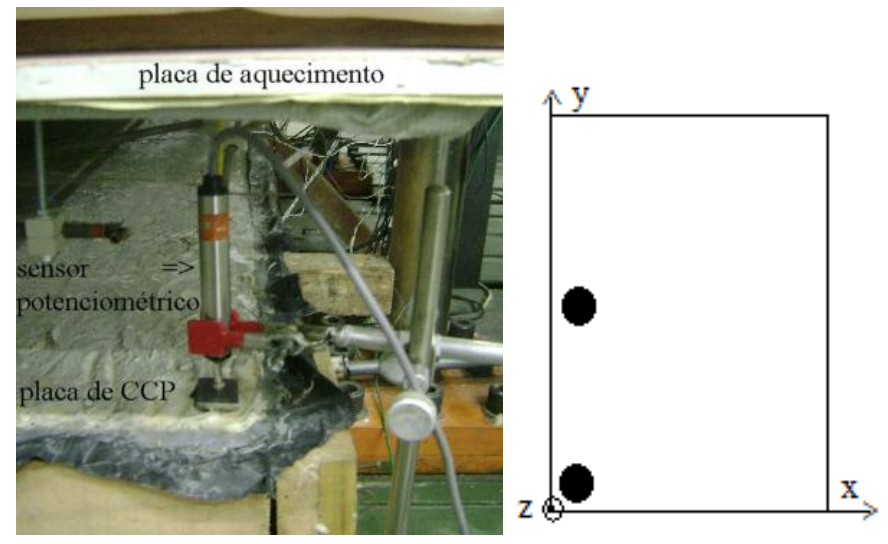

Fotografia 26. Sensor colocado no canto do pavimento para medida de deslocamento e, no desenho ao lado, as posições de medida dos deslocamentos.

Fonte: Acervo Próprio (2009). 


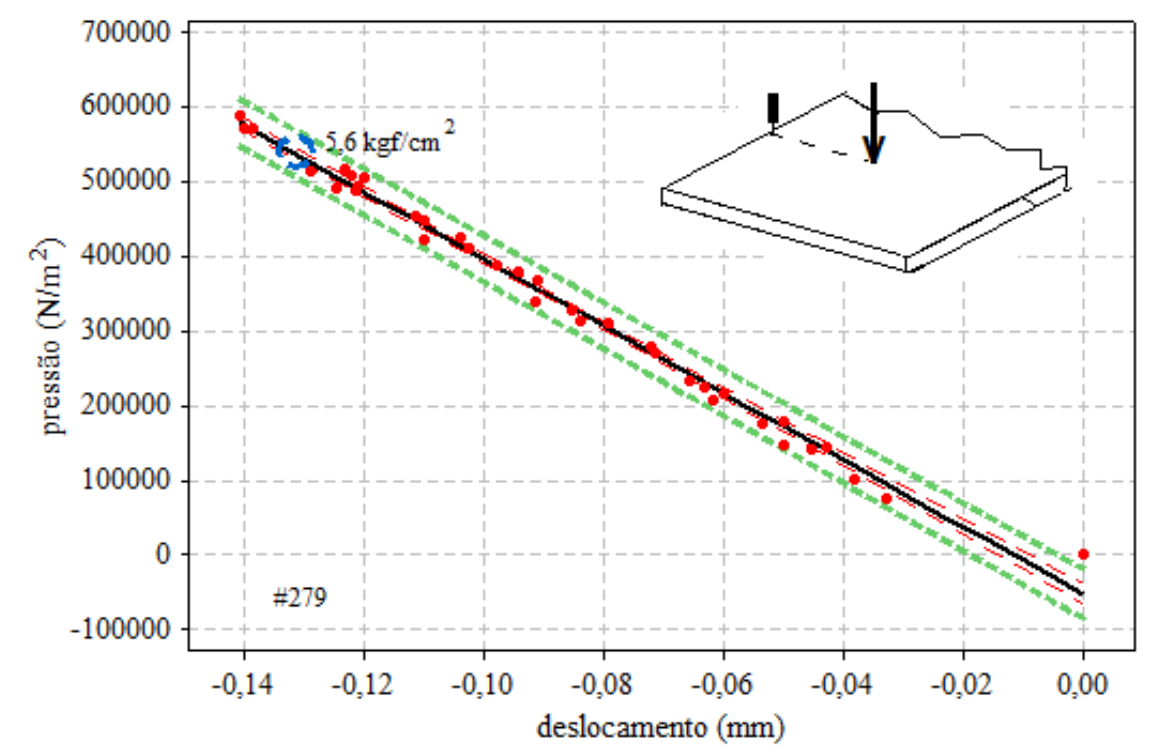

Gráfico 61 Deslocamento medido na lateral esquerda no sentido transversal em $(\mathrm{x}, \mathrm{y} / 2)$ devido a um carregamento central. Intervalo de confiança $95 \%$ e $\mathrm{R}^{2}=99,7 \%$.

Fonte: Elaborado a partir dos dados analisados (2009).

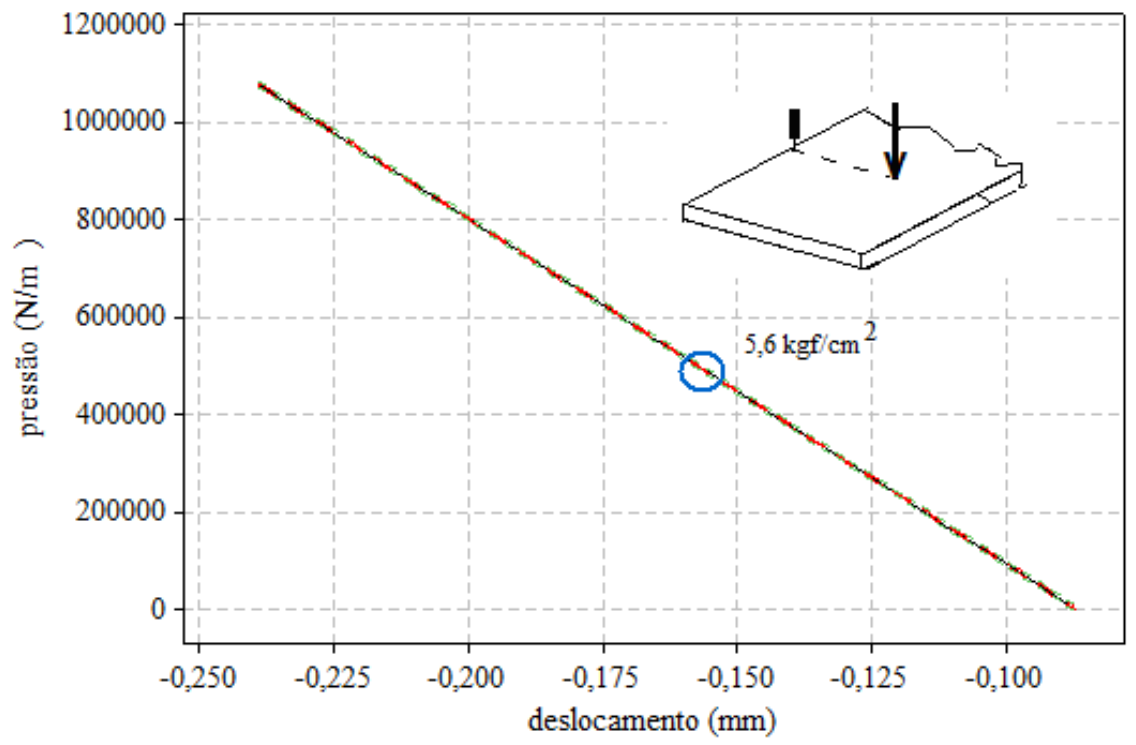

Gráfico 62 Deslocamento medido na lateral esquerda no sentido transversal em (x,y/2) devido a um carregamento central. Simulação no software EverFe 2.24. Intervalo de confiança $95 \%$ e $\mathrm{R}^{2}=100,0 \%$.

Fonte: Elaborado a partir dos dados analisados (2009).

O gráfico 63 mostra o resultado de um carregamento central com medida de deslocamento realizada no canto esquerdo da placa. Acompanhando esse teste, uma simulação, com as mesmas características, foi realizada pelo software EverFe e o resultado encontra-se no gráfico 64. 


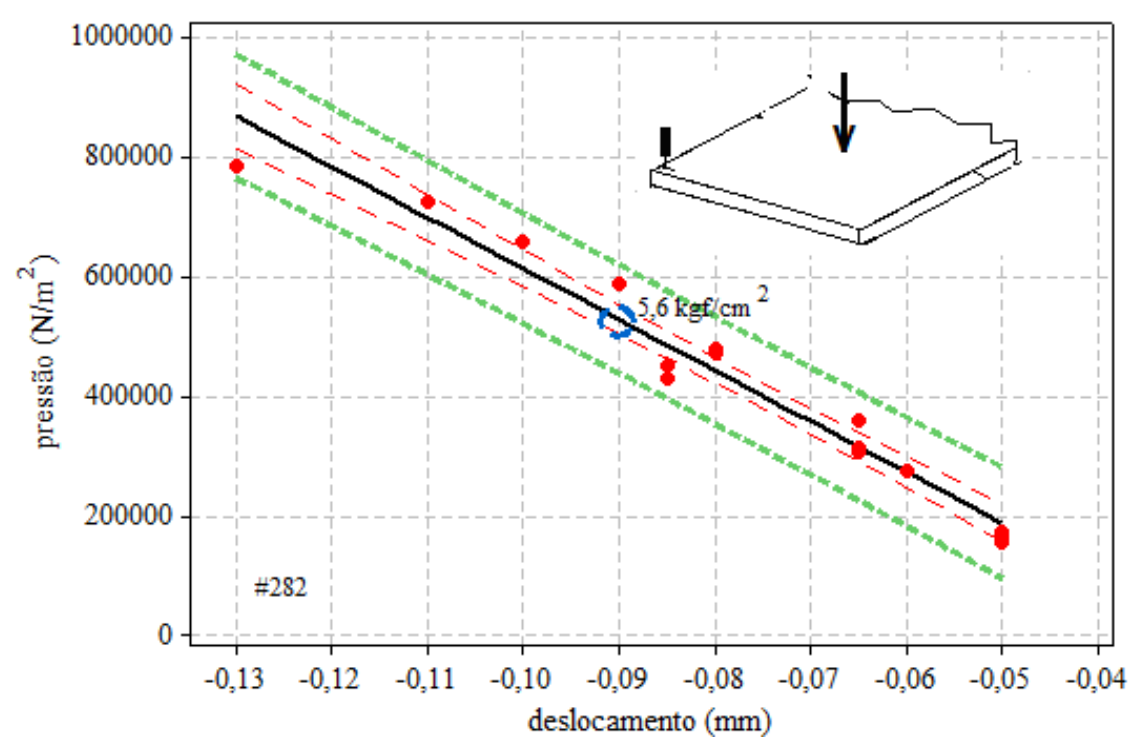

Gráfico 63 Deslocamento medido no canto esquerdo devido a um carregamento no centro da placa. Intervalo de confiança $95 \%$ e $\mathrm{R}^{2}=96 \%$.

Fonte: Elaborado a partir dos dados analisados (2009).

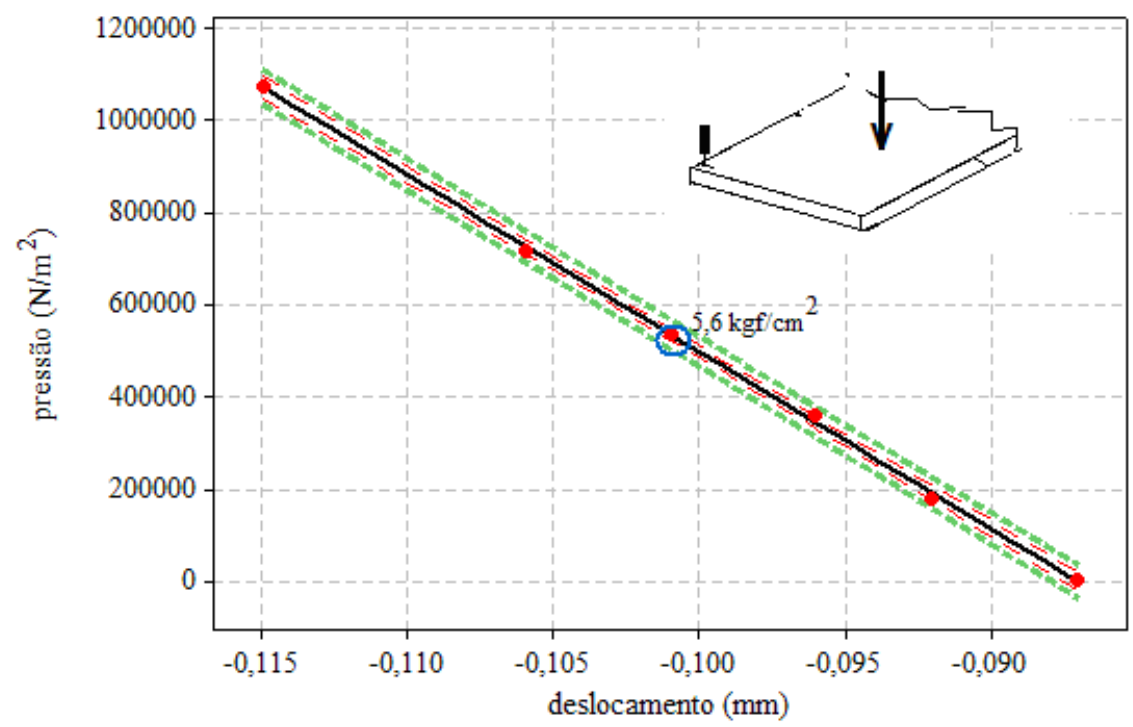

Gráfico 64 Deslocamento medido no canto esquerdo devido a um carregamento no centro da placa. Simulação realizada no sotware EverFe 2.24. Intervalo de confiança $95 \%$ e $\mathrm{R}^{2}=99,7 \%$.

Fonte: Elaborado a partir dos dados analisados (2009).

Para carregamentos na borda, foram realizados experimentos distintos com medidas efetuadas no centro e canto.

O gráfico 65 mostra o resultado do deslocamento frente a aplicação de força. $\mathrm{O}$ gráfico 66 mostra a simulação do mesmo teste realizado no EverFe. 


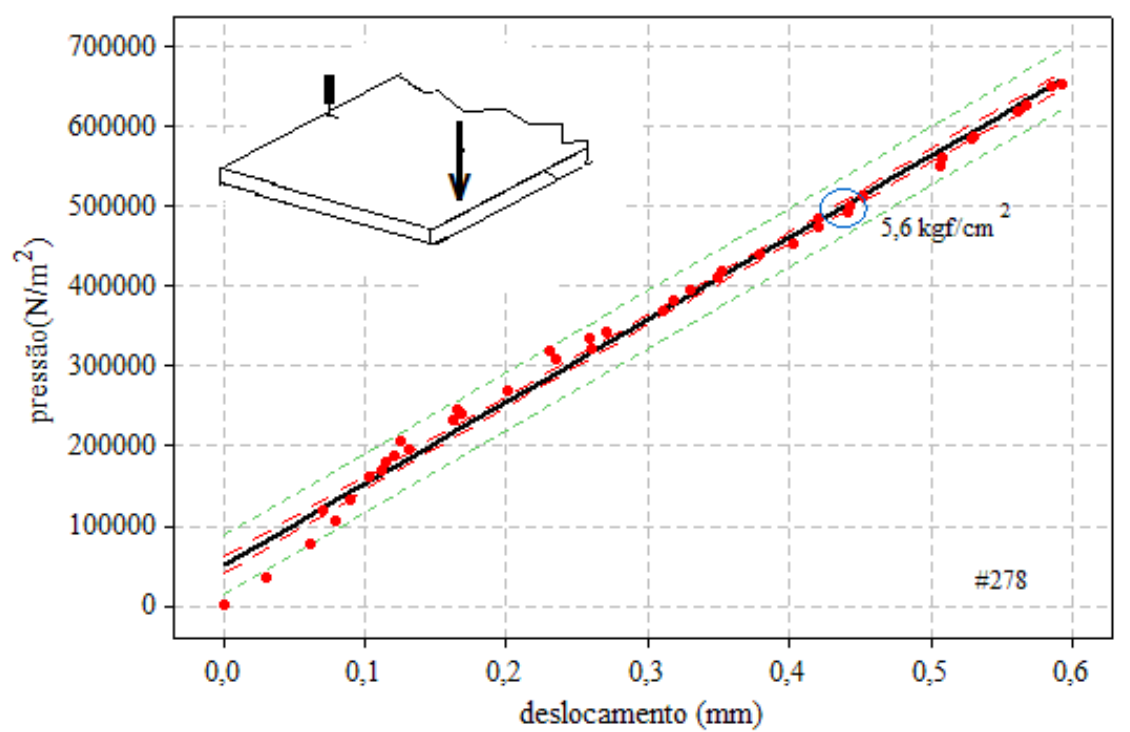

Gráfico 65. Deslocamento medido na lateral esquerda no sentido transversal em $(\mathrm{x}, \mathrm{y} / 2)$ devido a um carregamento na borda direita. Intervalo de confiança $95 \%$ e $\mathrm{R}^{2}=99,1 \%$.

Fonte: Elaborado a partir dos dados analisados (2009).

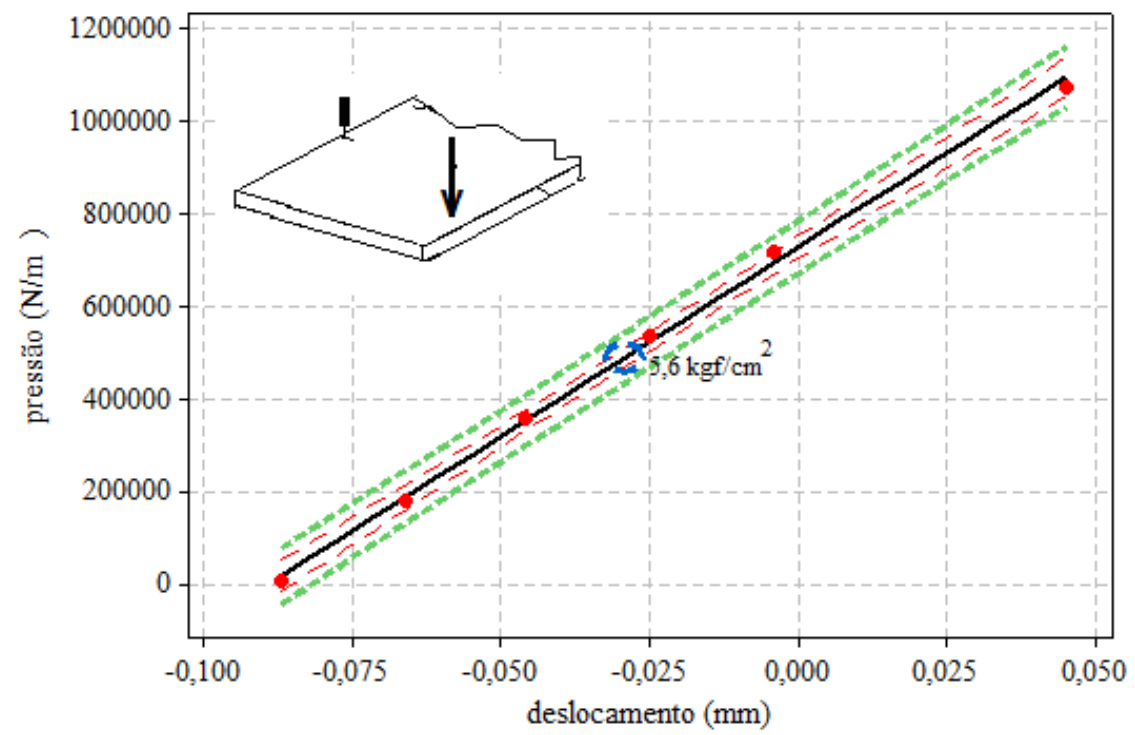

Gráfico 66. Deslocamento medido na lateral esquerda no sentido transversal em (x,y/2) devido a um carregamento na borda direita. Simulação no software EverFe 2.24. Intervalo de confiança $95 \%$ e $\mathrm{R}^{2}=99,8 \%$.

Fonte: Elaborado a partir dos dados analisados (2009).

Os resultados das medidas de deslocamento no canto, com carregamento na borda, encontra-se no gráfico 67. A simulação, com respeito aos deslocamentos, encontra-se no gráfico 68. 


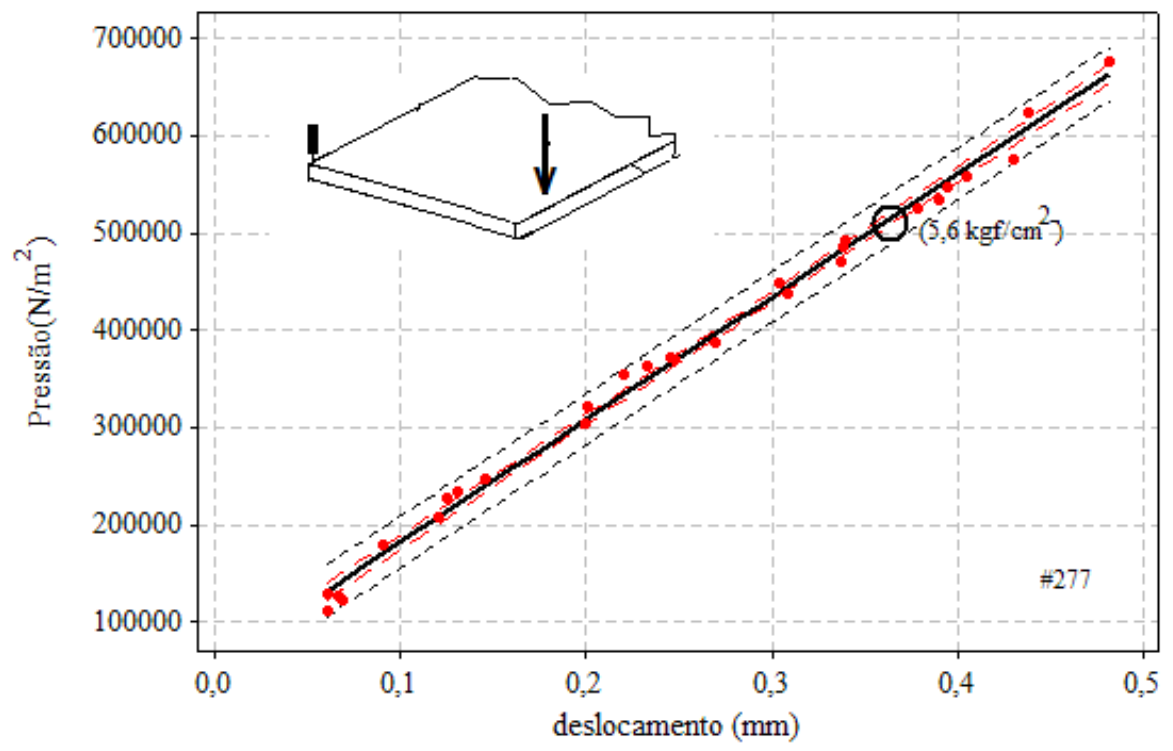

Gráfico 67. Deslocamento medido no canto esquerdo a um carregamento na borda direita. Intervalo de confiança $95 \%$ e $\mathrm{R}^{2}=99,2 \%$.

Fonte: Elaborado a partir dos dados analisados (2009).

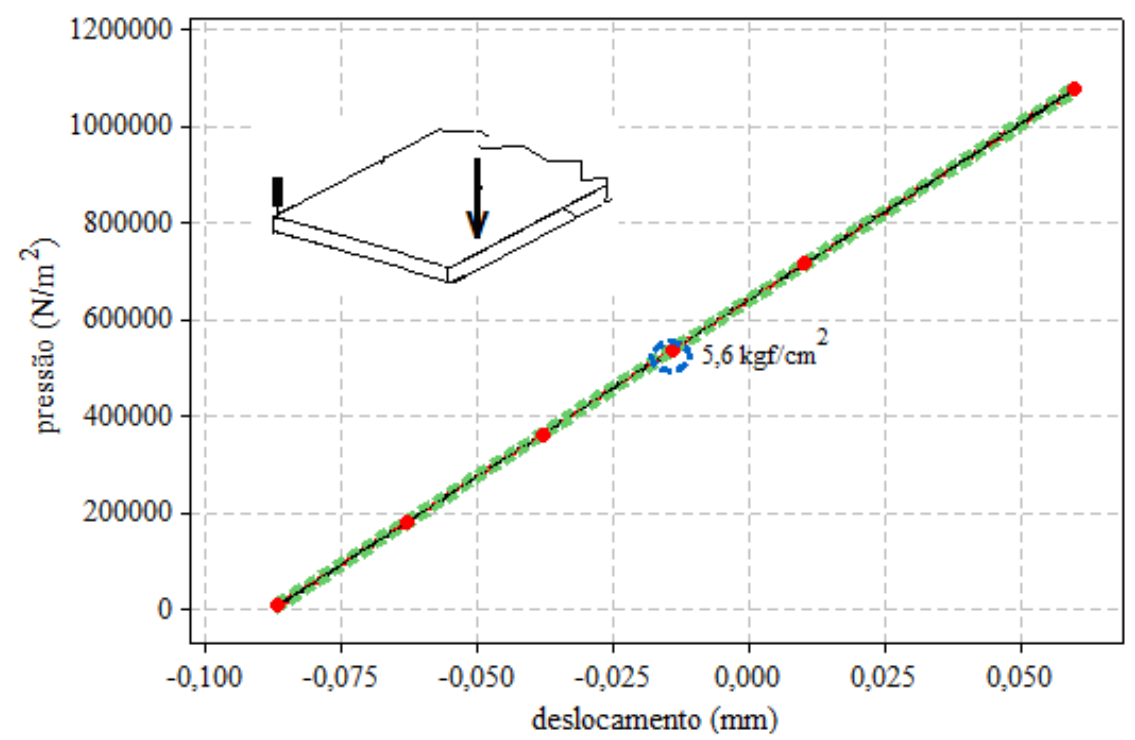

Gráfico 68. Deslocamento medido no canto esquerdo a um carregamento na borda direita.

Simulação no software EverFe 2.24. Intervalo de confiança $95 \%$ e $\mathrm{R}^{2}=100 \%$.

Fonte: Elaborado a partir dos dados analisados (2009). 


\begin{tabular}{|c|c|c|}
\hline & experimental & simulação \\
\hline $\begin{array}{c}\text { força meio } \\
\text { medida meio }\end{array}$ & $0,13 \mathrm{~mm}$ & $0,16 \mathrm{~mm}$ \\
\hline
\end{tabular}

Equação de regressão para os dados experimentais (a) e simulação (b). Relativas aos gráficos 61 e 62

(a) pressão $=-54127-4496528$ deslocamento

(b) pressão $=-608859+7055553$ deslocamento

força meio

medida canto

$0,09 \mathrm{~mm}$

$0,10 \mathrm{~mm}$

Equação de regressão para os dados experimentais (c) e simulação (d). Relativas aos gráficos 63 e 64

(c) pressão $=-237441-8506092$ deslocamento

(d) pressão $=-3319980-38243476$ deslocamento

força canto

medida canto

$0,39 \mathrm{~mm}$

$-0,012$

Equação de regressão para os dados experimentais (e) e simulação (f). Relativas aos gráficos 65 e 66

(e) pressão $=48165+1284039$ deslocamento

(f) pressão $=639377+7295666$ deslocamento

força canto

medida meio

$0,49 \mathrm{~mm}$

$-0,021$

Equação de regressão para os dados experimentais (g) e simulação (h). Relativas aos gráficos 67 e 68

(g) pressão $=50305+1025467$ deslocamento

(h) pressão $=728037+8169362$ deslocamento

Quadro 3. Comparativo entre o processo experimental e simulação, tomando-se como referência o valor de $548800,0 \mathrm{~N} / \mathrm{m}^{2}\left(5,6 \mathrm{kgf} / \mathrm{cm}^{2}\right.$ - eixo simples roda simples).

Fonte: Elaborada a partir dos dados extraídos dos ensaios (2009).

Os dados resumidos no quadro 3 mostram coerência entre os dados experimentais e de simulação para carregamentos estáticos, sem diferencial térmico, efetuados no centro da

placa. No entanto, para carregamentos na borda, sob as mesmas condições, percebe-se a ocorrência de uma dispersão entre os deslocamentos medidos no centro e no canto da placa. Essa incoerência incorreu na repetição dos testes de carga estática e verificação dos dados de entrada do software, os mesmos apresentados no quadro 1. Uma metodologia independente do sistema de aquisição de dados foi adotada com a colocação de um relógio comparador (o mesmo utilizado na determinação do coeficiente de dilatação do TVE) na borda oposta ao sensor potenciométrico e novos carregamentos foram impostos. E os resultados corroboraram os testes experimentais anteriores. A discordância ocorrida entre os testes experimentais e os simulados pelo software EverFe indica a necessidade de um processo de retroanálise para a calibração do software frente aos dados obtidos. Balbo (2009) comenta extensivamente as 
limitações dos modelos analíticos versus MEF e a problemática envolvendo a calibração em pista experimentais.

Por outro lado, as medidas efetuadas pelos sensores, nas bordas da placa, são transparentes ao tipo de material e, só indicam deslocamentos absolutos ocasionados pelos carregamentos impostos.

\subsection{COMPORTAMENTO TÉRMICO DA PLACA}

O empenamento produzido na placa do pavimento, devido ao diferencial de temperatura entre topo e fundo da placa, pôde ser verificado e as evidências mostram que existe a tendência do arqueamento da placa. Quanto ao aparecimento do gap entre placa e base, não se pôde afirmar com segurança a sua existência. No entanto, Houbem (1994) apud Rodolfo (2001) através da análise numérica, observa que para gradientes de $-0,03^{\circ} \mathrm{C} / \mathrm{mm}$ ocorre a perda de suporte ao longo da borda da placa e que quando é pequeno $\left(-0,01^{\circ} \mathrm{C} / \mathrm{mm}\right.$ a $0,01^{\circ} \mathrm{C} / \mathrm{mm}$ ) a placa está plenamente apoiada.

Esse comportamento se mostrou desde o início dos testes e perdurou em todos eles, mesmo para pequenos diferenciais de temperatura. Isso pode ser observado pelo gráfico 68, que mostra a indicação da célula de carga (transtec), em função da temperatura e do tempo. No caso, a taxa de aquecimento foi de $2,5^{\circ} \mathrm{C} / \mathrm{h}$ em um período de onze horas. Percebese um comportamento crescente de uma força atuante, no sentido de tracionar a célula. O que é o mesmo como se a placa estivesse levantando.

A resposta da célula de carga é tão rápida quanto as primeiras fibras da placa e apresentam um diferencial de temperatura capaz de iniciar seu empenamento. Infelizmente o ponto de partida na qual a temperatura inicia a contração das fibras do concreto não pôde ser avaliado, pois está dentro do próprio erro do termômetro $\left( \pm 0,5^{\circ} \mathrm{C}\right)$.

Nota-se que, no gráfico 69, o "zero" da escala de tensão corresponde a uma

referência física, porque essa célula foi fundida juntamente com a massa fresca do concreto e interligou o fundo da placa com o topo da laje de reação. 


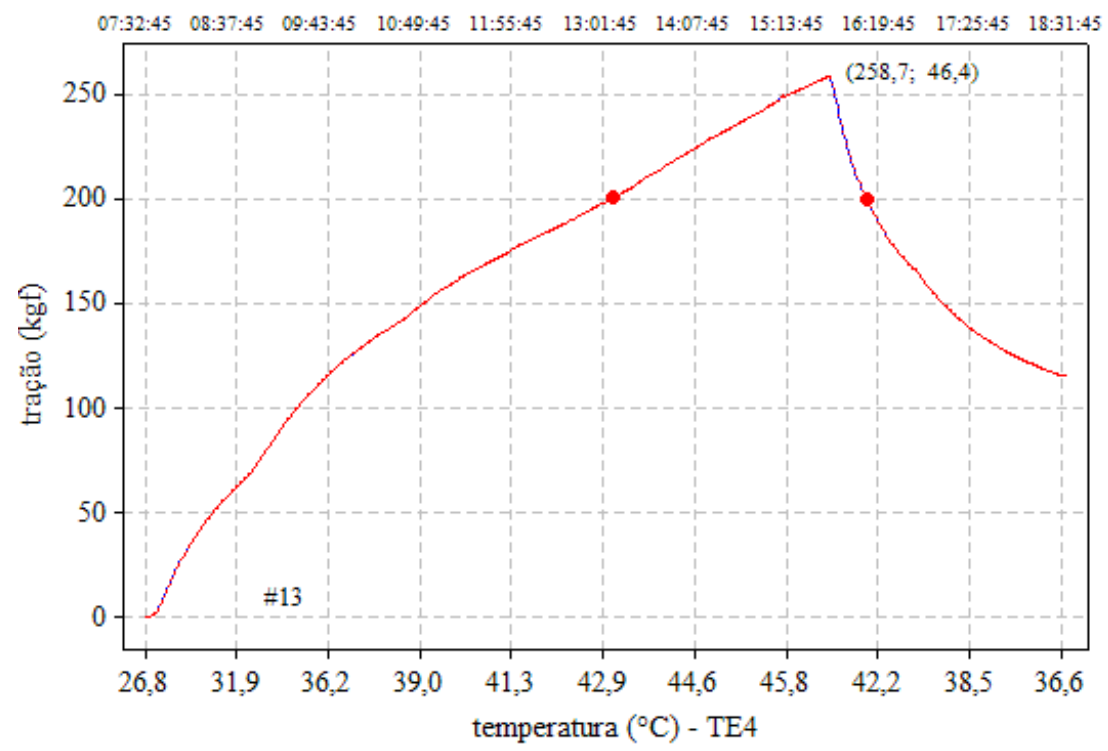

Gráfico 69. Comportamento de flexão da placa, devido à variação de temperatura. Fonte: Elaborado a partir dos dados analisados (2009).

Devido a não linearidade da distribuição da temperatura ao longo da espessura da placa, o gradiente térmico (diferencial térmico pela espessura) também se comporta da mesma maneira e pode ser visto por meio do gráfico70.

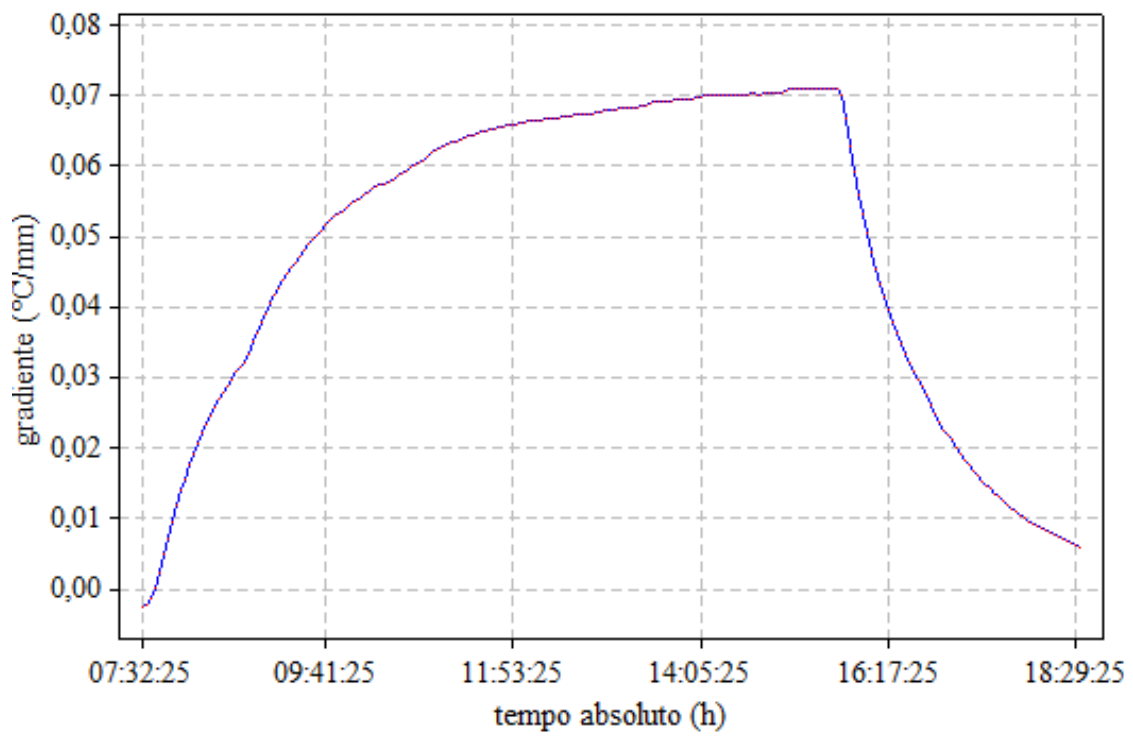

Gráfico 70. Gradiente térmico em função do tempo durante o processo de aquecimento da placa.

Fonte: Elaborado a partir dos dados analisados (2009). 
No gráfico71, o residual de tração indica que a placa ainda guarda empenamento de testes anteriores, ou ela está indicando que o conjunto base mais placa deformou o subleito.

O gráfico 72 é uma repetição do teste anterior, tendo como diferença o tempo de repouso da placa $(24 \mathrm{~h})$. É possível perceber que, após esse tempo a placa inverte sua concavidade exercendo uma compressão na célula. Isso pode ser verificado tomando-se como referência o valor residual de 7,0 kgf $(68,5 \mathrm{~N})$ no início do teste e comparando-se com o valor lido no final do teste $-2,8 \mathrm{kgf}(27,4 \mathrm{~N})$. Esse comportamento é bem semelhante às ocorrências cotidianas.

Observa-se que a força tensional atua com valores semelhantes para as mesmas temperaturas, tanto no período de aquecimento como no de resfriamento. Essa observação pode ser feita nos gráficos 69,71 e 72 .

A quantificação do empenamento foi verificado pelas informações retiradas do sensor potenciométrico durante os processos de aquecimento ou resfriamento.

Nesse período a célula de carga localizada no centro do pavimento já tinha sido trocada.

$\mathrm{Na}$ fase de aquecimento, o arqueamento provoca o deslocamento das bordas da placa no sentido contrário ao seu centro. Esse fenômeno pôde ser registrado nos testes de aquecimento superior, inferior e de resfriamento superior.

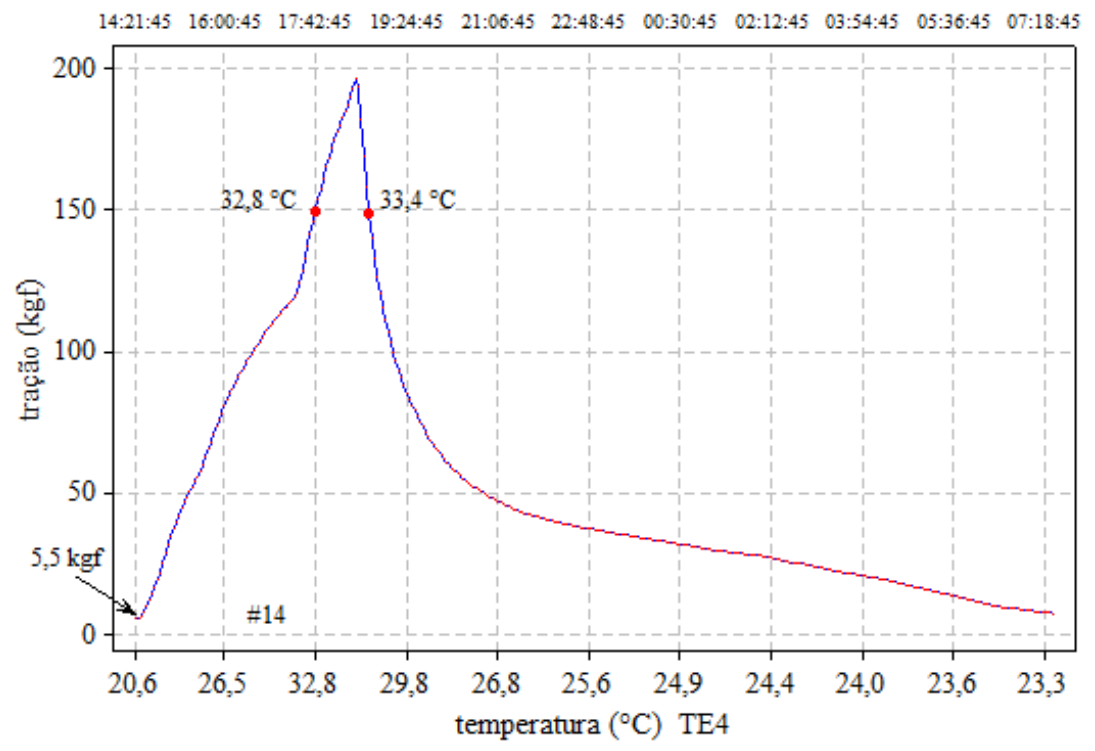

Gráfico 71. Comportamento tensional da placa, devido à variação de temperatura. Fonte: Elaborado a partir dos dados analisados (2009). 


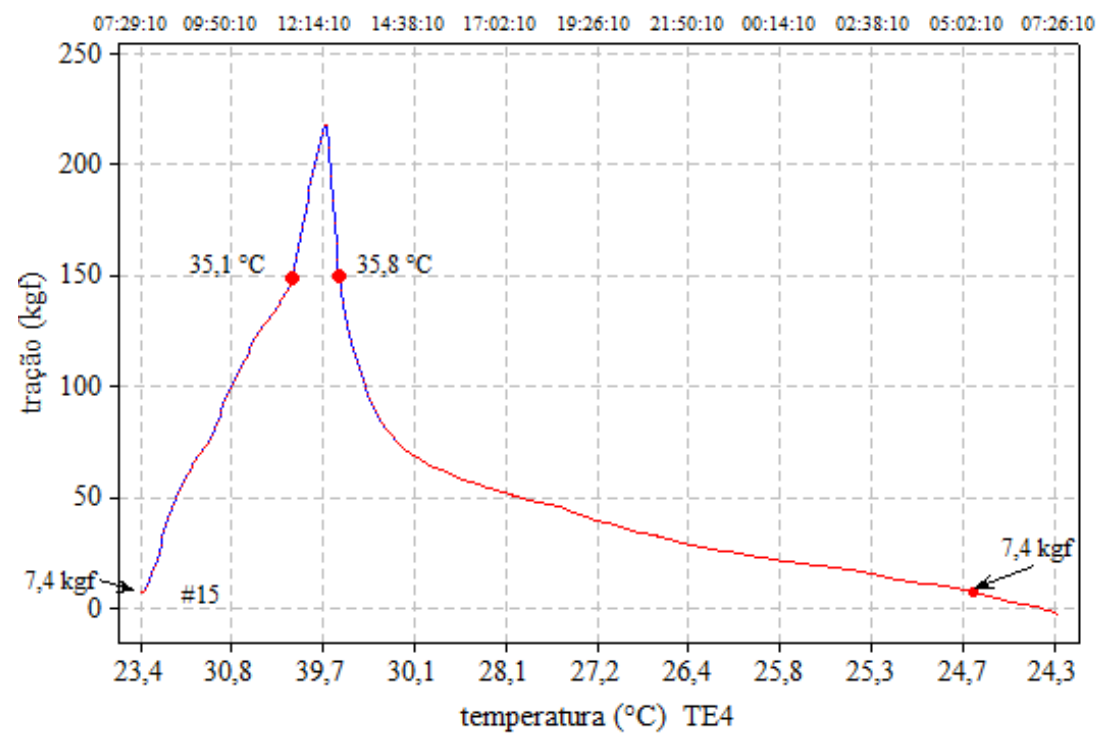

Gráfico 72. Comportamento tensional da placa, devido à variação de temperatura. Teste com ciclo de 24 horas.

Fonte: Elaborado a partir dos dados analisados (2009).

\subsection{DESLOCAMENTO DE CANTO DEVIDO AO AQUECIMENTO / RESFRIAMENTO NO TOPO DA PLACA.}

Para a verificação do deslocamento de borda, o pavimento foi sujeito a taxas de temperatura que variaram conforme valores descritos anteriormente (gráfico 20). Nesses testes de aquecimento, o sensor de deslocamento ficou isolado, termicamente, do calor gerado pela plataforma de aquecimento.

As medidas foram realizadas sob condições de carregamento térmico diferentes. Inicialmente a placa foi exposta a uma taxa de aquecimento de $1,7{ }^{\circ} \mathrm{C} / \mathrm{h}$ durante 5 horas dentro de um período de 24 horas. O gráfico 73 mostra a resposta da placa, segundo um sensor de deslocamento colocado em seu canto. Para períodos acima de 24 horas com taxa de aquecimento de $1,2{ }^{\circ} \mathrm{C} / \mathrm{h}$ em 7 horas e resfriamento de 72 horas, pode ser visto no gráfico 74 , que indica o deslocamento da borda da placa sob essas condições. Esse foi o tempo médio para que a estrutura atingisse o equilíbrio térmico.

O comportamento da estrutura com carregamento térmico constante foi analisado e testado e pode ser visto no gráfico75, que apresenta o deslocamento na borda da placa sob aquecimento, cuja taxa média foi de $1,0{ }^{\circ} \mathrm{C} / \mathrm{h}$. A potência de $1000,0 \mathrm{~W}$ forneceu energia durante um período de 8 horas. 


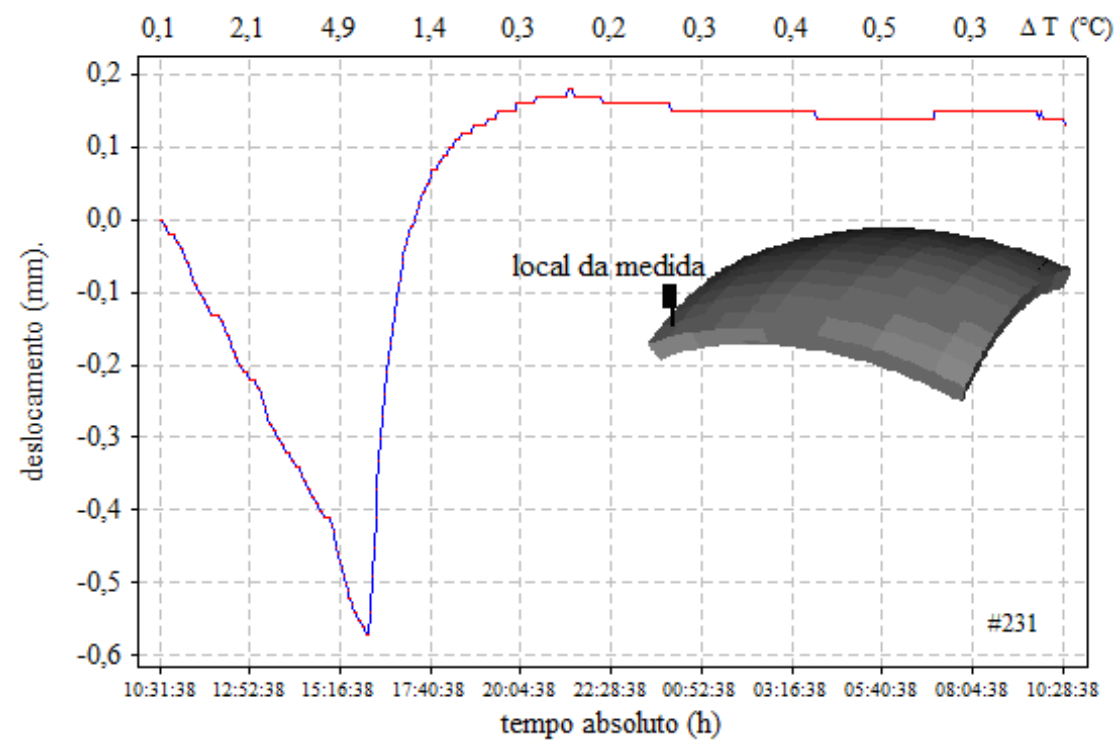

Gráfico 73. Deslocamento no canto da placa sob aquecimento superficial em função do diferencial de temperatura $\Delta \mathrm{T}$ e do momento do evento.

Fonte: Elaborado a partir dos dados analisados (2009).

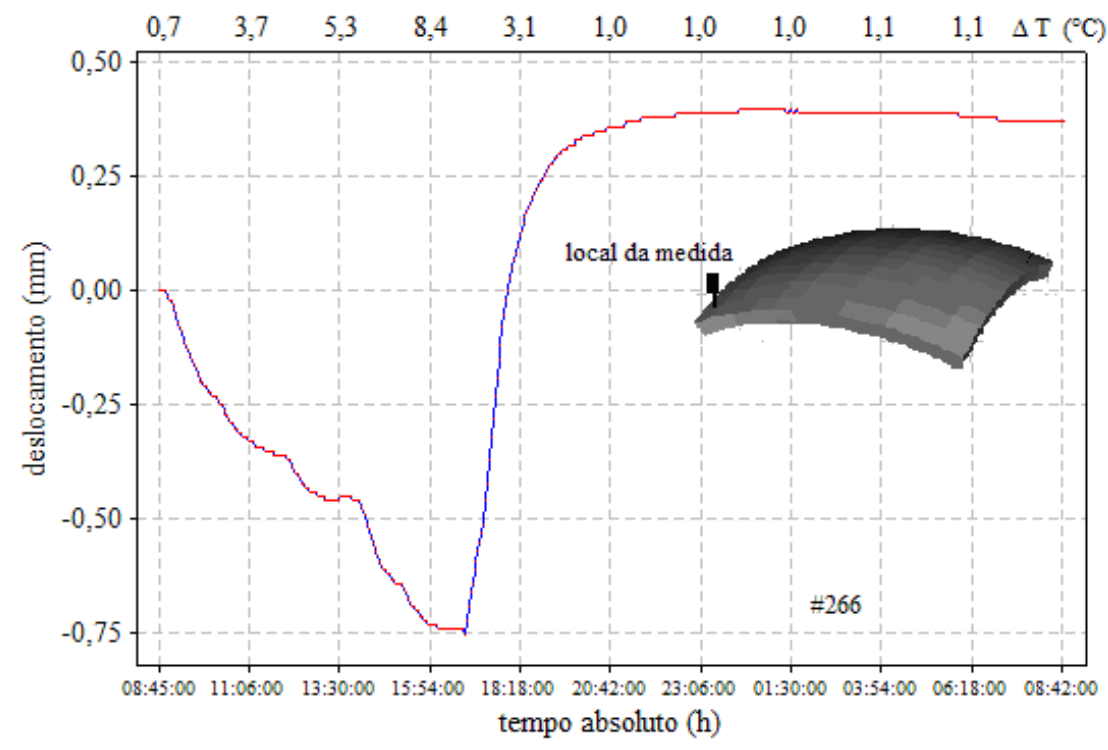

Gráfico 74. Deslocamento no canto da placa sob aquecimento superficial em função do diferencial de temperatura $\Delta \mathrm{T}$ e do momento do evento.

Fonte: Elaborado a partir dos dados analisados (2009). 


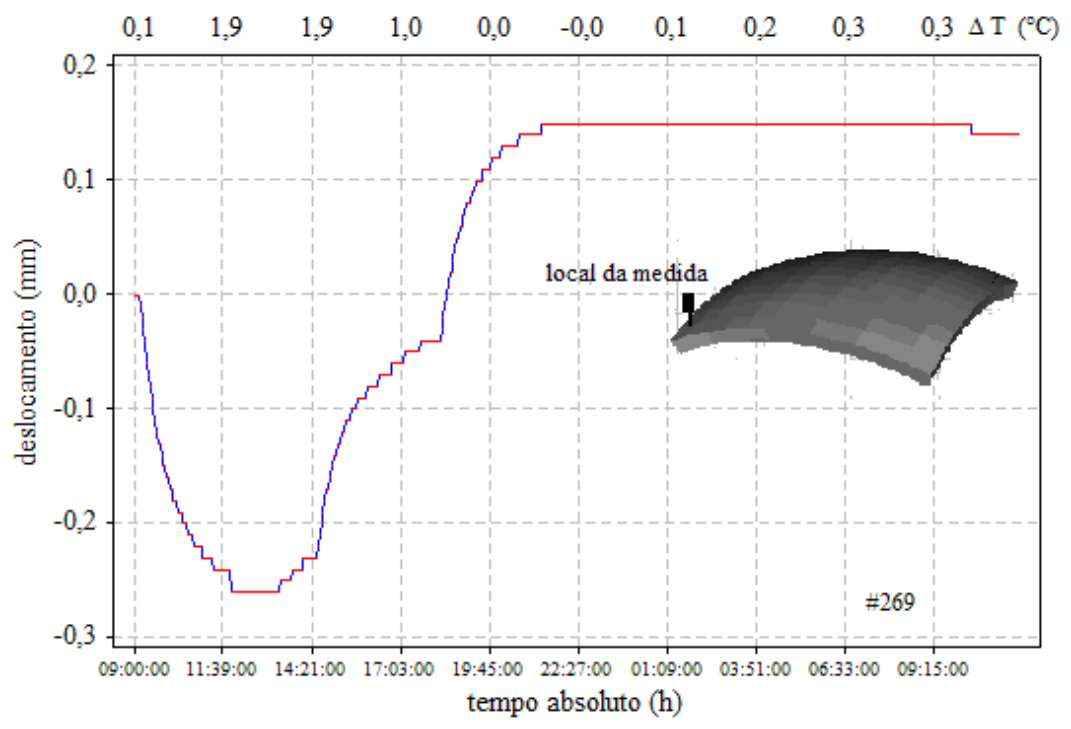

Gráfico 75. Deslocamento no canto da placa sob aquecimento superficial com potência constante e em função do $\Delta \mathrm{T}$ e do instante do evento.

Fonte: Elaborado a partir dos dados analisados (2009).

A inversão de concavidade foi ensaiada através de um aquecimento a taxa de 1,4 ${ }^{\circ} \mathrm{C} / \mathrm{h}$ durante três horas quando a placa foi molhada, seguindo os mesmos procedimentos utilizados na obtenção dos gráficos 37 e 59, ficando em espera por 10 minutos e posta a aquecer com a mesma taxa até completar um ciclo de aquecimento. $\mathrm{O}$ resultado pode ser visto no gráfico 75 , que mostra o período em que a placa apresenta concavidade convexa e que, após ser resfriada com água passa a apresentar uma tendência a uma concavidade côncava, no período posterior

Para situações de inversão térmica, foi simulado um dia com chuva no período para registrar o comportamento da placa nessa situação. O gráfico 76 ilustra o movimento de tendência de arqueamento quando o topo do pavimento sofre um resfriamento brusco. A convexidade não acontece como ilustrado, no entanto, a rápida variação do deslocamento no sentido positivo indica a tendência. Esse fenômeno não foi possível capturar nas simulações numéricas, no entanto, a estrutura responde a esse novo carregamento, cujo efeito pode ser visualizado entre os instantes $14 \mathrm{~h} 20 \mathrm{~min}$ a $14 \mathrm{~h} 50 \mathrm{~min}$.

Para caracterizar o empenamento no sentido côncavo, um teste de resfriamento superior foi conduzido para verificar a inversão de arqueamento. Para tanto 50,0 kg de gelo foi espalhado sobre a superfície da placa e o comportamento foi registrado pelo sensor potenciométrico, colocado em seu canto e pode ser visto através do gráfico77, onde a curva ascendente indica um aumento no deslocamento durante a fase de resfriamento e, logo após, a 
estrutura começa a se estabilizar devido ao decrescimento da temperatura. No sentido de confirmar o arqueamento, mais $10,0 \mathrm{~kg}$ de gelo foi acrescentado sobre a superfície gerando uma distorção no processo de aquecimento. Nesse caso, é possível verificar a concavidade da placa se voltando para o sentido côncavo.

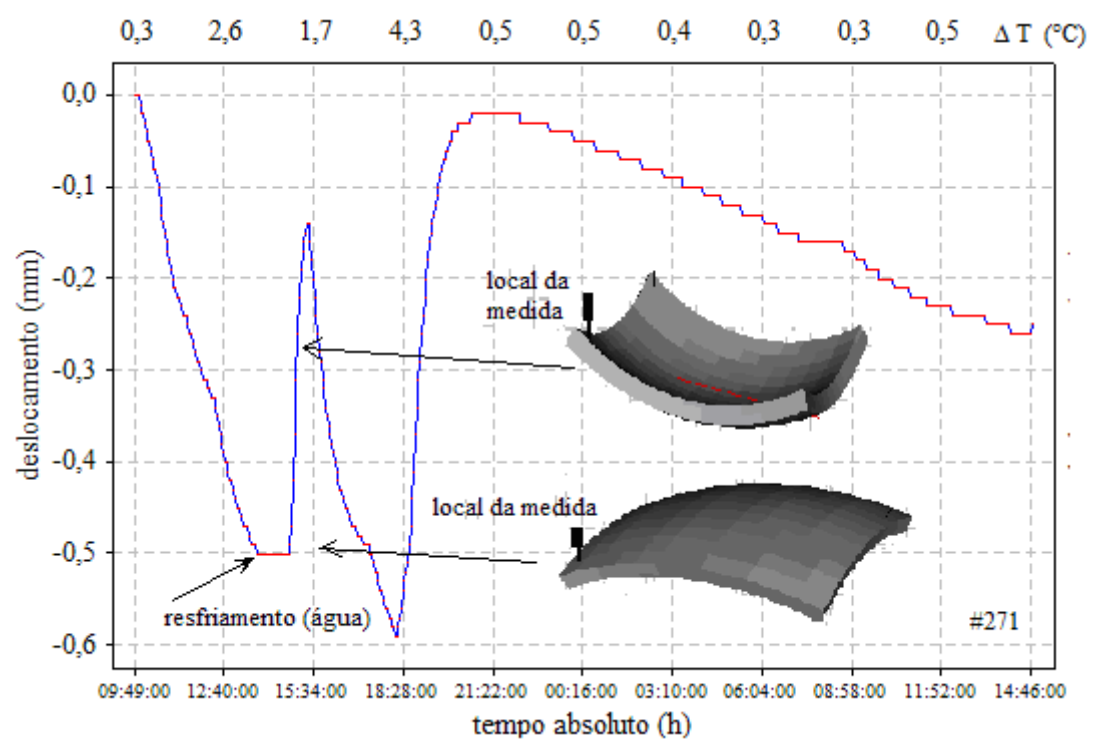

Gráfico 76. Deslocamento da borda, no canto da placa sob aquecimento e um resfriamento simulando um dia de chuva em função do instante do evento e do $\Delta \mathrm{T}$.

Fonte: Elaborado a partir dos dados analisados (2009).

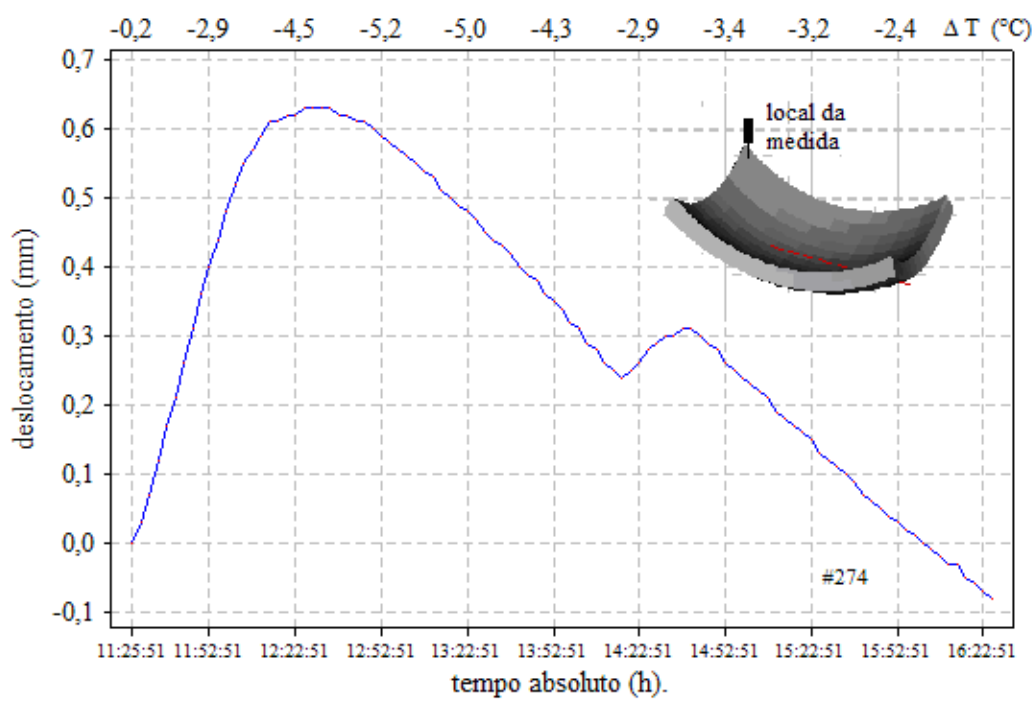

Gráfico 77. Deslocamento da borda, no canto da placa sob resfriamento superficial em função do instante do evento e do $\Delta \mathrm{T}$.

Fonte: Elaborado a partir dos dados analisados (2009). 
No sentido de confrontar resultados, dois trabalhos da literatura foram analisados e adaptados com a mesma formatação dos apresentados. Esses trabalhos referem-se a Armaghani et. al. (1987) e Yu et al. (1998), supracitados, que também realizaram medidas na borda de pavimentos sob carga térmica. No gráfico 78 , assim como no gráfico 79 , observa-se um deslocamento de canto em torno de $2,0 \mathrm{~mm}$. No entanto, simulações realizadas com o software EverFe, com os dados extraídos dos artigos, não reproduziram valores tão altos.

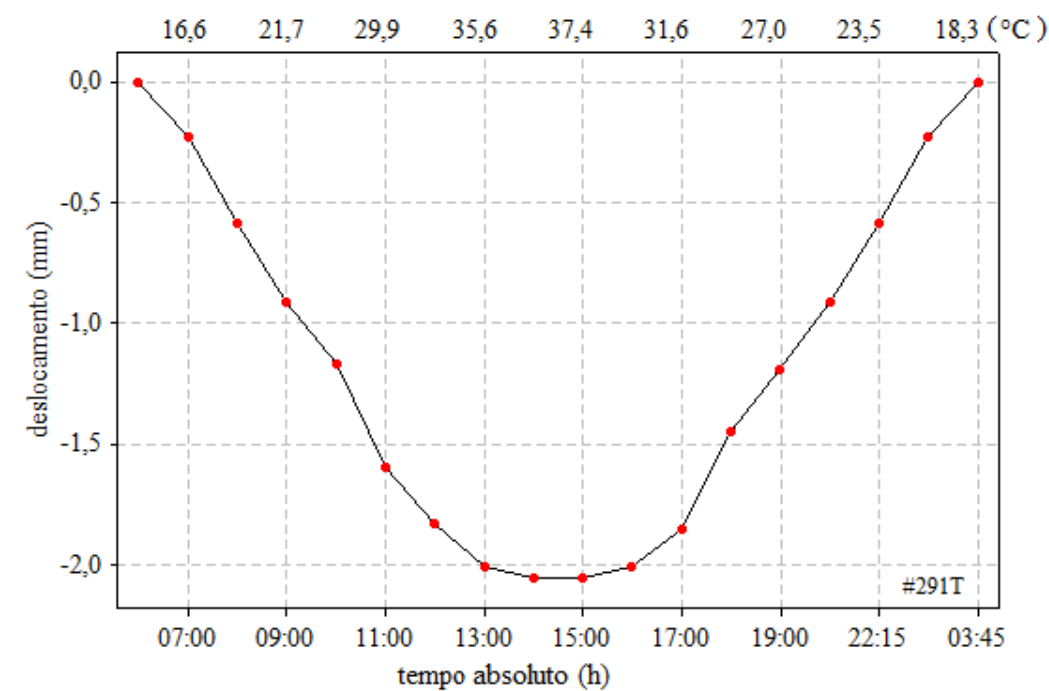

Gráfico 78. Medida do deslocamento no canto da placa de um pavimento real sob aquecimento natural.

Fonte: Adaptado e modificado segundo dados extraídos de Armaghani (1987).

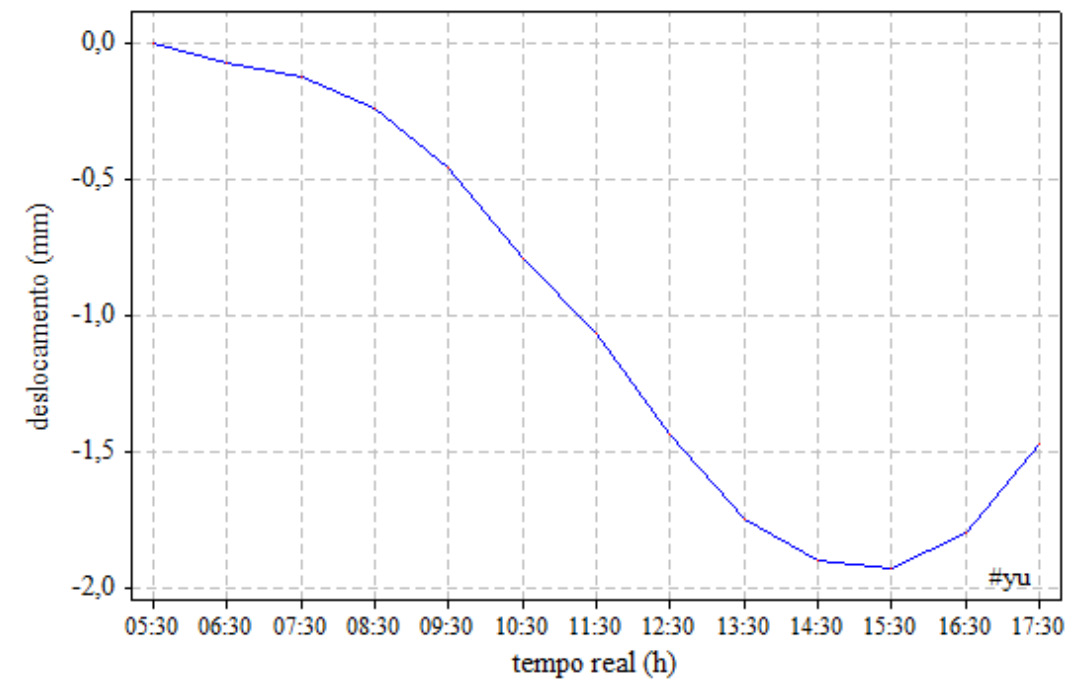

Gráfico 79. Medida do deslocamento no canto da placa de um pavimento real sob aquecimento natural.

Fonte: Adaptado e modificado segundo dados extraídos de Yu (1998). 


\begin{tabular}{|l|c|c|c|c|}
\hline \multicolumn{2}{|l|}{} & $\begin{array}{c}\text { Deslocamento } \\
\text { na borda }(\mathrm{mm})\end{array}$ & $\begin{array}{c}\text { Simulação } \\
\text { equivalente }(\mathrm{mm})\end{array}$ & Observação \\
\hline Gráfico 73 & & $-0,57$ & $-0,46$ & ----------------- \\
\hline Gráfico 74 & & $-0,74$ & $-0,54$ & ----------------- \\
\hline Gráfico 75 & & $-0,26$ & $-0,27$ & ----------------- \\
\hline \multirow{2}{*}{ Gráfico 76 } & $1^{\circ}$ pico & $-0,50$ & $-0,49$ & ---------------- \\
\cline { 2 - 5 } & $2^{\circ}$ pico & $-0,14$ & $-0,38$ & ---------------- \\
\hline Gráfico 77 & & $-0,58$ & $-0,39$ & ---------------- \\
\hline Gráfico 78 & & 0,63 & 0,23 & ----------------- \\
\hline Gráfico 79 & & $-2,2$ & ---------------- & Armaghani (1987) \\
\hline
\end{tabular}

Quadro 4. Resumos dos testes práticos e das simulações para deslocamento de borda. Fonte: Elaborado a partir dos dados extraídos do experimento e da literatura (2009).

O quadro 4 fornece um resumo dos testes práticos, das simulações numéricas e das medidas realizadas em pavimentos reais. È possível observar a correspondência entre as respostas, ou seja, quando a tendência é para o sentido côncavo ou para o sentido convexo todas as medidas têm correspondência, apesar de numericamente apresentarem discrepâncias.

Para taxas de aquecimento em torno de $1,5^{\circ} \mathrm{C}$ o pavimento comporta-se de maneira semelhante à simulação (gráfico 73). O mesmo ocorre com parâmetros semelhantes e taxa ligeiramente superior (gráfico 74). Para taxas constante de aquecimento existe uma semelhança bem acentuada entre simulação e dados medidos.

Por outro lado, em determinadas situações, tais como nos (gráficos 78 e 79) não foi possível entrar com dados práticos para que a simulação fosse adequada. As simulações não entendem a história passada da placa e as atividades térmicas ocorridas. Isso é flagrante na simulação de um dia chuvoso, onde nem foi possível informar na entrada de dados que tipo de estudo estava sendo realizado. O software só entende o diferencial de temperatura e não como ele surgiu.

Com relação aos gráficos 76 e 77, a simulação não foi totalmente possível, pois os parâmetros de entrada, com respeito aos materiais, estavam incompletos. Porém, os próprios 
autores comentam as discrepâncias em função do tipo de base, se está em contato ou não e que sob certas situações de carga a placa apresenta comportamento distinto.

Outra observação, que pode ser realizada por meio dos gráficos 63 e 73 é que pequenos diferencias de temperatura induzem deformações semelhante a carregamentos próximos àquele tomado como referência $\left(5,6 \mathrm{kgf} / \mathrm{cm}^{2}\right)$.

\subsection{DESLOCAMENTO DE CANTO DEVIDO AO AQUECIMENTO / RESFRIAMENTO NO FUNDO DA PLACA.}

O aquecimento no fundo da placa, também foi alvo de investigação nos processos de simulação e teve a intenção de, não só confrontar resultados com aquecimento superficial, mas também mostrar que a metodologia proposta é capaz de cobrir variados aspectos térmicos.

Como comentado anteriormente, o sistema de troca de calor formado por tubos de "conduites" apresentou problemas de ordem construtiva. Aparentemente, os tubos se deslocaram dentro da massa fresca do concreto, ficando então em posições diferentes daquela planejada inicialmente. Isso impediu a feitura de curvas térmicas ao longo da espessura da placa. No entanto, o sistema de controle de temperatura do fluido funcionou adequadamente e foi possível a realização de procedimentos de aquecimento ou resfriamento no fundo da placa para estudar o comportamento da mesma, com relação aos deslocamentos de borda.

Para compensar a deficiência prática, foi realizada uma simulação, via software ANSYS $^{\circledR}$, de como seria a distribuição da temperatura se o sistema tivesse funcionado adequadamente. Isso pode ser visto no gráfico 80, que mostra as curvas térmicas simuladas, segundo os níveis N0, N4, N7, N11 e N15. A simulação foi realizada em período de 5 horas de aquecimento, tempo suficiente para aquecer o fundo e provocar o empenamento. Esse gráfico funcionou como balizamento nas análises realizadas. No anexo D encontra-se o os resultados em 2D e 3D das simulações em elementos finitos da distribuição da temperatura ao longo da espessura da placa, bem como o gráfico 153, que mostra como ficou a distribuição da temperatura provido pelo sistema de aquecimento de fundo. Nota-se que, apesar de ter cumprido a sua função, não foi suficiente para uma distribuição energética adequada ao longo do fundo da placa. Isso pode ser percebido comparando-se os dois gráficos 


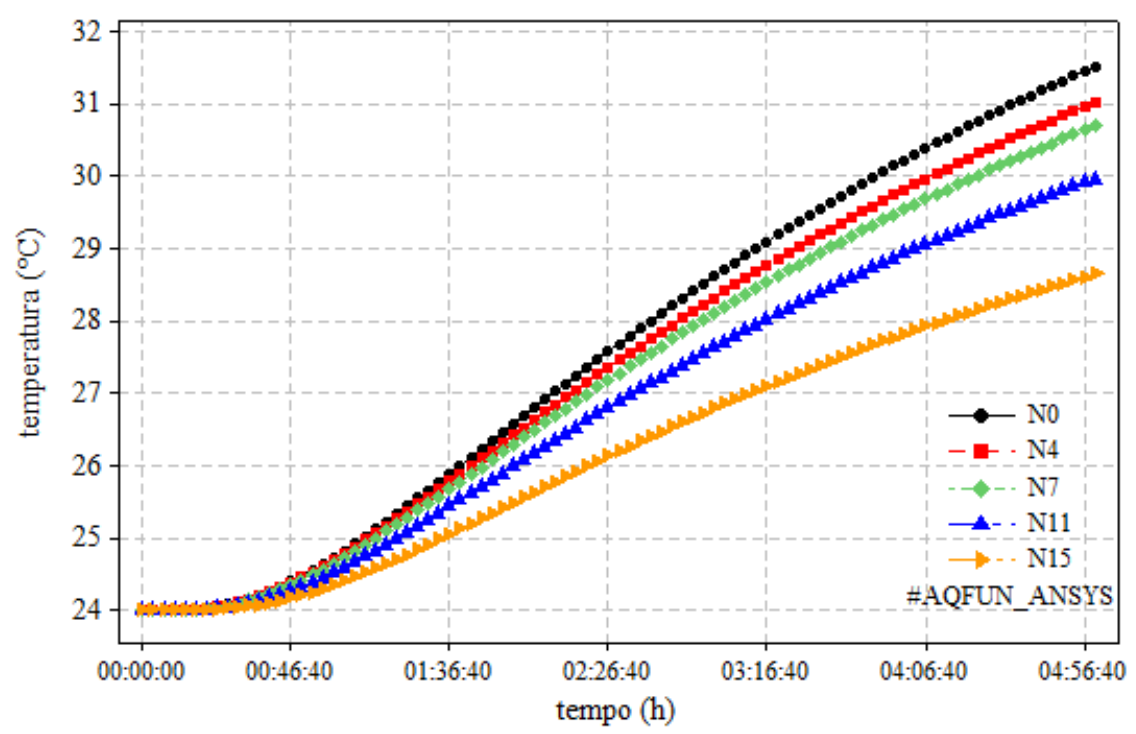

Gráfico 80. Distribuição temporal da temperatura ao longo da espessura da placa para aquecimento no fundo.

Fonte: Elaborado segundo dados resultantes da simulação pelo software $\operatorname{ANSYS}^{\circledR}$ (2009).

$\mathrm{O}$ aquecimento no fundo da placa tem a finalidade de provocar empenamento côncavo tal qual ocorre no meio natural, durante o período noturno. Para tanto, água quente percorrendo os dutos foi o veículo de transferência de calor para a estrutura.

O gráfico 81 apresenta o comportamento da placa mediante um aquecimento de fundo com duração de 7 horas, com mesmo ritmo mostrado no gráfico 80 de $1,8{ }^{\circ} \mathrm{C} / \mathrm{h}$, e resfriamento de 48 horas. Tempo esse, necessário para que a placa atingisse a temperatura ambiente. Nota-se que, após a vigésima hora do segundo dia a placa tende a inverter a concavidade. Aparentemente, isso ocorre devido ao fato da base apresentar uma concavidade convexa, enquanto que a placa, com diferencial térmico zero, tende a acompanhar o empenamento da base, curvando-se para baixo e levando o sensor a indicar esse a mudança de concavidade.

O gráfico 82 é uma repetição do caso anterior a menos do tempo de resfriamento e aquecimento. A intenção foi verificar se, em situações diferentes e em épocas distintas, inverno e verão, a placa apresentaria o mesmo comportamento. Observa-se que a resposta da estrutura é a mesma com ligeira diferença no deslocamento. 


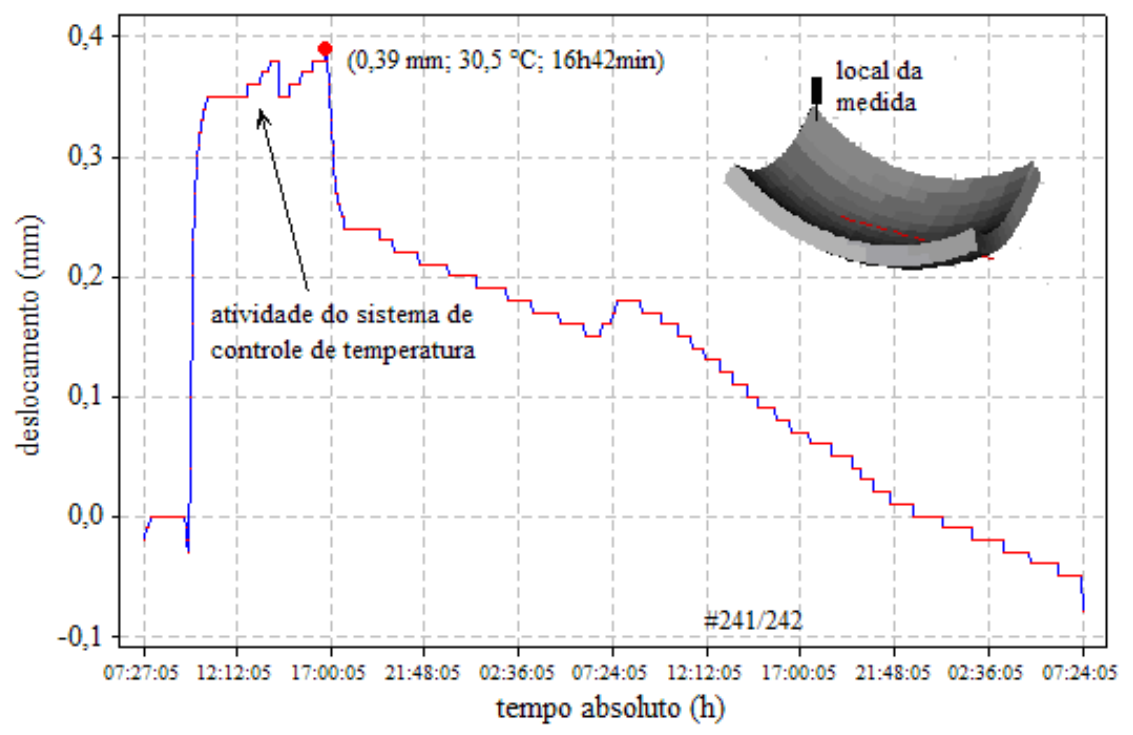

Gráfico 81. Deslocamento da borda, no canto da placa sob aquecimento no fundo da placa. Fonte: Elaborado a partir dos dados analisados (2009).

O resfriamento do fundo da placa não foi realizado devido a dificuldade da manutenção da circulação de água fria pelo trocador de calor por períodos longos. Atualmente, está sendo modificada a vazão de água de um bebedouro comum com adaptação no compressor, válvulas e serpentina para suprir a demanda de água fria.

Os dados obtidos com os gráficos 81 e 82 mostram que o deslocamento do canto da placa segue o mesmo padrão daquele apresentado no gráfico 77 . Onde pode ser observado que, o diferencial de temperatura de $-4,5^{\circ} \mathrm{C}$ leva a um deslocamento de $0,6 \mathrm{~mm}$, enquanto que um diferencial de temperatura de $-2,9{ }^{\circ} \mathrm{C}$, apresentado no gráfico 81, provoca um deslocamento de 0,35 mm. Essas situações confirmam que o empenamento côncavo ocorre para diferenciais negativos e que a ordem de grandeza do deslocamento é semelhante ao deslocamento de canto com carga na borda, apresentado no gráfico 63. 


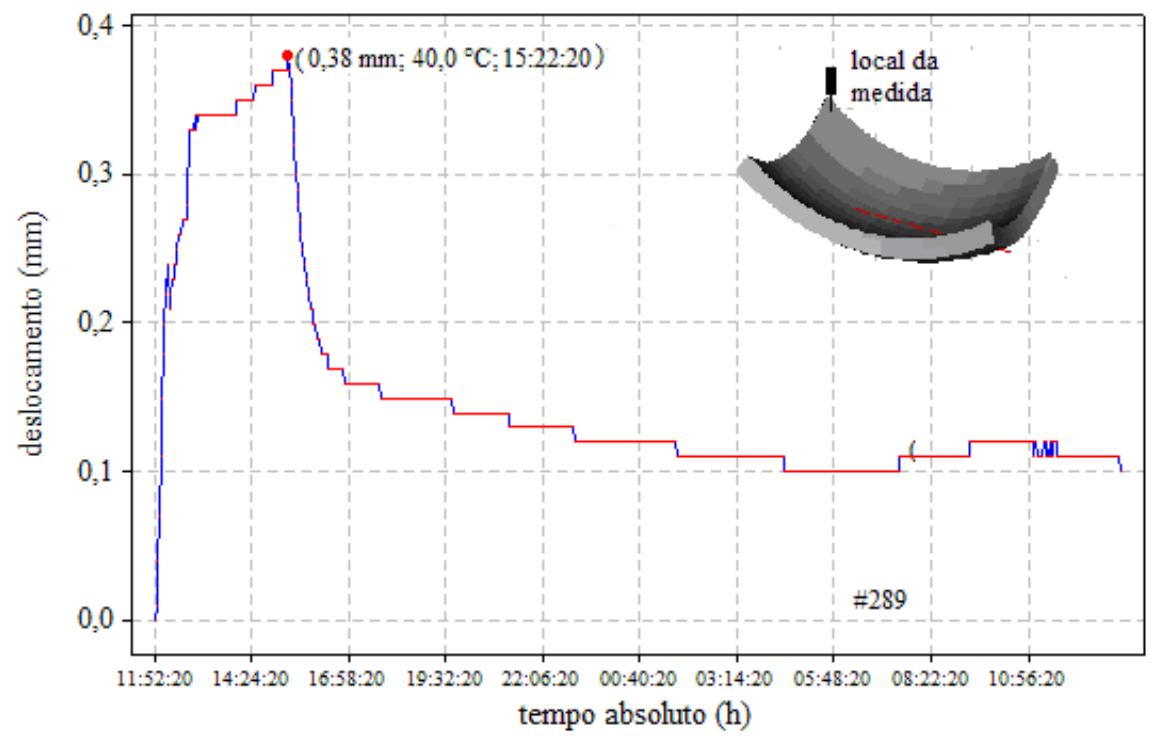

Gráfico 82. Deslocamento da borda, no canto da placa sob aquecimento no fundo da placa. Fonte: Elaborado a partir dos dados analisados (2009).

\subsection{DEFORMAÇÃO DA PLACA SOB CARGA ESTÁTICA}

A medida da deformação da placa pode ser medida por meio da CE7, posicionada a $6,0 \mathrm{~cm}$ do fundo da placa. Ela foi ligada em $1 / 4$ de ponte e, devido ao seu posicionamento foi possível observar quando a placa foi comprimida, sofreu uma flexão (foi tracionada), tal qual descrito nas páginas $97-98$.

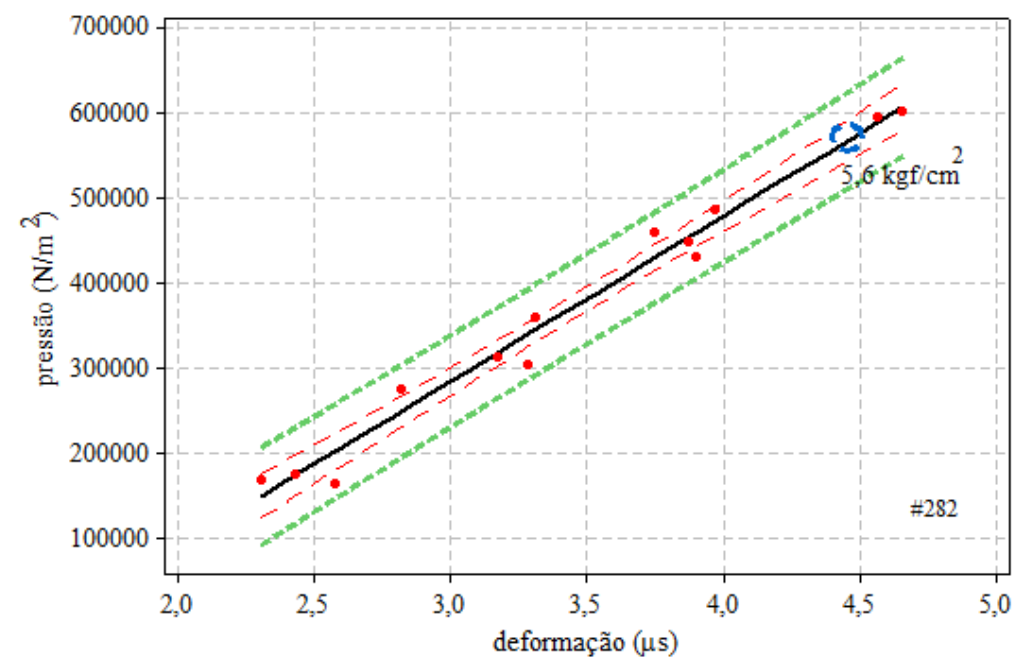

Gráfico 83. Deformação medida por CE7 devido a um carregamento no centro. Intervalo de confiança 95\% e R ${ }^{2}=97,8 \%$. Posição da célula $(81,149,6) \mathrm{cm}$, desenhos 18,19 e 20.

Fonte: Elaborado a partir dos dados analisados (2009). 
O resultado está mostrado no gráfico 83 que indica a deformação da placa sob carregamento estático. O comportamento linear é descrito pela regressão que indica forte correlação. No sentido de verificar a influência do estado térmico inicial da placa sob carga estática, foi realizado um teste com as mesmas proposições do gráfico 83 e os resultados estão relacionados pelo gráfico 84 . A diferença entre um teste e o outro está no estado térmico da placa, que se encontrava a uma temperatura menor que $20^{\circ} \mathrm{C}$ segundo dados do gráfico 83 e a $24^{\circ} \mathrm{C}$ segundo o gráfico 84 . O estado de deformação da placa foi modelado por meio do software EverFe 2.24 e pode ser observado no anexo C.

O gráfico 85 mostra o resultado da simulação pelo software EverFe 2.24 realizada com base nos parâmetros de carregamentos realizados sobre o pavimento.

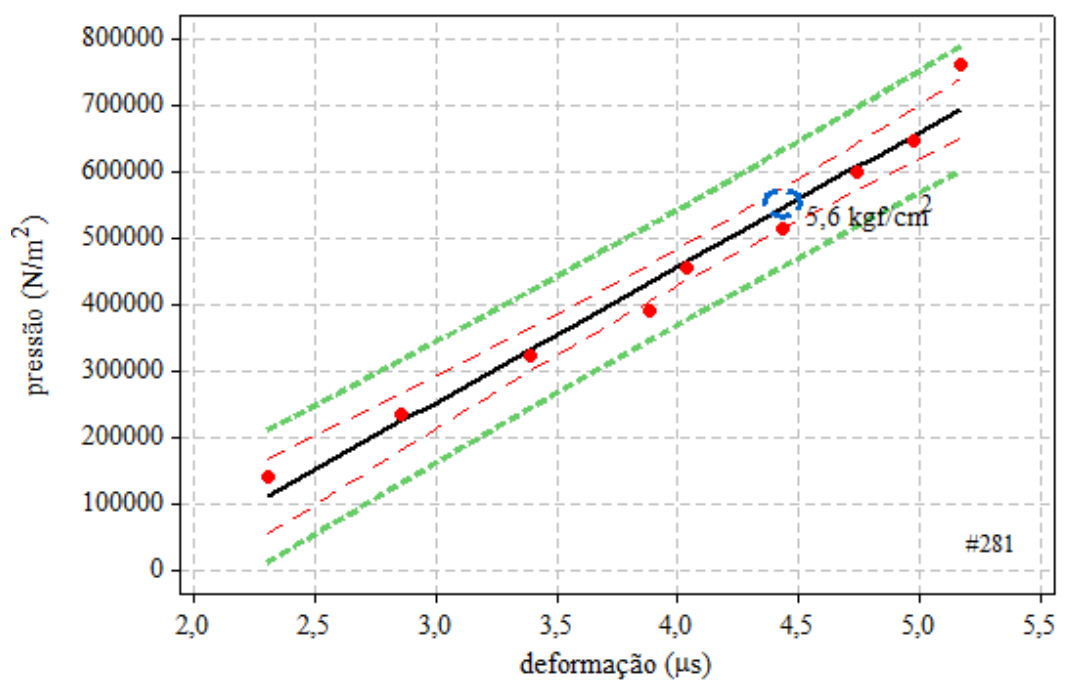

Gráfico 84. Deformação medida por CE7, a $1 / 4$ de ponte, devido a um carregamento no centro. Intervalo de confiança $95 \%$ e $\mathrm{R}^{2}=97 \%$. Posição da célula $(81,149,6) \mathrm{cm}$, desenhos $18,19 \mathrm{e}$ 20.

Fonte: Elaborado a partir dos dados analisados (2009).

Apesar da ordem de grandeza ser a mesma, nota-se um fator de 0,26 entre deformação simulada e deformação medida $\left(\varepsilon_{s}=0,26 \cdot \varepsilon_{m}\right)$. Diferença dessa natureza também foi percebido por Balbo et al. (2001), com base em medidas realizadas em campo.Yu et al. (1998) também perceberam tal ocorrência em placas instrumentadas assentadas sobre base asfáltica. Mesmo mudando a configuração das células e comparando com outras na mesma posição e alturas diferentes, percebeu-se esse fator. Os gráficos 86 e 87 representam a resposta das células CE7+CIT e CE9+CIT frente ao carregamento imposto no pavimento. 
A inclinação da reta no gráfico 87 indica que a célula está sendo tracionada, o sinal negativo é devido ao seu posicionamento. Para efeito de comparação, o quadro 5 mostra a resposta simultânea das células, uma tabela com dados colhidos, fatores de conversão e uma fotografia mostrando o posicionamento de CE7 e CE9.

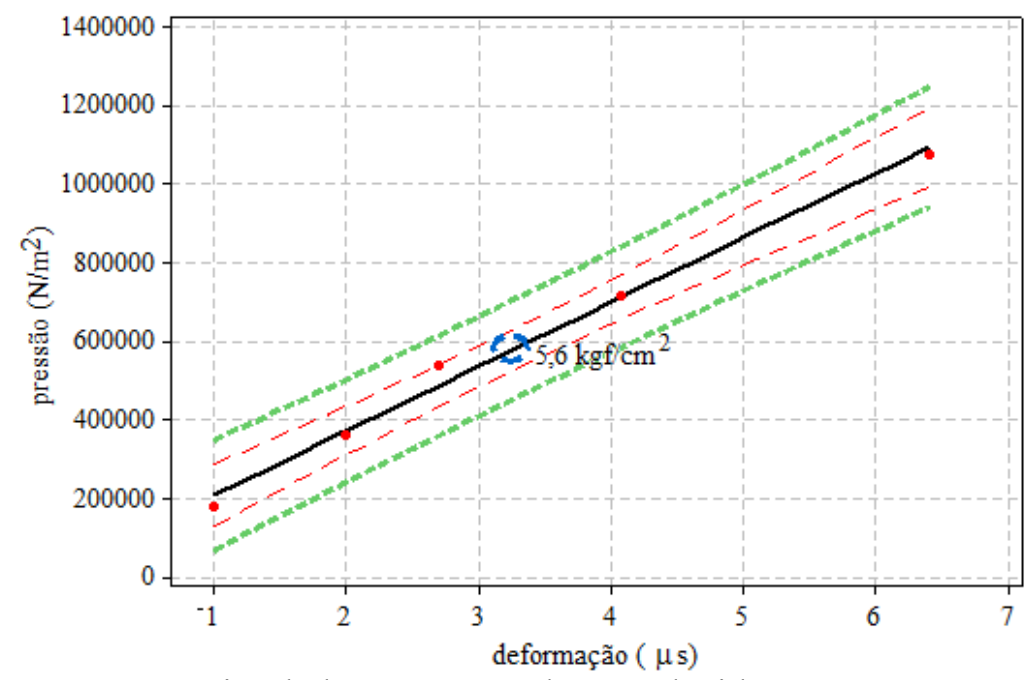

Gráfico 85. Deformação simulada na posição de CE7 devido a um carregamento no centro. Intervalo de confiança $95 \%$ e $\mathrm{R}^{2}=98,9 \%$. Posição da célula $(81,149,6) \mathrm{cm}$, desenhos 18,19 e 20.

Fonte: Elaborado a partir dos dados analisados (2009).

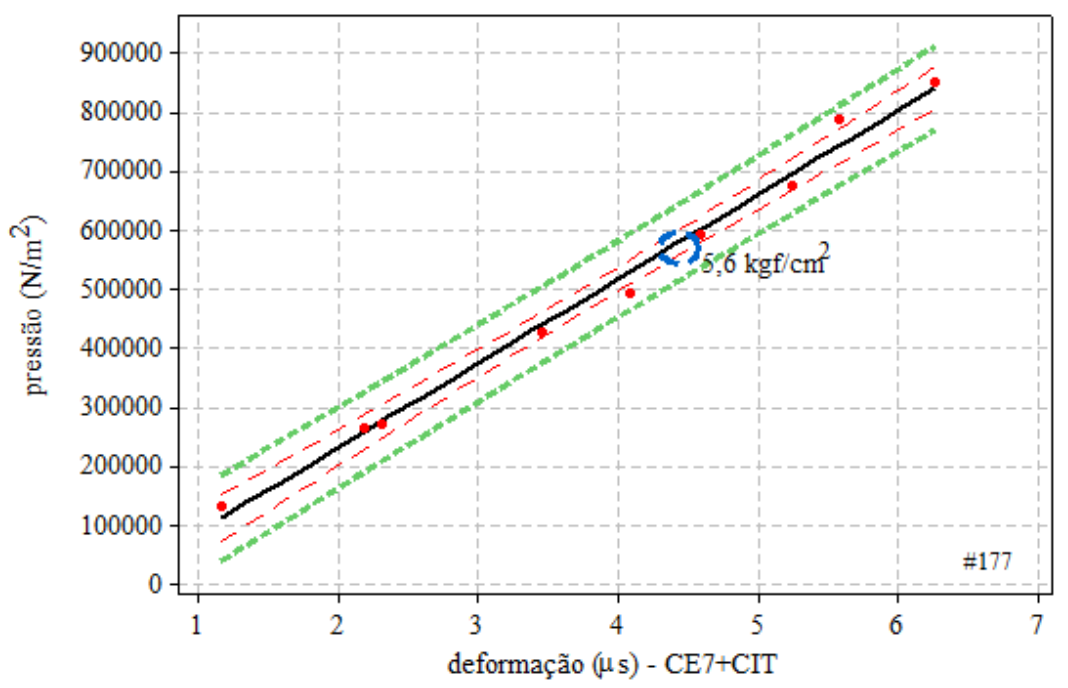

Gráfico 86. Deformação medida por CE7+CIT, em $1 / 2$ de ponte, devido a um carregamento no centro. Intervalo de confiança $95 \%$ e $\mathrm{R}^{2}=98,9 \%$. Posição da célula $(81,149,6) \mathrm{cm}$, desenhos 18,19 e 20.

Fonte: Elaborado a partir dos dados analisados (2009). 


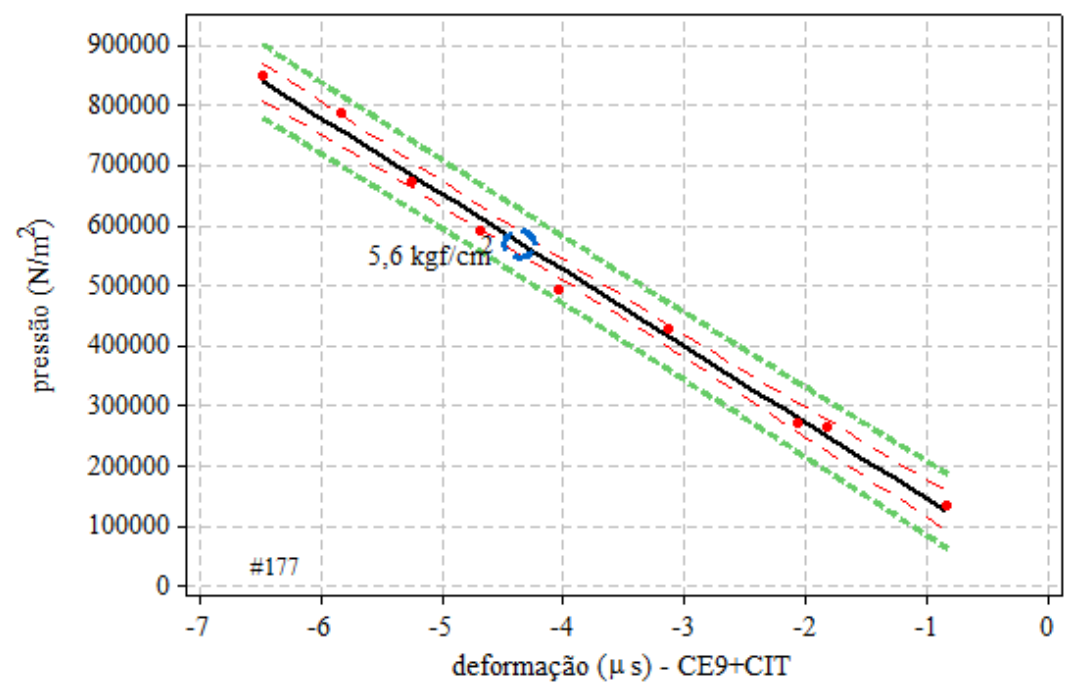

Gráfico 87. Deformação medida por CE9+CIT, em $1 \frac{1}{2}$ de ponte, devido a um carregamento no centro. Intervalo de confiança $95 \%$ e $\mathrm{R}^{2}=99,2 \%$. Posição da célula $(81,149,13) \mathrm{cm}$, desenhos 18,19 e 20.

Fonte: Elaborado a partir dos dados analisados (2009).

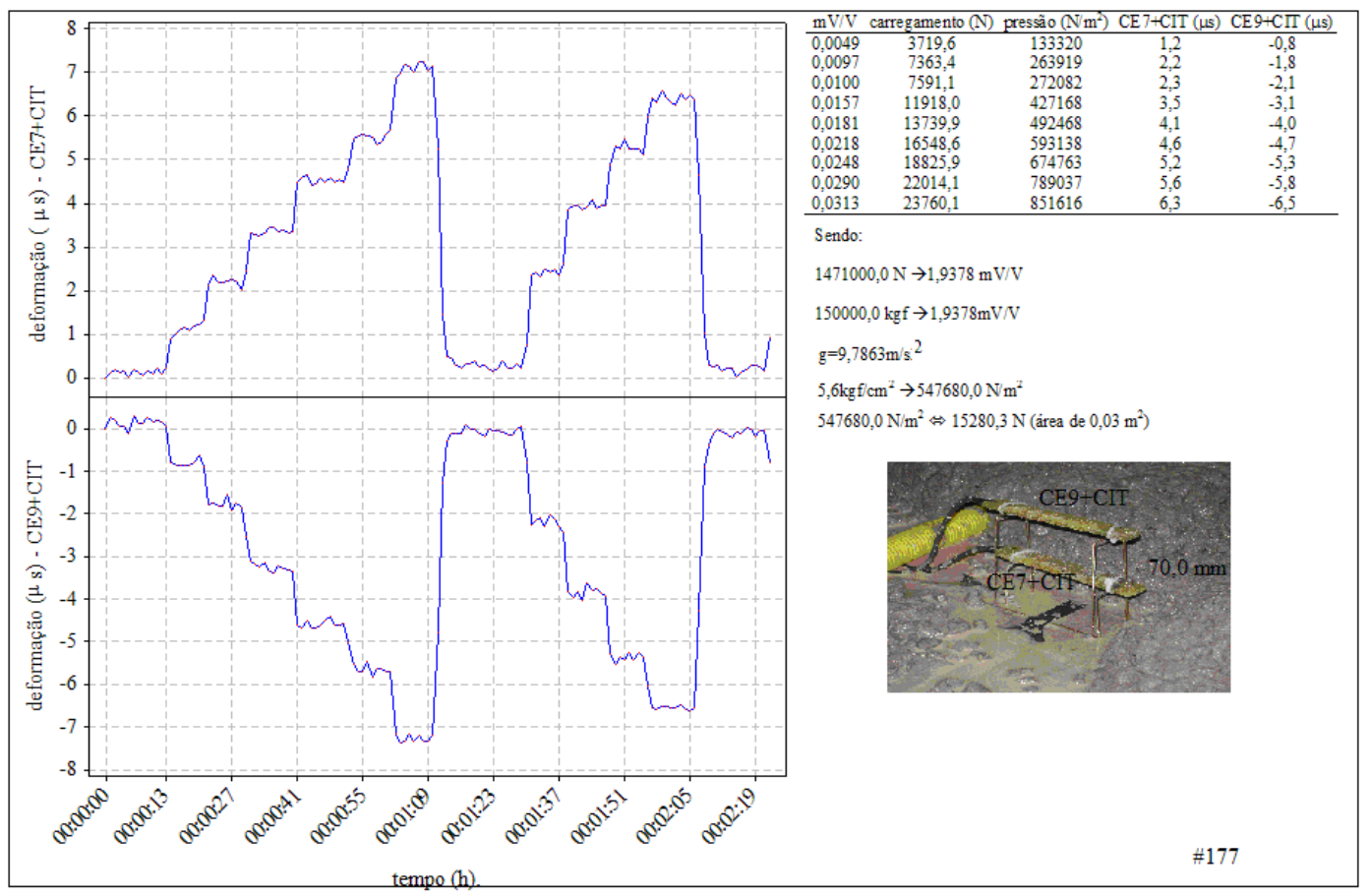

Quadro 5. Aplicação de carga no centro do pavimento. Comportamento das células embutidas CE7+CIT e CE9+CIT.

Fonte: Elaborado a partir dos dados coletados (2009).

No quadro 6 estão dispostas as equações de regressão de cada um dos testes realizados. Apesar delas apresentarem pouca diferença entre os testes experimentais e a simulação, notou-se que a deformação sem carga térmica, em simulações com o software 
EverFe 2.24, é muito suscetível à mudança do coeficiente de Poisson e ao módulo de elasticidade do concreto. Outras simulações indicaram dependência com o módulo de reação do subleito. Apesar de a estrutura atual permitir a troca da base ou do sub-leito, não foi possível a realização de testes experimentais com outro tipo de sub-leito.

\begin{tabular}{|l|l|l|}
\hline Gráficos & \multicolumn{1}{|c|}{ Equação } & Referências \\
\cline { 1 - 2 } Gráfico 83 & $\mathrm{P}=-301351+195085 \mathrm{~d}$ & $\mathrm{~d} \rightarrow$ deformação (microstrain) \\
\cline { 1 - 2 } Gráfico 84 & $\mathrm{P}=-360742+204187 \mathrm{~d}$ & \multirow{2}{*}{$\mathrm{N} \rightarrow$ pressão $\left(\mathrm{N} / \mathrm{m}^{2}\right)$} \\
\cline { 1 - 2 } Gráfico 85 & $\mathrm{P}=42948+163946 \mathrm{~d}$ & \multirow{2}{*}{$5,6 \mathrm{kgf} / \mathrm{cm}^{2} \rightarrow 547680,0 \mathrm{~N} / \mathrm{m}^{2}$} \\
\hline Gráfico 86 (CE7+CIT) & $\mathrm{P}=-54674+143132 \mathrm{~d}$ & \\
\cline { 1 - 2 } Gráfico 87 (CE9+CIT) & $\mathrm{P}=17650-126936 \mathrm{~d}$ & \\
\hline
\end{tabular}

Quadro 6. Equações de regressão dos experimentos realizados.

Fonte: Elaborada a partir dos dados coletados nos experimentos (2009).

\subsection{DEFORMAÇÃO DA PLACA SOB CARREGAMENTO TÉRMICO}

O estudo das deformações, mediante carregamento térmico, foi realizado de acordo com as taxas de temperatura apresentadas no presente trabalho. Condições especiais também foram simuladas ou testadas, tais como: dia normal ensolarado, dia com sol e presença de nuvem, dia com sol passando a chuvoso e novamente ensolarado. Apresenta-se, ainda, uma situação hipotética que é o resfriamento brusco. Para facilitar a observação das deformações ao longo da espessura, dois gráficos aparelhados são apresentados. O primeiro, sempre a esquerda, representa as deformações ao longo do tempo e outro, à direita, o estado térmico ao longo da espessura nos níveis de referência.

Empenamento côncavo:

Dia ensolarado, estudo em $1 / 2$ ponte duas células ativas: CE10-CE13D, localizadas em: $(1200,1750,110)-(1510,1200,110) \mathrm{mm}$, com taxa de aquecimento de $1,6^{\circ} \mathrm{C} / \mathrm{h}$., gráfico $88,2,6^{\circ} \mathrm{C} / \mathrm{h}$ gráfico 89 e $2,3^{\circ} \mathrm{C} / \mathrm{h}$ gráfico 90 . As células estão posicionadas segundo a seção transversal (direção do eixo x) da placa. Apresentam-se, lado a lado, os gráficos referentes às deformações ocorridas no período de teste e as curvas de aquecimento de topo e fundo da placa.

É possível observar que as deformações seguem a variação ditada pelo aquecimento superficial, quer seja pela taxa de aquecimento ou pelo tempo de "insolação" ou radiação. 

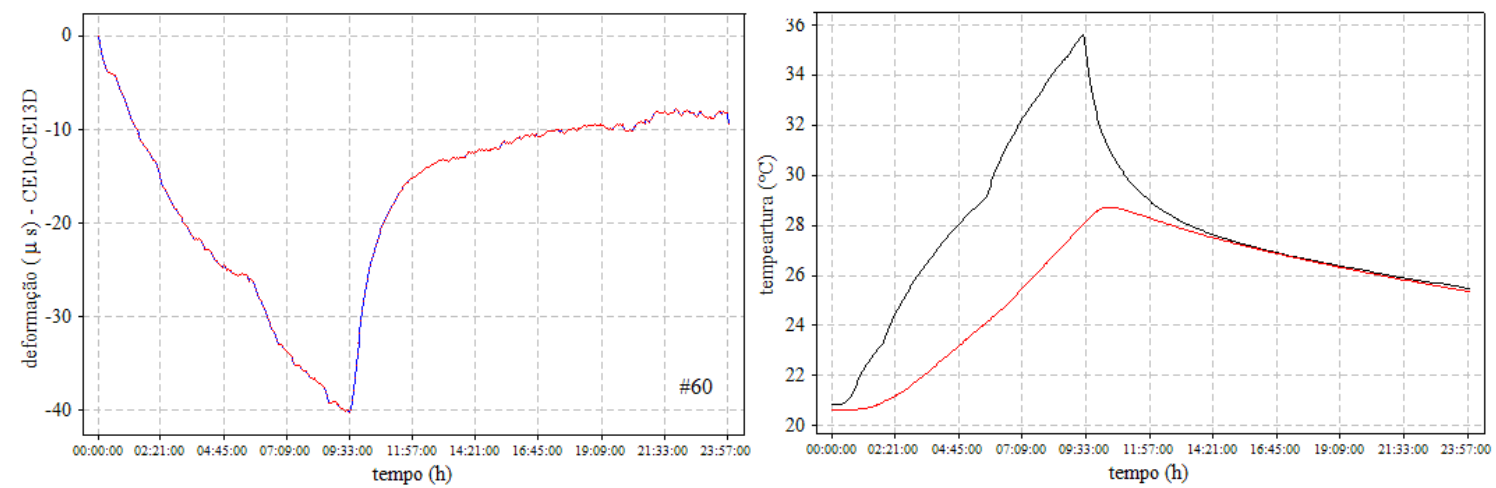

Gráfico 88. Deformação ocasionada em CE10+CE13D, transversal à placa, segundo a simulação de um dia ensolarado.

Fonte: Construído a partir dos dados coletados (2009).
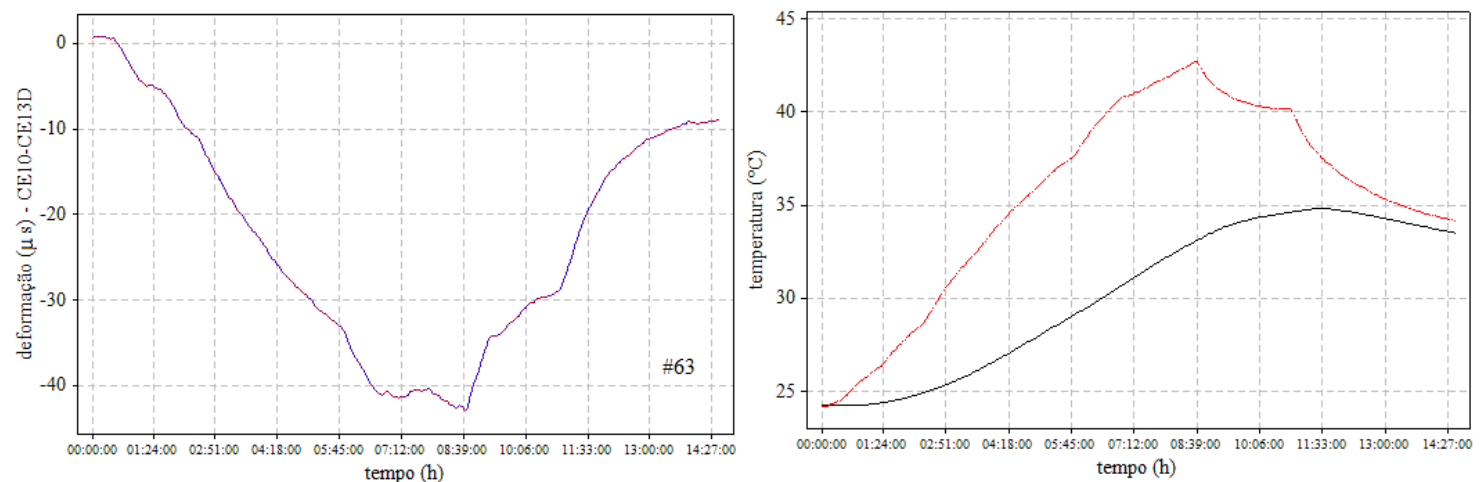

Gráfico 89. Deformação ocasionada em CE10+13D, segundo simulação de um dia ensolarado com variação na taxa de aquecimento.

Fonte: Construído a partir dos dados coletados (2009).
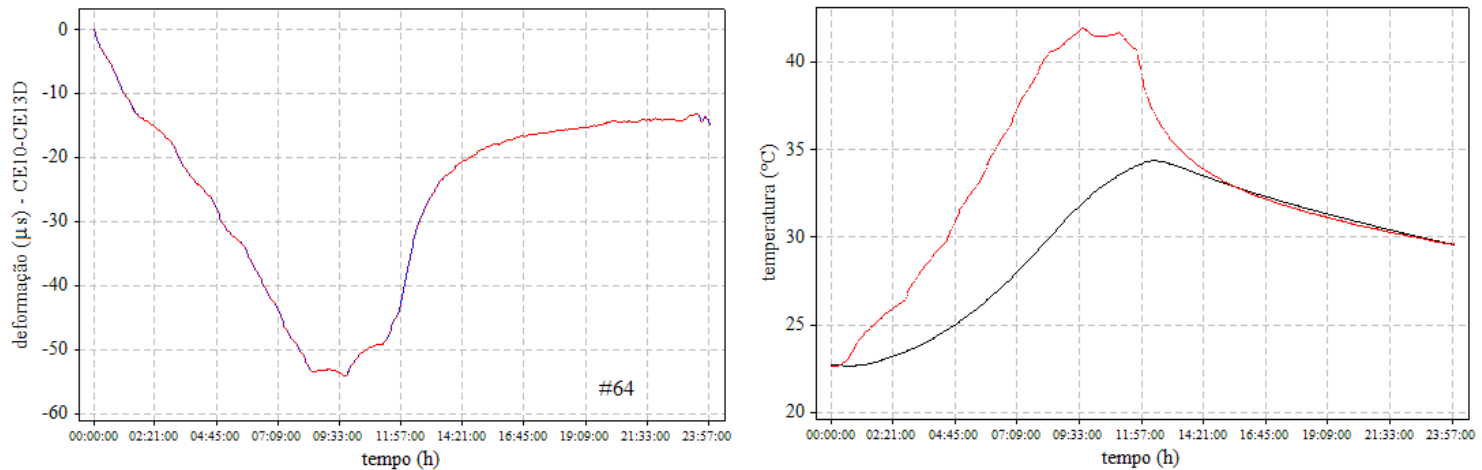

Gráfico 90. Deformação ocasionada em CE10+CE13D, segundo simulação de um dia ensolarado com variação na taxa de aquecimento.

Fonte: Construído a partir dos dados coletados (2009). 
Dia ensolarado, estudo em $1 / 2$ ponte duas células ativas: CE7-CE8, localizadas em: $(810,1490,60)-(147,1520,80) \mathrm{mm}$, com taxa de aquecimento de $2,6^{\circ} \mathrm{C} / \mathrm{h}$, gráfico $91,2,3^{\circ} \mathrm{C} / \mathrm{h}$ gráfico 92 e $2,2^{\circ} \mathrm{C} / \mathrm{h}$ gráfico 93 . As células estão posicionadas segundo a seção longitudinal (direção do eixo y) da placa. Como nas observações anteriores, é possível notar que as deformações seguem a variação ditada pelo aquecimento superficial, quer seja pela taxa de aquecimento ou pelo tempo de "insolação" ou radiação.
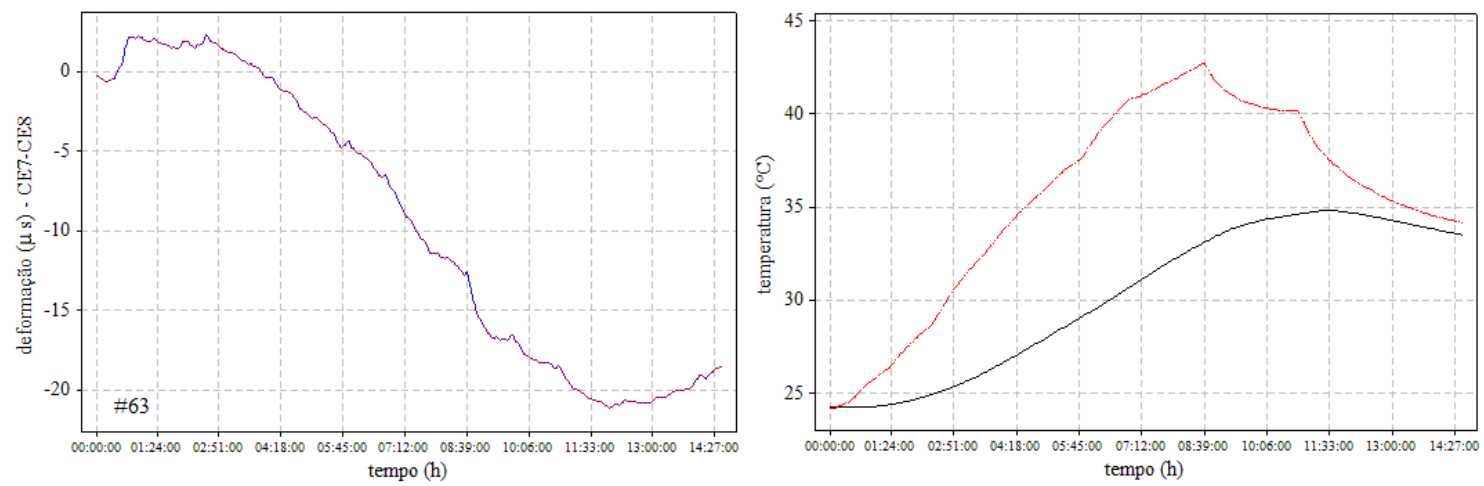

Gráfico 91. Deformação ocasionada em CE7+CE8, segundo simulação de um dia ensolarado com variação na taxa de aquecimento.

Fonte: Construído a partir dos dados coletados (2009).
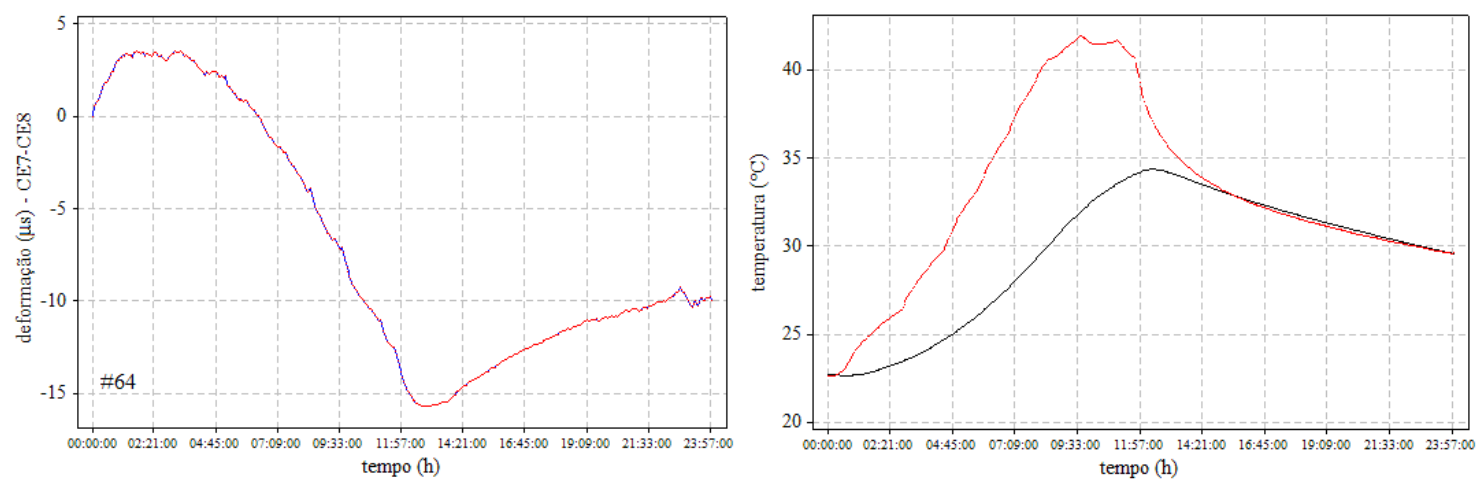

Gráfico 92. Deformação ocasionada em CE7+CE8, segundo simulação de um dia ensolarado com variação na taxa de aquecimento.

Fonte: Construído a partir dos dados coletados (2009). 

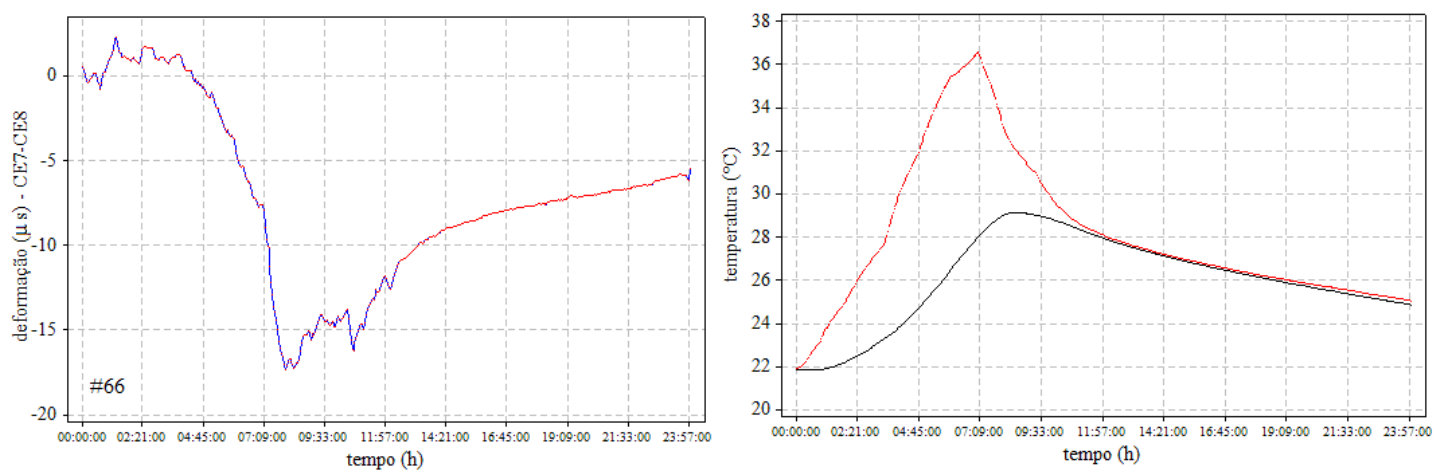

Gráfico 93. Deformação ocasionada em CE7+CE8, segundo simulação de um dia ensolarado com variação na taxa de aquecimento.

Fonte: Construído a partir dos dados coletados (2009).

Dia ensolarado, estudo em $1 / 2$ ponte duas células ativas: CE8-CE9, localizadas em: $(147,1520,80)-(1470,1520,130) \mathrm{mm}$, com taxa de aquecimento de $1,6^{\circ} \mathrm{C} / \mathrm{h}$, gráfico 94 , $1,4^{\circ} \mathrm{C} / \mathrm{h}$ gráfico 95 e gráfico 96 . As células estão posicionadas segundo a seção longitudinal (direção do eixo y) da placa.

Como nas observações anteriores, é possível notar que as deformações seguem a variação ditada pelo aquecimento superficial, no entanto, a resposta temporal da deformação apresenta um aspecto mais complexo que pode ser devido ao posicionamento das CE, elas estão em profundidades diferentes a $50,0 \mathrm{~mm}$ uma da outra. No ponto 1 é o instante em que cessa o carregamento térmico, o trecho 1-2 a CE9 está resfriando mais rápido que a CE8, causando um desequilíbrio na ponte. Na fase 3 ocorre um reequilíbrio da ponte e a placa está a uma temperatura constante e as células estão sujeitas à tração (vide desenho 29).
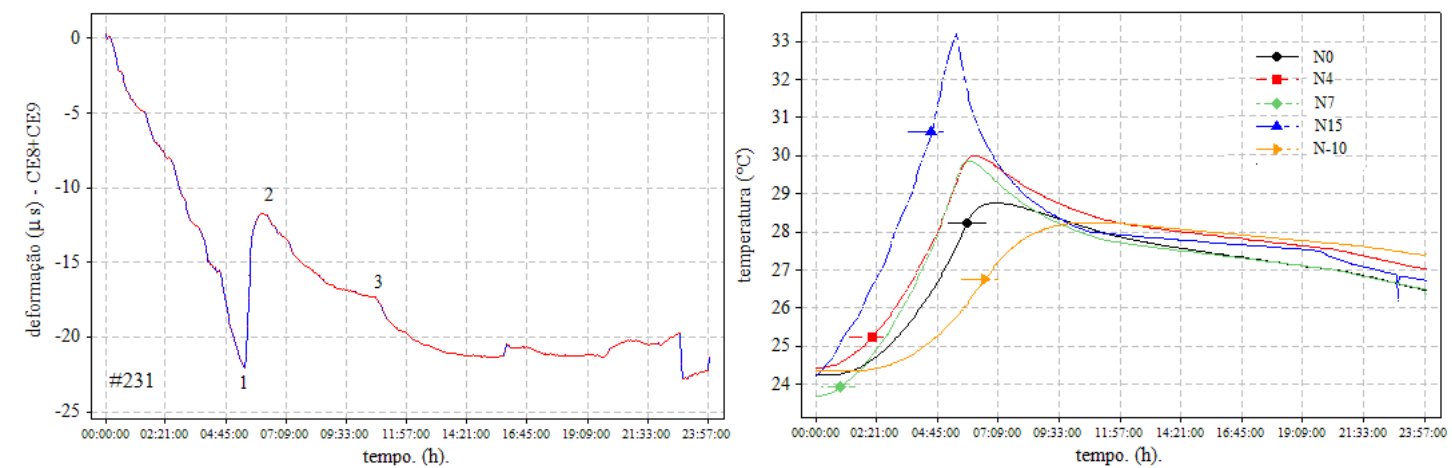

Gráfico 94. Deformação ocasionada em CE8+CE9, segundo simulação de um dia ensolarado com variação na taxa de aquecimento.

Fonte: Construído a partir dos dados coletados (2009). 
Como o processo de aquecimento depende da manipulação do variac, percebeu-se que, mesmo em taxas iguais (ou parecidas) o comportamento térmico da placa é diferente, e isso, induz mudanças na deformação da placa. No gráfico 95, apesar da taxa de aquecimento ser a mesma observada pelo gráfico 94, o processo de aquecimento foi diferente, ou seja, o intervalo de tempo para a manipulação do variac foi feito em passos maiores do observado anteriormente.

No trecho 1, gráfico 95, é o instante em que foi incrementado um passo no variac. No trecho 2, é o momento em que ocorre circulação de ar sobre a placa, com sistema de aquecimento ligado. No trecho 3 é o instante em que o sistema de aquecimento foi desligado. No trecho 4 é o instante em que se inicia o resfriamento próximo a CE8 e a taxa de resfriamento, em CE9, é mais acentuada.
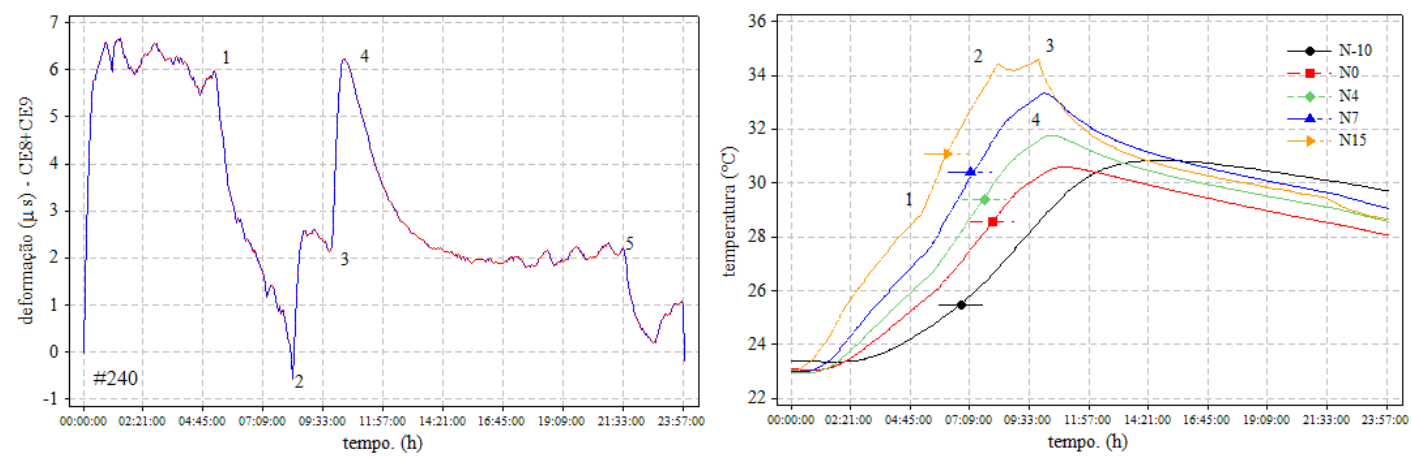

Gráfico 95. Deformação ocasionada em CE8+CE9, segundo simulação de um dia ensolarado com variação na taxa de aquecimento.

Fonte: Construído a partir dos dados coletados (2009).

As mesmas observações realizadas acima, se aplicam ao comportamento da placa representada pelo gráfico 96. Porém, a repetição de resultados, em termos de deformação, não parece adequada e, aparentemente, os valores dependem de outros fatores que não foram capturados pelo sistema de aquisição. Outro aspecto que pode ser considerado é que as células trabalham de forma independente ocasionando a subtração de sinais, ao invés da soma. A disposição é a mesma utilizada segundo o desenho 22, exceto que se utilizou as CIT.

Dia ensolarado, estudo em $1 / 2$ ponte uma célula ativa e outra dummy: CE7-CIT, localizadas em: $(810,1490,60)-(78,1490,60) \mathrm{mm}$, com taxa de aquecimento de $1,9^{\circ} \mathrm{C} / \mathrm{h}$, gráfico $97,1,1^{\circ} \mathrm{C} / \mathrm{h}$ gráfico 98 e $1,0^{\circ} \mathrm{C} / \mathrm{h}$, gráfico 99 . A célula está posicionada segundo a seção longitudinal (direção do eixo y) da placa e, nessa posição, está próxima do nível N7. 

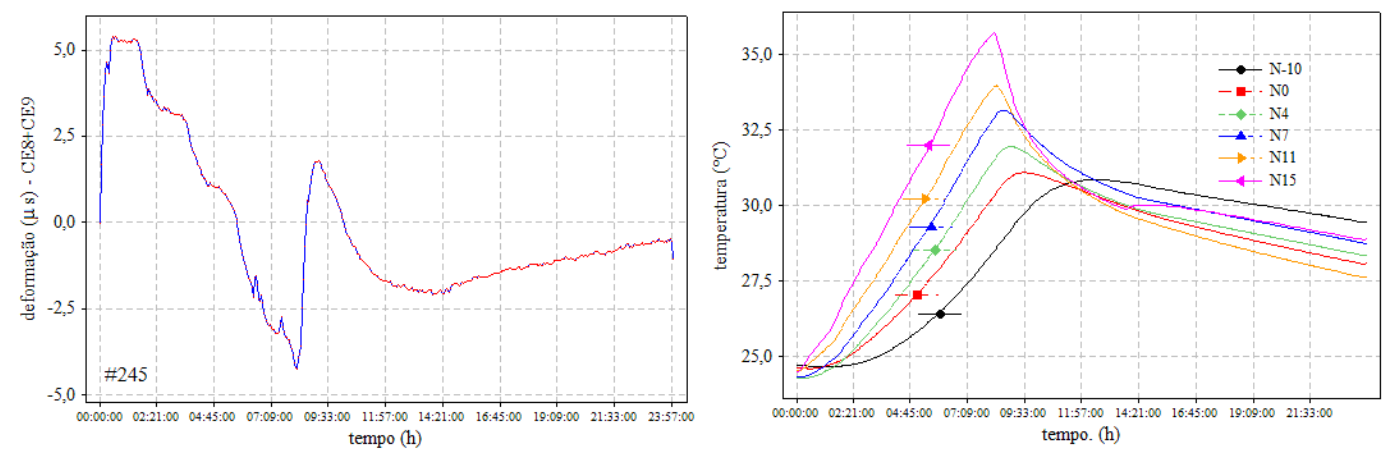

Gráfico 96. Deformação ocasionada em CE8+CE9, segundo simulação de um dia ensolarado com variação na taxa de aquecimento.

Fonte: Construído a partir dos dados coletados (2009).

Como nas observações anteriores, é possível notar que as deformações seguem a variação ditada pelo aquecimento superficial, para tanto, foi colocado um termômetro (semelhante aos embutidos) sobre a superfície. A intenção é mostrar a inter-relação entre essa temperatura e aquela mostrada no topo. Por outro lado, esse termômetro facilitou a visualização da transferência de energia para a placa, bem como auxiliou nas pré análises de deformação sob os dados da CIT-CE7. A forma pela qual a placa é aquecida, como dito anteriormente, afeta o seu comportamento em função das deformações.

No gráfico 97, pode ser visto como a deformação evolui ditada pelo comportamento térmico da fibra do concreto na posição da célula.

A sequência dos testes 97, 98 e 99 mostra que, apesar do tempo de exposição à radiação e os passos de condução na dosagem da energia térmica ter sido a mesma, não conduziram, necessariamente, a uma identidade entre os testes. Percebeu-se, entretanto, que pequenas variações causam diferença em termos de deformação. Nesse sentido, foi realizada uma verificação mais detalhada em cada um dos gráficos 97, 98 e 99.

Inicialmente, foi feita uma verificação da diferença máxima de temperatura entre o nível 15 e o 7 (localização da célula), posteriormente se verificou a temperatura máxima em N15, verificou-se a deformação máxima, o tempo de aquisição e a área compreendida entre as curvas descritas pelo comportamento térmico dos níveis 15 e 7 . Esses dados foram colocados no quadro 7, o qual mostra os valores calculados.

As deformações são compatíveis entre si e, pelos dados apresentados, quem comanda o comportamento da placa é a diferença de temperatura entre os níveis em estudo. 

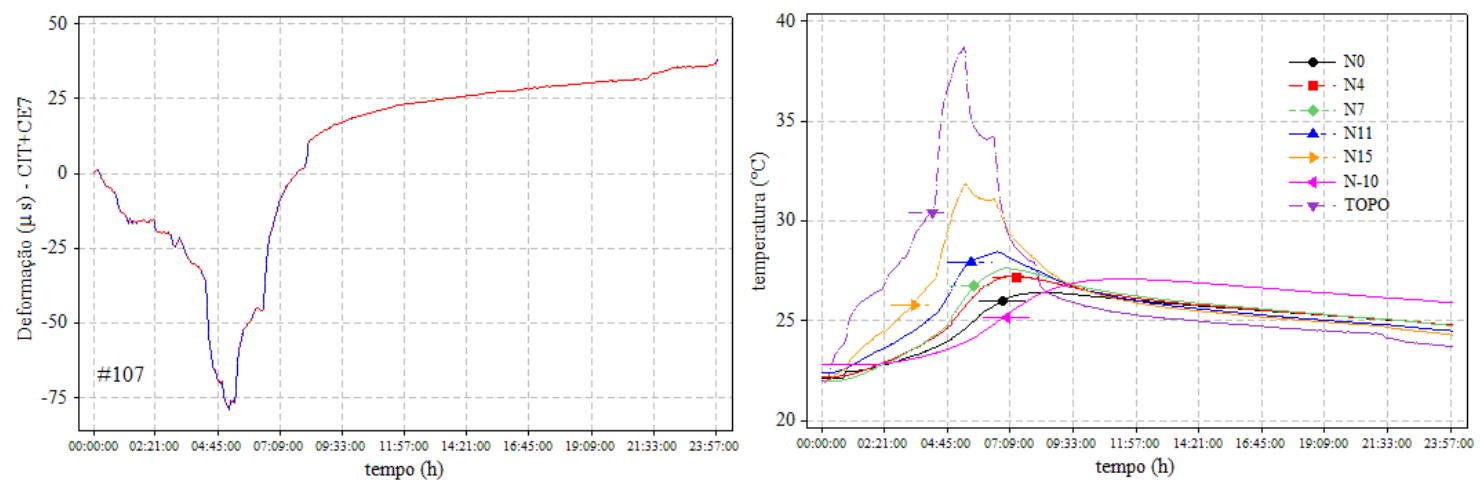

Gráfico 97. Deformação ocasionada em CE7+CIT, segundo simulação de um dia ensolarado com pequena variação na taxa de aquecimento.

Fonte: Construído a partir dos dados coletados (2009).

\begin{tabular}{|l|c|c|c|c|c|c|}
\hline & $\begin{array}{l}\Delta \mathrm{T}_{\max } \\
\left({ }^{\circ} \mathrm{C}\right)\end{array}$ & $\begin{array}{l}\mathrm{T}_{\max } \\
\left({ }^{\circ} \mathrm{C}\right)\end{array}$ & $\begin{array}{l}\text { Taxa de } \\
\text { aquecimento } \\
\left({ }^{\circ} \mathrm{C} / \mathrm{h}\right)\end{array}$ & $\begin{array}{l}\text { deformação } \\
(\mu \mathrm{s})\end{array}$ & $\begin{array}{l}\text { tempo de } \\
\text { aquisição } \\
(\mathrm{h})\end{array}$ & $\begin{array}{l}\text { área entre os } \\
\text { níveis }-\mathrm{N} 15- \\
\mathrm{N} 7\left({ }^{\circ} \mathrm{C}\right)^{2}\end{array}$ \\
\hline Gráfico 97 & 5,7 & 31,8 & 1,9 & $-78,8$ & $5 \mathrm{~h} 24 \mathrm{~min}$ & 150,6 \\
\hline Gráfico 98 & 6,5 & 34,4 & 1,1 & $-77,1$ & $5 \mathrm{~h} 24 \mathrm{~min}$ & 108,7 \\
\hline Gráfico 99 & 5,2 & 32,8 & 1,0 & $-74,1$ & $5 \mathrm{~h} 45 \mathrm{~min}$ & 153,5 \\
\hline
\end{tabular}

Quadro 7. Dados analisados e calculados em relação aos níveis N15 e N7

Fonte: Elaborada a partir dos dados apresentados nos gráficos (2009).
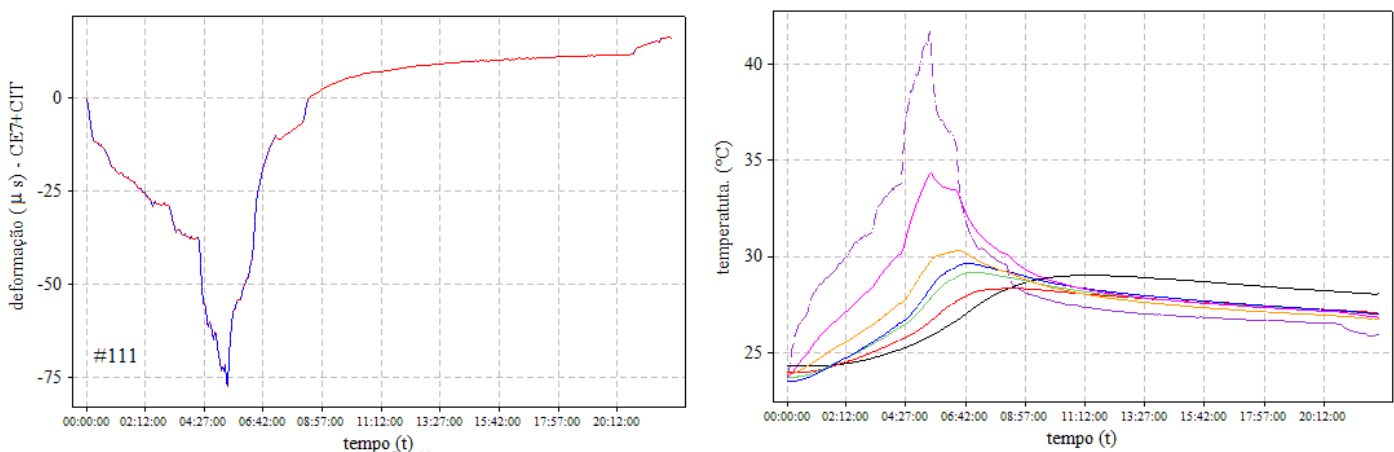

Gráfico 98. Deformação ocasionada em CE7+CIT, segundo simulação de um dia ensolarado com pequena variação na taxa de aquecimento.

Fonte: Construído a partir dos dados coletados (2009). 

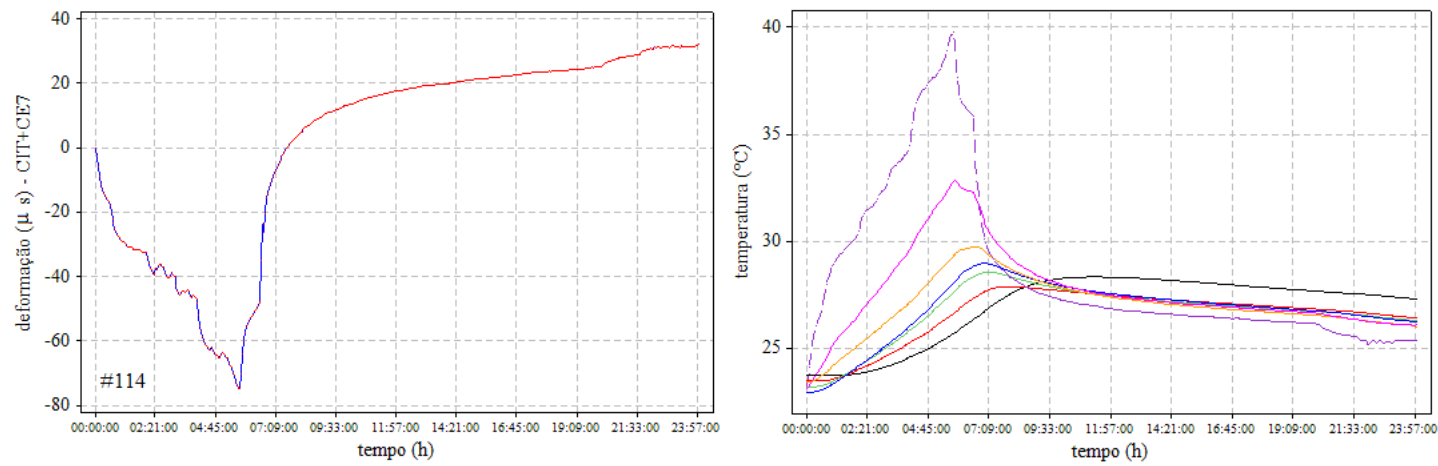

Gráfico 99. Deformação ocasionada em CE7+CIT, segundo simulação de um dia ensolarado com pequena variação na taxa de aquecimento.

Fonte: Construído a partir dos dados coletados (2009).

Dia ensolarado, estudo em $1 / 2$ ponte uma célula ativa e outra dummy: CE10-CIT, localizadas em: $(1200,1750,110)-(1200,1755,110) \mathrm{mm}$, com taxa de aquecimento de $1,0^{\circ} \mathrm{C} / \mathrm{h}$, gráfico 100 e $1,9^{\circ} \mathrm{C} / \mathrm{h}$ gráfico 101 . A célula está posicionada segundo a seção transversal (direção do eixo x) da placa e, nessa posição, ela está no nível N11.

Os gráficos 100 e 101 descrevem o comportamento da placa em termos das deformações ocorridas. Apesar das medidas serem referidas á mesma célula, é possível verificar diferença entre ambos. Observa-se que, nos gráficos auxiliares (100 e 101) de temperatura, as diferenças podem ser devido ao tempo de exposição e a taxa de temperatura. Tendo em vista que, os dados apresentados pelo no gráfico 101 foram obtidos com 8 horas de aquecimento e uma manipulação rápida no controle do variac. Os dados apresentados no gráfico 100 foram obtidos por processo mais lento, com baixa taxa de aquecimento e menor tempo de exposição. Aparentemente o modo de aquecimento e a história dos aquecimentos anteriores, afetam o comportamento da placa em termos de deformações.
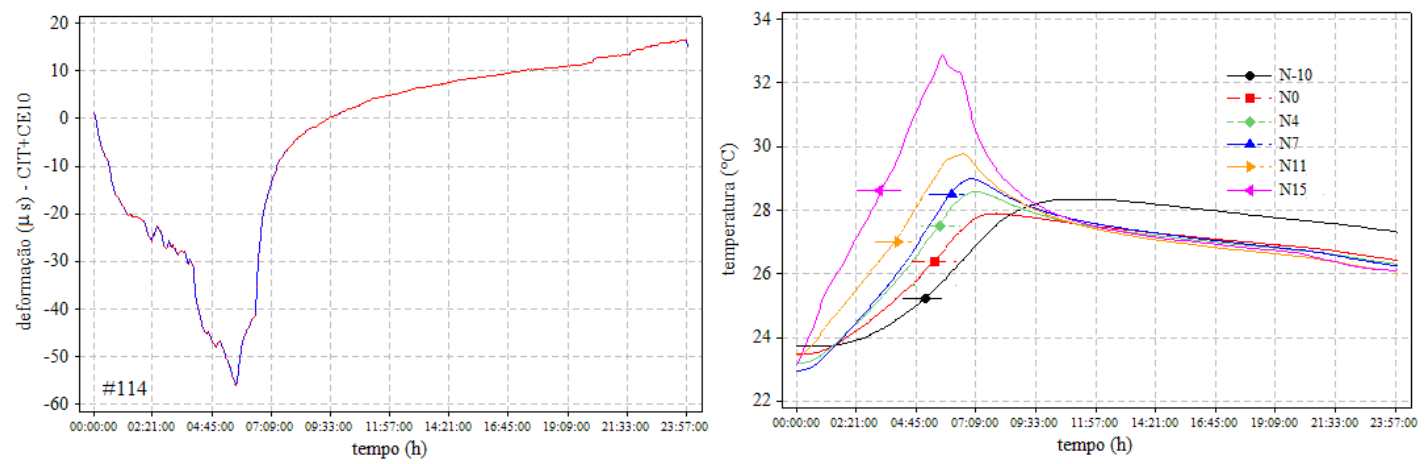

Gráfico 100. Deformação ocasionada em CE10+CIT, segundo simulação de um dia ensolarado com variação na taxa de aquecimento.

Fonte: Construído a partir dos dados coletados (2009). 

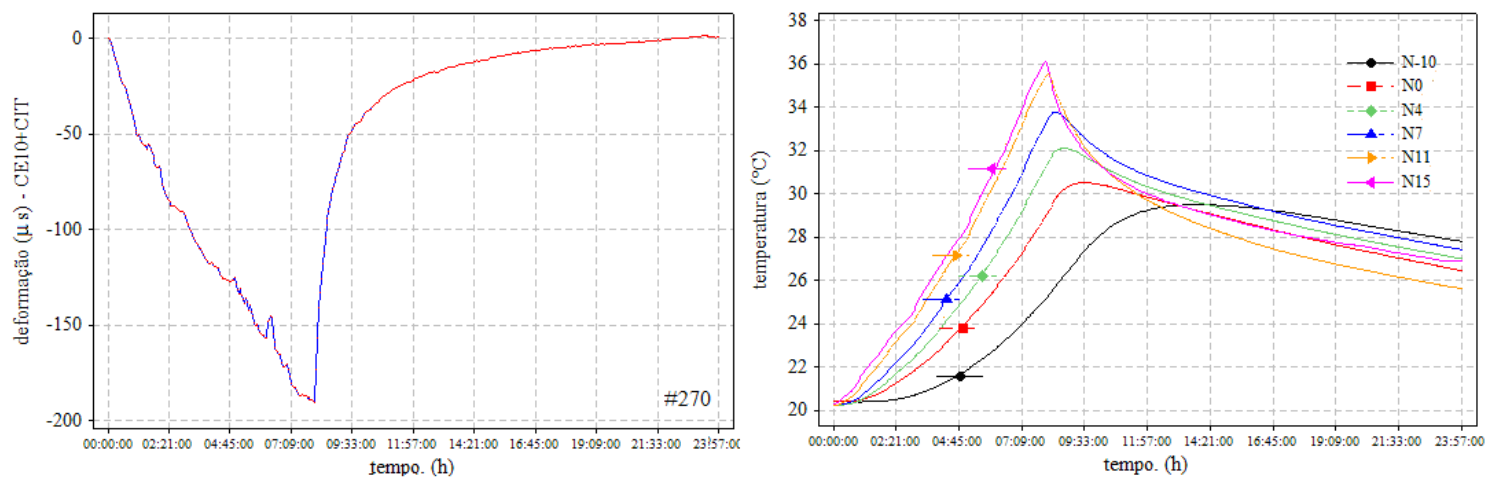

Gráfico 101. Deformação ocasionada em CE10+CIT, segundo simulação de um dia ensolarado com variação na taxa de aquecimento.

Fonte: Construído a partir dos dados coletados (2009).

Dia ensolarado com chuva no período, estudo em $1 / 2$ ponte uma célula ativa e outra dummy: CE7-CIT, CE10+CIT e CE11-CIT localizadas em: $(810,1490,60),(1200,1750,110) \mathrm{e}$ $(1510,120060) \mathrm{mm}$, com taxa de aquecimento de $1,5^{\circ} \mathrm{C} / \mathrm{h}$ nas três situações. A célula CE7CIT fica posicionada na direção longitudinal e a CE10-CIT, CE11-CIT segundo a seção transversal (direção do eixo x). A CE7-CIT e a CE11-CIT estão localizadas no nível sete (N7) e a CE10-CIT localiza-se em N11.

Os gráficos 102, 103 e 104 descrevem o comportamento da placa em termos das deformações ocorridas durante o período de teste.

As deformações ocorridas no meio do período devem-se à mudança no "humor" da placa, quando a mesma foi submetida a uma quantidade de água equivalente a uma chuva rápida de verão.

No gráfico 102, o ponto 1 foi no momento em que a alimentação elétrica das resistências foram desligadas e imediatamente foi realizada a "chuva artificial" sobre a placa. $\mathrm{O}$ ponto 2 indica o instante em que a alimentação das resistências foi religada, mantendo a potência anterior. O ponto 3 indica o instante em que ocorre a retirada da proteção térmica da placa e passa a circular, sobre a mesma, ar frio. O ponto 4 indica quando o sistema de aquecimento é desligado. As mesmas considerações podem ser realizadas para os outros gráficos. Devido à posição da célula CE10-CIT, fibra superior, ela apresenta uma deformação maior em relação às outras. 

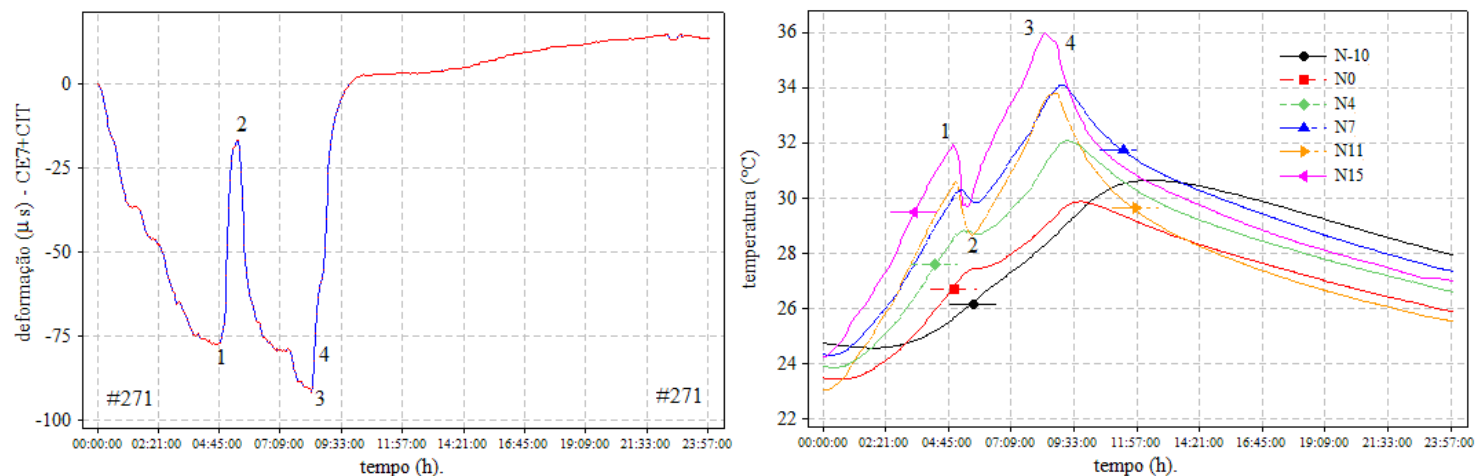

Gráfico 102. Deformação ocasionada em CE7+CIT, segundo simulação de um dia ensolarado com chuva no período.

Fonte: Construído a partir dos dados coletados (2009).
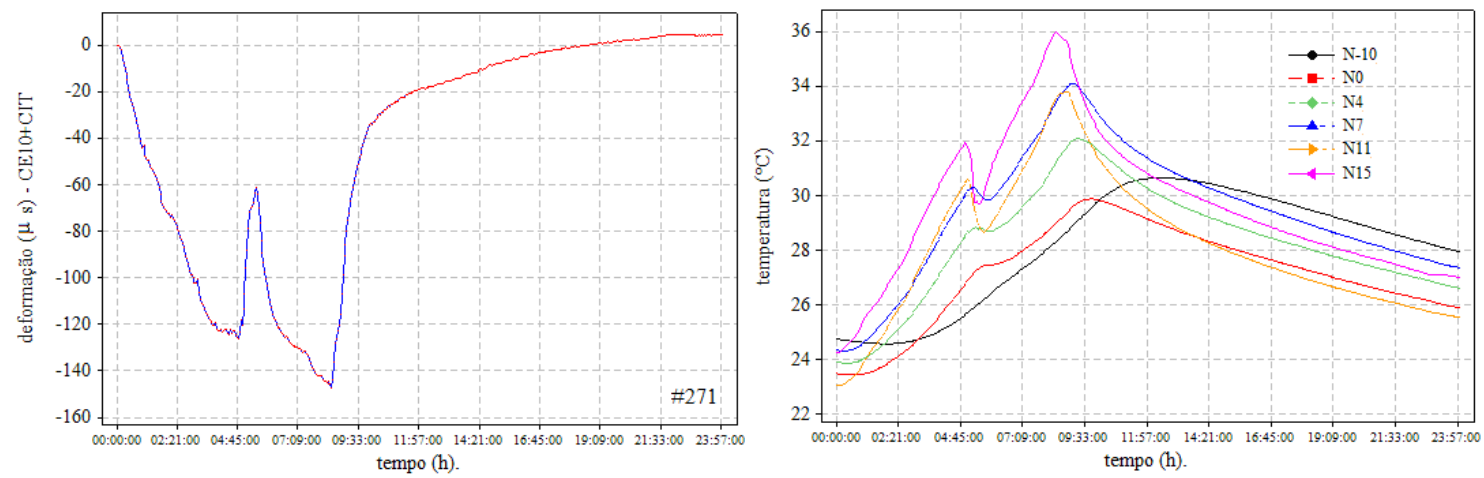

Gráfico 103. Deformação ocasionada em CE10+CIT, segundo simulação de um dia ensolarado com chuva no período.

Fonte: Construído a partir dos dados coletados (2009).
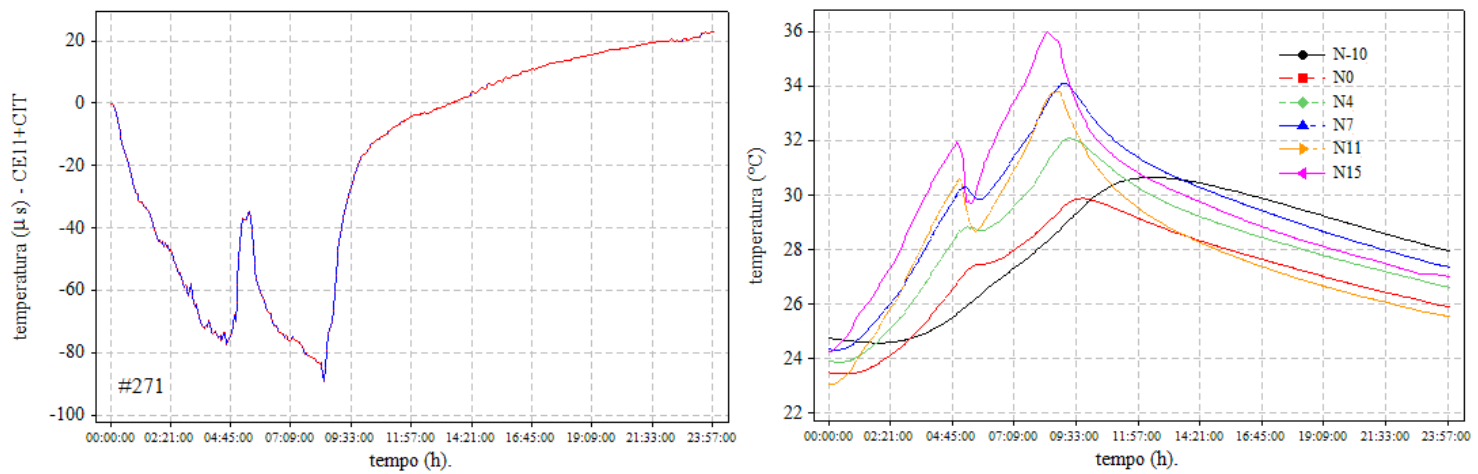

Gráfico 104. Deformação ocasionada em CE11+CIT, segundo simulação de um dia ensolarado com chuva no período.

Fonte: Construído a partir dos dados coletados (2009). 
Esses resultados indicam que a metodologia foi capaz de capturar a modificação do comportamento da placa em termos de deformações, quando eventos repentinos, tal qual uma chuva de verão, atua sobre uma estrutura rígida.

Dia ensolarado, passando a nublado no período, estudo em $1 / 2$ ponte uma célula ativa e outra dummy: CE7-CIT, CE8-CIT e CE12+CIT localizadas em: $(810,1490,60)$, $(1470,1520,80)$ e $(1500,500,40) \mathrm{mm}$, com taxa de aquecimento de $1,0^{\circ} \mathrm{C} / \mathrm{h}$ nas três situações. A célula CE8-CIT e CE7-CIT estão posicionadas na direção longitudinal e a CE12-CIT segundo a seção transversal (direção do eixo x). A CE7-CIT e a CE8-CIT estão localizadas no nível sete (N7) e a CE12-CIT localiza-se em N4.

As deformações ocorridas durante esse período descrevem um dia ensolarado passando a nublado ao fim da tarde.
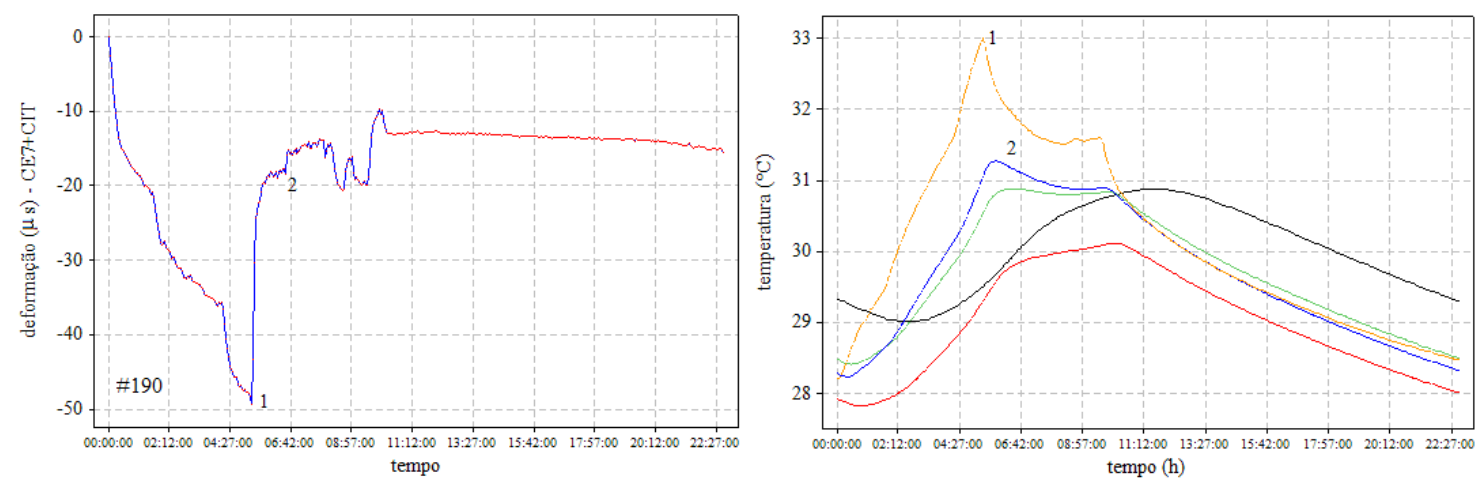

Gráfico 105. Deformação ocasionada em CE7+CIT, segundo simulação de um dia ensolarado passando a nublado no período.

Fonte: Construído a partir dos dados coletados (2009).

No gráfico 105 o ponto 1 indica o momento em que ocorre a diminuição da taxa de aquecimento (surgimento de uma nuvem) e a deformação é percebida pela mudança do estado térmico superficial. O ponto 2 indica o instante em que ocorre a temperatura máxima no nível onde se encontra a célula. Aparentemente, o comportamento da base não provocou influência no comportamento da célula. Talvez porque as medidas foram realizadas sob essas condições.

No gráfico 106 o ponto 1 indica o momento em que ocorre a diminuição da taxa de aquecimento (surgimento de uma nuvem) e a deformação é percebida pela mudança do estado térmico superficial.

As mesmas considerações podem ser feitas para o gráfico 107. Exceto que, as pequenas "ondulações" se referem a alterações ocorridas durante o processo de resfriamento. 

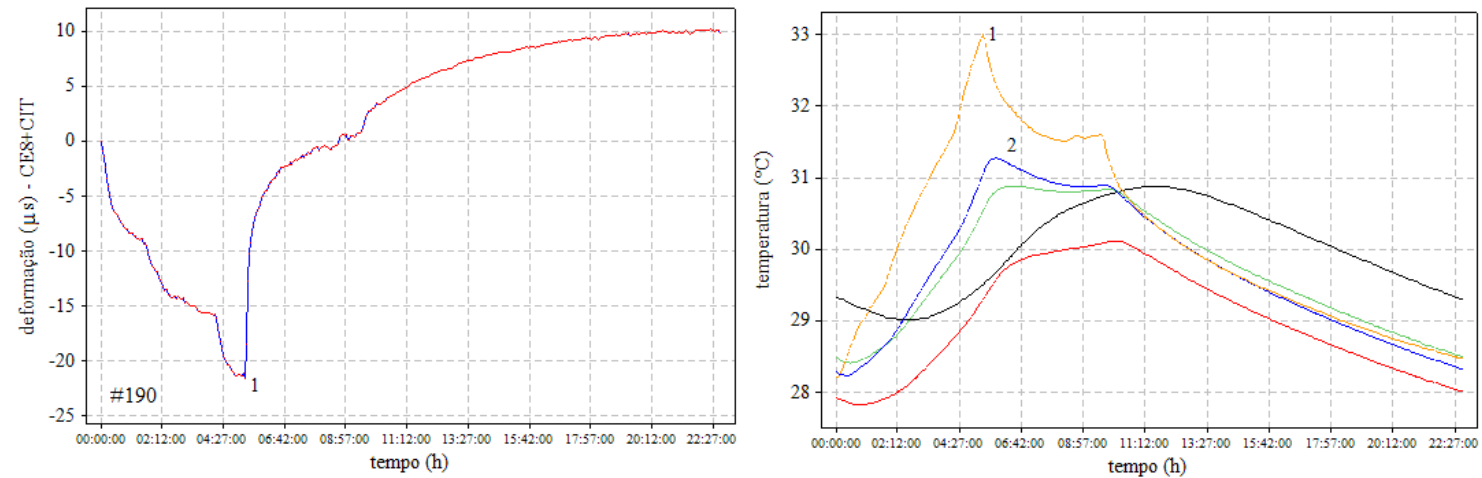

Gráfico 106. Deformação ocasionada em CE8+CIT, segundo simulação de um dia ensolarado passando a nublado no período.

Fonte: Construído a partir dos dados coletados (2009).
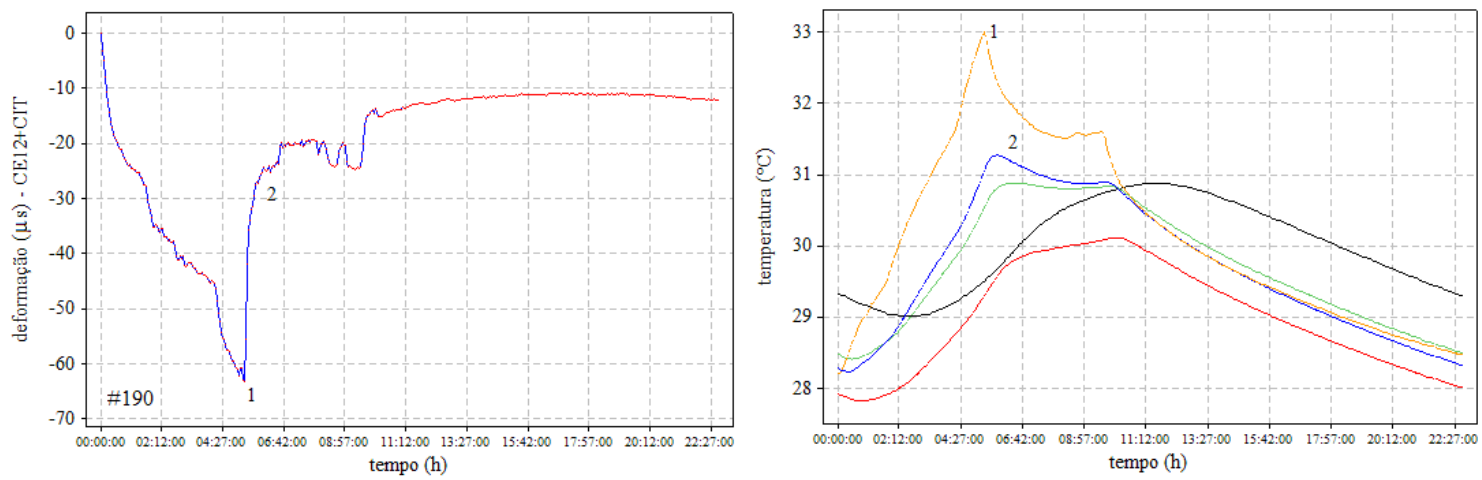

Gráfico 107. Deformação ocasionada em CE12+CIT, segundo simulação de um dia ensolarado passando a nublado no período.

Fonte: Construído a partir dos dados coletados (2009).

Essa seqüência de testes mostra um aspecto importante, que o pavimento, placa com mais intensidade, acompanhando as mudanças das condições meteorológicas e mudando seu aspecto geométrico conforme o estado térmico.

Nesses testes é possível observar um aspecto interessante, que é a temperatura do fundo da base maior que a temperatura de fundo da placa. Fenômeno que pode ser comum nos pavimentos reais e que merece uma investigação mais detalhada.

Empenamento convexo.

Situação hipotética de resfriamento brusco e seu efeito sobre o pavimento. Estudo em 1/2 ponte uma célula ativa e outra dummy: CE7-CIT, CE10-CIT e CE11+CIT localizadas em: $(810,1490,60),(1200,1750,110)$ e $(1510,1200,60) \mathrm{mm}$, com taxa de resfriamento de $3,0^{\circ} \mathrm{C} / \mathrm{h}$ nas três situações. A célula CE7-CIT está posicionada na direção longitudinal e as 
células CE10-CIT e CE11-CIT, segundo a seção transversal (direção do eixo x). A CE7-CIT e a CE11-CIT estão localizadas no nível sete (N7) e a CE10-CIT localiza-se em N11.

O gráfico 108 mostra o comportamento do pavimento no nível N7 com a resposta da CE7 após resfriamento brusco realizado no topo do pavimento. O ponto 2 indica o momento em que foi acrescentado mais gelo sobre a superfície.

Devido a impossibilidade na uniformização da camada de gelo sobre o pavimento, resultando em regiões com diferentes densidades de gelo, foram obtidas respostas temporais diferentes mas com deformações semelhantes. Isso pode ser observado no gráfico 108 cuja rápida resposta é semelhante à aquela vista no gráfico 110 .

O gráfico 109, apesar da rápida resposta, apresentou uma deformação diferente ao longo do teste. Uma investigação posterior mostrou que a CIT estava úmida e, devido a isso, influenciou na resposta da célula.

Outra observação é sobre o diferencial de temperatura entre o topo do pavimento e o fundo da base que, nesse teste, em determinado instante, chegou a $-7^{\circ} \mathrm{C}$. Ocasionando um "casamento" de concavidade entre placa e base.
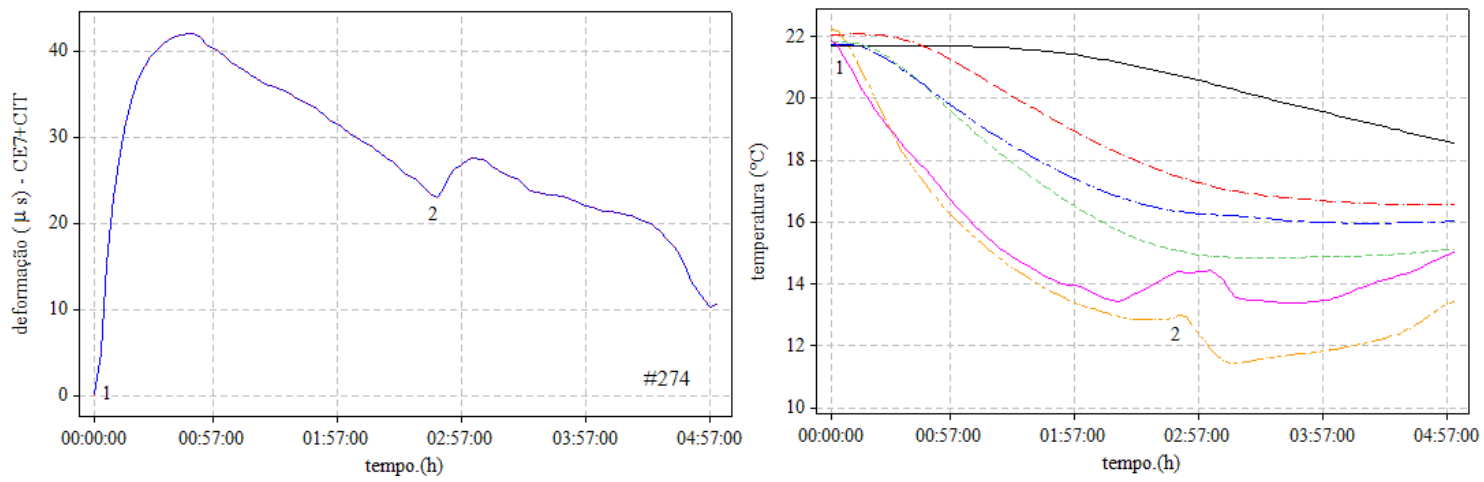

Gráfico 108. Deformação ocasionada em CE7+CIT, devido a ocorrência de um resfriamento no topo do pavimento.

Fonte: Construído a partir dos dados coletados (2009). 

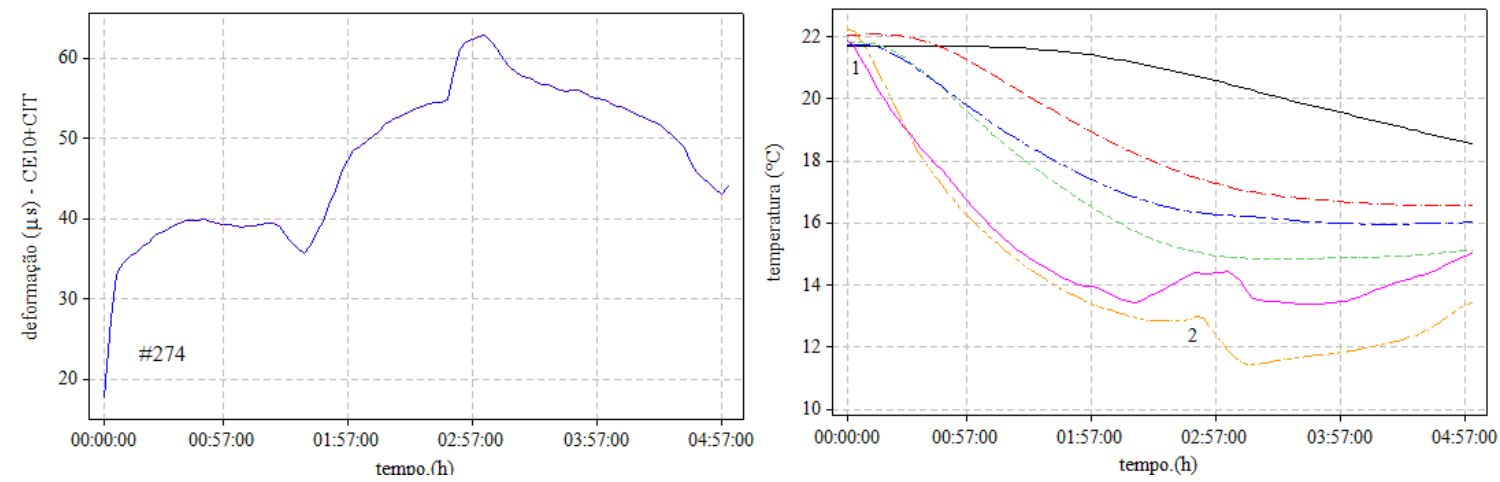

Gráfico 109. Deformação ocasionada em CE10+CIT, devido a ocorrência de um resfriamento no topo do pavimento.

Fonte: Construído a partir dos dados coletados (2009).
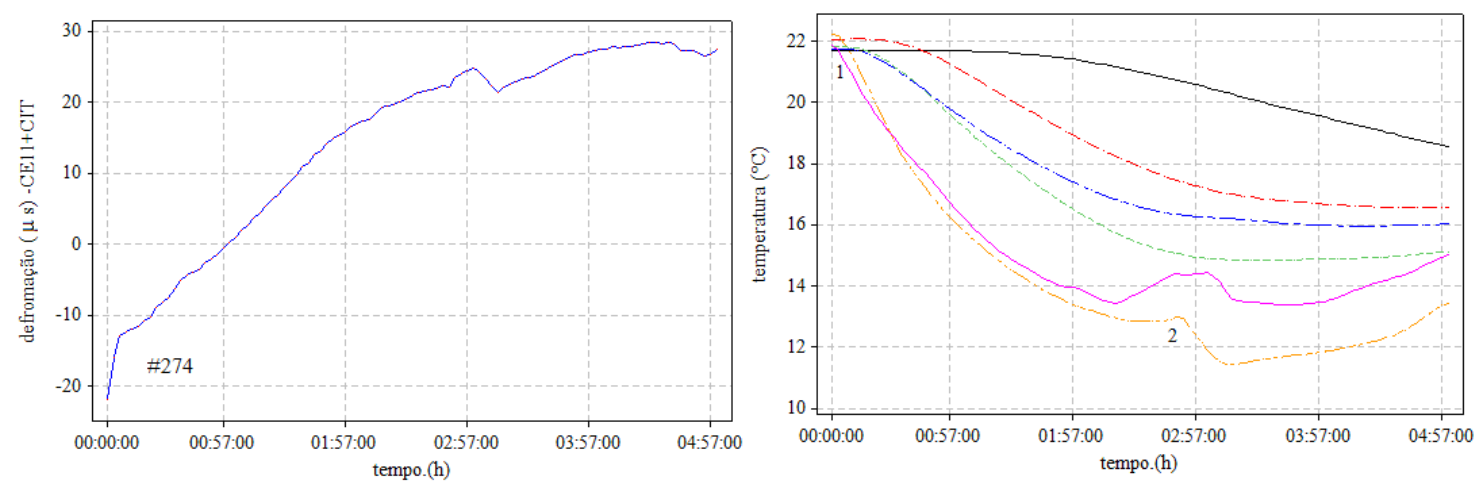

Gráfico 110. Deformação ocasionada em CE11+CIT, devido a ocorrência de um resfriamento no topo do pavimento.

Fonte: Construído a partir dos dados coletados (2009).

\subsection{DEFORMAÇÃO E DESLOCAMENTO DA PLACA SOB CARREGAMENTO ESTÁTICO E TÉRMICO}

Além dos carregamentos individuais, a metodologia também permitiu a combinação de testes de carregamento estático sobre carregamento térmico. Isso foi realizado com aquecimento de topo (provocando empenamento convexo) com aplicação de carga estática no centro e borda da estrutura em instantes distintos. As deformações foram medidas pelas CE, especificamente pela CE10+CIT, o deslocamento foi medido pelo sensor potenciométrico e a força de empenamento pela célula de carga sob a placa.

Foram conduzidos testes de aquecimento de topo com taxa de $1,9{ }^{\circ} \mathrm{C} / \mathrm{h}$ durante 6 (seis) horas. No final do período de aquecimento, a estrutura foi solicitada com carregamento de centro e borda semelhantes aqueles já realizados. O estado térmico nos níveis internos da placa, para esses testes, está mostrado pelo gráfico 111 e os carregamentos de centro e borda 
realizados pelo sistema hidráulico são apresentados no gráfico 112 onde também, pode ser visto uma linha de referência indicando o valor de $548800 \mathrm{~N} / \mathrm{m}^{2}\left(5,6 \mathrm{kgf} / \mathrm{cm}^{2}\right)$.

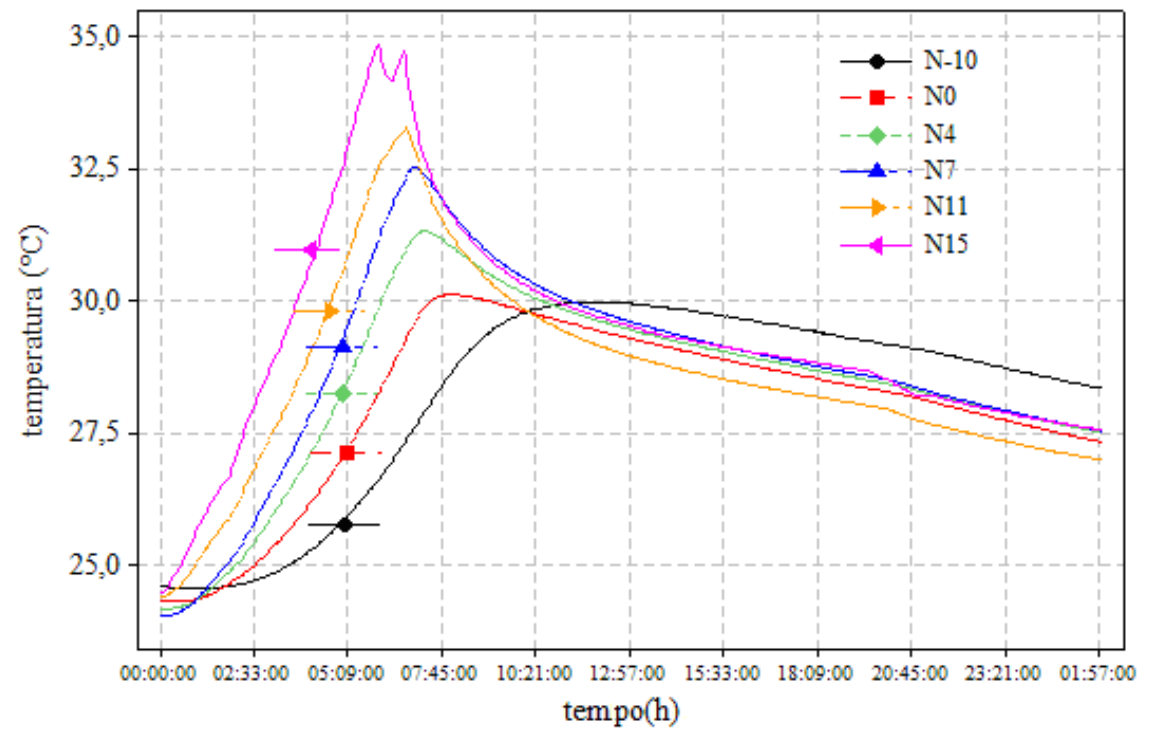

Gráfico 111. Temperatura nos níveis de referência durante os testes de carregamento combinado.

Fonte: elaborado a partir dos dados coletados (2009).

O gráfico 113 mostra o deslocamento do canto da placa e em detalhe a resposta da estrutura as seqüências dos carregamentos impostos sobre a estrutura. A placa responde a eles se deslocando conforme são aplicados, no entanto, tão logo cessa o esforço ela volta a posição anterior obedecendo ao carregamento térmico imposto.

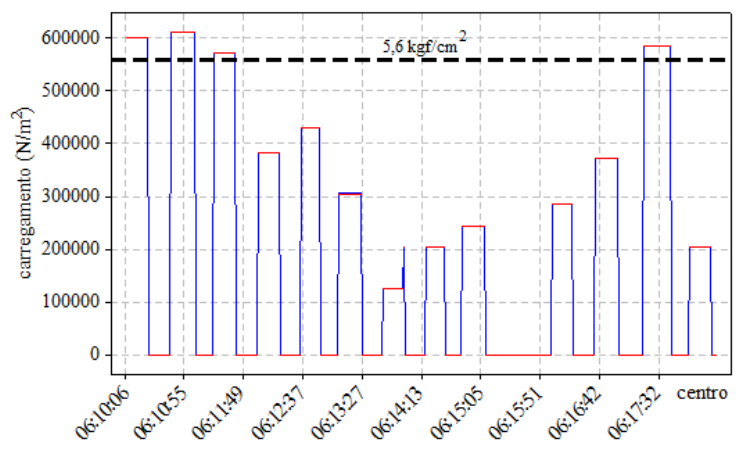

instante $(\mathrm{h})$

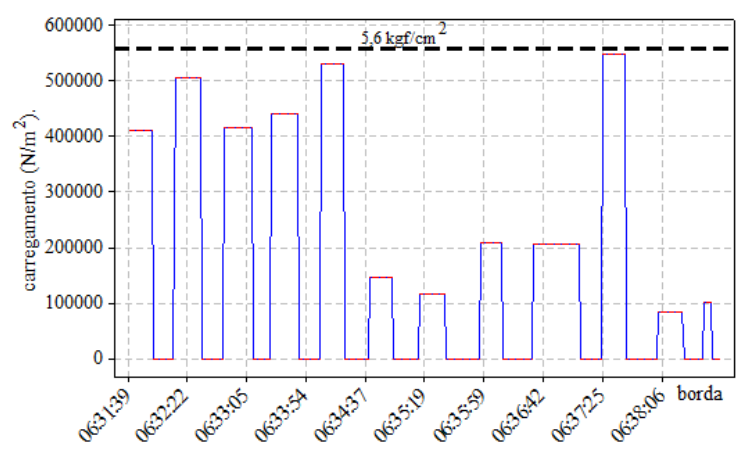

instante (h).

Gráfico 112. Aspecto do carregamento imposto sobre a estrutura em duas posições distintas, centro e borda.

Fonte: Elaborado a partir dos dados experimentais (2009). 


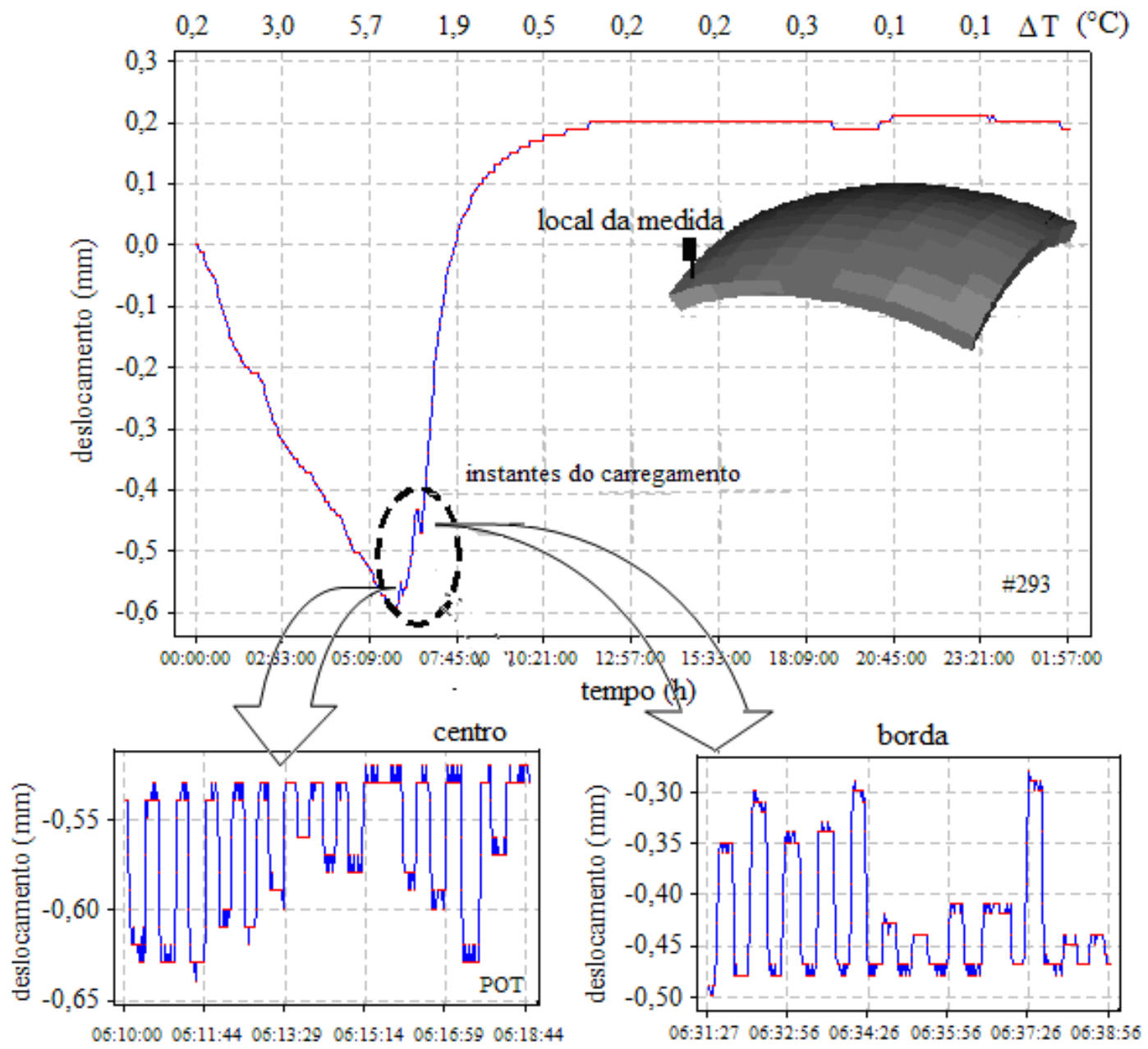

Gráfico 113. Deslocamento da placa mediante a um carregamento combinado, térmico e estático no centro e borda.

Fonte: Elaborado a partir de dados experimentais (2009).

Esse efeito está em destaque em uma elipse desenhada nos dois momentos em que foi realizada a solicitação mecânica. Nota-se quando a placa é solicitada pelo centro, o sensor potenciométrico indica o deslocamento no mesmo sentido da aplicação da força. Quando a placa é solicitada pela borda, o sensor mostra que o canto da placa tende a se levantar.

O gráfico 114 mostra o registro da deformação percebida pela CE10 localizada na transversal da placa. Em detalhe os carregamentos realizados e a resposta da placa. Ela responde a eles conforme são aplicados, no entanto, após cessado o esforço, ela volta a posição anterior obedecendo ao carregamento térmico imposto. No gráfico destaca-se o intervalo de tempo da aplicação da carga e, em detalhe as intensidades das deformações percebidas pela célula. 


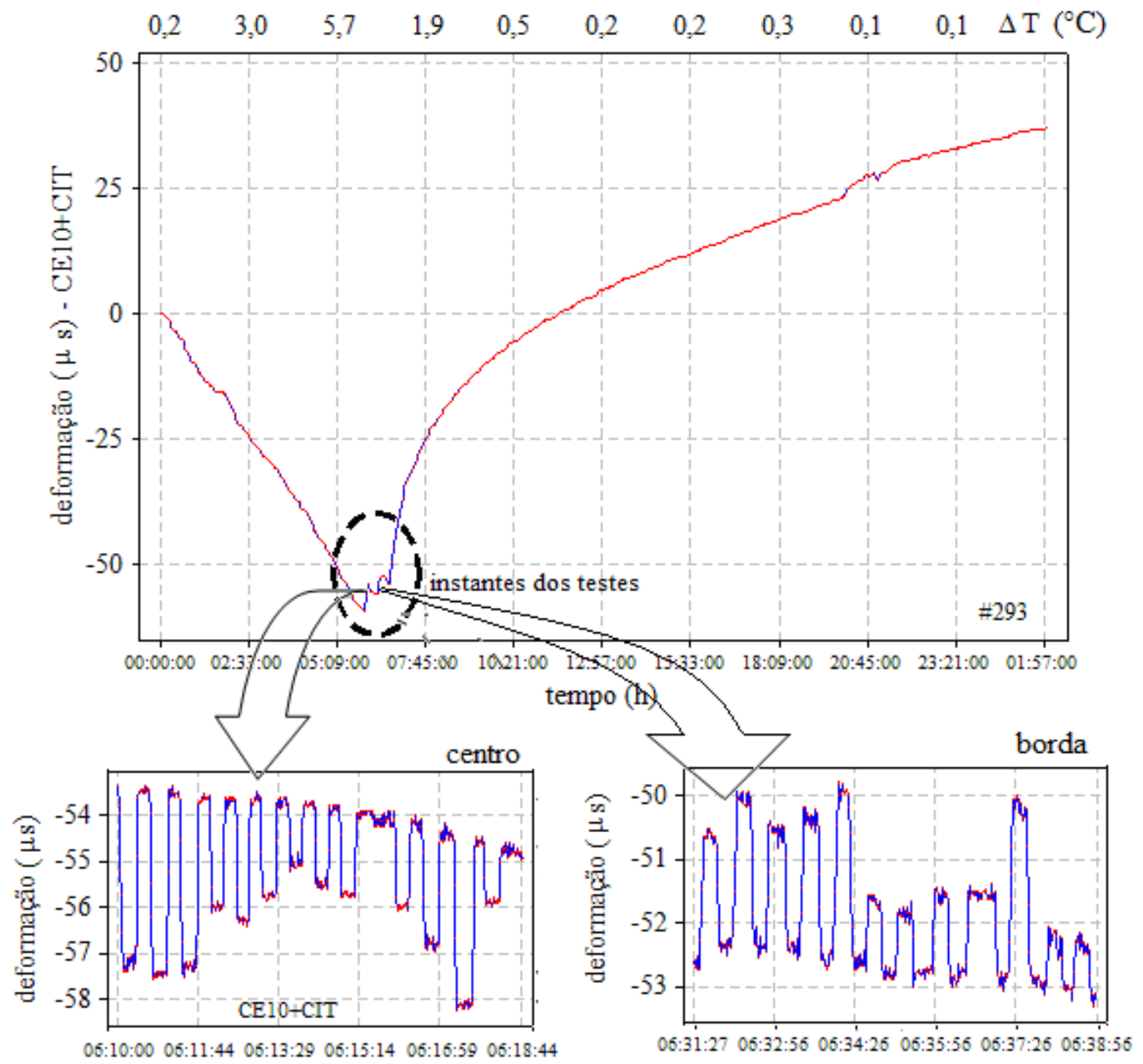

Gráfico 114. Deformação da placa mediante a um carregamento combinado, térmico e estático no centro e borda.

Fonte: Elaborado a partir de dados experimentais (2009).

O gráfico 115 mostra o reflexo da carga aplicada no topo da placa. No detalhe, percebe-se que a placa momentaneamente vota à posição inicial nos instantes em que o carregamento é aplicado. Isso pode ser visto nos gráficos auxiliares, que mostram os valores das forças percebidas no fundo da placa. A situação mais evidente é vista quando a placa é carregada pelo centro. Nessa situação a célula de fundo (transtec) sai de uma posição de tração á posição de compressão. A mesma observação pode ser realizada para aplicação de carregamento na borda da placa. No gráfico destaca-se o intervalo de tempo da aplicação da carga e o diferencial de temperatura no momento do teste.

111.

O estado térmico da placa durante esses procedimentos é mostrado pelo gráfico 


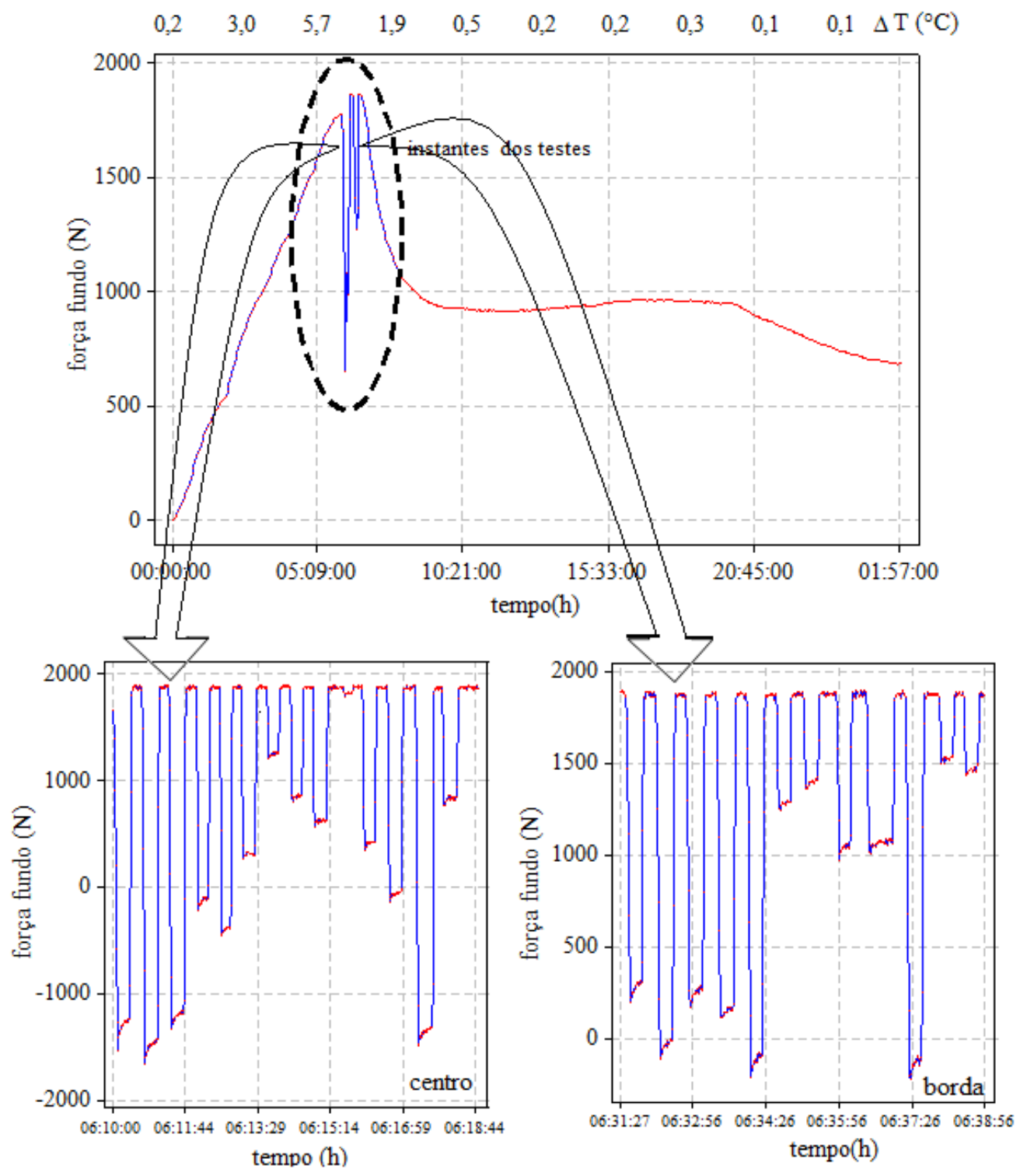

Gráfico 115. Força no fundo da placa mediante a um carregamento combinado, térmico e estático no centro e borda.

Fonte: Elaborado a partir de dados experimentais (2009).

Esses testes indicaram o comportamento da placa quando submetida a carregamentos combinados. As deformações, deslocamentos e força no fundo mostraram uma correspondência qualitativa e quantitativa da resposta da placa frente aos carregamentos impostos. 


\subsubsection{COMPARAÇÕES DOS RESULTADOS OBTIDOS COM TRABALHOS REALIZADOS EM PISTAS REAIS E EXPERIMENTAIS}

Para efeito de comparação foram selecionados cinco trabalhos encontrados na literatura e que descrevem situações semelhantes aos testes realizados no presente trabalho. Entre eles encontram-se testes dinâmicos, que não fazem parte do presente trabalho, porém, os resultados concordam com os valores de deformação encontrados nos testes estáticos realizados.

O primeiro trabalho refere-se a um carregamento dinâmico sem aquecimento, desenvolvido por Pereira (2003) em prova dinâmica com passagem de veículos sobre o pavimento com sensor de deformação a $30,0 \mathrm{~mm}$ do fundo. $\mathrm{Na}$ situação exposta no gráfico 116 a ação da carga de um ESRS provocou a deformação de 2,2 $\mu$ s no pavimento. Esse valor, de certa forma, concorda com aqueles obtidos na preparação dos gráficos 83, 84, 85 (simulação) e 86. As diferenças se devem às características elásticas do pavimento que impedem uma acomodação imediata, minimizando a ação mecânica no sensor. Esse fenômeno deve-se à influência da velocidade de passagem do veículo.

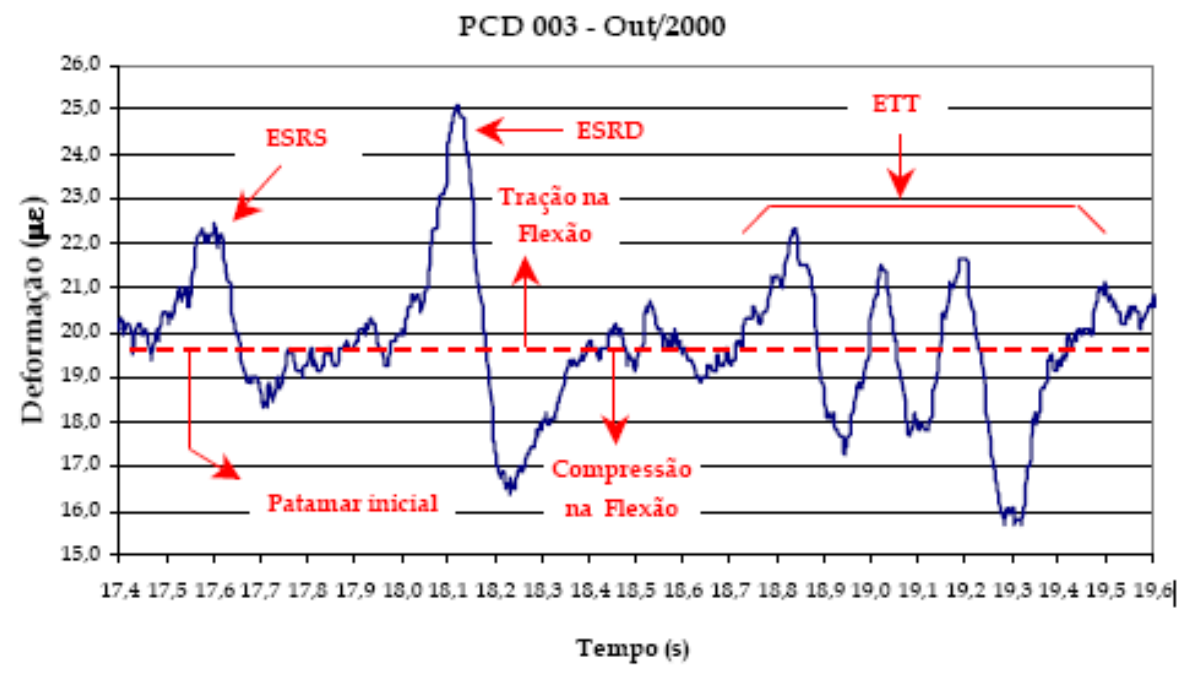

Gráfico 116. Deformação causada por carga dinâmica em pavimento real instrumentado. Fonte: adaptado de Pereira (2003).

O segundo trabalho se refere à avaliação da temperatura em pavimento de concreto realizado por Mahboub et al. (2004), cujos dados, sobre deformação com carga térmica e carga devido ao tráfego, também se equivalem à aqueles medidos durante os ensaios de carga estática, item 4.9, especificamente, gráfico 114. O gráfico 117 mostra a curva de resposta de deformação em duas situações distintas. 


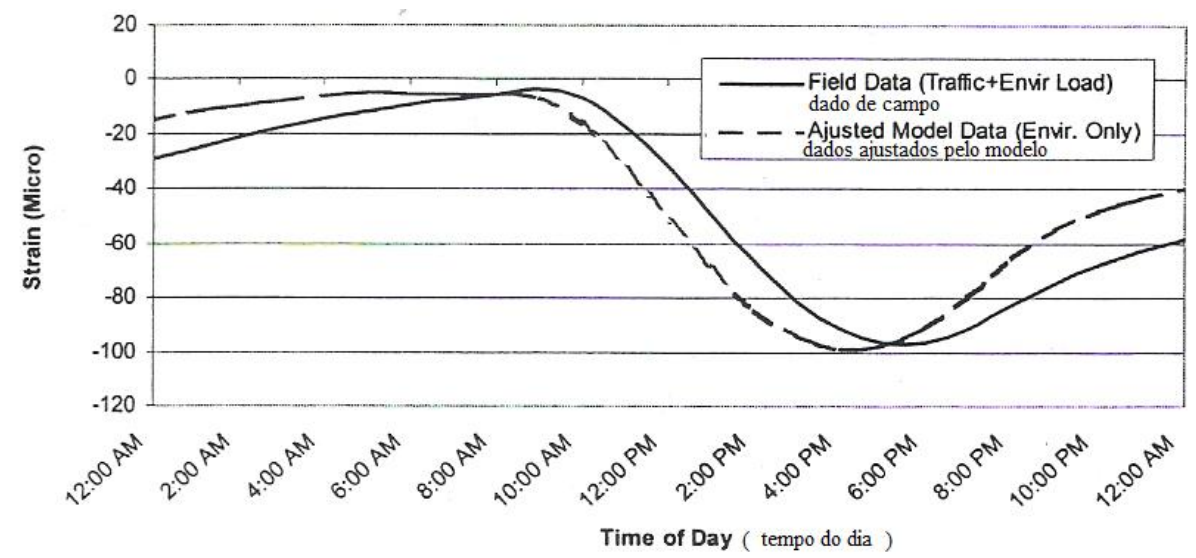

Gráfico 117. Deformação devido a carga térmica e devido ao tráfego em uma seção da estrada I-265 -Kentucky -USA.

Fonte: Adaptado do trabalho de Mahboub et al. (2004).

O terceiro trabalho que pode ser tomado como comparação são os resultados obtidos por Yu (1998) em pista instrumentada construída sobre outra existente no Colorado USA. Nesse caso uma prova de carga dinâmica de $80,0 \mathrm{kN}$, foi sentida por extensômetros posicionados próximos a duas placas contíguas munidas com barras de transferência. Apesar desse tipo de construção não ser semelhante ao projeto em estudo, percebe-se que a ordem de grandeza obtida, aproximadamente $20,0 \mu$ s é compatível com valores obtidos em testes estáticos. O gráfico 118 mostra o momento em que a carga solicita a região onde se encontra o extensômetro.

O quarto trabalho foi escolhido para comparar dados de deslocamentos obtidos nos testes com aqueles obtidos em campo. Nesse sentido, cita-se o trabalho de Poblete et al. (1988) que fornece dados que se afinam com aqueles conseguidos no ensaios de laboratório. No caso são deslocamentos ocorridos no pavimento na época de inverno em um trecho da Pan -American Highway devido a uma carga de $81,0 \mathrm{kN}$. O gráfico 119 mostra tais deslocamentos que podem ser comparados com os resultados indicados nos gráficos 65 e 67 . 


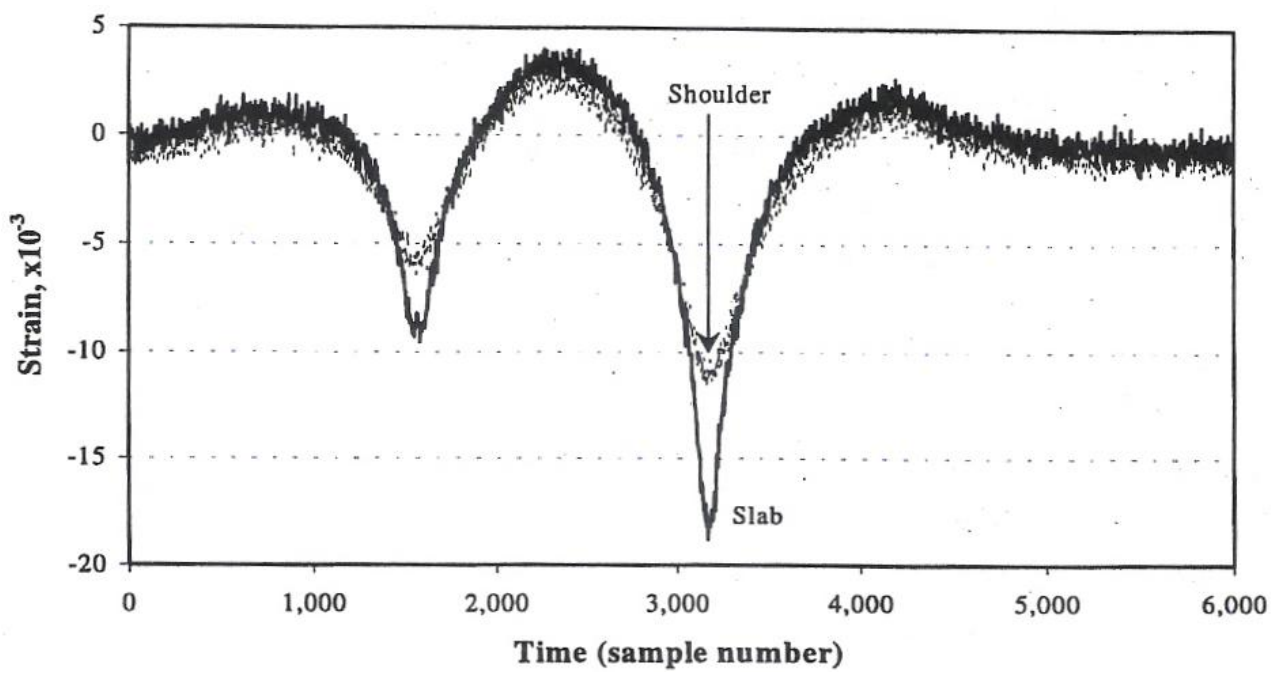

Gráfico 118. Deformação em pavimento instrumentado quando da ocorrência de carga móvel. Fonte : Adaptado de Yu (1998).

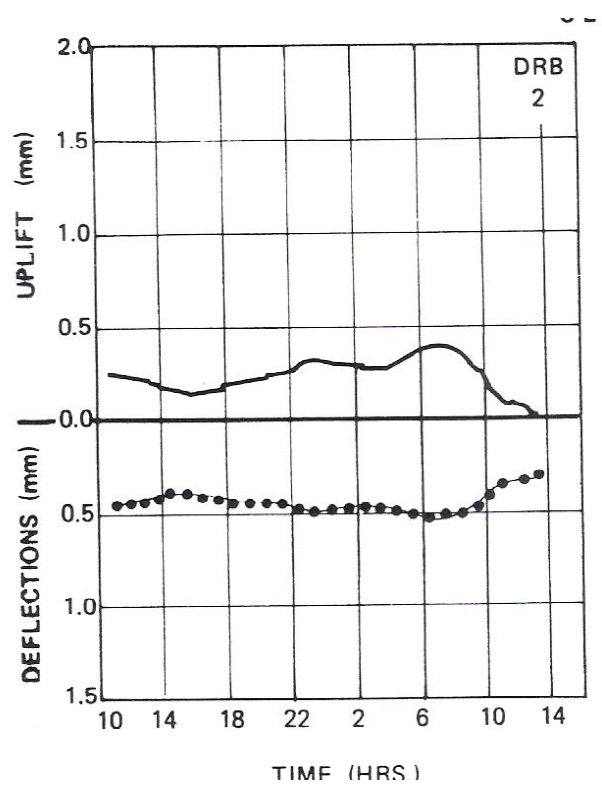

Gráfico 119. Deslocamento de placa de pavimento em um trecho da Pan-Americam Highway - Chile.

Fonte: Adaptado do trabalho de Poblete et al. (1988).

O quinto, já mencionado e utilizado em outras situações é o de Armaghani et al. (1987). Cujos dados vêm corroborar com aqueles obtidos durante os ensaios e que foram descritos pelos gráficos 73, 74 e 75. O gráfico 120, mostra o deslocamento de uma placa de pavimento construída pelo Bureau of Materials and Research of the Florida Departament of transportation - USA. Mediante a carga térmica. 


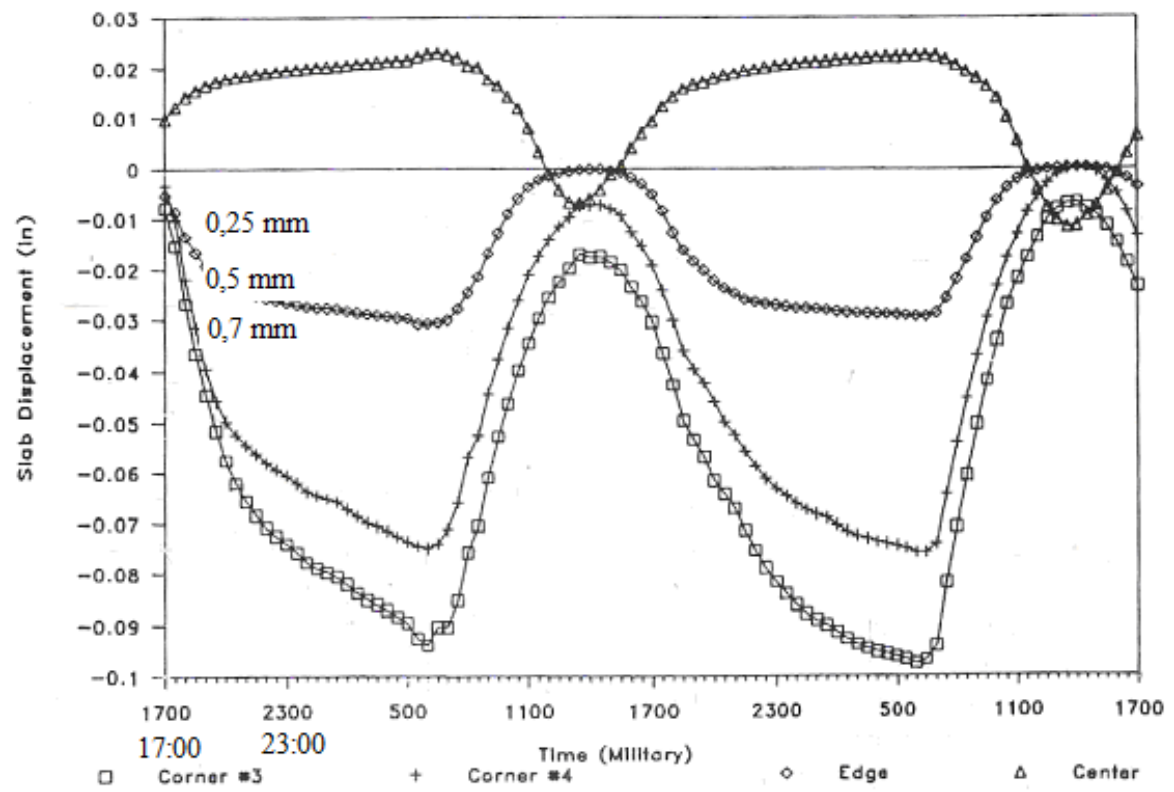

Gráfico 120. Comportamento de placa de pavimento sob carga térmica. Os deslocamentos foram medidos no centro, borda e canto através de LVDT $(1$ " $\rightarrow 2,54 \mathrm{~cm})$. Fonte; adaptado de Armaghani et al. (1987). 


\section{CONCLUSÃO}

A metodologia utilizada para estudar, em laboratório, os fenômenos que ocorrem nos pavimentos, apresentou respostas adequadas e coerentes. Os procedimentos utilizados se mostraram eficientes e reprodutíveis. Os resultados alcançados sobre a distribuição não linear da temperatura, ao longo da espessura da placa, e sua reprodução em laboratório com controle do seu estado térmico deram uma visão mais sistemática sem as interferências encontradas em campo.

O processo de carregamento estático referenciado a um ESRS possibilitou comparações com as ocorrências em campo e com as simulações numéricas, sendo que nesse caso alguns resultados se mostraram divergentes, principalmente aos testes com carga localizada na borda. As deformações, devido ao carregamento estático, foram bem registradas pelas células de embutimento, que mostraram boa repetibilidade e coerência de resultados, tanto nos testes simulados como nas comparações de campo. As simulações sazonais como os dias com chuva, sombra e resfriamento puderam ser realizadas sem prejuízo aos resultados. As deformações devido ao aquecimento de topo apresentaram valores compatíveis com a literatura e com os resultados obtidos pelas simulações numéricas. O resfriamento de fundo se mostrou difícil de ser realizado com o sistema construído, no entanto, o aquecimento feito pelo aquecedor se mostrou bem eficiente e capaz transferir calor ao fundo da placa. Tal procedimento foi capaz de alternar a direção da concavidade da placa, conforme feito no topo ou no fundo. A ação de aquecimento mostrou-se eficiente, mesmo depois da realização de trezentos testes. Não foi possível a realização de um processo de retroanálise devido à impossibilidade na colocação de sensores de deslocamento na direção transversal à placa. Isso impediu uma calibração mais efetiva entre os dados experimentais e numéricos.

A construção do pavimento proporcionou capacitação técnica para atender às exigências de manufatura dos sensores, bem como induziu a busca de métodos de teste e calibração mais apurados, segundo normas nacionais e internacionais. Os sensores mostraram-se robustos e não pereceram após dois anos embutidos na placa. O processo de aquisição de dados mostrou-se confiável, pois em várias situações executou tarefas além de 48 horas seguidas. Durante os testes que foram realizados no período de janeiro de 2008 a 
novembro de 2009, a placa de concreto comportou-se dentro do padrão esperado e preconizado pela literatura. Os experimentos realizados em laboratório, com o objeto de estudo, revelaram facetas não observadas no cotidiano, demonstrando que a placa parece possuir uma "vida" devido ao constante movimento côncavo e convexo durante todo o período. E isso só pode ser observado em laboratório, pois em certos períodos em que a placa não foi submetida ao tratamento térmico, a estabilização da temperatura de topo igualava-se à temperatura de fundo. Nesse caso, as respostas de deformação não acusavam qualquer atividade da placa. Esse fato, em campo, dificilmente seria observado, porque o período entre o ciclo diurno e o noturno não permite que ocorra essa igualdade de temperatura entre esses extremos, bastando dizer que a monitoração off door não possui, na realidade, uma referência absoluta do estado de deformações e os resultados sempre vêm contaminados pelo comportamento passado da placa, ao passo que, em experimentos indoor, a referência é possível, pois pode-se "esperar" que a placa cesse os movimentos no sentido de se obter dados sem as influências passadas. Outro aspecto a ser considerado, é que ao relento a placa sempre está em um estado térmico que produz tensões e deformações, tornando difícil a tomada de uma referência para início de testes. Em laboratório, foi percebido que, como comentado na literatura, a temperatura no interior da placa atinge valores máximos após a retirada da fonte de calor. Isso permitiu observar a obediência ao gradiente de temperatura e boa relação com os dados de campo. Outra observação relevante diz respeito à ocorrência de decaimento linear no período do final da noite, ao final da madrugada ou, entre $20 \mathrm{~h} 0 \mathrm{mim}$ e 6h0min, como visto nas simulações de temperatura.

Os resultados obtidos com testes combinados também se mostraram adequados em relação aqueles obtidos em campo. Mostrando inclusive que, mesmo após os carregamentos a placa retorna à posição original respectivo ao estado térmico em que se encontrava.

Uma evidência importante, observada durante a realização do trabalho, foi a indicação do descolamento da placa feita pela célula de carga localizada no centro do pavimento. Ela mostrou essa tendência ao descolamento, no entanto não foi observado o aparecimento de um gap com os diferenciais de temperatura impostos. Os fatores limitantes são a espessura da placa e o ritmo de aquecimento ditado pelo ciclo diurno.

A medição da temperatura no fundo da base mostrou como ela se comporta durante os períodos de aquecimento e, mais importante, no período de resfriamento. Esse comportamento, por certo, afeta o desempenho da placa durante os ciclos contínuos que ocorrem natureza. Não obstante, devido a rigidez da base, é possível que as suas deformações 
venham afetar o próprio comportamento da placa. Apesar que em situações cotidianas elas parecem "dançar um balé continuo", ora no sentido convexo ou côncavo.

As experiências indoor possibilitaram uma representação adequada das intempéries que ocorrem no cotidiano sobre um pavimento de concreto. A possibilidade da repetição de testes térmicos é um diferencial deste estudo, conforme mostram os resultados. Outra vantagem que o experimento propiciou, foi a verificação da rápida resposta que a placa apresenta quando ocorrem variações de temperatura em sua superfície e seus efeitos nas fibras internas que chegam a dobrar com relação aos carregamentos estáticos

Outro aspecto a se considerar refere-se ao baixo custo na construção do pavimento, mesmo não sendo motivo de estudo e não aparecer no objetivo principal deste trabalho. Tendo em vista que a estrutura foi construída apenas como um elemento de um pavimento, ao invés de um pavimento real, ou uma pista experimental. Então, ocorre a redução de custos operacionais, tais como transporte, aluguel de máquinas e segurança, caso o estudo seja em pista real e distante do local de análise. Um recurso não explorado, mas possível de ser realizado, devido à facilidade de se manobrar o pavimento, é a troca dos elementos estruturais inferiores para estudos específicos. Além disso, outros testes podem ser realizados que não necessariamente façam parte daqueles apresentados pela natureza, tais como ciclos rápidos de aquecimento ou testes acelerados.

Porém a grande vantagem é que os dados obtidos podem ser levados para as pistas experimentais, servindo assim como pré-teste para ensaios mais completos e próximos da realidade.

Sob o aspecto da segurança, o laboratório oferece abrigo aos diversos equipamentos e sensores que obrigatoriamente se conectam ao objeto em estudo. A ausência da interferência dos vários elementos da via pública facilita o estudo e as manipulações que ocorrem na estrutura. Sem mencionar o alcance aos recursos próprios de um laboratório.

Algumas deficiências do presente estudo, tais como falta de controle da umidade e da taxa de aquecimento ou resfriamento no fundo do pavimento podem ser entendidas como desvantagens tal qual o processo de resfriamento da placa que não seguiu seu curso natural. Isso ocorreu pela ausência da circulação da massa de ar (vento) responsável pela troca de calor entre a estrutura e o meio, ocasionando uma perda de tempo entre um ensaio e outro, pois a placa não conseguia apresentar temperaturas adequadas de topo e fundo, como acontece no meio real. O tempo de espera chegava, às vezes, até 72 horas e essa característica, por vezes, pôde distanciar dados reais em campo dos dados obtidos no laboratório. Porém, 
admite-se como vantagem o fato de se poderem controlar algumas condições para a obtenção de dados menos contaminados.

È fato que algumas situações não planejadas ocorreram e que outras planejadas, não tiveram a eficiência desejada. Em uma possível continuidade do presente trabalho, seria interessante construir a placa com uma espessura maior, isso para abrigar uma quantidade maior de termômetros. Essa providência tornaria mais preciso a leitura das temperaturas ao longo da espessura. $\mathrm{O}$ aumento de termômetros na base traria mais informações a respeito do estado térmico durante os testes de aquecimento.

A automação dos ensaios traria um ganho de tempo para o pesquisador, para tanto, seria pertinente o aperfeiçoamento no sistema de aquecimento por meio de tiristores, programação automática e comunicação de dados via Internet.

Melhorar a eficiência térmica do sistema de troca de calor para o fundo da placa, principalmente para resfriamento.

Melhorar a sensibilidade dos sensores de deformação, apesar de terem cumprido sua função com eficiência.

Aliar a automação do processo de aplicação de cargas estáticas com a automação do processo de aquecimento seria um passo importante para estudo e proposições para ensaios acelerados nas pesquisas de fadiga da placa do pavimento. 


\section{REFERÊNCIAS}

ADKINS, D. F.; MERKELEY, P. G. Mathematical model of temperature changes in concrete pavements. Journal of Transportation Engineering, New York, v. 116, n. 3, p. 349- 358, 1990.

AMARANTE, M. L.; CUNHA, L. M.; SILVA, M. C. Desenvolvimento e perspectivas da indústria de cimento. BNDES Setorial, Rio de Janeiro, n. 15, p. 35-62, mar. 2002.

Disponível em:

<http://www.bndes.gov.br/SiteBNDES/export/sites/default/bndes_pt/Galerias/Arquivos/conhe cimento/bnset/set1502.pdf>. Acesso em: 28 jul. 2008.

AMERICAN CONCRETE INSTITUTE. ACI manual of concrete inspection: SP- 2. 8. ed., Detroit, 1988.

ANDOLFATO, R. P. Desenvolvimento das técnicas de produção de blocos de concreto para alvenaria estrutural na escala (1:4). 2002.110 f. Dissertação (Mestrado em Engenharia Civil)- Faculdade de Engenharia, Universidade Estadual Paulista Júlio de Mesquita Filho, Ilha Solteira, São Paulo, 2002.

ARMAGHANI, M. J.; LARSEN, J.T.; SMITH, L.L. Temperature response of concrete pavements. Transportation Research Record, Washington, DC, n. 1.121, p. 23-33, 1987.

ASSOCIAÇÃO BRASILEIRA DE CIMENTO PORTLAND. Prática recomendada PR-2: controle tecnológico da qualidade da camada de concreto rolado. São Paulo,2008. Disponível em: <http://www.abcp.org.br/downloads/index.shtml>. Acesso em: 5 dez 2007.

ASSOCIAÇÃO BRASILEIRA DE NORMAS TÉCNICAS. NBR 5738: moldagem e cura de corpos-de-prova cilíndricos ou prismáticos de concreto. Rio de Janeiro, 2008.

NBR 7583: execução de pavimentos de concreto simples por meio mecânico. Rio de Janeiro, 1984.

1987.

. NBR 9895: solo: Índice de Suporte Califórnia: método de ensaio. Rio de Janeiro,

. NBR7207: terminologia e classificação de pavimentação. Rio de Janeiro, 1982.

AUGUSTO JUNIOR, Fernando. Manual de pavimentação urbana. São Paulo: Ipt, 1992. 233 P.22 (Publicação IPT-Instituto de Pesquisas Tecnológicas-N. 1871)

BALBO, J. T. Pavimentação asfáltica: materiais, projeto e restauração. São Paulo: Oficina de Textos, 2007.

Pavimentos de Concreto. São Paulo: Oficina de Textos, 2009. 
BALBO, J. T.; SEVERI, A. A. Thermal gradients in concrete pavements in tropical environment: experimental appraisal. Transportation Research Record, Washington, DC, v. 1.809 , p. 12-22, 2002.

BALBO, J.T.; RODOLFO, M. P; PEREIRA. D, S.;SEVERI, A. A. Calibração de tensões em pavimentos de concreto simples com base em medidas físicas experimentais. Laboratório de Mecânica de Pavimentos, PTR, USP, São Paulo, 2001 Disponível em http://www.ptr.usp.br/lmp/artnac.htm, acesso em 01/07/2008.

BEZERRA, M. A. Aplicações térmicas da energia solar. Paraíba: Ed. Universitária da UFPB, 1979.

BRASIL. Ministério dos Transportes. Departamento Nacional de Infra-estrutura de Transportes. Diretoria de Planejamento e Pesquisa. Instituto de Pesquisas Rodoviárias. Norma DNIT 055/2004-ME: pavimento rígido: prova estática para determinação do coeficiente de recalque de subleito e sub - base em projeto de avaliação de pavimentos: método de ensaio. Rio de Janeiro, 2004a.

. Ministério da Agricultura, Pecuária e Abastecimento. Instituto Nacional de Meteorologia. Dados climáticos. 2006. Disponível em: <http://www.inmet.gov.br/html/observacoes.php?lnk=Gráficos>. Acesso em: 27 jul. 2006.

Departamento Nacional de Infra-Estrutura de Transportes. Diretoria de Planejamento e Pesquisa. Coordenação do Instituto de Pesquisas Rodoviárias. Manual de pavimentos rígidos. 2. ed., Rio de Janeiro, 2005b. Publicação IPR-714.

Ministério dos Transportes. Departamento Nacional de Infra-estrutura de Transportes. Diretoria de Planejamento e Pesquisa. Instituto de Pesquisas Rodoviárias. Norma DNIT 059/2004-ES: pavimento rígido: pavimento de concreto de cimento portland, compactado com rolo: especificação de serviço. Rio de Janeiro, 2004.

BURDEN, R. L.; FAIRES, J. D. Análise numérica. São Paulo: Thomson, 2003.

CARNEIRO, L. F. Análise dimensional e teoria da semelhança e dos modelos fisicos. 2. ed. Rio de Janeiro: Ed.UFRJ, 1996.

CERVO, C. T. Estudo da resistência à fadiga de concretos de cimento portland para pavimentação. 2006. 220 f. Tese (Doutorado em Engenharia Civil)-Universidade de São Paulo, Escola Politécnica, São Paulo, 2006.

CHOUBANE, B.; TIA, M. Analysis and verification of thermal-gradient effects on pavement. Journal of Transportation Engineering, New York, v.121, n.1, jan./feb., 1995.

DALOGLU, A. T.; VALLABHAN, C. V. G. Values of k for slab on Winkler foundation. Journal of Geotechnical and Geoenvironmental Engineering, Reston, v.126, n.5, 2000.

DAVIS, B. EverFE: software for the 3D finite element analysis of jointed plain concrete pavements. Disponível em: <http://www.civil.umaine.edu/EverFE/>. Acesso em: 19 jan. 2007 
DAVIDS, W. G.; WANG, Z.; TURKIYYAH, G. M.; MAHONEY, J. P.; BUSH, D. ThreeDimensional finite element analysis of jointed plain concrete pavement with EverFe 2.2. Transportation Research Record, Washington, DC, v.1.853, p. 92-99, 2003.

DELIJAICOV, S. Extensometria elétrica. Apostila da disciplina Resistência dos Materiais, do curso de Extensometria, oferecido pela UniFEI. São Bernardo do Campo: Perandini, 2006.

GIUSTI, R. J. Os pavimentos de concreto duram mais de 50 anos. Revista Engenharia, São Paulo, n.565, p. , ano 62, nov. 2004.

HALL, T. K.; DARTER, I. M.; KUO. C. M. Improved methods for selection of k value for concrete pavement design. Transportation Research Record, Washington, DC, v. 1.505, p. 128-136, 1995.

HARIK, E. I.; JIAPING, P.; SOUTHGATE, H.; ALLEN, D. Temperature effects on rigid pavements. Journal of Transportation Engineering, New York, v. 120, n.1, p.127-143, jan./feb. 1994.

HARR, E. M.; LEONARDS, G. A. Warping stress and deflections in concrete pavements. Highway Research Board Proceedings, Washington, DC, v. 38, p. 286-320, 1959.

HEYDINGER, A, G. Evaluation of seasonal effects on subgrade soils. Transportation Research Record, Washington, DC, n.1.821, p. 47-55, 2003.

HOFFMANN, K. An introduction to measurements using strain gages. Alsbach, Alemanha: Ed. Hottinger Baldwin, 1989.

HUANG, Y, H. Pavement analysis and design. New Jersey: Prentice-Hall, 1993.

IOANNIDES, A. M; DAVIS, C. M.; WEBER, C. M. Westergaard curling solution reconsidered. Transportation Research Record, Washington, DC, n.1.684, p. 61-70, nov. 1999.

IOANNIDES, M. A.; MURUA, R, A. Temperature curling in rigid pavements. an application of dimensional analysis. Transportation Research Record, Washington, DC, n. 1.227, p.1-11, 1989.

LEE, Y. H. Tupav: stress analysis and thickness design program for rigid pavements. Journal of Transportation Engineering, New York, v. 125, n.4, p. 338-346, jul./aug., 1999.

LIANG, R. Y; NIU,Y. Z. Temperature and curling stress in concrete pavements: analytical solutions. Journal of Transportation Engineering, New York, v.124, n.1, p. 91-100, jan./feb., 1998.

LOULIZI, A; AL-QADI, L. I; EESEFI, M. Difference between in sito pavement measure and calculated stress and strains. Journal of Transportation Engineering, New York, v. 132, n. 7, p. 574-579, 2006. 
MAHBOUB, K. C.; LIU, Y.; ALLEN, D. L. Evaluation of temperature responses in concrete pavement. Journal of Transportation Engineering, New York, v.130, n.3, p. 395-401, may/jun., 2004.

MALLELLA, J.; ABBAS, A.; HARMAN, T.; RAO, C.; LIU, R.; DARTER, M. Measurement and Significance of the coeffcient of thermal expansion of concrete in rigid pavement design. Transportation Research Board, , Whashington, DC, n 1919, p.38-45 2005.

MARTINS, A. R. Técnicas experimentais para aplicação de modelos de microconcreto. 1990. 150f. Tese (Doutorado em Engenharia Civil)-Escola Politécnica, Universidade de São Paulo, São Paulo, 1990.

MAURÍCIO, M. R. Estudo teórico e experimental das ligações diretas contra-fiadas entre paredes de blocos de concreto em escala real e reduzida 1:4. 2005. 206f. Dissertação (Mestrado em Engenharia Civil)-Faculdade de Engenharia, Universidade Estadual Paulista Júlio de Mesquita Filho, Ilha Solteira, São Paulo, 2005

MEDINA, J. Mecânica dos pavimentos. Rio de Janeiro: Ed. UFRJ, 1997.

MOREIRA, L, S. Sensores de temperatura: princípios e calibração. Apostila de curso. Help Temperatura \& Metrologia: Treinamento e Consultoria. Disponível sob pedido no site da empresa: <http://www.help-temperatura.com.br/html/servicos/menu_curs.html >. Acesso em: 2 mar. 2006.

NASCIMENTO, D. M. Análise comparativa de modelos de previsão de desempenho de pavimentos flexíveis. 2005. 140f. Dissertação (Mestrado em Engenharia Civil)-Escola de Engenharia de São Carlos, Universidade de São Paulo, São Carlos, São Paulo, 2005.

NISHIZAWA,T.; MATSUNO, S. Applicability of finite element method for mechanical analysis of concrete pavements. Transactions of JSCE, v. 15, n.338, p.512-513, 1983.

NOGUEIRA, C. Pavimentação. Rio de Janeiro: Ed. Ao Livro Técnico e Científico, 1961.

OLIVEIRA, P, L. Projeto estrutural de pavimentos rodoviários e de pisos industriais de concreto. 2000. 218f. Dissertação (Mestrado em Engenharia de Estruturas)-Escola de Engenharia de São Carlos, Universidade de São Paulo, São Carlos, São Paulo, 2000.

PAPALLARDO. A. J.; BANDEIRA, A.; PRISZKULNIK, S. Comportamento à flexão de vigas de concreto armadas com barras de fibra de vidro (GFRP). In: SIMPÓSIO EPUSP SOBRE ESTRUTURAS DE CONCRETO, 6., 2006, São Paulo. Anais...São Paulo: Escola Politécnica da Universidade de São Paulo, 2006.

PEREIRA, D. S. Estudo de gradientes térmicos e deformações em whitetopping ultradelgado. 2001. 107f. Dissertação (Mestrado em Engenharia Civil)-Escola Politécnica, Universidade de São Paulo, São Paulo, 2001.

Estudo do comportamento de pavimentos de concreto simples em condições de aderência entre placa de concreto e base cimentada ou asfaltíco. 2003. 299f. Tese (Doutorado em Engenharia Civil)-Escola Politécnica, Universidade de São Paulo, São Paulo, 2003. 
PINTO, C,S. Curso básico de mecânica dos solos. São Paulo: Oficina de Textos, 2002.

PITTA, M. R. Estado da arte dos pavimentos de concreto na América Latina. In: SIMPÓSIO INTERNACIONAL DE MANUTENÇÃO E RESTAURAÇÃO DE PAVIMENTOS E CONTROLE TECNOLÓGICO, 2000, São Paulo. Anais. São Paulo: Escola de Engenharia/Universidade Presbiteriana Mackenzie, 2000. 1 CD-ROM.

PITTA, M. R. Dimensionamento de pavimentos rodoviários e urbanos de concreto pelo método da PCA/84. São Paulo: ABCP, 1998. Publicação ET-97.

POBLETE, M.; SALSILLI, R.; VALENZUELA, R.; BULL, A.; SPRATZ, P. Field evaluation of thermal deformations in undoweled PCC pavement slabs. Transportation Research Record, Washington, DC, n. 1.207, p. 217-228, 1988.

RICHARDSON, J. M.; ARMAGHANI, J. M. Stress caused by temperature gradient in portland cement concrete pavements. Transportation Research Record, Washington, DC, n.1.121, p.7-13, 1987.

RODOLFO, M. P. Análise de tensões em pavimentos de concreto com base cimentada e sujeitos a gradientes térmicos. 2001. 203f. Dissertação (Mestrado em Engenharia Civil)Escola Politécnica, Universidade de São Paulo, São Paulo, 2001.

ROESLER, R. J.; BARENBERG, E. J. Fatigue and static testing of concrete slabs. Transportation Research Record, Washington, DC, n. 1.684, p.71-80, 1999.

RUFINO, D.; ROESLER, J. Effect of slab-base interaction on measured concrete pavement responses. Journal of Transportation Engineering, New York, v.132, n.5, p. 425-434, may 2006.

SABNIS, G, M., MIRZA, S. M. Size effects in model concretes. Journal of the Structural Division, New York, v.105, n.6, p. 1.007-1.020, jun.1979.

SÃO PAULO (SP). Secretaria de Infra- estrutura. Instruções de projeto. 2002. Disponível em: $<$ http://portal.prefeitura.sp.gov.br/secretarias/infraestruturaurbana/pavimentacao_comunitaria/ normas/0001>. Acesso em: 18 jan. 2007.

SARGAND, S. M.; KHOURY, I. S. Sensor installation in rigid pavement. Experimental Techniques, v. 23, n.3, may/jun. 1999.

SAXENA, S. K. Pavement slabs resting on elastic foundation. Highway Research Record, Washington, DC, n. 466, p.163-178, 1973.

SENÇO, W. Manual de técnicas de pavimentação. 2. ed. São Paulo: Pini, 1999. v. 1.

SEARS, F. W.; ZEMANSKY, M. W.; YOUNG, H., D. FREEDMAN, R. A.

Física II: termodinâmica e ondas. 10. ed., São Paulo: Addison Wesley, 2003. v. 2.

SEVERI, A. A.; BALBO, J. T. Gradientes térmicos em pavimentos de concreto nas condições de clima tropical. In: CONGRESSO DE PESQUISA E ENSINO EM TRANSPORTES, 15., 
2001, Campinas. Panorama Nacional da Pesquisa em Transporte. Rio de Janeiro: J. R. A Setti/O. F. Lima Júnior, 2001. v. 1, p.299-308.

SEVERI, A. A. Estudo dos gradientes térmicos em pavimentos de concreto de cimento portland no ambiente tropical. 2002. 256f. Tese (Doutorado em Engenharia Civil)-Escola Politécnica, Universidade de São Paulo, São Paulo, 2002.

SIDDIQUE, Z. Q.; HOUSSAIN, M.; MEGGERS, D. Temperature and curling measurements on concrete pavement. Transportation Research Board. Proceedings of the 2005 MidContinent Research Symposium, Ames, Iowa, p. 1-12, 2005.

SILVA, P. D. E. A. Estudo do reforço de concreto de cimento portland (whitetopping) na pista circular experimental do instituto de pesquisas rodoviárias. 2001. 358f. Tese (Doutorado em Engenharia Civil)-Faculdade de Engenharia Civil, Universidade Federal do Rio de Janeiro, Rio de Janeiro, 2001.

SILVEIRA, A, F. As variações da tempeartura nas barragens. Laboratório nacional de Engenharia Civil, Ministério das Obras Públicas, memória nº 77, Lisboa, 1961.

SIMONS, J. W.; SEAMAM, L. Finite-element analysis of fatigue lifetime in pavements. Transportation Research Record, n.1.709, p. 36-42, 2000.

SITEGAR. Termoflex Lite v.1.1 para Windows ${ }^{\circledR}$ [software]. 2006. Disponível em: <http://www.sitegar.com/Default.aspx>. Acesso em: 23 fev. 2006.

SOUZA, L.M. A Problemática do Dimensionamento De Pavimentos, Relatório Parcial do Instituto de Pesquisas Rodoviárias, setor de Pesquisa e Planejamento, Rio de Janeiro, 1972.

. Pavimentação rodoviária. 2 ed., Rio de Janeiro: LTC/DNER- Instituto de Pesquisas Rodoviárias, Rio de Janeiro, 1980. v.1.

TANG, T.; ZOLLINGER, D. G.; SENADHEERA, S. Analysis of concave curling in concrete slabs. Journal of Transportation Engineering, New York, v. 119, n.4, p. 618-633, july/aug. 1993.

THOMLINSON, J. Temperature variations and consequent stress produced by daily and sazonal temperature cycles in concrete slabs. Concrete Construtional Engineering, v.36, n.6, p.298-307, 1940.

THOMPSON, M. R.; DEMPSEY, B. J.; HILL, H.; VOGEL, J. Characterizing temperature effects for pavements analysis design. Transportation Research Record, Washington, DC, n.1.121, p.14-22, 1987.

TIMOSHENKO, S, P., GOODIER, J, N. Teoria da Elasticidade $3^{\mathrm{a}}$ ed. Tradução de Sérgio Fernandes Villaça, S, F. Rio de Janeiro, Editora Guanabara Dois, 1980. 
USA. U.S. Army Corps of Engineers. Engineering and design: rigid pavement for roads, streets, walks and open storage areas: mobilization construction. Washington, DC, 1984. Engineer Manual n. 1110-3-132. Disponível em:

<http://www.knovel.com/web/portal/browse/display?_EXT_KNOVEL_DISPLAY_bookid=2 465>. Acesso em: 22 dez. 2007.

USA. National Academy of Sciences. National Research Council. Division of Engineering and Industrial Research. The AASHO Road Test: report 5: pavement research. Highway Research Board Special Report, Washington, DC, n. 61, part E, 1962.

VEDACIT. Resina base epóxi para pisos e revestimentos. COMPOUND S 200. Disponível em: http://www.vedacit.com.br/. Acesso em 15 mai 2006.

YU, H. T.; KHAZANOVICH, L.; DARNER, M. I.; ARDANI, A. Analysis of concrete pavement responses to temperature and wheel loads measured from instrumented slabs. Transportation Research Record, Washington, DC, v. 1.639, p. 94-95, 1998.

WALRAVEN. J. C. Fundamental analysis of aggregate interlock. Journal of the Structural Division, v.107, n.11, p. 2.245-2.270, nov. 1981.

WELLS, S.A.; PHILIPS, B. M.; VANDENBOSSCHE, J. M. Characterizing strain induced by environmental loads in jointed plain concrete pavements: immediately after paving and throughout first ten months. Transportation Research Record, Washington, DC, n.1.947, 2006.

WESTERGAARD, H. M. Stress in concrete pavements computed by theoretical analysis. Public Roads, Washington, DC, v. 7, n. 2, p.25-35, 1926.

Analysis of stresses in concrete roads caused by variations of temperature, Public Roads, Washington, DC, v.8, n.3, p.54-60, 1927. 


\section{APÊNDICE A - CONSTRUÇÃO E CALIBRAÇÃO DAS CÉLULAS DE EMBUTIMENTO}

\section{CONSTRUÇÃO DA CÉLULA DE EMBUTIMENTO}

Conforme exposto anteriormente, as células foram construídas a partir de sensores resistivos do tipo extensômetro colados com cola tipo cianocrilato sobre um substrato de (TVE) TECHGLASS FTVE-G10 (NEMA G-10) que é um laminado com base de tecido de vidro e resina epóxi que apresenta propriedades mecânicas, elétricas e térmicas adequadas para serem embutidas na massa de concreto. Segundo o fabricante ${ }^{30}$, esse material é utilizado em equipamentos eletrônicos e pode trabalhar sob regimes de tensão (elétrica), temperatura e umidade mais elevados.

A célula é composta por duas partes, sendo uma tampa colada na base com cola epóxi bi-componente marca ARALDITE ${ }^{\circledR}$. A ligação dos fios do extensômetro com o cabo de sinal foi realizada por meio de uma placa de circuito impresso de $0,8 \mathrm{~mm}$ de espessura. $\mathrm{Na}$ base do substrato foram feitos rebaixos para a colagem do extensômetro, colagem do circuito impresso e encaixe do cabo de ligação. A ligação foi feita a três fios para minimizar a influência da temperatura. O cabo de sinal, marca TIAFLEX ${ }^{\circledR}$, micro stereo de secção $3 \mathrm{x} 0,14 \mathrm{~mm}^{2}$, foi escolhido com revestimento de borracha, a três condutores envoltos por uma malha de blindagem.

A CE tem como dimensões, 150,0 $\mathrm{mm}$ de comprimento, 5,0 $\mathrm{mm}$ de espessura e 20,0 mm de largura. A tampa possui as mesmas dimensões de comprimento e largura, porém 1,0 $\mathrm{mm}$ de espessura. A fotografia 27 apresenta as partes constituintes da célula, mostrando o extensômetro tipo PA-06-1000BA-120L, com fator gage 2,1, material Constantan (liga de composta por $57 \% \mathrm{Cu}$ e $43 \% \mathrm{Ni}$ ), pouco sensível variação de temperatura e alta resistividade. Ele foi colado e protegido com borracha de silicone para extensometria, bem como a ligação com o cabo de ligação e o desenho 46 mostra, esquematicamente, a célula com seus componentes.

\footnotetext{
${ }^{30}$ As especificações estão disponíveis no site do fabricante e pode ser acessado em http://www.fenotech.com.br/home/
} 


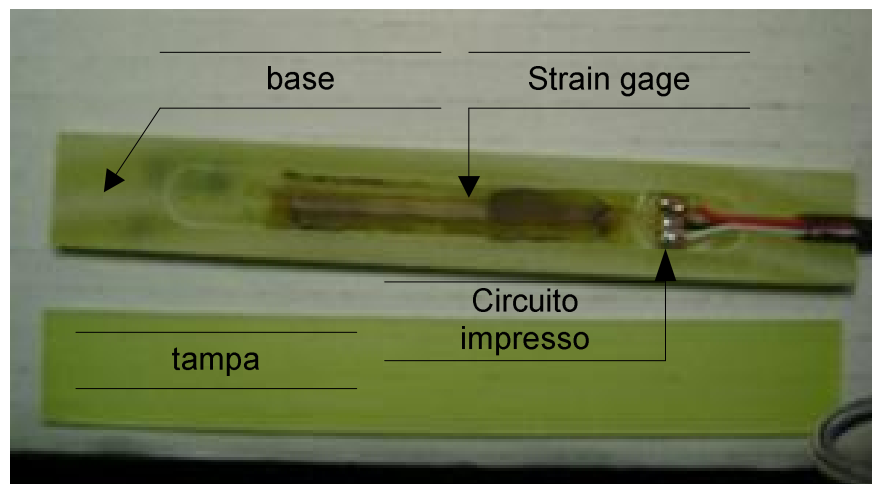

Fotografia 27. Vista das partes que compõem a célula de embutimento. Fonte: Acervo próprio (2008).

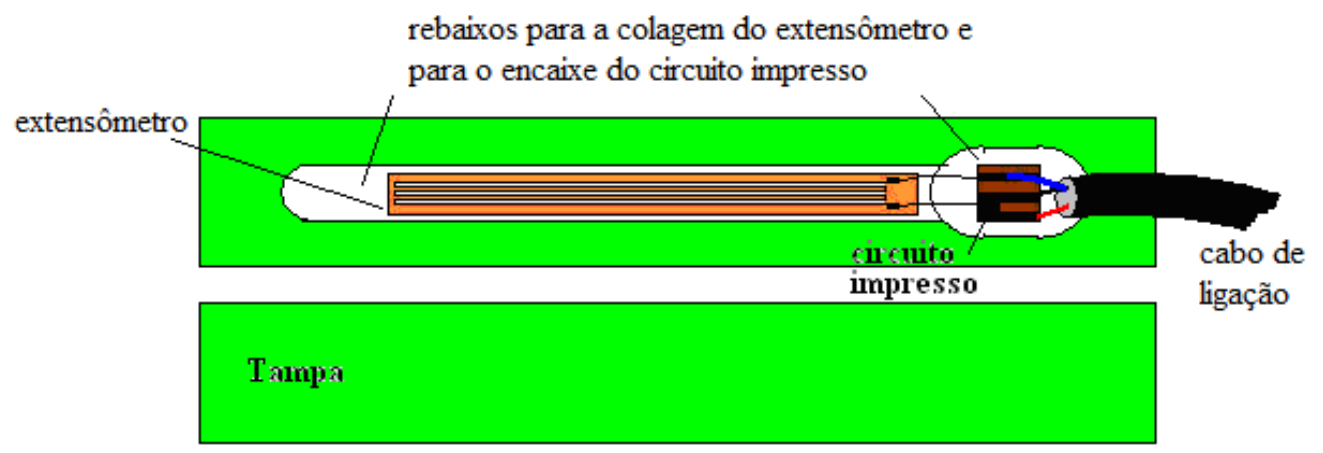

Desenho 46. Desenho esquemático das partes constituintes da célula de embutimento Fonte: Acervo próprio (2008).

\section{DETERMINAÇÃO DO COEFICIENTE DE DILATAÇÃO LINEAR DA CÉLULA DE EMBUTIMENTO}

O coeficiente de dilatação linear do material do qual foi feita a célula de embutimento foi determinado por metodologia experimental tradicional, utilizada nos laboratórios didáticos dos cursos iniciais da área de Engenharias e Ciências da Terra. $\mathrm{O}$ material foi colocado em uma estufa e aquecido até $60^{\circ} \mathrm{C}$ e mantido assim durante cinco minutos. Após esse período, o material foi retirado e as medidas realizadas em um dispositivo construído para essa finalidade. A fotografia 28 mostra a célula posicionada para realização das medidas na variação de comprimento $(\Delta \mathrm{L})$ da $\mathrm{CE}$, que foi realizada por meio de um relógio comparador, marca Mitutoyo mod. ID-C112B com incerteza de 0,001 milímetros, fixado em um suporte rígido. 
As medidas de temperatura foram feitas com um sensor termopar tipo K, fixado no corpo da $\mathrm{CE}$ por meio de uma fita teflon. As leituras de temperatura foram realizadas através de um multímetro marca MINIPA mod. ET-2082 com incerteza, na escala de temperatura, de $0,5^{\circ} \mathrm{C}$.

Os dados, colhidos manualmente, geraram a Tabela 12 e, por meio dela, foi construído o gráfico 121, no qual foi aplicado um processo de regressão linear para determinação do coeficiente de dilatação linear do material que apresentou um valor de $1,2.10^{-5}{ }^{\circ} C^{-1}$. De acordo com Furnas (2007) apud Balbo (2009), o coeficiente de expansão térmica do concreto varia de $0,5 \cdot 10^{-5}{ }^{\circ} \mathrm{C}^{-1}$ a $1,4 \cdot 10^{-5}{ }^{\circ} \mathrm{C}^{-1}$. Mallella et al. (2005) declara que esse fator é uma propriedade fundamental do concreto e determina que o intervalo de variação situa-se na faixa de $0,4 \cdot 10^{-5} \quad{ }^{\circ} \mathrm{F}^{-1}$ até $0,8 \cdot 10^{-5} \quad{ }^{\circ} \mathrm{F}^{-1}\left[\frac{4 \cdot 10^{-6}}{\left(\frac{9}{5}{ }^{0} C+32\right)}\right.$ até $\left.\frac{8 \cdot 10^{-6}}{\left(\frac{9}{5}{ }^{0} C+32\right)}\right]$. Equivalente ao intervalo descrito acima.

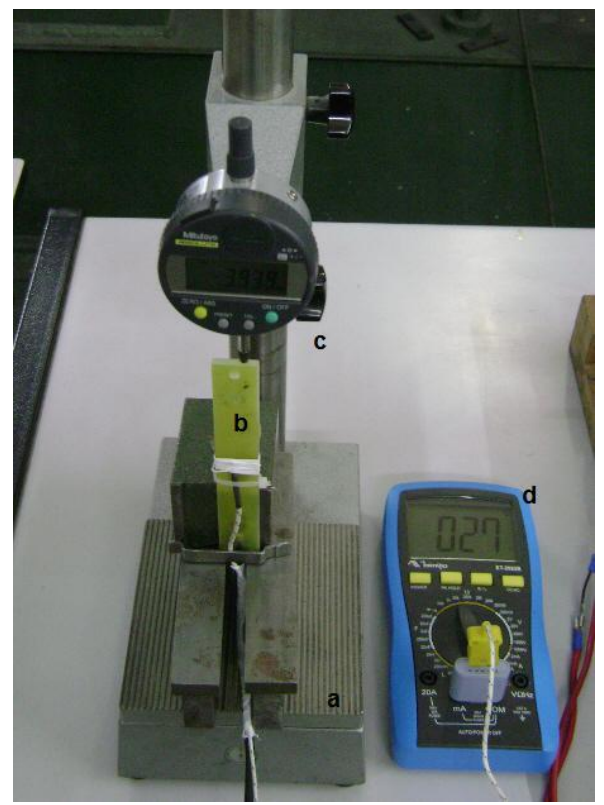

Fotografia 28. Dispositivo para medida da dilatação linear do TVE. (a) base, (b) TVE, (c) micrômetro e (d) multímetro. Fonte: Acervo próprio (2008). 
Tabela 12. Dados de temperatura e de deformação do ensaio da CE para determinação do coeficiente de dilatação térmica do TVE.

\begin{tabular}{cccc}
\hline temperatura $\left({ }^{\circ} \mathrm{C}\right)$ & $\Delta \mathrm{L}$ & desvio padrão & $\Delta \mathrm{L} / \mathrm{L}$ \\
\hline 60 & 0 & 0 & 0 \\
59 & 0,005000 & 0,000005 & 0,0000385 \\
58 & 0,013333 & 0,0030551 & 0,000103 \\
56 & 0,015800 & 0,0034928 & 0,000122 \\
54 & 0,018667 & 0,0048028 & 0,000144 \\
52 & 0,021833 & 0,0038687 & 0,000168 \\
50 & 0,023500 & 0,0075056 & 0,000181 \\
48 & 0,029667 & 0,0037238 & 0,000228 \\
46 & 0,031571 & 0,0057694 & 0,000243 \\
44 & 0,032571 & 0,0073679 & 0,000251 \\
42 & 0,036286 & 0,0059642 & 0,000279 \\
40 & 0,040143 & 0,006283 & 0,000309 \\
38 & 0,042571 & 0,0061334 & 0,000328 \\
36 & 0,045286 & 0,0061567 & 0,000348 \\
34 & 0,047000 & 0,0066933 & 0,000362 \\
27 & 0,057333 & 0,0047258 & 0,000441 \\
\hline
\end{tabular}

Fonte: Elaborada a partir dos dados experimentais (2008).

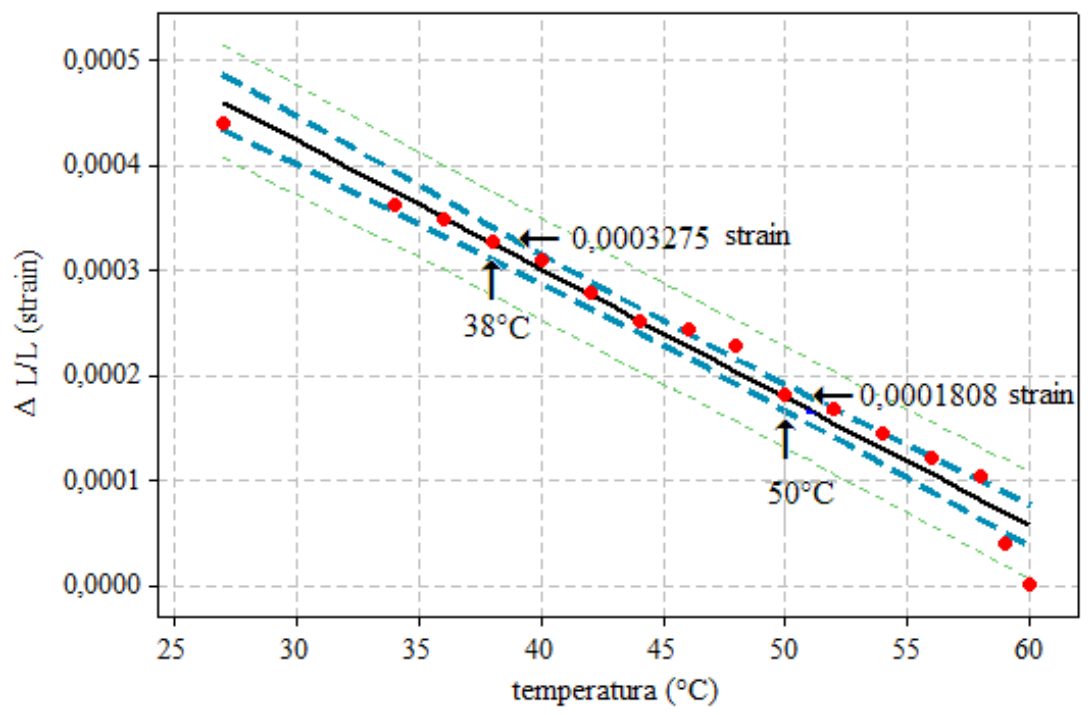

Gráfico 121. Estabelecimento da dependência da temperatura e determinação do coeficiente de dilatação do material TVE - DUROFLEX. Intervalo de confiança 95\% e R ${ }^{2}=97 \%$.

Fonte: Elaborado a partir dos dados experimentais (2008).

Esse valor é importante, pois indica que a CE e o concreto irão "trabalhar" sem interferência significativa, por causa das concentrações de tensões que, por ventura, iriam surgir devido à contração ou dilatação do concreto quando estivesse sob carregamento térmico (os dados estão disponíveis no arquivo\#tve no CD-ROM anexo B). 
Como comparação, outra metodologia foi utilizada, desta vez, uma célula de embutimento (CE) associada a uma de compensação de temperatura (CIT) em $1 / 2$ ponte, foram colocadas em um banho térmico fixo a $60,0{ }^{\circ} \mathrm{C}$ e deixadas até que as leituras ficassem estáveis. A partir de então, foram retiradas e deixadas na temperatura ambiente. Os dados desse procedimento gerou o gráfico 122, onde é possível observar o comportamento da deformação do TVE em função da temperatura. As perturbações no instante da colocação e no instante da retirada do banho térmico, se devem à resposta do conjunto ponte de Wheatstone e condicionador a rápidas variações de temperatura. Os pontos em destaque indicam o intervalo utilizado para calcular o coeficiente de dilatação do TVE, que indicou o valor de $1,0.10^{-5}{ }^{\circ} \mathrm{C}^{-1}$.

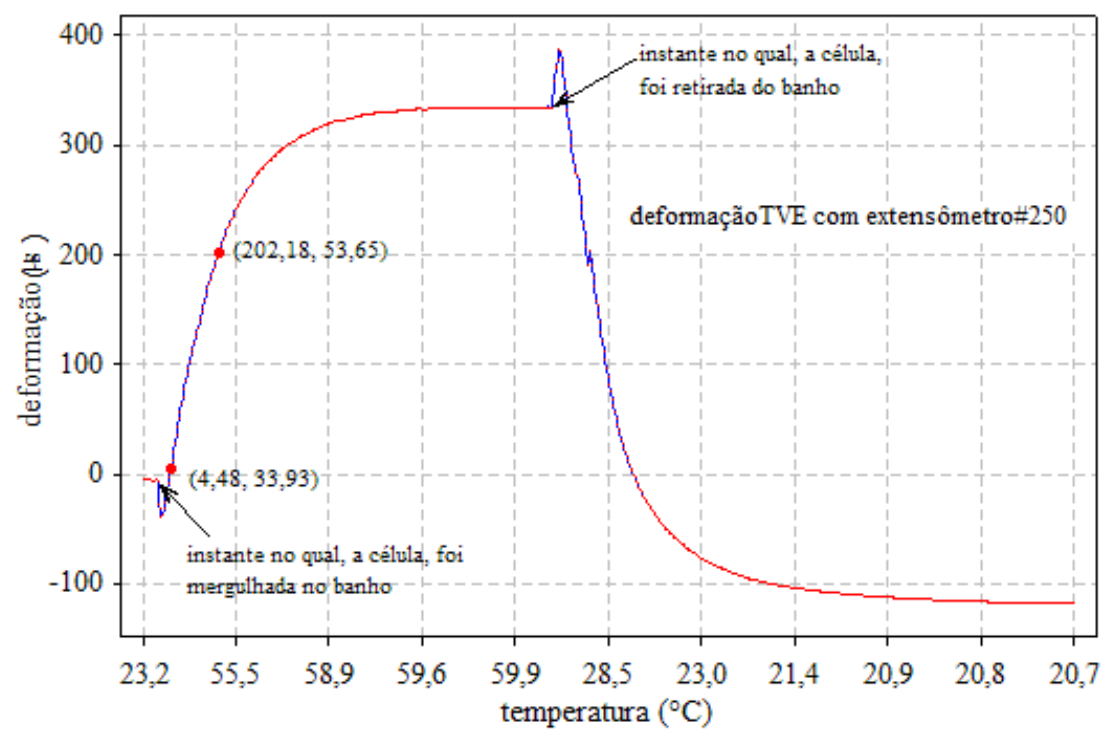

Gráfico 122. Estabelecimento da dependência da temperatura e determinação do coeficiente de dilatação do material TVE - DUROFLEX por meio da associação CE+CIT.

Fonte: Elaborado a partir dos dados experimentais (2008).

\section{ESTIMATIVA DA INCERTEZA NA MEDIDA DO COEFICIENTE DE DILATAÇÃO TÉRMICA}

O cálculo da incerteza baseou-se nos dados de fundo de escala fornecidos pelos fabricantes dos equipamentos e o cálculo do coeficiente de dilatação foi realizado de acordo com a equação 29 de acordo com Sears e Zemansky (2003), tendo como referência os pontos assinalados na reta do gráfico 121. Eles foram selecionados, convenientemente, com os respectivos desvios padrão para elaboração do cálculo da incerteza do coeficiente de dilatação. 


$$
\begin{gathered}
\Delta L=\alpha L \Delta T \\
\frac{\Delta L}{L}=\alpha \Delta T \Leftrightarrow \varepsilon=\alpha \Delta T \\
\alpha=\frac{\varepsilon}{\Delta T}
\end{gathered}
$$

A variação de temperatura apresentou um valor de: $\Delta \mathrm{T}=12 \pm 1^{\circ} \mathrm{C}$ e a variação de comprimento apresentou um valor de: $\Delta \mathrm{L}=0,01907 \pm 0,00137 \mathrm{~mm}$ ou $(2,0 \pm 0,1) \cdot 10^{-2} \mathrm{~mm}$

Utilizando a expressão $29 \varepsilon=\frac{\Delta L}{L}, L=130,00 \pm 0,05 \mathrm{~mm}, \varepsilon$ assume o seguinte valor: $\varepsilon=0,00014669 \mathrm{~mm}$. A incerteza, após a propagação do erro

$$
\Delta \varepsilon=\varepsilon\left(\frac{d \Delta L}{\Delta L}+\frac{d L}{L}\right)
$$

assume o valor: $\Delta \varepsilon=0,000011 \mathrm{~mm}$. Combinando os dois valores: $\varepsilon=(1,4 \pm 0,1) \cdot 10^{-4} \mathrm{~mm}$.

Para a determinação do valor de $\alpha$, pela equação 31, que forneceu o valor de $\alpha=$ $0,00001166^{\circ} \mathrm{C}^{-1}$ e após a propagação do erro

$$
\Delta \alpha=\alpha\left(\frac{\Delta \varepsilon}{\varepsilon}+\frac{\Delta T}{T}\right)
$$

que assumiu o valor de: $\Delta \alpha=0,000002569^{\circ} \mathrm{C}^{-1}$.

Pode-se determinar o valor de $\alpha$ como sendo: $\alpha=(1,2 \pm 0,3) \cdot 10^{-5}{ }^{\circ} C^{-1}$.

O erro percentual com relação ao valor obtido pelo gráfico 121 é:

$$
\begin{aligned}
& E_{\%}=\frac{\left|V_{\mathrm{T}}-V_{E}\right|}{V_{T}} 100 \\
& E_{\%}=\frac{\left|1,2.10^{-5}-1,0.10^{-5}\right|}{1,2.10^{-5}} 100=16 \%
\end{aligned}
$$

Esse valor é aceitável, pois é bem inferior ao intervalo considerado para a dilatação do concreto.

\section{CALIBRAÇÃO DAS CÉLULAS DE EMBUTIMENTO}

O procedimento de calibração das células de embutimento foi realizado em duas etapas. Inicialmente, foi verificada a linearidade da resposta das células em relação a uma 
célula de carga de sensibilidade $1,607 \mathrm{mV} / \mathrm{V}$ com capacidade $(0,0 \mathrm{kgf}-50,0 \mathrm{kgf})^{31}$ calibrada e rastreada, marca Sodmex modelo N320. A partir dessa informação foi calculada a sensibilidade de cada célula, em termos de força, em relação à célula de carga, por meio da disposição experimental mostrada na fotografia 29, em que a força de tração produzida pelos massores foi transferida para a célula de embutimento, por meio de um cabo de aço através de uma polia parafusada em uma mesa de desempeno cuja rigidez estrutural garantiu que as deformações fossem oriundas apenas das células de embutimento. A forma em que foram impostos os vínculos sobre a célula de embutimento eliminou a possibilidade que forças provocadas por torção e flexão tivessem pouco efeito. Ou seja, a célula ficou sujeita à tração simples.

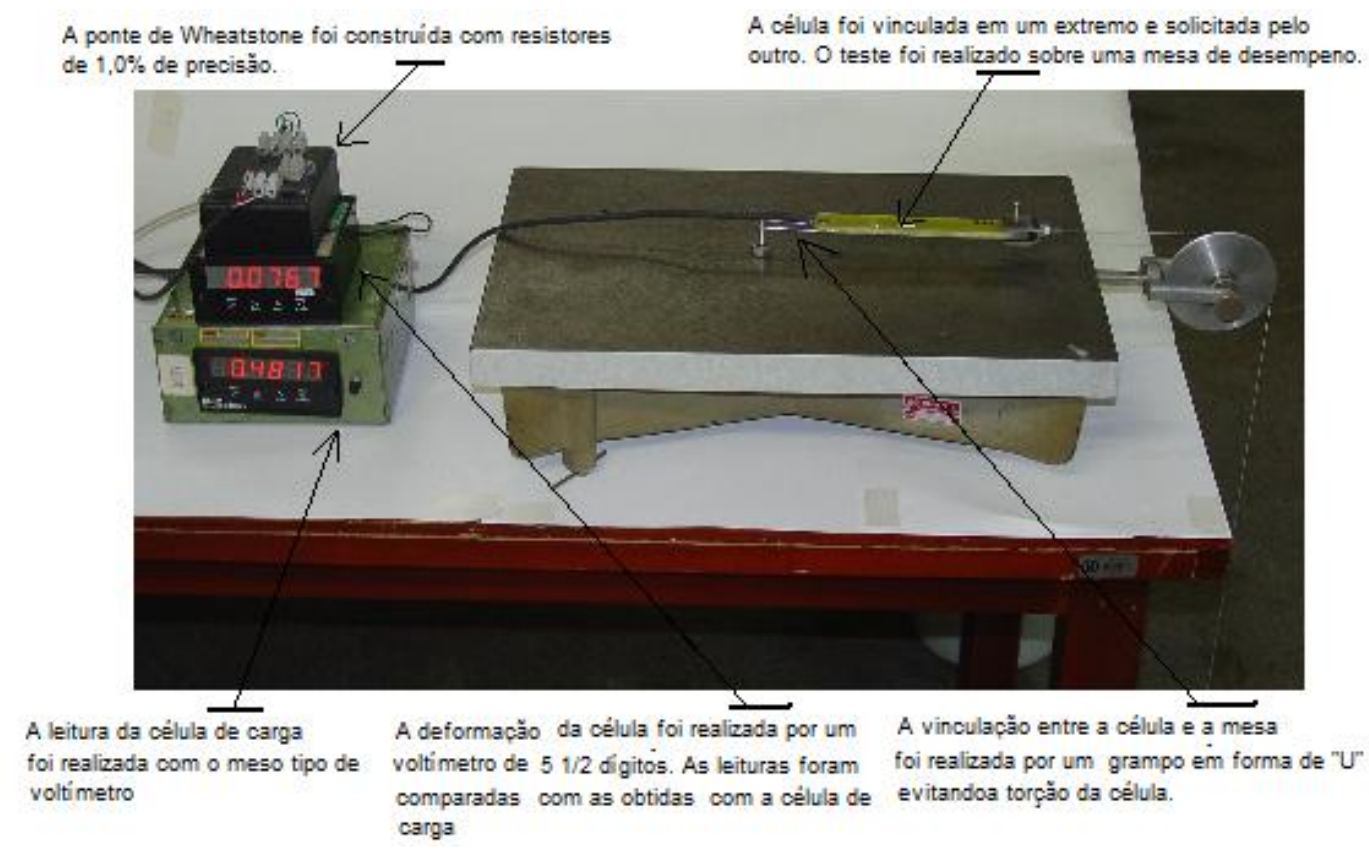

Fotografia 29. Notas explicativas de cada componente da mesa de testes. A mesa de desempeno em todos os testes foi nivelada e fixada na bancada.

Fonte: Acervo próprio (2008).

A escala de medida (range) foi calculada teoricamente e para tanto, foi utilizada uma década resistiva, fazendo o papel de um shunt de calibração, colocada diretamente na ponte de Wheatstone. (DELIJAICOV, 2006). Todos os testes foram conduzidos no laboratório de Ensaios Mecânicos da Escola de Engenharia da Universidade Presbiteriana Mackenzie.

31 Unidade fornecida de acordo com o fabricante 
As leituras foram feitas em milivolt por volt $(\mathrm{mV} / \mathrm{V})$ em dois equipamentos da marca Electro-Numerics, modelo microseries digital process, cujas características indicadas pelo fabricante são: resolução de $10,0 \mathrm{mV}$ na escala de $+/-200,000 \mathrm{mV}$ a 0,1\% FS (fundo de escala) a $25,0{ }^{0} \mathrm{C} .{ }^{32}$

A fotografia 30 mostra em detalhe a célula de carga suportando uma massa de 15,0 kg. O sinal gerado pela célula de carga foi utilizado para realizar a calibração, por comparação, da leitura realizada na célula de embutimento.

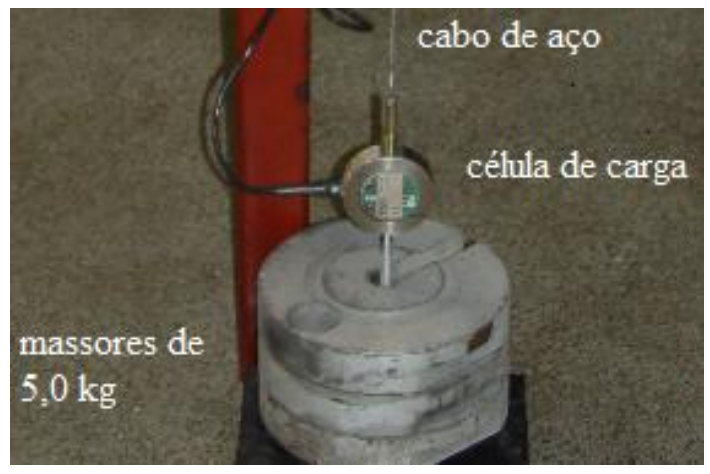

Fotografia 30. A célula de carga foi posicionada na haste de suporte dos massores. Fonte: Acervo próprio (2008).

Esquematicamente, o desenho 47 indica a disposição dos equipamentos, bem como o sentido dos sinais elétricos gerados pelas células. As células de embutimento sempre foram tracionadas da mesma forma e, sobre cada uma, foram realizadas três medidas que serviram para o estudo estatístico no estabelecimento da sensibilidade individual, cujos resultados encontram-se no quadro 3.

\footnotetext{
${ }^{32}$ Outras características podem ser encontradas no site do fabricante em: http://www.electronumerics.com/micro/micro_process.htm.
} 


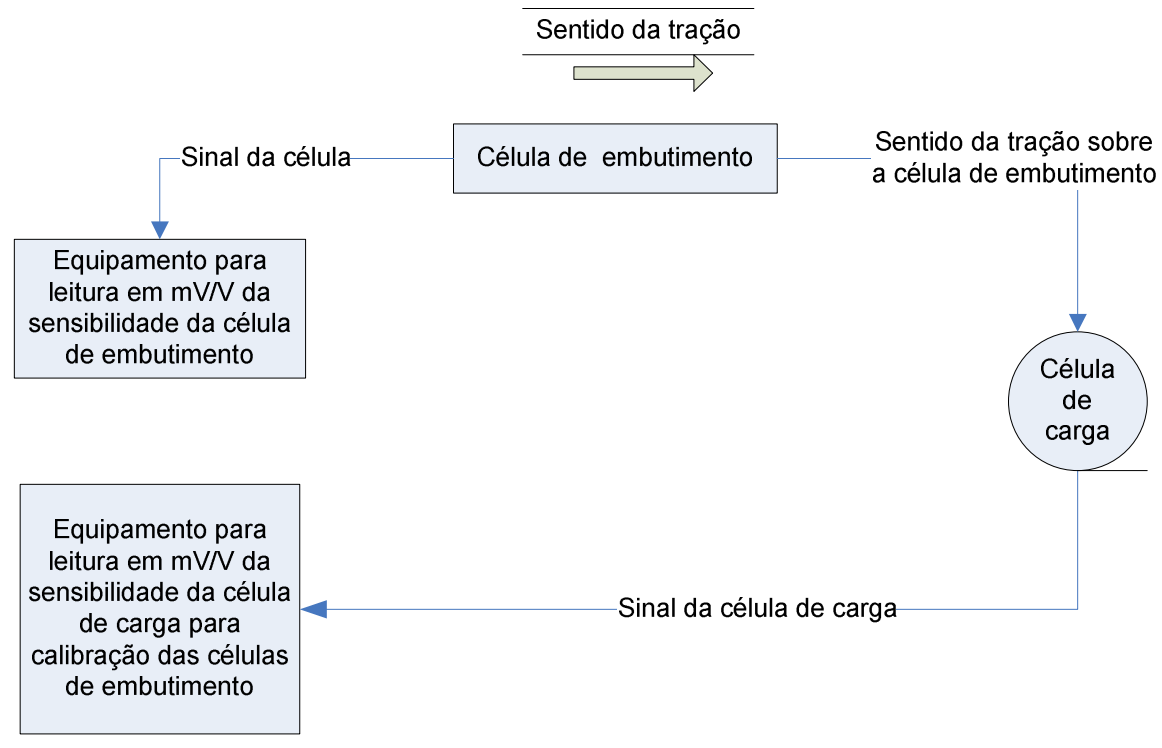

Desenho 47. Diagrama esquemático da ligação para verificação da sensibilidade da célula de embutimento.

Fonte: Acervo próprio (2008).

\begin{tabular}{|c|c|c|c|c|c|}
\hline carregamento $(\mathrm{kgf})$ & $\mathrm{CE} 1(\mathrm{mV} / \mathrm{V})$ & $\mathrm{CE} 2(\mathrm{mV} / \mathrm{V})$ & $\mathrm{CE} 3(\mathrm{mV} / \mathrm{V})$ & $\mathrm{CE} 4(\mathrm{mV} / \mathrm{V})$ & $\mathrm{CE} 5(\mathrm{mV} / \mathrm{V})$ \\
\hline 0,649 & 0,0027 & 0,0026 & 0,003 & 0,0022 & 0,0025 \\
\hline 1,6492 & 0,0069 & 0,0072 & 0,0067 & 0,0052 & 0,0055 \\
\hline 2,6486 & 0,011 & 0,0113 & 0,0109 & 0,0086 & 0,009 \\
\hline 3,649 & 0,0153 & 0,0151 & 0,015 & 0,012 & 0,0122 \\
\hline 4,6493 & 0,0193 & 0,0193 & 0,0192 & 0,0156 & 0,0157 \\
\hline 5,6487 & 0,0242 & 0,0238 & 0,0238 & 0,0187 & 0,0194 \\
\hline 10,6475 & 0,0465 & 0,0464 & 0,0464 & 0,0383 & 0,0379 \\
\hline 15,6443 & 0,0687 & 0,0688 & 0,0688 & 0,0578 & 0,0569 \\
\hline carregamento $(\mathrm{kgf})$ & $\mathrm{CE} 6(\mathrm{mV} / \mathrm{V})$ & $\mathrm{CE} 7(\mathrm{mV} / \mathrm{V})$ & $\mathrm{CE} 8(\mathrm{mV} / \mathrm{V})$ & $\mathrm{CE} 9(\mathrm{mV} / \mathrm{V})$ & $\mathrm{CE} 10(\mathrm{mV} / \mathrm{V})$ \\
\hline 0,649 & 0,0031 & 0,0053 & 0,0041 & 0,0053 & 0,005 \\
\hline 1,6492 & 0,0069 & 0,0096 & 0,008 & 0,0098 & 0,0094 \\
\hline 2,6486 & 0,0108 & 0,014 & 0,012 & 0,0144 & 0,0142 \\
\hline 3,649 & 0,015 & 0,0187 & 0,0161 & 0,0191 & 0,019 \\
\hline 4,6493 & 0,0193 & 0,0232 & 0,0202 & 0,0236 & 0,0239 \\
\hline 5,6487 & 0,0234 & 0,0279 & 0,0244 & 0,0268 & 0,0287 \\
\hline 10,6475 & 0,0451 & 0,0522 & 0,0457 & 0,0529 & 0,0537 \\
\hline 15,6443 & 0,0664 & 0,0769 & 0,0669 & 0,0772 & 0,0783 \\
\hline carregamento $(\mathrm{kgf})$ & CE11(mV/V) & CE12(mV/V) & CE13(mV/V) & CE14mV/V) & CE15(mV/V) \\
\hline 0,649 & 0,0065 & 0,0066 & 0,005 & 0,0051 & 0,0063 \\
\hline 1,6492 & 0,0116 & 0,0105 & 0,0094 & 0,0091 & 0,0113 \\
\hline 2,6486 & 0,0168 & 0,0133 & 0,014 & 0,0134 & 0,0162 \\
\hline 3,649 & 0,0222 & 0,0192 & 0,0186 & 0,0178 & 0,0211 \\
\hline 4,6493 & 0,0275 & 0,0236 & 0,0227 & 0,0221 & 0,0262 \\
\hline 5,6487 & 0,0329 & 0,0282 & 0,0279 & 0,0265 & 0,0312 \\
\hline 10,6475 & 0,0602 & 0,0517 & 0,0519 & 0,0485 & 0,0567 \\
\hline 15,6443 & 0,087 & 0,0752 & 0,0759 & 0,0704 & 0,0825 \\
\hline
\end{tabular}

Quadro 8. Valores médios individuais em $\mathrm{mV} / \mathrm{V}$ em função do carregamento.

Fonte: Elaborado a partir dos dados experimentais (2008). 
A carga foi calculada adotando-se a aceleração da gravidade $g=9,786329 \mathrm{~m} / \mathrm{s}^{2}$ cujo valor está impresso na estação gravimétrica colocada no piso do laboratório pelo INMETRO e pode ser visto através da fotografia 31 .

A análise dos dados do quadro 4 gerou o quadro 5 em que o carregamento foi calculado em newtons e as células de embutimento ou deformação (CE) foram separadas em grupos com sensibilidades semelhantes. Os gráficos 123 a 127 foram construídos com esses dados e mostram o comportamento das células frente ao carregamento.

Para cada gráfico foi calculado o coeficiente e a reta de regressão. Os grupos escolhidos foram: Grupo 1 - Células CE1, CE2, CE4 e CE5; Grupo 2 - Células CE3 e CE6; Grupo 3 - Célula CE8; Grupo 4 - Células CE7, CE9, CE10 CE13 e CE14; Grupo 5 - Células CE11, CE12 e CE15

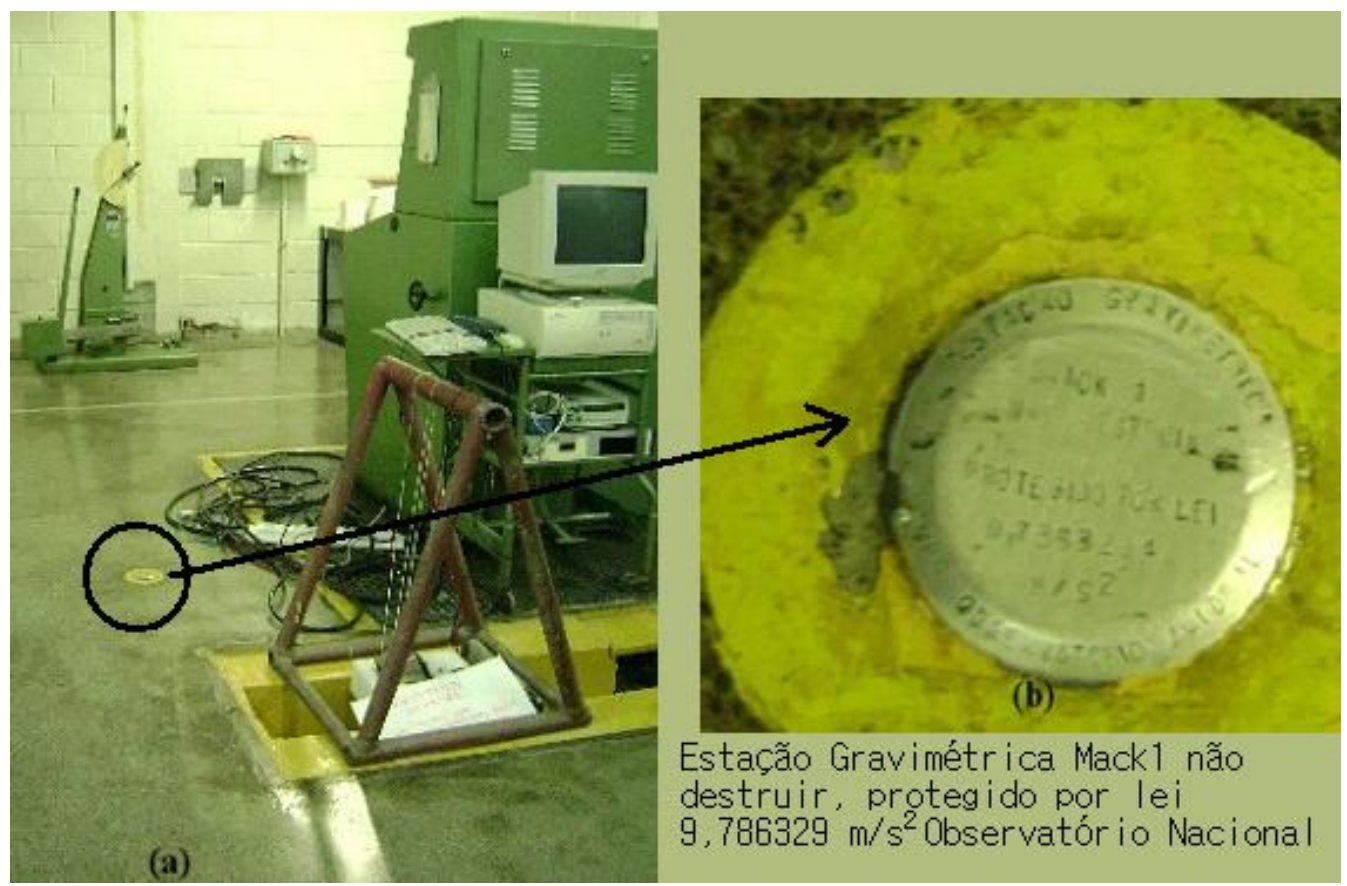

Fotografia 31. a) Estação gravimétrica colocada no piso do laboratório de ensaios mecânicos;

b) detalhe identificando a estação com o respectivo valor de "g". Fonte: Acervo próprio (2008). 


\begin{tabular}{|c|c|c|c|c|c|c|c|c|}
\hline & \multicolumn{8}{|c|}{ Carga $(\mathrm{N})$} \\
\hline Sensor $(\mathrm{mV} / \mathrm{V})$ & 6,351 & 16,14 & 25,92 & 35,71 & 45,5 & 55,28 & 104,2 & 153,1 \\
\hline CE1 - G1 & 0,0027 & 0,0070 & 0,0110 & 0,0150 & 0,0190 & 0,0240 & 0,0460 & 0,0690 \\
\hline desvio padrão & 0,0006 & 0,0010 & 0,0020 & 0,0020 & 0,0030 & 0,0020 & 0,0030 & 0,0050 \\
\hline CE2 - G1 & 0,0026 & 0,0070 & 0,0110 & 0,0150 & 0,0190 & 0,0240 & 0,0460 & 0,0690 \\
\hline desvio padrão & 0,0009 & 0,0020 & 0,0030 & 0,0040 & 0,0040 & 0,0040 & 0,0050 & 0,0060 \\
\hline CE3 - G2 & 0,0030 & 0,0070 & 0,0110 & 0,0150 & 0,0190 & 0,0240 & 0,0500 & 0,0700 \\
\hline desvio padrão & 0,0008 & 0,0010 & 0,0020 & 0,0020 & 0,0030 & 0,0040 & 0,0100 & 0,0200 \\
\hline CE4 - G1 & 0,0022 & 0,0052 & 0,0090 & 0,0120 & 0,0160 & 0,0190 & 0,0380 & 0,0600 \\
\hline desvio padrão & 0,0003 & 0,0009 & 0,0020 & 0,0020 & 0,0030 & 0,0050 & 0,0080 & 0,0100 \\
\hline CE5 - G1 & 0,0025 & 0,0055 & 0,0090 & 0,0120 & 0,0160 & 0,0190 & 0,0380 & 0,0570 \\
\hline desvio padrão & 0,0005 & 0,0004 & 0,0007 & 0,0010 & 0,0010 & 0,0020 & 0,0050 & 0,0080 \\
\hline CE6 - G2 & 0,0031 & 0,0069 & 0,0190 & 0,0150 & 0,0190 & 0,0230 & 0,0450 & 0,0660 \\
\hline desvio padrão & 0,0006 & 0,0008 & 0,0010 & 0,0020 & 0,0020 & 0,0020 & 0,0030 & 0,0040 \\
\hline CE7 - G4 & 0,0050 & 0,0096 & 0,0140 & 0,0190 & 0,0230 & 0,0280 & 0,0520 & 0,0770 \\
\hline desvio padrão & 0,0010 & 0,0007 & 0,0010 & 0,0010 & 0,0010 & 0,0010 & 0,0030 & 0,0040 \\
\hline CE8 - G3 & 0,0040 & 0,0080 & 0,0120 & 0,0160 & 0,0200 & 0,0240 & 0,0500 & 0,0700 \\
\hline desvio padrão & 0,0020 & 0,0020 & 0,0030 & 0,0040 & 0,0050 & 0,0060 & 0,0100 & $\overline{0,0100}$ \\
\hline CE9 - G4 & 0,0050 & 0,0100 & 0,0140 & 0,0190 & 0,0240 & 0,0270 & 0,0530 & 0,0770 \\
\hline desvio padrão & 0,0010 & 0,0020 & 0,0020 & 0,0020 & 0,0020 & 0,0030 & 0,0020 & 0,0020 \\
\hline CE10 - G4 & 0,0050 & 0,0094 & 0,0142 & 0,0190 & 0,0239 & 0,0287 & 0,0540 & $\overline{0,0780}$ \\
\hline desvio padrão & 0,0001 & 0,0004 & 0,0005 & 0,0005 & 0,0005 & 0,0007 & 0,0020 & 0,0020 \\
\hline CE11 - G5 & 0,0060 & 0,0120 & $\overline{0,0170}$ & 0,0220 & 0,0280 & 0,0330 & 0,0600 & 0,0870 \\
\hline desvio padrão & 0,0010 & 0,0010 & 0,0020 & 0,0020 & 0,0020 & 0,0020 & 0,0020 & 0,0030 \\
\hline CE12 - G5 & 0,0066 & 0,0100 & 0,0130 & 0,0200 & 0,0240 & 0,0280 & 0,0520 & 0,0750 \\
\hline desvio padrão & 0,0004 & 0,0010 & 0,0030 & 0,0020 & 0,0020 & 0,0020 & 0,0020 & $\overline{0,0020}$ \\
\hline CE13 - G4 & 0,0050 & 0,0094 & 0,0140 & 0,0186 & 0,0230 & 0,0280 & 0,0520 & $\overline{0,0760}$ \\
\hline desvio padrão & 0,0006 & 0,0007 & 0,0006 & 0,0007 & 0,0010 & 0,0010 & 0,0020 & 0,0020 \\
\hline CE14 - G4 & 0,0050 & 0,0091 & 0,0134 & 0,0178 & 0,0221 & 0,0265 & 0,0485 & 0,0704 \\
\hline desvio padrão & 0,0010 & 0,0007 & 0,0007 & 0,0007 & 0,0008 & 0,0007 & 0,0006 & 0,0009 \\
\hline CE15 - G5 & 0,0060 & 0,0110 & 0,0160 & 0,0210 & 0,0260 & 0,0310 & 0,0520 & $\overline{0,0820}$ \\
\hline desvio padrão & 0,0010 & 0,0010 & 0,0010 & 0,0010 & 0,0010 & 0,0010 & 0,0020 & 0,0020 \\
\hline CE-média G1 & 0,0025 & 0,0060 & 0,0100 & 0,0140 & 0,0180 & 0,0220 & 0,0420 & 0,0640 \\
\hline desvio padrão G1 & 0,0002 & 0,0010 & 0,0010 & 0,0020 & 0,0020 & 0,0030 & 0,0050 & 0,0060 \\
\hline CE-média G2 & 0,0031 & 0,0070 & 0,0150 & 0,0150 & 0,0190 & 0,0235 & 0,0480 & 0,0680 \\
\hline desvio padrão G2 & 0,0001 & 0,0001 & 0,0060 & 0,0000 & 0,0000 & 0,0007 & 0,0040 & 0,0030 \\
\hline CE-média G3 & 0,0040 & 0,0080 & 0,0120 & 0,0160 & 0,0200 & 0,0240 & 0,0500 & 0,0700 \\
\hline desvio padrão G3 & 0,0001 & 0,0001 & 0,0060 & 0,0001 & 0,0001 & 0,0007 & 0,0040 & 0,0030 \\
\hline CE-média G4 & 0,0050 & 0,0095 & 0,0139 & 0,0187 & 0,0232 & 0,0276 & 0,0519 & 0,0757 \\
\hline desvio padrão G4 & 0,0000 & 0,0003 & 0,0003 & 0,0005 & 0,0008 & 0,0009 & 0,0021 & 0,0030 \\
\hline CE-média G5 & 0,0062 & 0,0110 & 0,0150 & 0,0210 & 0,0260 & 0,0310 & 0,0550 & 0,0810 \\
\hline desvio padrão G5 & 0,0003 & 0,0010 & 0,0020 & 0,0010 & 0,0020 & 0,0020 & 0,0050 & 0,0060 \\
\hline
\end{tabular}

Quadro 9. Valores das leituras das células em $\mathrm{mV} / \mathrm{V}$ acompanhadas do respectivo desvio. Fonte: Elaborado a partir dos dados experimentais (2008). 


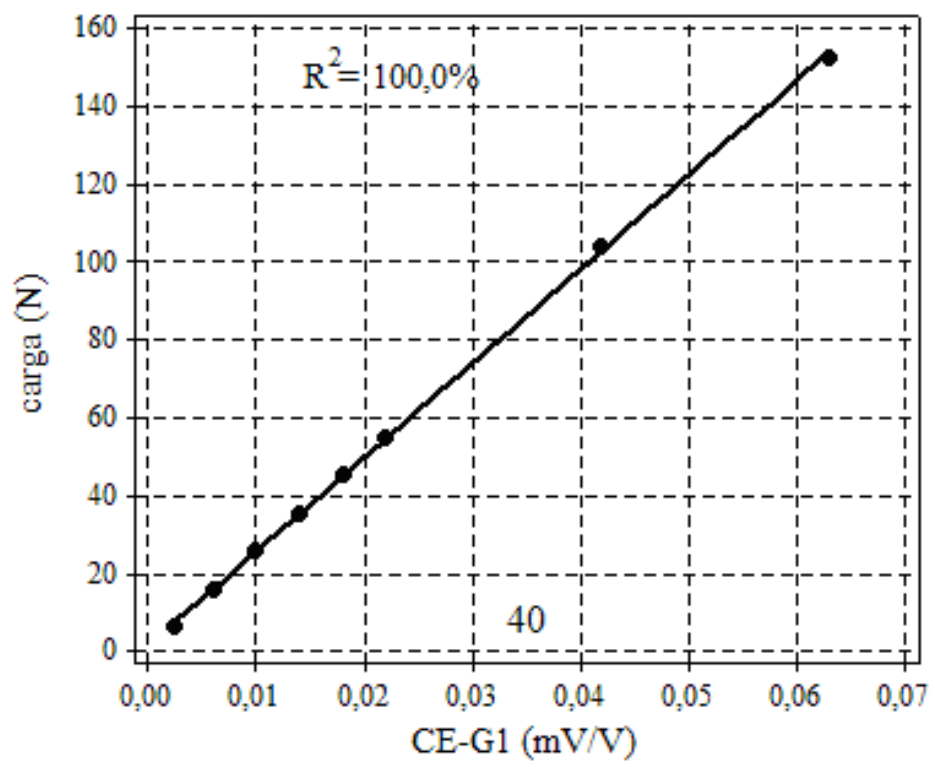

Gráfico 123 Resposta das células com respeito ao carregamento. Fonte: Elaborados a partir dos dados experimentais (2008).

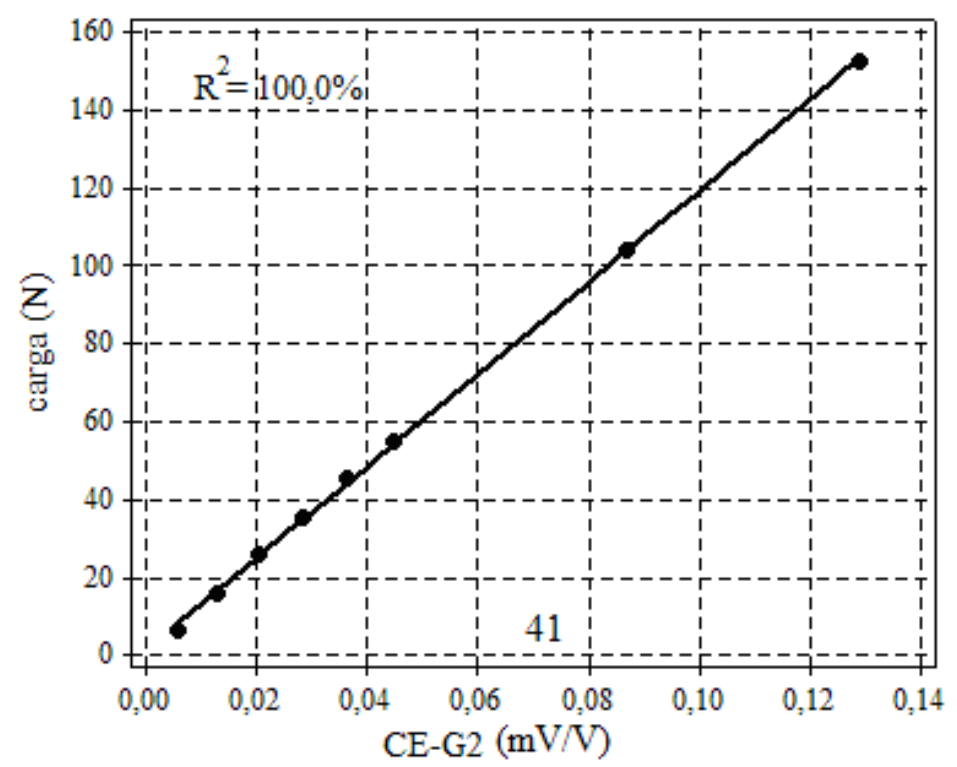

Gráfico 124 Resposta das células com respeito ao carregamento. Fonte: Elaborados a partir dos dados experimentais (2008). 


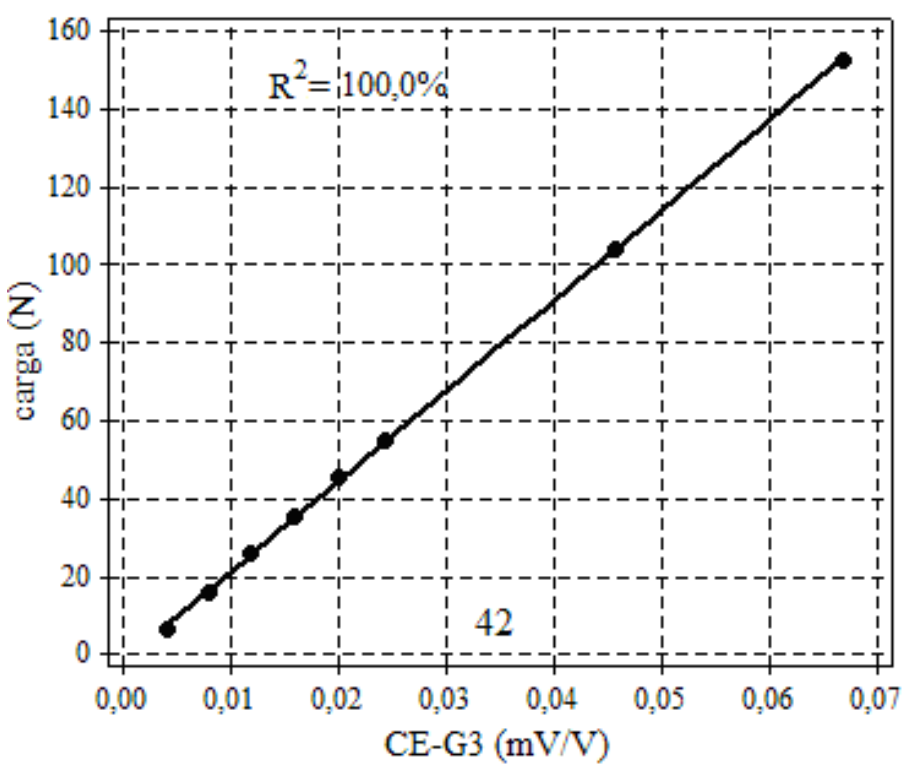

Gráfico 125 Resposta das células com respeito ao carregamento.

Fonte: Elaborados a partir dos dados experimentais (2008).

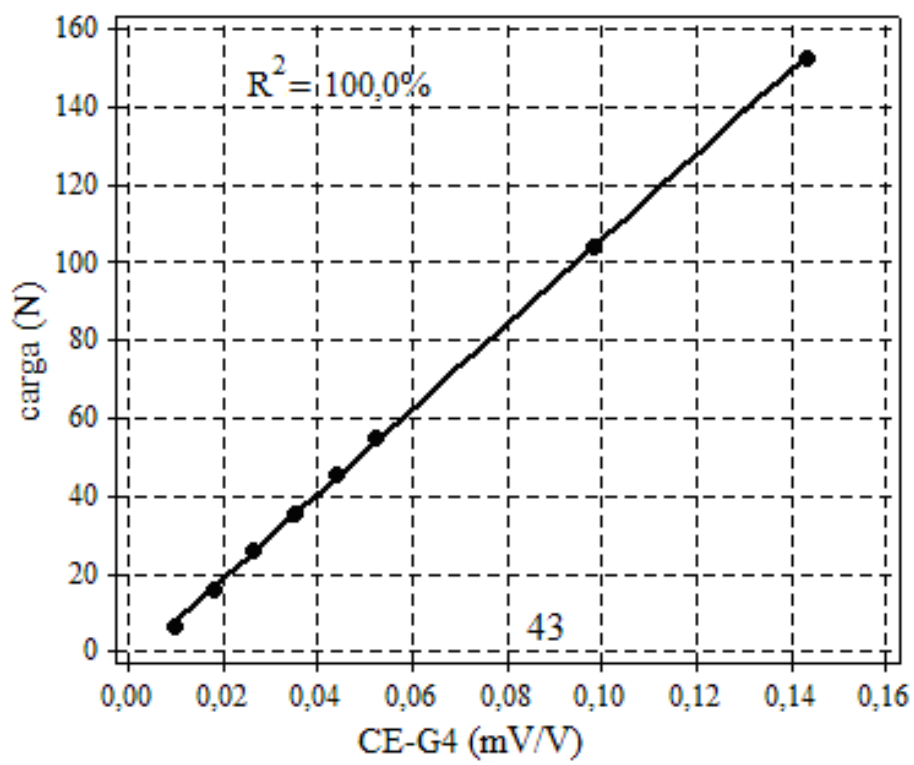

Gráfico 126 Resposta das células com respeito ao carregamento. Fonte: Elaborados a partir dos dados experimentais (2008). 


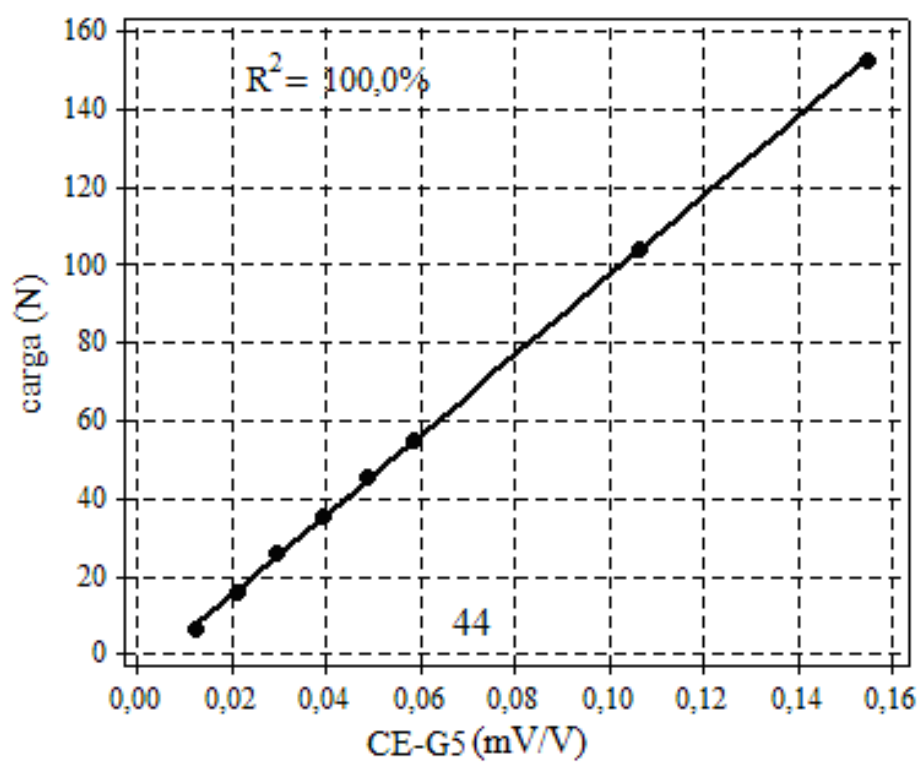

Gráfico 127. Resposta das células com respeito ao carregamento.

Fonte: Elaborados a partir dos dados experimentais (2008).

Os gráficos 128 a 132 mostram a resposta das células em função da deformação. A equação 52 (apêndice D) foi utilizada para os cálculos de deformação.

A escala de trabalho ou range foi determinada utilizando um resistor para simular uma deformação. Para tanto, um resistor shunt foi adicionado em paralelo em um dos braços da ponte de Wheatstone. Essa associação simulou uma deformação mecânica, equação 35, onde a variação da resistência $\Delta \mathrm{R}$ é dada pela equação 36. Por observação, percebeu-se que o comportamento, em termos da simulação de cada célula, estava situado entre $6,0 M \Omega \pm 1 \%$ e $200 \mathrm{k} \Omega \pm 1 \%$, a menos do fator gage todas as células foram consideradas semelhantes pois o valor ôhmico $R_{i}$, fornecido pelo fabricante, era de $121,0 \Omega \pm 1 \%$. A resistência de shunt foi conseguida por meio de uma década resistiva da marca PHYWE, modelo 06194.10, constituída por resistores de 1,0\% de precisão. O mesmo procedimento foi utilizado na calibração dos canais de aquisição do sistema ADS 500.

O valor do resistor de calibração ou shunt pôde ser obtido a partir da definição de deformação específica ocasionada no elemento sensor. Dado por:

$$
\begin{gathered}
\varepsilon=\frac{1}{K} \cdot \frac{\Delta R}{R} \\
\Delta R=R_{\text {final }}-R_{\text {inicial }}
\end{gathered}
$$




$$
R_{f}=\frac{R_{i} \cdot R_{c a l}}{R_{i}+R_{c a l}}
$$

Combinando as equações (35), (36) e (37) se obtém:

$$
\varepsilon=-\frac{1}{K} \cdot \frac{R_{i}}{R_{i}+R_{c a l}}
$$

Sendo possível determinar $\mathrm{R}_{\text {cal }}$ para uma determinada deformação.

Onde: $\mathrm{K}$ - gage factor, $\mathrm{R}_{\mathrm{i}}$ - resistência do gage, $\Delta \mathrm{R}$ - variação da resistência, $\varepsilon$ - deformação específica, $\mathrm{R}_{\mathrm{cal}}$ - resistência shunt ou de calibração.

$$
\begin{aligned}
\Delta \varepsilon & =\varepsilon\left[\frac{\Delta R_{i}}{R_{i}}+\frac{\Delta R_{i}+\Delta R_{c a l}}{R_{i}+R_{c a l}}\right] \\
R_{i} & \rightarrow 121,0 \pm 1 \%, R_{c a l} \rightarrow 6,0 M \Omega \text { até } 250,0 \mathrm{k} \Omega \pm 5 \%
\end{aligned}
$$

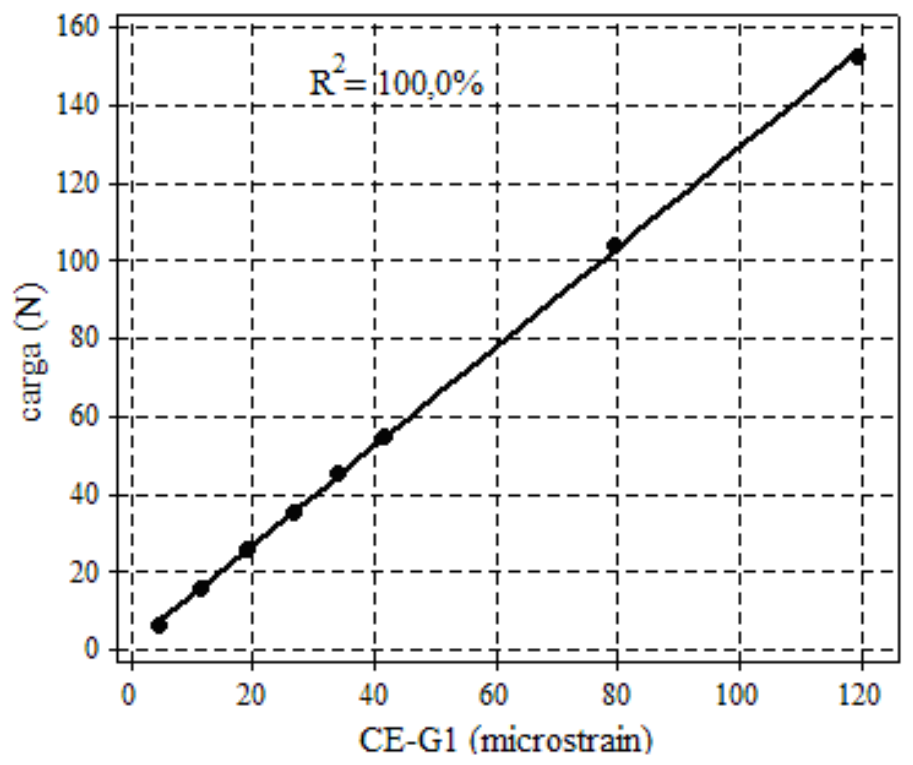

Gráfico 128. Resposta das células em $\mu$ s em função do carregamento. Fonte: Elaborados a partir dos dados experimentais (2008). 


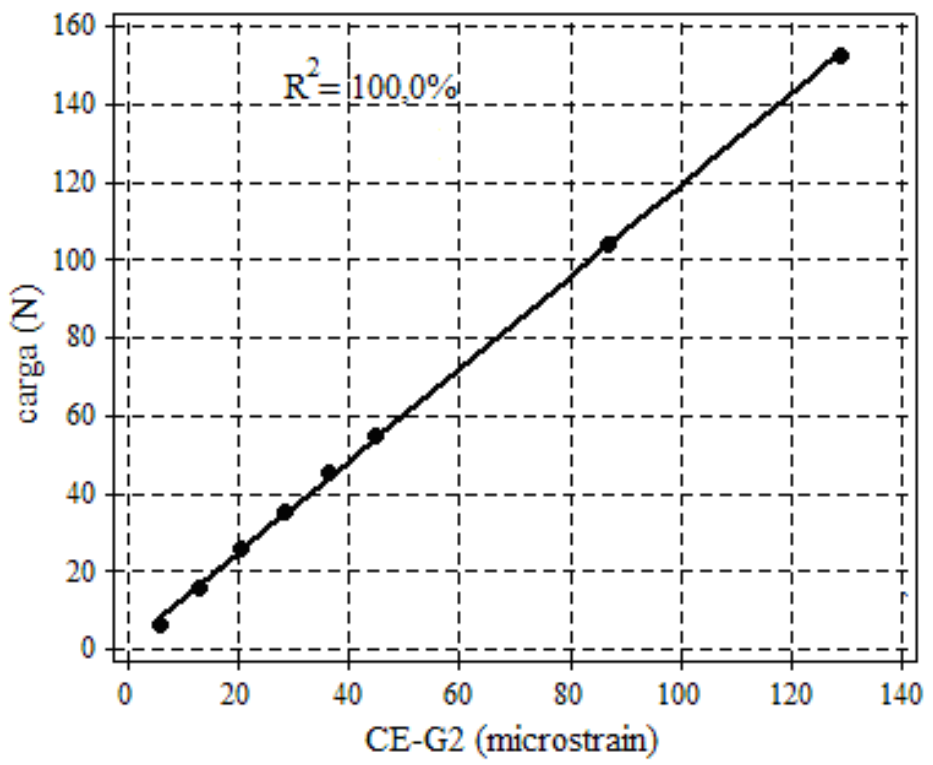

Gráfico 129. Resposta das células em $\mu$ s em função do carregamento. Fonte: Elaborados a partir dos dados experimentais (2008).

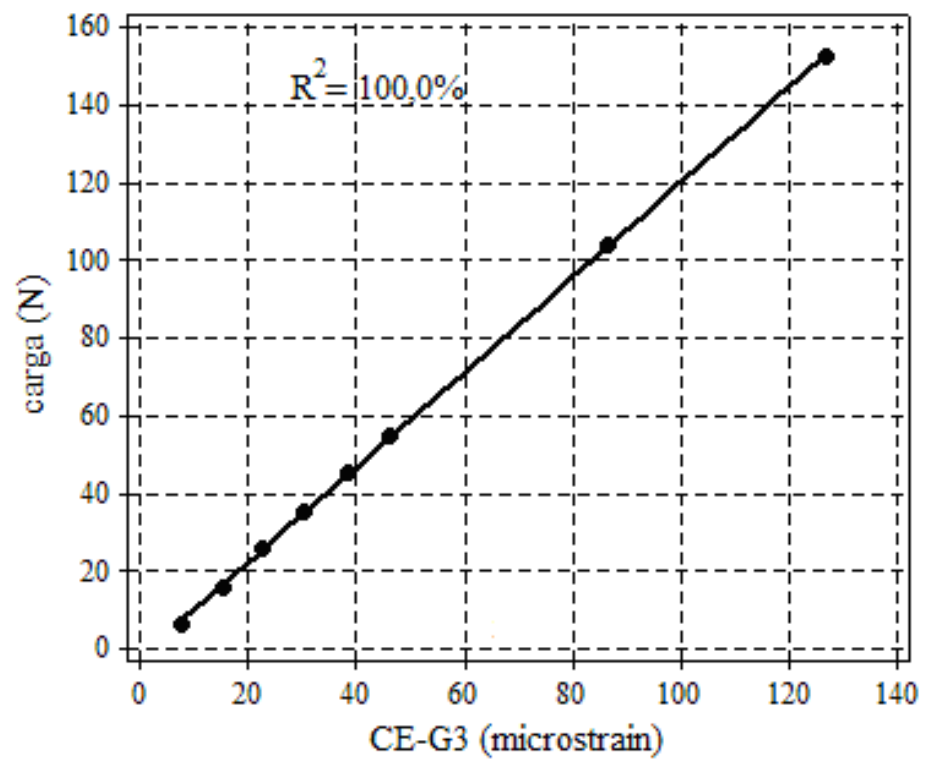

Gráfico 130. Resposta das células em $\mu$ s em função do carregamento. Fonte: Elaborados a partir dos dados experimentais (2008). 


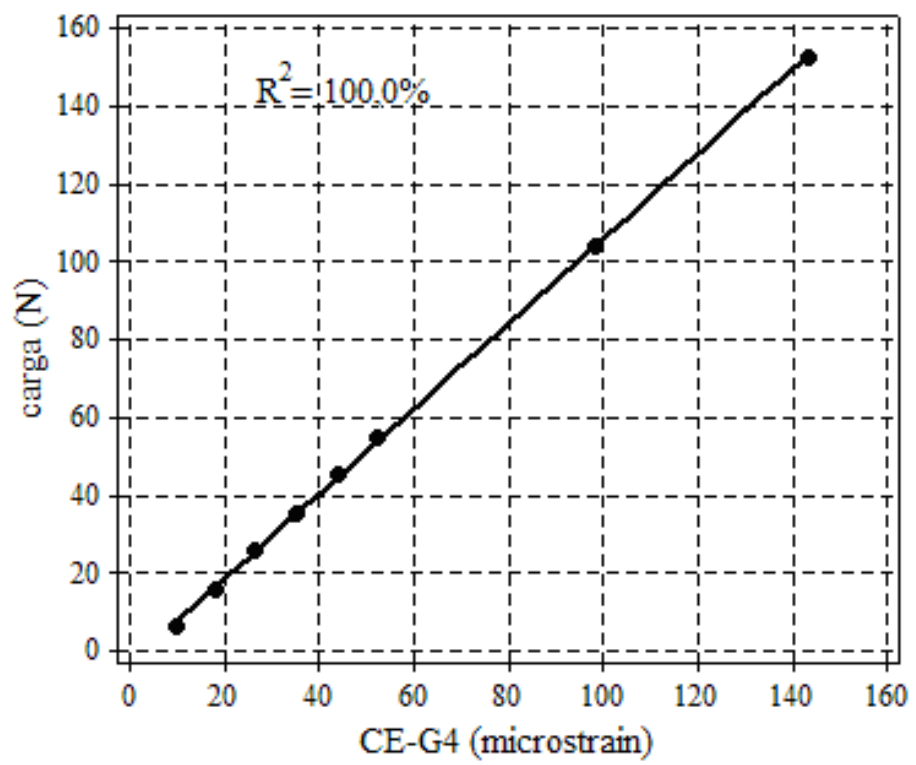

Gráfico 131. Resposta das células em $\mu$ s em função do carregamento. Fonte: Elaborados a partir dos dados experimentais (2008).

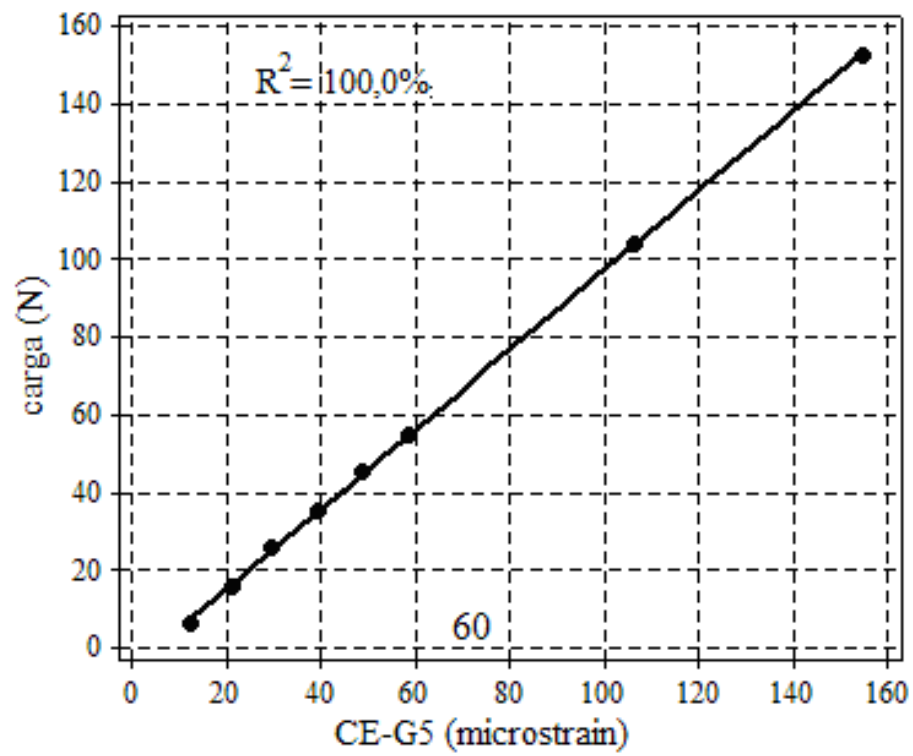

Gráfico 132. Resposta das células em $\mu$ s em função do carregamento.

Fonte: Elaborados a partir dos dados experimentais (2008).

$\mathrm{Na}$ fotografia 32, está indicada a disposição dos equipamentos utilizados para a simulação de uma deformação ocasionada na célula de embutimento. Para cada célula, foi feito um ajuste na década, até que o valor em $\mathrm{mV} / \mathrm{V}$ correspondesse ao valor em $\mathrm{mV} / \mathrm{V}$ para cada carregamento imposto. Por exemplo, um carregamento equivalente a 1,648 kg impõe na 
célula de embutimento um valor de $0,007 \mathrm{mV} / \mathrm{V}$. Através da década resistiva procura-se esse valor em $\mathrm{mV} / \mathrm{V}$ e, quando encontrado, registra-se o valor do shunt correspondente.

O gráfico 133 mostra a reta de calibração juntamente com uma reta de regressão indicando coerência e linearidade dos resultados. A reta foi obtida plotando-se o valor médio das médias em mV/V em função dos valores de deformações, obtidos utilizando-se a relação do quadro 7.

Cada célula ou grupo de células possui um fator gage diferente, dependendo do lote de fabricação, e é especificado pelo fabricante.

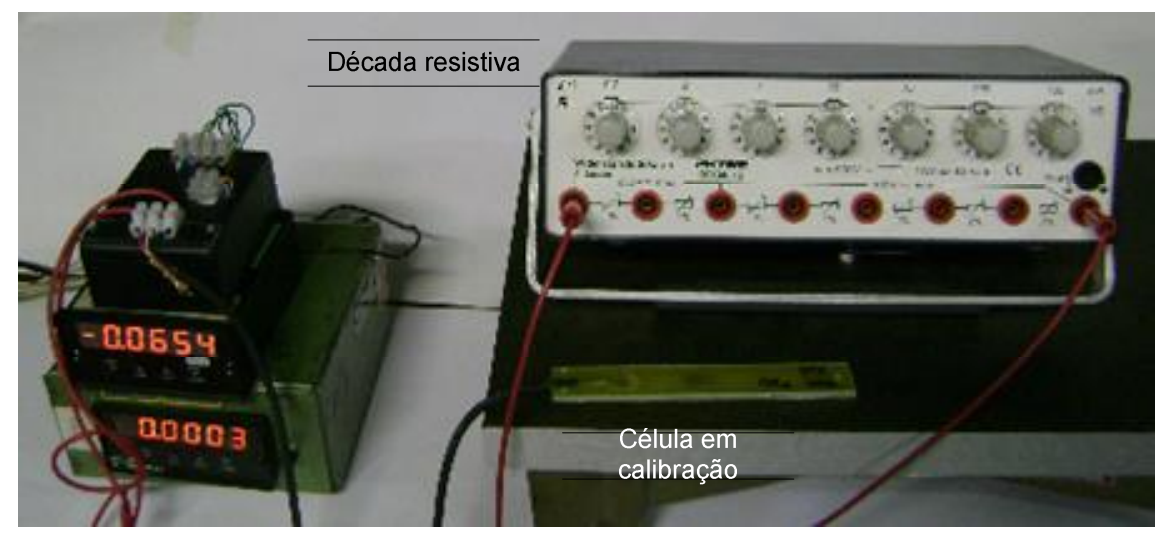

Fotografia 32. Disposição dos equipamentos utilizados nos testes de calibração por meio de um shunt resistivo.

Fonte: Acervo próprio (2008).

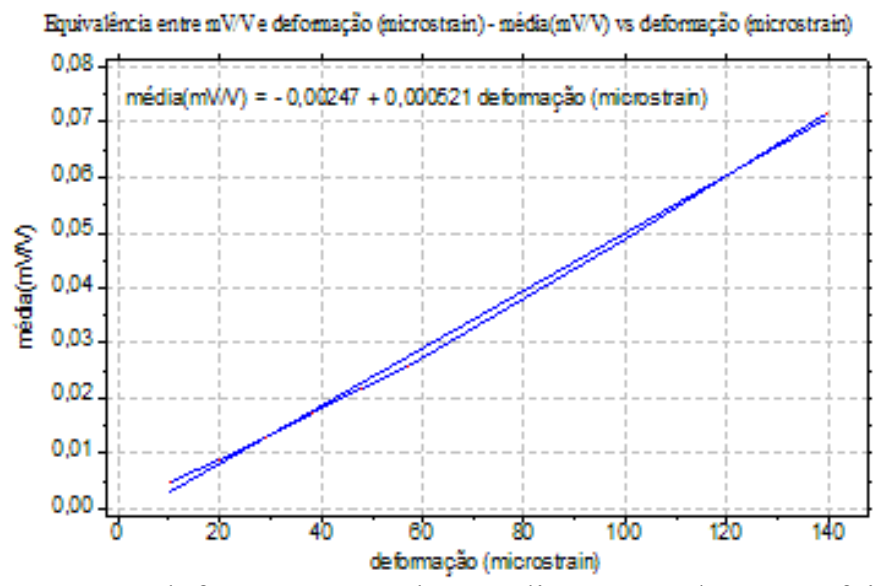

Gráfico 133. Relação entre deformação e valor médio em mV/V para efeito de calibração da célula de embutimento em função da deformação.

Fonte: Elaborado a partir dos dados experimentais (2008). 
A análise da reta de regressão, gráfico 128, mostrou a equivalência de 2000,0 $\mu \mathrm{s} / \mathrm{mV} / \mathrm{V}$. O cálculo da incerteza do valor da deformação foi realizado conforme a equação 48.

\begin{tabular}{|c|c|c|c|c|}
\hline $\mathrm{CE} 1(\mathrm{mV} / \mathrm{V})$ & $\mathrm{CE} 2(\mathrm{mV} / \mathrm{V})$ & $\mathrm{CE} 3(\mathrm{mV} / \mathrm{V})$ & $\mathrm{CE} 4(\mathrm{mV} / \mathrm{V})$ & $\mathrm{CE} 5(\mathrm{mV} / \mathrm{V})$ \\
\hline 0,0027 & 0,0026 & 0,003 & 0,0022 & 0,0025 \\
\hline 0,0069 & 0,0072 & 0,0067 & 0,0052 & 0,0055 \\
\hline 0,011 & 0,0113 & 0,0109 & 0,0086 & 0,009 \\
\hline 0,0153 & 0,0151 & 0,015 & 0,012 & 0,0122 \\
\hline 0,0193 & 0,0193 & 0,0192 & 0,0156 & 0,0157 \\
\hline 0,0242 & 0,0238 & 0,0238 & 0,0187 & 0,0194 \\
\hline 0,0465 & 0,0464 & 0,0464 & 0,0383 & 0,0379 \\
\hline 0,0687 & 0,0688 & 0,0688 & 0,0578 & 0,0569 \\
\hline $\mathrm{CE} 6(\mathrm{mV} / \mathrm{V})$ & CE7(mV/V) & $\mathrm{CE} 8(\mathrm{mV} / \mathrm{V})$ & $\mathrm{CE} 9(\mathrm{mV} / \mathrm{V})$ & CE10(mV/V) \\
\hline 0,0031 & 0,0053 & 0,0041 & 0,0053 & 0,005 \\
\hline 0,0069 & 0,0096 & 0,008 & 0,0098 & 0,0094 \\
\hline 0,0108 & 0,014 & 0,012 & 0,0144 & 0,0142 \\
\hline 0,015 & 0,0187 & 0,0161 & 0,0191 & 0,019 \\
\hline 0,0193 & 0,0232 & 0,0202 & 0,0236 & 0,0239 \\
\hline 0,0234 & 0,0279 & 0,0244 & 0,0268 & 0,0287 \\
\hline 0,0451 & 0,0522 & 0,0457 & 0,0529 & 0,0537 \\
\hline 0,0664 & 0,0769 & 0,0669 & 0,0772 & 0,0783 \\
\hline CE11(mV/V) & $\mathrm{CE} 12(\mathrm{mV} / \mathrm{V})$ & CE13(mV/V) & CE14mV/V) & CE15(mV/V) \\
\hline 0,0065 & 0,0066 & 0,005 & 0,0051 & 0,0063 \\
\hline 0,0116 & 0,0105 & 0,0094 & 0,0091 & 0,0113 \\
\hline 0,0168 & 0,0133 & 0,014 & 0,0134 & 0,0162 \\
\hline 0,0222 & 0,0192 & 0,0186 & 0,0178 & 0,0211 \\
\hline 0,0275 & 0,0236 & 0,0227 & 0,0221 & 0,0262 \\
\hline 0,0329 & 0,0282 & 0,0279 & 0,0265 & 0,0312 \\
\hline 0,0602 & 0,0517 & 0,0519 & 0,0485 & 0,0567 \\
\hline 0,087 & 0,0752 & 0,0759 & 0,0704 & 0,0825 \\
\hline média $(\mathrm{mV} / \mathrm{V})$ & des. padr & Rcal (shunt) $(\Omega)$ & Deformação (strain) & - \\
\hline 0,0044 & 0,0016 & 5700000 & 0,00001 & - \\
\hline 0,0085 & 0,002 & 2900000 & 0,00002 & - \\
\hline 0,0127 & 0,0024 & 2000000 & 0,000029 & - \\
\hline 0,0171 & 0,003 & 1500000 & 0,000038 & - \\
\hline 0,0214 & 0,0035 & 1200000 & 0,000048 & - \\
\hline 0,0259 & 0,0039 & 1000000 & 0,000057 & - \\
\hline 0,0489 & 0,0062 & 600000 & 0,0001 & - \\
\hline 0,0718 & 0,0083 & 400000 & 0,00014 & - \\
\hline
\end{tabular}

Quadro 10. . Valores médios em $\mathrm{mV} / \mathrm{V}$ e valores médios da média com respectivo desvio padrão.

Fonte: Elaborado a partir dos dados experimentais (2008).

As células de embutimento foram construídas com três fatores gage diferentes, 2,12, 2,11 e 2,08. Por uma questão de praticidade, sem comprometer a calibração das células, 
optou-se por usar um valor médio para o fator gage que, nesse caso, foi o valor de 2,109 ou 2,11 .

Os gráficos 134 a 148 mostram as características individuais de cada uma das células de embutimento ou deformação $(\mathrm{CE})$ em mV/V versus carregamento $(\mathrm{N})$.

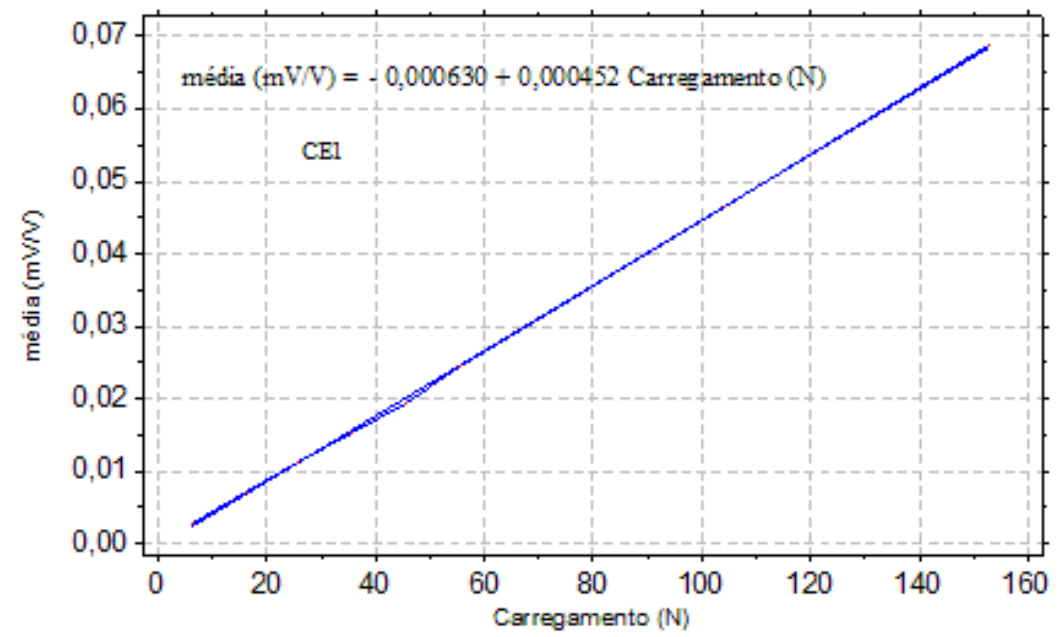

Gráfico 134. Resposta das CE em mV/V em função do carregamento. Fonte: Elaborados a partir dos dados experimentais (2008).

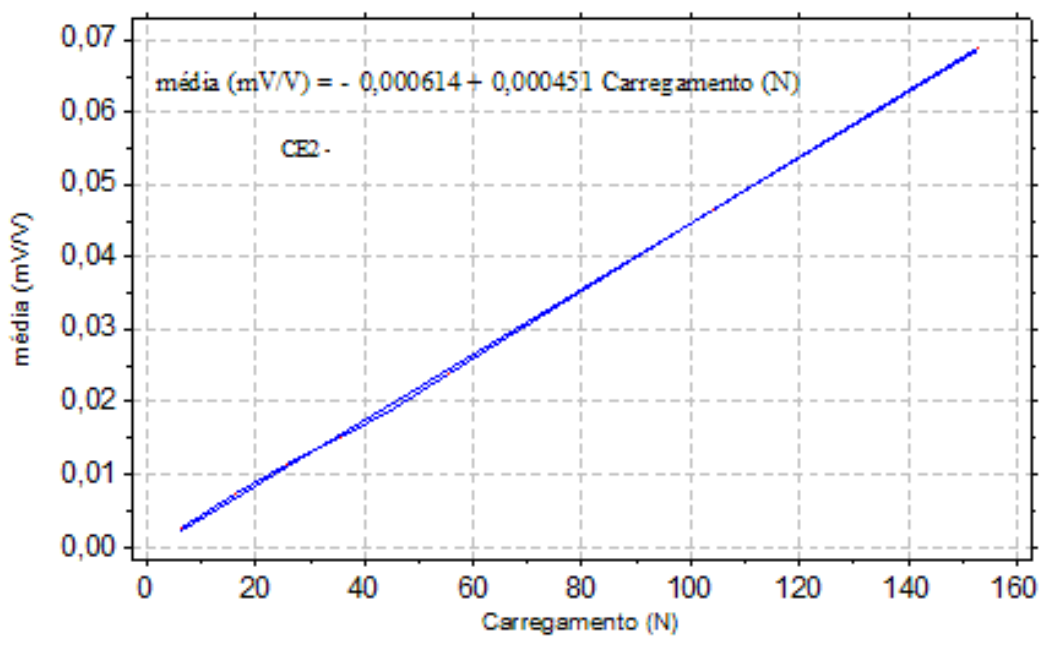

Gráfico 135. Resposta das CE em mV/V em função do carregamento.

Fonte: Elaborados a partir dos dados experimentais (2008). 


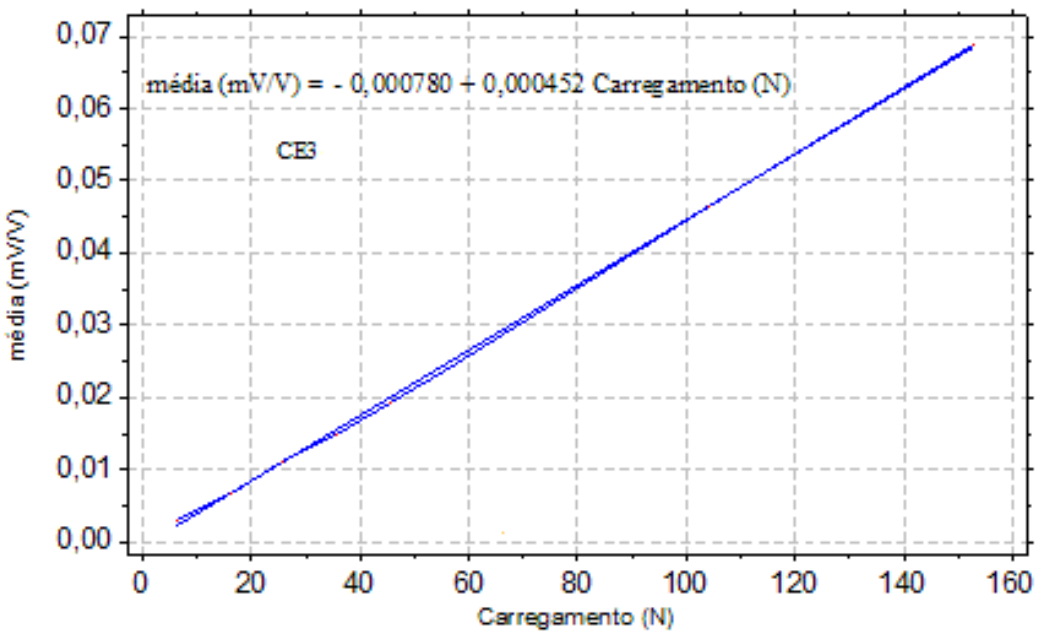

Gráfico 136. Resposta das CE em mV/V em função do carregamento. Fonte: Elaborados a partir dos dados experimentais (2008).

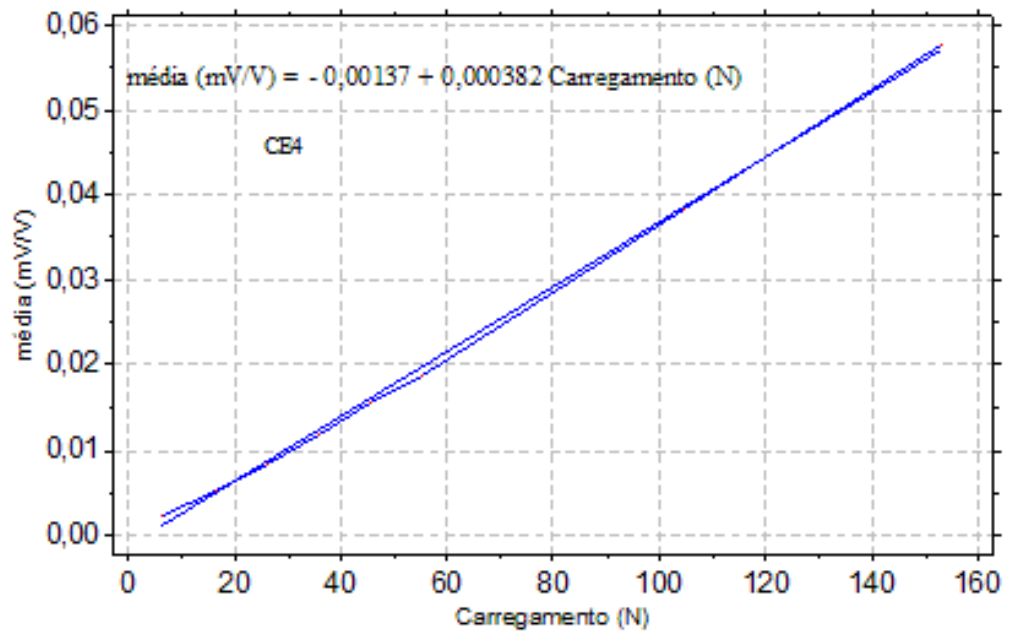

Gráfico 137. Resposta das CE em mV/V em função do carregamento.

Fonte: Elaborados a partir dos dados experimentais (2008). 


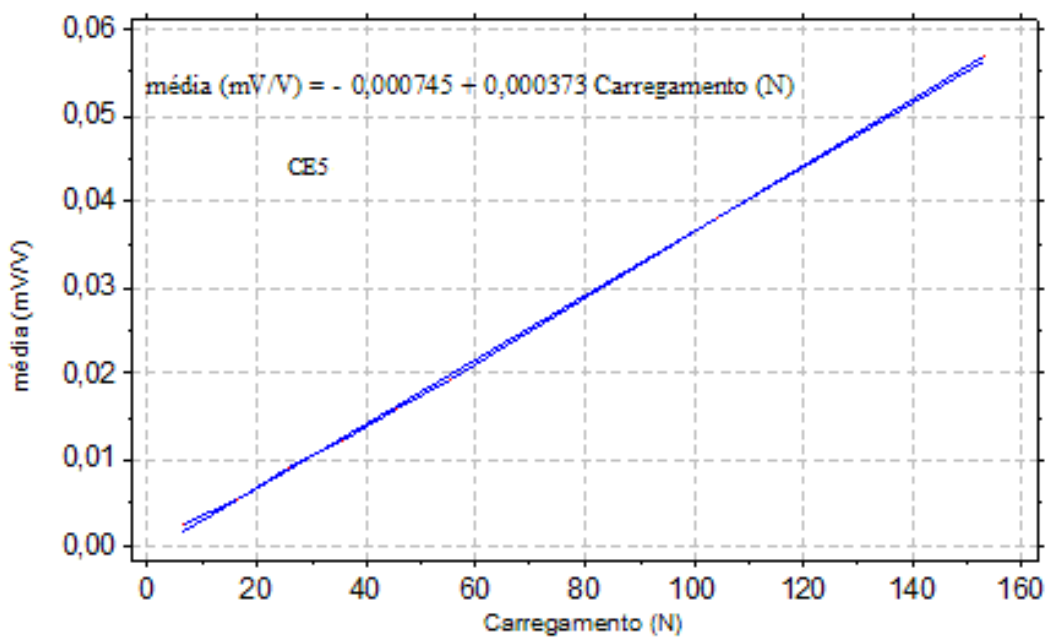

Gráfico 138. Resposta das CE em mV/V em função do carregamento. Fonte: Elaborados a partir dos dados experimentais (2008).

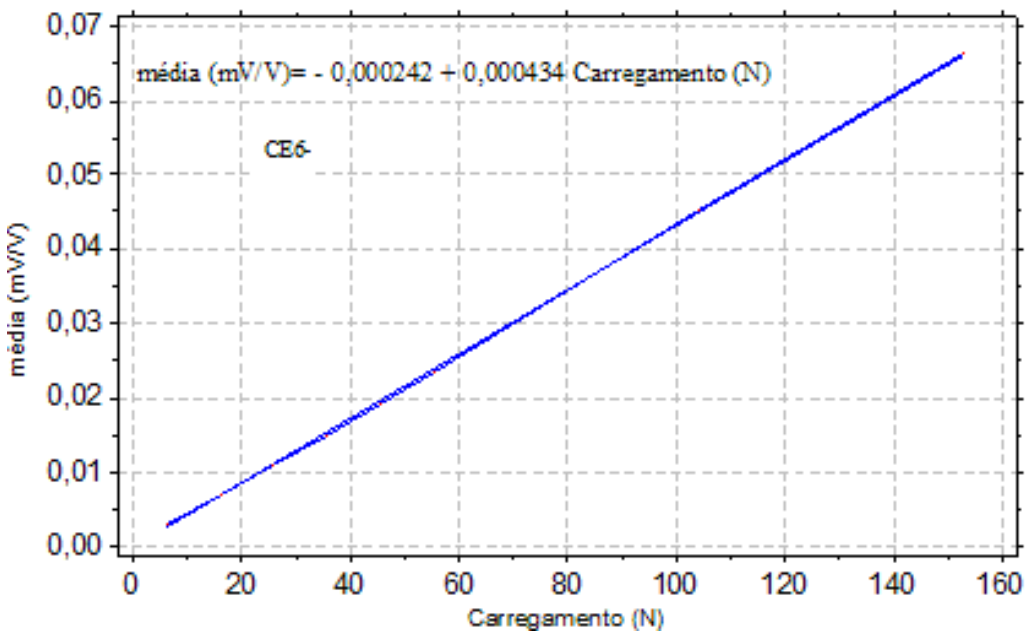

Gráfico 139. Resposta das CE em mV/V em função do carregamento. Fonte: Elaborados a partir dos dados experimentais (2008). 


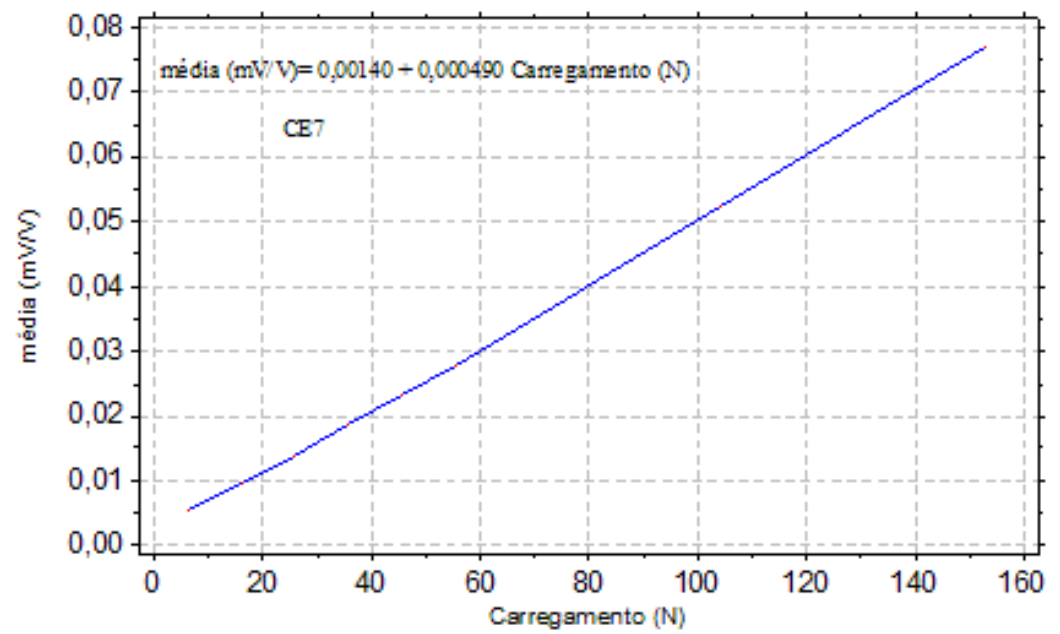

Gráfico 140. Resposta das CE em mV/V em função do carregamento.

Fonte: Elaborados a partir dos dados experimentais (2008).

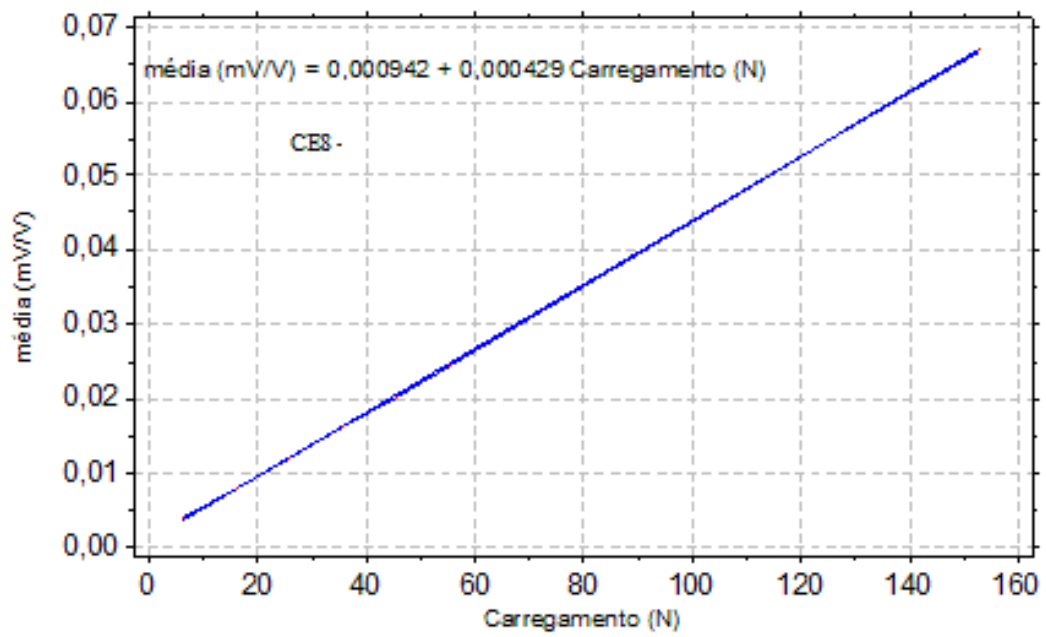

Gráfico 141. Resposta das CE em mV/V em função do carregamento.

Fonte: Elaborados a partir dos dados experimentais (2008). 


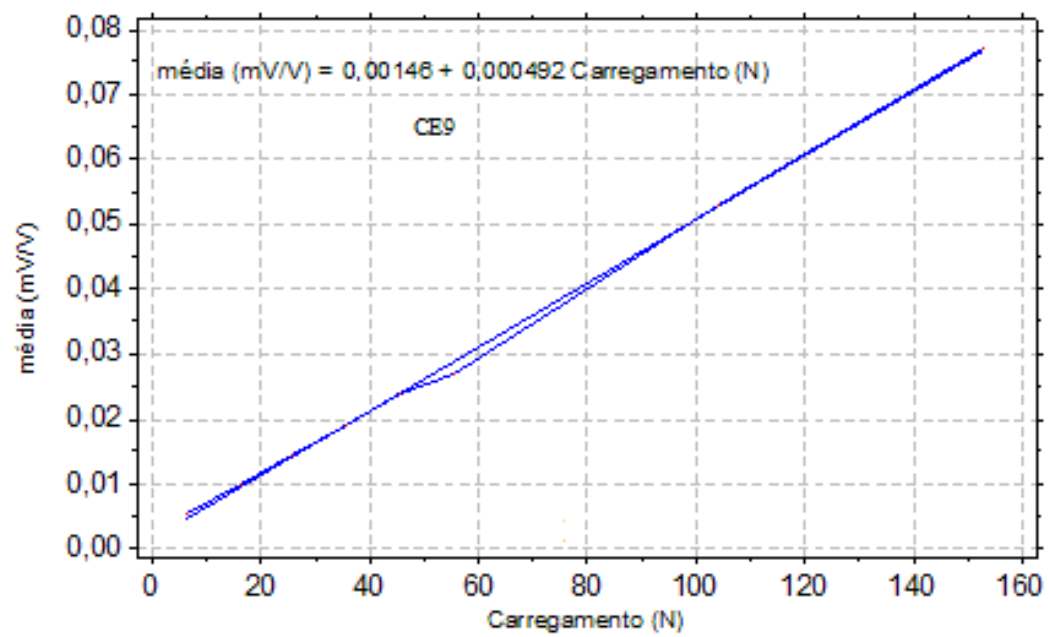

Gráfico 142. Resposta das CE em mV/V em função do carregamento.

Fonte: Elaborados a partir dos dados experimentais (2008).

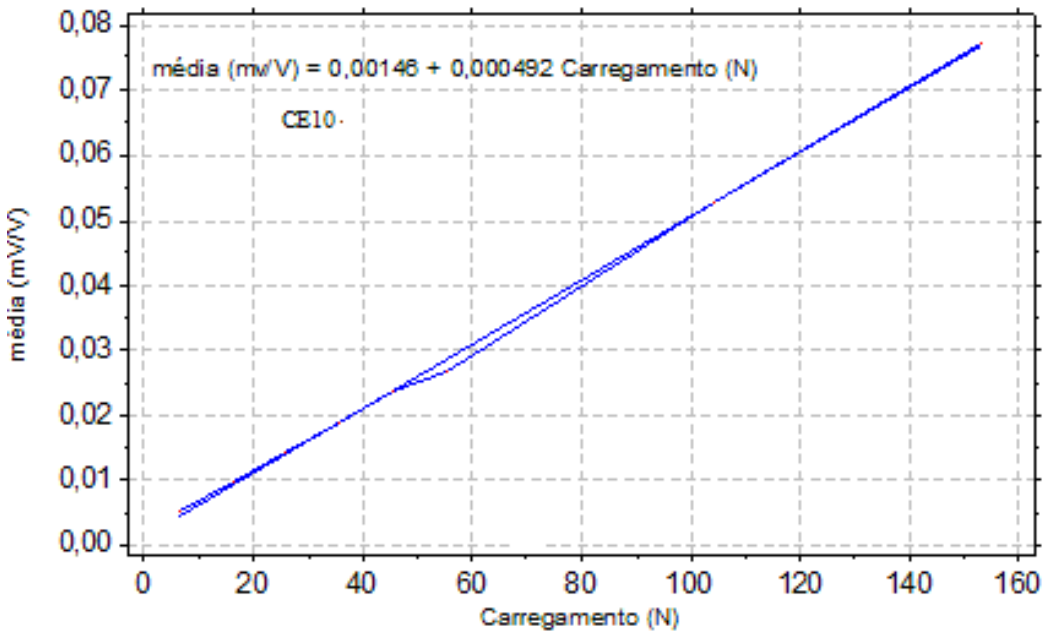

Gráfico 143. Resposta das CE em mV/V em função do carregamento.

Fonte: Elaborados a partir dos dados experimentais (2008). 


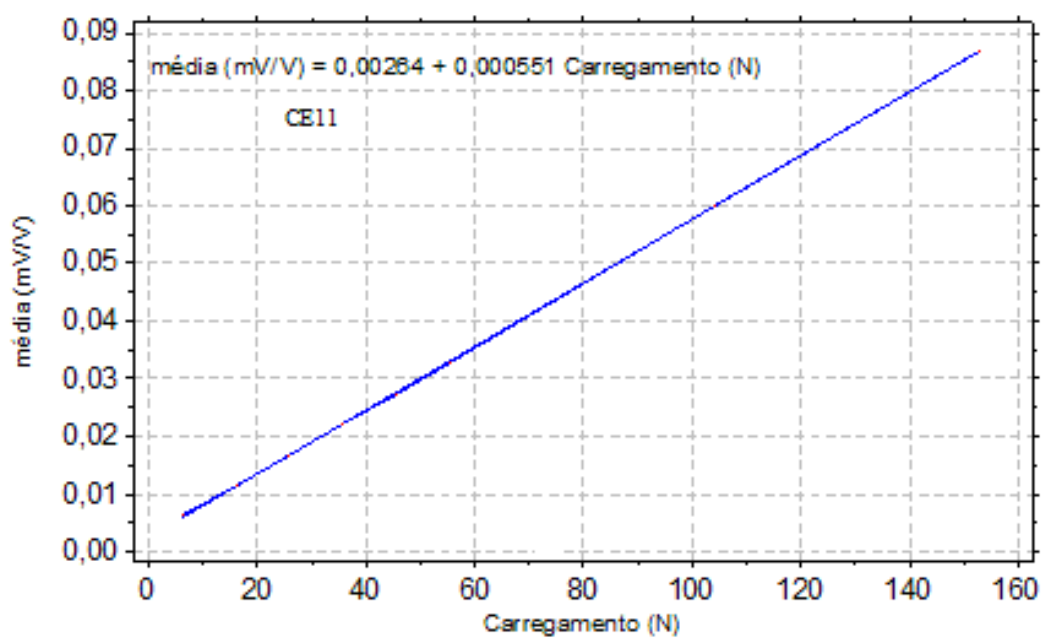

Gráfico 144. Resposta das CE em mV/V em função do carregamento. Fonte: Elaborados a partir dos dados experimentais (2008).

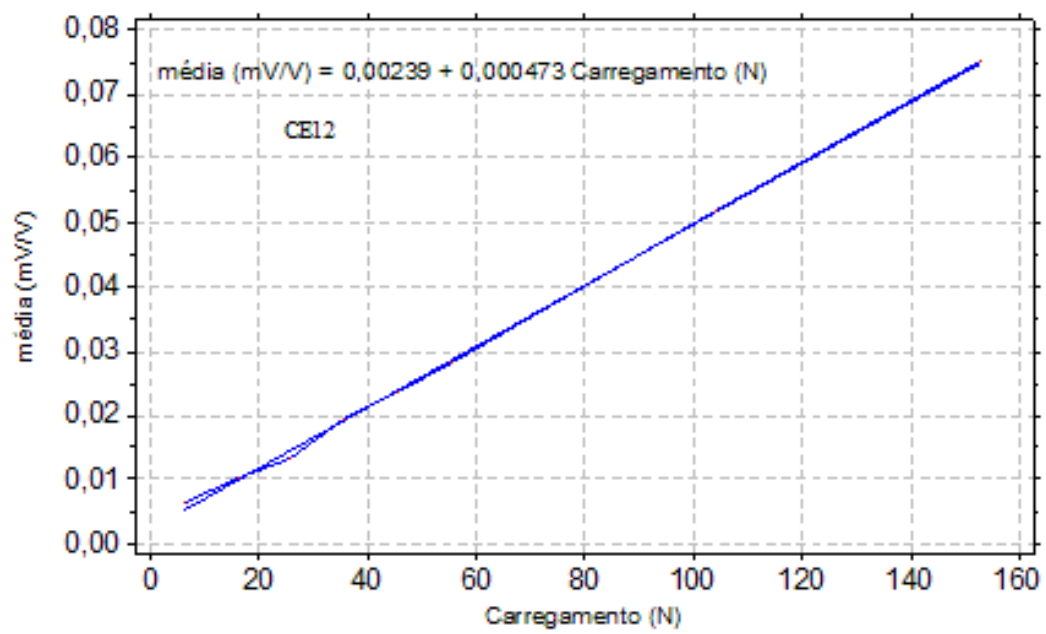

Gráfico 145. Resposta das CE em mV/V em função do carregamento. Fonte: Elaborados a partir dos dados experimentais (2008). 


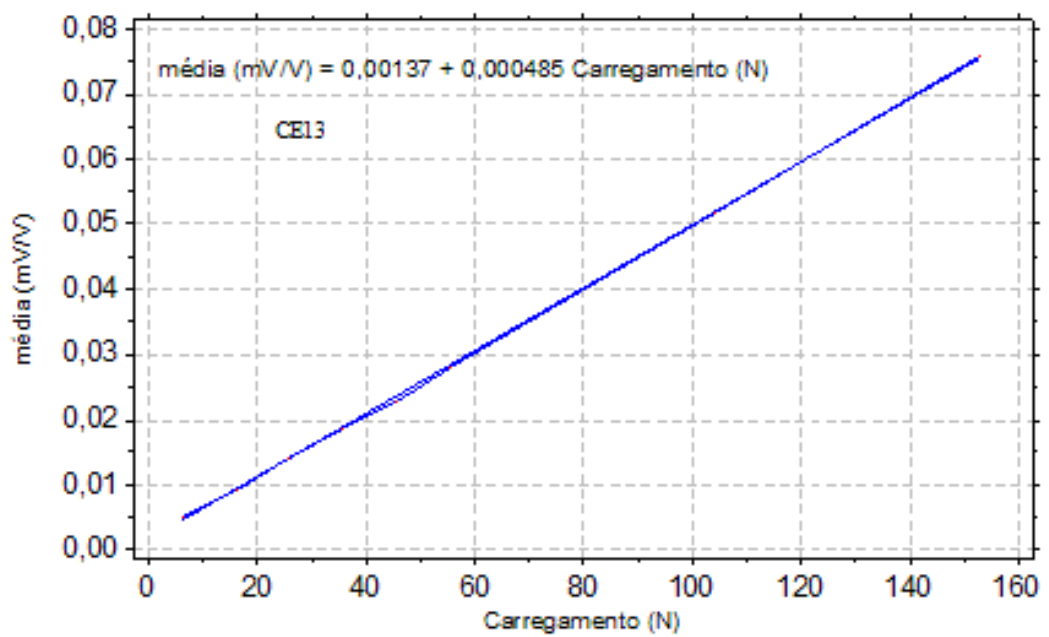

Gráfico 146. Resposta das CE em mV/V em função do carregamento.

Fonte: Elaborados a partir dos dados experimentais (2008).

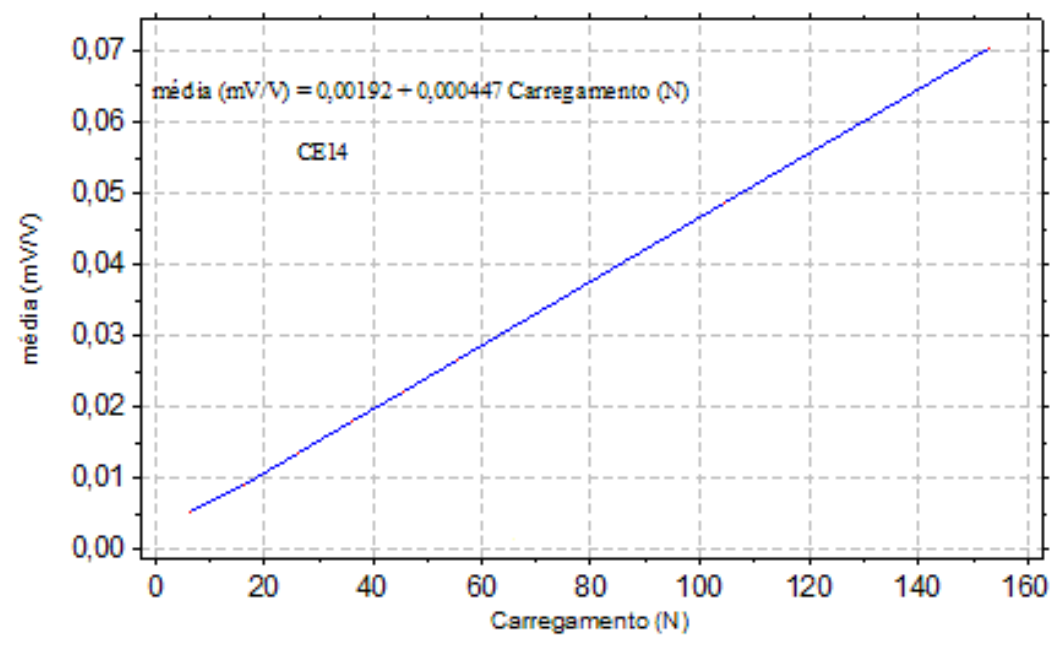

Gráfico 147. Resposta das CE em mV/V em função do carregamento. Fonte: Elaborados a partir dos dados experimentais (2008). 


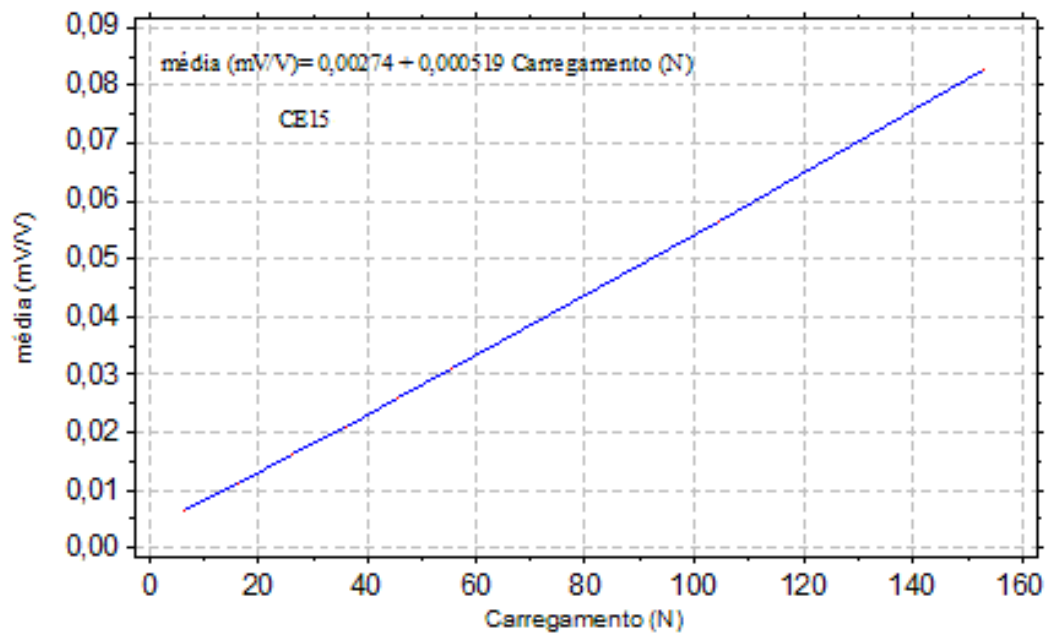

Gráfico 148. Resposta das CE em mV/V em função do carregamento. Fonte: Elaborados a partir dos dados experimentais (2008). 


\section{APÊNDICE B - CONSTRUÇÃO, TESTES DE CALIBRAÇÃO PARA OS TERMÔMETROS E CANAIS DE AQUISIÇÃO DE DADOS}

O procedimento de calibração dos termômetros foi realizado em duas etapas. Inicialmente, foi verificada a linearidade da resposta dos termômetros à variação de temperatura no intervalo de $30,0{ }^{\circ} \mathrm{C}$ a $60,0{ }^{\circ} \mathrm{C}$, situação em que foram levados a um banho termostático com circulação de água em grupos de quatro. A fotografia 33 mostra um conjunto de quatro termômetros sendo testados. Nessa etapa, os testes foram conduzidos no laboratório de Materiais da EEUPM.

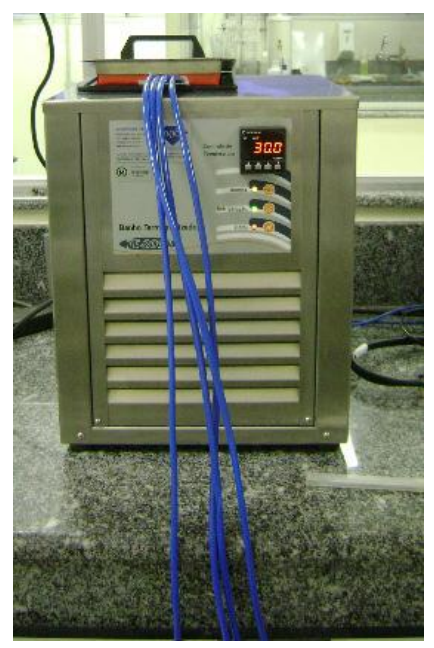

Fotografia 33. Banho termostatizado com quatro sensores em teste.

Fonte: Acervo próprio (2008).

$\mathrm{Na}$ etapa seguinte, um termômetro dentre aqueles ensaiados, especificamente o TE5 (termômetro 5), foi utilizado como referência para calibração dos demais. Para tanto, utilizou-se um forno para calibração, com um termômetro calibrado e rastreado pela Rede Brasileira de Calibração (RBC) e um indicador modelo Cappo Plus do fabricante Ecil Temperatura Industrial, também calibrado, para as leituras do termômetro calibrado e as do termômetro a ser calibrado. A fotografia 34 mostra o aspecto do forno e os termômetros já inseridos na cavidade de teste. A incerteza no aquecimento do forno pode ser vista no gráfico 149 (informações fornecidas pelo fabricante). Nessa etapa, os testes foram realizados nos laboratórios do Centro de Engenharia Nuclear, pertencente ao IPEN, São Paulo. 


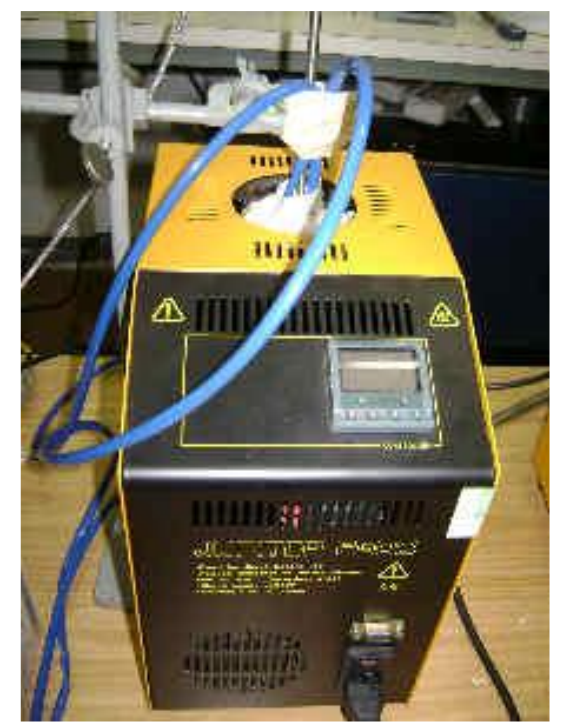

Fotografia 34. Forno utilizado para a calibração dos termômetros. Fabricante ECIL Temperatura Industrial Modelo Júpiter 650. Fonte: Acervo próprio (2008).

Incerteza do Calibrador JUPITER 650 (Gráfico 1)

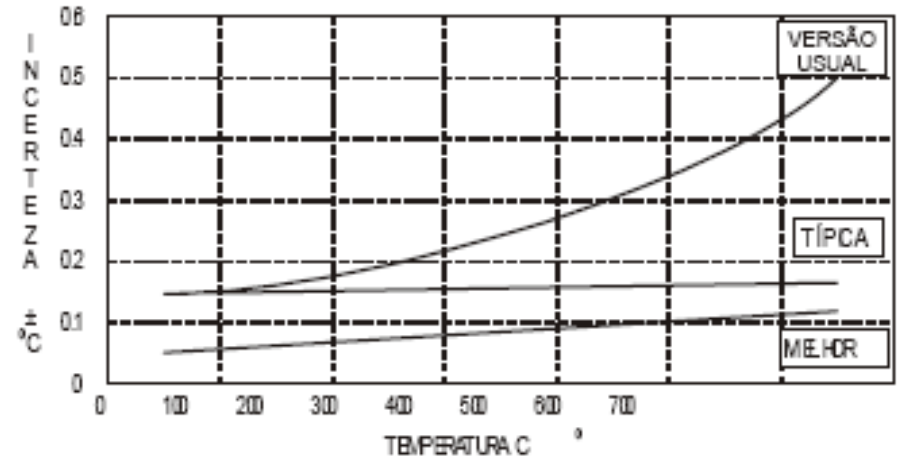

Gráfico 149. Incerteza indicada pelo fabricante do forno. Fonte: Adaptado de ECIL Temperatura Industrial (2007).

A calibração foi feita por comparação, com a temperatura indicada por um termômetro de bulbo de vidro de imersão com algarismo duvidoso na segunda casa decimal, calibrado no IPT. Os termômetros foram colocados no banho termostático, fotografia 35, modelo TE-2000 da marca UNION. Os termômetros foram ligados ao sistema de aquisição de dados TermoFlex e foram submetidos a quatro temperaturas diferentes, $30^{\circ} \mathrm{C}, 40^{\circ} \mathrm{C}, 50^{\circ} \mathrm{C}$ e $60^{\circ} \mathrm{C}$. A cada temperatura, esperava-se o banho estabilizar por cinco minutos e então eram realizadas as aquisições por três minutos à taxa de 10 amostras por minuto. 


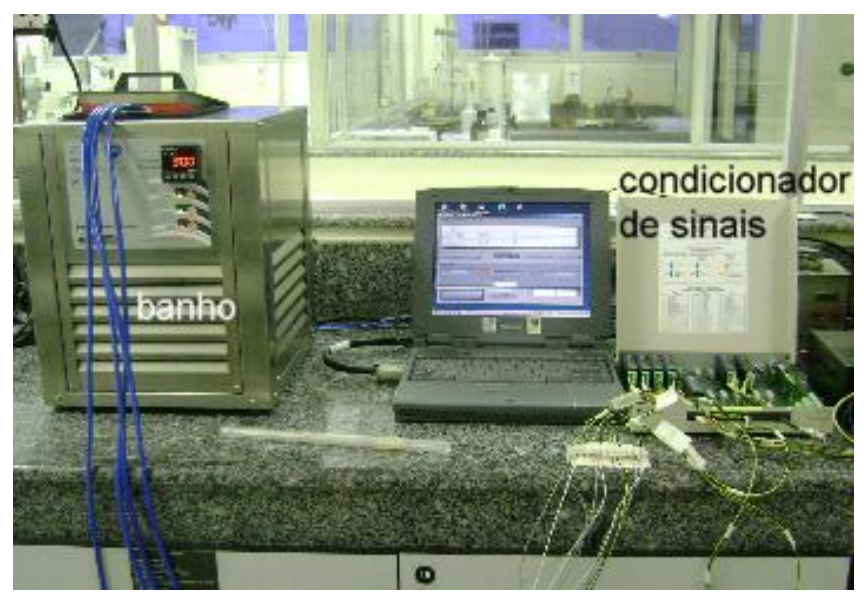

Fotografia 35. Conjunto de calibração envolvendo banho termostatizado, termômetros (em azul), condicionadores de sinal e notebook com placa de aquisição. Fonte: Acervo próprio (2007).

Os dados obtidos estão listados nas Tabelas de 13 a 16, nas quais, por exemplo, TE2 é a indicação para o termômetro 2. Os dados colhidos foram tratados estatisticamente pelo software MINITAB ${ }^{\circledR}$, apresentando os valores médios e os respectivos desvios padrão de cada termômetro. Os canais de aquisição foram calibrados por meio dos termômetros após o estudo do desvio das leituras individuais e da calibração realizada a $0,0^{\circ} \mathrm{C}$. A penúltima coluna mostra a média dos valores na temperatura de teste com o respectivo desvio padrão.

O termômetro TE1 não foi calibrado juntamente com os demais, pois foi utilizado em testes anteriores para ajustes dos equipamentos. Ele apresentou valores semelhantes aos termômetros ensaiados. O TE14 foi construído posteriormente para monitorar a temperatura entre subleito e base. Ele foi avaliado em comparação aos demais e apresentou os mesmos resultados. 
Tabela 13. Valores para temperatura de $30^{\circ} \mathrm{C}$

\begin{tabular}{|c|c|c|c|c|c|c|c|c|c|c|c|c|c|c|}
\hline tempo(s) & TE2 & TE3 & TE4 & TE5 & TE6 & TE7 & TE8 & TE9 & TE10 & TE11 & TE12 & TE13 & média & $\begin{array}{l}\text { desvio } \\
\text { padrão }\end{array}$ \\
\hline 0 & 31,59 & 31,43 & 31,64 & 31,34 & 31,20 & 31,24 & 31,00 & 31,36 & 31,80 & 31,22 & 31,61 & 31,63 & 31,40 & 0,2 \\
\hline 6 & 31,65 & 31,53 & 31,74 & 31,39 & 31,21 & 31,24 & 30,99 & 31,36 & 31,81 & 31,21 & 31,60 & 31,63 & 31,40 & 0,3 \\
\hline 12 & 31,64 & 31,53 & 31,7 & 31,38 & 31,21 & 31,25 & 30,99 & 31,36 & 31,81 & 31,25 & 31,60 & 31,63 & 31,40 & 0,2 \\
\hline 18 & 31,63 & 31,52 & 31,7 & 31,37 & 31,21 & 31,25 & 30,99 & 31,36 & 31,8 & 31,21 & 31,60 & 31,63 & 31,40 & 0,2 \\
\hline 24 & 31,64 & 31,52 & 31,73 & 31,38 & 31,21 & 31,25 & 30,98 & 31,36 & 31,81 & 31,23 & 31,60 & 31,63 & 31,40 & 0,2 \\
\hline 30 & 31,63 & 31,51 & 31,71 & 31,38 & 31,21 & 31,26 & 31,00 & 31,36 & 31,79 & 31,21 & 31,59 & 31,63 & 31,40 & 0,2 \\
\hline 36 & 31,63 & 31,5 & 31,73 & 31,37 & 31,21 & 31,25 & 31,00 & 31,36 & 31,79 & 31,23 & 31,59 & 31,63 & 31,40 & 0,2 \\
\hline 42 & 31,62 & 31,5 & 31,77 & 31,38 & 31,21 & 31,25 & 31,00 & 31,35 & 31,78 & 31,21 & 31,57 & 31,63 & 31,40 & 0,2 \\
\hline 48 & 31,62 & 31,47 & 31,73 & 31,37 & 31,21 & 31,26 & 31,00 & 31,35 & 31,78 & 31,21 & 31,57 & 31,63 & 31,40 & 0,2 \\
\hline 54 & 31,62 & 31,48 & 31,71 & 31,37 & 31,21 & 31,26 & 30,97 & 31,34 & 31,76 & 31,21 & 31,57 & 31,63 & 31,40 & 0,2 \\
\hline 60 & 31,62 & 31,48 & 31,71 & 31,36 & 31,21 & 31,25 & 30,98 & 31,33 & 31,76 & 31,21 & 31,58 & 31,63 & 31,40 & 0,2 \\
\hline 66 & 31,61 & 31,48 & 31,71 & 31,35 & 31,21 & 31,25 & 30,99 & 31,32 & 31,74 & 31,19 & 31,55 & 31,63 & 31,40 & 0,2 \\
\hline 72 & 31,62 & 31,48 & 31,72 & 31,37 & 31,21 & & & & & & & & & 0,2 \\
\hline 78 & 31,62 & 31,49 & 31,72 & 31,36 & 31,21 & 31,25 & 30,99 & 31,33 & 31,74 & 31,19 & 31,55 & 31,63 & 31,40 & 0,2 \\
\hline 84 & 31,61 & 31,47 & 31,71 & 31,36 & 31,22 & 31,25 & 30,99 & 31,33 & 31,75 & 31,19 & 31,56 & 31,63 & 31,40 & 0,2 \\
\hline 90 & 31,62 & 31,46 & 31,72 & 31,36 & 31,22 & 31,25 & 30,99 & 31,33 & 31,76 & 31,19 & 31,56 & 31,63 & 31,40 & 0,2 \\
\hline 96 & 31,62 & 31,46 & 31,72 & 31,35 & 31,22 & 31,24 & 30,99 & 31,33 & 31,75 & 31,17 & 31,54 & 31,63 & 31,40 & 0,2 \\
\hline 102 & 31,61 & 31,46 & 31,71 & 31,35 & 31,22 & 31,25 & 31,00 & 31,33 & 31,75 & 31,19 & 31,55 & 31,63 & 31,40 & 0,2 \\
\hline 108 & 31,61 & 31,46 & 31,73 & 31,35 & 31,22 & 31,25 & 31,02 & 31,32 & 31,74 & 31,18 & 31,54 & 31,63 & 31,40 & 0,2 \\
\hline 114 & 31,60 & 31,45 & 31,73 & 31,35 & 31,22 & 31,25 & 31,00 & 31,32 & 31,74 & 31,18 & 31,52 & 31,63 & 31,40 & 0,2 \\
\hline 120 & 31,59 & 31,45 & 31,71 & 31,35 & 31,22 & 31,25 & 30,99 & 31,33 & 31,75 & 31,19 & 31,55 & 31,64 & 31,40 & 0,2 \\
\hline 126 & 31,60 & 31,44 & 31,70 & 31,34 & 31,23 & 31,25 & 30,99 & 31,32 & 31,74 & 31,19 & 31,56 & 31,63 & 31,40 & 0,2 \\
\hline 132 & 31,60 & 31,45 & 31,71 & 31,35 & 31,22 & 31,25 & 31,01 & 31,32 & 31,74 & 31,02 & 31,56 & 31,63 & 31,40 & 0,2 \\
\hline 138 & 31,60 & 31,45 & 31,72 & 31,35 & 31,22 & 31,25 & 31,03 & 31,32 & 31,74 & 31,19 & 31,56 & 31,63 & 31,40 & 0,2 \\
\hline 144 & 31,62 & 31,46 & 31,72 & 31,36 & 31,22 & 31,25 & 31,05 & 31,32 & 31,73 & 31,20 & 31,55 & 31,63 & 31,40 & 0,2 \\
\hline 150 & 31,60 & 31,45 & 31,72 & 31,36 & 31,22 & 31,26 & 31,04 & 31,32 & 31,73 & 31,19 & 31,55 & 31,63 & 31,40 & 0,2 \\
\hline 156 & 31,60 & 31,44 & 31,72 & 31,35 & 31,22 & 31,26 & 31,03 & 31,32 & 31,74 & 31,19 & 31,54 & 31,63 & 31,40 & 0,2 \\
\hline 162 & 31,60 & 31,44 & 31,73 & 31,35 & 31,22 & 31,25 & 31,02 & 31,32 & 31,74 & 31,20 & 31,56 & 31,64 & 31,40 & 0,2 \\
\hline 168 & 31,60 & 31,43 & 31,70 & 31,35 & 31,21 & 31,24 & 31,01 & 31,32 & 31,73 & 31,18 & 31,53 & 31,63 & 31,40 & 0,2 \\
\hline 174 & 31,60 & 31,44 & 31,71 & 31,34 & 31,21 & 31,25 & 31,00 & 31,31 & 31,72 & 31,19 & 31,53 & 31,63 & 31,40 & 0,2 \\
\hline 180 & 31,59 & 31,44 & 31,72 & 31,35 & 31,21 & 31,25 & 31,02 & 31,31 & 31,73 & 31,17 & 31,53 & 31,63 & 31,40 & 0,2 \\
\hline
\end{tabular}

Fonte: Elaborada a partir dos dados experimentais (2007). 
Tabela 14Valores para temperatura de $40^{\circ} \mathrm{C}$.

\begin{tabular}{|c|c|c|c|c|c|c|c|c|c|c|c|c|c|c|}
\hline tempo(s) & TE2 & TE3 & TE4 & TE5 & TE6 & TE7 & TE8 & TE9 & TE10 & TE11 & TE12 & TE13 & média & $\begin{array}{l}\text { Desvio } \\
\text { padrão }\end{array}$ \\
\hline 0 & 42,01 & 41,69 & 41,95 & 41,7 & 41,36 & 41,39 & 41,34 & 41,16 & 41,58 & 41,04 & 41,08 & 41,8 & 41,50 & 0,3 \\
\hline 6 & 42,19 & 41,69 & 41,93 & 41,69 & 41,37 & 41,38 & 41,34 & 41,17 & 41,62 & 41,05 & 41,11 & 41,81 & 41,50 & 0,4 \\
\hline 12 & 42,25 & 41,70 & 41,93 & 41,69 & 41,36 & 41,39 & 41,34 & 41,17 & 41,62 & 41,07 & 41,12 & 41,81 & 41,50 & 0,4 \\
\hline 18 & 42,24 & 41,71 & 41,95 & 41,71 & 41,38 & 41,4 & 41,35 & 41,19 & 41,65 & 41,09 & 41,15 & 41,8 & 41,60 & 0,4 \\
\hline 24 & 42,22 & 41,71 & 41,95 & 41,71 & 41,38 & 41,39 & 41,35 & 41,2 & 41,66 & 41,09 & 41,16 & 41,8 & 41,60 & 0,3 \\
\hline 30 & 42,01 & 41,70 & 41,95 & 41,68 & 41,37 & 41,39 & 41,35 & 41,21 & 41,67 & 41,10 & 41,16 & 41,81 & 41,50 & 0,3 \\
\hline 36 & 42,00 & 41,69 & 41,94 & 41,68 & 41,37 & 41,39 & 41,35 & 41,21 & 41,69 & 41,14 & 41,18 & 41,81 & 41,50 & 0,3 \\
\hline 42 & 42,08 & 41,71 & 41,95 & 41,71 & 41,38 & 41,38 & 41,35 & 41,24 & 41,71 & 41,15 & 41,22 & 41,82 & 41,60 & 0,3 \\
\hline 48 & 42,00 & 41,71 & 41,96 & 41,71 & 41,39 & 41,39 & 41,34 & 41,25 & 41,71 & 41,16 & 41,22 & 41,82 & 41,60 & 0,3 \\
\hline 54 & 41,99 & 41,70 & 41,95 & 41,70 & 41,39 & 41,41 & 41,35 & 41,26 & 41,72 & 41,18 & 41,23 & 41,83 & 41,60 & 0,3 \\
\hline 60 & 42,19 & 41,69 & 41,93 & 41,68 & 41,37 & 41,40 & 41,35 & 41,28 & 41,73 & 41,19 & 41,26 & 41,82 & 41,60 & 0,3 \\
\hline 66 & 42,23 & 41,67 & 41,92 & 41,67 & 41,38 & 41,39 & 41,35 & 41,30 & 41,74 & 41,21 & 41,27 & 41,82 & 41,60 & 0,3 \\
\hline 72 & 42,18 & 41,68 & 41,93 & 41,69 & 41,37 & 41,37 & 41,35 & 41,31 & 41,75 & 41,22 & 41,29 & 41,81 & 41,60 & 0,3 \\
\hline 78 & 42,13 & 41,67 & 41,94 & 41,69 & 41,37 & 41,37 & 41,35 & 41,34 & 41,76 & 41,25 & 41,31 & 41,80 & 41,60 & 0,3 \\
\hline 84 & 42,22 & 41,69 & 41,94 & 41,69 & 41,38 & 41,38 & 41,34 & 41,36 & 41,77 & 41,25 & 41,32 & 41,80 & 41,60 & 0,3 \\
\hline 90 & 42,23 & 41,70 & 41,95 & 41,70 & 41,39 & 41,38 & 41,35 & 41,39 & 41,81 & 41,29 & 41,35 & 41,81 & 41,60 & 0,3 \\
\hline 96 & 42,23 & 41,70 & 41,95 & 41,71 & 41,37 & 41,39 & 41,35 & 41,42 & 41,83 & 41,3 & 41,36 & 41,81 & 41,60 & 0,3 \\
\hline 102 & 42,21 & 41,70 & 41,95 & 41,71 & 41,39 & 41,38 & 41,36 & 41,43 & 41,85 & 41,31 & 41,38 & 41,82 & 41,60 & 0,3 \\
\hline 108 & 42,15 & 41,69 & 41,94 & 41,69 & 41,38 & 41,36 & 41,35 & 41,44 & 41,86 & 41,31 & 41,39 & 41,81 & 41,60 & 0,3 \\
\hline 114 & 42,14 & 41,69 & 41,95 & 41,71 & 41,4 & 41,38 & 41,35 & 41,45 & 41,88 & 41,32 & 41,39 & 41,81 & 41,60 & 0,3 \\
\hline 120 & 42,21 & 41,68 & 41,95 & 41,71 & 41,39 & 41,38 & 41,35 & 41,45 & 41,88 & 41,33 & 41,40 & 41,81 & 41,60 & 0,3 \\
\hline 126 & 42,25 & 41,69 & 41,95 & 41,68 & 41,39 & 41,39 & 41,35 & 41,46 & 41,90 & 41,33 & 41,42 & 41,81 & 41,60 & 0,3 \\
\hline 132 & 42,16 & 41,70 & 41,94 & 41,72 & 41,37 & 41,39 & 41,35 & 41,46 & 41,92 & 41,35 & 41,41 & 41,82 & 41,60 & 0,3 \\
\hline 138 & 42,13 & 41,69 & 41,94 & 41,70 & 41,37 & 41,40 & 41,35 & 41,47 & 41,93 & 41,37 & 41,44 & 41,83 & 41,60 & 0,3 \\
\hline 144 & 42,16 & 41,68 & 41,94 & 41,70 & 41,37 & 41,39 & 41,35 & 41,48 & 41,94 & 41,37 & 41,43 & 41,83 & 41,60 & 0,3 \\
\hline 150 & 42,12 & 41,68 & 41,95 & 41,68 & 41,38 & 41,38 & 41,35 & 41,47 & 41,93 & 41,36 & 41,42 & 41,83 & 41,60 & 0,3 \\
\hline 156 & 42,18 & 41,70 & 41,94 & 41,69 & 41,37 & 41,37 & 41,34 & 41,47 & 41,93 & 41,39 & 41,44 & 41,84 & 41,60 & 0,3 \\
\hline 162 & 42,08 & 41,70 & 41,93 & 41,69 & 41,36 & 41,38 & 41,34 & 41,48 & 41,95 & 41,39 & 41,46 & 41,84 & 41,60 & 0,3 \\
\hline 168 & 42,14 & 41,68 & 41,94 & 41,68 & 41,36 & 41,39 & 41,34 & 41,48 & 41,94 & 41,37 & 41,44 & 41,83 & 41,60 & 0,3 \\
\hline 174 & 42,13 & 41,68 & 41,93 & 41,67 & 41,37 & 41,38 & 41,34 & 41,48 & 41,95 & 41,38 & 41,45 & 41,82 & 41,60 & 0,3 \\
\hline 180 & 42,07 & 41,67 & 41,93 & 41,67 & 41,38 & 41,39 & 41,35 & 41,48 & 41,94 & 41,39 & 41,45 & 41,82 & 41,60 & 0,3 \\
\hline
\end{tabular}

Fonte: Elaborada a partir dos dados experimentais (2007). 
Tabela 15. Valores para a temperatura de $50^{\circ} \mathrm{C}$.

\begin{tabular}{|c|c|c|c|c|c|c|c|c|c|c|c|c|c|c|}
\hline tempo(s) & TE2 & TE3 & TE4 & TE5 & TE6 & TE7 & TE8 & TE9 & TE10 & TE11 & TE12 & TE13 & Média & $\begin{array}{l}\text { desvio } \\
\text { padrão }\end{array}$ \\
\hline 0 & 51,43 & 51,13 & 51,38 & 51,11 & 50,27 & 50,44 & 50,32 & 50,54 & 51,02 & 50,43 & 50,54 & 50,56 & 50,80 & 0,4 \\
\hline 6 & 50,98 & 51,05 & 51,32 & 51,02 & 50,32 & 50,49 & 50,36 & 50,40 & 50,87 & 50,32 & 50,44 & 50,59 & 50,70 & 0,3 \\
\hline 12 & 51,02 & 50,87 & 51,14 & 50,85 & 50,37 & 50,55 & 50,41 & 50,33 & 50,81 & 50,23 & 50,34 & 50,61 & 50,60 & 0,3 \\
\hline 18 & 51,18 & 50,74 & 51,08 & 50,71 & 50,41 & 50,59 & 50,45 & 50,26 & 50,7 & 50,16 & 50,25 & 50,65 & 50,60 & 0,3 \\
\hline 24 & 50,86 & 50,61 & 50,94 & 50,6 & 50,47 & 50,64 & 50,5 & 50,16 & 50,61 & 50,10 & 50,18 & 50,72 & 50,50 & 0,3 \\
\hline 30 & 50,88 & 50,54 & 50,82 & 50,51 & 50,51 & 50,67 & 50,54 & 50,1 & 50,58 & 50,07 & 50,12 & 50,78 & 50,50 & 0,3 \\
\hline 36 & 50,63 & 50,4 & 50,7 & 50,38 & 50,55 & 50,71 & 50,59 & 50,09 & 50,55 & 50,04 & 50,09 & 50,82 & 50,50 & 0,3 \\
\hline 42 & 50,41 & 50,33 & 50,6 & 50,31 & 50,59 & 50,77 & 50,64 & 50,07 & 50,49 & 49,99 & 50,07 & 50,85 & 50,40 & 0,3 \\
\hline 48 & 50,60 & 50,27 & 50,57 & 50,23 & 50,63 & 50,82 & 50,69 & 50,04 & 50,42 & 49,95 & 50,03 & 50,89 & 50,40 & 0,3 \\
\hline 54 & 50,52 & 50,17 & 50,52 & 50,14 & 50,67 & 50,86 & 50,72 & 50,01 & 50,4 & 49,93 & 50,0 & 50,97 & 50,40 & 0,4 \\
\hline 60 & 50,48 & 50,11 & 50,45 & 50,11 & 50,72 & 50,9 & 50,76 & 49,98 & 50,37 & 49,9 & 49,99 & 51,04 & 50,40 & 0,4 \\
\hline 66 & 50,15 & 50,10 & 50,39 & 50,09 & 50,77 & 50,95 & 50,82 & 49,98 & 50,37 & 49,88 & 49,98 & 51,08 & 50,40 & 0,4 \\
\hline 72 & 50,56 & 50,09 & 50,35 & 50,08 & 50,81 & 51,01 & 50,87 & 49,95 & 50,35 & 49,88 & 49,95 & 51,10 & 50,40 & 0,4 \\
\hline 78 & 50,67 & 50,07 & 50,33 & 50,07 & 50,86 & 51,05 & 50,92 & 49,94 & 50,35 & 49,88 & 49,95 & 51,12 & 50,40 & 0,5 \\
\hline 84 & 50,42 & 50,06 & 50,32 & 50,05 & 50,93 & 51,09 & 50,97 & 49,94 & 50,35 & 49,87 & 49,95 & 51,17 & 50,40 & 0,5 \\
\hline 90 & 50,65 & 50,04 & 50,33 & 50,05 & 50,97 & 51,1 & 51,0 & 49,96 & 50,36 & 49,89 & 49,95 & 51,24 & 50,50 & 0,5 \\
\hline 96 & 50,23 & 50,04 & 50,33 & 50,05 & 50,99 & 51,11 & 51,03 & 49,97 & 50,37 & 49,89 & 49,97 & 51,29 & 50,40 & 0,5 \\
\hline 102 & 50,60 & 50,03 & 50,32 & 50,04 & 51,03 & 51,15 & 51,06 & 50,02 & 50,39 & 49,90 & 49,98 & 51,31 & 50,50 & 0,5 \\
\hline 108 & 50,62 & 50,03 & 50,32 & 50,04 & 51,06 & 51,21 & 51,10 & 50,03 & 50,41 & 49,95 & 50,01 & 51,34 & 50,50 & 0,5 \\
\hline 114 & 49,94 & 50,04 & 50,33 & 50,05 & 51,09 & 51,26 & 51,15 & 50,06 & 50,47 & 49,98 & 50,04 & 51,36 & 50,50 & 0,6 \\
\hline 120 & 50,42 & 50,06 & 50,34 & 50,07 & 51,14 & 51,29 & 51,19 & 50,08 & 50,52 & 50,01 & 50,07 & 51,37 & 50,50 & 0,5 \\
\hline 126 & 50,18 & 50,07 & 50,35 & 50,09 & 51,21 & 51,36 & 51,24 & 50,09 & 50,55 & 50,04 & 50,08 & 51,42 & 50,60 & 0,6 \\
\hline 132 & 50,21 & 50,09 & 50,39 & 50,10 & 51,28 & 51,43 & 51,29 & 50,10 & 50,58 & 50,06 & 50,11 & 51,52 & 50,60 & 0,6 \\
\hline 138 & 50,37 & 50,09 & 50,42 & 50,10 & 51,34 & 51,49 & 51,34 & 50,14 & 50,6 & 50,1 & 50,14 & 51,59 & 50,60 & 0,6 \\
\hline 144 & 50,15 & 50,10 & 50,49 & 50,12 & 51,38 & 51,57 & 51,41 & 50,20 & 50,63 & 50,12 & 50,18 & 51,63 & 50,70 & 0,6 \\
\hline 150 & 50,15 & 50,13 & 50,54 & 50,16 & 51,45 & 51,64 & 51,48 & 50,26 & 50,68 & 50,16 & 50,22 & 51,74 & 50,70 & 0,7 \\
\hline 156 & 50,37 & 50,18 & 50,57 & 50,23 & 51,50 & 51,69 & 51,53 & 50,30 & 50,78 & 50,23 & 50,3 & 51,81 & 50,80 & 0,6 \\
\hline 162 & 50,14 & 50,25 & 50,59 & 50,29 & 51,56 & 51,73 & 51,59 & 50,33 & 50,81 & 50,26 & 50,33 & 51,85 & 50,80 & 0,7 \\
\hline 168 & 50,14 & 50,30 & 50,62 & 50,34 & 51,61 & 51,77 & 51,64 & 50,37 & 50,86 & 50,32 & 50,38 & 51,87 & 50,90 & 0,7 \\
\hline 174 & 51,22 & 50,34 & 50,71 & 50,38 & 51,66 & 51,82 & 51,70 & 50,43 & 50,9 & 50,38 & 50,44 & 51,92 & 51,00 & 0,6 \\
\hline 180 & 50,26 & 50,38 & 50,79 & 50,43 & 51,70 & 51,83 & 51,74 & 50,5 & 50,96 & 50,42 & 50,48 & 51,98 & 51,00 & 0,7 \\
\hline
\end{tabular}

Fonte: Elaborada a partir dos dados experimentais (2007). 
Tabela 16. Valores para a temperatura de $60^{\circ} \mathrm{C}$.

\begin{tabular}{|c|c|c|c|c|c|c|c|c|c|c|c|c|c|c|}
\hline tempo(s) & TE2 & TE3 & TE4 & TE5 & TE6 & TE7 & TE8 & TE9 & TE10 & TE11 & TE12 & TE13 & média & $\begin{array}{l}\text { desvio } \\
\text { padrão }\end{array}$ \\
\hline 0 & 51,51 & 61,24 & 61,74 & 61,39 & 60,94 & 61,12 & 61,06 & 61,19 & 61,53 & 61,04 & 61,1 & 61,03 & 61,20 & 0,2 \\
\hline 6 & 61,55 & 61,26 & 61,74 & 61,39 & 60,95 & 61,15 & 61,05 & 61,18 & 61,52 & 61,01 & 61,08 & 61,03 &, 20 & 0,3 \\
\hline 12 & 61,57 & 61,27 & 61,76 & 61,44 & 60,95 & 61,14 & 61,05 & 61,19 & 61,52 & 61,02 & 61,08 & 61,03 & 1,30 & 0,3 \\
\hline 18 & 61,59 & 61,27 & 61,75 & 61,42 & 60,95 & 61,14 & 61,04 & 61,19 & 61,53 & 61,03 & 61,09 & 61,03 & 61,30 & 0,3 \\
\hline 24 & 61,59 & 61,28 & 61,74 & 61,43 & 60,96 & 61,16 & 61,04 & 61,19 & 61,52 & 61,03 & 61,09 & 61,05 & 1,30 & 0,3 \\
\hline 30 & 61,61 & 61,28 & 61,78 & 61,46 & 60,96 & 61,17 & 61,05 & 61,21 & 61,53 & 61,04 & 61,10 & 61,05 & 61,30 & 0,3 \\
\hline 36 & 61,60 & 61,29 & 61,77 & 61,45 & 60,94 & 61,12 & 61,04 & 61,23 & 61,54 & 61,05 & 61,11 & 61,04 & 61,30 & 0,3 \\
\hline 42 & 61,60 & 61,28 & 61,75 & 61,43 & 60,94 & 61,14 & 61,04 & 61,23 & 61,55 & 61,07 & 61,12 & 61,05 & 61,30 & 0,3 \\
\hline 48 & 61,60 & 61,29 & 61,79 & 61,48 & 60,95 & 61,13 & 61,04 & 61,21 & 61,54 & 61,06 & 61,12 & 61,04 & 1,30 & 0,3 \\
\hline 54 & 61,62 & 61,3 & 61,80 & 61,49 & 60,95 & 61,14 & 61,04 & 61,21 & 61,54 & 61,07 & 61,12 & 61,05 & 1,30 & 0,3 \\
\hline 60 & 61,62 & 61,31 & 61,80 & 61,49 & 60,92 & 61,13 & 61,02 & 61,22 & 61,54 & 61,04 & 61,10 & 61,05 & 61,30 & 0,3 \\
\hline 66 & 61,64 & 61,31 & 61,79 & 61,48 & 60,92 & 61,12 & 61,02 & 61,21 & 61,54 & 61,04 & 61,09 & 61,05 & 61,30 & 0,3 \\
\hline 72 & 61,62 & 61,31 & 61,80 & 61,49 & 60,94 & 61,13 & 61,02 & 61,19 & 61,53 & 61,06 & 61,10 & 61,05 & 61,30 & 0,3 \\
\hline 78 & 61,62 & 61,31 & 61,78 & 61,48 & 60,94 & 61,13 & 61,03 & 61,22 & 61,55 & 61,06 & 61,12 & 61,05 & 61,30 & 0,3 \\
\hline 84 & 61,62 & 61,31 & 61,78 & 61,49 & 60,93 & 61,12 & 61,02 & 61,23 & 61,55 & 61,05 & 61,12 & 61,05 & 1,30 & 0,3 \\
\hline 90 & 61,63 & 61,31 & 61,80 & 61,5 & 60,93 & 61,12 & 61,02 & 61,22 & 61,54 & 61,04 & 61,10 & 61,04 & 1,30 & 0,3 \\
\hline 96 & 61,63 & 61,31 & 61,79 & 61,48 & 60,92 & 61,12 & 61,02 & 61,22 & 61,54 & 61,03 & 61,10 & 61,03 & 1,30 & 0,3 \\
\hline 102 & 61,65 & 61,3 & 61,78 & 61,48 & 60,9 & 61,1 & 61,01 & 61,21 & 61,54 & 61,03 & 61,10 & 61,03 & 1,30 & 0,3 \\
\hline 108 & 61,63 & 61,31 & 61,79 & 61,48 & 60,91 & 61,12 & 61,01 & 61,22 & 61,55 & 61,05 & 61,12 & 61,03 & 1,30 & 0,3 \\
\hline 114 & 61,62 & 61,3 & 61,76 & 61,45 & 60,93 & 61,15 & 61,02 & 61,20 & 61,54 & 61,05 & 61,11 & 61,03 & 1,30 & 0,3 \\
\hline 120 & 61,63 & 61,3 & 61,80 & 61,48 & 60,94 & 61,13 & 61,02 & 61,20 & 61,54 & 61,05 & 61,11 & 61,04 & 1,30 & 0,3 \\
\hline 126 & 61,62 & 61,29 & 61,77 & 61,45 & 60,93 & 61,11 & 61,02 & 61,19 & 61,53 & 61,04 & 61,09 & 61,04 & 1,30 & 0,3 \\
\hline 132 & 61,59 & 61,3 & 61,77 & 61,47 & 60,94 & 61,14 & 61,02 & 61,19 & 61,53 & 61,06 & 61,11 & 61,04 & 1,30 & 0,3 \\
\hline 138 & 61,60 & 61,29 & 61,76 & 61,43 & 60,92 & 61,12 & 61,01 & 61,19 & 61,53 & 61,03 & 61,10 & 61,05 & 61,30 & 0,3 \\
\hline 144 & 61,60 & 61,29 & 61,78 & 61,45 & 60,95 & 61,13 & 61,02 & 61,21 & 61,54 & 61,04 & 61,10 & 61,05 & 61,30 & 0,3 \\
\hline 150 & 61,60 & 61,29 & 61,77 & 61,45 & 60,94 & 61,10 & 61,03 & 61,23 & 61,54 & 61,04 & 61,11 & 61,05 & 61,30 & 0,3 \\
\hline 156 & 61,58 & 61,28 & 61,76 & 61,43 & 60,93 & 61,10 & 61,03 & 61,24 & 61,55 & 61,06 & 61,12 & 61,05 & 61,30 & 0,3 \\
\hline 162 & 61,60 & 61,28 & 61,76 & 61,44 & 60,93 & 61,11 & 61,03 & 61,23 & 61,54 & 61,06 & 61,11 & 61,05 & 61,30 & 0,3 \\
\hline 168 & 61,57 & 61,28 & 61,75 & 61,41 & 60,94 & 61,12 & 61,02 & 61,22 & 61,54 & 61,04 & 61,10 & 61,05 & 61,30 & 0,3 \\
\hline 174 & 61,56 & 61,28 & 61,75 & 61,41 & 60,91 & 61,12 & 61,00 & 61,22 & 61,55 & 61,04 & 61,11 & 61,04 & 61,20 & 0,3 \\
\hline 180 & 61,57 & 61,28 & 61,73 & 61,35 & 60,9 & 61,11 & 60,98 & 61,22 & 61,54 & 61,05 & 61,11 & 61,03 & 61,20 & 0,3 \\
\hline
\end{tabular}

Fonte: Elaborada a partir dos dados experimentais (2007).

Para calibração dos canais de aquisição, os termômetros foram imersos em um banho a álcool a $0,0{ }^{\circ} \mathrm{C}$, utilizando o mesmo equipamento anterior. As leituras foram feitas através de um pirômetro marca OMRON, modelo E5AX. Os termômetros foram mergulhados um a um no banho com um tempo de espera de cinco minutos para o equilíbrio térmico. Após esse tempo, eram realizadas as leituras no pirômetro. A Tabela 17 mostra os valores obtidos durante o banho: na coluna 2 os valores obtidos pelos termômetros a $0,0{ }^{\circ} \mathrm{C}$, e na coluna 3 , a temperatura ambiente.

O cálculo das médias e dos desvios padrão, devidamente arredondado, apresentou os seguintes resultados: 
Para a temperatura de $30^{\circ} \mathrm{C} \quad \bar{T}=31,4 \pm 0,2{ }^{\circ} \mathrm{C}$

Para a temperatura de $40^{\circ} \mathrm{C} \quad \bar{T}=41,6 \pm 0,3{ }^{\circ} \mathrm{C}$

Para a temperatura de $50^{\circ} \mathrm{C} \quad \bar{T}=50,6 \pm 0,5{ }^{\circ} \mathrm{C}$

Para a temperatura de $60^{\circ} \mathrm{C} \quad \bar{T}=61,3 \pm 0,3{ }^{\circ} \mathrm{C}$

Tabela 17. Valores a $0,0^{\circ} \mathrm{C}$ apresentados pelos termômetros.

\begin{tabular}{cccc}
\hline termômetro & temp. no pirômetro $\left({ }^{\circ} \mathrm{C}\right)$ & temp. amb. pirômetro ${ }^{\circ} \mathrm{C}$ & resistência ôhmica \\
\hline 2 & 0,8 & 22,8 & 100,5 \\
3 & 0,8 & 23,2 & 100,6 \\
4 & 0,9 & 23,0 & 100,6 \\
5 & 0,8 & 21,7 & 100,6 \\
6 & 0,6 & 24,2 & 100,7 \\
7 & 0,2 & 23,0 & 100,3 \\
8 & 0,3 & 22,8 & 100,2 \\
9 & 0,5 & 22,9 & 100,3 \\
10 & 0,4 & 22,3 & 100,3 \\
11 & 0,7 & 22,3 & 100,4 \\
12 & 0,4 & 22,3 & 100,4 \\
13 & 0,4 & 22,2 & 100,5 \\
14 & 1,5 & 23,8 & 100,8 \\
\hline
\end{tabular}

Fonte: Elaborada a partir dos dados experimentais (2007).

Os resultados indicam que o sistema de aquisição, juntamente com os termômetros, tende a desviar a leitura para aproximadamente $+1,4{ }^{\circ} \mathrm{C}$ além dos valores indicados pelo banho. Para verificar qual componente, sistema de aquisição ou termômetros estavam desviando os valores de temperatura, foi feito um outro teste, desta vez sem a presença do sistema de aquisição. Para tanto, utilizou-se um pirômetro para realizar as leituras de temperatura. Nessa situação, o banho foi levado à temperatura de $0,0^{\circ} \mathrm{C}$ e calibrado com termômetro de bulbo de vidro. Feito isso, cada termômetro foi levado ao banho e sua leitura observada no pirômetro. A Tabela 17 mostra os valores colhidos.

Para a temperatura de $0,0^{\circ} \mathrm{C}$ foi obtido o valor de $\bar{T}=0,6 \pm 0,3{ }^{\circ} \mathrm{C}$. Esses resultados mostram um valor de $0,6{ }^{\circ} \mathrm{C}$ acima da temperatura do banho. A linearidade mostrou-se adequada entre o valor adquirido e o valor indicado pelo banho. O gráfico 150 mostra a relação entre os valores. 


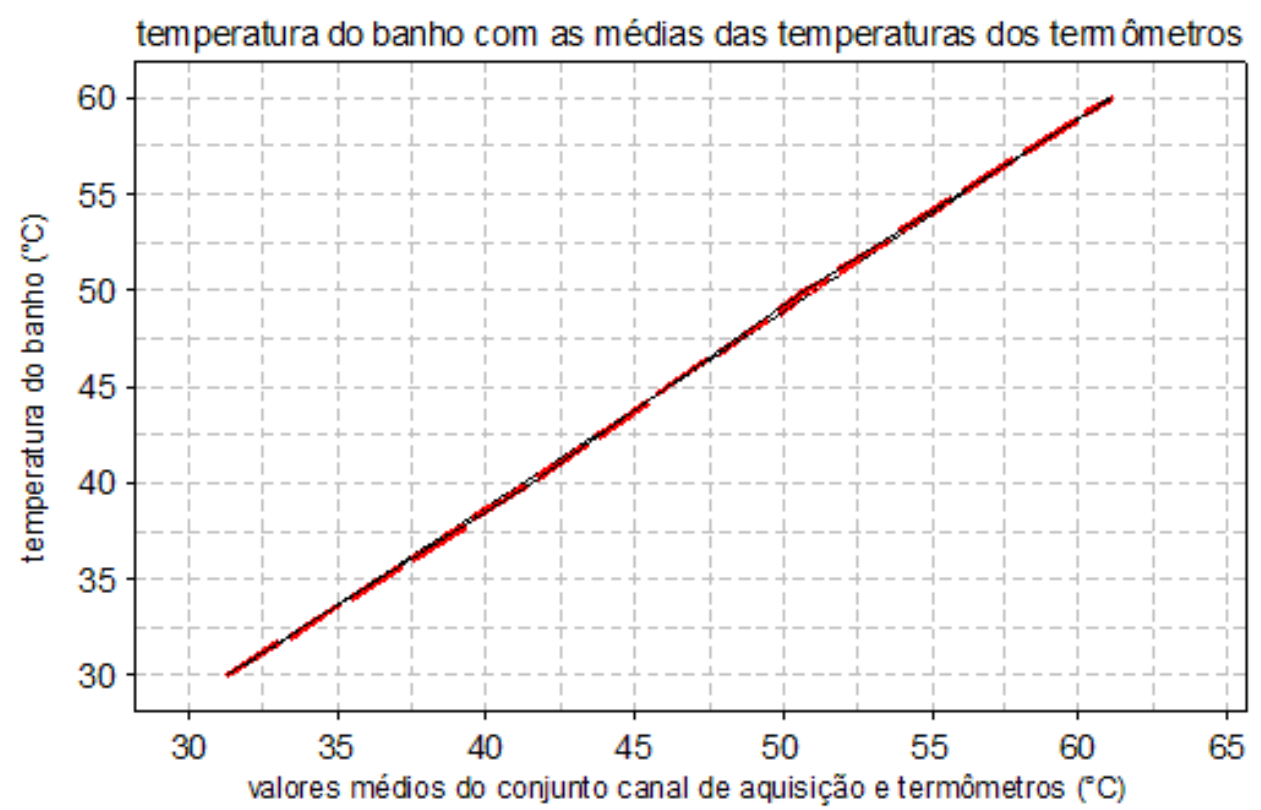

Gráfico 150. Comparação entre os valores de temperatura do banho com os valores médios de temperatura indicados acima.

Fonte: Elaborado a partir dos dados experimentais (2008).

A segunda etapa foi necessária para verificação dos valores apresentados pelo sistema de aquisição mais termômetros e pelo sistema pirômetro mais termômetros. Para tanto, o termômetro TE5, um termômetro de teste T1, e um termômetro padrão foram colocados nas cavidades do forno e submetidos à variação de temperatura de $35,0{ }^{\circ} \mathrm{C}$ até 65,0 ${ }^{\circ} \mathrm{C}$, com tempo de estabilização de 15 minutos para cada leitura. $\mathrm{O}$ teste ainda serviu para calibração do pirômetro que servirá para calibração das leituras de temperatura durante os testes efetuados na placa de concreto. A fotografia 36 mostra a disposição dos equipamentos utilizados durante a calibração. 


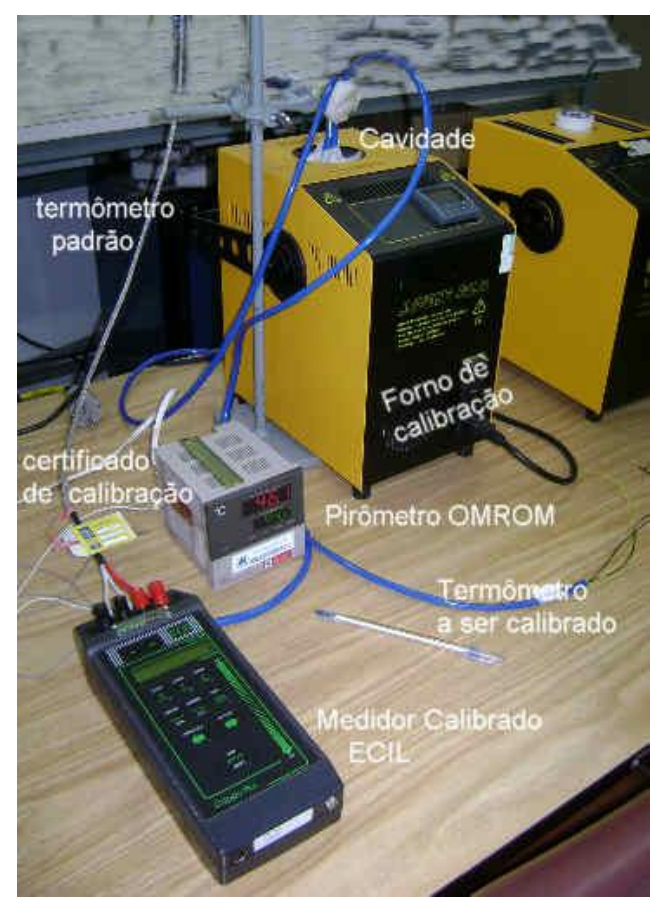

Fotografia 36. Disposição dos equipamentos utilizados para calibração do termômetro e do pirômetro.

Fonte: Acervo próprio (2008).

Nesse procedimento de calibração, o forno foi sendo graduado nas temperaturas indicadas e, a cada vez que o patamar era atingido, as leituras das temperaturas eram realizadas pelo termômetro padrão no equipamento de medida (cappo plus), a seguir eram realizadas as leituras do termômetro TE5 no mesmo equipamento, enquanto o termômetro de teste TE1 mantinha-se conectado ao pirômetro. Esse procedimento foi feito para todas as medidas no intervalo especificado. Os valores obtidos estão indicados na Tabela 18.

Tabela 18Valores comparativos para calibração do sistema de aquisição.

\begin{tabular}{lrrrr}
\hline Forno & $35^{\circ} \mathrm{C}$ & $45^{\circ} \mathrm{C}$ & $55^{\circ} \mathrm{C}$ & $65^{\circ} \mathrm{C}$ \\
\hline Pirômetro + T de teste & 36,4 & 46,1 & 56,1 & 66,1 \\
Cappo Plus + TE5 & 35,6 & 45,4 & 55,3 & 65,2 \\
Cappo Plus + Padrão & 35,8 & 45,6 & 55,6 & 65,5 \\
\hline \multicolumn{7}{l}{ Fonte: Elaborada a partir dos dados experimentais (2008). }
\end{tabular}

Observa-se que ocorre um desvio de aproximadamente $0,3{ }^{\circ} \mathrm{C}$ entre a leitura padrão e a leitura efetuada pelo TE5. Isso indica que o desvio esperado para os outros termômetros, devido à linearidade dada pelo gráfico150, também seja do mesmo valor. 
Quanto ao pirômetro, foi realizada uma simulação de temperatura por meio do equipamento Cappo plus. Os dois equipamentos foram conectados conforme mostra a fotografia 37 por meio de fios e as temperaturas de $0,0^{\circ} \mathrm{C}$ até $65,0^{\circ} \mathrm{C}$ foram simuladas. Os resultados encontram-se na Tabela 19.

Tabela 19 Valores simulados para calibração do pirômetro.

\begin{tabular}{lllllll}
\hline Valor simulado & $0,0^{\circ} \mathrm{C}$ & $20,{ }^{\circ} \mathrm{C}$ & $35,0^{\circ} \mathrm{C}$ & $45,0^{\circ} \mathrm{C}$ & $55,0^{\circ} \mathrm{C}$ & $65,0^{\circ} \mathrm{C}$ \\
\hline Cappo Plus & 0 & 20 & 35 & 45 & 55 & 65 \\
Pirômetro & 0,4 & 20,3 & 35,3 & 45,4 & 55,4 & 65,4 \\
\hline
\end{tabular}

Fonte: Elaborada a partir dos dados experimentais (2008).

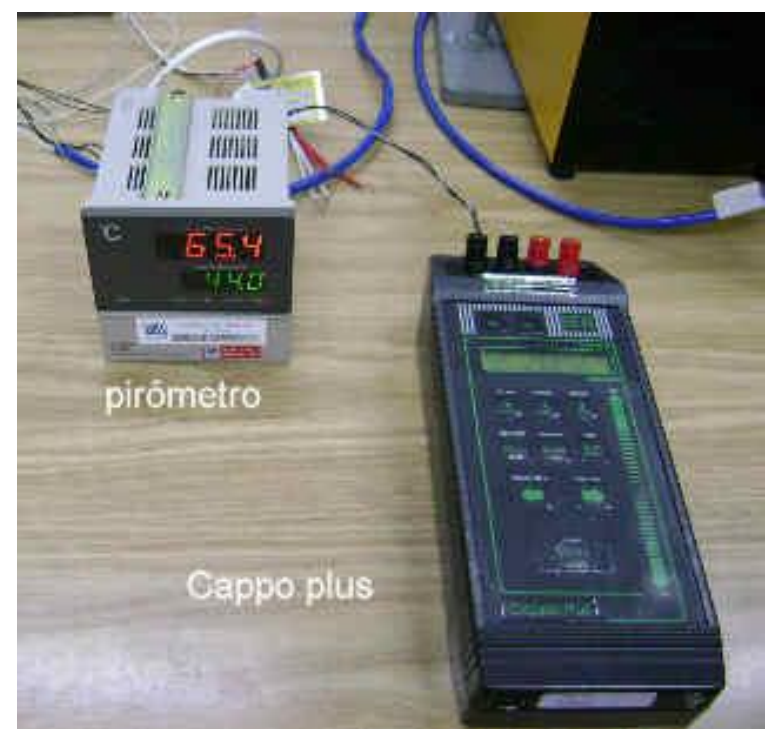

Fotografia 37. Ligação entre o medidor de simulação Cappo plus e o pirômetro.

Fonte: Elaborada a partir dos dados experimentais (2008).

A observação da Tabela 19 mostra que a leitura do pirômetro tem um desvio de $0,4^{\circ} \mathrm{C}$ em relação ao medidor padrão.

$\mathrm{O}$ sistema de aquisição deverá ser ajustado para apresentar as medidas com $1,3^{\circ} \mathrm{C}$ a menos nos valores indicados no momento da aquisição.

O cálculo das médias e dos desvios padrão, devidamente arredondado e com a correção efetuada, apresentaram os seguintes resultados:

Para a temperatura de $30{ }^{\circ} \mathrm{C}$

$\bar{T}=30,1 \pm 0,2^{\circ} \mathrm{C}$

Para a temperatura de $40{ }^{\circ} \mathrm{C}$

$\bar{T}=40,3 \pm 0,3{ }^{\circ} \mathrm{C}$

Para a temperatura de $50{ }^{\circ} \mathrm{C}$

$\bar{T}=49,3 \pm 0,5^{\circ} \mathrm{C}$ 
Para a temperatura de $60{ }^{\circ} \mathrm{C} \quad \bar{T}=60,0 \pm 0,3{ }^{\circ} \mathrm{C}$

Para o sistema ADS 500, os canais de aquisição foram calibrados pelo fabricante, e em conjunto com os termômetros, não apresentando diferenças significativas daquelas apresentadas acima.

\section{CONSTRUÇÃO DO SENSOR}

Para a construção do sensor, foi utilizado o método de ligação a três fios com a finalidade de compensar erros relativos à temperatura e resistência dos fios. O sensor Pt100 foi soldado em uma placa de circuito impresso de $0,5 \mathrm{~mm}$, na qual os três fios de cobre 0,326 $\mathrm{mm}^{2}$ (AWG 22) também foram soldados. O conjunto foi embutido dentro de um tubo de cobre e preenchido com pasta térmica. Os fios foram protegidos contra a umidade com uma capa de PVC (espagueti) e, na junção do conjunto, a capa foi vestida sobre o tubo de cobre para garantir a vedação. Em cima da capa foi colocada uma camada de silicone em pasta, que foi pressionada por um material termoretrátil da Raychem ${ }^{\circledR}$. O desenho 48 mostra o corte transversal do sensor e seus componentes.

Algumas incertezas, relativas à construção dos sensores não foram objeto de avaliação, tais como o efeito do tempo de resposta na leitura da temperatura (medido e mostrado no gráfico 151), influência da capacidade térmica do sensor perante o banho térmico, auto-aquecimento, expansão térmica, resistência de isolação e resistência dos condutores (este compensado pela ligação em três fios). Esses aspectos tendem a influenciar na calibração e os desvios devido ao processo de fabricação do sensor.

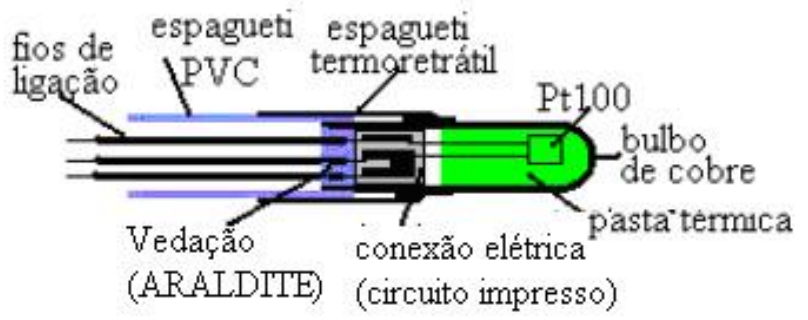

Desenho 48. Vista em corte transversal do termômetro. Fonte: Acervo próprio (2008). 


\section{SENSIBILIDADE DO SENSOR}

O termômetro foi colocado em um banho à temperatura de $60,0^{\circ} \mathrm{C}$, partindo da temperatura ambiente, com o sistema de aquisição realizando quinhentas amostras por segundo. A operação foi repetida três vezes e o resultado está plotado no gráfico 151, o qual mostra comportamento do termômetro quando submetido a variação brusca de temperatura.

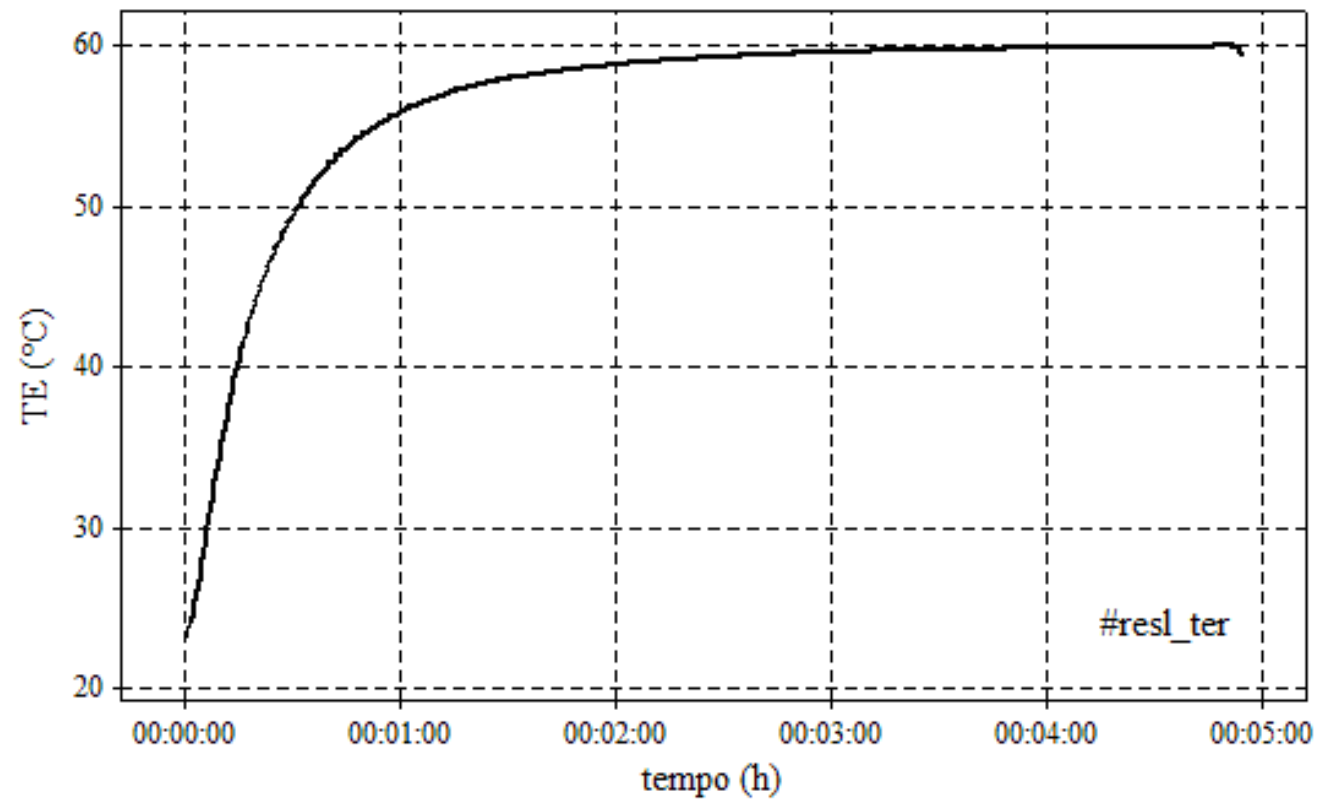

Gráfico 151. Comportamento dos termômetros para variação de temperatura. Fonte: Elaborado a partir dos dados experimentais (2008).

Tomando como base a temperatura inicial e aquela a meio segundo, pode-se dizer que os termômetros respondem a $1,0^{\circ} \mathrm{C} / \mathrm{s}$. Essa resposta foi suficiente para as condições às quais os termômetros ficaram sujeitos. 


\section{APÊNDICE C - CONSTRUÇÃO E INSTRUMENTAÇÃO DA PLACA DE CONCRETO DO PAVIMENTO 1}

A metodologia aplicada na confecção da placa do pavimento 2 foi adquirida através dos experimentos realizados durante a construção da placa do pavimento 1. A placa foi construída de CCP e seguiu os procedimentos normais para dimensionamento de um pavimento comum, encontrado em pisos industriais e pavimentos rodoviários. Ou seja, a estrutura 1,2 m por 1,2 $\mathrm{m}$ foi composta por três camadas de um solo siltroso com $0,1 \mathrm{~m}$ de espessura e atingiu um CBR de 10\%, uma base de CCP com espessura de 0,1 m com resistência de 20,0 MPa e uma placa (revestimento) de $0.1 \mathrm{~m}$ que, conforme projetada, atingiu uma resistência de $30,0 \mathrm{MPa}$ aos 28 dias. O conjunto foi apoiado sobre o piso do laboratório de ensaios mecânicos da EEUPM durante toda a fase de testes. Os dados técnicos do ensaio à compressão e os ensaios de solo foram realizados nos laboratórios de materiais de construção e laboratório de mecânica do solo.

A fotografia 38 mostra o molde da placa já com o solo colocado e compactado. O exame de CBR foi realizado na escolha do solo. A correlação do módulo de reação do subleito foi feita conforme a prática IP-07 utilizada pela prefeitura da cidade de São Paulo (SÃO PAULO, 2002).

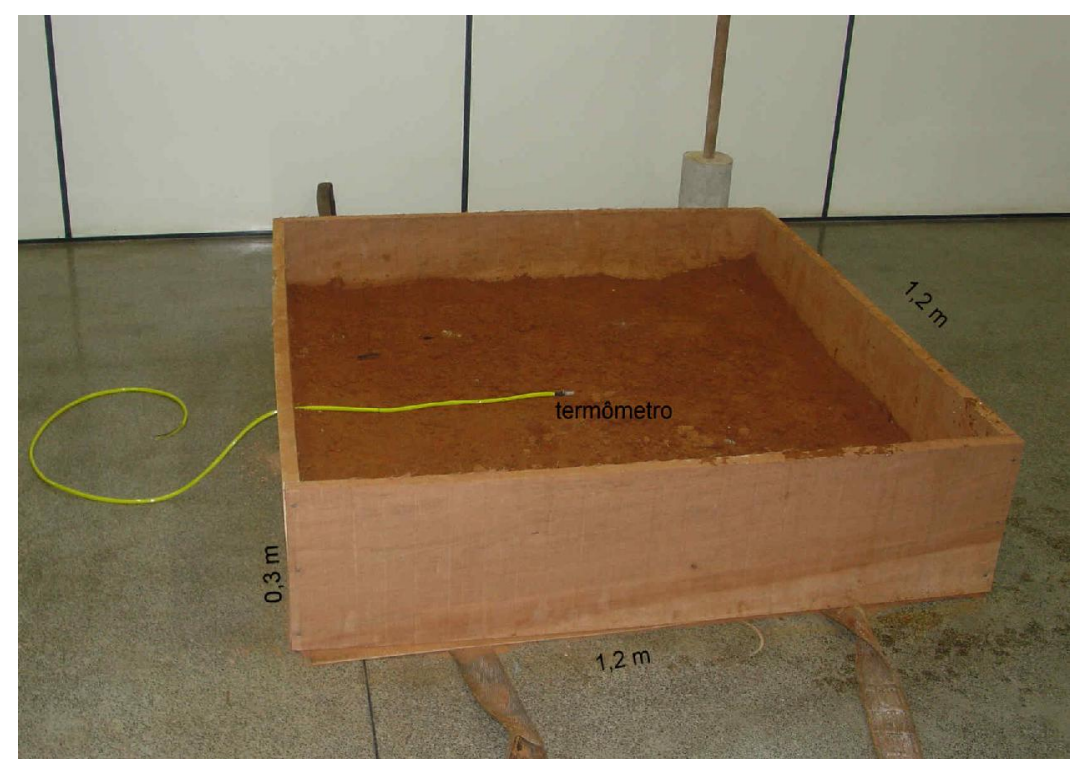

Fotografia 38. Aspecto do molde da placa já com o solo compactado e um termômetro no centro da placa para leitura da temperatura no subleito.

Fonte: Acervo próprio (2006). 
A placa foi feita com concreto de cimento classe CPII-20 e apoiada sobre o subleito. A fotografia 39 mostra o subleito colocado e devidamente adensado. A cura foi realizada mantendo-se a placa coberta com lona plástica, para evitar a perda de água por evaporação.

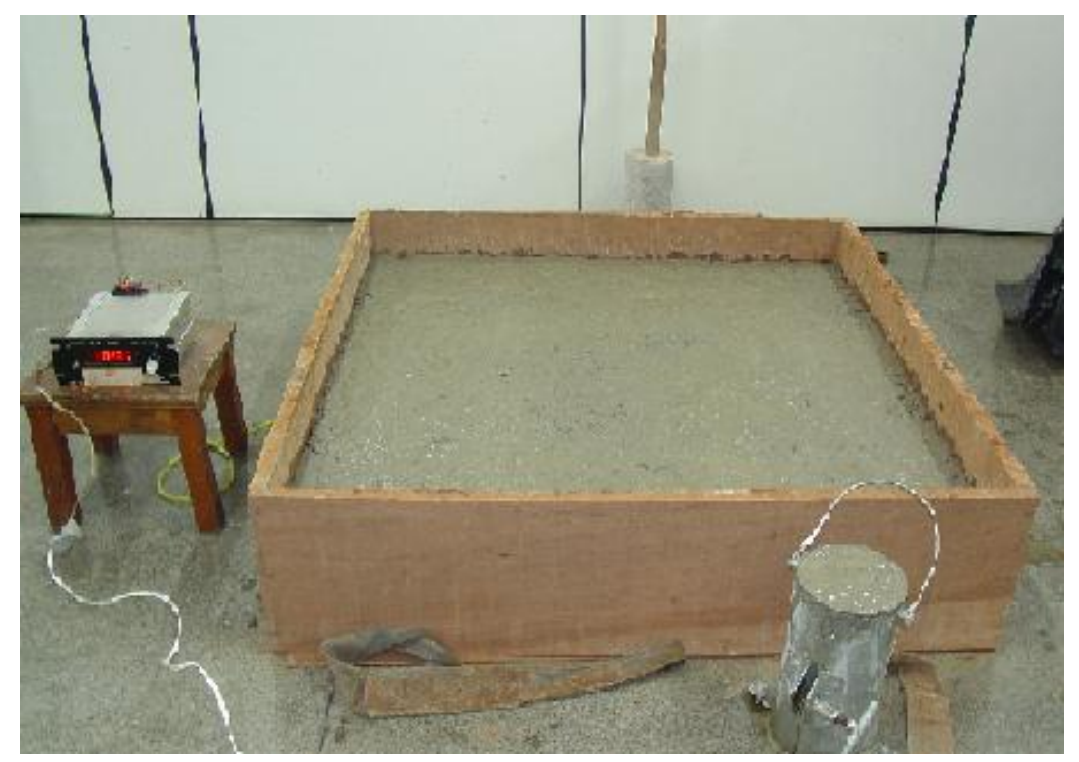

Fotografia 39. Colocação da base da placa. Fonte: Acervo próprio (2006).

Após a cura da base, procedeu-se à confecção da placa e, como o estudo está baseado em uma placa não aderida, foi colocada sobre a base uma capa plástica para evitar a aderência da base com à placa. As laterais do molde foram furadas para a passagem dos cabos dos sensores e um reforço foi realizado para evitar a deformação do molde. A fotografia 40 mostra a disposição dos sensores sobre a lona plástica. Os sensores foram colocados em lugares estratégicos e devidamente mapeados conforme indica o desenho 48. A fixação dos sensores, tanto de deformação como de temperatura, foi realizada por meio de "cavaletes" simplesmente apoiados sobre a base, como mostram as fotografias 41 e 42 . Os sensores foram fixados por meio de presilhas de plástico tire up (enforca gato ou cable ties) nos cavaletes. $\mathrm{O}$ desenho 49 mostra a secção transversal da placa com a denominação utilizada no trabalho, bem como as dimensões. 


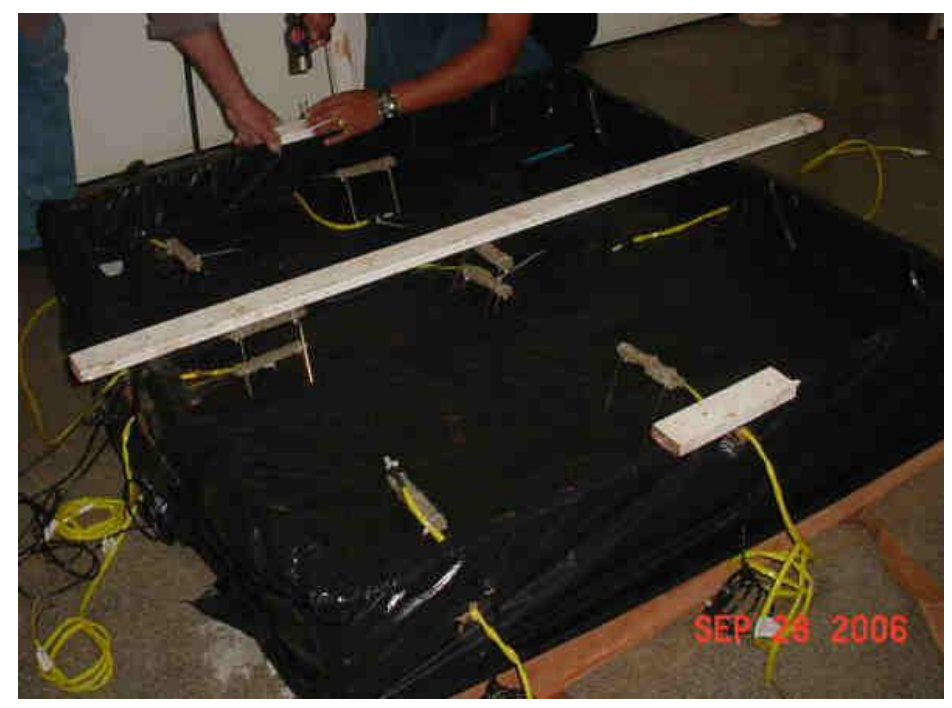

Fotografia 40. Colocação da manta plástica para evitar a aderência da placa de concreto. Vista do posicionamento dos sensores na placa e colocação de reforços nas paredes do molde. Fonte: Acervo próprio (2006).

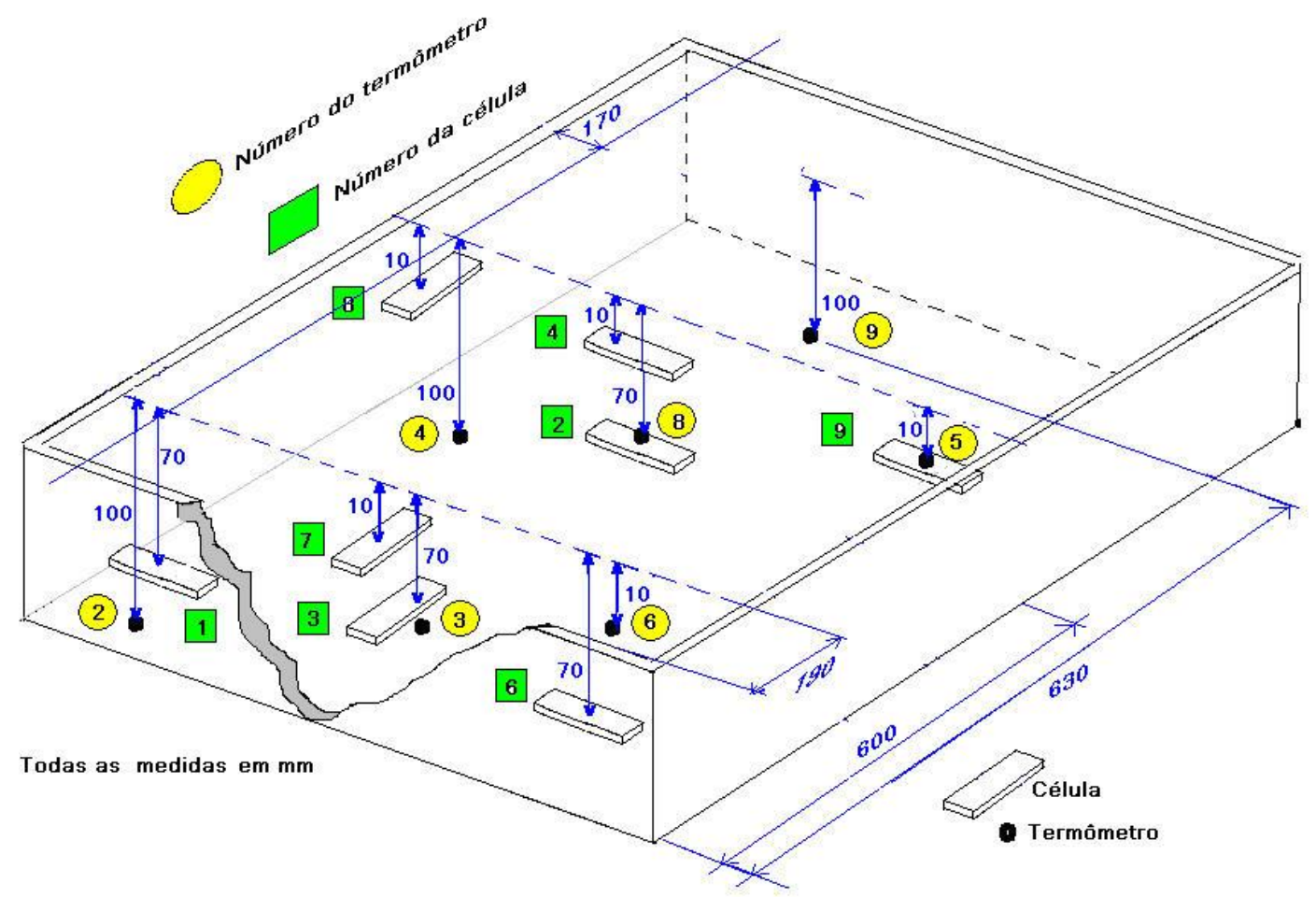

Desenho 49. Mapa da localização dos sensores internos na placa.

Fonte: Acervo próprio (2006). 


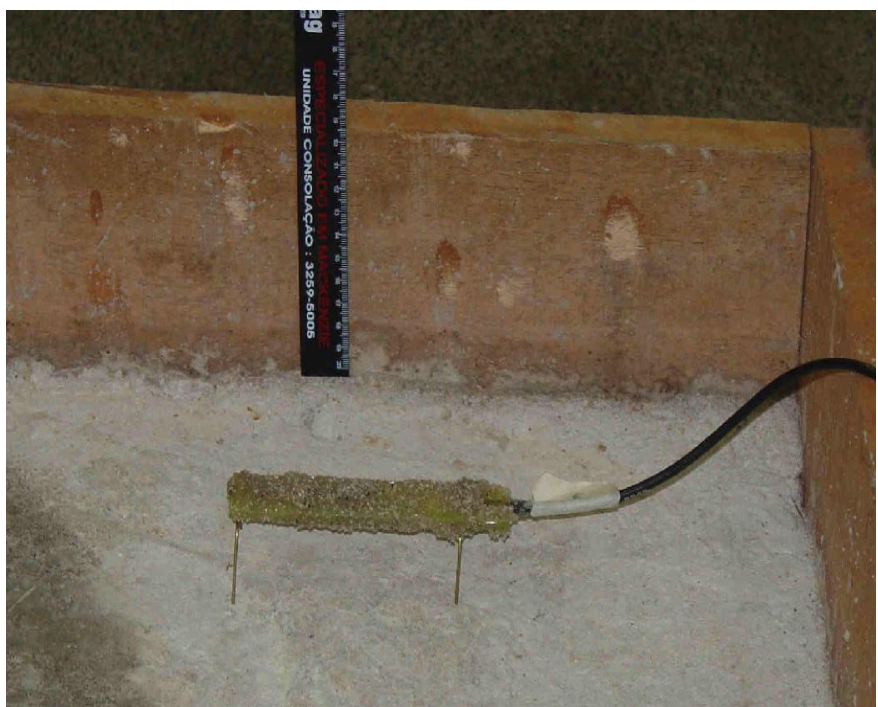

Fotografia 41. Vista de um sensor de deformação apoiado sobre um cavalete e, no detalhe, mostrando a dimensão da capa de revestimento a ser colocada.

Fonte: Acervo próprio (2006).

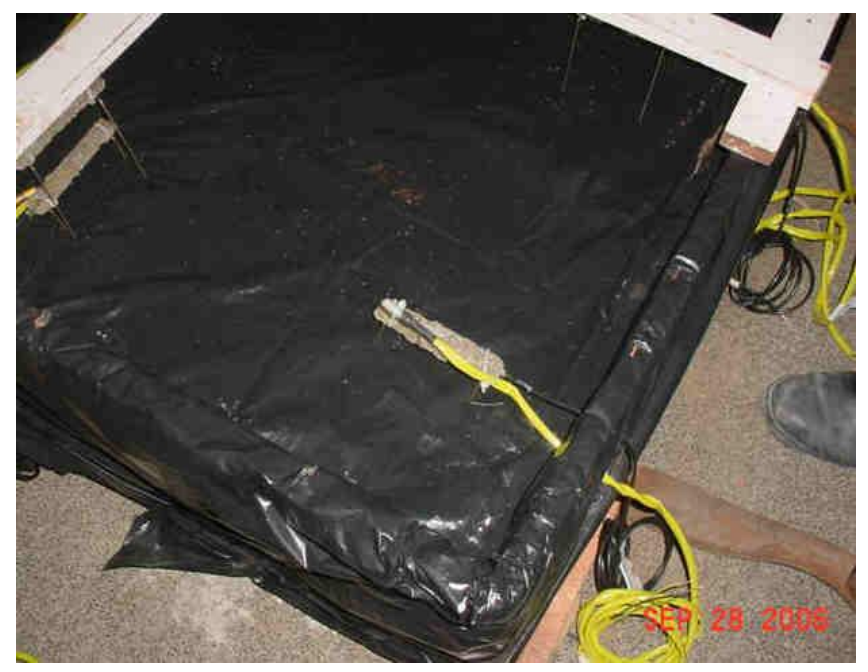

Fotografia 42. Detalhe de um conjunto termômetro e célula de deformação presos no cavalete. Fonte: Acervo próprio (2006).

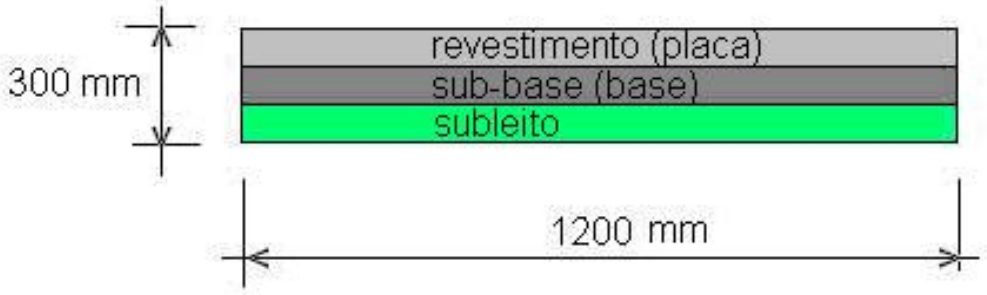

Desenho 50. Dimensões da placa de concreto. Fonte: Acervo próprio (2006). 
Durante a concretagem, foi realizada uma pré-cobertura dos sensores para evitar o deslocamento durante os trabalhos. Essa metodologia foi utilizada por Sargand e Khoury (1999). A fotografia 43 mostra como foi efetuada a proteção, a fotografia 44 mostra a finalização da placa e os sensores embutidos.

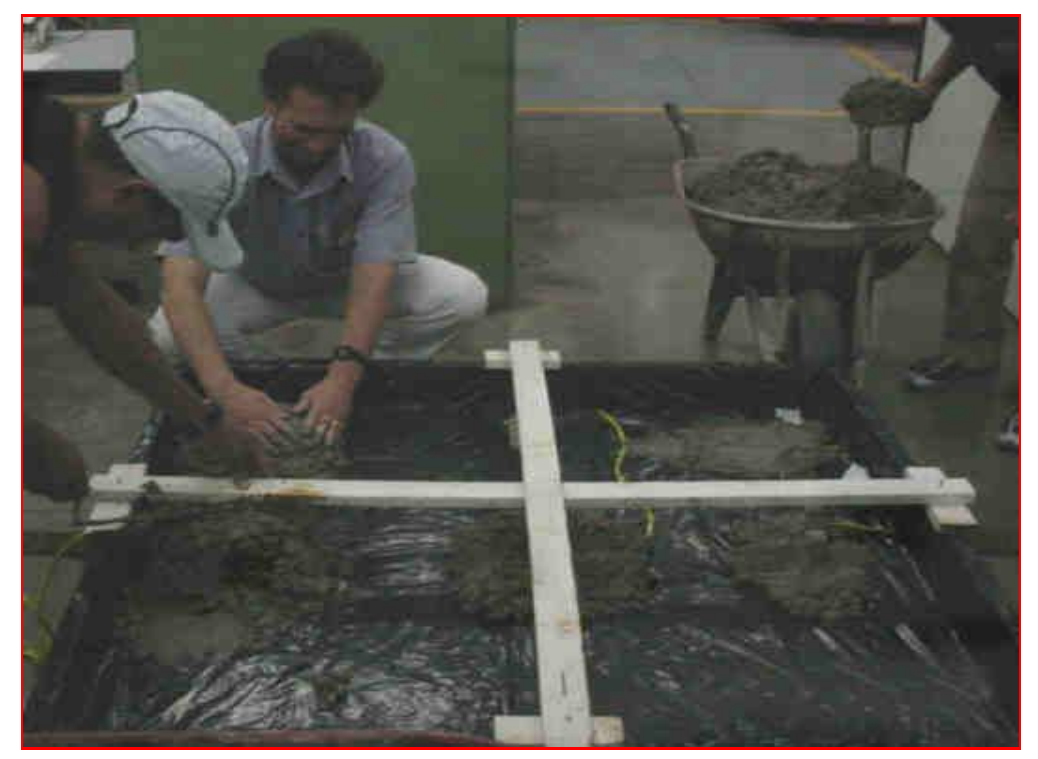

Fotografia 43. Proteção dos sensores com concreto antes da colocação da totalidade de massa. Isso evita que ocorra algum deslocamento dos sensores, devido à pressão que a massa impõe sobre esses componentes.

Fonte: Acervo próprio (2006).

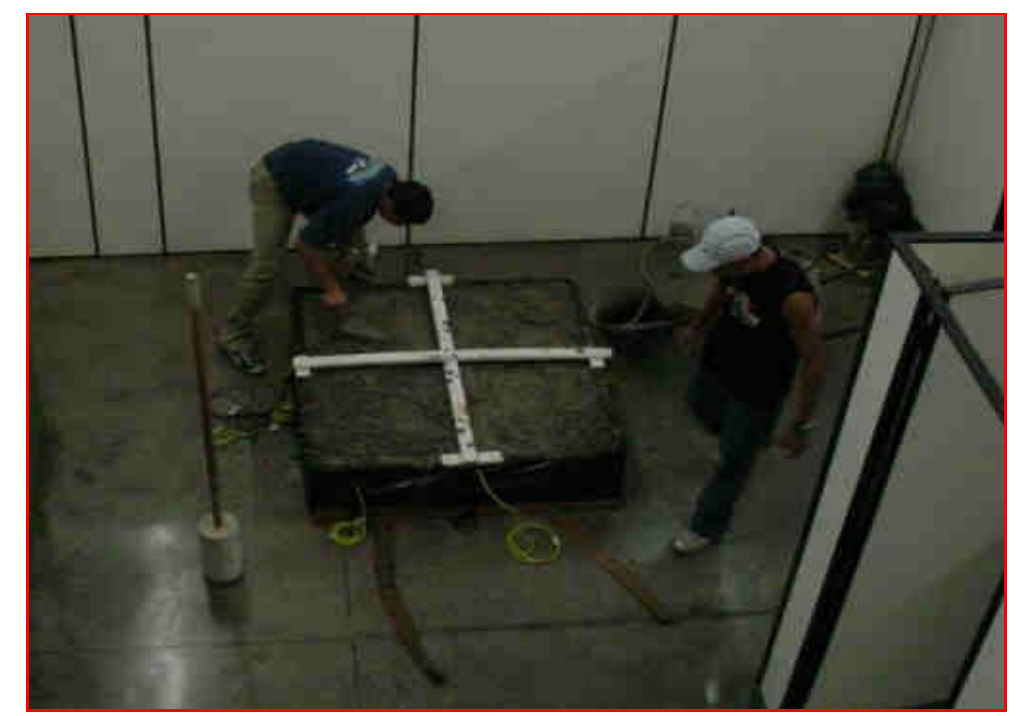

Fotografia 44. Aspecto da placa em sua fase final de construção. Fonte: Acervo próprio (2006). 


\section{DESENVOLVIMENTO DO SISTEMA DE AQUISIÇÃO DE DADOS}

Devido ao grande número de sensores e, consequentemente, um volume grande de dados a serem tabelados, foi necessário acrescentar ao projeto um sistema de aquisição de dados capaz de ler e armazenar todas as informações. Por motivos de ordem econômica e técnica, optou-se pelo desenvolvimento de um sistema que tivesse as características exigidas e que pudesse ser utilizado em outras aplicações. Como a Escola de Engenharia já possuía uma placa de aquisição e um módulo de condicionamento de sinais da National Instruments e software de programação, decidiu-se, então, desenvolver o sistema de aquisição na plataforma de programação LabView ${ }^{\circledR}$.

Condicionadores específicos para sensores de deformação e de temperatura foram adquiridos e uma consultoria externa foi contratada para o desenvolvimento da aplicação.

Algumas exigências para o software, que ficou conhecido como TERMOFLEX, foram solicitadas, tais como ajuste de zero dos termômetros e células, descrição da experiência, data de início e fim dos testes, possibilidade da geração de arquivos com os dados coletados e visualização gráfica dos fenômenos (SITEGAR, 2006).

A fotografia 43 mostra o aspecto da tela de apresentação exibindo os vários controles e recursos disponíveis no software.

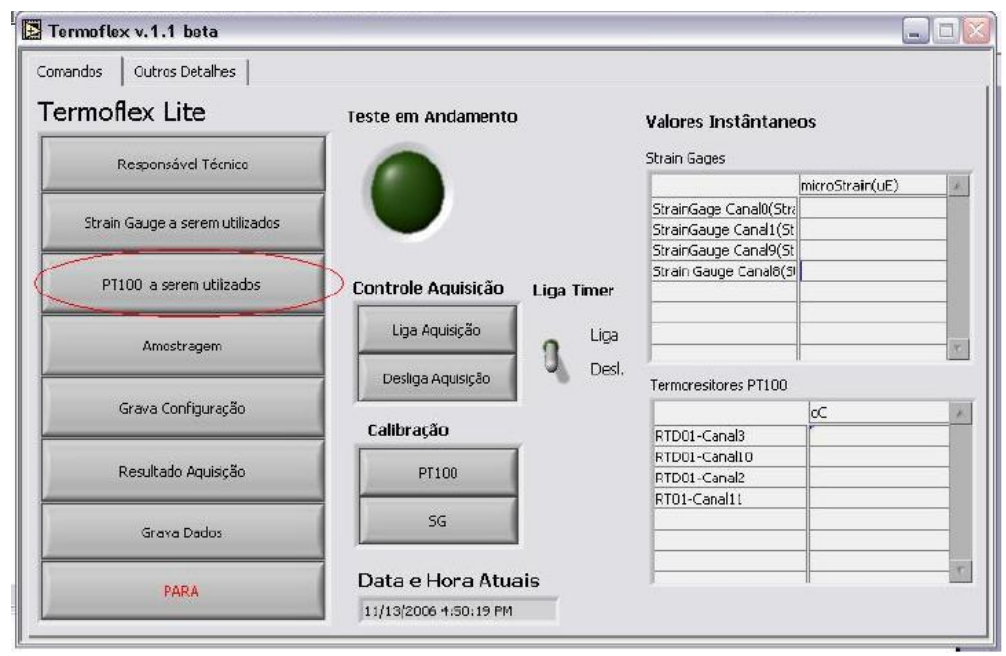

Fotografia 43. Painel de controle do software TERMOFLEX, utilizado para a coleta de dados da placa de concreto.

Fonte: Imagem da tela de operação do software TERMOFLEX (2007). 


\section{CONDICIONAMENTO DE SINAIS}

Os sinais foram condicionados através de módulos específicos para cada tipo de sensor. Para o condicionamento dos sensores de deformação, foi utilizado o modelo SCCSG01, 2-Channel, e para os sensores de temperatura (Pt100) foi utilizado o modelo SCCRTD01-RTD, ambos da National Instruments. Os condicionadores têm a função de prover alimentação estabilizada à ponte resistiva, filtragem de ruídos, calibração mecânica de zero e comunicação com o barramento digital para a transferência de dados.

SCC-SG têm em seu interior uma ponte de Wheatstone ${ }^{33}$ e funcionam a um quarto de ponte a três fios.

Cada módulo de condicionamento foi fixado ao módulo modelo SC 2345 da National Instruments capaz de receber até 16 canais analógicos e 16 canais digitais e que tem a função de se comunicar com circuito de aquisição de dados utilizando-se, nesse caso, um cartão tipo PCMCIA ${ }^{34}$, modelo 6025 da National Instruments.

A fotografia 45 mostra a disposição desses condicionadores internos ao módulo de aquisição, bem como a tela de gerenciamento do software.

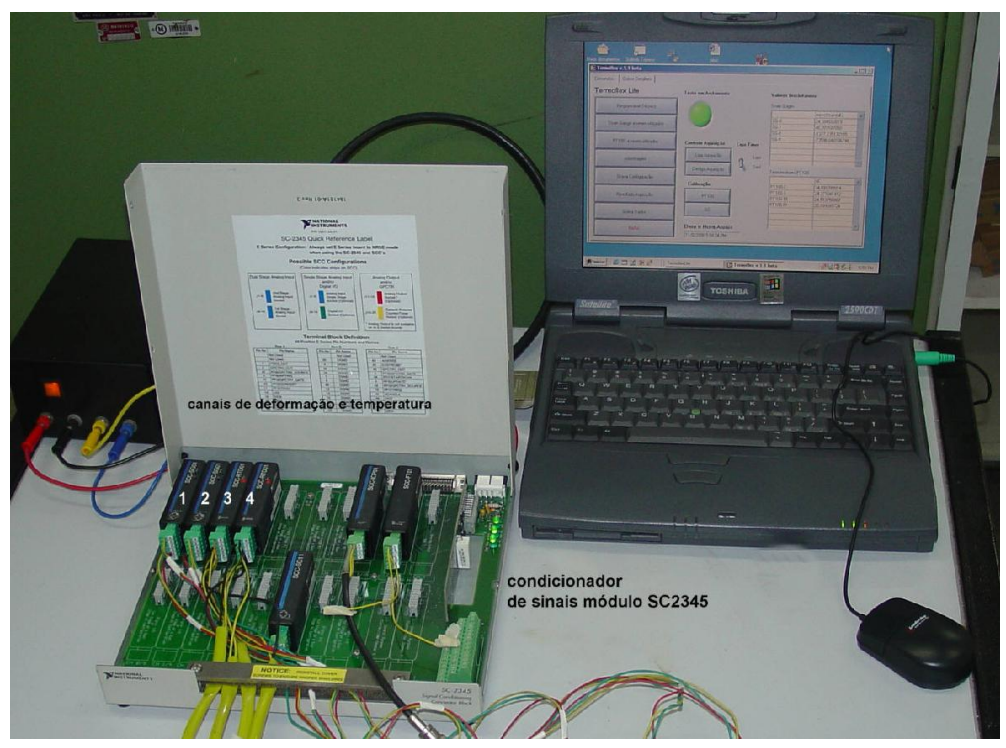

Fotografia 45. Disposição do sistema de gerenciamento e aquisição de sinais TERMOFLEX. Fonte: Acervo próprio (2006).

\footnotetext{
${ }^{33}$ Charles Wheatstone (1802 - 1875) professor e físico inglês de Gloucester

${ }^{34}$ PCMCIA é sigla de Personal Computer Memory Card International Association. Consórcio de empresas de Informática que produziu a especificação homônima para uma interface de 16 bits de expansão de computadores portáteis e os cartões que usam essa interface.
} 


\section{METODOLOGIA PARA AQUISIÇÃO DOS DADOS}

Durante o processo de cura, foram feitas as ligações dos sensores ao sistema de aquisição de dados, através de uma barra de conexão construída com conectores de ação rápida. As malhas de blindagem dos cabos dos extensômetros foram interligadas a uma barra de cobre, para que todos ficassem submetidos ao mesmo referencial. Esse procedimento visou evitar possíveis interferências eletromagnéticas oriundas do ambiente que poderiam afetar as medidas de deformação.

Todos os cabos foram soldados aos conectores, para que os canais do condicionador pudessem ser ligados de forma conveniente e de acordo com a escolha dos sensores na placa.

Após os 28 dias, com a placa pronta para a realização dos testes, estabeleceu-se a ligação dos sensores à barra dos conectores e uma ligação genérica ao módulo condicionador foi realizada para testes iniciais, como pode ser visto na fotografia 46.

Devido à configuração dos módulos condicionadores estabelecida pelo fabricante, os módulos para os extensômetro foram classificados como: SG0 (strain gage canal 0), SG1, SG8 e SG9. Para os termômetros, a denominação ficou: TE2 (termômetro canal 2), TE3, TE10 e TE11.

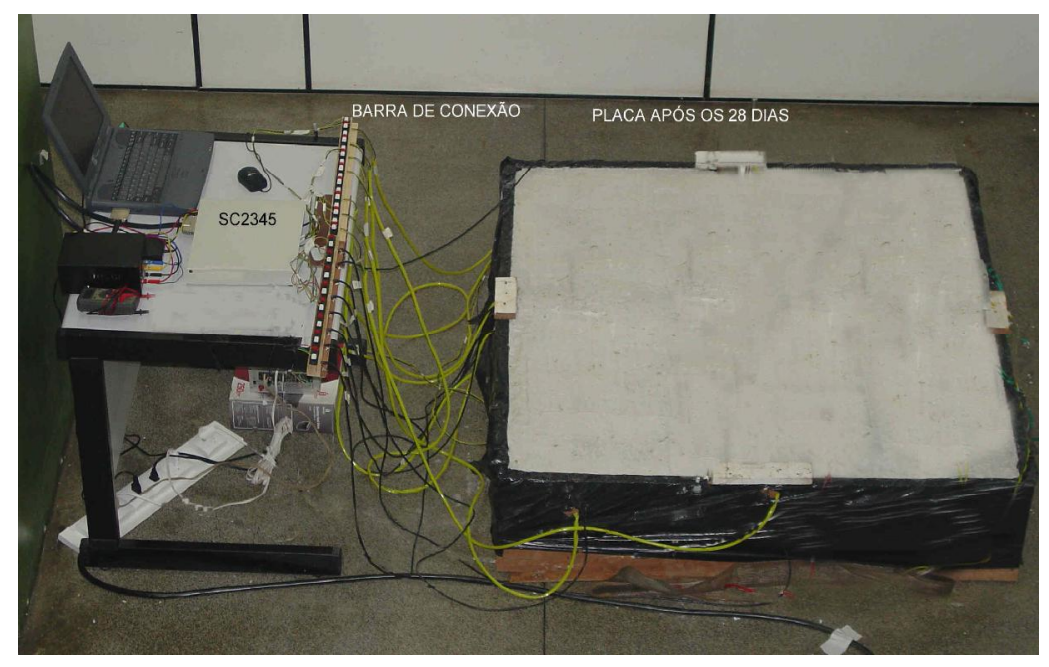

Fotografia 46. Ligação dos sensores ao sistema de aquisição de dados. Fonte: Acervo próprio (2006).

Os sensores de deformação foram distribuídos em dois níveis a partir do topo, 30,0 mm e 70,0 mm nas posições longitudinal e transversal em relação à placa. Os sensores de 
temperatura foram distribuídos em quatro níveis, $10,0 \mathrm{~mm}, 30,0 \mathrm{~mm}, 70,0 \mathrm{~mm}$ e 100,0 mm. Um termômetro foi colocado entre a placa e a base no ponto central (meio da placa) e outro a $300,0 \mathrm{~mm}$ de uma lateral e a $600,0 \mathrm{~mm}$ da outra lateral do molde.

A codificação para geração dos arquivos no TERMOFLEX e posterior análise no MINITAB $^{\circledR}$ seguiu o seguinte processo: SG1 - 7, strain gage 7 ligado ao canal 1 do módulo do SC 2345 e TE3 - 8 o termômetro 8 está ligado no canal 3 do módulo do SC 2345. 


\section{APÊNDICE D - DESENVOLVIMENTO DA RELAÇÃO V/V 0}

O desenho 51 indica a disposição dos extensômetros e resistores, bem como a posição relativa dos elementos utilizados na formação da ponte.

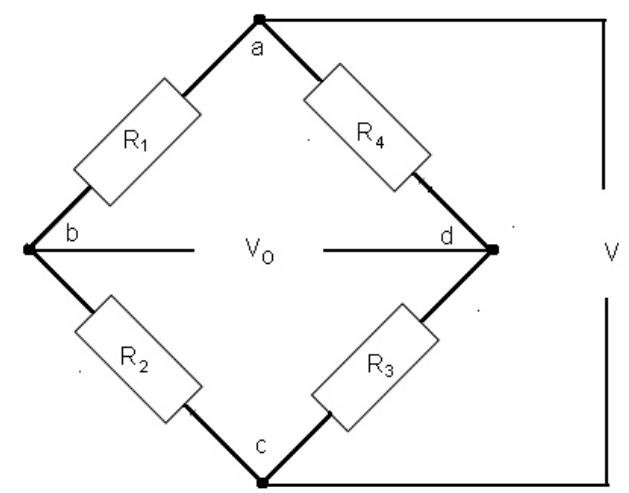

Desenho 51. Nomenclatura dos resistores e malhas da ponte de Wheatstone, conforme utilizado nas demonstrações.

Fonte: Acervo próprio (2008).

O potencial entre ' $a$ ' $e$ ' $b$ ' é tal que:

$$
V_{a b}=\frac{R_{1}}{R_{1}+R_{4}} V
$$

O potencial entre 'a' e 'd' é tal que

$$
V_{a d}=\frac{R_{2}}{R_{2}+R_{3}} V
$$

A d.d.p $\mathrm{V}_{0}$ é tal que:

$$
V_{0}=V_{a b}-V_{a d}
$$

$\mathrm{Ou}:$

$$
V_{0}=\frac{R_{1}}{R_{1}+R_{4}} V-\frac{R_{2}}{R_{2}+R_{3}} V
$$

Quando a ponte estiver equilibrada $\mathrm{V}_{0}=0$ volts ou ;

$$
R_{1} R_{3}=R_{2} R_{4}
$$


Caso ocorra uma variação na resistência elétrica causada por uma deformação, em qualquer um dos resistores, poderemos ter:

$$
\begin{aligned}
& R_{1}=R+\Delta R_{1} \\
& R_{2}=R+\Delta R_{2} \\
& R_{3}=R+\Delta R_{3} \\
& R_{4}=R+\Delta R_{4}
\end{aligned}
$$

Se $\Delta \mathrm{R}>0$ teremos uma deformação devido à tração. Caso contrário, $\Delta \mathrm{R}<0$ teremos compressão.

Reescrevendo a equação 43 e substituindo as equações 45 a 48 se obtém:

$$
V_{0}=V\left[\frac{\left(R+\Delta R_{1}\right)\left(R+\Delta R_{2}+R+\Delta R_{3}\right)-\left(R+\Delta R_{2}\right)\left(R+\Delta R_{1}+R+\Delta R_{4}\right)}{\left(R+\Delta R_{1}+R+\Delta R_{4}\right)\left(R+\Delta R_{2}+R+\Delta R_{3}\right)}\right]
$$

Desenvolvendo a expressão 49 e eliminando os termos com baixa contribuição, se obtém:

$$
\frac{V_{0}}{V}=\left[\frac{\frac{\Delta R_{1}}{R}+\frac{\Delta R_{2}}{R}+\frac{\Delta R_{3}}{R}+\frac{\Delta R_{4}}{R}}{4}\right]
$$

De acordo com o apêndice E:

$$
\frac{\Delta R}{R}=K \varepsilon
$$

Substituindo na equação 50 se obtém:

$$
\frac{V_{0}}{V}=\frac{K}{4}\left(\varepsilon_{1}-\varepsilon_{2}+\varepsilon_{3}-\varepsilon_{4}\right)
$$




\section{APÊNDICE E - DETERMINAÇÃO TEÓRICA DO GAGE FACTOR DE UM E.E.R (ERE)}

A resistência elétrica de um condutor, que obedece a lei de Ohm, é dada por :

$$
R=\rho \frac{L}{A}
$$

Isso implica dizer que a resistência elétrica é função da resistividade $\rho$, do comprimento L do condutor e da área A, da seção transversal do condutor.

$$
R=f(\rho, L, A)
$$

Calculando o incremento de $\mathrm{R}$, devido à variação simultânea de $\mathrm{L}$ e A, através da diferencial total da função 1, tem-se:

$$
d R=\frac{\partial R}{\partial \rho} d \rho+\frac{\partial R}{\partial L} d L+\frac{\partial R}{\partial A} d A
$$

Onde:

$$
\begin{gathered}
\frac{\partial R}{\partial \rho}=\frac{L}{A} \\
\frac{\partial R}{\partial L}=\frac{\rho}{A} \\
\frac{\partial R}{\partial A}=-\rho L A^{-2}
\end{gathered}
$$

Colocando da expressão 53

$$
d R=\frac{L}{A} d \rho+\frac{\rho}{A} d L-\frac{\rho L}{A^{2}} d A
$$

Dividindo a expressão (59) por $R=\frac{\rho L}{A}$

$$
\frac{d R}{R}=\frac{d \rho}{\rho}+\frac{d L}{L}-\frac{d A}{A}
$$

Fazendo $d \rho / \rho$ como $d L / L$ e supondo uma seção transversal retangular como $A=x . y$ e aplicando a diferencial total na expressão da área, tem-se:

$$
\begin{gathered}
d A=\frac{\partial A}{\partial x} d x+\frac{\partial A}{\partial y} d y \\
d A=y d x+x d y
\end{gathered}
$$

Dividindo pela área:

$$
\frac{d A}{A}=\frac{y d x}{x y}+\frac{x d y}{x y}
$$




$$
\frac{d A}{A}=\frac{d x}{x}+\frac{d y}{y}
$$

Podendo ser escrita como:

$$
\frac{d A}{A}=\varepsilon_{x}+\varepsilon_{y}
$$

Sabendo que a relação entre a deforrmação específica transversal pela deformação específica longitudinal é conhecida como coeficiente de $\operatorname{Poisson}^{35}(\mathrm{v})$, podemos reescrever a expressão 65 como:

$$
\frac{d A}{A}=-v \frac{d L}{L}-v \frac{d L}{L}
$$

ou

$$
\frac{d A}{A}=-2 v \frac{d L}{L}
$$

A resistividade pode ser escrita em função do volume que, a menos de uma constante, pode ser escrito como:

$$
\frac{d \rho}{\rho}=c^{t e} \frac{d V}{V}
$$

Onde $\mathrm{c}^{\text {te }}$ é conhecida como constante de Bridgmam ${ }^{36}$. Desenvolvendo a expressão do volume através da diferencial total, $V_{o l}=x \cdot y \cdot L$ fica:

$$
d V=\frac{\partial V}{\partial x} d x+\frac{\partial V}{\partial y} d y+\frac{\partial V}{\partial L} d L
$$

Simplificando:

$$
\frac{d V}{V}=\frac{d x}{x}+\frac{d y}{y}+\frac{d L}{L}
$$

Levando em consideração as expressões 68 e 69, a expressão 70 pode ser escrita como:

$$
\frac{d V}{V}=-v \frac{d L}{L}-v \frac{d L}{L}+\frac{d L}{L}
$$

Colocando na expressão 76

$$
\frac{d \rho}{\rho}=c^{t e}\left(-v \frac{d L}{L}-v \frac{d L}{L}+\frac{d L}{L}\right)
$$

Colocando as expressões 67 e 72 na 60

\footnotetext{
${ }^{35}$ Siméon Denis Poisson $(1781$ - 1840) matemático e físico francês.

${ }^{36}$ Percy Williams Bridgman (1882 - 1961) físico norte-americano.
} 


$$
\frac{d R}{R}=c^{t e}\left(-v \frac{d L}{L}-v \frac{d L}{L}+\frac{d L}{L}\right)+\frac{d L}{L}+2 v \frac{d L}{L}
$$

Rearranjando

$$
\frac{d R}{R}=\left[(1+2 v)+c^{t e}(1-2 v)\right] \frac{d L}{L}
$$

Onde $K=\left[(1+2 v)+c^{t e}(1-2 v)\right]$ é conhecido como gage factor.

Sendo:

$$
\frac{d R}{R}=K \frac{d L}{L}
$$

$\mathrm{Ou}$ :

$$
\frac{d R}{R}=K \varepsilon_{x}
$$


ANEXO A - CORRELAÇÃO CBR - MÓDULO DE REAÇÃO

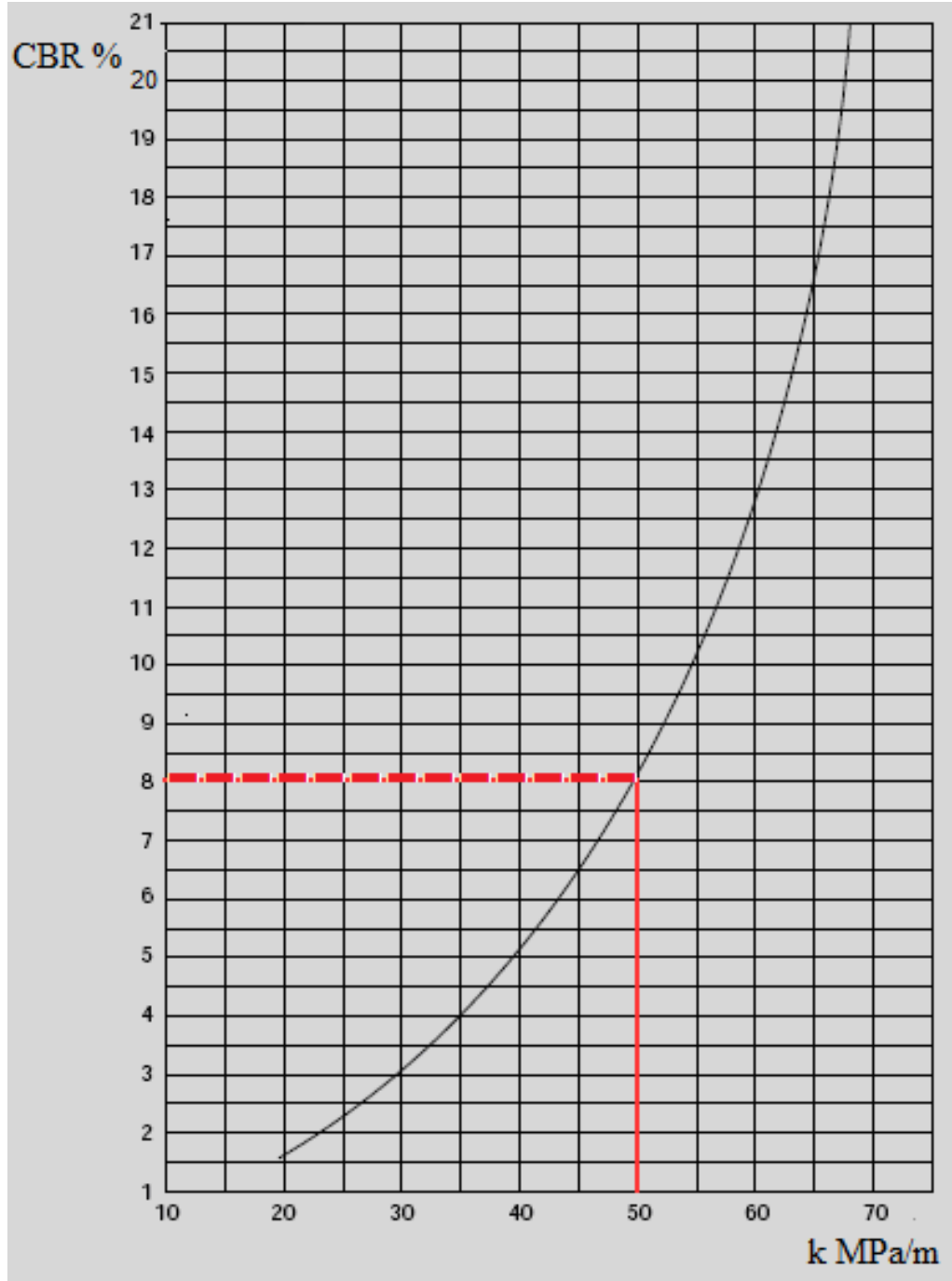

Gráfico 152. Correlação entre o módulo de reação (coeficiente de recalque) e o CBR. Fonte: Pitta (1998). 


\section{ANEXO B - ARQUIVOS}

CD - ROM. Planilhas em EXECEL e MINITAB com dados dos experimentos realizados. 


\section{ANEXO C - PLACA SOB CARGA ESTÁTICA CENTRO E BORDA}
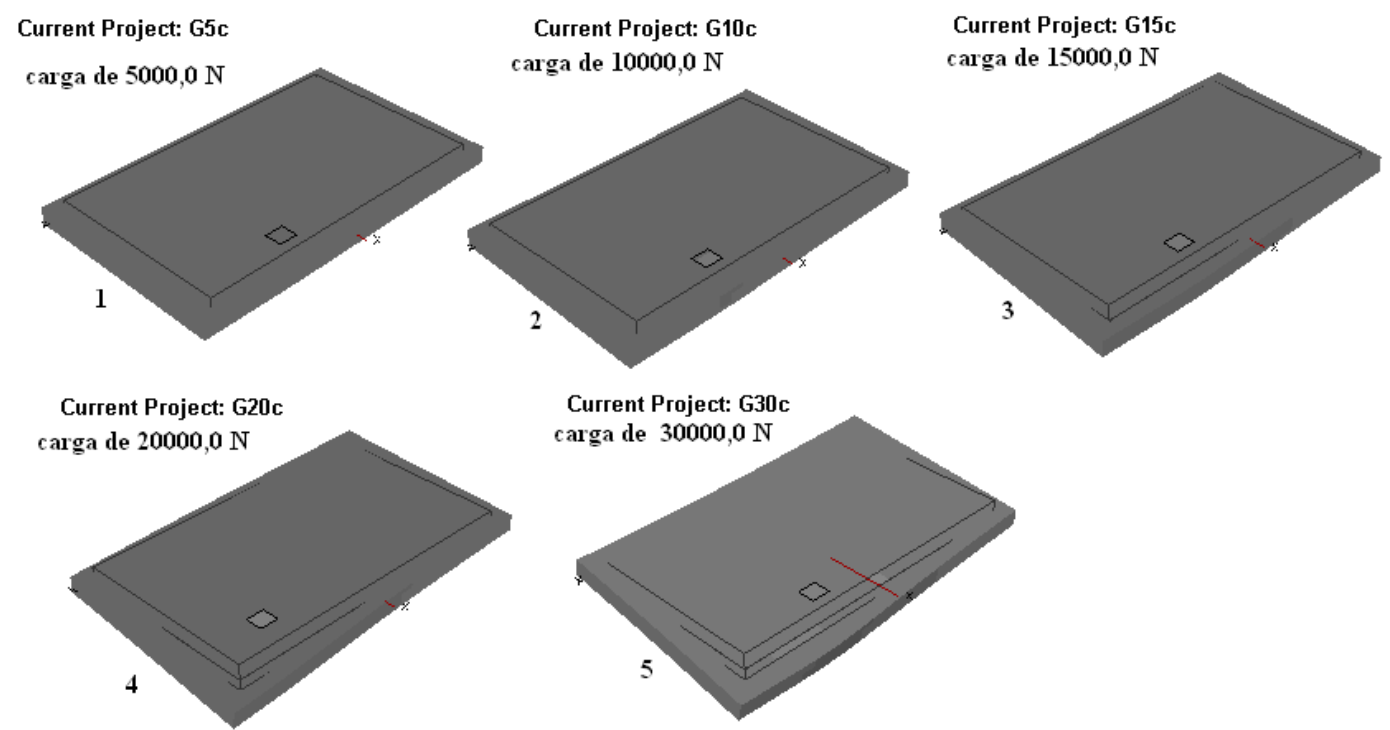

Desenho 52. Aspecto da deformação da placa sob carga estática quando aplicada na borda. A placa e a base, não deformadas, aparecem traçadas sob a placa em linhas contínuas.

Fonte: Acervo próprio - obtidos a partir do software EverFe 2.24 (2009).
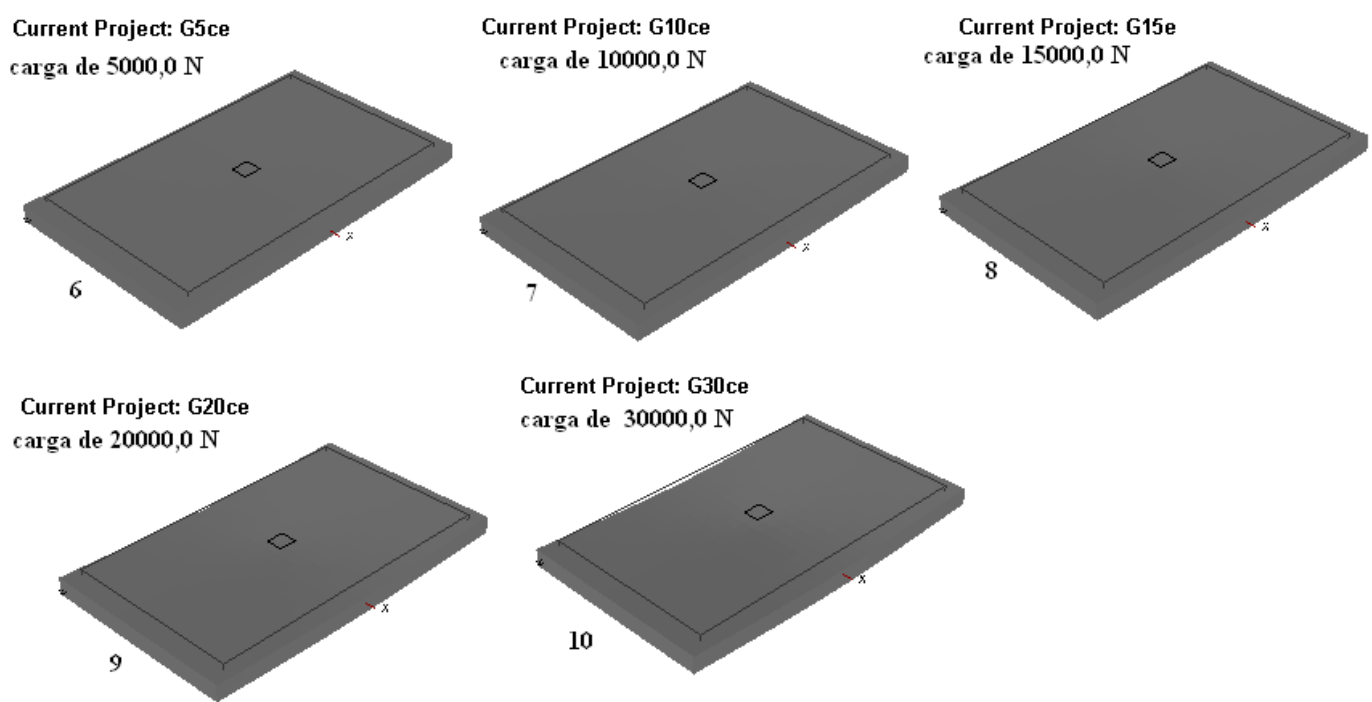

Desenho53. Aspecto da deformação da placa sob carga estática quando aplicada no centro. A placa e a base não deformadas aparecem traçadas sob a placa em linhas contínuas.

Fonte: Acervo próprio - obtidos a partir do software EverFe 2.24 (2009). 


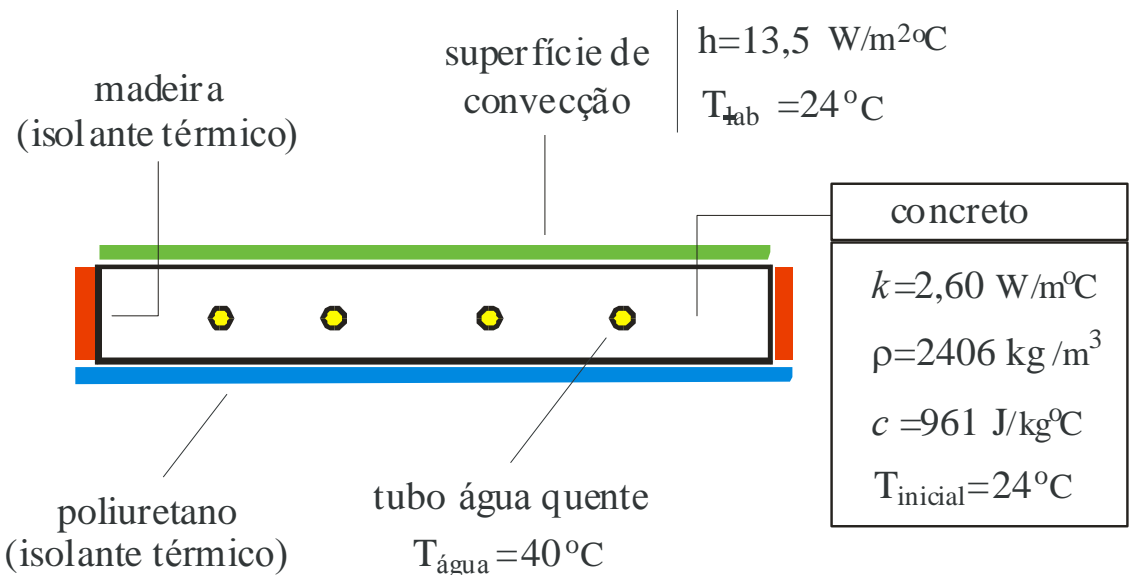

Desenho 54. Corte transversal do pavimento, propriedades físicas e condições de contorno da análise térmica transiente.

Fonte: Elaborado a partir dos dados do pavimento (2009).
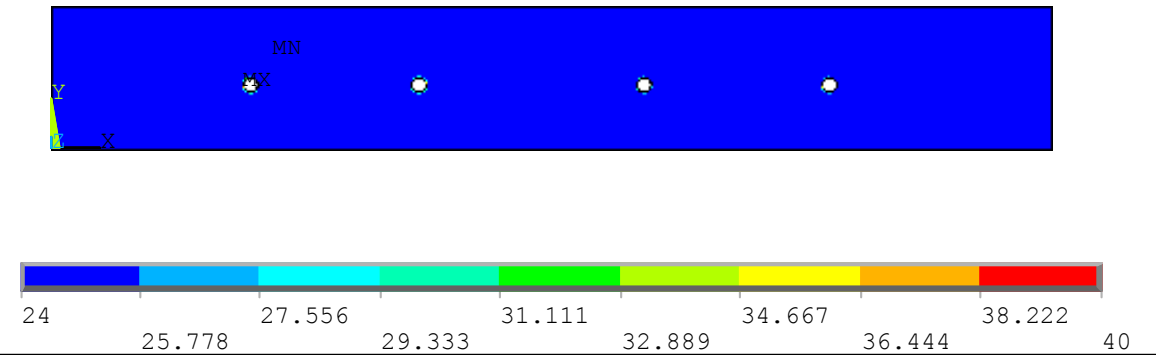

Desenho55. Corte transversal do pavimento, campo de temperatura incial.

Fonte: Elaborado a partir dos dados do pavimento (2009).
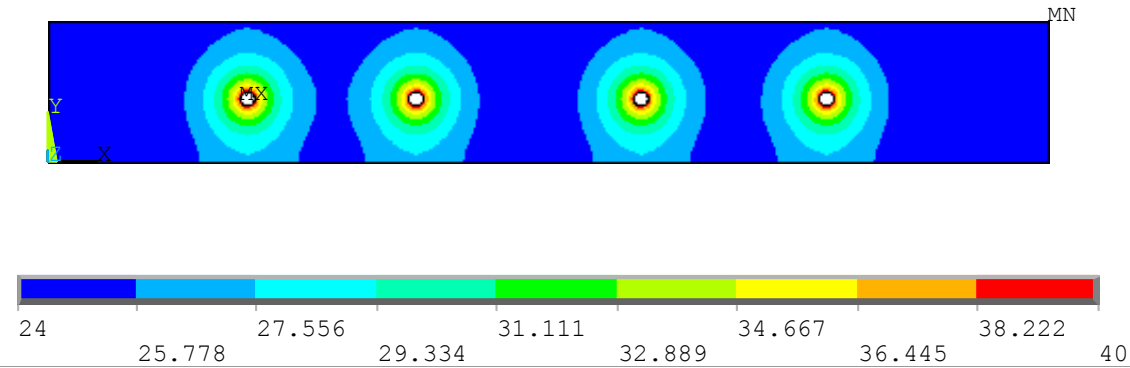

Desenho 56. Corte transversal do pavimento, campo de temperatura após 1 hora. Fonte: Elaborado a partir dos dados do pavimento (2009). 

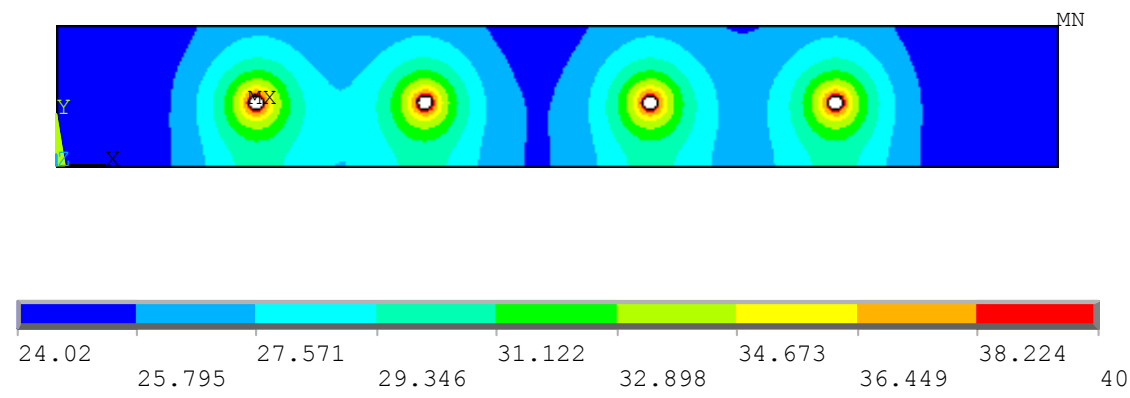

Desenho 57. Corte transversal do pavimento, campo de temperatura após 2 horas. Fonte: Elaborado a partir dos dados do pavimento (2009).
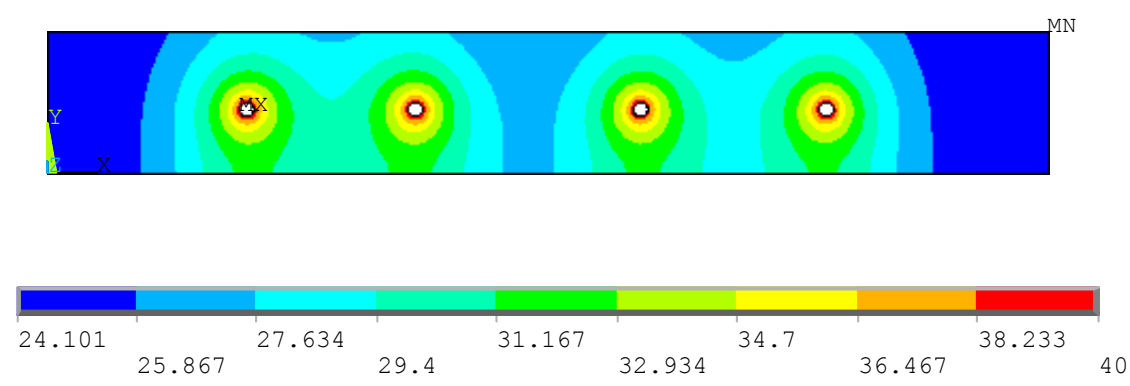

Desenho 58. Corte transversal do pavimento, campo de temperatura após 3 horas. Fonte: Elaborado a partir dos dados do pavimento (2009).
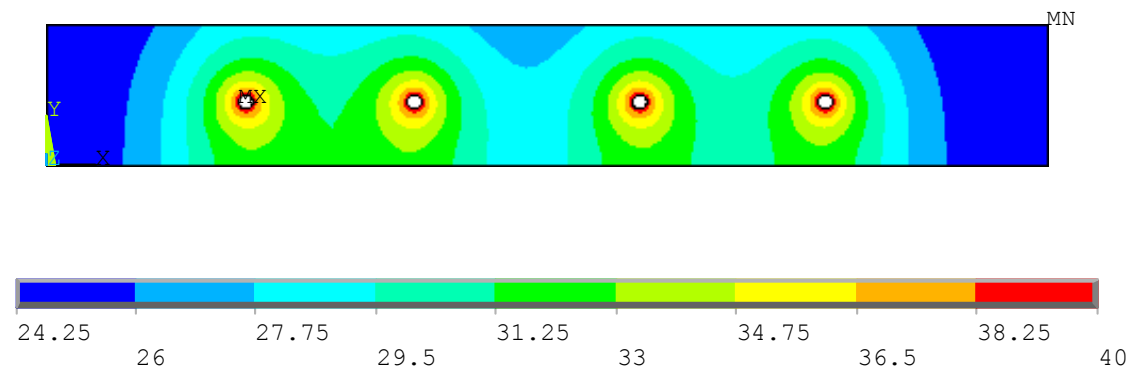

Desenho 59. Corte transversal do pavimento, campo de temperatura após 4 horas. Fonte: Elaborado a partir dos dados do pavimento (2009).
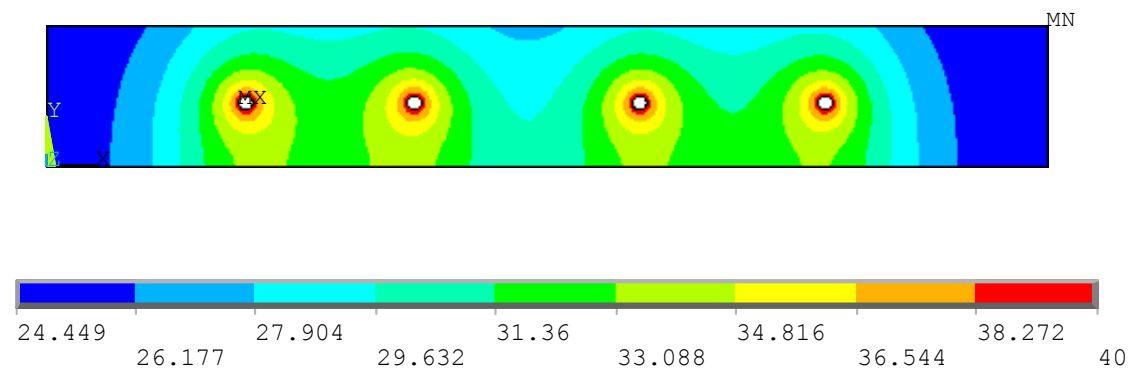

Desenho 60. Corte transversal do pavimento, campo de temperatura após 5 horas. Fonte: Elaborado a partir dos dados do pavimento (2009). 


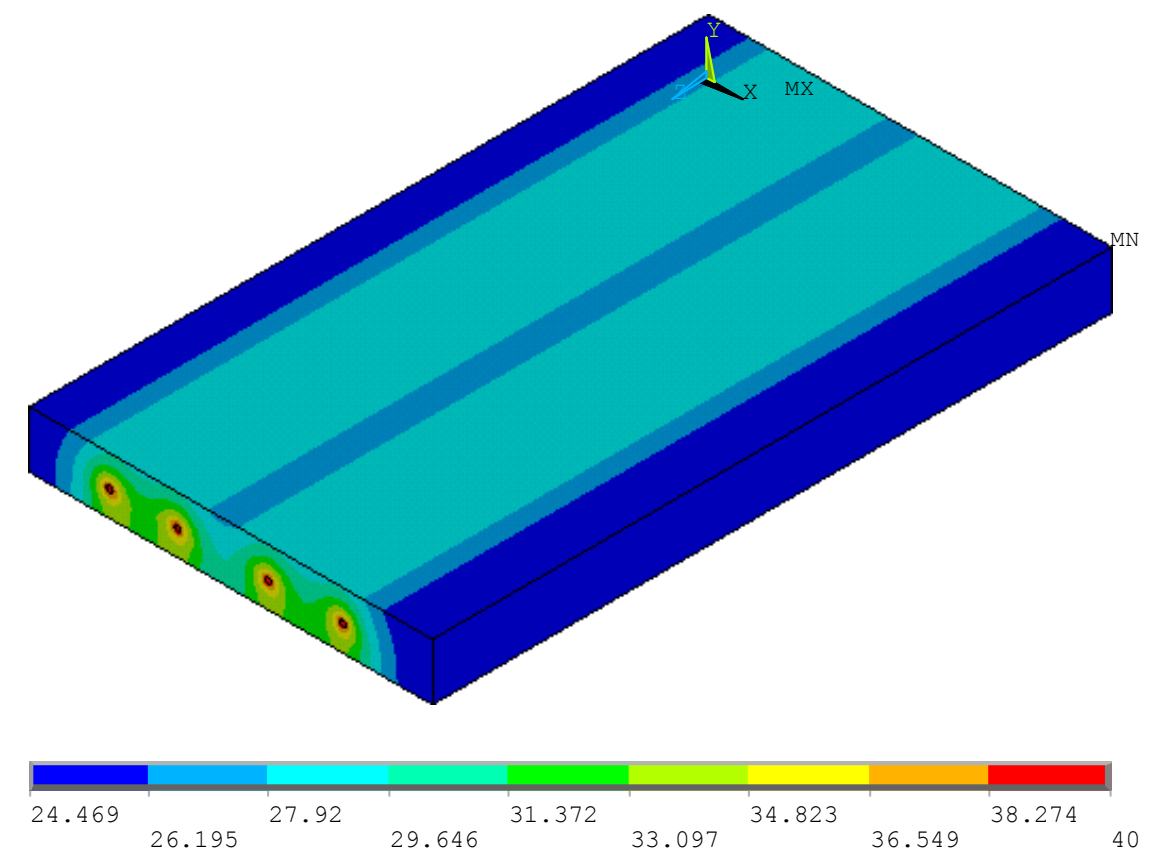

Desenho 61. Vista do pavimento, campo de temperatura após 5 horas (modelo 3D). Fonte: Elaborado a partir dos dados do pavimento (2009).
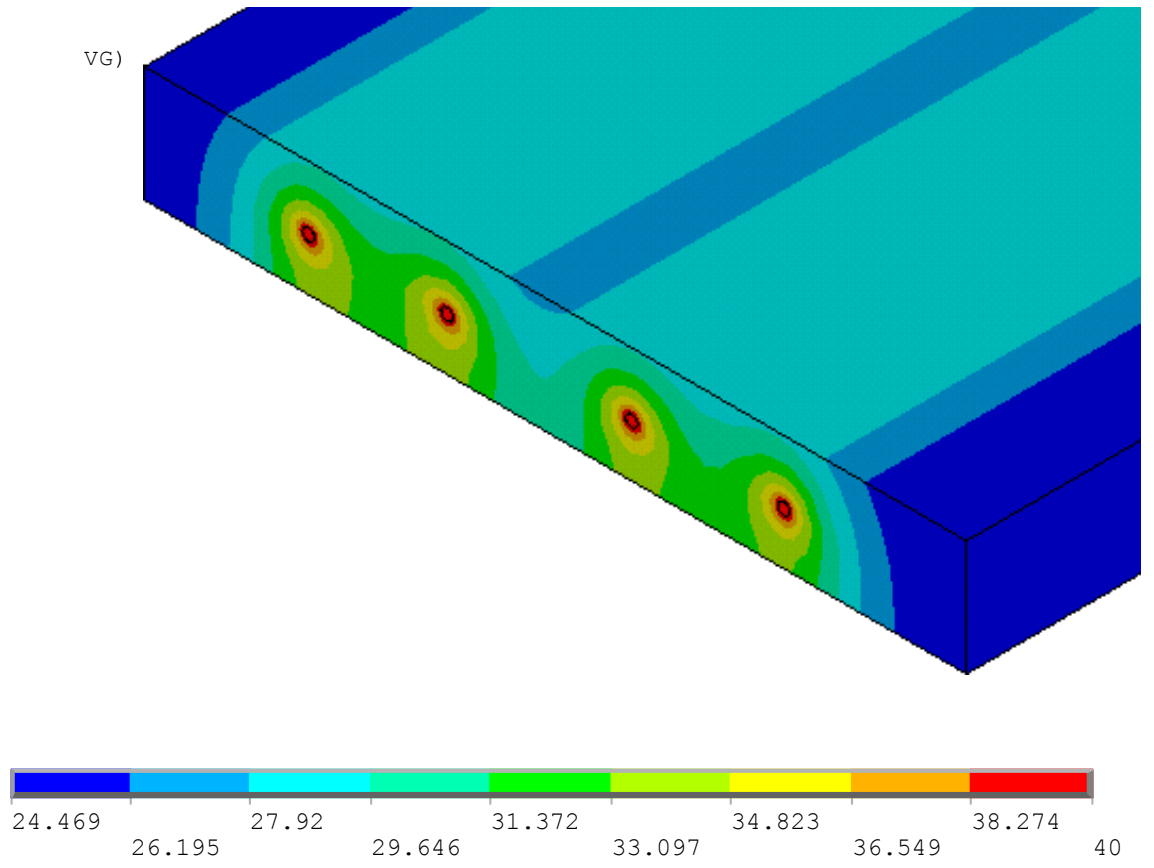

Desenho 62. Corte transversal do pavimento, detalhe do campo de temperatura após 5 horas (modelo 3D).

Fonte: Elaborado a partir dos dados do pavimento (2009). 


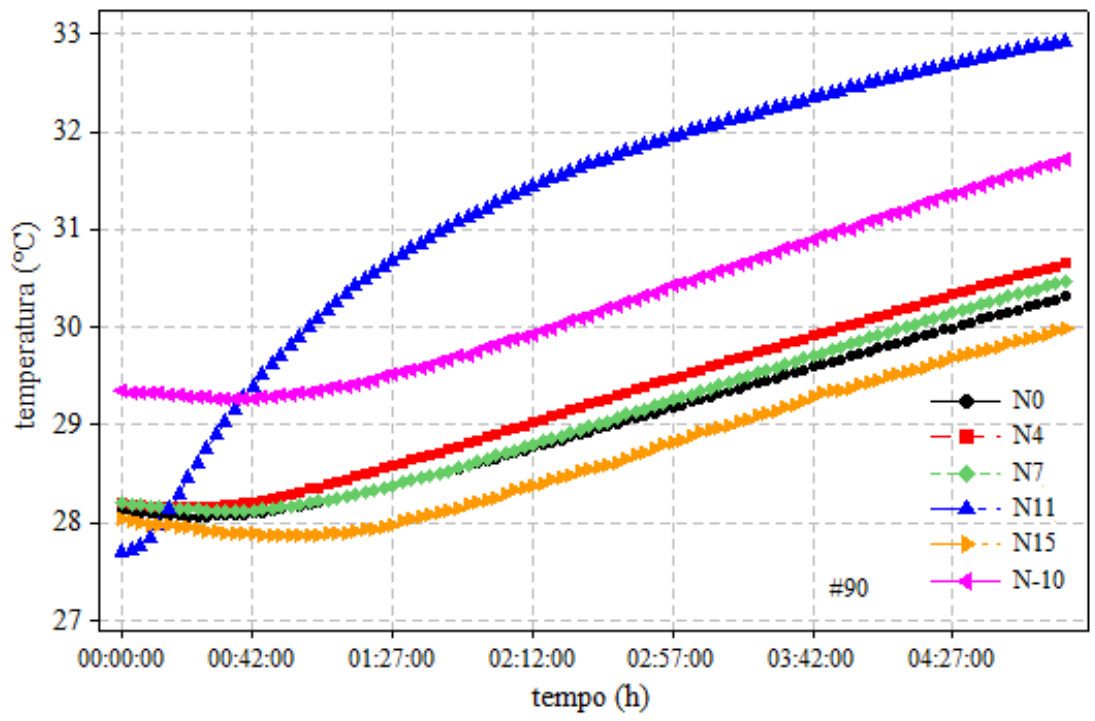

Gráfico 153. Distribuição da temperatura ao longo da espessura da placa para um aquecimento no fundo, em um período de 5 horas. Ė possível observar a discrepância que existe entre a temperatura de topo (N15) para a temperatura imediatamente abaixo (N11) Isso mostra que houve algum problema com os tubos do trocador de calor. È por esse motivo que se optou para a simulação com elementos finitos.

Fonte: Elaborado a partir dos dados retirados da experiência (2009). 


\section{ANEXO F - PROCEDIMENTO PARA INTERPRETAÇÃO DOS DADOS SOB CARGA ESTÁTICA}

Sobre a placa foram aplicadas cargas que variaram de $0,0 \mathrm{~N}$ até $20000,0 \mathrm{~N}$. Os dados coletados seguiram várias configurações, em $1 / 2$ ou $1 / 4$ de ponte. Quando não havia aquecimento os dados foram coletados em $1 / 4$ de ponte, caso contrário em $1 / 2$ ponte. O gráfico 154 mostra as respostas brutas sobre o carregamento imposto na placa. Como exemplo, foram escolhidas as respostas das células 5, 79 e 10. Sendo que a CE5 e a CE7 estão em localizadas nas mesmas coordenadas (x,y), porém com alturas diferentes. Além disso, estão dispostas a apresentarem respostas contrárias na flexão (como se estivessem coladas em superfícies opostas de uma barra).

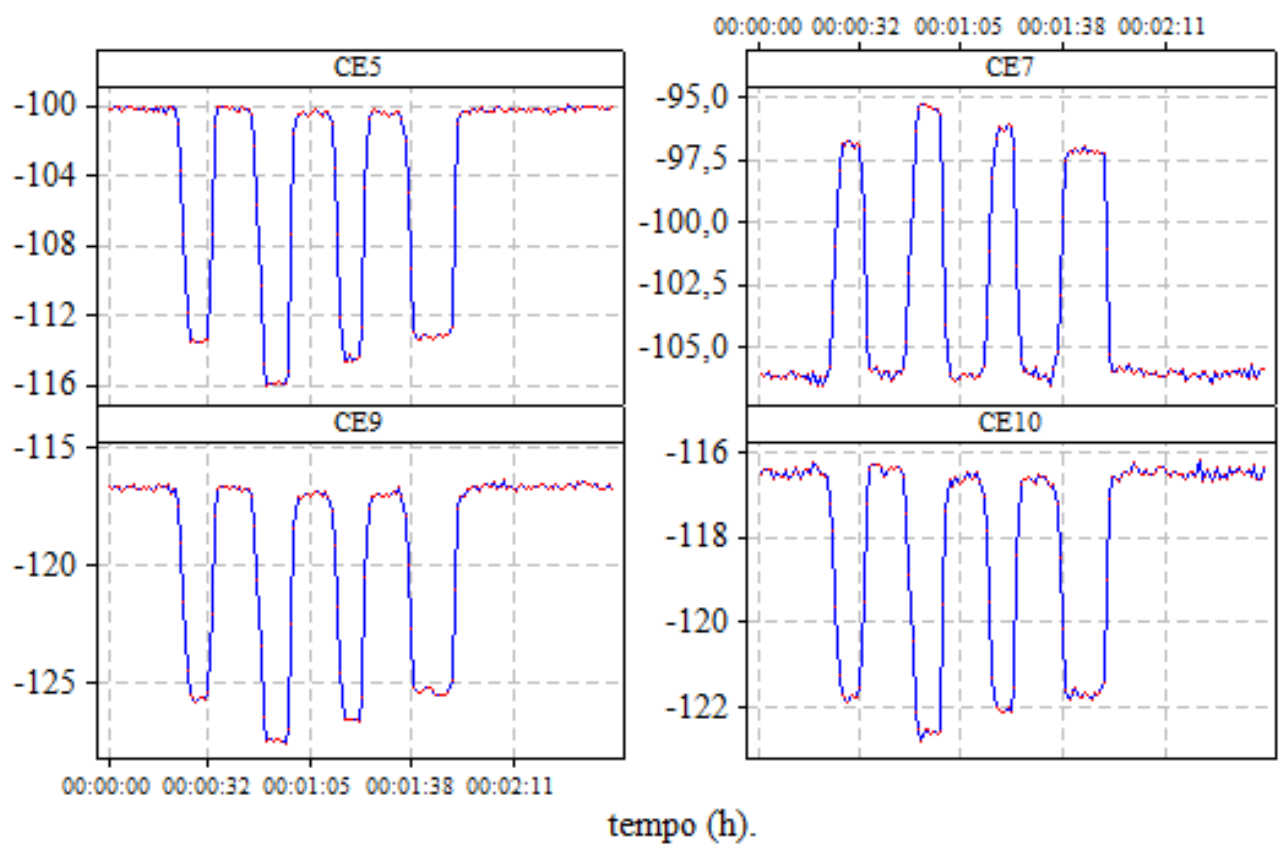

Gráfico 154 Aspecto da resposta bruta das células embutidas com carregamento variado em função do tempo.

Fonte : Dados obtidos nos processos de carregamento (2009).

Tomando como referência os valores mínimos do gráfico xy e fazendo a diferença com os outros dados, é possível montar o gráfico 155, onde é possível observar os dados referenciados em "zero" com a leitura em microstrain. Os valores dos carregamentos impostos pela máquina hidráulica e medidos por uma célula de carga fixada nela, estão anotados no gráfico 156. 

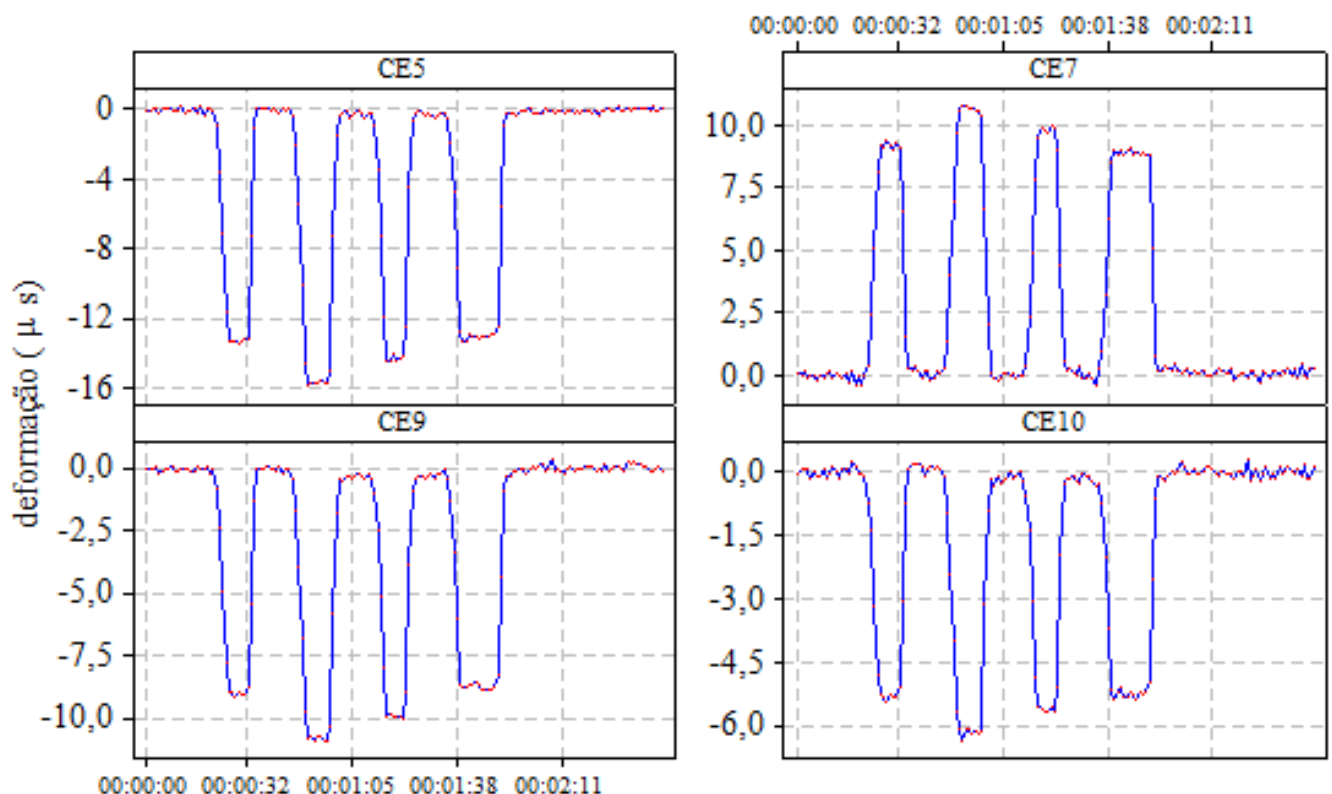

tempo (h).

Gráfico 155. Valores referenciados em função do tempo.

Fonte: Dados obtidos nos processos de carregamento (2009).
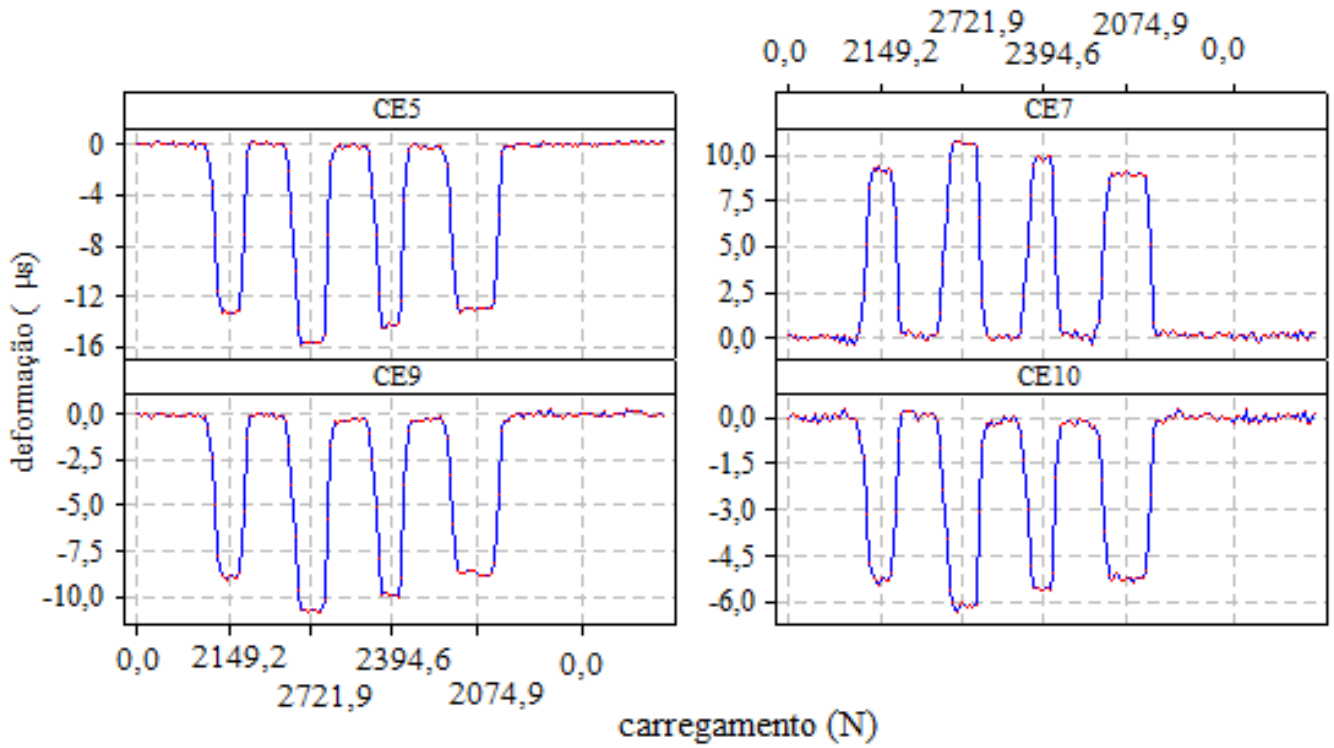

Gráfico 156. Valores dos carregamentos aplicados sobre a estrutura e respectiva deformação.

Fonte : Dados obtidos nos processos de carregamento (2009).

Os valores das deformações foram colhidos entre os instantes em que a carga foi aplicada (aproximadamente 10,0 s) e deles foi feita a média e o desvio padrão. Após esse procedimento, gráficos tal como apresentados no item 4 , foram construídos.

Como exemplo, gráfico 157, construído a partir da tabela 20, ilustra o procedimento. 
Tabela 20. Dados obtidos a partir do carregamento na célula CE7.

\begin{tabular}{ccc}
\hline Carregamento $(\mathrm{N})$ & deformação mádia $(\mu \mathrm{s})$ & desvio padrão $(\mu \mathrm{s})$ \\
\hline 0 & 0 & 0 \\
2074,9 & 8,9 & 0,1 \\
2149,2 & 9,2 & 0,1 \\
2394,6 & 9,7 & 0,4 \\
2721,9 & 10,7 & 0,1 \\
\hline
\end{tabular}

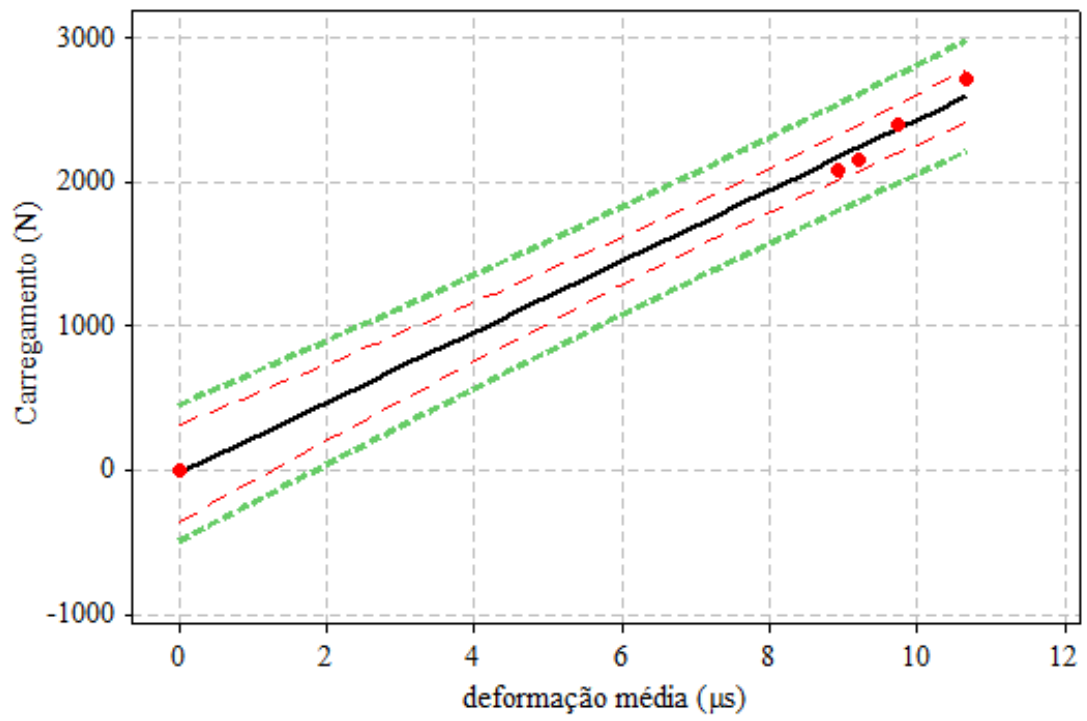

Gráfico 157. Reta de regressão mostrando a deformação sofrida pela célula CE7 devido a carregamento estático. Intervalo de confiança $95 \%$ e $\mathrm{R}^{2}=99 \%$.

Fonte: Construído a partir dos dados coletados (2009). 